Portland State University

PDXScholar

Summer 1-1-2012

\title{
Where Is the Rain-on-Snow Zone in the West-Central Washington Cascades?: Monte Carlo Simulation of Large Storms in the Northwest
}

Matthew John Brunengo

Portland State University

Follow this and additional works at: https://pdxscholar.library.pdx.edu/open_access_etds

Part of the Climate Commons, Hydrology Commons, and the Other Ecology and Evolutionary Biology Commons

Let us know how access to this document benefits you.

\section{Recommended Citation}

Brunengo, Matthew John, "Where Is the Rain-on-Snow Zone in the West-Central Washington Cascades?: Monte Carlo Simulation of Large Storms in the Northwest" (2012). Dissertations and Theses. Paper 689. https://doi.org/10.15760/etd.689

This Dissertation is brought to you for free and open access. It has been accepted for inclusion in Dissertations and Theses by an authorized administrator of PDXScholar. Please contact us if we can make this document more accessible: pdxscholar@pdx.edu. 
Where Is the Rain-on-Snow Zone in the West-Central Washington Cascades?

Monte Carlo Simulation of Large Storms in the Northwest

by

Matthew John Brunengo

A dissertation submitted in partial fulfillment of the requirements for the degree of

\section{Doctor of Philosophy}

in

Environmental Sciences and Resources: Geology

Dissertation Committee:

Andrew G. Fountain, Chair

Scott F. Burns

Daniel Johnson

Roy W. Koch

J. Alan Yeakley

Portland State University

(C) 2012 


\begin{abstract}
Rain-on-snow (ROS) occurs when warm, wet air moves into latitudes and/or elevations having vulnerable snowpacks, where it can alter water inputs to infiltration, runoff and erosion. The Pacific Northwest is particularly susceptible: winter storms off the Pacific cause locally heavy rain plus snowmelt almost annually, and disastrous flooding and landsliding intermittently. In maritime mountainous terrain, the effects seem more likely and hydrologically important where warm rains and seasonal snowpacks are liable to coincide, in middle elevations. Several questions arise: (1) In the PNW, does ROS affect the long-term frequency and magnitude of water delivery to the ground, versus total precipitation (liquid and solid), during big storms? Where and how much? (2) If so, can we determine which elevations experience maximum hydrologic effects, the peak ROS zone?

Probabilistic characteristics of ROS are difficult to establish because of geographic variability and sporadic occurrence: scattered stations and short observational records make quantitative frequency analysis difficult. These problems dictate a modeling approach, combining semi-random selection of storm properties with physical rules governing snow and water behavior during events. I created a simple computer program to perform Monte Carlo simulation of large storms over 1000 "years", generating realizations of snowpack and storm-weather conditions; in each event precipitation falls, snow accumulates and/or melts, and water moves to the ground. Frequency distributions are based on data from the Washington Cascades, and the model can be applied to specific sites or generalized elevations.
\end{abstract}

Many of the data sets were based on observations at Stampede Pass, where high- 
quality measurements of weather and snow at the Cascade crest have been made since the 1940s. These data were used to inform the model, and to test its reliability with respect to the governing data distributions. In addition, data from ROS events at Stampede, and at research sites in southwest Oregon, were used to confirm that the model's deterministic calculations of snow accumulation, snowmelt, and percolation (yielding water available for runoff) adequately simulate conditions observed in the field.

The Monte Carlo model was run for elevations ranging from 200 to $1500 \mathrm{~m}$, each over a hypothetical millennium. Results indicate that the presence of snow in some storms reduces the amount of water reaching the ground. This occurred more often in highlands but also at middle and lower elevations, affecting the long-term frequencymagnitude relations across the landscape. In these conditions, the rain-gauges overestimate the amount of liquid water actually reaching the ground.

For many storms, however, ROS enhances water reaching the ground, most significantly at elevations between $\sim 500-1100 \mathrm{~m}$. At lower and higher elevations, the water available for runoff exceeds precipitation in $\sim 2 \%$ of events, but this proportion rises to $\sim 20-30 \%$ at $\sim 800 \mathrm{~m}$. Other metrics (e.g., series statistics, exponential regression coefficients, frequency-magnitude factors) also indicate that this middle-elevation band (around $\sim 800 \mathrm{~m}$ ) experiences ROS most often and with greatest water available for runoff. Of the west-central Washington Cascades study region, about one-third to one-half the landscape is susceptible to significant ROS influence. These results indicate areas where ROS currently has the greatest hydrologic consequence on ecosystems and human works, and possibly the greatest sensitivity to changes in land-use and climate. 


\section{ACKNOWLEDGEMENTS}

Although my interest in rain-on-snow was first tickled by the Christmas floods of 1964, it really developed in the late 1970s, when I studied at the University of Washington and worked on several projects demonstrating the power of ROS events to affect hydrologic and geomorphic processes in forested mountains. The first attempt at a dissertation petered out in the late 1980s: the approach, the computers and the investigator all required additional seasoning. I kept up with ROS issues while working at the Washington Department of Natural Resources, and applied some preliminary insights and results to forest-practices regulatory and watershed analysis procedures. The project was rebaptized by the February storm of 1996, leading to my enrollment at Portland State in order to complete the modeling and produce scientifically credible results.

As should be expected for a project $\sim 30$ years old, many people have contributed to the shape of the work and its products. Dennis Harr of the U.S. Forest Service (Corvallis) and the UW College of Forest Resources, set off a revival in ROS studies among many colleagues and students in the 1970 s and ' 80 s, particularly concerning interactions with timber harvest across the Northwest; besides major concepts, he provided me with many information sources, loaned field equipment and some funding. Tom Dunne, my academic supervisor at the UW Dept. of Geological Sciences, was a fountainhead of ideas on geomorphology and hydrology, from the pseudo-mythologic (the "great stochastic rain gods" pitching infinitely variable storms off the Pacific Ocean), to the practical (field techniques), to the doctoral-obligatory: the insistence that empirical observations of ROS had to be supplemented and generalized by probabilistic modeling.

The modeling far outlived the initial field study of $1980-85$, but thanks are never- 
theless due its collaborators and funders. Access and permits for field work in the Green River basin were granted by Tacoma Public Utilities, Weyerhaeuser, and BN Timberlands/Plum Creek Timber Co.; the Mt Baker-Snoqualmie National Forest allowed me to use their Lester Guard Station. Financial support came from the Forest Service $(\$ 5000$, contract PNW-80-172) and the Geological Society of America (\$500, GSA Research Grant 2961-82). Much greater (and uncountable) funding, including a pick-up truck with well-appointed canopy, flowed from my parents John and Iris Brunengo over many years. My father constructed field snow pans; Neil Humphrey helped build data loggers. Many friends and colleagues served as field helpers at the "Russian Front": Dave Borns, John \& Iris Brunengo, Colin Cool, Kevin Cooney, Barb Cosens, Lee Fairchild, Gerty Fortmann, Rollie Geppert, Carol Levine, Dave Mogk, Diane Moore, Mike Noll, and Maureen Shea; special thanks to the slow learners who came multiple times (Lee, Carol, Colin). While working at Washington DNR in the late 1980s and '90s, I received plenty of moral support to keep working on ROS. In particular, my direct supervisors over that time - Steve Bernath, Nancy Sturhan, Tim Walsh - allowed me to keep a hand in these issues, even though usually peripheral to the jobs I was hired to do, and to work part-time and ultimately leave DNR to go back to school. WDNR's librarians, GIS and graphics staff were always helpful when I needed it (Fig. 2.1 and 7.2 are adapted from a presentation figure originally drafted by Nancy Eberle in 1990). Other scientific colleagues within the Timber/Fish/Wildlife consortium were involved in some of the ROS-related issues and projects of that period, including Kevin Lautz (WDFW), Glen MacDonald (USFS), Terry Cundy (UWCFR, Potlatch Corp.), Steve Berris (USGS), Marijke van Heeswijk (USGS), Pascal Storck (then UW), and T.H. Wu (Ohio State Univ.). In addition, I have 
benefitted from many discussions with colleagues when I've presented bits and pieces of this work at Western Snow Conference meetings.

Several people and agencies deserve thanks for supplying data and other information. Cooperative Snow Survey/SNOTEL program staff have always been forthcoming, since my early contacts with Bill Weller of the old Soil Conservation Service (Spokane, retired), and more recently with NRCS personnel Scott Pattee (Mount Vernon), Jon Lea, Sheila Strachan and Melissa Clark (Portland). Todd Bohle of Seattle Public Utilities arranged for me to ride along on a monthly check of snow sites in the Cedar River watershed (April 2004). Paul Wetherbee graciously allowed the use of data collected for his master's thesis (UW CFR) from DEMO sites in southwest Oregon in my model testing.

At Portland State Univ., the Geology Department faculty and my fellow students have tolerated an aging graduate student far longer than they expected. Thanks to my requalification committee for creating and reviewing a test so quickly: Marc Kramer, Scott Burns, Jim Jackson, and especially Christina Hulbe, for proctoring the exam over a threeday weekend, and also for running interference with multiple levels of upper administration in trying to get me finished and out. Not least, thanks to my committee: Andrew Fountain and Scott Burns (Geology), Dan Johnson (Geography), Alan Yeakley (ESR), and Roy Koch (formerly CE and ESR). I first discussed coming to PSU to pursue a doctorate with Scott and Roy in 1996; when I applied, the department "volunteered" Andrew to be my supervisor, a fortunate choice for me. Thanks all, for sticking with me.

And to all the family, friends and colleagues who have endured my (perhaps decreasingly credible) assurances that I would, indeed, make an end of this thing:

questo lavoro è finito - gràzie a tutti ! 


\section{TABLE OF CONTENTS}

Abstract $\quad$ i

Acknowledgements $\quad$ iii

List of Tables viii

List of Figures $\quad$ ix

List of Abbreviations \& Symbols $\quad$ xi

1 Introduction

1.1 What is rain-on-snow? 1

1.2 When \& where do ROS events occur? 3

1.3 ROS literature review 8

$\begin{array}{lll}1.4 & \text { Importance of ROS } & 12\end{array}$

1.5 Variability \& probabilistic aspects of ROS frequency \& location 16

2 Research Questions, Hypotheses, Approach

2.1 Research questions 25

2.2 Modeling approach 29

2.3 Hypotheses in model terms 32

3 Model Components, Architecture, Input \& Operations

3.1 Deterministic model components: theoretical \& empirical background 34

3.2 Probabilistic model components: Monte Carlo approach 45

3.3 Program architecture \& operations 49

$4 \quad$ Study Region \& Sites

4.1 West-central Cascades study region 68

4.2 Climate of the region; interannual variability 71

4.3 Interaction of climate \& terrain in the western Cascades 81

4.4 Observation sites 86

4.5 Inputs \& parameters: data records, series, statistics 91

$5 \quad$ Model Calibration, Testing \& Initial Applications

5.1 Introduction 101

5.2 Model calibration \& testing, ROS hypothetical \& observed events 103

5.3 Monte Carlo simulation specific to Stampede Pass (StpP EXP) 114

5.4 Monte Carlo simulation for Stampede Pass elevation (1065 EXE) 131

$6 \quad$ Monte Carlo Results for Elevation Zones

6.1 Introduction 141

$\begin{array}{lll}6.2 & \text { Example event } & 144\end{array}$

6.3 EXE series across elevation zones: basic statistics 147

6.4 Frequency analysis of EXE results 156 
$\begin{array}{lll}\text { 6.5 Model sensitivity } & 165\end{array}$

6.6 Probabilistic elements if the Monte Carlo simulations - discussion 172

$7 \quad$ Discussion, Summary \& Conclusions

$\begin{array}{lll}7.1 & \text { Storm simulation model - discussion } & 182\end{array}$

7.2 Hydrologic significance \& favored elevations of rain-on-snow 185

$\begin{array}{lll}7.3 & \text { Summary \& conclusions } & 201\end{array}$

$\begin{array}{lll}7.4 & \text { Future work } & 203\end{array}$

$\begin{array}{ll}\text { References Cited } & 207\end{array}$

Appendix A Summary of Selected Studies Involving ROS (Table A.1) 235

Appendix B Simulation Model for Single Events 245

B.1 ROS Simulation for SE - Excel Workbook supplemental files

B.2 VBA Code for Simulation for Single Events 246

Appendix C Monte Carlo Simulation Model 263

C.1 ROS Simulation for MC - Excel Workbook supplemental files

C.2 VBA Code for Monte Carlo Simulation 264

Appendix D Weather and Climate Observation Sites 290

D.1 Weather Stations (Table D.1) supplemental files

D.2 Snow Stations (Table D.2) supplemental files

Appendix E Summary of Precipitation Model Parameters 291

supplemental files

Appendix F Exponential Distribution: Math \& Applications 292

Appendix G Description of Storm Events Utilized in SE Model Tests 301

Appendix H Summary of Selected SE Calibration and Test Runs (Table H.1) 305 supplemental files

Appendix I Output \& summary of StpP EXP tests and runs supplemental files

Appendix J Output \& summary of 1065 EXE tests and runs

supplemental files

Appendix K Output \& summary of EXE runs at $800 \mathrm{~m} \quad 308$

supplemental files

Appendix L Summary of EXE experiment runs for all elevations, high- and lowprecipitation areas (tables and graphs)

supplemental files 


\section{LIST OF TABLES}

3.1 Summary of Simple to Complex Model Approaches, and Approaches Utilized in This Project

4.1 Summary of Model Parameters, Sources, Statistical Models and Associations

$$
93-94
$$

5.1 Summary of Stampede Pass EXP Test Results

6.1 Model Realization Statistics for Elevation Experiments (MC Version EXE, HighPrecipitation Sites)

7.1 Hypothesis Testing Using Series Statistics

7.2 Evaluation of Rain-on-Snow Elevations Using Parameters from MC - EXE Experiments

7.3 Interpretation of Hydrologic Zones from MC - EXE Experiments

193

7.4 Studies Identifying ROS / Transient Snow Areas in the Pacific Northwest \& Adjacent Regions 


\section{LIST OF FIGURES}

1.1 SNOTEL data for the month around ROS event of 4-9 Feb $1996 \quad 17$

2.1 Elevation transect before/after a hypothetical storm 26

3.1 Flow chart: operations of the single event model 52

3.2 Flow chart: operations of the Monte Carlo model 54

4.1 A: Map of Washington, study area; B: West-central Cascades terrain 69

4.2 Average monthly precipitation and temperatures, for three weather stations in the study region; A: Stampede Pass; B: Cedar Lake; C: Landsburg 72-73

4.3 Time series of NWS divisional climatic averages, for water years 1940-2005;

A: Temperature; B: Precipitation 76

4.4 Hypsometric curve for the project area, west-central Washington Cascades $\quad 84$

4.5 Observation sites in the central-western Cascade Range 86

4.6 Facilities at Stampede Pass; A: Instrument platform at weather station; B: Snow pillow and precipitation storage gauge $\quad 88$

4.7 Snow survey by Seattle Public Utilities personnel, Cedar River watershed;

A: Weighing snow tube; B: Measurement for ground truth at SNOTEL 90

4.8 Precipitation data from Stampede Pass NWS weather station, 58 WYs 98

5.1 Comparison of SE model outputs with Colbeck's (1976) case

5.2 Comparison of SE model output and field measurements for DEMO event \#4;

precipitation, rain + melt, net SWE

5.3 Comparison of SE model output and field measurements for DEMO event \#4; snow $\begin{array}{ll}\text { depth and SWE } & 110\end{array}$

5.4 Comparison of SE model output and field measurements for DEMO event \#4;

WAR

5.5 Comparison of SE model outputs and field measurements; A: DEMO event \#1;

B: Jan 2005 at Stampede Pass; C: Dec 2005 at Stampede Pass

$112-113$

5.6 Hourly temperatures for StpP EXP event 3230

5.7 Hourly water input and output values, StpP EXP event 3230

5.8 Summary of maximum total precipitation, rain + melt, and water available for runoff over various time periods, StpP EXP event 3230 
5.9 Realizations of total precipitation for StpP EXP

5.10 Realizations of initial snow volume, StpP EXP 125

5.11 Realizations of initial snow-water equivalent vs snow depth, StpP EXP 127

5.12 Realizations of event initial temperatures, StpP EXP 129

5.13 Water available for runoff compared to total precipitation, StpP EXP 130

5.14 Regression lines for realizations of water inputs and outputs, StpP EXP 131

5.15 Realizations of total precipitation for 1065 EXE 136

5.16 Realizations of initial snow water equivalent, 1065 EXE 137

5.17 Frequency lines for realizations of water inputs and outputs, StpP EXP and 1065 EXE

6.1 Realizations of weather and hydrologic elements for example event 3359; A: Storm duration, snow depth and SWE; B: Event temperature; precipitation and WAR 146 6.2 Elevation trends of series statistics from EXE realizations; A: Wetter areas; B: Drier areas 152

6.3 Proportion of hydrologic event types; A: Wetter areas; B: Drier areas 155 6.4 Exponential regression coefficients from realizations for EXE precipitation and WAR series; A: Wetter areas; B: Drier areas 158 6.5 Exponential trends for realizations of precipitation and water outputs, EXE runs for sample of five site elevations $\quad 160$ 6.6 Integral of magnitude-frequency product, EXE runs at various site elevations 164 6.7 Realizations and frequency-magnitude lines of water inputs and outputs, EXE runs at 800 m elevation

6.8 Frequency-magnitude lines produced by three $800-\mathrm{m}$ EXE model runs using different random-number seeds

7.1 Estimates of elevations of significant rain-on-snow occurrence in the west-central Washington Cascades

7.2 Elevation transect before/after a storm, illustrating model results for WAR given each hypothetical $\mathrm{P}$ trend

7.3 Hypsometric curve for the project area, west-central Washington Cascades, indicating the zone of significant rain-on-snow 


\section{LIST OF ABBREVIATIONS \& SYMBOLS}

Values, dimensions, important references, etc. indicated as appropriate. Abbreviations used locally in tables or appendices are defined therein. Some duplication unavoidable ( $T$ as temperature and time, $\mathrm{W}$ as wind and west, etc.); distinctions indicated by regular versus italic fonts in a few cases.

a factor in frequency plotting formula ( 0.44) (Gringorten, 1963)

A, $A_{n} \quad$ regression slope (by common or natural logs) for exponential distribution

$\mathrm{AM}$ annual-maximum series of data

$\mathrm{AM}_{\min } \quad$ minimum threshold of $\mathrm{AM}$ series

AR atmospheric river (circulation pattern; see PEx)

biv[ariate]-N bivariate-normal statistical relationship

cdf cumulative [probability] distribution function

CdrL Cedar Lake weather station (NWS-COOP)

COOP NWS Cooperative Observation Program network

CoopSS (Federal-State-Private) Cooperative Snow Survey

$\mathrm{COV} \quad$ coefficient of variation, ratio of standard deviation to mean $(=\sigma / \mu)$

CSSL Central Sierra Snow Laboratory (USFS)

d snow depth [cm]

DEM digital elevation model

DEMO Demonstration of Ecosystem Management Options project, sites (USFS)

Dur precipitation duration $[\mathrm{h}]$

DurE model event duration (usually Dur $+6 \mathrm{~h}$ )

ENSO El Niño-Southern Oscillation (atmospheric/oceanic pattern)

$\mathrm{Eq} \quad$ equation (numbered in text)

EV, EV-1 extreme value; EV type 1 (Fisher-Tippett or Gumbel) distribution

ExpD exponential distribution

ExDa, ExDp intercept and slope parameters for ExpD regression

EXE MC model version: exponential distribution, elevation parameters

EXP MC model version: exponential distribution, particular site parameters

$\mathrm{F} \quad$ frequency (in frequency-magnitude context)

F forested site (in SE tests; appendix $\mathrm{H}$ )

F test statistical test on variances

FDR frontal-diurnal ratio of temperature variations in large storms

FluxK factor in kinematic wave speed calculation $\left(3 \mathrm{~K}^{1 / 3} / \phi_{\mathrm{e}} ; \mathrm{Eq} 6\right)$

FluxV wave speed, the product of FluxK and water input (R+M) factor (Eq 6)

g acceleration of gravity $\left(980 \mathrm{~cm} / \mathrm{s}^{2}\right)$

GCM general circulation model, global climate model

$\mathrm{g}_{\mathrm{d}} \quad$ snow grain diameter $[\mathrm{cm}]$

GIS geographic information system 


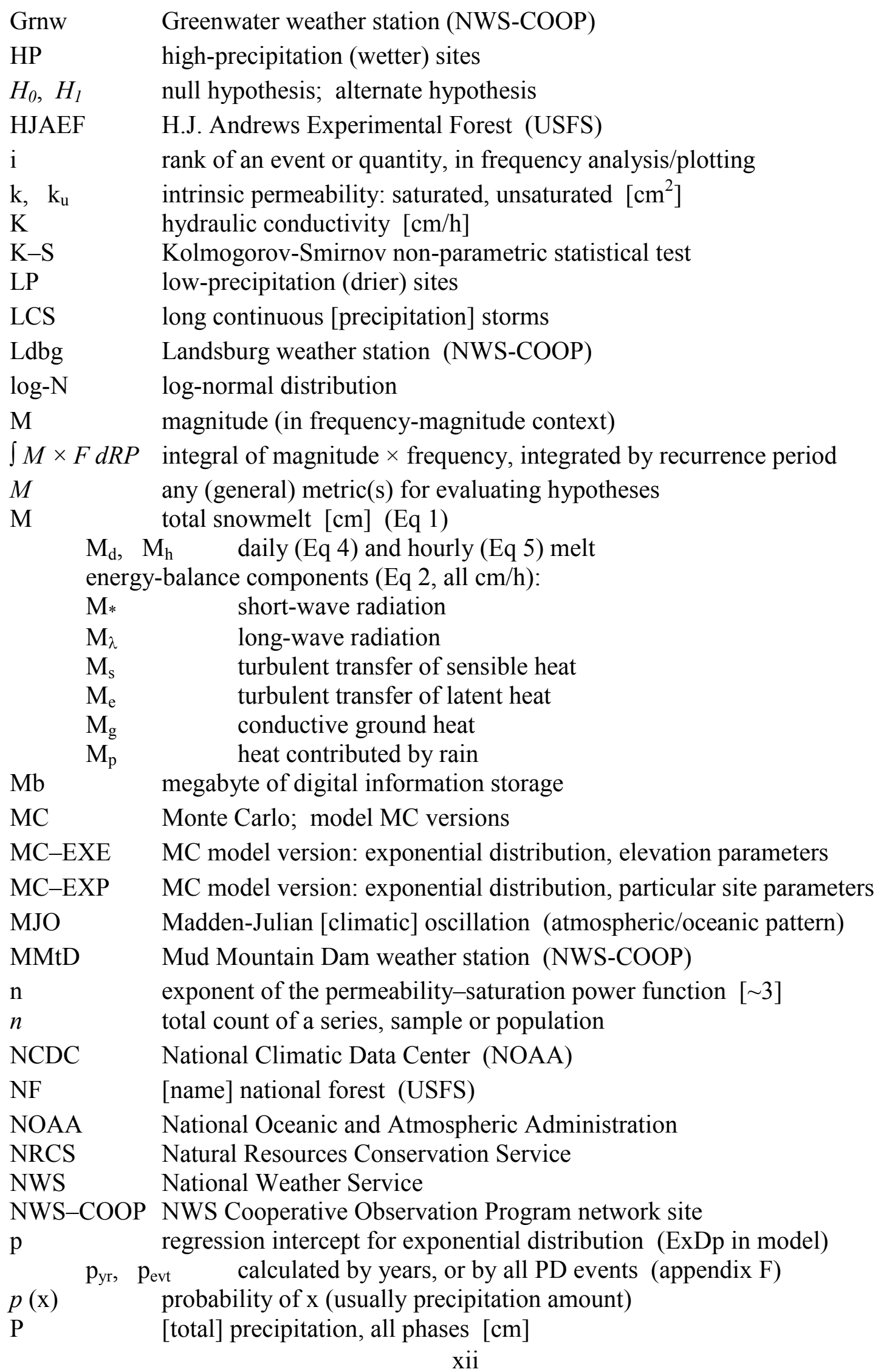




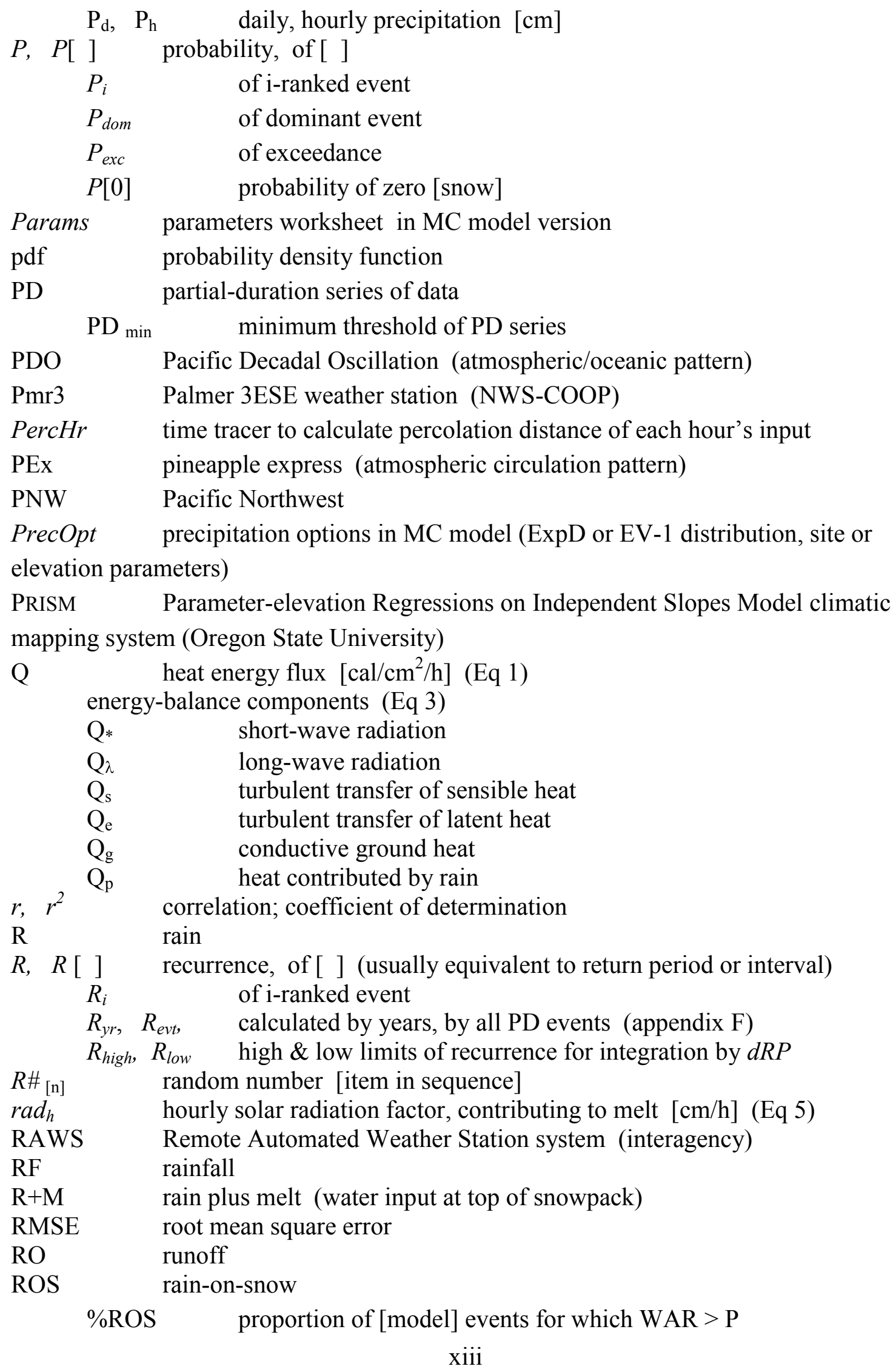




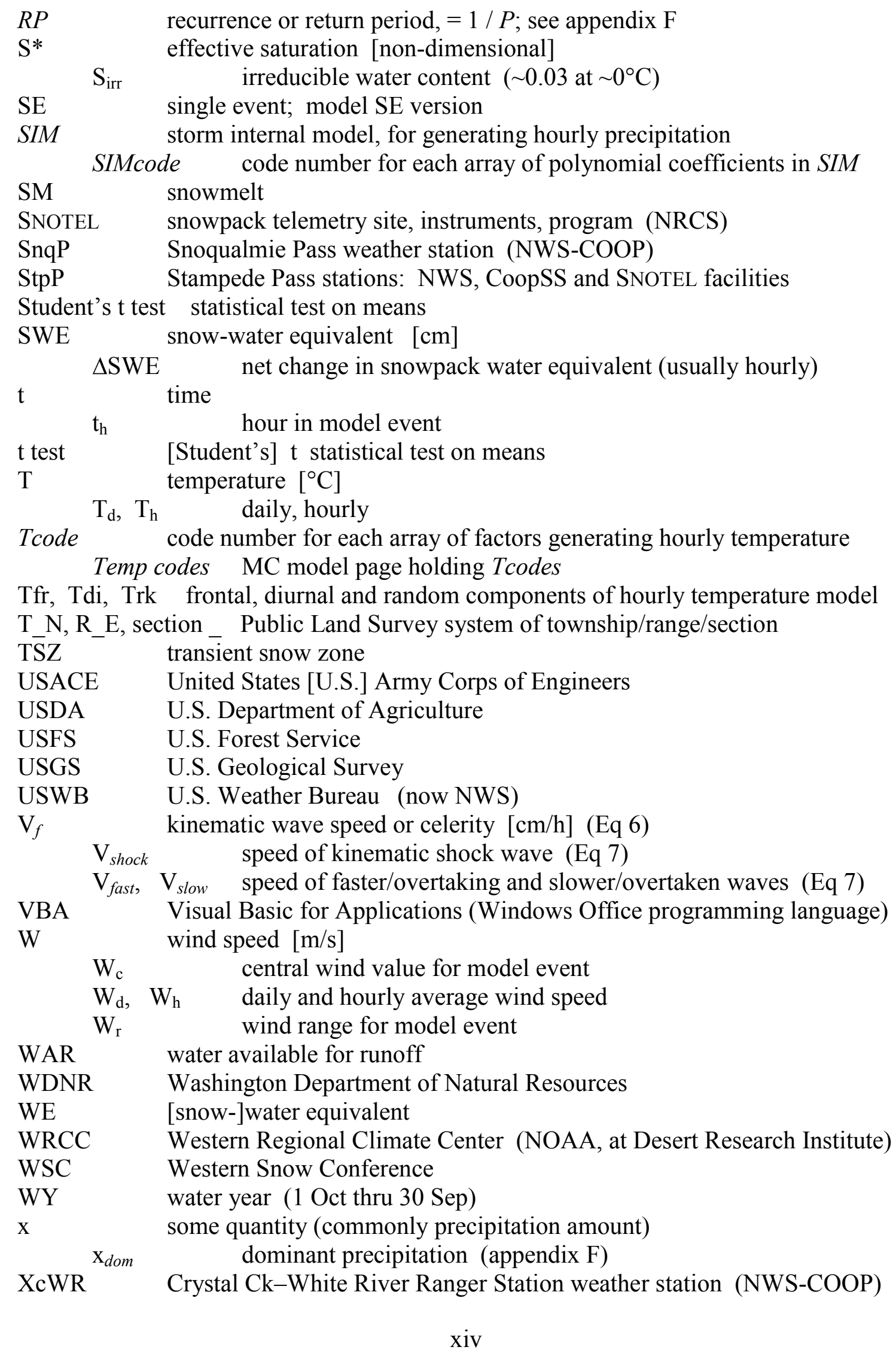


$\alpha$

$\beta$

$\gamma$

$\lambda$

$\Lambda_{f}$

$\mu$

$\mu$

$\rho$

$\rho_{\mathrm{w}}$

$\rho_{\mathrm{i}}$

$\sigma, \sigma^{2} \rho_{\mathrm{s}}$

$\phi$ statistical significance level (probability of type I error)

snow thermal quality ( 0.97 for wet snow) (Eq 1)

location parameter of exponential distribution (appendix F)

$\gamma_{\mathrm{AM}}$ scale parameter of exponential distribution (appendix F)

latent heat of fusion for water $(79.7 \mathrm{cal} / \mathrm{g})(\mathrm{Eq} \mathrm{1})$

mean of a series, sample, population or distribution

dynamic viscosity of water $(0.017921 \mathrm{~g} /[\mathrm{s} \mathrm{cm}])$

density [generally $\mathrm{g} / \mathrm{cm}^{3}$; temperature dependent]

liquid water $\left(\sim 1 \mathrm{~g} / \mathrm{cm}^{3} ; 0.999841 \mathrm{~g} / \mathrm{cm}^{3}\right.$ at $\left.0^{\circ} \mathrm{C}\right)$ water ice $\left(0.917 \mathrm{~g} / \mathrm{cm}^{3}\right.$ at $\left.0^{\circ} \mathrm{C}\right)$

snow density, here generally $=\mathrm{SWE} /$ depth $[\rightarrow$ nondimensional $]$

standard deviation, variance of a series, sample, population or distribution

porosity of porous medium (snow) [non-dimensional] $(\mathrm{Eq} 8,9)$

effective porosity, $\phi$ less voids occupied by water (Eq 10) 


\section{INTRODUCTION}

\subsection{What is rain-on-snow?}

Rain-on-snow (ROS) refers to the hydrometeorologic processes that occur when relatively warm storms invade snow-covered terrain and deliver rain plus meltwater to the runoff system. Though the concept has greater antiquity (Horton, 1915; Clyde, 1929), the first mention of ROS in American scientific literature was by Miller (1950) in an event report of the joint Corps of Engineers-Weather Bureau snow investigations (USACE, 1956). In simplest terms, ROS happens whenever rain falls on a snowpack; but to have broader hydrologic consequence the snow must be in a state allowing water to move through it to infiltrate the soil and/or flow into streams. Indeed, it is the possibility that the water flux leaving a snowpack exceeds rainfall that makes ROS an important phenomenon in some regions.

Hydrologists have long recognized this potential for snowmelt enhancement of storm precipitation. In estimating the magnitude and frequency of the sum of rain and melt for upper Columbia and Snake river basins, Frederick and Tracey (1976) and Richards et al. (1983a,b) adopted the term water available for runoff (WAR; apparently from footnotes in Thornthwaite, 1948) as the total combined liquid that can supply soil infiltration or overland flow (quantified as depth per unit area over some time period). On bare land, WAR is simply the rain amount; but when snow is present, it is the sum of rain plus meltwater, potentially the entire snow-water equivalent $[\mathrm{SWE}]$ of the pack. Note that WAR includes water going both into the soil and off the ground surface, and some workers use the more inclusive water available for infiltration and runoff (e.g., Maclean et al., 1995), but the shorter acronym has been common in ROS studies for at least three dec- 
ades (e.g., Coffin and Harr, 1992).

Although common parlance applies the term to big regional events, it should be noted that there are no particular or unique "rain-on-snow storms". Rather, in any geographic/climatic region, there are suites of storms capable of producing hydrologically significant precipitation; depending on the location, some of these might occur while snow is present, accompanied by enough energy to cause melting and allow liquid passage to the ground surface. But keep in mind that, even in suitable places and seasons, heavy rains can occur with no snow; or, a big storm can produce little or no water for runoff, because most precipitation is snowfall and/or any liquid is absorbed by a deep snowpack. It is the combination of water from rain plus melt exiting the snowpack that makes ROS important, especially when the sum exceeds the event's rainfall alone.

Thus, we can speak of rain-on-snow events, although their definitions depend on context and purpose. Researchers attempting to label events based on weather records use simple, measurable criteria, commonly involving above-freezing temperatures, snow on the ground, and rainfall (e.g., Ferguson, 2000). Groisman et al. (2003) defined a ROS event in the Arctic as a day when $\geq 1 \mathrm{~mm}$ of rain fell on snow at least $3 \mathrm{~cm}$ deep; in the western U.S., McCabe et al. (2007) counted any day on which precipitation occurred and snow depth decreased, inferring that it rained and some snow melted. These definitions treat each observational day meeting the criteria as a separate event, though it may have been part of a longer episode. In contrast, working with data from three research weather stations in the Oregon Cascades, Mazurkiewicz et al. (2008) classified as ROS events any eight or more consecutive 3 -h time periods in which $\geq 0.254 \mathrm{~mm}$ ( $\geq 0.01 \mathrm{in})$ of rain fell on snow-covered ground (capturing $\sim-10$ events per winter, as small as $2 \mathrm{~mm}$ in $24 \mathrm{~h}$ ). 


\subsection{Where \& when do ROS events occur?}

Of Earth's climatic zones, many are too warm for snow, too cold for winter rain, or too dry for much precipitation at all. Most regions receive their heaviest rainfall during the warmer seasons, so ROS is common only where snowpacks can persist into spring months, when precipitation changes from snow to rain. However, many mid- to high-latitude regions support seasonal and/or mountain snowpacks, and can experience heavy rains delivered either by the passage of cool-season cyclonic-frontal systems or warmseason monsoonal or convective storms, producing rain-on-snow. The most vulnerable regions seem to be temperate latitudes in the path of warm-moist air flow, having highelevation (cooler) terrain capable of supporting snowpacks for much of the year.

The geographic scope and variability of ROS is suggested by regional and global inventories of flooding and mass movement, in which the attribution of impacts to ROS has been limited but is increasing. Compendia of floods (Jarvis, 1939; Hoyt and Langbein, 1939; Matthai, 1990; O'Connor and Costa, 2003, 2004; Ashley and Ashley, 2008a,b) commonly classify rainfall and snowmelt as separate causes; they mention combined rain plus snowmelt less frequently, and those chiefly due to spring/summer storms in high mountains such as the Alps and Himalayas. Similarly, in compilations of landslide occurrence (Eisbacher and Clague, 1984; Brabb and Harrod, 1989; Schuster and Highland, 2001), reference to rain plus snowmelt as a triggering mechanism has been uncommon. However, we see growing appreciation that ROS is contributory to these and other hydrologic, geomorphic, and ecosystem processes (e.g., Onesti and Hestnes, 1989; Putkonen et al., 2009). Table A.1 (appendix A) lists a sample of ROS cases and studies in many parts of the world, including Europe, central Asia, Japan, New Zealand, and the 
circum-Arctic.

Among areas where ROS is recognized as a significant hydrometeorological process, the North American midlatitudes from the Rocky Mountains to the west coast are particularly predisposed to heavy rain onto snowpacks. Within this subcontinental span, the Pacific Northwest (PNW) is most liable to frequent ROS, and the focus of my study. For the purposes of this dissertation, I delineate the PNW as generally coincident with rainy, cool-temperate maritime climates, thus including the coastal regions from southern Alaska to northwest California, and inland to the Coast Mountains of British Columbia, the Cascade Range from southern B.C. through Washington and Oregon to northern California, and the Sierra Nevada of central California. The upper Columbia Basin and surrounding mountains, from the eastern Cascades to the Northern Rockies, are occasionally affected by marine air and ROS, and considered here in some discussions.

As westerly winds occasionally direct warm Pacific air toward North America, the windward mountain slopes are most susceptible to orographic precipitation and rising snowlines. In major incidents of rain-on-snow, large fluxes of water delivered rapidly to soils and streams over broad areas are capable of major flooding, channel erosion and mass movement. More commonly, small and moderate ROS events occur almost annually somewhere within this region, with less catastrophic - but nevertheless potentially significant - consequences.

Across this spectrum of potential event magnitudes, ROS happens when seasonal weather circumstances combine rainstorms with existing snow, so storm meteorology is a significant factor. (This description is synthesized from Houze and Hobbs, 1982; Miller, 2002; and Mass, 2008; additional discussion in chapter 4.) Typically, the cool-season 
climate of northwestern North America is controlled by synoptic-scale low-pressure systems, generated on subpolar or subtropical jet streams, approaching from the Pacific Ocean. Because they form over relatively warm and evaporating oceanic waters, such midlatitude cyclones and associated frontal systems can deliver significant amounts of moisture to the continent. Precipitation activity changes as a storm evolves, but the heaviest rains usually fall in the cyclonic warm sector and under frontal bands, and can be prolonged and enhanced during passage over the mountains. A single storm can affect areas up to $\sim 10^{3}-10^{6} \mathrm{~km}^{2}$ and last several days; series of storms rapidly following overlapping tracks can cover larger areas for longer periods. Extreme rainfall commonly involves fast flow of moist air from the Pacific Ocean in filamentous, stationary or slowly shifting low-level jets called atmospheric rivers (Zhu and Newell, 1994, 1998; Ralph and Dettinger, 2011), particularly those paths tapping subtropical air streaming northeastward, sometimes labeled pineapple express. ROS in the PNW is not linked exclusively with such patterns, which can occur without antecedent snow on the ground (see section 4.2). However, major to catastrophic ROS events tend to happen when snow has accumulated down to lower elevations; then large storms deliver heavy rain over several days, while warm moist air causes rapid snowmelt that releases water over a broad region.

Midlatitude cyclonic-frontal systems are most frequent and vigorous from late autumn to mid-winter, coincident with mountain (and sometimes lowland) snow accumulation, making these the prime seasons for ROS in the Northwest (e.g., Dettinger, 2004b). Fewer storms arrive in the warmer months, but monsoonal and convective rains can cause ROS in summer or early autumn, mainly at high elevations. However, I am less concerned with localized summer ROS, or with other kinds of rain- and wind-storms that can 
affect the PNW (Taylor and Hatton, 1999; Miller, 2002; Mass, 2008).

In western North America, the near-coastal mountains are most prone to midwinter melt because they typically support warm snowpacks, in which temperatures remain near $0^{\circ} \mathrm{C}$ for most of the cold season, not just in spring (Smith, 1974). Warm snow is more susceptible to ROS because it requires little additional energy input for melt, and allows percolation without initially freezing most of the water within the snow. Warm packs, characteristic of maritime midlatitude regions, have irregular accumulation and ablation patterns; in contrast, cold snowpacks $\left(<<0^{\circ} \mathrm{C}\right)$ are common in polar, mid-continental or high alpine climates, and are more stable through the winter. The warmer snows of low- and mid-elevations are most vulnerable to winter rainstorms, as well as long-term warming (Nolin and Daly, 2006).

The geographic and seasonal setting of ROS in the Northwest influences the magnitude and frequency of water inputs. Over durations of many hours to many days, rainfall plus snowmelt in significant ROS events can produce water volumes greater than can be generated either by cool winter rainstorms without melt, or by spring melt without rain. At shorter durations, maximum rainfall intensities in this region (up to $\sim 3 \mathrm{~cm} / \mathrm{h}$ for $\sim 1-3 \mathrm{~h}$, according to rain-gauge data) are usually delivered by thunderstorms or convective cells embedded in frontal systems; but the structural collapse of a saturated snowpack during ROS can also release large amounts of water over a short time.

The relative contributions of rain versus meltwater in ROS usually differ seasonally. Rain is the main water input during most events (Mazurkiewicz et al., 2008), especially in autumn to winter and at lower to middle elevations, and the increment of snowmelt enhances the rain's effects. For example, in the great storm of 5-9 February 1996, 
Saddle Mountain $(990 \mathrm{~m}$ ) in the Oregon Coast Range received $\sim 52 \mathrm{~cm}$ of rain while a snowpack with $\sim 35 \mathrm{~cm}$ SWE melted, combining for $\sim 87 \mathrm{~cm}$ total water input over five days (maximum observed, though other stations had more rain or more melt; Taylor, 1997, Marks et al., 1998; Colle and Mass, 2000). But during spring, particularly at higher elevations with more persistent packs, snowmelt runoff normally occurs over many weeks, during which a rainstorm can increase the melt and runoff rates. This was the situation in 1948, when a heavy snowpack in the inland Columbia Basin finally began melting fast under warm temperatures in late May; then several moderate monsoon storms accelerated melt and added rainwater, causing flooding from Montana to Oregon (Paulsen, 1949; Speers et al., 1990).

These two were extreme cases, but significant augmentation of rain with snowmelt can be responsible for increased runoff and erosion during many lesser events. Most of the major episodes of flooding and slope instability in the PNW occur during ROS conditions. Information on many regional events has been compiled by Harr (1981), Williams (1991), Hubbard (1991, 1994), Taylor and Hatton (1999), Miller (2002), and Mass (2008), providing basic information for the discussion below; case studies are listed in Table A.1. The Northwest's recorded history of ROS starts no later than December 1852January 1853, an event mentioned in pioneer newspapers and memoirs (The [Olympia] Columbian, at www.sos.wa.gov/history/newspapers; Meeker, 1905). Disastrous flooding struck from California to Washington in 1861-62, destroying several pioneer towns in the Willamette Valley (Miller, 1999). In February-March 1910, warming and rains contributed to avalanches claiming more than 110 lives, most of them when trains and buildings were swept downhill by huge wet snow-slides at the west portal of the Stevens Pass tun- 
nel in the North Cascades, the deadliest avalanche in U.S. history (Beals, 1910; Krist, 2007). The flood that drowned Vanport on Memorial Day 1948 was caused by spring ROS in the upper Columbia Basin (Paulsen, 1949). The catastrophic December 1964 and February 1996 events were triggered by a combination of low-elevation snow followed by very warm and heavy rainfall across the PNW lasting several days (Lucia, 1965; Waananen et al., 1970, 1971; Laenen, 1997). ROS also occurred in western Washington and/or Oregon in the winters of $1965,1975-76,1977,1980,1983,1989-90,1990-91,1996-$ 97, 2007, 2009, and 2011 (see Table A.1). Most of these events involved landslides and other problems as well as flooding and channel erosion: e.g., in December 1964 (Dyrness, 1967; Rothacher and Glazebrook, 1968), December 1980 (Gallino and Pierson, 1984, 1985), and 1996-97 (Harp et al., 1996; Gerstel et al., 1997; Laenen, 1997; Burns et al., 1998; Hofmeister, 2000).

\section{$\underline{1.3 \text { ROS literature review }}$}

The history of snow hydrology has been summarized by Colbeck (1987) and Mergen $(1993,1997)$, sources for much of the synthesis here. Investigations have followed multiple intertwining paths, with many aspects pertinent to rain-on-snow and applicable to this project. Table A.1 (appendix A) presents a partial catalog of such studies.

Scientific appreciation of ROS grew through the $20^{\text {th }}$ century. Research and commentary on the association of rain plus snowmelt by Robert Horton $(1905,1915,1941$, 1945), Walter Parsons (1940, 1941), James Church (1933, 1935), George Clyde (1929), R.W. Gerdel $(1945,1948 a, b)$ and other hydrologists appeared in proceedings of the American Geophysical Union Hydrology Section, the Western Interstate Snow Survey Conference (later Western Snow Conference), and international publications. A particular 
focus of attention was the role of ROS in flooding in the U.S., especially in mid-elevation mountain regions of the West (Jarvis, 1939; Hoyt and Langbein, 1939; Parsons, 1940; P.E. Church, 1940).

This early work was facilitated by the growing network of weather stations and snow courses in North America (section 4.4), and stimulated by engineering projects addressing mountain transportation, water supplies, hydroelectric generation and flood-control facilities, plus cold-regions warfare during and after World War II. Most notably, the U.S. Army Corps of Engineers and U.S. Weather Bureau conducted the Cooperative Snow Investigations project in the West in 1945-60 (USACE, 1956, 1960). From the 1960s through 1990s, much effort focused on the energetics of snowmelt, and the hydraulic properties and processes of water movement through snow. Samuel Colbeck's (1972 and later papers) adaptation of porous-medium flow equations was followed by many theoretical and field studies of snowpack percolation having applications for ROS.

Particular attention regarding ROS in the West has concentrated on forestry, as logging in mountainous terrain motivated examination of the consequences of harvest on snow accumulation before and melt rates during ROS, and consequently on runoff and erosion (e.g., Griffin, 1918; Anderson and Hobba, 1959). The ROS-forest hydrology work of Dennis Harr $(1981,1986)$ and colleagues (Christner and Harr, 1982; Berris and Harr, 1987; Coffin and Harr, 1992) helped inspire more studies, including this one, some of which were initially reported at the ROS-themed 1983 Western Snow Conference.

McCabe et al. (2007) extracted data on ROS days from 4318 weather stations throughout the continental western U.S. (1949-2003), to examine the broad-scale spatial and temporal characteristics. Their findings documented many ideas already in circula- 
tion: ROS can occur almost anywhere, but is more common in the Pacific Northwest; most events happen in October through May, although they can fall in other months, particularly at higher sites; ROS tends to occur more often in the northern states in $\mathrm{La}$ Niña winters, and during El Niño years in the southern tier; long-term trends suggest that the frequency of ROS is shifting uphill as warming reduces snowpacks at lowland sites but delivers more rain at higher elevations.

Several research projects have attempted to explore ROS in the Northwest by combining the instrumental record and energy-balance techniques, with varying success. Van Heeswijk et al. (1996) tried to merge standard weather observations with plot studies from the Cascades to investigate and model the effects of climate and local conditions on ROS; they concluded that there were not enough data to precisely simulate snow accumulation and melt over extended time periods. Other investigators had the benefit of specialized instruments and models. For the February 1996 ROS event, Marks et al. (1998) examined weather records and research-site data (radiation, humidity, etc.) along an elevation transect across the western Oregon Cascades to determine that sensible and latent heat exchange contributed most of the energy for snowmelt. For the same storm, Colle and Mass (2000) used weather radar along with rain-gauge data from southwest Washington and northwest Oregon to help evaluate and improve the forecasting ability of a mesoscale meteorological model. In the Oregon Cascades, Mazurkiewicz et al. (2008) analyzed eight years of weather and snow data from three well-instrumented sites (H.J. Andrews Experimental Forest) to ascertain the energy components of snowmelt throughout the year, including the contributions of ROS events, and the variations with elevation, aspect and wind exposure. They found significant differences among melt days, with 
ground heat and net radiation contributing more energy most of the time, although turbulent sensible and latent transfer are often dominant in major ROS events.

Overall, the research history has illuminated five generalizations about coolseason ROS events in the Pacific Northwest. (1) ROS is favored by shifts from cooler weather, during which snow accumulates/persists, to warmer and rainy conditions, with a rise in freezing level; this is a common occurrence in the PNW, where the weather oscillates as trains of low- and high-pressure centers and associated fronts pass across the region (Miller, 2002). (2) Accounting for winter streamflows in the Northwest "must include the determination not only of the precipitation that falls during the [storm], but also of the antecedent precipitation stored in the form of snow and of the factors that accelerate or retard its melting", particularly in the most ROS-susceptible middle mountain elevations (Hopkins, 1940, p 1006). Effects can differ greatly, for example between light rain on deep snow versus prolonged rain on a thinner pack (Horton, 1941). (3) Energy sources causing snowmelt during ROS differ from those during clear-weather spring conditions (USACE, 1956; Harr, 1981; Mazurkiewicz et al., 2008). Turbulent transfer of sensible and latent heat and long-wave radiation usually dominate during ROS, in proportions depending on site exposure and specific weather conditions; solar radiation is minor in cloudy weather, short days and low sun angles. Rain itself adds little heat, but can carry it deep into the pack and release latent heat by freezing there. These conditions allow simplification of snowmelt energy-balance calculations for ROS. (4) ROS should be most hydrologically important in middle elevations, where warm, shallow snowpacks are common and can quickly yield meltwater to the ground; as opposed to the warmer but normally snow-free lowlands, and snowy but colder highlands where any liquid can be held 
and refrozen in the pack (Hopkins, 1940; Brunengo, 1990). (5) Especially in middle and lower elevations, mature forest vegetation can affect the amount of snow available for melt. Accumulation on the ground is commonly depressed by ablation of snow caught in the canopy; then during a subsequent rainstorm, limited wind speed in the forest reduces the melt due to turbulent heat transfer. Consequently, relative to forest stands, natural or harvested clearings in mid-elevations tend to accumulate greater amounts of snow and allow accelerated melt during ROS conditions (Harr, 1981; Marks et al., 1998; Storck et al., 2002).

\subsection{Importance of ROS}

Rain-on-snow most directly affects elements of the hydrologic cycle, but water is closely involved in geomorphic and ecosystem processes, as well as land use and engineered structures, so ROS can influence many components of the natural and built environment. Some of these issues (flooding, landslides) have been mentioned; scientific interest has also focused on several other topics in which ROS has practical consequences.

The short-term hydrologic effects of ROS are obvious: melt augments rainfall, so infiltration and runoff exceed magnitudes expected from storm precipitation alone. In natural and artificial drainage systems (roof drains, ditches, storm sewers), the immediate result can be discharges beyond usual or design flows, causing flooding, channel erosion, or structural failure; many references cited above (and Table A.1) deal with such effects from historic ROS events. Beyond event-scale flow effects, ROS can change the temporal distribution of seasonal runoff. In the western U.S. and Canada (and many other regions), water stored in natural snowpacks is a crucial component of spring and summer runoff, important for natural processes and human infrastructure (Meier, 1990). Early ROS- 
spawned melt can increase autumn-winter outflow and so reduce streamflows later in the year (Mote, 2003; Mote et al., 2005), perhaps exacerbated by early spill from reservoirs to ensure flood-holding capacity. Even in a winter with adequate precipitation, major ROS can reduce the water available in spring and summer, almost imitating a drought year. In some basins, when runoff comes too early in the season, low discharge in the dry season might affect municipal, industrial, hydropower and transport operations; anadromous fish passage or agricultural irrigation may be especially sensitive to deviations in flow volume and timing (Mote et al., 2005).

Over many years, a changing balance among rain, snow and ROS in a managed watershed could alter the requirements for water supplies and storage. Runoff in western North America naturally fluctuates at interannual to multidecadal scales with warm/dry and cool/wet El Niño-Southern Oscillation (ENSO) episodes and Pacific Decadal Oscillation (PDO) cycles (McCabe and Clark, 2005). Long-term warming through the late $20^{\text {th }}$ century, with essentially no long-term precipitation trend, is causing reductions in snowpack water content and rising snowline elevations in the PNW and elsewhere in the West, increasing the occurrence of rainfall relative to snowfall (Mote, 2003; Mote et al., 2005; Knowles et al., 2006; McCabe et al., 2007). As temperatures warm and snowpacks thin, ROS occurs at higher elevations (McCabe et al., 2007), changing the frequency and damage potential. Researchers have examined climate scenarios for the next century in the Northwest (Mote et al., 1999; Nolin and Daly, 2006), using models that combine climatic drivers with snowpack and watershed responses to explore possible changes; for example, identifying British Columbia rivers in which flows are likely to increase or decrease under potential future conditions (Loukas et al., 2000, 2002). Others apply global 
climate models to evaluate long-term rising snowlines and shrinking snowpacks, and possible alterations of water resources and their allocations (McCabe and Wolock, 1999); Salathé et al. (2009) adapted several regionally focused models to estimate potential monthly average temperature and precipitation, 1 April snowpacks, and frequency of extreme precipitation events through 2060 .

Although most hydrologic attention has been on water quantity, some has focused on chemical transport during rain-on-snow. Field studies in southern Ontario measured solutes (hydrogen, sulfate and nitrate ions) and isotopes $\left({ }^{18} \mathrm{O}\right)$ in snow, soil and streams, finding that significant export takes place during mid-season ROS (Maclean et al., 1995; Eimers et al., 2007). These amounts often exceed the proportional snow-water volumes lost during an event, and constitute chemical outputs from the snowpack (and probably the soil) that are shifted from spring to winter, affecting groundwater and stream chemistry and biota.

Water is the dominant weathering and erosion agent in humid temperate climate zones such as the PNW, so storm or seasonal alterations in water movement due to ROS can influence geomorphic processes, especially if maintained over a long time. Influx of water causing saturation in weak slopes is the triggering mechanism for a large proportion of landslides and debris flows (Eisbacher and Clague, 1984; Wieczorek, 1996; Wieczorek and Glade, 2005; Sidle and Ochiai, 2006), and big ROS events in the Northwest usually cause widespread mass movement (cases in section 1.2 and Table A.1). Debris flows and floodwaters further translate ROS inputs into major channel-forming episodes, especially important in mountain streams (e.g., Grant and Swanson, 1995).

In higher/colder snow-dominated environments, rainfall and melt can cause in- 
stability by saturating the snow mantle, initiating movement and subsequent entrainment of soil, vegetation and anything (or anybody) in the way. Avalanches and snow slides are familiar in steep mountains, and can be exacerbated by ROS in the Cascades and other ranges (Conway and Raymond, 1993; Krist, 2007). In addition, ROS can trigger wetsnow movements variously called slushflows, slush avalanches and slush lahars, as identified in midlatitude Asia (Elder and Kattelmann, 1993; Anma et al., 1997) and high-latitude regions of North America, Scandinavia and Russia (Onesti, 1985; Hestnes and Sandersen, 1987; Nyberg, 1989; Rapp, 1995; Gude and Scherer, 1995; Hestnes, 1998; Scherer et al., 1998; Larocque et al., 2001).

Rain-on-snow can affect ecosystem conditions and processes as well. In the Pacific Northwest, forest plant communities are partly governed by the presence and persistence of snowpacks; snow tends to be transient under frequent winter ROS, influenced by local elevation, aspect, and microclimate (Franklin and Dyrness, 1973; Henderson et al., 1992). Pre-storm snow accumulation, and energy input and melt during ROS, can be affected by the location and size of forest openings, as mentioned (section 1.3, Table A.1). In circum-Arctic regions, snowmelt and/or ice-layer formation associated with ROS can reduce access to forage, sometimes resulting in mass mortality of ungulates and resulting food shortages among subsistence herders and hunters (Putkonen and Roe, 2003; Grenfell and Putkonen, 2008; Putkonen et al., 2009; Rennert et al., 2009).

Rain-on-snow processes can constitute direct problems or even hazards for people if they strike vulnerable populations, structures and resources. Besides the potential for extreme ROS-enhanced water inputs to yield damaging high flows and mass movement, already addressed, other effects on human works have been recognized. Heavy snow can 
damage structures, prompting development of methods to anticipate probable snowpack size (Isyumov and Davenport, 1974; Tobiasson et al., 2002); the addition of water in snow increases the weight (especially if slush and ice inhibit drainage), possibly exceeding structural design limits, so estimates of ROS loading must be a consideration in some environments (Colbeck, 1977c; Azuma, 1985). In steep, snowy mountains such as the North Cascades, ROS can trigger snow avalanches and slushflows (Conway and Raymond, 1993; Conway and Benedict 1994), obstructing transport routes and damaging resource-exploitation facilities, recreation areas, houses and shops (and their occupants).

In summary, ROS redistributes the quantities and timing of water flows through the hydrogeomorphic system, within a storm or across a winter or over many years. It can alter the water balance, discharge characteristics, and biogeochemistry of hillslopes to large basins; change the ability of mass-wasting and fluvial processes to transport sediment and debris; present problems ranging from minor engineering complications to serious but manageable hazards to occasional calamity. The degree of consequence posed by ROS depends on its occurrence rates and quantity in an area.

\subsection{Variability \& probabilistic aspects of ROS frequency \& location}

Even within a specific region such as the Pacific Northwest, there is no canonical "rain-on-snow storm" because its incidence depends on a large array of environmental variables. Whether ROS occurs in a specific place and time, and the magnitude of its hydrologic effects, are contingent on appropriate storm characteristics and an available snowpack. The variability in the interrelated controlling factors makes ROS phenomena profoundly probabilistic. 


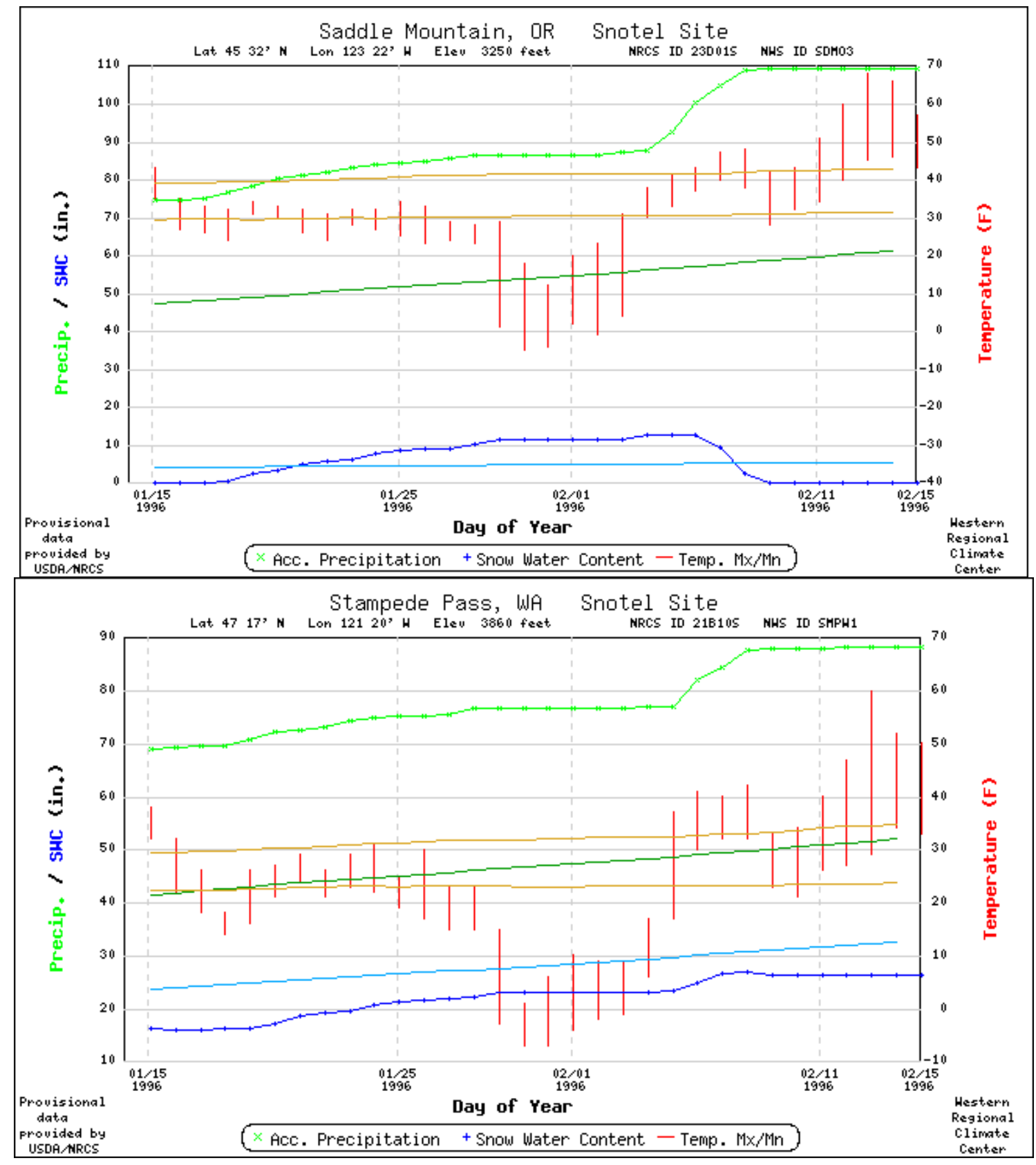

Figure 1.1. SNOTEL (snowpack telemetry) data for the month around ROS event of 4-9 Feb 1996. Vertical red bars represent range of daily temperatures; upper green lines indicate cumulative precipitation, rising during the storm; note that warming and heavy rain started a day later at Stampede than at Saddle Mtn. Bottom blue lines show daily SWE, dropping steeply at Saddle Mtn (melt-out), rising and then dropping slightly at Stampede Pass (snow accumulation followed by minor melt and/or outflow). Smooth lines in similar colors show average seasonal values of precipitation, high/low temperature, and SWE. Graphs from NRCS SNOTEL web sites (www.wcc.nrcs.usda.gov/snow/).

The irregularity is obvious even within one event. Differences in local outcomes are illustrated by the major regional ROS of early February 1996 using charts from two 
observation sites (Fig. 1.1; case studies in Laenen, 1997; Marks et al., 1998; Colle and Mass, 2000; McCabe et al., 2007). Beginning in mid-January, much of the Northwest experienced cold snowy weather, followed by several days of heavy precipitation with unseasonably warm temperatures. As mentioned (section 1.2), Saddle Mountain in the Oregon Coast Range $(990 \mathrm{~m})$ collected $\sim 52 \mathrm{~cm}$ of rain along with complete melt of $\sim 35 \mathrm{~cm}$ water-equivalent of snow, combining for $87 \mathrm{~cm}$ over four days. But at Stampede Pass in the Washington Cascades, higher in elevation $(1175 \mathrm{~m})$ but off the main storm track until a day later, much of $\sim 28 \mathrm{~cm}$ rain and $\sim 8 \mathrm{~cm}$ melt was absorbed by a deeper snowpack, with net $\sim 20 \mathrm{~cm}$ to the ground. This single ROS event had critically different behavior and hydrologic effects not only at these two sites, separated by $\sim 200 \mathrm{~km}$ distance and 185 m elevation, but among other locations much closer to either of them (Taylor, 1997).

Thus, it is not surprising that rain-on-snow also varies tremendously among different events and across broader spatial scales, especially in a mountainous landscape. For the subset of storms that interact with snow and become ROS events, the occurrence and characteristics are governed by several kinds of interacting variables. (1) Climate and weather patterns prior to an event determine whether snow is present, and if so its distribution, depth, and hydraulic properties. (2) Hemispheric- and synoptic-scale atmospheric circulation dictate whether a warm wet storm will approach a particular area. (3) Mesoscale to local weather during the storm controls temperature and wind; precipitation amount, duration, phases and intensity; and their variations (such as changes in the freezing level). (4) Snowpack properties (density, porosity, etc.) regulate its reaction to energy inputs and the introduction of rain and meltwater. (5) Regional to local elevation, aspect, terrain, exposure and vegetation affect the microclimate, distribution and character of the 
snowpack, orographic effects on precipitation, and the ability of available energy to cause melting.

Most of these factors have a wide range of possible values, varying spatially and temporally; each in turn might be affected by other conditions or processes. Some are fixed (such as site elevation), or constant through a storm but perhaps not over a longer time (e.g., vegetation). However, some vary over hours and days, among them the major inputs (precipitation) and outputs (melt rate, water to infiltration and runoff) of ROS. Ultimately, many factors can be imagined and expressed as probabilistic (or stochastic) quantities: as frequency distributions of random variables.

Probabilistic thinking is easier for some components than others. Certain conditions at the beginning of an event (e.g., thickness and water content of the snowpack) and characteristics of the storm itself (e.g., initiation date, duration, precipitation amount) are simple quantities amenable to observation and statistical analysis. Conversely, the patterns of rainfall and temperature through an event are controlled by complex meteorological mechanisms, in which randomness may be one ingredient. Some processes during ROS can be better described using deterministic physical principles, such as the energy balance causing melt and percolation of meltwater through a pack. Nevertheless, with a conceptual model of multiple interconnected frequency distributions, it is clear that a vast number of combinations are available to be sampled in any given storm and possible ROS event, ultimately producing a huge potential pool of specific outcomes.

Furthermore, many issues of ROS phenomena are reduced to questions about the frequency and magnitude of water flux occurring over some duration: especially whether the delivery of water to infiltration and runoff, as distinguished from the total precipita- 
tion, is in greater or lesser amounts, more or less often. These problems are amenable to other probabilistic techniques, particularly the methods of frequency analysis long applied to precipitation and streamflow. Such tools are utilized in this project; however, as will be seen, the kinds of observational records on which frequency analysis normally depends are inadequate for my purposes, requiring estimation and modeling strategies.

The frequency and impact of rain-on-snow, in individual events and long-term, also depend on location. Within the Pacific Northwest, the distribution and macro-behavior of storms (category 2 on page 18) are at the whim of stochastic weather forces. But in any limited subregion or watershed, meso- to micro-scale responses to storms (perhaps ROS) depend on conditions such as elevation, aspect and vegetation (category 5), which collectively govern exposure to sun, wind, rain and snow. Among these, elevation should be a dominant attribute of a site or basin, having first-order control on temperature and snowpack, and substantial influence on precipitation amount, duration, intensity and phase (Barros and Lettenmaier, 1994). Orographic effects are evident in most cool-season storms and ROS events in the PNW, typically involving rain at low levels, snow high in the mountains, and irregular oscillation among rain, snow, and sleet/graupel/freezing rain in a fluctuating middle band.

To define the geographic localities where ROS occurs most often, and where it is liable to have the greatest significance in terms of runoff and landscape response, attention in the wet western Northwest concentrates on the middle elevations, where seasonal snowpacks are likely to be present yet winter storms can be warm enough to allow rain and cause melt. Accordingly, scientists and land managers have spent some effort determining the regional elevations in which ROS frequency and significance are maximized. 
Given the probabilistic nature of ROS, a subordinate notion such as "middle elevation zone conducive to ROS" must also be quantitatively flexible. First, the term zone does not require precise limits in area or elevation (although such might be necessary in management or regulatory applications of the concept); I expect the bounding and optimal elevations to be approximate, if they can be identified at all. Moreover, several concepts and terms have mixed and overlapped in practice and literature. Hydrologists have described a transient snow zone (TSZ) as a broad elevation range in which the snow level fluctuates through the winter: as cold and warm air-masses alternate over a region, packs accumulate on snowy days and melt to some extent during warmer weather (slowly under cool sunshine, quickly in wind and warm rain). In western North America, much of the midwinter ablation in this zone is due to rain-on-snow. Hopkins (1940) estimated the TSZ by noting that winter floods in the Puget Sound region usually emanate from storm rainfall plus snowmelt at elevations of 2000-6000 ft ( 600-1800 m). Others reckoned TSZ elevations in Washington and Oregon at 300-1100 m (e.g., Berris and Harr, 1987; Coffin and Harr, 1992; van Heeswijk et al., 1996). Department of Natural Resources staff mapped approximate elevations of five precipitation bands for most of Washington, including a peak-ROS zone and adjacent rain- and snow-dominated areas; boundary levels varied locally, based primarily on 1 January SWE available for melt by a standard 10-y 24-h storm as modified by other geographic attributes (Brunengo et al., 1992a,b; Brunengo, 1995). From weather records, McCabe et al. (2007) found a slight elevation mode for ROS at $\sim 500-1000 \mathrm{~m}$ across the western U.S.

In the Northwest, we expect rain-on-snow to be rare at lower elevations where snow is uncommon and sparse, and also rare at higher elevations where colder tempera- 
tures limit winter rain and melt. If we deduce that ROS should thus be more common in middle elevations, and also more often hydrologically significant there in terms of infiltration and runoff, it follows that the effects of ROS should also be concentrated in the middle elevations.

We know that big storms can bring about substantial to permanent changes in the landscape, such as huge landslides, newly-dammed lakes, channels reamed by debris flows, and river avulsion. Many such episodes occur during major rain-on-snow events, particularly in the Pacific Northwest (section 1.2, Table A.1). I have speculated (Brunengo, 1990) that a long-term prevalence of ROS events in mid-elevation zones might increase the action of mass movement and high flows in such preferred elevations sufficiently to affect landforms and channel morphology. If any geomorphic or ecosystem processes occur with greater frequency and efficacy within a middle-elevation ROS zone, then such areas (and perhaps those downhill and downstream) might show evidence of this enhancement in the form of distinct rates, landforms, or habitat conditions.

Such geographic issues also come into play while contemplating potential change in some aspects or effects of ROS in western highlands. If a long-term concentration of ROS events in mid-elevation zones can boost hydrogeomorphic processes sufficiently to affect hillslope or channel morphology, then altering the timing, frequency and location of ROS might modify the behavior of regionally important landforming processes over the long term. Such changes may be possible: at minimum, extensive land-use alterations such as basin-scale forest harvest seem able to modify the frequency and magnitude of some flows in some streams (e.g., Harr, 1986; Jones and Perkins, 2010). Furthermore, shifts in the elevation distribution of ROS frequency as a response to climatic warming 
could alter the geography of hazard and risk for flooding, mass wasting, and engineering problems. For example, apparent snowpack shrinkage reduces the occurrence of ROS at lower elevations, especially in autumn and spring (McCabe et al., 2007). Uphill migration of the snowline can also change geomorphic processes and rates: the absence of a snowpack to absorb heavy rainfall and buffer infiltration can allow increased mass movement and winter streamflows in mountains heretofore snow-covered for more of the year. On Cascade volcanoes the rains of November 2006 (Neiman et al., 2008b; Pirot, 2010), on bare slopes below $\sim 1300 \mathrm{~m}$, could have produced quite different local effects: probably worse (ROS enhancement) if/where melt of deeper yet vulnerable snowpacks added to runoff; maybe not as bad if/where thick snow was able to absorb the rain.

Thus, storm behavior is governed by numerous interrelated physical processes, many having random components; then, ROS behavior expands the range of relevant environmental variables (is there snow? how much melts?). The inconsistencies, even in a single event (illustrated by February 1996), show some of the limitations of the instrumental record in analyzing one ROS event across broad areas and elevation ranges, let alone generalizing over many decades. Part of the problem is geographic - few observation sites, especially at high elevations; part is temporal - most records are short; part is operational - they don't measure everything we would like to know, particularly the amount of liquid water reaching the ground.

Among other problems, this makes it difficult to establish a quantitative catalog of past ROS events. Classification criteria would have to specify a semi-arbitrary combination of location (e.g., a particular station, basin or elevation band), amounts and proportions of rain versus snow falling in a certain duration, minimal snowpack in that time per- 
iod, and liquid output from the snowpack. Such quantities are necessary to perform comparative frequency analysis of historic precipitation and WAR, but even for observation stations, most are ambiguous or absent in the instrumental record. Consequently, most identifications of the TSZ or ROS zone are based on local experience (see section 7.2); elevations of a peak ROS zone have not been documented using the record or modeling in this or any other region, apparently. This is unsurprising: given the multitude of controlling factors and processes, over time, the transient-snow or peak-ROS zone must be considered a probabilistic elevation band. 


\section{RESEARCH QUESTIONS, HYPOTHESES, APPROACH}

\section{$\underline{2.1 \text { Research questions }}$}

The goal of my dissertation is to address certain issues of frequency-magnitude and elevation tendency of rain-on-snow activity. Specifically, I hope to determine the location of the probabilistic mid-elevation ROS zone, with respect to observation sites and across a representative part of the Pacific Northwest landscape.

We have seen (chapter 1) that ROS is an important hydrometeorological phenomenon, in much of western North America and particularly in the PNW, yet many facets are elusive due to the sporadic occurrence and geography of the events. The climaticmeteorologic processes contributing to ROS are profoundly variable, as are the effects in any particular event or site. Nevertheless, some of this variability can be attacked using probabilistic concepts: in particular, the association between the amount of precipitation falling during a storm and the amount of liquid water entering the runoff system in a comparable time period; and the ways in which this association varies with elevation, over the long term. Resolving these initial problems should advance our understanding of this branch of snow hydrology: the knowledge and methods developed here can be applied to examine ROS-influenced frequency relations among areas having different terrain elements (location, aspect, wind exposure, etc.), vegetation (mature forest, plantation, natural or harvest clearings), and spatial/temporal shifts associated with changes in land use and climate.

This research addresses two fundamental aspects of water input during large storms and rain-on-snow, to better define which kinds of events are most hydrologically significant over the long term, and the timing and location of their occurrence: 
- Precipitation versus water available for infiltration and runoff: Can the magnitude of liquid water delivered to the ground during ROS events differ significantly from the measured total (liquid plus solid) precipitation - i.e., do rain-gauge records during such events over- or underestimate water available for infiltration and runoff? If so, what are the "true" frequency characteristics of water inputs for a station?

- Elevation: Is the inference correct that ROS is more common in the middle elevations, where winter rain is most liable to fall on existing snowpacks? Is there a definable elevation zone of maximum long-term hydrologic and geomorphic significance for ROS?
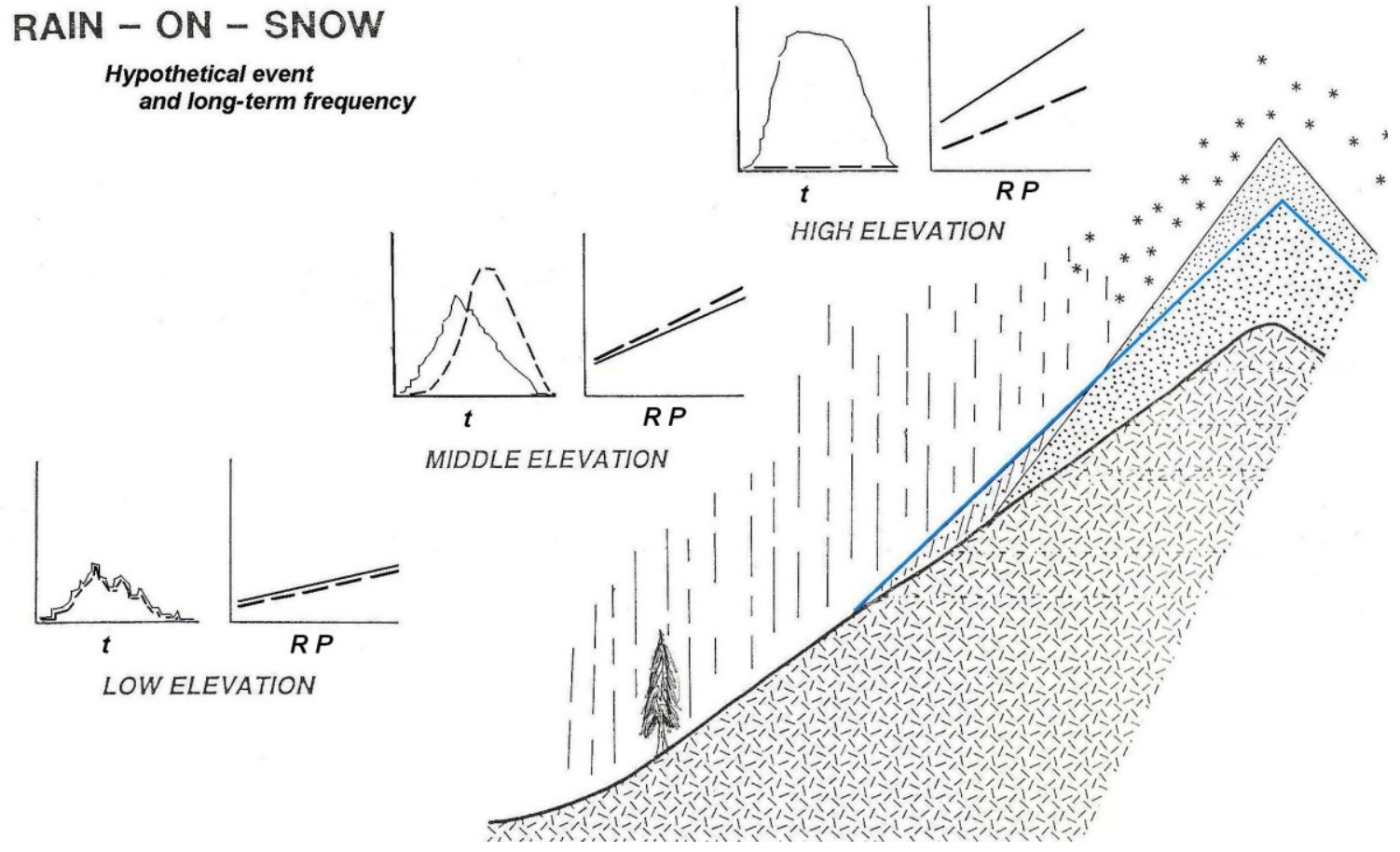

Figure 2.1. Elevation transect before/after a hypothetical storm. Downhill edge of preexisting snow (blue) melts, but new snow accumulates at higher elevation. At three supposed weather stations, left: combined hyetographs (precipitation gauges)-hydrographs (snow pillows or lysimeters), $t=$ time during storm event; right: frequency-magnitude graphs, for some duration (here entire events), $R P=$ recurrence period ( $=1$ / probability). In all plots, $\mathrm{y}$-axis is amount of precipitation (solid lines) and water available for runoff (dashed lines). 
Hypotheses regarding the frequency and significance of ROS are illustrated on a simplified PNW mountain range during a typical storm (Fig. 2.1). Rain falls in the foothills and a rising freezing level causes melt at the lower edges of the snowpack, while snowfall continues at higher elevations. The volume of liquid water generated at any location is sensitive to the preexisting pack properties; the magnitude, duration and phases of precipitation; and the local weather (temperature, wind, etc.) during the storm.

At low elevations there is liable to be little or no snow on the ground when such events begin, so the contribution of snowmelt to runoff will typically be rare and minor, and thus little difference between the hydrographs for precipitation (hyetograph) and WAR. Exceptions occur: snow can accumulate down to sea level, so sometimes melt enhances WAR in the lowlands. At highest elevations, storm precipitation is likely to be greater in volume and longer in duration due to orographic enhancement, but falls as snow during many storms. Even if rain falls or meltwater is generated, some proportion is apt to be refrozen while passing through deep snow. So although ample precipitation might be gauged through the event, perhaps little liquid would pass through a snow lysimeter, and the WAR hydrograph would show sparse or no outflow. Again, exceptions occur: when the pack is absent or thin in autumn, after spring melt, and in dry winters, the graphs would be about the same; and exceptionally warm storms can cause ROS on the highest peaks. Over time, although upper-elevation sites can possess greater orographically enhanced frequency-magnitude for total precipitation, the lines for WAR should be lower, indicating that the ground there is receiving less water (for a given return period) than the "standard" curve for total precipitation indicates. At intermediate elevations, the presence of a moderate amount of snow and warm temperatures combine to supplement 
the rainfall with melt; somewhere the sum will be maximized, and the hydrograph will show the greatest outflow relative to the hyetograph. Such a peak ROS elevation varies among individual storms, but over time there should be a zone where these conditions occur most often, and where the frequency curve for WAR is the highest and/or steepest, especially with respect to precipitation.

To restate the research questions and diagrammed relations in hypothesis terms:

- If the magnitude of liquid water delivered to the ground during rain-on-snow events can be different from the measured total precipitation, then the frequency-magnitude characteristics of WAR will be different from those for precipitation at any site experiencing ROS to a considerable degree.

- If ROS really is most common in middle elevations of the PNW, where winter rain is liable to fall on existing snowpacks, then it should be possible to identify the zone susceptible to maximum long-term hydrologic and geomorphic significance for ROS in a given subregion.

We prefer to establish such relations empirically, from available meteorologic and hydrologic records. Unfortunately, relative to the spatial and temporal variability of ROS, the record is insufficiently long and geographically broad to answer these questions in much detail. Several research projects have attempted to explore ROS using the observational record, with little success (section 1.3): data were too limited in time, space and instrument types for most of their purposes, and for mine. If the goal is to assess the long-term characteristics of ROS events in even a sector of the mountainous Pacific Northwest, we must conclude from the literature that the standard observational equipment and methods are inadequate to completely illuminate the phenomena. 


\subsection{Modeling approach}

Because rain-on-snow is a probabilistic event involving multiple combinations of many contributing meteorologic (storm, snowpack) and geographic factors, a very long and/or spatially dense observational record would be necessary to sample enough events to gain a thorough appreciation of the range and modes of its behavior. But even after choosing a study area having an unusual abundance of stations spanning a relatively long period (section 4.4), the record in the Northwest seems too short and the sites too scattered to adequately assess the wide variation of ROS events. A statistical modeling approach seems appropriate.

In this project, I perform a set of "virtual experiments" with Monte Carlo techniques: first building a computer model that can simulate major storm conditions, operating over thousands of "years", for sites (real or generalized) of my choosing; then examining the statistical character of the outputs. Based on an approach adopted in 1981, portions of this work have been presented previously (e.g., Brunengo, 1990, 2007; Wu et al., 1995). To my knowledge, no one else has tried to use Monte Carlo methods to examine the frequency characteristics of the large storms that cause rain-on-snow in the Pacific Northwest.

I developed a model combining probabilistic and deterministic elements involved in large storms in the Pacific Northwest, to explore those that lead to ROS (see chapter 3). A single-event (SE) version of the model takes specified initial and hourly precipitation, temperature and wind values to calculate the resulting snow and outflow quantities, using well-known deterministic functions (section 3.1). But to overcome observational limitations over space and time I adopt Monte Carlo (MC) simulation, a common prob- 
abilistic modeling technique employing random sampling to incorporate uncertainty and variability in generating approximate solutions to physical problems (section 3.2; McCracken, 1955; Mishra, 2001).

Terminology relevant to probabilistic modeling should be established. In natural science, individual measurements (data) of observed events constitute the record, which can be split into series of distinct data types (e.g., total precipitation for each storm). In simulations the individual outcomes of model events are realizations, analogous to data but not measured in nature. A model run can generate any number of events, comprising many kinds of realizations; again, a series of any particular kind can be isolated for analysis, including comparison with the parallel series of the parent record. Model sampling of the various physical properties is controlled by their frequency distributions, the parameters of which are informed by observations. Monte Carlo methods seemingly "expand" a population by creating combinations of outcomes that may not have happened yet - but could, statistically - over time periods much longer than the instrumental record.

My MC model simulates the frequency of high-precipitation storms over runs of hundreds to thousands of model "years", for either a real place or a hypothetical site having a certain elevation and/or other characteristics. In each event, the model generates realizations of the starting date and time; initial snowpack thickness; precipitation magnitude and duration; mean and range of temperature and wind speed; and the hourly values of each through the event. Once a "storm" has begun, the deterministic parts of the model calculate hourly snow accumulation or melt (if any), depending on heat energy correlated to the major driving variables of temperature, rainfall and wind. If liquid rain plus snowmelt is present in the snowpack, percolation volume and rate are calculated, 
and the output is water volume at the ground surface.

The model is a computational apparatus built to run the virtual experiments, generalizing and extending the instrumental record. I use it to simulate the big cool-season storms that hit the Northwest, to explore (through the statistical properties of output realizations) the frequency of rain-on-snow, when and where events are most likely to happen, and determine how hydrologically significant they are in various places. Initially, I examine the frequency relationships among series from events simulated for one welldocumented weather station (Stampede Pass), to estimate the probability and magnitude of ROS conditions and the differences between total precipitation and WAR. Next, I compare those quantities for a range of elevations, based on measurements from multiple sites and generalized for the region. If major storm processes are reasonably well understood, and their behavior can be mathematically modeled to generate realistic virtual series, then it should be possible to compare the long-term frequency-magnitude properties for total precipitation and liquid WAR of the simulated outcomes to derive information about large storms and rain-on-snow.

The results of individual events are useful for some purposes (model SE mode), but because my research questions address the frequency of storms and ROS events on the landscape, I focus here on the long-term patterns of large storms and ROS rather than individual events. Thus, my questions involve the evaluation of series statistics at chosen sites and across elevation zones: to find the likelihood and hydrologic significance of ROS at those places, and especially to determine an optimal elevation zone for ROS within a part of the Washington Cascades.

Note that the model is limited in scope, and I do not treat several aspects and ex- 
tensions at this stage. The model is based on individual events (not tracking continuously through seasons or years) at specific sites (not distributed across hillslopes or basins). The simulations are intended to produce series that mimic long-term frequency characteristics under supposedly stable climate, but they are unlikely to replicate any particular interannual patterns. Runoff forecasting, flooding, slope instability, landform development, and climatic change are all important reasons for studying ROS in the Pacific Northwest, though my data and modeling do not go there yet; implications for other problems are mentioned, but later work will be required to extend this inquiry to further issues and the landscape scale. If the model works in this simple elevation-based system, it can then be applied to more complex situations.

\subsection{Hypotheses in model terms}

Accordingly, I use the Monte Carlo model to evaluate two sets of propositions. Here and in the results (chapters 5-7), the hypotheses $\left(H_{1}\right.$ and $\left.H_{0}\right)$ entail supposed relations among statistical or graphical parameters of the realizations, most involving the collective model outcomes of total event precipitation versus water delivered to the ground. Simple abbreviations represent individual events, for example WAR $>$ P; I use brackets to signify relevant statistical or frequency parameters of the series of P or WAR realizations: e.g., WAR [series parameters: mean, variance, skew, etc.] > P [series parameters.... is simplified as WAR [ ] P [ ].

The first set of hypotheses concerns single sites, the second deals with elevation bands.

A) Hypothesis for an individual site The first test is for a high-elevation station at which the differences between P and WAR series should be large and easily detectable (Fig. 2.1, 
top). The highest station in my study region, Stampede Pass ( 1200 m), has yielded quality weather and snow measurements for most of 65 years. Stampede should behave like a high site with respect to ROS, so I propose hypothesis $H_{I}$ : WAR [ ] < P [ ], in terms of volume and/or frequency parameters; and the null hypothesis $H_{0}$ : WAR [ ] $\geq \mathrm{P}[$ ]. B) Hypotheses regarding elevation Presuming that the model works for an individual station and can be extrapolated to other elevations, the next set of propositions addresses determination of the elevation where melt-enhanced infiltration and runoff is likely to be most significant over the long term, with a preferred ROS zone identifiable from the realization series. $H_{1}$ for higher elevation sites would be WAR [ ] $<\mathrm{P}[$ ]; at middle elevations WAR [ ] $>\mathrm{P}[$ ] (maximal or peak ROS); and at lower sites, WAR [ ] $\approx \mathrm{P}[$ ]. Then $H_{0}$ says that total P and WAR do not differ significantly from each other at any elevations; or, that there are no clear distinctions indicating ROS significance in any definable elevation zone.

The model's validity determines whether the apparatus can enable me to evaluate these hypotheses. After confirming that the math and codes are operating as intended, the chief steps of model testing are to ensure that the results agree satisfactorily with the statistical properties of the governing inputs, and the outputs of relevant field observations. I use Stampede Pass to evaluate the model's ability to apply generalized elevation parameters to simulate series that correspond reasonably well to those generated with site-specific information. The semi-stochastic and deterministic components calculating hourly values of weather, snow and percolation are likewise tested with respect to the meteorological record of storms and ROS event. These procedures are described in chapters 5 and 6 , as are the metrics used to evaluate the model results. 


\section{MODEL COMPONENTS, ARCHITECTURE, INPUT \& OPERATIONS}

\subsection{Deterministic model components: theoretical \& empirical background}

The probabilistic approach to simulation of large storms and ROS is the chief innovation of this work, but before considering my application of Monte Carlo methods we must explore the physically determined parts of the model. From the start of the project, I chose to deal with hourly increments of the hydrologic quantities through each "storm". Thus the objective of the model is to calculate hourly delivery of water to the ground, controlled by weather conditions as affected by percolation through any snowpack. One version of the model performs these calculations for a single event, given a set of hourly forcing variables. But the deterministic single-event algorithms also constitute the core of the Monte Carlo simulations, so they dictate the kinds of meteorologic and hydrologic quantities that must be supplied by the probabilistic components (section 3.2).

These deterministic components were adapted from established treatments of the relevant physical processes, with several kinds of simplifications employed in the translation from theory to computer programs. Some are essential, for realism (e.g., conservation of mass); situational, relating to rain-on-snow as opposed to a broader range of weather conditions; empirical, based on environmental observations; or utilitarian, to create efficient model code. The theoretical and observational aspects of the deterministic model components are treated in this section, and the stochastic components in the next; operational facets of the model appear in section 3.3.

A) Snow accumulation The net change in snow amount is the balance between accumulation and ablation, both affected by local weather. In the model, I am not concerned with snowfall processes or snow's areal extent, just with snowpack on the ground at a point. 
Snow amount is expressed in two primary quantities, depth and snow-water equivalent; SWE is commonly gauged as a volume per unit area (or calibrated from the mass of a sampled volume), so its dimensions are typically also considered as length. Snow density, strictly mass per unit volume, is usually computed as the ratio of SWE $(\mathrm{cm})$ to depth $(\mathrm{cm})$ and so deemed dimensionless.

In simulation and reconstruction, snow accumulation is normally estimated from the solid-phase proportion of total precipitation, based on air temperature. However, this calculation is inexact because snow, rain and assorted other forms (freezing rain, sleet, graupel, etc.) occur over a range of temperatures around freezing, as demonstrated in field studies. In a large sample of events in the Sierra Nevada, the Cooperative Snow Investigations (USACE, 1956) found rain to $29^{\circ} \mathrm{F}$ and snow to $40^{\circ} \mathrm{F}\left(-1.7\right.$ to $\left.+4.4^{\circ} \mathrm{C}\right)$, with the most even mix at $34^{\circ} \mathrm{F}\left(+1.1^{\circ} \mathrm{C} ; 44 \%\right.$ snow, $25 \%$ mixed, and $31 \%$ rain events $)$. Based on western U.S. weather data and model tests for application to climate-model (GCM) predictions of April snowpacks, McCabe and Wolock (1999) used monthly average temperatures of $0^{\circ} \mathrm{C}$ to indicate all snowfall and no melt; $5^{\circ} \mathrm{C}$ to indicate all rain and maximum melt; and linear ratios for accumulation and melt in between. From observations in Sweden, Feiccabrino and Lundberg (2007) determined that $+1.0^{\circ} \mathrm{C}$ is the best single temperature threshold to distinguish rain from snow, but that mixed precipitation commonly occurs in the -2 to $+4^{\circ} \mathrm{C}$ range. And in calibrating radar detection of precipitation phases against ground observations in the Sierra Nevada, Lundquist et al. (2008) ascertained that precipitation can be snow, rain or a mixture from 0 to $+3^{\circ} \mathrm{C}$; at $1.5^{\circ} \mathrm{C}$, it falls as $50 \%$ each rain and snow; between $2.5^{\circ}$ and $3^{\circ} \mathrm{C}$, snow is equally likely to melt or accumulate. In my study region, phase observations at the Stampede Pass and Olympia weath- 
er stations during large storms (chiefly in WY 1970-89) show that rain can be seen at $\sim 27^{\circ} \mathrm{F}$ and snowfall can persist to $\sim 39^{\circ} \mathrm{F}\left(-2.8^{\circ} \mathrm{C}\right.$ to $\left.+3.9^{\circ} \mathrm{C}\right)$; mixtures of rain, snow and other forms span this temperature interval. Based on such information, for the model I chose to partition precipitation into liquid and solid phases linearly in a narrower range, between -1.5 and $+2.5^{\circ} \mathrm{C}$, with exclusively snow or rain outside these limits. Snow accumulation is thus the hourly increment of "snowfall", calculated as the water equivalent of the proportion of solid precipitation, then translated to depth using an appropriate density (depth $=\mathrm{SWE} /$ density); as possibly modified by melt during the same hour.

B) Snowmelt Snow ablation includes melt, sublimation, wind erosion and avalanching; I ignore all but melt. Energy balance methods for calculating potential snowmelt (Sverdrup, 1936; Anderson, 1968, 1976; Marks and Dozier, 1992) were adapted for rain-onsnow by USACE (1956) and later modified for different conditions and metric units (e.g., Dunne and Leopold, 1978; Harr, 1981; Marks et al., 1998; Mazurkiewicz et al., 2008). The satisfactory performance of ROS-based energy-balance equations was confirmed in field tests by Beaudry and Golding (1983), Kattelmann (1985), Berris and Harr (1987), Wetherbee (1995), and others. The treatment below focuses on the simplified procedures adopted for my model.

Potential snowmelt per unit time is a function of total energy input $\left(\mathrm{Q}, \mathrm{cal} / \mathrm{cm}^{2} / \mathrm{h}\right)$, water density $\left(\rho_{\mathrm{w}} \sim 1 \mathrm{~g} / \mathrm{cm}^{3}\right)$, latent heat of fusion $\left(\Lambda_{f}=79.7 \mathrm{cal} / \mathrm{g}\right)$, and snow thermal quality ( $\beta \sim 0.97$ with some free water). Given enough snow for potential melt to be realized, the total melt flux $(\mathrm{M}, \mathrm{cm} / \mathrm{h})$ is

$$
M=\stackrel{\cap}{\rho \Lambda}
$$


(Dunne and Leopold, 1978; Singh and Singh, 2001). The total is the sum of component melt amounts caused by the various energy inputs:

$$
M=++\quad+\quad+\quad+
$$

The right-hand terms of Eq 2 (defined below) could be expressed as in Eq 1, yielding

$$
M=\quad\lceil\quad j
$$

Under fair-weather conditions such as spring-summer ablation, most of the melt is typically due to short-wave solar radiation (the melt signified by $\mathrm{M} *$ ) and long-wave thermal radiation $\left(\mathrm{M}_{\lambda}\right)$. The sum of all radiant energy (direct, reflected, emitted) is net radiation, fluctuating through the day and the seasons with the incoming and outgoing fluxes. Melt caused by turbulent transfer of sensible and latent heat $\left(\mathrm{M}_{\mathrm{s}}\right.$ and $\left.\mathrm{M}_{\mathrm{e}}\right)$ depend on temperature, humidity and wind speed. Heat conducted from the ground can also induce melt $\left(\mathrm{M}_{\mathrm{g}}\right)$, varying seasonally and with exposure (bare ground gets cold or warm faster).

However, the dominant energy sources are different under rain-on-snow conditions (USACE, 1956; Harr, 1981). Most of the energy supplied for ROS melt is usually long-wave radiation, sensible heat and latent heat. Depending on its temperature, heat is also contributed by the rain itself, which can cause melt $\left(\mathrm{M}_{\mathrm{p}}\right)$ by conduction or as latent heat on freezing. (Although small in quantity, rain can carry its heat into the pack interior before releasing it, whereas most other energy forms act chiefly near the snow surfaces.) Conversely, short-wave radiation is subdued during cloudy days and long winter nights; conductive heat from the ground is also considered minor, especially as infiltrating water counters upward heat flows (Smith, 1974).

Field studies of energy sources during ROS generally confirm these generalities 
(Berris and Harr, 1987; Wetherbee, 1995; Marks et al., 1998; Table A.1). Minor revision to this consensus comes from Mazurkiewicz et al. (2008), whose analysis of meteorological observations during snowmelt in the Oregon Cascades found net radiation (which includes long-wave) to be usually greater than sensible plus latent heat, even in ROS, when events of all months and magnitudes are examined; ground heat can be more significant in autumn, before winter cooling. Their results show turbulent transfer still considerable during ROS, and the mix of energy contributions for any site and event are sensitive to elevation, solar aspect, wind exposure, canopy/shading, and date in the season.

Nevertheless, common ROS conditions allow simplification of snowmelt calculations. Given reasonable assumptions, such as full air-moisture saturation (100\% humidity) during rainfall, the major energy sources of long-wave, sensible, latent, and precipitation heat can be indexed to three commonly measured weather variables (USACE, 1956; Harr, 1981). Most forms of ROS-adapted equations calculate daily potential melt (here $\mathrm{M}_{\mathrm{d}}$, in cm SWE) as a function of average daily air temperature $\left(\mathrm{T}_{\mathrm{d}},{ }^{\circ} \mathrm{C}\right)$, affecting all four sources; average wind speed $\left(\mathrm{W}_{\mathrm{d}}, \mathrm{m} / \mathrm{s}\right)$, affecting the turbulent transfer of sensible and latent heat; and 24-h precipitation $\left(\mathrm{P}_{\mathrm{d}}, \mathrm{cm}\right)$, affecting rain melt. Coefficients for these factors are combined, with a small empirically based increment to account for short-wave and ground-heat melt. In tests of seven such index methods for calculating ROS melt against measurements at Central Sierra Snow Lab and Blue Canyon, Kattelmann (1985) found that a variant of Dunne and Leopold's (1978) version performed best:

$$
M_{d}=\lfloor\lfloor\rfloor
$$

My simulations run at hourly time steps of input and output, hence snowmelt, so I recast this equation to account for hourly values of the heat-source indices. The coeffi- 
cients in Eq 4 related to air temperature (0.142), wind speed (0.051) and ground heat ( $\sim 0.05$ of 0.25 ) had to be divided by $24 \mathrm{~h}$ to apply to hourly $\mathrm{T}_{\mathrm{h}}$ and $\mathrm{W}_{\mathrm{h}}$. The heat of hourly rainfall $\left(\mathrm{P}_{\mathrm{h}}\right)$ depends on its amount (and temperature, assumed equal to $\mathrm{T}_{\mathrm{h}}$ ), so its local coefficient (0.0125) is unchanged. The estimated short-wave input (part of the last term in Eq 4) should vary during daylight hours, so I calculate the hourly solar radiation factor $\left(\mathrm{rad}_{\mathrm{h}}\right)$ as a triangular function sufficient to melt $\sim 0.2 \mathrm{~cm} / \mathrm{d}$, but distributed across $9 \mathrm{~h}$ peaking at midday. With these adjustments, the hourly potential melt rate is calculated as

$$
M_{h}=\lfloor\rfloor
$$

Some of the weather factors in these melt equations contained empirical or operational assumptions that are ignored in my model. The coefficients of Eq 4 were based on measurements of wind $2 \mathrm{~m}$ and temperature $1 \mathrm{~m}$ above the snow surface, while other versions assumed different heights (e.g., wind at $15 \mathrm{~m}$ in USACE, 1956). Also, most equations applied to open terrain, so wind velocity should be reduced for forested areas: as an inverse function of increasing canopy density (minimum $\sim 20 \%$ in heavy cover; USACE, 1956; Dunne and Leopold, 1978); or with a constant slow value ( 2.4 m/s in Harr, 1981). I make no adjustments in my model calculations for observation height, but do modify wind speed in tests of events in forested sites (section 5.2).

More sophisticated energy-balance models account for the satisfaction of snowpack cold content before generating melt, and/or allow melt at subfreezing temperatures if sufficient energy is available (e.g., Marsh and Woo, 1984b; Illangasekare et al., 1990; R. Jordan, 1991). However, I assume warm snowpacks (always near $0^{\circ} \mathrm{C}$ ), and make no explicit accommodation for heat flow in cold packs. Also, the model precludes melt generation when $\mathrm{T}_{h} \leq 0^{\circ} \mathrm{C}$, when no melt is calculated by Eq 5 related to the weather condi- 
tions ( $\mathrm{T}_{\mathrm{h}}, \mathrm{W}_{\mathrm{h}}$ and $\mathrm{P}_{\mathrm{h}}$ terms); the very small amount of conductive and short-wave heat implied by the last two terms (maximum $\sim 0.046 \mathrm{~cm} / \mathrm{h}$ around noon) is here considered to be "warming the snowpack" and yielding no meltwater.

But in an hour with $\mathrm{T}_{\mathrm{h}}>0^{\circ} \mathrm{C}$, the modeled potential melt is compared with any solid precipitation that hour to find the net change in snow-water equivalent $\left(\triangle \mathrm{SWE}_{\mathrm{h}}\right)$. If positive (snowfall $>$ melt) then snow accumulates, with the depth increase calculated from the ratio of $\Delta \mathrm{SWE}_{\mathrm{h}}$ to a snow density related to temperature (based on observations and model calibration; see sections $3.3 \mathrm{~B}, 5.2$ ). If $\Delta \mathrm{SWE}_{\mathrm{h}}$ is nil or negative (snowfall $\leq$ melt), the potential melt is applied first to that hour's snowfall, then the surplus goes to melt some of the preexisting pack, if any. All quantities are recalculated hourly, including liquid and solid precipitation amounts, snow accumulation and melt, net change in SWE, and the resulting pack depth, SWE and density.

C) Percolation through snow For each hour having a snowpack and rain and/or meltwater, the model must route the liquid through the snow. The procedures for water transmission are based on the kinematic wave theory formulated by Lighthill and Whitham (1955). Pairing conservation of mass (continuity) with a suitable function relating flux to the concentration of the moving entity results in $1^{\text {st }}$-order partial differential equations, describing propagation as waves with velocities determined by the flow concentration (Singh, 2001). Percolation in snow is a case of 1-dimensional (vertical) gravity-dominated, unsaturated flow through a porous medium, in which the water's movement rate is proportional to its amount, which can be described by uniting the kinematic-wave approximation with Darcy's law and the moisture and conductivity characteristics for unsaturated flows (e.g., Beven, 1982). 
Application of this theory to percolation in snow was pioneered by Colbeck and colleagues (Colbeck, 1972, 1974, 1975b; Colbeck and Davidson, 1973; Colbeck and Anderson, 1982; Dunne et al., 1976), and adapted by others (e.g., Bengtsson, 1982; Marsh and Woo, 1985; McGurk and Kattelmann, 1986; Albert and Krajeski, 1998). Further work by Colbeck (e.g., 1973a,b, 1975a, 1976, 1979) expanded the analysis to heterogeneous and layered snow. Other research teams have pursued physically based models incorporating energy and mass flow, typically using more complex 1- and 2-dimensional finite-difference procedures (e.g., P. Jordan, 1983b; Akan, 1984; Marsh and Woo, 1984a,b; Illangasekare et al., 1990; R. Jordan, 1991; Tseng et al., 1994). However, besides being overly elaborate or data-intensive for my purposes, most of these advanced models are less suitable for rain-on-snow conditions and/or multi-year Monte Carlo simulation. Thus, I chose to adapt older, simpler formulations of the kinematic-wave approximations for percolation through snow. My model development is adapted primarily from Colbeck (1972) and Dunne et al. (1976).

The basic kinematic-wave equation for this situation estimates the flux of a packet of water having wave speed $\mathrm{V}_{f}(\mathrm{~cm} / \mathrm{h})$ through the snow as a function of the liquid input (rain plus snowmelt $\mathrm{R}+\mathrm{M}, \mathrm{cm} / \mathrm{h}$ ) for the hour. Following Darcy's law, infiltration depends on properties of the water (specific weight and viscosity, $\rho_{\mathrm{w}} \mathrm{g} / \mu$ ); and the snow's effective porosity ( $\phi_{\mathrm{e}}=$ total porosity less irreducible water content; see Eq 10$)$ and hydraulic conductivity, derived from intrinsic permeability $\mathrm{k}$, as $\mathrm{K}=\mathrm{k} \rho_{\mathrm{w}} \mathrm{g} / \mu$. The snow's unsaturated permeability is a power function of its effective saturation $\left(\right.$ as $\mathrm{k}_{\mathrm{u}}=\mathrm{k} \mathrm{S}^{*}$ ). Empirical results from lab and field drainage tests show the exponent $\mathrm{n}$ to be $\sim 2.5-5$ (Colbeck and Davidson, 1973; Denoth et al., 1979; P. Jordan, 1983b; McGurk and Kattel- 
mann, 1986). The permeability and flow calculations are not sensitive to the exponent value in this range, and an integer simplifies the calculus, so I follow most previous work and assume constant $n=3$. Then, wave speed is

$$
V_{f}=\boldsymbol{\rho}^{1 / 3}\lfloor\rfloor^{\cdots}
$$

Although rain and meltwater enter the snowpack almost continuously, they are treated numerically as accruing for an hour and then moving down as a coherent packet or slug. This discretization is necessary to program algorithms imitating methods of characteristics for kinematic waves; its validity has been confirmed in theoretical and field studies (Colbeck, 1974, 1977a; Dunne et al., 1976; Borah et al., 1980; P. Jordan, 1983a,b; Miller, 1984; Marsh and Woo, 1985).

Because kinematic-wave velocities are proportional to water volume, larger inputs generate faster waves that overtake slower ones formed by smaller inputs. Interacting waves create discontinuities (kinematic shocks), which then proceed as separate waves with a combined flux volume and a new velocity $\left(\mathrm{V}_{\text {shock}}\right)$ intermediate between those of the slower and faster waves, as determined by the larger and smaller inputs:

$$
V_{\text {shock }}=\boldsymbol{D}^{\boldsymbol{V}^{1 / 3} \Gamma-}
$$

(Though ultimately canceling, the coefficients [3] are mathematically different and parts of separate model calculations, and so are maintained in $\mathrm{Eq} 7: \mathrm{n}=3$ in the numerator, whereas the denominator factor is averaging the three input terms.) While it may seem that a shock wave combining the fast and slow fluxes should have a speed greater than the fast wave, the equations reflect that the merged wave is slowed somewhat by first 
having to soak the pores it is moving down into (associated with smaller inputs and slower waves) so that they can accommodate the faster speed of the greater flux (Dunne et al., 1976). The model's percolation algorithms must identify shock interactions by comparing each flux's depth at every hour with the locations of the preceding ones; model calculations of shock-wave properties redistribute water to smooth the outflow hydrograph while ensuring conservation of mass (Borah et al., 1980).

Some of the hydraulic properties incorporated in Eq 6 and Eq 7 (and used in my model) are governed by physical relationships in the snow, whereas others are based on laboratory and field data from several sources (Kattelmann, 1986; and papers cited above). Snow's porosity $(\phi)$ and effective porosity $\left(\phi_{e}\right)$ are estimated from its density $\left(\rho_{s}\right.$ $=\mathrm{SWE} /$ depth $)$ and phase relations. If the snow is dry, then $\rho_{\mathrm{s}}=\rho_{\mathrm{i}}(1-\phi)$ and for ice density $\rho_{\mathrm{i}}=0.917 \mathrm{~g} / \mathrm{cm}^{3}$ at $0^{\circ} \mathrm{C}$ :

$$
\phi=-\quad=-\frac{-}{0.91 /}
$$

Alternately, it can be assumed that the snow already contains some liquid held against gravity (irreducible water content, $\mathrm{S}_{\text {irr }}$ ), so it includes both solid and liquid phases. Then the snow density is $\rho_{\mathrm{s}}=\rho_{\mathrm{i}}(1-\phi)+\rho_{\mathrm{w}} \mathrm{S}_{\text {irr }} \phi$, and

$$
\phi={ }_{\left(S_{i r r} \rho-\right.} \rho-
$$

In the wet case, the effective porosity is total pore space less the voids occupied by immobile water along grain surfaces:

$$
\phi=\quad-
$$

A reasonable value for the irreducible water content at $\sim 0^{\circ} \mathrm{C}$ is $\sim 0.03$ by volume (Singh 
and Singh, 2001).

The Darcian hydraulic conductivity is rarely measured in snow, but can be estimated from other factors. For conductivity $\mathrm{K}=\mathrm{k} \rho_{\mathrm{w}} \mathrm{g} / \mu$ (here in $\mathrm{cm} / \mathrm{h}$ ), we assume temperatures at $0^{\circ} \mathrm{C}$, as likely in snowpack percolation, so values of water density $\left(\rho_{\mathrm{w}}=\right.$ $\left.0.999841 \mathrm{~g} / \mathrm{cm}^{3}\right)$ and viscosity $(\mu=0.017921 \mathrm{~g} /[\mathrm{s} \mathrm{cm}])$ are specified. Snow's intrinsic permeability $\left(\mathrm{k}, \mathrm{cm}^{2}\right)$ is estimated using Shimizu's (1970) empirical equation as a function of snow density and grain diameter $\left(\mathrm{g}_{\mathrm{d}}, \mathrm{cm}\right)$ :

$$
k=\quad-
$$

Despite some contradictory evidence (Denoth et al., 1979; Sommerfeld and Rocchio, 1993; Hardy and Albert, 1993), this relationship has been corroborated by measurements and is commonly used (Jordan et al., 1999). A precise value for $\mathrm{g}_{\mathrm{d}}$ is uncertain since snow includes a range of grain sizes that change with time, especially when wetted (Colbeck, 1982; Conway and Raymond, 1993; Sturm and Holmgren, 1993). Most of the literature considers a range of $0.1-0.2 \mathrm{~cm}$; larger grains result in greater conductivity and faster infiltration (calibration in section 5.2).

Besides the universal model constants cited above ( $\mathrm{n}=3$ and $\left.\mathrm{S}_{\mathrm{irr}}=0.03\right)$, the numbers used for most other hydraulic properties also involve simplifications. My model sets the snow's conductivity and porosity as functions of the pack's initial snow density, the ratio of SWE to depth at the beginning of an event. The evolution of the pack through an event is tracked hourly by changes in SWE, depth and density; but though snow hydraulic properties $\left(K, \phi_{e}\right)$ also change with time, especially in the presence of water, I assume they remain constant during the model event. More realistic models can account for dry to wet, cold to warm snowpacks (Bengtsson, 1982; Akan, 1984; Marsh and Woo, 
1984b; Illangasekare et al., 1990; R. Jordan, 1991; Tseng et al., 1994). However, I chose to assume a starting condition of warm snowpack $\left(\sim 0^{\circ} \mathrm{C}\right)$ with existing tension water, and avoid the problems posed by polythermal snowpacks, simplifications that were necessary to make my percolation procedures efficient. Furthermore, within the limits of the model's values for $\rho_{\mathrm{s}}, \phi_{\mathrm{e}}, \mathrm{K}$, and typical water-input rates, these assumptions do not introduce unreasonable quantities for flux velocities (Eq 6) or other model realizations, especially considering the broad variability of the probabilistic model elements (see section 3.3C).

However, an issue remains regarding discrepancies between my equations and those used by Albert and Krajeski (1998), whose snowmelt numerical-analytical package (SNAP) is based on a similar approach. Proceeding from first principles (including no restrictions on the value of the saturation power constant $n, 1 / n$, etc.), they derive a wave velocity that seems dimensionally incorrect, having time to the -3.3 power and flux in $\mathrm{cm} / \mathrm{s}^{0.333}$; the error may be in assigning a time dimension to their normalized time coordinate. Following most of Colbeck's and others' papers (e.g., approximating $n=3$ ), my model generates flux in $\mathrm{cm} / \mathrm{s}$ (ultimately $\mathrm{cm} / \mathrm{h}$ ). Despite attempts to reconcile the differences, I received no adequate explanations of the disparity. I believe my model adheres faithfully to the earlier work in this subject, and provides results that are dimensionally correct and quantitatively reasonable. Yet the inability to resolve the inconsistency remains an annoying mystery and an avenue for future investigation.

\subsection{Probabilistic model components: Monte Carlo approach}

As shown in section 3.1, the deterministic model components for each event require a set of forcing quantities: chiefly storm characteristics such as total precipitation, duration, and initial snowpack amounts; and hourly values of temperature, wind speed, 
and precipitation. These might be known for a particular occurrence, but to address the temporal and spatial variability of rain-on-snow I adopted a Monte Carlo approach (section 2.2) to simulate conditions and events over many years. So for each model event, values of the forcing variables must be supplied by probabilistic components or generated by reasonable approximation, conveyed via model programs.

The "probabilistic paradigm" allows us to address uncertainties arising from natural randomness and incomplete knowledge of a system: it helps utilize the information we have, extend it to a fuller range of possible outcomes (and associated probabilities), and identify key drivers of ambiguity in forecasting (Mishra, 2001). Among probabilistic techniques, Monte Carlo simulation is one of the most common methods for incorporating uncertainty in systems models. The term was first applied as a code-name during the Manhattan Project (1941-46) by John von Neumann and Stanislaw Ulam, who adapted the technique to sidestep a difficult theoretical calculation with a virtual roulette wheel (McCracken, 1955).

This approach estimates solutions to physical problems by incorporating random sampling into execution of numerical algorithms. It allows examination of the range of a model's parameters and inputs, typically expressed as series statistics or probability distributions, and the subsequent uncertainty in model predictions/outputs. In Monte Carlo methods a large number of simulated outcomes can be generated from randomly derived combinations of the controlling variables, themselves determined by information or speculation. If empirical, measurements of the individual contributing factors are used to estimate their statistical properties. Random numbers determine probabilities, and values of the physical input factors are calculated by inversion from their cumulative distribution 
functions. These may be applied in deterministic algorithms (usually in computer code) to simulate the processes of interest, creating a set of outcome realizations.

In my applications for large storms and ROS, the stochastic part of the program samples from a wide but reasonable array for values for storm duration, precipitation, snow depth, temperature range, etc.; simulates an event, calculating melt and percolation fluxes; then repeats the calculations with another set of randomly chosen values for the next "storm". Results from 1000-year model runs, comprising several thousand simulated events, are then analyzed to reveal the long-term frequency characteristics of the stochastic processes. One can treat the output realizations of important characteristics by the same statistical techniques used to create the empirical frequency distributions. In particular, output series of event precipitation, rain plus snowmelt, and water available for runoff can be manipulated in the same way as observational precipitation records, with statistics applied to annual-maximum or partial-duration series to generate frequencymagnitude-duration graphs based on hundreds or thousands of "years" of simulated events. This kind of Monte Carlo experiment imitates the way many physical elements or processes interact in nature, by allowing their probability distributions to interact within a computer program; the products of the experiment are the realizations and their statistical properties.

Monte Carlo models have limitations. They normally require some empirical data for input, to be physically reasonable, and their fitness depends on the degree to which input records (and associated deterministic components) are representative of reality. Given the chance selection of extreme random numbers, some realizations may be exceptionally unlikely (e.g., deep snow at low elevation in August) or physically impossible. Outland- 
ish outcomes can be avoided by controls within the program code, but such measures reduce a model's mathematical elegance.

Another consideration is the application of model results with respect to assumptions. Monte Carlo models risk the fallacy of long-term stability: they can simulate "records" seemingly millennia long, but the results will not be valid that long. In this project, I suppose that 1000-yr model runs can provide insights regarding possible conditions during a more limited time period, based on a record from a few decades. We do not assume that the climate of 1940-2005 will remain stationary for $1000 \mathrm{yr}$, but that this record is sufficient to characterize the statistical distributions of the period. If the hydrometeorological characteristics of the region have been reasonably well sampled by the observational record, and if the climate and storm behavior during this 65 -yr period were to persist for $1000 \mathrm{yr}$, and if the various processes (such as snow accumulation/melt and percolation) act in the ways portrayed in my algorithms, then the model will bestow a more comprehensive picture of the frequency and magnitude of big storms/ROS than does the record by itself. So, as an example of a possible question leading to new insight: what is the proportion of big storms in the PNW in which the amount of water reaching the ground exceeds the storm's total precipitation (i.e., significant ROS)? We might get one answer from a particular station's record, if the appropriate measurements have been made; but that answer would be restricted to that site location and its record length. On the other hand, Monte Carlo simulation can provide an answer (actually many answers) generalized among many sites and longer time periods - a different kind of solution, but nevertheless potentially very informative.

Hypotheses should be applied to probabilistic modeling, but there is difficulty in 
testing them, and it is impossible to completely validate the results. The calculated outcomes may not be predictions regarding nature in the normal sense (Mishra, 2001): they might simulate a system operating over very long time periods, perhaps in the unobserved past or an imagined future. Reality will not duplicate the model's premises and outcomes, and we won't be around 1000 years to see if it did. At best, the model results allow us to better understand the frequency-magnitude relations of storms and ROS as determined by the current climate, as if we had a much longer record.

Monte Carlo methods have been applied to snow hydrology problems before (Singh, 2001). Isyumov and Davenport (1974) employed random sampling of weather variables to forecast possible daily snowpacks through winter seasons; then combined them with deterministic melt, evaporation and other functions to estimate the probabilities of maximum roof snow loads. Woo and Steer (1986) stochastically simulated the average snow depth in a forest based on location relative to trees as a function of distance and azimuth. As mentioned (section 2.2), I here adopt the Monte Carlo approach to perform model experiments simulating storm conditions over thousands of years, to examine frequency characteristics of rain-on-snow events in the Pacific Northwest.

\section{$\underline{3.3 \text { Program architecture \& operations }}$}

The model is structured to simulate major precipitation events, some occurring on a snow-covered landscape, as are common in the Pacific Northwest. The program has two versions, one operating on single events and the other on multiple events over many years. Both share the deterministic algorithms for snow accumulation/melt and percolation, but the multi-year Monte Carlo version has additional components for generating probabilistic state and forcing variables, so there are big differences in program size and 
running time.

The single-event configuration takes specified (either measured or conjectural) hourly values of precipitation, temperature and wind speed, along with initial snow conditions, and calculates hourly snowpack changes and percolation. Output products include spreadsheet tables and graph templates for visualizing the hydrologic response. Model runs using observed weather and snow conditions simulate outflows that can be compared with measurements at snow pillows or lysimeters, so this version is used to evaluate the efficacy of snowpack and percolation algorithms, and for calibration and sensitivity analysis of adjustable parameters and functions.

The main focus of this project is the multiple-event model version, producing 1000-yr-long sets of hypothetical storms that effectively expand the record to longer time periods and broader areas. It is based on a Monte Carlo simulation (hence MC mode) that combines probabilistically chosen weather and snow conditions with deterministic accumulation/melt and percolation components. It can be run with site-based or elevationgeneralized parameters; in either case, most input quantities and all hydrologic outputs are probabilistic, and used to examine their frequency characteristics and test hypotheses. Tables exhibit event results and run summaries, and graph templates are available to display outputs from individual events.

I adapted the stochastic and deterministic components into programs simple enough to run quickly on desk-top computers, and several intentional design limitations should be noted (see also Tables 3.1, 4.1). (1) It is a point model, applicable to specific sites or elevations, but does not reach over the landscape or below the ground surface. (2) It is based on events, and does not simulate conditions between storms or continuously 
through the year. The events have variable durations, set by the operator in the singleevent version and chosen by random sampling in Monte Carlo mode. The latter are derived from the records of long continuous storms (LCS), periods of nearly uninterrupted precipitation measured at hourly precipitation gauges, bounded by gaps of at least $6 \mathrm{~h}$ (section 4.5). (3) Total event precipitation is the controlling input: rather than creating storms with certain durations, temperature patterns, etc. and then letting those factors govern the rainfall - closer to the situation in nature - the model is driven by the frequency and magnitude of LCS precipitation, and the other weather characteristics either follow from the selected amount or are chosen independently. MC model events imitate the statistical properties of these variable "storms", and their series are eventually compared with the realization series of precipitation and water outputs. (4) Many calculations are simplified as feasible, focusing on the cool-season storms and snow conditions typical of the humid Northwest. The snowmelt equations assume cloudy days with little solar-induced melt; percolation is considered uniform movement through a homogeneous snowpack at $0^{\circ} \mathrm{C}$, ripe or rapidly ripening during rainfall, ignoring possible compaction, ice lenses, saturation, concentrated drainage (finger flow), cold content and refreezing (section 3.1). Despite irregular inputs of rain plus snowmelt in the model, the kinematic-wave equations are numerically coded to move the percolating water in hourly increments, so the algorithms cannot have the analytical rigor of those dealing with simple waves of daily melt; they include approximations for shock waves, but not the drying fronts that would follow the wetting hydrograph limbs. Although the model code lacks elegance and/or maximum efficiency in places, I believe it adheres to the essential physics and mathematics of the modeled processes. 


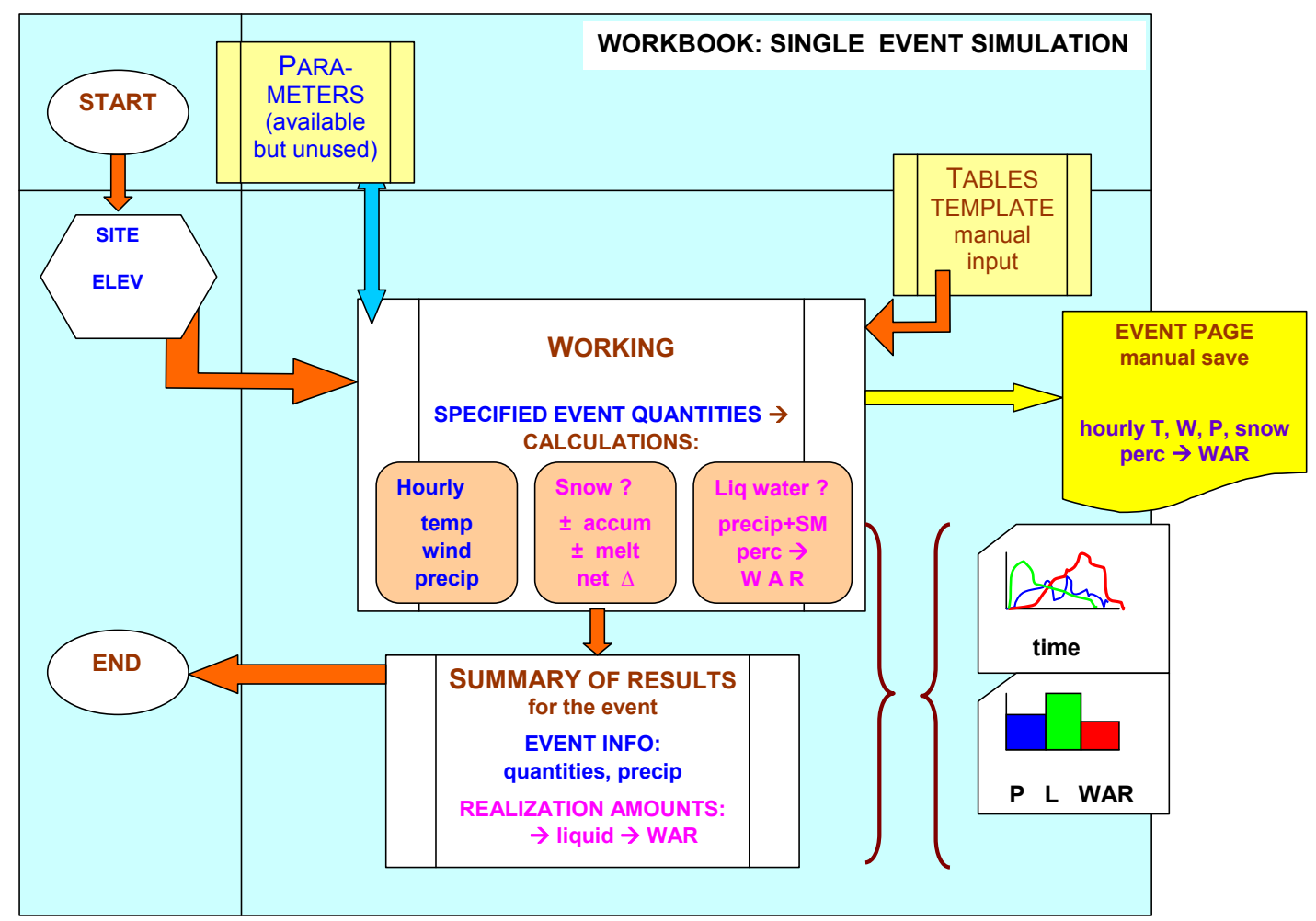

Figure 3.1. Flow chart showing operations of the single event model for simulation of major storms. In the SE version, storm properties and hourly weather values are specified (rather than being chosen probabilistically); the blocks calculating snowpack evolution and liquid water percolation are the same as in the Monte Carlo version.

Model architecture for the single event version is illustrated in Figure 3.1, and for the Monte Carlo version in Figure 3.2; the full programs are provided digitally in appendices B and C. Both configurations share a basic platform: operating within Excel workbooks, using programs written in VisualBasic for Applications (VBA) to manipulate information contained on several formatted worksheets. SE occupies $<0.6 \mathrm{Mb}$ of disk space; the code (appendix B) is $\sim 9$ pages long, and running time is a few seconds. Model version MC is much larger, 17 pages of code (appendix C) and $\sim 27.6 \mathrm{Mb}$ of disk space, $\sim 60 \%$ of that in a large table of random numbers. At $3 \mathrm{GHz}$ processor speed, a full $\mathrm{MC}$ run of 1000 yr takes about an hour, \pm 15 min depending on site elevation, thus the likelihood of snow and time-consuming accumulation/melt and percolation routines. For the 
most part, the descriptions below are based on the longer and more intricate Monte Carlo version; distinctions for the single event configuration are noted.

As mentioned, in the single-event version the forcing elements of storm duration, initial snowpack properties, and hourly precipitation and weather conditions are simply specified before the run, based on either observed or hypothetical values. But the Monte Carlo version requires more than a dozen quantities or parameters regarding event timing, precipitation magnitude and duration, snow amount and storm weather. For each, there is a spectrum of modeling approaches ranging from very simple to very complex; my choices are compromises among relevance to the storms of interest, data availability, and computational simplicity. Table 3.1 lists the model factors and the approaches adopted. Most of the numerical elements are based on data from sites in the west-central Washington Cascades (chapter 4); Table 4.1 summarizes the parameters used in the model, their sources and frequency distributions. Some of these are combined into empirical functions (illustrated as curves or trend surfaces) relating the parameters to other variables such as elevation and seasonal date. Most variables used by the Monte Carlo model are stored on the parameters sheet (Params in the workbook), from which they are accessed to inform an entire run or an individual event. Variables based on recorded hourly precipitation and temperature patterns during storms are stored on the SIM (storm internal model) codes and Temp codes pages, respectively.

Monte Carlo simulation requires a pool of random numbers $(R \#)$ providing the probabilities that are inverted to supply values of rainfall, duration, snow depth, etc. Because of limitations in Excel's random-number generator, and to control the sampling (e.g., to ensure that the date of the $3^{\text {rd }}$ event of the $468^{\text {th }}$ year is based on the same prob- 
ability regardless of site or other factors) and thus eliminate one source of variance, a set of 1.285 million random numbers is stored on a separate Random numbers sheet, accommodating 1000-yr runs. To avoid certainties (probability $=1$ ) and impossibilities or division by zero (probability $=0$ ), the random number range is limited to $0.000001 \leq R \# \leq$ 0.999999 for all variables.

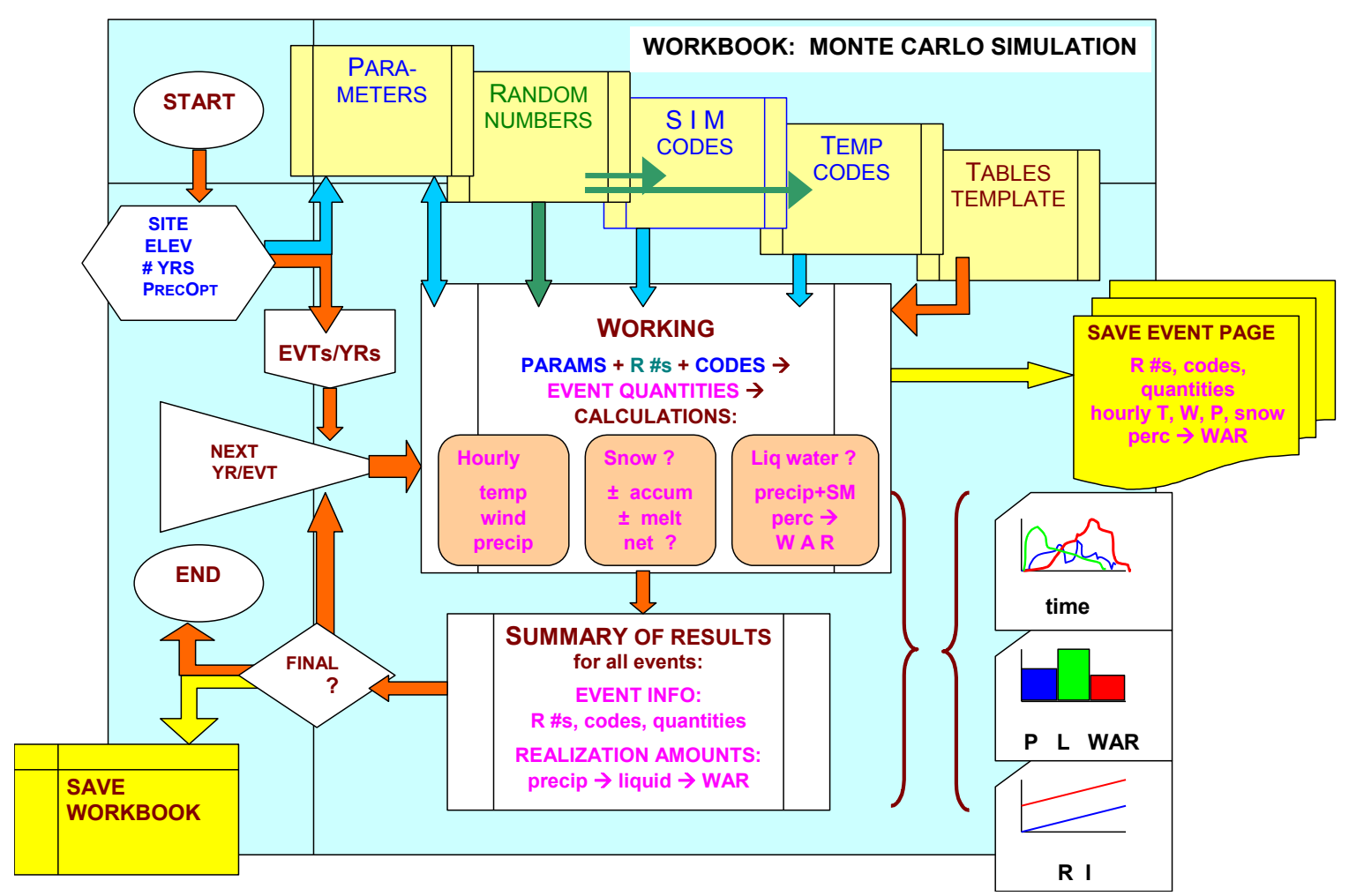

Figure 3.2. Flow chart showing operations of the Monte Carlo model for simulation of major storms. The MC version executes multiple events over 1000 years, with storm properties and hourly weather values chosen probabilistically; the blocks calculating snowpack evolution and liquid water percolation are the same as in the single event version. 


\begin{tabular}{|c|c|c|c|c|}
\hline $\begin{array}{c}\text { Model Element, } \\
\text { Parameter }\end{array}$ & Simpler & Model Approach & More Complex & Notes \\
\hline \multicolumn{5}{|l|}{ Storm timing } \\
\hline $\begin{array}{l}\text { Number of model } \\
\text { events per water year }\end{array}$ & $\begin{array}{l}\text { - single event per WY } \\
\text { - constant number per } \\
\text { WY }\end{array}$ & $\begin{array}{l}\text { variable number }(1-12 / \mathrm{WY})-\mathrm{EXP} \\
\text { based on site stats; EXE same for all } \\
\text { sites, averages of } 8 \text { NWS stations }\end{array}$ & $\begin{array}{l}\text { - } \log -\mathrm{N} \text { distribution } \\
\text { - EXE: variable with elev }\end{array}$ & $\begin{array}{l}\text { little evidence of } \\
\text { differences among sites, } \\
\text { elevations }\end{array}$ \\
\hline Event starting date & - random & $\begin{array}{l}\text { variable - EXP from site stats; EXE } \\
\text { same for all sites, based on combined } \\
\text { stats; independent of other event } \\
\text { properties }\end{array}$ & $\begin{array}{l}\text { - EXE: variable with elev } \\
\text { - within WY: sequence } \\
\text { events, w/o overlaps }\end{array}$ & $\begin{array}{l}\text { some evidence for elev- } \\
\text { related differences; } \\
\text { possible bimodality of } \\
\text { event dates - real or not? }\end{array}$ \\
\hline Starting time & - random: used $\rightarrow$ & same likelihood for all hours & & \\
\hline Event duration & $\begin{array}{l}\text { - constant } \\
\text { - stochastic but } \\
\text { independent }\end{array}$ & $\begin{array}{l}\text { variable; calc as bivariate log-N by } \\
\text { correlation with event precip amount, } \\
\text { so indirect } \mathrm{f}[\mathrm{elev}] \text {; based on average } \\
\text { of all sites }\end{array}$ & $\begin{array}{l}\text { more direct } \mathrm{f} \text { [elev] - } \\
\text { sets of params for high- } \\
\& \text { low-precip sites, or by } \\
\text { elev }\end{array}$ & $\begin{array}{l}\text { column limits due to } \\
\text { Excel } 2003 \text { spreadsheets } \\
\rightarrow \text { max storm duration } \\
\text { (currently } 255 \mathrm{~h} \text { ); min } \\
\text { duration set at } 12 \mathrm{~h} \\
\end{array}$ \\
\hline \multicolumn{5}{|l|}{ Precipitation } \\
\hline Total amount & $\begin{array}{l}\text { - directly from site or elev } \\
\text { data/record } \\
\text { - simple log-N } \\
\text { distribution } \\
\text { - annual max series } \rightarrow 1 \\
\text { WY event, EV-1 } \\
\text { distribution } \\
\end{array}$ & $\begin{array}{l}\text { from partial duration series, } \\
\text { exponential distribution - params } \\
\text { f [elev], split high- \& low-precip NWS } \\
\text { stations; independent variable (affects } \\
\text { duration) }\end{array}$ & $\begin{array}{l}\text { - index the LCS PD } \\
\text { records for variable } \\
\text { record periods, date, etc. } \\
\text { - modify params by other } \\
\text { geographic/climatic } \\
\text { characteristics (annual } \\
\text { precip, relief, etc.) } \\
\end{array}$ & $\begin{array}{l}\text { more realistic to calculate } \\
\text { event precip from date, } \\
\text { duration, temperature, } \\
\text { etc. - but magnitude is } \\
\text { the driving variable in } \\
\text { this model }\end{array}$ \\
\hline Hourly distribution & $\begin{array}{l}\text { - constant avg intensity } \\
\text { (total precip/duration) } \\
\text { for entire event } \\
\text { - simple pattern of precip } \\
\text { increase \& decrease (as } \\
\text { waves?) thru event } \\
\text { - no random element }\end{array}$ & $\begin{array}{l}\text { random choice among storm internal } \\
\text { model (SIM) codes } \\
\text { each event modeled by reconstruction } \\
\text { of } 4^{\text {th }} \text {-order polynomial on cumulative } \\
\text { event precip (from data, } 1000 \text { storms), } \\
\text { plus random kicker }\end{array}$ & $\begin{array}{l}\text { - add to sample of record } \\
\text { events } \\
\text { - SIM code choice as } \\
\text { function of date, } \\
\text { duration, precip } \\
\text { - incorporate stats for } \\
\text { storm internal periods } \\
\text { (1-48-h) } \\
\text { - coordinate with patterns } \\
\text { of temperature, wind }\end{array}$ & $\begin{array}{l}\text { could select directly from } \\
\text { collection of hourly } \\
\text { precip amounts - but } \\
\text { huge storage load, and } \\
\text { less variability in possible } \\
\text { realizations } \\
\text { (many other ways to } \\
\text { generate hourly precip) }\end{array}$ \\
\hline
\end{tabular}




\begin{tabular}{|c|c|c|c|c|}
\hline \multicolumn{5}{|l|}{ Snow } \\
\hline $\begin{array}{l}\text { Initial SWE } \\
\text { Initial depth }\end{array}$ & $\begin{array}{l}\text { - non-stochastic: average } \\
\text { SWE for date and elev } \\
\text { - simple distribution (log- } \\
\text { N?) } \\
\text { - calculate SWE \& depth } \\
\text { independently }\end{array}$ & $\begin{array}{l}\text { variable: calc SWE independently as } \\
\mathrm{f} \text { [date, elev]; calc depth as biv-N by } \\
\text { correlation with initial SWE; both } \\
\text { based on trends from all available } \\
\text { snow courses, SNOTEL, NWS; mixed } \\
\text { log-normal distribution }\end{array}$ & $\begin{array}{l}\text { - index params for } \\
\text { variable record periods } \\
\text { - split params into sets for } \\
\text { high- \& low-precip } \\
\text { and/or snow sites, } \\
\text { terrain }\end{array}$ & $\begin{array}{l}\text { model first outlined in } \\
\text { Brunengo (1990), based } \\
\text { on work by Thom (1966) } \\
\text { and Isyumov \& } \\
\text { Davenport (1974) }\end{array}$ \\
\hline $\begin{array}{l}\text { Snow accumulation } \\
\text { or melt during event }\end{array}$ & $\begin{array}{l}\text { - none: assume snowpack } \\
\text { set } \\
\text { - daily calculations } \\
\text { - simple thresholds at } 0^{\circ} \mathrm{C} \\
\text { - simple/constant amounts } \\
\text { of accum or melt of } \\
\text { depth from } \Delta \mathrm{WE}\end{array}$ & $\begin{array}{l}\text { hourly calculation: for melt, using form } \\
\text { of USACE equation for ROS in warm } \\
\text { pack, = f }[\mathrm{T}, \mathrm{W}, \mathrm{P}] \\
\text { rates affected by temperature: mixed } \\
\text { rain }+ \text { snow in range }-1.5 \text { to }+2.5^{\circ} \mathrm{C}, \\
\text { no melt } \leq 0^{\circ} \text {; change in depth with } \\
\Delta \mathrm{SWE} \text { also } \mathrm{f}[\mathrm{T}]\end{array}$ & $\begin{array}{l}\text { - use more complete } \\
\text { energy balance methods } \\
\text { - solar radiation and/or } \\
\text { ground heat variable } \\
\text { thru year } \\
\text { - account for satisfaction } \\
\text { of cold content } \\
\text { - account for layered pack }\end{array}$ & $\begin{array}{l}\text { many kinds of info not } \\
\text { available, especially at } \\
\text { hourly intervals } \\
\text { (radiation, humidity, etc.) }\end{array}$ \\
\hline Density & $\begin{array}{l}\text { - constant \& invariant } \\
\text { thru event }\end{array}$ & $\begin{array}{l}\text { from initial WE/d (if no snow at start } \\
\rightarrow \text { default values); uniform with depth } \\
\text { thru pack, but recalculated hourly }\end{array}$ & $\begin{array}{l}\text { - account for layered pack } \\
\text { with variable density }\end{array}$ & $\begin{array}{l}\text { calc density of new snow } \\
\text { accum as } \mathrm{f} \text { [air } \mathrm{T}] \text {, range } \\
0.15 \text { (cold) to } 0.85 \\
\text { (warm) } \\
\text { * applies also to SE } \\
\text { version }\end{array}$ \\
\hline $\begin{array}{l}\text { Porosity (effective) } \\
\text { Permeability } \rightarrow \\
\text { hydraulic } \\
\text { conductivity }\end{array}$ & $\begin{array}{l}\text { - constant \& invariant } \\
\text { - as stochastic variables }\end{array}$ & $\begin{array}{l}\text { calc porosity as } \mathrm{f}[\text { initial density], } \\
\text { permeability as } \mathrm{f}[\text { initial density, grain } \\
\text { diameter }=0.1 \mathrm{~cm}] \text {; defaults if no } \\
\text { initial snow; both then constant thru } \\
\text { event }\end{array}$ & $\begin{array}{l}\text { - vary hourly } \\
\text { - account for satisfaction } \\
\text { of irreducible moisture } \\
\text { in cold/dry pack }\end{array}$ & $\begin{array}{l}\text { assumes irreducible } \\
\text { moisture satisfied at start } \\
\text { (warm pack); } \\
\text { limits generally taken } \\
\text { from field \& lab literature } \\
* \text { applies also to SE } \\
\text { version }\end{array}$ \\
\hline $\begin{array}{l}\text { Percolation of } \\
\text { precipitation }+ \\
\text { meltwater }\end{array}$ & $\begin{array}{l}\text { - immediate infiltration of } \\
\mathrm{R}+\mathrm{M} \rightarrow \mathrm{WAR} \text { (no lag) } \\
\text { - simple lag time as } \\
\mathrm{f} \text { [depth] }\end{array}$ & $\begin{array}{l}\text { kinematic wave model: 1-dimensional } \\
\text { water percolation into homogeneous } \\
\text { snow, with wetting shocks; hourly } \\
\text { increments; maintains water balance/- } \\
\text { conservation, maximum water-holding } \\
\text { and transit capacities }\end{array}$ & $\begin{array}{l}\text { - allow layered snowpack } \\
\text { - slower initial percola- } \\
\text { tion into dry and/or cold } \\
\text { snow } \\
\text { - explicit drainage after } \\
\text { fast-percolating wave } \\
\text { passage }\end{array}$ & $\begin{array}{l}* \text { applies also to SE } \\
\text { version }\end{array}$ \\
\hline
\end{tabular}




\begin{tabular}{|c|c|c|c|c|}
\hline \multicolumn{5}{|l|}{ Temperature } \\
\hline $\begin{array}{l}\text { Initial temperature } \\
\text { Temperature range }\end{array}$ & $\begin{array}{l}\text { - invariant for all events } \\
\text { - initial T as stochastic } \\
\text { variable without date } \\
\text { function }\end{array}$ & $\begin{array}{l}\text { data from storm periods with } \sim \text { hourly } \\
\text { obs, to calc starting T and range for } \\
\mathrm{StpP} \text { elev as } \mathrm{f}[\text { date], then lapse } \\
-0.00625 \mathrm{C} / \mathrm{m} \rightarrow \mathrm{T} \text { at model-run elev }\end{array}$ & $\begin{array}{l}\text { - base on more stations } \\
\text { - find elev fcns for } \\
\text { params that seem } \\
\text { constant }\end{array}$ & \multirow{2}{*}{$\begin{array}{l}\text { NWS-COOP stations } \\
\text { record just max \& min T } \\
\text { other NWS airways } \\
\text { stations far outside study } \\
\text { area (Olympia, Sea-Tac } \\
\text { airports) } \\
\text { a few RAWS sites - } \\
\text { possible additional info }\end{array}$} \\
\hline Hourly temperature & $\begin{array}{l}\text { - constant thru event } \\
\text { - diurnal thru event } \\
\text { - no random component }\end{array}$ & $\begin{array}{l}\text { modeled from frontal segments of } \\
\text { event } \mathrm{T} \text { (from data), plus diurnal waves } \\
\text { and random kicker, varying in the } \\
\text { range around initial T }\end{array}$ & $\begin{array}{l}\text { - base patterns on larger } \\
\text { station sample } \\
\text { - more consistent method } \\
\text { for setting ratios, } \\
\text { segments }\end{array}$ & \\
\hline \multicolumn{5}{|l|}{ Wind } \\
\hline $\begin{array}{l}\text { Central/median wind } \\
\text { speed } \\
\text { Wind speed range } \\
\text { from std dev }\end{array}$ & $\begin{array}{l}\text { - invariant for all events } \\
\text { - central W as stochastic } \\
\text { variable without range }\end{array}$ & $\begin{array}{l}\text { data from storm periods with } \sim \text { hourly } \\
\text { obs, to calc central } \mathrm{W} \text { and range for } \\
\text { StpP; no change with elev or date }\end{array}$ & $\begin{array}{l}\text { - base on more stations } \\
\text { - find relations with elev, } \\
\text { date, site, etc. }\end{array}$ & $\begin{array}{l}\text { NWS-COOP - no wind } \\
\text { data } \\
\text { other NWS airways } \\
\text { stations outside area; } \\
\text { RAWS possible }\end{array}$ \\
\hline Hourly wind speed & $\begin{array}{l}\text { - constant thru event } \\
\text { - no random component }\end{array}$ & $\begin{array}{l}\text { modeled as random variation within } \\
\pm 3 \text { std dev around central } \mathrm{W}\end{array}$ & $\begin{array}{l}\text { - correlate with precip, } \mathrm{T} \text {, } \\
\text { frontal passage }\end{array}$ & $\begin{array}{l}\text { future: find a better } \\
\text { model for wind }\end{array}$ \\
\hline \multicolumn{5}{|c|}{ Notes } \\
\hline \multicolumn{5}{|c|}{$\begin{array}{l}\text { Abbreviations as defined in the text (see also list of abbreviations and symbols). } \\
\text { In this and other tables: arrows }(\leftarrow, \rightarrow) \text { indicate functional dependence or procedural/arithmetic paths. } \\
\text { For most properties, another simple approach would be to base the distributions/parameters on the data from one station alone (i.e., the approach used } \\
\text { for temperature and wind speed, and in EXP mode). } \\
\text { * Approaches regarding snow density and hydraulic properties also apply in the snowpack and percolation calculations of the single event (SE) model } \\
\text { version. }\end{array}$} \\
\hline
\end{tabular}


Program operation for both versions starts with dimension statements, followed by dialog boxes querying site name and elevation. The Monte Carlo version also asks for run length (years) and the type of precipitation distribution (PrecOpt), of which two options are currently available: using exponential distributions either with values from a particular place or a generalized elevation, hence EXP and EXE. (Alternate formulations based on extreme-value type 1 distribution are designated EVP and EVE in place-holders in the code; other frequency distributions could also be applied.) Based partly on the responses, initiating and default parameters of storm timing, weather and snow conditions are assigned into variables for the run, and this information is copied onto the Summary page and Tables template. The first stochastic action calculates the number of events: based on the regional average of $\sim 4.4 \mathrm{LCS} / \mathrm{yr}$ for stations in the record, the model randomly allocates $\sim 4400$ events into the 1000 yr of a run, as $1-12$ storms in each year.

The heart of the model procedures are represented by the central panels in Figures 3.1 and 3.2. These core operations are recorded on the Working and Summary pages, carried out in five blocks of procedures (so organized and named in the program code, appendices B, C).

A) First block This segment of the program deals with initial values of event timing and duration, total precipitation, and initial snow depth and water equivalent; and subsequently, the hourly weather-related factors that drive the snowpack and percolation routines. For the single event mode these are decided previously, and the event features (duration, total precipitation, initial snowpack) and hourly values of temperature, wind speed and precipitation are entered manually into appropriate cells of the Working table.

The Monte Carlo version must generate these state and forcing variables probabil- 
istically. Beginning with the first event of the first year (and eventually for each subsequent event), the program applies the sequence of stored random numbers to the governing parameters, commonly by inversion of cumulative normal or log-normal distribution functions. The model selects a starting date, hour and nominal duration; total precipitation and SIM code number; initial snow depth and SWE (determining snow density, porosity and permeability); event air temperature expressed in an initial value and range; frontal/diurnal ratio and event code for hourly temperature (see below); and a central value and range of the event's wind speed. Instead of using constant values of the weather variables or simple changes within the ranges, I developed procedures to generate hourly quantities using a set of algorithms combining physically-based and random components (Table 3.1, 4.1).

First in the sequence, the generation of hourly air temperature contains three elements. The day-night cycle is represented by a simple cosine wave, but passing fronts and warm/cold air masses typically overwhelm daily oscillations during big winter storms. A variable number of time segments reflecting periods of generally rising, stable or falling temperatures are applied to the event period, selected from a set of stored Temp codes (Fig. 3.2; based on 100 storms at Stampede Pass; bivariate-normal with event duration). The diurnal and frontal effects are apportioned by a randomly selected frontal-diurnal ratio $(0.01 \leq \mathrm{FDR} \leq 0.99)$, empirically tending to high ratios (average 0.86$)$ indicating strong frontal signals in major storms. Fluctuation with some persistence among contiguous hourly values is provided by random factors (kickers in the code); for temperature, these are calculated as running sums of two random numbers (range $-1<\left[R \#_{n}+R \#_{n+1}-\right.$ $1]<+1)$. The sum of an hour's diurnal, frontal and random increases/decreases deter- 
mines its temperature for an hour by the change from the previous hour, producing realistic patterns of $\mathrm{T}_{\mathrm{h}}$ (see Fig. 5.6).

Lacking a simple physically-based alternative, the model calculates hourly wind speed from random fluctuations around the central value. The means and standard deviations of winds measured during a sample of storms (at Stampede Pass) are used to set the event's central and range values; then, a moving sum of three random numbers is used to calculate a point within three standard deviations around the mean (i.e., range $-3<2\left[R \#_{\mathrm{n}}\right.$ $\left.\left.+R \#_{\mathrm{n}+1}+R \#_{\mathrm{n}+2}\right]-3<+3\right)$. This factor is added to the central value to give $\mathrm{W}_{\mathrm{h}}$, dominantly random but with persistence; speed limits are set at $0-25 \mathrm{~m} / \mathrm{s}$.

Hourly precipitation is estimated with $4^{\text {th }}$-order polynomials emulating the cumulative mass curves of 1000 observed storms, modified with a random component. These amounts are reconstructed by the storm internal model from the five polynomial coefficients (stored and selected as SIM codes) with event hour as the independent variable. Fluctuation with persistence among contiguous hours is provided by multiplying each hour's basic value by running sums of two random numbers $\left(0<\left[R \#_{\mathrm{n}}+R \#_{\mathrm{n}+1}\right]<2\right)$. The proportions of each hour's precipitation that are rain and snow are determined by temperature; both can exist near freezing, calculated by a linear ratio when $\mathrm{T}_{\mathrm{h}}$ is -1.5 to $+2.5^{\circ} \mathrm{C}$ (section 3.1). Precipitation "ends" when cumulative $\mathrm{P}_{\mathrm{h}}$ reaches the designated storm total.

Designed to simulate the rainfall patterns of big storms, this method combines actual observations with infinite variations but sacrifices some realism at short durations. The procedure results in a preponderance of smaller $\mathrm{P}_{\mathrm{h}}$ over the largest amounts, smoothing the greatest precipitation peaks (perhaps similar to rain being intercepted by vegetation or snow). However, any bias to smaller values is minor: in a later review of 50 model 
events (\#187-236 from a model run at $1250 \mathrm{~m}), 14 \%$ had maximum $\mathrm{P}_{\mathrm{h}}$ amounts of 1-2 $\mathrm{cm}$; the record of 1-h maximum rainfall at Stampede Pass shows $\sim 16 \%$ between 1-3 cm ( $3 \mathrm{~cm}$ questionable; next largest $\sim 2 \mathrm{~cm}$ ). Based on this correspondence, and checking several dozen patterns generated by the SIM during its development, the algorithms seem to produce a decent representation of the patterns of hourly storm precipitation (Fig. 5.7).

Although improvised, I believe that these procedures yield generally satisfactory hourly weather quantities. Their numbers are based on recorded events and quantities, measured in the region of interest (mainly at Stampede Pass); and the algorithms are designed to address the kinds of long, rainy storms that occur in the Northwest. In tests and runs described later (chapters 5,6), the values and patterns generated appear acceptably realistic: I have detected no quantities that abuse credulity (e.g., temperature changing tens of degrees in one hour), but the near-infinite variability of the possible patterns creates some that are less realistic than others.

Nevertheless, this is a theoretically primitive set of approximations, suffering particularly in the lack of integration. In actual storms hourly temperature, wind speed and precipitation are physically linked: storm duration, temperature and wind together affect the amount and phase of precipitation; wind speed is related to frontal passage and other weather variations. My simple procedures treat $\mathrm{T}_{h}, \mathrm{~W}_{\mathrm{h}}$ and $\mathrm{P}_{\mathrm{h}}$ independently, with only initial temperature dependent on a separate variable, storm date. However, it is still more realistic than calculating hourly weather conditions either as constants or averages through an event, or as entirely random values. For now, these formulae occupy reasonable points on the complexity spectrum (Table 3.1); accounting for the weather interactions is an area for future improvement. 
B) Second block Once the weather factors are set, whether specified in SE or selected by Monte Carlo procedures, the model next accumulates or melts snow through the event. If a snowpack is present and/or snowfall occurs during any given hour, potential melt is calculated using energy-balance equations for rain-on-snow conditions, adapted for hourly increments of the heat-source indices (section 3.1B). With these adjustments, hourly melt is calculated from the temperature, wind speed and precipitation for that hour, along with a daytime-dependent solar-radiation factor:

$$
M_{h}=\lfloor\rfloor
$$

No melt occurs if the modeled hourly temperature is $\leq 0^{\circ} \mathrm{C}$. For $\mathrm{T}_{\mathrm{h}}>0^{\circ} \mathrm{C}, \mathrm{M}_{\mathrm{h}}$ is compared with the mass of solid precipitation gain to determine possible changes in the new snow and any existing pack. If snowfall exceeds melt, the net change in SWE is positive and snow accumulates, with the increase in depth calculated from the ratio of net change to a temperature-dependent density $\left(\Delta \mathrm{d}=\Delta \mathrm{SWE} / \rho_{\mathrm{S}[\mathrm{Th}]}\right.$; range 0.15 for cold snow and greater increase, to 0.85 for warm dense snow and small increase; calibration in section 5.2). If $\Delta \mathrm{SWE}_{\mathrm{h}}$ is negative, $\mathrm{M}_{\mathrm{h}}$ is first applied to that hour's snowfall, with any surplus melting part of the preexisting pack. Lastly, the bulk snowpack density is recalculated from the SWE and depth for each hour. The resultant quantities are listed on the Working table, including the hour's sum of any liquid water (rain plus melt) available to move through the snowpack.

C) Third block In both single- and multi-event versions, for each hour having rain and/or net melt, the model routes that water down through the snowpack, if present, or directly into the ground. Snow percolation is computed using the kinematic wave approximation based on the adaptations of Colbeck (1972) and Dunne et al. (1976); section 3.1C). 
The wave speed of water $(\mathrm{cm} / \mathrm{h})$ through the snow is proportional to the snow's hydraulic properties (conductivity and porosity) and the rain plus melt rate for the hour:

$$
V_{f}=\stackrel{\rho}{\nu^{1 / 3}}\lfloor\quad\rfloor^{\cdots}
$$

Some simplifications for code efficiency have been mentioned. The percolation routines solve the kinematic-wave equations by discretizing each hour's water input as a coherent packet moving with a uniform speed (unless interacting with other waves; see below); and the snowpack hydraulic properties are calculated from initial snow density and then remain constant during the event. Conductivity $\mathrm{K}=\mathrm{k} \rho_{\mathrm{w}} \mathrm{g} / \mu=54,713 \mathrm{k} \times 3600$ to convert to $\mathrm{cm} / \mathrm{h}$, with permeability $\mathrm{k}$ estimated as a function of initial $\rho_{\mathrm{s}}$ and grain diameter (Eq 11); effective porosity $\phi_{\mathrm{e}}$ is a function of snow density and irreducible water content (Eq 9 and 10).

This program block first computes the non-varying exponents (from $n=3$ ) and $3 \mathrm{~K}^{1 / 3} / \phi_{\mathrm{e}}($ called $F l u x K)$. Then, for each event hour generating liquid water, a do-loop routes the flux through the snow to the ground, calculating time of arrival (limited by the event's duration). The wave velocity for each hour's input $\left(\mathrm{V}_{f}\right.$ in Eq 6$)$ is calculated as Flux $V=F l u x K \times(\mathrm{R}+\mathrm{M})^{2 / 3}$. Then the vertical location of a flux at any subsequent hour $(\mathrm{PercHr})$ is specified by travel distance $\mathrm{FluxV} \times \mathrm{PercHr}$ below the snow surface. Travel time is usually not an exact multiple of 60 minutes, so the water volume of each flux is allocated proportionally to WAR over the two clock hours it overlaps, based on time of arrival.

Larger water inputs create faster kinematic waves that can overtake slower ones. The percolation algorithms compare each flux's depth at every hour with the locations of 
those that started earlier; if one catches another, they are combined into one packet with a summed volume and celerity (ShockV) between those of the slower and faster waves:

$$
V_{\text {shock }}=\underbrace{\rightarrow \nu^{1 / 3} \Gamma-}
$$

This resultant kinematic-shock wave is then routed downward through the pack, and the tests for interactions continue. The model's tracking of wave and shock-wave movements incorporate numerical simplifications, yet ensure conservation of mass.

After routing through a storm's duration, the hourly amounts of water reaching the ground are summed; totals for some hours are adjusted based on the snow's maximum drainage rate or water-holding capacity. This latter function serves to smooth the WAR hydrograph, and approximate the slower waves trailing the larger fluxes. As another way to account for mass conservation, the program computes and lists hourly SWE and bulk density both with and without the liquid water in transit as well as the snow. This was particularly important for comparisons in SE test runs against the measurements at snow pillows, which detect the overlying weight of snow and water combined.

A major model simplification is that hydraulic properties stay constant, either universally $\left(\mathrm{n}=3, \mathrm{~S}_{\mathrm{irr}}=0.03\right.$ so $\left.\phi_{\mathrm{e}}=0.97 \phi\right)$ or through each individual event, based on initial snowpack density. This is unavoidable given the frugal structure of my percolation routines, in which each hourly input is tracked immediately through the pack from starting hour to arrival at the ground. The kinematic wave and shock speeds depend on $\mathrm{K}$ and $\phi_{\mathrm{e}}$, but the model doesn't know what their later values might be. Procedures allowing for hourly changes in all these properties would tax the intended simplicity of this model.

Even so, these simplifications produce plausible results. Over the model's allowed 
range for snow density of $0.1-0.8, \phi_{\mathrm{e}}$ spans $\sim 0.124-0.867$, while $\mathrm{k}$ and $\mathrm{K}$ vary over two and three orders of magnitude, respectively $(\mathrm{K}=69,524 \mathrm{~cm} / \mathrm{h}$ for loose to $296 \mathrm{~cm} / \mathrm{h}$ for dense snow; Tables 5.1, 5.2). Although the density-forced ranges of effective porosity (maximum $>$ minimum by a factor of $8 \times$ ) and hydraulic conductivity $(20 \times)$ seem large, their effects on flux are offset because $\mathrm{V}_{\mathrm{f}}$ is proportional to $\mathrm{K}^{1 / 3} / \phi_{\mathrm{e}}(\mathrm{Eq} 6)$. For $\rho_{\mathrm{s}}=0.1$ that ratio is 47.4 and at 0.8 it is 53.7 , declining in between to a minimum (at $\rho_{\mathrm{s}} \sim 0.5$ it is $\sim 32.8$ ). Given model water inputs of $\sim 0.1-5 \mathrm{~cm} / \mathrm{h}$, wave velocities range $\sim 30-470 \mathrm{~cm} / \mathrm{h}$ $(\sim 15 \times)$, within the range of field measurements (e.g., Gerdel, 1954; Dunne et al., 1976; P. Jordan, 1983a; Singh et al., 1997). Thus, a wide span of hydraulic-property values does not produce a similarly wide range of percolation rates, as the latter are damped by the counteracting effects of snow density on effective porosity and conductivity.

D) Fourth block This part also operates in both SE and MC versions. Summation filters pass through the event's realizations of hourly precipitation, liquid input (rain plus snowmelt), and liquid output (water available for runoff) to find the maximum values of each for 1-, 6-, 12-, 24- and 48-h periods and for nominal storm durations. In addition, the filters continue $6 \mathrm{~h}$ past the end of precipitation to account for some additional snowpack drainage; $6 \mathrm{~h}$ was chosen to equal the precipitation gaps originally used to define long continuous storms from the station records. These longer durations (called DurE) were the time periods employed in most of my subsequent statistical and frequency analyses. E) Fifth block In both versions, all of the specified and model-generated initial and hourly values for an event are printed on the Working page. In single-event mode, it is up to the operator to save active pages and workbook files (Fig. 3.1). A summary table can be useful for storing results of multiple SE runs, for comparison among those obtained 
using various state and forcing variables, as in model testing (chapter 5). At the end of a run, realizations are automatically linked to three chart templates used to visualize the results: a graph of hourly temperature and wind speed (not shown on Fig. 3.1); a hydrograph of precipitation, snow, water inputs, and WAR; and a histogram of maximum P, $\mathrm{R}+\mathrm{M}$ and WAR in the durations filtered in block 4 . At this point, the SE model run ends.

In the Monte Carlo version (Fig. 3.2), the event Working pages are held in the workbook until 50 "years" worth ( 220 events) are cut from the active program (where their growing size slows operations) and saved to hard drive, where they can be inspected later for proper model operation and interesting examples of storm results. All important information (probabilities and values of input variables, constants, summary of outputs) is copied onto the Summary page at the end of each event. The chart templates are available in MC mode, but linked only to the currently active event; this makes them useful for debugging if an error stops the run. Otherwise, the operator can manually copy realizations from a particular event into the graphs (except the frequency graphs shown in Fig. 3.2 , which must be created separately).

Also in Monte Carlo mode, when these blocks are completed the program moves on to the next event, selects new variables, sets up a new Working page, and repeats the procedures. After the last event of the last year of the run, the entire model workbook is renamed and saved.

Several post-run processing steps are carried out for Monte Carlo experiments, mainly using the Summary page, the chief source for later analysis of the run's results. Events are sorted by model year and date, and arranged to reflect water years (i.e., storm dates for Jul-Aug-Sep reallocated to the previous WY). Summary statistics are calculated 
for each of the parameters and outputs, for comparison and statistical testing; the events are also scrutinized to identify the kinds of hydrologic events as indicated by the relative amounts of precipitation and WAR for each, a key metric in evaluation of ROS relative to simple precipitation. Regression calculations are normally also performed on this page, to generate the exponential distribution parameters for frequency analysis of precipitation, water input and WAR for a given run, and among runs at various sites and elevations. 


\section{STUDY REGION \& SITES}

\section{$\underline{4.1 \text { West-central Cascades study region }}$}

For relevance to my focus region, observations from someplace in the Pacific Northwest are essential input for the model. Storm magnitude is the chief forcing variable so hourly precipitation is essential, but the simulations also require snow on the ground, air temperature, and wind speed, all expected to change during and among large storms and ROS events. For any candidate study area, data-collection sites must be sufficiently numerous to allow statistical generalization across years and elevations, but its size cannot be so large that variations in storm passage, precipitation, snow, weather, etc. hide the trends being estimated (i.e., signals should be distinguishable from noise). My choices are limited by the customary siting of weather stations in lowlands and snow courses in highlands; intermediate elevations, presumed key to ROS, tend to be underrepresented.

I selected a portion of the west-central Cascade Range of Washington (Fig. 4.1, 4.5). The soggy, forested, mountainous terrain between the South Snoqualmie Valley and the northern foothills of Mt Rainier typify the ROS-susceptible landscape of the Northwest. As important, it boasts a wealth of long-term hydrometeorologic observations due to the presence of (1) Seattle and Tacoma municipal watersheds in the Cedar and Green river basins, respectively; (2) flood-control projects at Howard Hanson (Green) and Mud Mountain (White) dams; (3) major transportation corridors: Interstate 90 and the old Milwaukee Road railway along the South Snoqualmie; Burlington Northern-Santa Fe (originally Northern Pacific) Railroad through the Green River valley; State Route 410 up the White River; plus flight paths over the locally lower Cascade crest; and (4) scattered small towns, sawmills and auxiliary facilities (most abandoned), and recreation areas 
through the valleys and in the mountains.
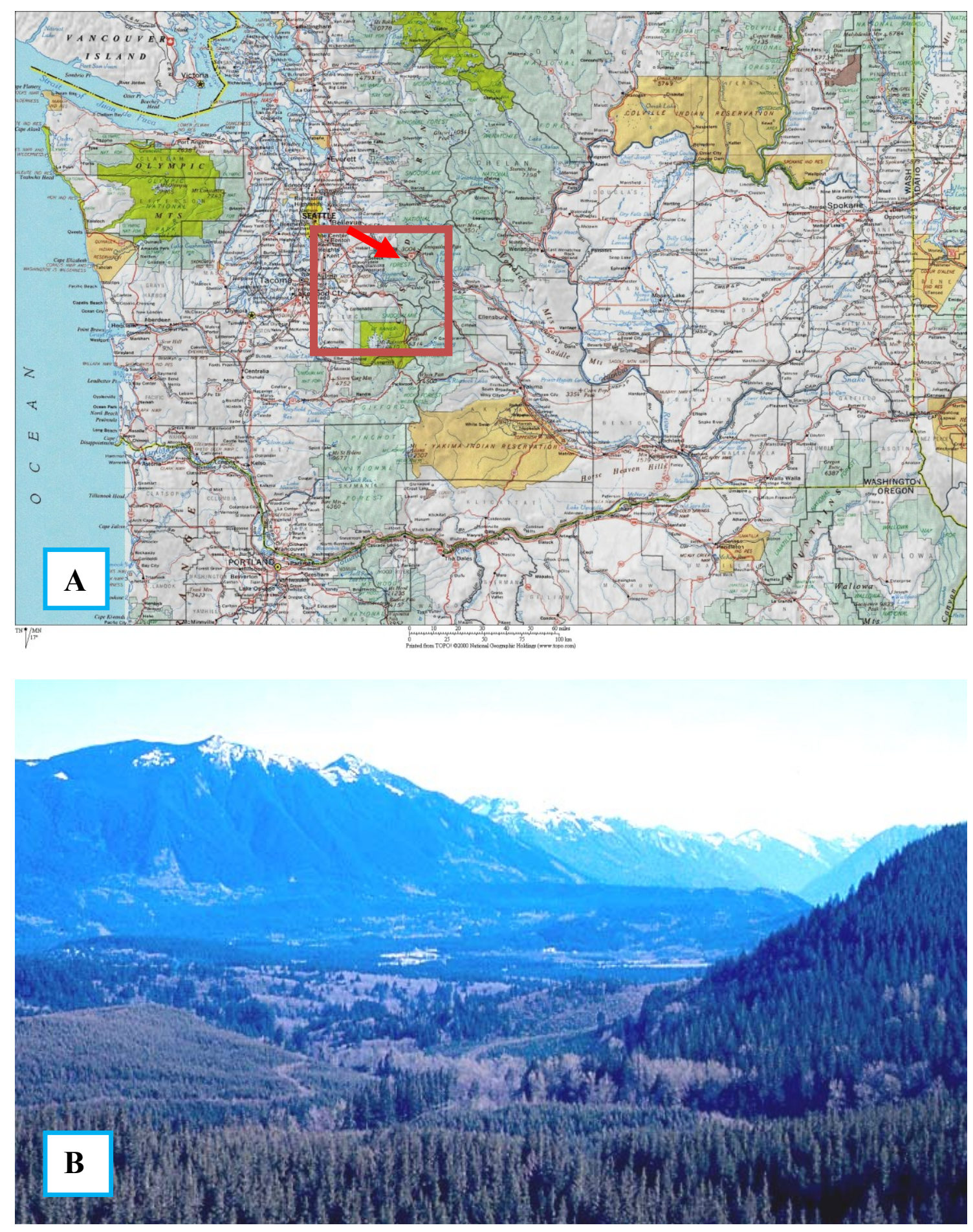

Figure 4.1 A: Map of Washington; box shows study area of Figure 4.5 (printed from TOPO! (C 2000, National Geographic Holdings). B: West-central Cascades terrain - view SE into the upper Cedar River valley (arrow in A), Seattle municipal watershed. (Photo by M.J. Brunengo, 2 Apr 2004.) 
In brief, the western Cascades study region is bounded roughly by $46^{\circ} 50^{\prime}$ to $47^{\circ} 25^{\prime} \mathrm{N}$ latitude and $121^{\circ} 15^{\prime}$ to $122^{\circ} \mathrm{W}$ longitude. The terrain generally slopes from the Puget Lowlands, below $\sim 200 \mathrm{~m}$ elevation, up to the drainage divide at $\sim 2000 \mathrm{~m}$ (section 4.3). However, this conceptual ramp starts at a rather abrupt mountain front and is broken by many valleys; the eastern drainage divide lies in a broad saddle between higher summits to the north and south, the lowest part of the Cascade crest between the Fraser and Columbia gorges (so-called Stampede Gap; Steenburgh et al., 1997).

Most of this segment of the Cascade Range is underlain by Tertiary volcanic, volcaniclastic, sedimentary and minor intrusive rocks, with Rainier's volcanic pile at the southern edge, and older metasedimentary, metavolcanic, and crystalline rocks on the northern periphery (compilation maps by Schasse, 1987a,b; Walsh, 1987; Walsh et al., 1987; Tabor et al., 1993, 2000; Dragovich et al., 2002; Washington geologic mapping at www.dnr.wa.gov/ResearchScience/Topics/GeosciencesData/Pages/geology_portal.aspx). In the Puget Lowlands and the larger Cascade valleys, bedrock is typically mantled by variable thicknesses of unconsolidated sediments of glacial, fluvial and volcanic origin (Mackin, 1941; Crandell, 1963, 1971; Crandell and Miller, 1974; Porter, 1976; Booth, 1990; Goldin, 1992; Booth et al., 2004).

Vegetation of the western Cascades before ca 1850 was dominated by coniferous forests of Douglas-fir, western hemlock, western redcedar, and Pacific silver fir (Franklin and Dyrness, 1973; Franklin and Blinn, 1988; del Moral and Long, 1977; Henderson et al., 1992). Climax stands of big ancient trees (along with myriad associated species of trees, shrubs, forbs, etc.) were interspersed with younger patches reset by fires, insect and disease infestations, floods, landslides, and volcanic eruptions (Hemstrom and Franklin, 
1982; Swanson et al., 1990; Agee, 1993). Deciduous riparian zones, wetlands, subalpine parkland, alpine meadows, rocky bluffs and talus fields persist in appropriate environments, each supporting distinct plant and animal communities (Ewing, 1982). These ecosystems have shifted geographically over centuries to millennia, notably in response to climatic changes at various time scales (e.g., glacial to interglacial; Whitlock and Bartlein, 1997).

In the past 150 years, most of the study region has undergone timber harvest up to several times, and vegetation in the lowlands and major valleys has been considerably altered for farms, mills, mines, towns, roads and recreation areas. Much of the uplands remains in commercial forestry, under private, federal and state ownership, presenting a vegetal mosaic ranging from recent clearcuts to mature stands (but little true old-growth). However, significant forest blocks are now managed primarily for municipal water supplies, by Seattle in the Cedar and Tacoma in the Green watersheds; or for preservation and recreation, in Mt Rainier National Park and the Alpine Lakes, Norse Peak, and Clearwater wilderness areas.

\subsection{Climate of the region; interannual variability}

The humid-maritime climate of the western Pacific Northwest is dominated by the westerly flow of air and moisture from the Pacific Ocean, influenced by weather variability across synoptic to seasonal to interannual time scales (Phillips, 1968; Taylor and Hatton, 1999; Miller, 2002; Mass, 2008; PRISM maps at www.prism.oregonstate.edu). The semi-stable Aleutian low and California high pressure centers guide subpolar and subtropical jet streams and associated storm systems approaching western North America. Pressure-circulation patterns experience annual $\mathrm{N} \leftrightarrow \rightarrow \mathrm{S}$ latitudinal cycles, making temper- 
ature and precipitation in the PNW strongly seasonal: the cool wet winters and warm dry summers are manifest in the monthly averages (Fig. 4.2). Extreme temperatures are typically due to high-pressure systems feeding hot (in summer, to $+40^{\circ} \mathrm{C}$ ) or cold (in winter, to $-20^{\circ} \mathrm{C}$ ) continental air from the east, especially through low areas in the Cascade crest such as the Columbia Gorge and Stampede Gap.

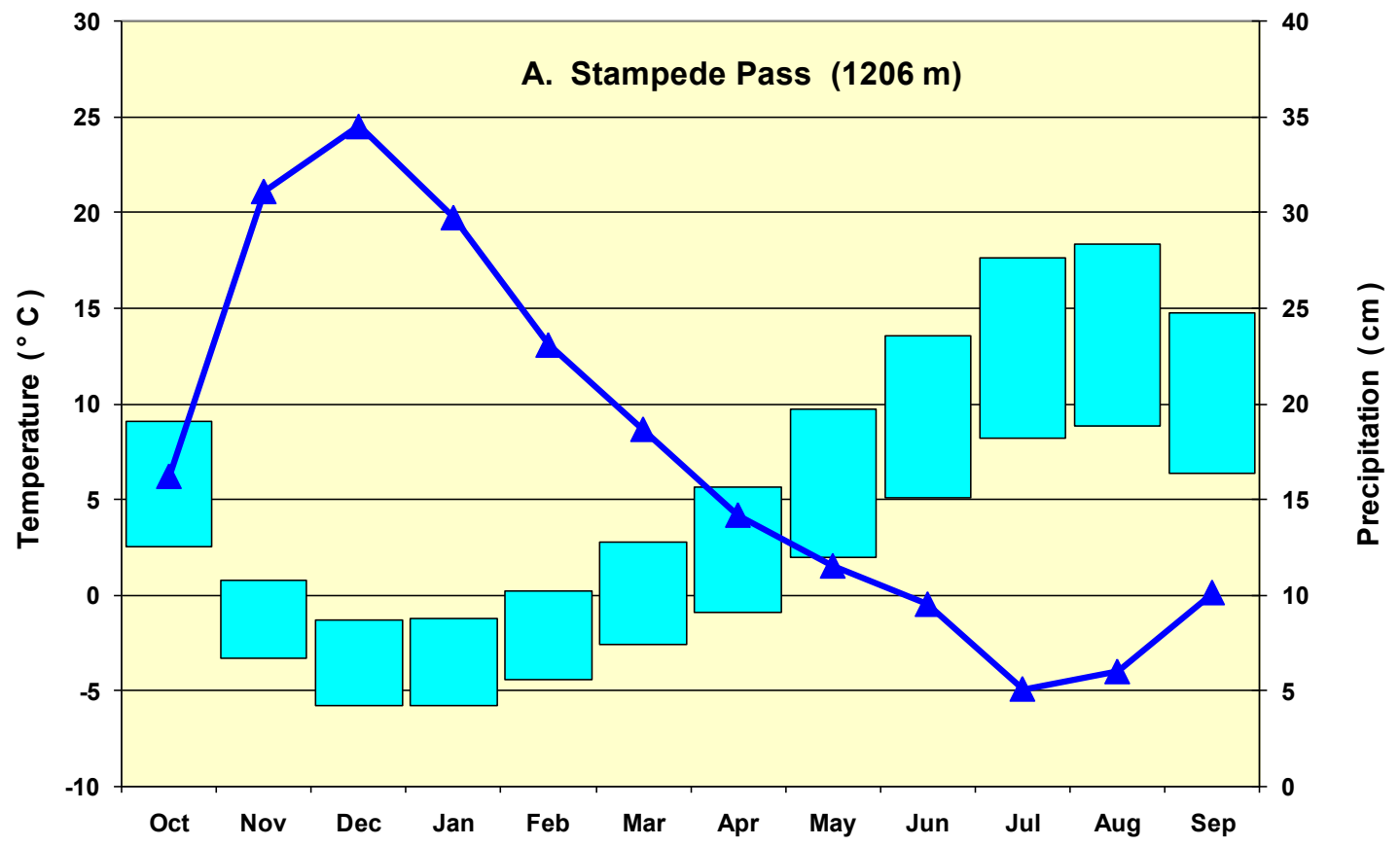



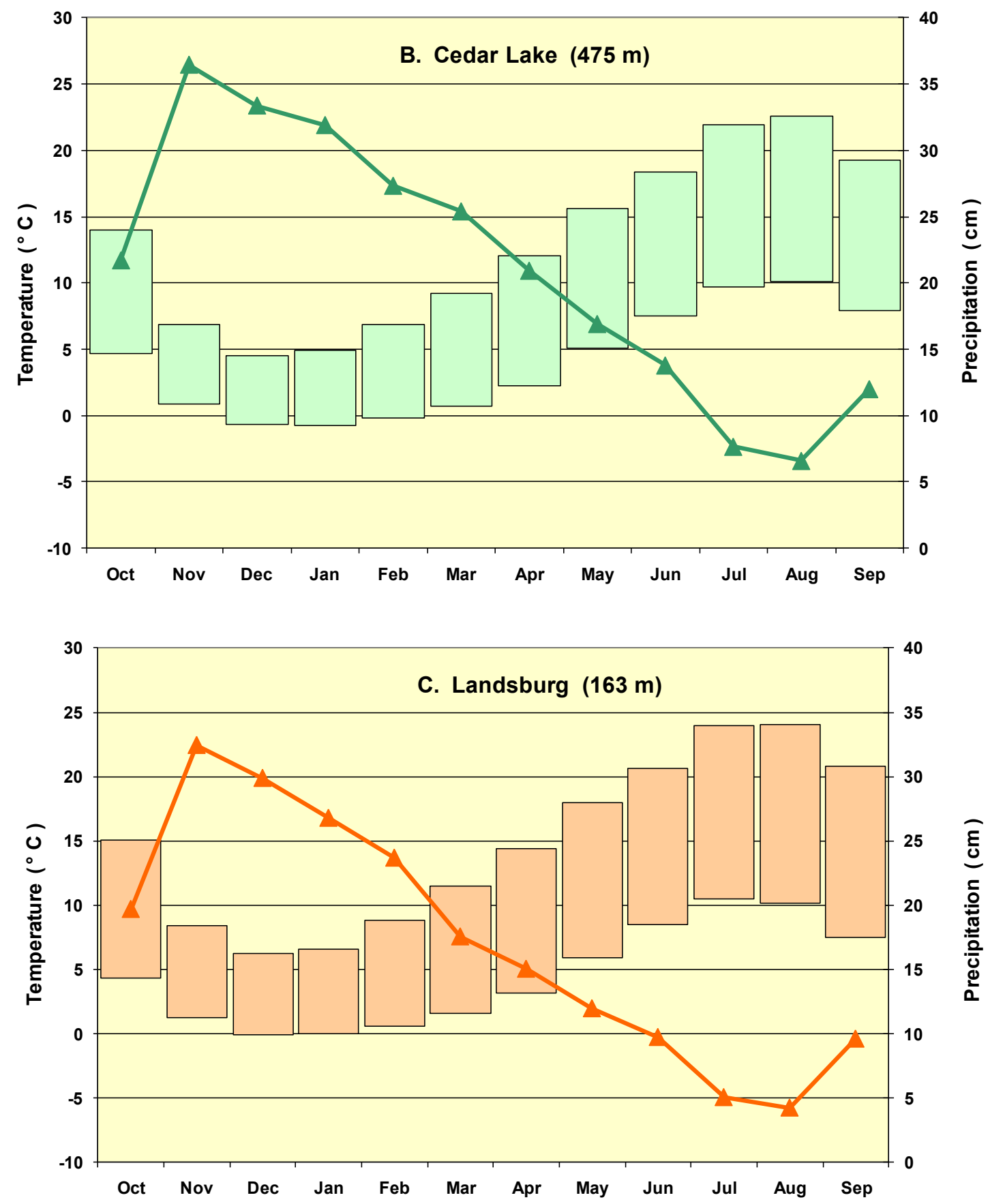

Figure 4.2. Average monthly precipitation (lines) and average high and low temperatures (boxes), for three weather stations in the study region (with elevations), 1971-2000. A: Stampede Pass, highland site on Cascade crest. B: Cedar Lake, middle elevation site in valley near mountain front. C: Landsburg, lowland site in Puget Lowland. Data collected by National Weather Service and cooperators; acquired from Western Regional Climate Center (www.wrcc.dri.edu).

Climatic data (WRCC compilations; Phillips, 1968; Mass, 2008; and collected in 
this project) show that average annual precipitation at Washington Cascades weather stations ranges over $\sim 150-300 \mathrm{~cm}$, with $\sim 400 \mathrm{~cm} / \mathrm{yr}$ extremes depending on elevation and terrain. Most precipitation occurs in the cooler months: $\sim 70 \%$ from October through April, only $\sim 10 \%$ in June through August. Heavy and persistent precipitation is normally due to midlatitude cyclonic storms and associated fronts, moving onshore from the north and central Pacific in the cooler seasons. Rainfall records indicate that storm arrival and precipitation increase to a peak in late November and December, followed by a slight lull and a secondary (lower) peak in late January, declining through late winter and spring. Orographic enhancement generally produces longer and heavier precipitation over the high terrain during winter storms; on the other hand, more rain can fall at the mountain front in warm-season convective storms that do not penetrate the range interior.

Snowfall contributes $<5 \%$ of annual precipitation in the lowlands to $75 \%$ or more in the mountains, varying from year to year. Snow depth can exceed $500 \mathrm{~cm}$ at high and cold locations, including Stampede and Snoqualmie passes where cold air flowing over from the east enhances accumulation. From 1 April SNOTEL data throughout the West, Serreze et al. (1999) found that in the mountainous PNW on average $\sim 50 \%$ of annual precipitation is stored in the snowpack; but this is one of the lowest ratios of SWE to precipitation in the West, due to autumn and winter rains and early melt loss in this region.

Aside from regular seasonal changes, climate in the Pacific Northwest also experiences several kinds of irregular cycles over longer periods, as weather conditions during individual years are influenced by interacting global atmospheric-oceanic processes. These can affect cool-season temperature, precipitation, and snow volume, as illustrated by time series for WY 1940-2005 (Fig. 4.3; the period of data used in the model), for the 
two NWS climatic divisions covering the study region.

For temperature (Fig. 4.3A), the 30-90-d Madden-Julian Oscillation (MJO; Zhang, 2005) intermittently directs streams of tropical air toward western North America; persistence of such short-term warming can influence temperatures over an entire winter. El Niño-Southern Oscillation (ENSO) cycles occur at $\sim 3-8$ yr intervals: El Niño winters tend to bring clearer and warmer winter weather to the PNW; La Niña years are commonly cooler; neutral years are mixed (Wooster and Fluharty, 1985; Ropelewski and Halpert, 1986; Enfield, 1989). Over longer intervals, temperatures in the Northwest also shift with the Pacific Decadal Oscillation (PDO), with cooler phases (such as the mid-1940s to 1976) and warmer phases (1977 to present?; e.g., Roden, 1989; Mantua et al., 1997). There is also a broader warming trend over the several decades (Mote et al., 2005); the WY data shown rise at $\sim 0.011-0.035 \mathrm{C}^{\circ} \mathrm{yr}$.

Temperature observations used in the model (Stampede Pass station, mean and variance of hourly temperature for 133 storms, and hourly temperatures for 100; Table 4.1) all come from WY 1970-2004, encompassing many MJO and ENSO cycles but the dominantly warmer part of the record. However, these are measurements during individual events, so are less closely linked to long-term trends; if anything, there may be a slight tendency for the sampled storms to have occurred in the cooler (wetter) winters. 

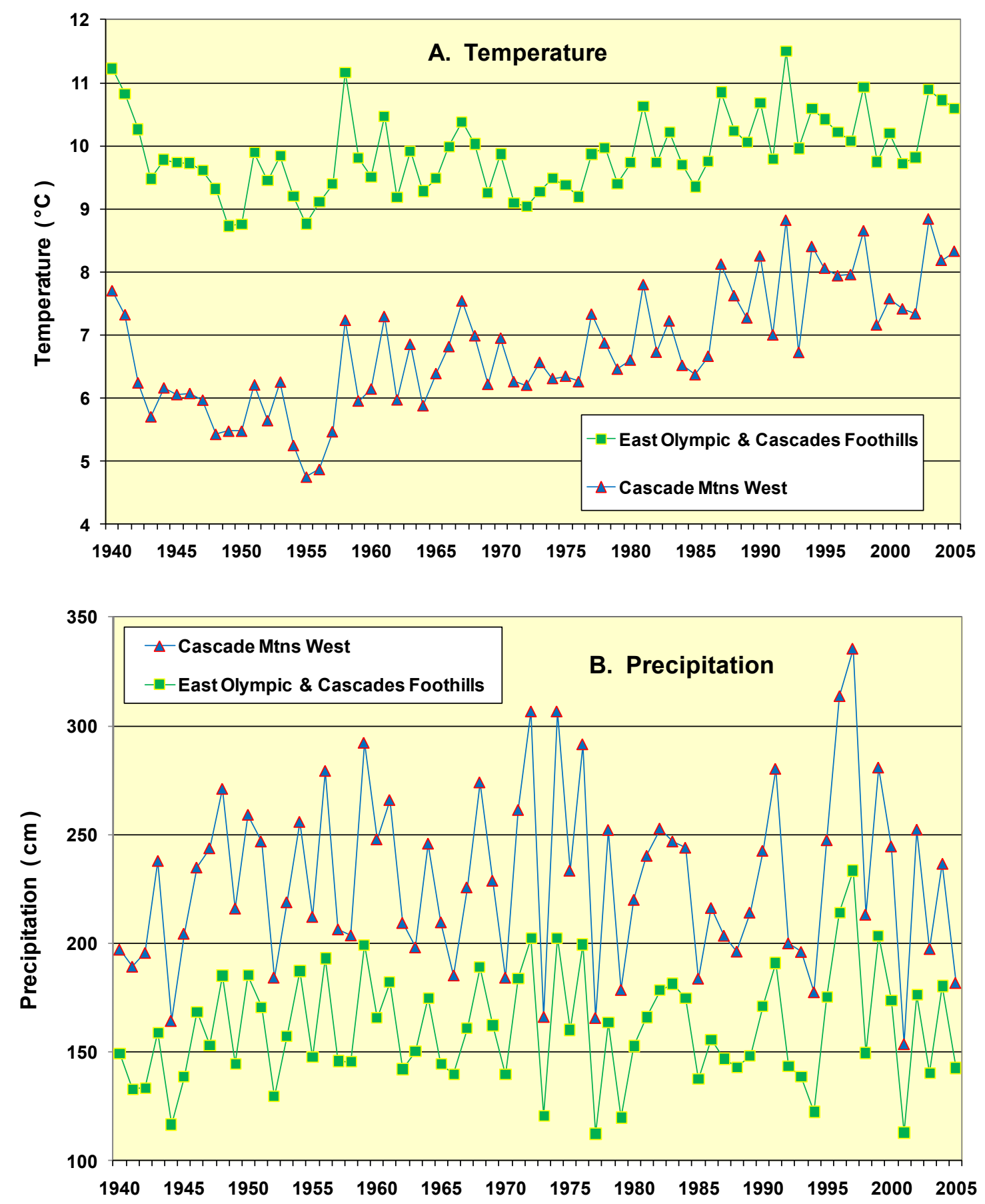

Figure 4.3. Time series of NWS divisional climatic averages, for water years (Oct-Sep) 1940-2005. Cascade Mountains West division comprised $\sim 10$ stations, including Cedar Lk, Snoqualmie Pass, Crystal CkWhite R Ranger Sta and Stampede Pass in my study area; East Olympic and Cascades Foothills division comprised $\sim 30$ stations, including Landsburg, Palmer 3ESE, Mud Mtn Dam and Greenwater (Table D.1; division membership depends on sites active in any year). A: Temperature. B: Precipitation.

These climatic patterns and phases also affect precipitation. Intraseasonally, 
anomalous but potentially persistent hemispheric pressure and circulation modes (such as the Pacific-North America and other teleconnections) and shorter bursts of subtropical moisture (MJO) can generate heavy storm precipitation in North America (Cayan and Peterson, 1989; Redmond and Koch, 1991; Mo and Higgins, 1998; Bond and Vecchi, 2003). In particular, heavy cool-season rains commonly strike the west coast under strong southwesterly flow, bringing warmth and moisture from the central Pacific. Relatively narrow low-level streams of air from tropical into middle latitudes are labeled atmospheric rivers (AR) and the subset pineapple express (PEx) (Newell et al., 1992; Zhu and Newell, 1994, 1998; Lackmann and Gyakum, 1999; Higgins et al., 2000; Dettinger, 2004a). They seem to be responsible for enhanced delivery of water vapor to western North America, with approximately double the precipitation on winter (Dec-Feb) AR days and greater contributions to major storms and floods (Neiman et al., 2008a).

However, despite considerable overlap between AR/PEx and ROS events, they are not matching sets: the former do not always cause big storms, let alone ROS. Consider Dettinger's (2004b) identification of possible PEx days, when strong moisturetransport paths extended back from the west coast to the subtropical Pacific (1948-99; 206 days, $\sim 150$ separate events); specifically, those relevant to my area, crossing latitude 45.0 $-47.5^{\circ} \mathrm{N}$ for northeastward flow to the central Washington Cascades. Comparing this subset to the records compiled in my study: two-thirds or more of the identified PEx patterns resulted in significant precipitation at my weather stations, but about one-third produced little. Furthermore, many of the biggest events do not appear in this PEx list: among the heaviest 48-h precipitation observations at Stampede Pass and Cedar Lake weather stations, only two to three are identified as PEx events, none of them ranking 
higher than $13^{\text {th }}$. Note that these comparisons are for precipitation magnitude only, not the entire suite of warm-wet conditions and enhanced water-inputs of rain-on-snow; and that Dettinger (2004b) acknowledged that his $2.5^{\circ}$ latitude-longitude grid might miss shorter/narrower PEx jets. Likewise, the list of AR plumes in WY 1998-2005ARs making landfall on the Washington-Oregon coast compiled by Neiman et al. (2008a) includes many that registered as major precipitation events among the stations in my study area; but a lot of the storms at my stations are not on that list, and many of the listed AR days were not particularly wet at my sites.

The precise relationship of AR/PEx and significant ROS events remains to be evaluated in greater detail. According to the analysis of Neiman et al. (2008a), they approach the PNW most often in Jul-Aug-Sep, when little snow remains. But a significant number of AR plumes make landfall in Oct-Jan, when meridional transport of heat and moisture into the continental margin is more likely, and there is greater possibility of snowpacks vulnerable to melting. At any given time, an AR plume might or might not cause heavy rain in the PNW; if it does, there may or may not be snow to be melted and enhance runoff. Considering the lack of concurrence even between AR/PEx days and large precipitation events in the Washington Cascades, terms such as "atmospheric river" and "pineapple express" cannot be simple analogues for "ROS event".

Regardless of the causes, relatively wet or dry short-term patterns persisting through entire seasons can produce up to $\sim 2 \times$ variability in yearly precipitation maxima over minima (Fig. 4.3B). Much of the strong interannual variation in rain and snow is governed by ENSO cycles, commonly with drier conditions in the Northwest in El Niño phases such as WY 1973 and 1977, and wetter winters during La Niña years such as 
1972, 1974 and 1976 (Ropelewski and Halpert, 1986; Cayan and Peterson, 1989; Redmond and Koch, 1991; Koch et al., 1991; Johnson and Koch, 1992; Cayan et al., 1999). These patterns are not wholly consistent: the strong El Niño of WY 1983 brought heavier rains; the very wet 1996 was mild La Niña but the even wetter 1997 was neutral; and the very dry 2001 had mild La Niña conditions (based on the Oceanic Niño Index, www.cpc.ncep.noaa.gov/products/analysis_monitoring/ensostuff).

Longer cycles also influence precipitation in western North America, probably interacting with the short-period processes (Roden, 1989). More precipitation is delivered to the Northwest during cold PDO phases and less during warm phases, as suggested by the change from a generally wetter to a drier period in the late 1970s; the cluster of wet years in 1995-2000 was thought to signal a shift from warm-dry back to cold-wet PDO (Mantua et al., 1997; Cayan et al., 1998), but subsequent conditions have not entirely supported that idea (Table 4.3B). Interplay among ENSO and PDO processes also appears to affect climate in the PNW. North Pacific circulation tends to split the jets toward Alaska and California during El Niño periods and warm PDO phases, so these conditions are likely to bring drier winters to the Northwest as many storms bypass the region. Alternately, more winter-season precipitation falls and streamflows are higher during La Niña winters (cold ENSO) and during cold PDO years, and especially when they are concurrent (Koch and Fisher, 2000).

Multidecadal trends in precipitation show positive or negative changes of a few percent in the PNW, depending on the areas and periods examined (Mote et al., 2005). My study region shows slight increase, $\sim 0.1-0.2 \mathrm{~cm} / \mathrm{yr}(\sim 4-7 \%)$ over $65 \mathrm{yr}$, but with miniscule correlation $\left(r^{2}<0.02\right.$; Fig. 4.3B). Again, precipitation data incorporated in the 
model are event-based, so annual averages and trends are less dominant. It is likely that a larger proportion of the storms sampled occurred in the wetter years just because they usually have more storms.

Snowpack also experiences interannual variability, correlated with cool-season temperature and precipitation (Koch et al., 1991; Cayan, 1996; Clark et al., 2001). Across the West, PDO and ENSO together account for $\sim 61 \%$ of the interannual variation in 1 April SWE; in the Northwest, more snow accumulates during the wetter-cooler La Niña and cold PDO phases, while typically drier-warmer El Niño and warm PDO years tend to produce smaller packs (McCabe and Dettinger, 2002). Warming since the early $20^{\text {th }}$ century has caused regional reduction in springtime SWE in most of the U.S. West, based on snowpack measurements and model simulations (Mote, 2003; Mote et al., 2005; Hamlet et al., 2005). Declines have been more considerable at elevations near snowline and in milder mountain climates such as the Cascades, including my study area. These trends seem to stem from a combination of less snowfall as a proportion of precipitation, especially in late autumn and early spring (Knowles et al., 2006); more frequent mid-winter melt episodes, especially in Oregon and southern Washington (Mote et al., 2005); and earlier spring melt of smaller snowpacks (McCabe and Clark, 2005).

Accordingly, the incidence and magnitude of rain-on-snow integrate all these intraseasonal, interannual and long-term processes influencing the arrival of big rainstorms and the presence of snow on the ground when they hit. Generally, years with more precipitation and temperatures cool enough for substantial snow accumulation are likely to have more ROS events than those that are persistently dry and warm. In the scale of days to weeks, atmospheric circulation patterns that cause quick shifts between polar jets and 
subtropical jets approaching the PNW can be especially effective in generating major ROS, first spreading snow into the middle and even low elevations, followed soon after by heavy rains as southwesterly flow brings very warm, moist air from the central Pacific (Lackmann and Gyakum, 1999; Miller, 1999; Higgins et al., 2000; Dettinger, 2004a,b).

Big ROS-favoring storms can occur in Niña, Niño, or neutral winters, and throughout both cold and warm PDO phases, but some correlations appear: 1-3 day temperature, precipitation and streamflow data in the West show a likelihood of extreme events in Niña and Niño winters compared to neutral years, though perhaps less significantly in the PNW (Cayan et al., 1998; Gershunov and Barnett, 1998). Like mountain snowpacks, low-elevation snow in the Puget Lowland also seems more likely in La Niña winters (Ferber et al., 1993). So for ROS, McCabe et al. (2007) showed that events are more common in the Northwest during La Niña (and less common in El Niño) years; and that the frequency in this region has declined with increasing temperatures (WY 19492003) and with more Niño events since the mid-1970s.

Despite these variations in regional temperature, precipitation and snowpack, note that I do not manipulate the data from my observation stations to compensate for such interannual cycles or long-term trends. All statistics are derived for the entire available series (appendix D, Table D.1, D.2; appendix E).

\subsection{Interaction of climate \& terrain in the western Cascades}

My research questions (chapter 2) involve the association between rain-on-snow and elevation in the Pacific Northwest. Preparing the model to address them, I analyze variations of precipitation, snow, and storm weather with elevation, and develop quantitative functions describing their relationships (section 4.5). In general, I treat the west 
side of the Cascades as a simple ramp, though this approximation is imperfect: some sites statistically "act" higher or lower than their nominal elevations. It seems proper to briefly consider the ways that terrain (continental to local scale) interacts with storm behavior and climatic norms, so as to evaluate the suitability of the model's assumptions and results with respect to variability of ROS with elevation in the Cascade Range.

Most climatic characteristics change with elevation up the west side of the Cascades, either increasing (precipitation, snowpack) or decreasing (temperature). But these trends are not strictly linear across broad areas or at storm to seasonal intervals, as local controls on air-flow and rainfall weaken any simple elevation-based interpretations, especially in complex terrain. The basic generalization is that windward sides of mountains get more precipitation than adjacent lowlands or lee sides, increasing uphill (Danard, 1976; Houze and Hobbs, 1982; Parsons, 1982). But the precipitation divide of a range is usually upwind of the topographic divide, not at the crest (Barros and Lettenmaier, 1994), and many ancillary factors affect orographic precipitation in areas such as the PNW (Schermerhorn, 1967; Rasmussen and Tangborn, 1976; Mass, 1981, 2008; Speers, 1986; Loukas and Quick, 1996; Steenburgh et al., 1997). Likewise, snow accumulation is governed by heavier precipitation and cooler temperatures with greater elevation, but influenced also by interactions with terrain, aspect, wind and canopy. Despite integrating the suite of daily weather conditions over weeks and months, even the seasonal evolution of the snowpack is not entirely consistent with elevation (USACE, 1956; Yamada et al., 1979; Lundquist et al., 2004). Many of these complications have been included in models aimed at describing and forecasting precipitation and runoff in mountains of the West, using various combinations of elevation-lapse relations, smoothed topography, and event- 
to annual-scale storm behavior (Schermerhorn, 1967; Miller, 1970; Rasmussen and Tangborn, 1976; Danard, 1976, 1977; Daly et al., 1994; Westrick and Mass, 2001; Hayes et al., 2002).

Accordingly, the weather and climate of my study area are affected by many regional to local topographic elements influencing the movement of air and its cargo of energy and moisture into the Cascade Range: the presence, location and orientation of major barriers such as the Olympics, the Cascade mountain fronts, and Mt Rainier; and passageways such as the Juan de Fuca and Chehalis gaps to the west, Stampede Gap across the crest, and valleys within the range (Fig. 4.1, 4.5). Collectively, these cause local areas of warmth (south-facing slopes, valley mouths on the Cascades' west edge) and cold (in and down-valley of Stampede and Snoqualmie passes, where cold air moves from the east). Measurements and maps (Miller, 1970; PRISM maps) demonstrate that precipitation is quite variable in the west-central Cascades: wettest in the higher ground around Rainier and north of Snoqualmie Pass, but with a broad precipitation divide curving west toward the mountain front around the Green River; drier in the wider valleys and especially the rain-shadow northeast of Rainier.

Approximating the west side of the Cascades as a simple ramp is valid in macroform: the ridge crests and average elevations rise fairly consistently across my study area, as shown on a graph of cumulative area by elevation (Fig. 4.4). Such a hypsometric curve can be used to identify proportions of land within any particular elevation range, so it can also help evaluate the zones most likely to experience some climatic or hydrologic conditions related to elevation (such as rain-on-snow; see section 7.2). About $90 \%$ of the area is 200 to $1500 \mathrm{~m}$ above sea level, and the smooth central cumulative curve indicates a 
uniform average incline. The minor deviation at $\sim 200-300 \mathrm{~m}$ suggests the relatively steep mountain front rising from the Puget Lowlands around Enumclaw and Landsburg ( 200 $250 \mathrm{~m}$ elevation), eastward onto glacial and bedrock benches ( $250-500 \mathrm{~m})$, then abruptly $(\sim 500-1000 \mathrm{~m}$ in $4-5 \mathrm{~km})$ to the west ends of the major ridges between Cedar Falls and Buckley ( $\sim 900-1400 \mathrm{~m}$; Fig. 4.5). Within the range, several broad secondary ridges extend $\sim 25-50 \mathrm{~km}$, climbing gently toward the range crest. The topographic analysis of Mitchell and Montgomery (2006; their Fig. 3) also reveals this form, including the mountain front and upward slope $\left(\sim 9.3 \mathrm{~m} / \mathrm{km}, \sim 0.5^{\circ}\right)$ of the ridges; four major valleys traversing the region reduce the areally averaged elevation profile by $\sim 600 \mathrm{~m}$. The major divide area here is relatively low (Stampede Gap): elevations drop from 2000 m north of Snoqualmie Pass to $\sim 1550 \mathrm{~m}$ around Stampede Pass and south to Naches Pass; then rise to 2000 m east of Mt Rainier.

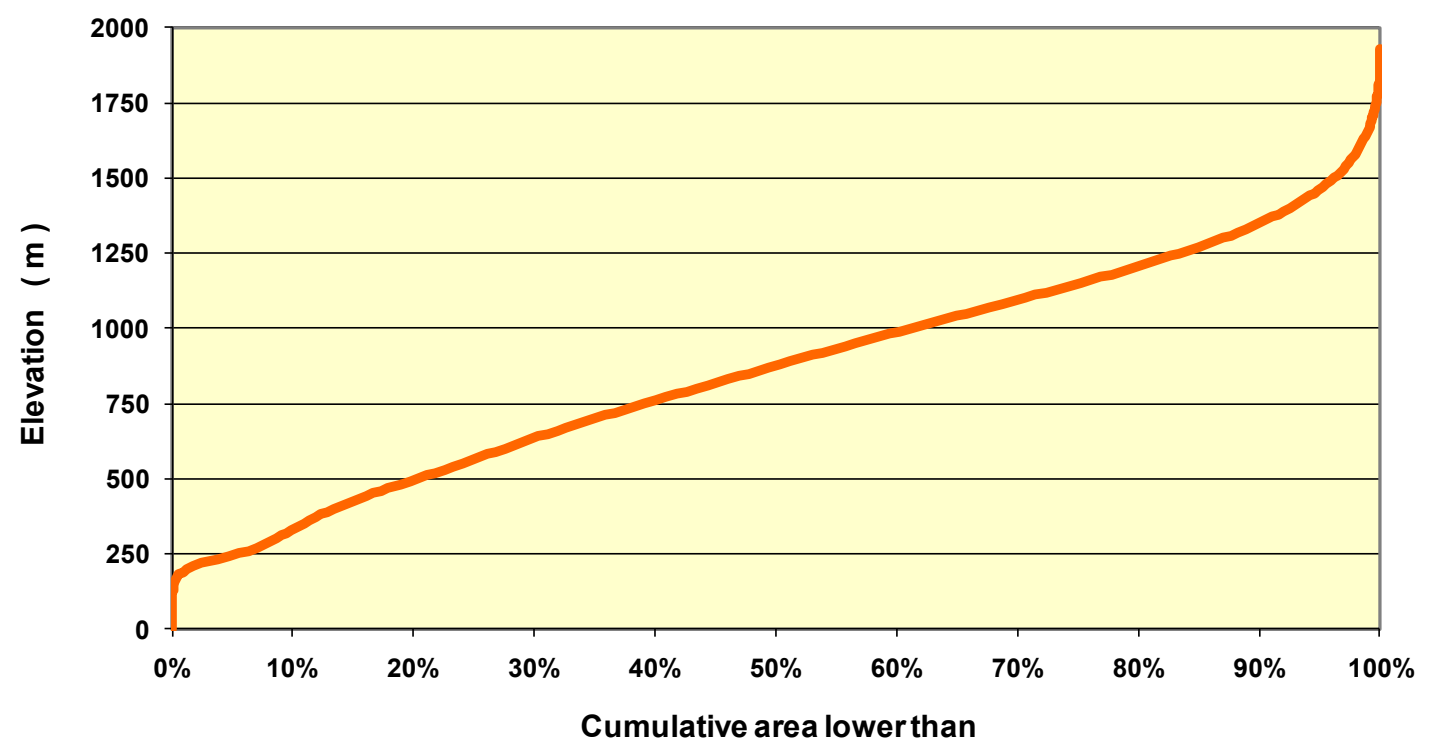

Figure 4.4. Hypsometric curve for the project area, west-central Washington Cascades. From 10-m USGS DEM data, calculated with ESRI ArcGIS Spatial Analyst. Location approximately central area of Fig. 4.5: north edge of Mt Rainier National Park to latitude of Snoqualmie Pass (T18N to T22N), eastern Puget Lowland to Cascade divide/county lines (east sections of R6E to irregular line in R11-12E); 2250 $\mathrm{km}^{2}$. The same DEMs show that the majority of slopes in the region have gradients of $\sim 10-40^{\circ}$ and slope aspects preferentially to the NW-W-SW. 
So climate and weather are influenced by both range-scale and local terrain across the Cascades study region, in turn affecting the measurements at observation sites (section 4.4). To incorporate at least the gross effects of broad-scale topography on storm weather (particularly precipitation) and snowpack into the model parameters, effective elevations were assigned based on the average elevations in circles around the weather stations, snow courses and SNOTEL sites (procedural details in section 4.5F; nominal and effective elevations for observation sites in Tables D.1, D.2). Weather stations located in valleys seem higher when the nearby uplands are averaged in, which jibes with the more abundant rain and snow at most of them. (Palmer 3ESE, at $275 \mathrm{~m}$ the second lowest of my NWS stations but sitting in Eagle Gorge between high ridges, receives more precipitation than some higher sites; its recalculated elevation is $548 \mathrm{~m}$.) On the other hand, the effective elevation of the Stampede station is lower than the true elevation, because much of the surrounding ground falls away to the pass and down off the Cascade crest.

Despite the complexities, elevation remains a first-order control on orographic precipitation, and even more so for temperature and snowpack. In this project I assume that storm-weather and climatic processes and parameters can be plausibly lapsed against elevation; that my region of the west-central Cascades approximates a simple ramp; and that my estimated of effective elevations adequately characterize the locations of the observation stations, for the creation of basic functions and trends relating elevation to climatic values. Elaborations for complex topography and more intricate weather-orography functions are left to future work. 


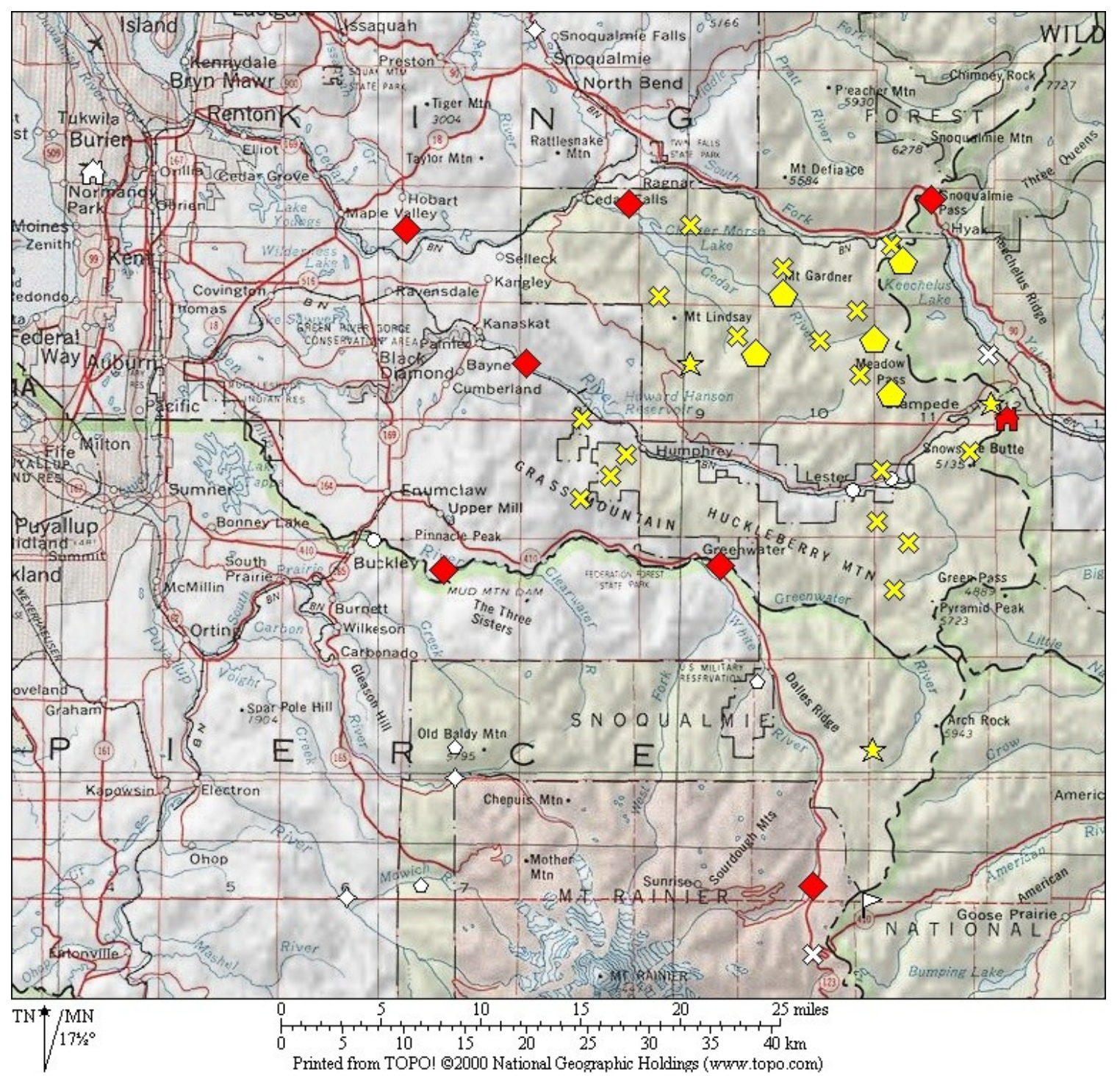

Figure 4.5. Observation sites in the central-western Cascade Range, King and Pierce counties, Washington. Seattle is at the NW corner (Sea-Tac Airport marked by hut symbol); dashed county lines near east edge follow the Cascades drainage divide. Weather/climate observation stations (darker symbols = sites used in project analysis and modeling): Stampede Pass hut marks NWS airways station, snow course and pillow; diamond $=$ NWS - COOP station with hourly rain gauge; $\mathrm{X}=$ snow course; pentagon $=$ SNOTEL; star $=$ longterm course and SNOTEL. Sites marked by smaller/white symbols (as above, plus circle = non-hourly COOP) not used due to short/incomplete record, geographic inconsistency, etc. See Tables D.1, D.2.

\subsection{Observation sites}

In this project I rely heavily on two sets of observation systems, described below.

Sites are plotted on Figure 4.5; in appendix D, the locations, record periods, instrumentation, etc. for the eight weather stations used in this project are described in Table D.1, and 
for the 28 snow courses and SNOTEL facilities in Table D.2. References to information sources and methods are provided in the table notes; statistics derived from station records are summarized in appendix E.

National Weather Service Cooperative Observer Program (NWS-COOP) stations gauge precipitation (hourly and/or daily increments), daily high and low temperatures, and daily snow depth. Many of these have been operating since the early $20^{\text {th }}$ century; hourly rain gauges were introduced in the 1940s. NWS-staffed first-order airways observation facilities, generally at major airports but also at Stampede Pass (a cross-Cascades air corridor), measure a wider suite of variables (wind, humidity, barometric pressure, SWE, etc.) at shorter intervals. However, most NWS stations are located in populated areas at lower elevations, or along transportation routes through valleys and passes.

Within this data-rich environment the main site is the Stampede Pass station (StpP), the only NWS first-order facility on the Washington Cascade crest. Though first established as a Weather Bureau outpost in 1935, easily accessed and useful data extend from October 1943, when the hourly rain gauge was moved uphill from the west portal of Stampede Tunnel $(792 \mathrm{~m})$ to the gentle slopes $\sim 1.2 \mathrm{~km}$ above and southeast of the pass (1206 m; Fig. 4.6). Over most of the time since, Stampede operated as a staffed airways observation station and reliably reported high-quality data, though interrupted during three periods of budget cuts and automation (two in the 1990s). Measurements have included daily and hourly precipitation (the latter usually in a heated tipping-bucket gauge), daily snowfall and depth (with SWE since 1952), and daily high and low air temperatures; at least since 1948, observers recorded wind speed and direction, sky cover, relative humidity, barometric pressure, etc. many times per day (commonly 1 - to 3 -h inter- 
vals). Besides measurements at the main station, average snow depth and water equivalent were determined at a nearby snow course up to bi-monthly (Dec-Jun) until 1982, and since have been monitored (along with cumulative precipitation and temperature) at the succeeding SNOTEL site.
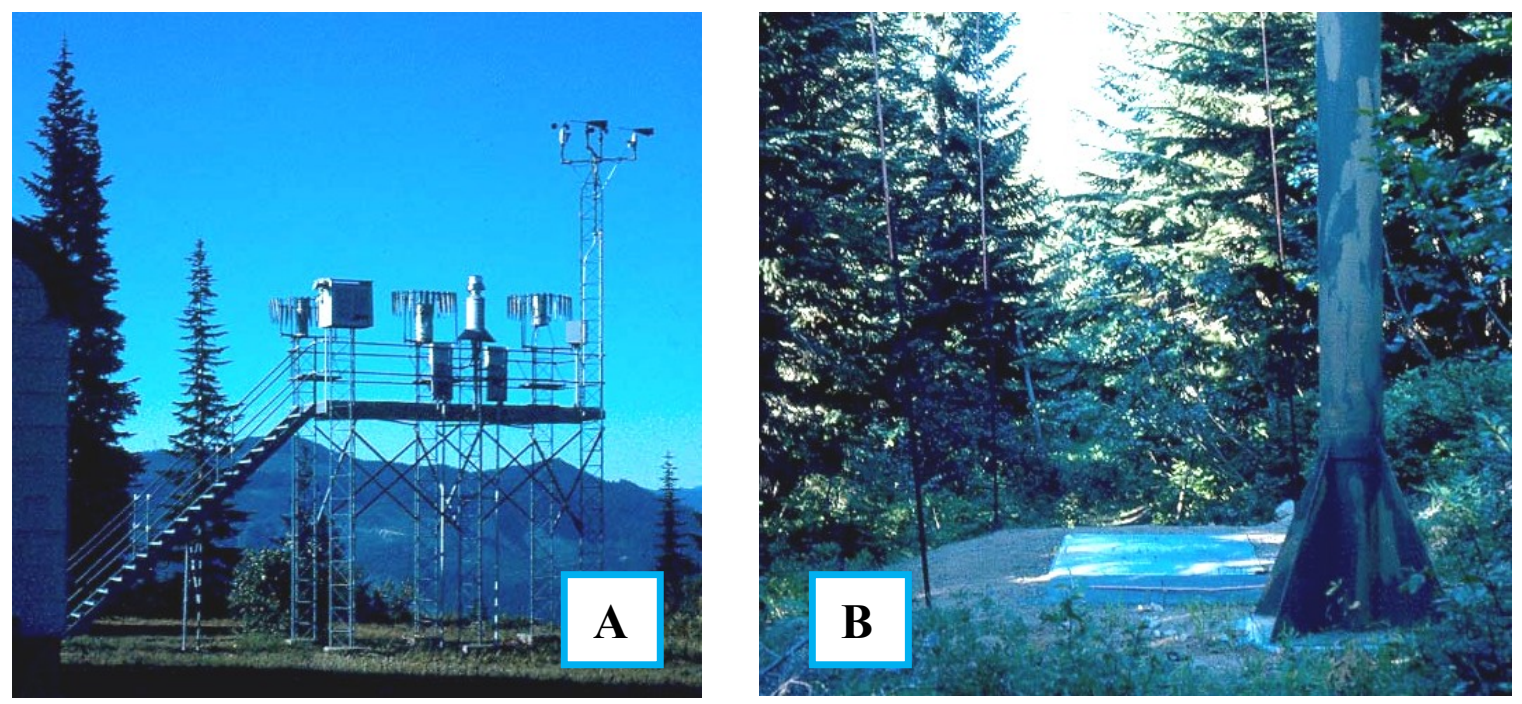

Figure 4.6. Facilities at Stampede Pass. A: Instrument platform at weather station, $1206 \mathrm{~m}$. B: Snow pillow (center) and precipitation storage gauge (right), $\sim 0.4 \mathrm{~km}$ west and $\sim 30 \mathrm{~m}$ lower (1175 m elevation); the former snow course is nearby. (Photos by M.J. Brunengo, 14 Jul 1985.)

This broad suite of long-term instrumental observations makes Stampede Pass the best data source for my project. I use StpP data to inform and test both the single-event and Monte Carlo model versions, and to evaluate the program's ability to apply multi-site elevation trends to simulate realizations analogous to those produced using site-specific parameters (chapters 5, 6).

Seven National Weather Service Cooperative network stations in the region have hourly precipitation records of sufficient quality and length for my purposes ( $\sim 35$ to $60+$ yr; Table D.1). NWS-COOP sites range in elevation from $163 \mathrm{~m}$ at Landsburg (Ldbg) in the lowlands to $920 \mathrm{~m}$ at Snoqualmie Pass (SnqP) on the northern crest, and $\sim 1075 \mathrm{~m}$ at Crystal Creek-White River Ranger Station (XcWR, counted as one site) northeast of Mt 
Rainier. Instruments at Palmer 3ESE (Pmr3, 275 m), Mud Mountain Dam (MMtD, 400 m), Cedar Lake (CdrL, $475 \mathrm{~m}$ ), and Greenwater (Grnw, $527 \mathrm{~m}$ ) span part of the middle elevations. These stations measure precipitation at both daily (Standard rain gauge) and hourly (Universal or Fischer-Porter weighing gauge) intervals. They typically report daily snowfall and snow depth, and observation-time and daily high/low temperatures. Thus I use their data to calculate statistics of hourly precipitation and daily snow depth, but they cannot supply the model with parameters for SWE, or hourly temperature or wind during storms. (See measurement procedures, instruments, etc. for the NWS-COOP network at www.weather.gov/om/coop/index.htm; data are available for downloading from the National Climatic Data Center [NCDC] site at www.ncdc.noaa.gov.)

The next group of data sources (Table D.2) comprises the snow measurement sites of the Cooperative Snow Survey (CoopSS) and snowpack telemetry (SNOTEL) systems, administered by the Natural Resources Conservation Service (NRCS). Their data allow calculation of statistics on likelihood and amount of snow on the ground through the winter. In contrast to the NWS stations, these typically operate in higher terrain.

At snow courses, snow depth and water equivalent are determined manually with sampling tubes thrust into the pack at 5-12 points per survey site. Depth is determined directly from penetration; tubes are then weighed in scales calibrated to SWE (Fig. 4.7A). NRCS personnel or cooperators typically visit courses around the first of the month, for two to (rarely) seven months in winter and spring. (See Agricultural Handbook 169, Snow Survey Sampling Guide, www.wcc.nrcs.gov/factpub/ah169/ah169.htm.)

At SNOTEL sites, the weight on fluid-filled snow pillows is converted by pressure transducers into records of SWE, measured almost continuously. Cumulative seasonal 
precipitation is measured in antifreeze-charged storage gauges; combining data from the pillows and storage gauges enables estimation of water input/output/storage of the pack. Sensors for temperature and snow depth have been installed at most facilities, which can be useful in examining individual events at a site (single-storm model calibration), but such records are still too short or inconsistent to provide long-term averages of anything but SWE. When interrogated (usually daily but potentially more often), data are transmitted by meteor-burst radio communication to receivers in Boise and Ogden, then to computers in Portland. The facilities are maintained at least annually, and staff commonly make ground-truth measurements by snow tube several times per winter (Fig. 4.7B).
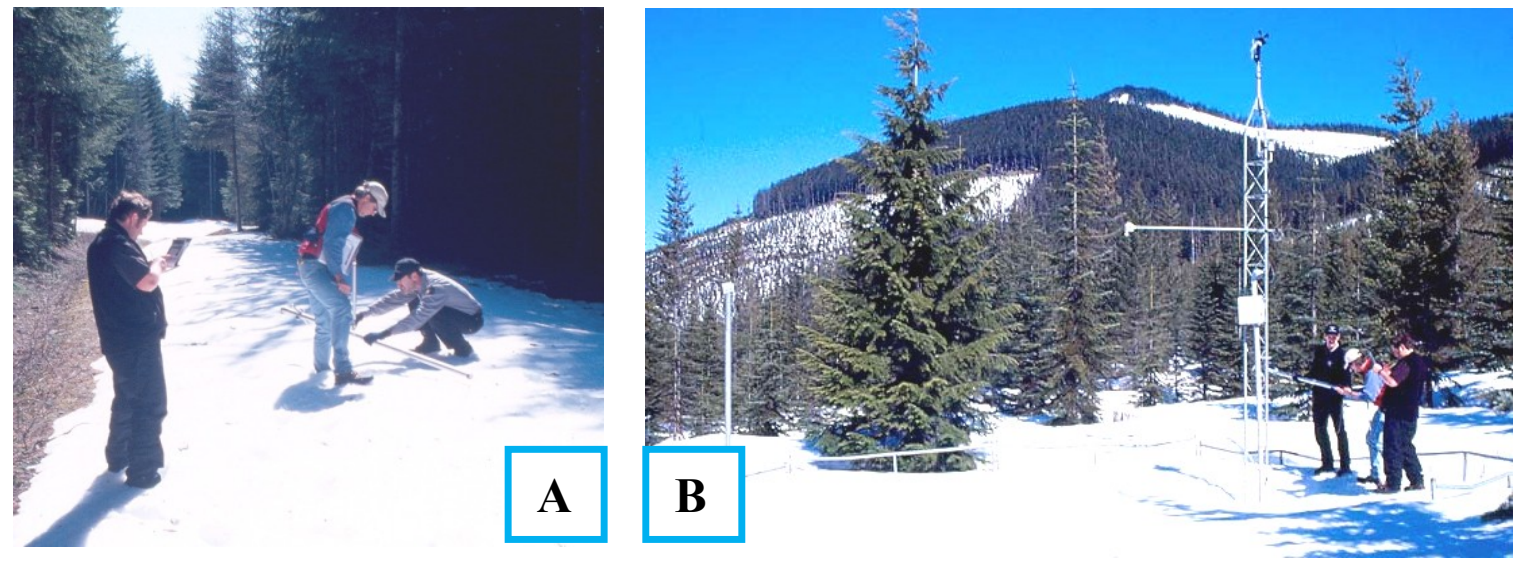

Figure 4.7. Snow survey by Seattle Public Utilities personnel, Cedar River watershed. A: Weighing snow tube, Mt Gardner snow course. B: Measurement for ground truth, Meadows Pass SNOTEL site; pillow is under snowpack in center. (Photos by M.J. Brunengo, 2 Apr 2004.)

Snow courses and SNOTEL sites are customarily placed to provide data useful for runoff forecasting, not necessarily to sample entire regions or all elevation zones. They vary in the degree to which they typify their nominal elevations in precipitation and temperature, both of which affect snow accumulation at a site. Because I use snow data for long-term statistical analysis, inclusion here is restricted to sites having at least $10 \mathrm{yr}$ of record. Expansion of SNOTEL since the 1980s has permitted cuts in the snow-course net- 
work; hence, some long-lived courses have been retired, yet many pillows have not been in place long. I use 20 snow courses and eight snow pillows (some co-located), most in the Cedar and Green watersheds, at elevations ranging from 365 to $1762 \mathrm{~m}$ (Fig. 4.5, Table D.2). Eighteen snow courses and eight SNOTEL sites in the region were excluded, chiefly because of distance from the core project area and/or short records.

My data collection and processing occurred from 1982 to 2006, spanning the change from paper reports to computer print-outs to digital downloads. There is an extensive literature regarding instrumental and procedural limitations, regarding: rain gauges, especially undercatch of snow by unshielded gauges (Goodison et al., 1981; Legates and DeLiberty, 1993; Yang et al., 1999; Singh and Singh, 2001); snow-survey techniques (USACE, 1956; Goodison et al., 1981; Singh and Singh, 2001); and snow pillows (Serreze et al., 1999; Johnson and Schaefer, 2002; Johnson and Marks, 2004). For the most part, I accept the data as reported by the responsible agencies (Tables D.1, D.2). My deletions and modifications are limited: for example, where the numbers are clearly erroneous but reparable (e.g., a day with SWE and snow depth transposed); or by estimating missing or accumulated precipitation values from associated instruments (e.g., using daily rain gauges to supplement hourly measurements).

\subsection{Inputs \& parameters: data records, series, statistics}

My Monte Carlo simulation model requires more than a dozen kinds of hydrometeorologic information regarding event timing, precipitation magnitude and duration, snow amount and storm weather. These are taken, to the extent possible, from appropriate regional measurements and probability distributions from the west-central Cascades. As shown in Table 3.1, the model's approaches and algorithms for each are at various points 
on a simplicity/complexity spectrum, based on compromises among relevance to the storms of interest, data availability, and computational simplicity. Table 4.1 summarizes the parameters used in the model, their sources (most from station records) and frequency distributions. Most of these elements are at least partly probabilistic, but some are generated from functional relationships and/or empirical information. Explanations of several particular model elements are provided below; additional details can be found in appendices $\mathrm{E}$ and $\mathrm{F}$.

A) Data sources \& units of measurement Statistics are derived from up to $65 \mathrm{yr}$ of station records, with all series based on water years (WY day $1 \equiv 1$ Oct). The oldest measurements utilized are from WY 1940 (snow courses, hourly rainfall) and the most recent from WY 2005, though few series span the entire period and some elements cover much less (e.g., hourly temperature and wind speed, 1970-89 and '97-2004). The parameters regarding event occurrence, duration and magnitude originated with hourly precipitation data from the eight weather stations; those involving snow come from weather and snow measurement sites and the literature; those concerning storm temperatures and winds are from the record at Stampede Pass. 


\begin{tabular}{|c|c|c|c|c|c|}
\hline $\begin{array}{l}\text { Model Element, } \\
\text { Parameter }\end{array}$ & Source in Record & Series & $\begin{array}{c}\text { Model, } \\
\text { Distribution }\end{array}$ & $\begin{array}{c}\text { Correlations \& } \\
\text { Functions }\end{array}$ & Notes \\
\hline \multicolumn{6}{|l|}{ Storm timing } \\
\hline $\begin{array}{l}\text { Number of model } \\
\text { events per water year }\end{array}$ & $\begin{array}{l}\text { hourly precip, NWS } \\
\text { stations }\end{array}$ & LCS PD series & $\begin{array}{l}\text { truncated normal } \\
(\geq 1 / \mathrm{yr})\end{array}$ & & $\begin{array}{l}\text { partial-duration series } \\
\text { comprise } 169-290 \text { events } \\
\text { per station }\end{array}$ \\
\hline $\begin{array}{l}\text { Event starting date } \\
\text { (water year: } 1 \text { Oct } \equiv 1 \text { ) }\end{array}$ & $\begin{array}{l}\text { hourly precip, NWS } \\
\text { stations }\end{array}$ & LCS PD series & $\begin{array}{l}\text { normal (mean } \\
\text { adjusted around } \\
\text { modal dates) } \\
\end{array}$ & $\begin{array}{l}\rightarrow \text { snow depth \& WE } \\
\rightarrow \text { initial temperature }\end{array}$ & \multirow{2}{*}{$\begin{array}{l}\text { randomly selected event } \\
\text { starts \& durations can } \\
\text { result in overlaps within } \\
\text { any given year }\end{array}$} \\
\hline Starting time & & & uniform & $\begin{array}{l}\rightarrow \text { radiation melt in } \\
\text { mid-day }\end{array}$ & \\
\hline Event duration & $\begin{array}{l}\text { hourly precip, NWS } \\
\text { stations }\end{array}$ & LCS PD series & log-normal & $\begin{array}{l}\leftarrow \text { elevation } \\
\leftarrow \text { total precip } \\
\rightarrow \text { temperature code }\end{array}$ & $\begin{array}{l}\text { bivariate log-normal with } \\
\text { total precip }\end{array}$ \\
\hline \multicolumn{6}{|l|}{ Precipitation } \\
\hline Total amount & $\begin{array}{l}\text { NWS stations: } 7 \text { COOP, } \\
1 \text { airways obs sta (StpP); } \\
\text { hourly rain gauges } \\
\text { (heated at StpP) }\end{array}$ & $\begin{array}{l}\text { PD series on long } \\
\text { continuous storms } \\
\text { (also: } \mathrm{PD} \text { on } 1-\text { to } \\
\text { 48-h periods) }\end{array}$ & $\begin{array}{l}\text { exponential (ExpD) } \\
\text { (by regression) }\end{array}$ & $\begin{array}{l}\leftarrow \text { elevation } \\
\rightarrow \text { event duration }\end{array}$ & $\begin{array}{l}\text { derive separate ExpD } \\
\text { elev fcns for high- and } \\
\text { low-precip stations } \\
* \text { Gringorten plotting } \\
\text { positions - see notes }\end{array}$ \\
\hline Hourly distribution & hourly precip, all stations & $\begin{array}{l}1000 \text { LCS events } \\
\text { (SIM codes) }\end{array}$ & $\begin{array}{l}4^{\text {th }} \text {-order polynomial } \\
\text { of cumulative precip } \\
\text { by hour } \\
+ \text { random component }\end{array}$ & $\begin{array}{l}\leftarrow \text { total precip } \\
\rightarrow \text { hourly snow } \\
\text { accum or melt }\end{array}$ & $\begin{array}{l}\text { event SIM codes chosen } \\
\text { randomly }\end{array}$ \\
\hline \multicolumn{6}{|l|}{ Snow } \\
\hline Initial SWE & $\begin{array}{c}\text { NRCS: } 20 \text { snow courses } \\
8 \text { SNOTEL sites } \\
\text { NWS: StpP station }\end{array}$ & $\begin{array}{l}\text { all avail daily data } \\
\text { ( } \geq 10 \text { yr record })\end{array}$ & $\begin{array}{l}\text { mixed log-normal } \\
\text { with } P[0]\end{array}$ & $\begin{array}{l}\leftarrow \text { elevation } \\
\leftarrow \text { event date } \\
\text { (polynomial fcns) } \\
\rightarrow \text { change in depth } \\
\text { during accum or melt }\end{array}$ & $\begin{array}{l}P[0] \text { estimated for depth } \\
\& \text { SWE together }\end{array}$ \\
\hline Initial depth & $\begin{array}{l}\text { NRCS: } 20 \text { snow courses } \\
\text { NWS: } \quad 8 \text { stations }\end{array}$ & $\begin{array}{l}\text { all avail daily data } \\
(\geq 10 \mathrm{yr} \text { record })\end{array}$ & $\begin{array}{l}\text { mixed log-normal } \\
\text { with } P[0]\end{array}$ & $\begin{array}{l}\leftarrow \text { initial SWE } \\
\rightarrow \text { percolation rate }\end{array}$ & $\begin{array}{l}\text { bivariate log-normal with } \\
\text { SWE }\end{array}$ \\
\hline Initial density & & & direct calculation & $\leftarrow$ SWE/depth & ** see notes \\
\hline
\end{tabular}




\begin{tabular}{|c|c|c|c|c|c|}
\hline Porosity (effective) & & & $\begin{array}{l}\text { direct calculation } \\
\text { from solid \& liquid } \\
\text { phases }\end{array}$ & $\begin{array}{l}\leftarrow \text { density \& } \\
\text { irreducible saturation } \\
\rightarrow \text { percolation rate }\end{array}$ & \\
\hline $\begin{array}{l}\text { Permeability } \rightarrow \\
\text { hydraulic } \\
\text { conductivity }\end{array}$ & & & $\begin{array}{l}\text { Shimizu empirical } \\
\text { eqn; then } \mathrm{k}\left(\mathrm{cm}^{2}\right) \rightarrow \\
\text { hydraulic } \mathrm{K}(\mathrm{cm} / \mathrm{h})\end{array}$ & $\begin{array}{l}\leftarrow \text { density } \& \\
\text { grain diameter } \\
\rightarrow \text { percolation rate }\end{array}$ & \\
\hline \multicolumn{6}{|l|}{ Temperature } \\
\hline $\begin{array}{l}\text { Initial temperature } \\
\text { Temperature range }\end{array}$ & $\begin{array}{l}\text { StpP station: 1-h to 3-h } \\
\text { temp; used to generate } \\
\text { winter-storm lapse rate }\end{array}$ & 133 LCS events & $\begin{array}{l}\text { both normal } \\
\text { init'l: std dev constant } \\
\text { range: params } \\
\text { constant }\end{array}$ & $\begin{array}{l}\leftarrow \text { event date } \\
\leftarrow \text { elevation (lapse of } \\
\text { site from StpP) }\end{array}$ & $\begin{array}{l}\text { set of } 120-133 \text { StpP LCS } \\
\text { events with } 1 \text {-h to } 3 \text {-h } \\
\text { obs } \rightarrow \text { all T params }\end{array}$ \\
\hline Hourly temperature & $\begin{array}{l}\text { StpP station: } 1-\mathrm{h} \text { to } 3-\mathrm{h} \\
\text { temp }\end{array}$ & $\begin{array}{l}100 \mathrm{~T} \text { codes } \\
\text { (based on LCS } \\
\text { events; } 123 \text { avail) }\end{array}$ & $\begin{array}{l}\text { frontal }(\mathrm{T} \text { codes })+ \\
\text { diurnal }+ \text { random } \\
\text { components on range }\end{array}$ & $\begin{array}{l}\leftarrow \text { duration } \\
\rightarrow \text { hourly snowmelt } \\
\text { rate }\end{array}$ & $\begin{array}{l}\text { number \& duration of } \\
\text { frontal segments calc'd } \\
\text { as bivariate-normal with } \\
\text { event duration }\end{array}$ \\
\hline \multicolumn{6}{|l|}{ Wind } \\
\hline $\begin{array}{l}\text { Central wind speed } \\
\text { Wind speed std dev }\end{array}$ & $\begin{array}{l}\text { StpP station: 1-h to 3-h } \\
\text { wind }\end{array}$ & 125 LCS events & $\begin{array}{l}\text { both normal } \\
\text { both with constant } \\
\text { params (no date or } \\
\text { elev fcns) }\end{array}$ & & $\begin{array}{l}\text { set of } 120-133 \text { StpP LCS } \\
\text { events with 1-h to } 3 \text {-h } \\
\text { obs } \rightarrow \text { all W params }\end{array}$ \\
\hline Hourly wind speed & $\begin{array}{l}\text { StpP station: 1-h to 3-h } \\
\text { wind }\end{array}$ & & $\begin{array}{l}\text { random component on } \\
\text { range }\end{array}$ & $\begin{array}{l}\rightarrow \text { hourly snowmelt } \\
\text { rate }\end{array}$ & no good model \\
\hline \multicolumn{6}{|l|}{ Notes } \\
\hline \multicolumn{6}{|c|}{$\begin{array}{l}\text { Abbreviations as defined in the text (see also list of abbreviations and symbols). } \\
\text { In this and other tables: arrows }(\leftarrow, \rightarrow) \text { indicate functional dependence or procedural/arithmetic paths. } \\
* \text { Plotting formula to assign probabilities for hydrologic series: Gringorten }(1963) \text { procedure, in which probability of } \mathrm{i}^{\text {th }}-\text { ranked of } \mathrm{n} \text { members } \\
P_{i}=(\mathrm{i}-\mathrm{a}) /(\mathrm{n}+1-2 \mathrm{a}) ; \mathrm{a} \approx 0.44 \text {, so } P_{i}=(\mathrm{i}-0.44) /(\mathrm{n}+0.12) \text {. Recurrence defined as } R_{i}=1 / P_{\mathrm{i}} \text { as general term, though different in AM vs PD series; see } \\
\text { appendix F. } \\
\text { Logarithms of these plotting positions are the independent variables in regression equations to find the parameters of exponential distribution (ExpD) for } \\
\text { the series of precipitation, rain plus snowmelt, and water available for runoff. (See appendix } \mathrm{F} \text {.) } \\
* * \text { Snow density is typically considered the amount of water that would be produced by melting, relative to the original snow volume; usually expressed } \\
\text { as the snow-water equivalent (SWE) (measured in the field by weighing a column of snow) divided by snow depth, assuming equal volumes (i.e., as } \mathrm{L} / \mathrm{L} \\
\rightarrow \text { a dimensionless value). However, because the masses of liquid and solid water are both } \sim 1 \mathrm{~g} / \mathrm{cm}^{3} \text { (slightly temperature-dependent), this is approxi- } \\
\left.\text { mately equivalent to the "true" density of the snow (as } \mathrm{M} / \mathrm{L}^{3}\right) \text {. } \\
\text { Modeled initial snow density held within range } 0.1-0.8 ; \text { value for no snow set at } 0.35 \text { to allow computation of hydraulic properties (not possible/error if } \\
\text { density } 0 \text { or undefined). These limits affect the statistics for density, porosity and conductivity dependent on density, presented in Tables } 5.1,5.2 \text {. }\end{array}$} \\
\hline
\end{tabular}


As with most U.S. sources, nearly all of the data used here were originally measured and reported in English units. For the most part, I performed initial collation and statistical analysis of data in the original feet, inches, degrees Fahrenheit, knots, etc., and then transformed summary numbers and statistics into metric units before incorporation into the mathematical functions used in the models (regressions, polynomials, trend-surface equations, etc.). In this dissertation, some of the quantities are provided in both English and metric (e.g., station elevations), but most are shown only in the transformed metric units. Also note that many values are presented in dimensions other than those sanctioned by the Système International. For example, depths of rain, snow and snow-water equivalent are given in centimeters rather than millimeters or meters, for consistency and easier comprehension; time periods are counted in years and hours (not seconds); and temperatures are reported in degrees Celsius (not Kelvin).

These matters of dimensions affect the issue of significant figures: given the mixture of units involved in this work, some ambiguity seems unavoidable. The instruments have varying levels of accuracy and precision, reflected in the data reported by the NWS and NRCS (see appendix G for brief descriptions of instruments at Stampede Pass). Some apparent precision is introduced in dimensional conversions (e.g., 1 in $\rightarrow 2.54 \mathrm{~cm}, 1 \mathrm{~F}^{\circ}$ $\left.\rightarrow 0.555 \ldots \mathrm{C}^{\circ}\right)$, which I usually represent by one or two additional digits. The reduction of series of numbers into their statistics (mean, variance, skew) and regression parameters (coefficients, error, $r^{2}$ ) also creates potentially meaningful additional figures. Lastly, note that model realizations are not the same as data: though usually controlled in some manner by observations, they are not directly the product of measurements, and so the concepts of instrumental accuracy and precision do not strictly apply; rather, the number of 
significant figures for model variables is determined by the dimensions defined for them (integer, single- or double-precision). In general, it is my policy to report converted data, realizations, and their statistics with enough "significant" figures to highlight differences among them, particularly in comparisons between model input and output series. Some of these will appear spurious to discriminating readers; I try to restrict the values used in reaching and reporting my conclusions to the truly significant figures.

B) Data compilations \& series Most of the frequency distributions and their parameters are developed from subsets of the record of hourly precipitation measurements and associated dates, durations, etc. I consider the collection of large events, but ideally several per winter and not just the year's biggest. Thus, to examine and model a large sample of events I use the partial duration (PD) series to generate frequency distributions, comprising all events larger than a minimum set by the smallest of the annual maximum events.

As mentioned (section 3.3), my analyses and simulations are organized around long continuous storms, periods of nearly uninterrupted precipitation as recorded at hourly precipitation gauges. LCS are bounded by gaps of at least $6-8 \mathrm{~h}$, the different limits applied to gauges reporting in 0.01 versus 0.1 inch (with special accounting for amounts reported as accumulated or missing). Applying these rules to the hourly-precipitation records from the eight NWS stations, I compiled series of $\sim 170-300$ events per station. (Annual maximum $[\mathrm{AM}]$ series could also be exploited for analysis, as could series for set storm durations such as 24 or $48 \mathrm{~h}$, but I have made little use of them at this stage.) C) Statistical functions \& analysis Several kinds of mathematical models are applied to the data series (Table 4.1; appendix E). Some of the data are reduced to simple means and standard deviations, based on normal or log-normal distributions; others are subject to 
more elaborate functions, such as bivariate normal relations or event-based models.

The precipitation input series and the realization series of precipitation, rain plus meltwater, and WAR are modeled using the exponential distribution, which is more appropriate for PD series than an extreme-value distribution such as the Fisher-Tippett or Gumbel/EV-1, preferred for AM series (de Ploey et al., 1991; appendix F). Figure 4.8 illustrates the graphic patterns generated from Stampede Pass hourly precipitation data, showing PD and AM series for 1-h to LCS durations, along with their respective exponential regression lines. The AM points fall off a straight-line trend near 1-yr recurrence, and are better fit using an EV-1 model. The PD points remain near the regression lines at the short-recurrence end; they are less true at the rare-storm end, where the precise locations of the largest 5-10 events are most sensitive to plotting position, and more likely to deviate from the regression lines controlled by the mass of data at small to moderate magnitudes. In particular, the LCS PD line for Stampede Pass seems to overestimate storm magnitude around $1 \mathrm{yr}$, and underestimate the amounts beyond $\sim 8 \mathrm{yr}$ recurrence. These peculiarities may result from the irregular lengths of the LCS events $(28-250 \mathrm{~h}$ for these storms at StpP), introducing greater variance into their exponential regressions than for those at set durations; and the largest might be plotted at far less than their "true" return periods, as commonly occurs in frequency analysis (a test elimination of just the maximum point improves the regression fit).

Frequency relations for the PD series of LCS at Stampede Pass figure prominently in my model development and testing (chapter 5), so these anomalies are at least noteworthy. Overall, since the partial-duration regression line's estimates are conservative, predicting less rainfall for $>5-10$ yr recurrence interval than the source data might sug- 
gest, I accept their usefulness (with appropriate error bars in mind). Further analysis of Stampede's precipitation characteristics may be warranted, perhaps using techniques that segregate the record into separate series of different kinds of storms (rain, snow), as done for flood flows generated by mixed processes (Waylen and Woo, 1982, 1983).

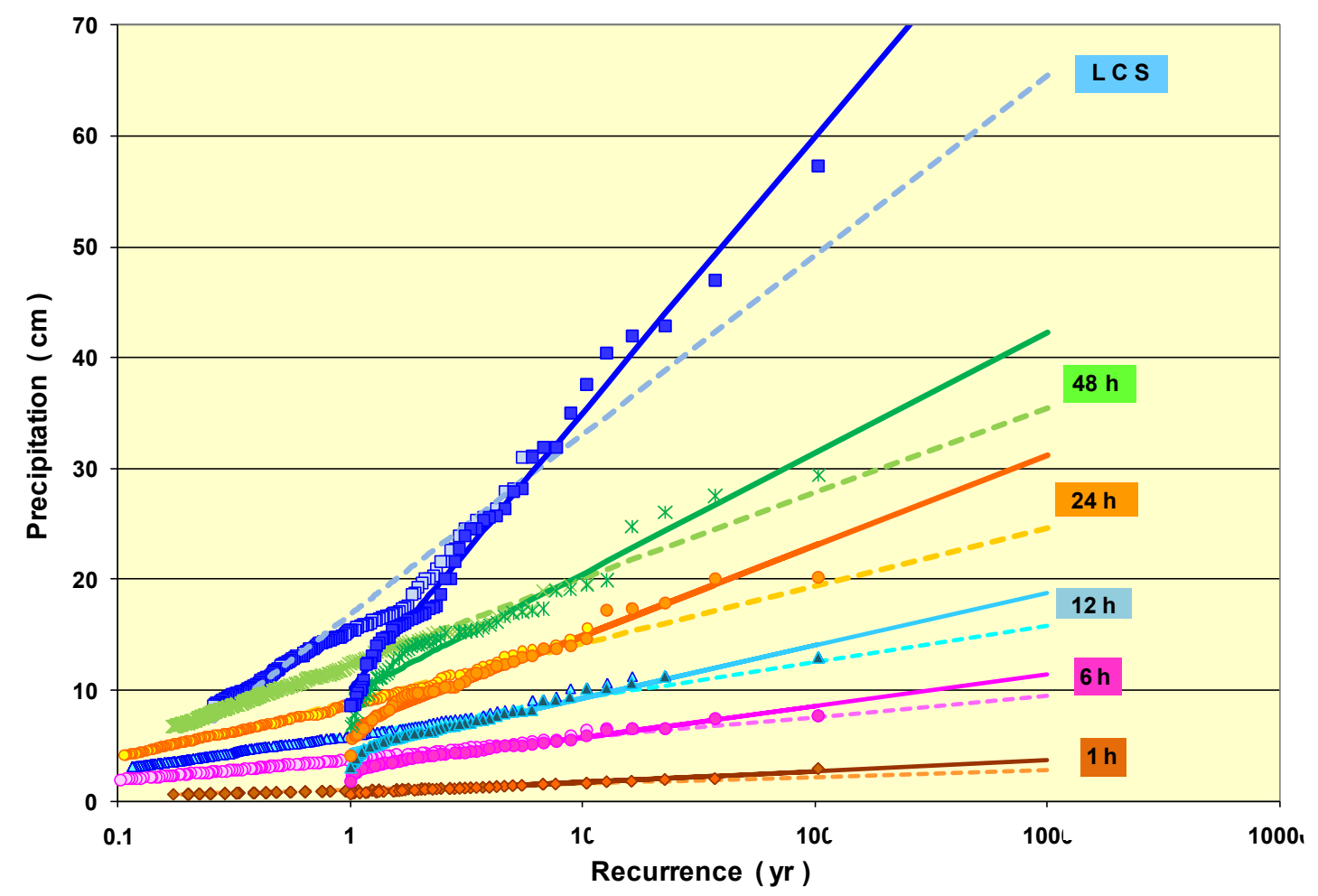

Figure 4.8. Precipitation data from Stampede Pass NWS weather station, 58 WYs (1944-2005): annual maximum (darker markers, solid lines) and partial duration (lighter markers if different, dashed lines) series at various durations, including long continuous storms (LCS). Plotting positions along the logarithmic recurrence axis determined by Gringorten (1963) method (thus, 104-yr recurrence for largest event in a 58yr record; see Table 4.1); trend lines calculated by regression following exponential distributions. Note that recurrence has different meanings for AM and PD series; see appendix F.

D) Interrelations among elements \& parameters Of the other factors listed on Table 4.1, some share physical and/or mathematical relationships, indicated by arrows $(\leftarrow, \rightarrow)$ showing the direction of influence or control. Consequently, many of the parameters are combined into functions that calculate values from one or more other properties, as informed by the processes and examination of the data. Most of these functions are at least 
partly empirical.

A few pairs of stochastic model factors, such as precipitation amount-duration and SWE-snow depth, are so tightly correlated $(r \approx \pm 0.8$ or better) that they are calculated using bivariate normal relations, in which the parameters (usually mean and variance) of the first element are involved in calculating the dependent element. For model simplicity other pairs (some having $r$ up to $\sim 0.5$ ) were treated independently; seemingly related pairs, such as storm date and total precipitation, were found to be poorly correlated.

Hourly precipitation and temperature during storms are based on a sampling of actual events, reduced to simpler mathematical patterns: as polynomial equations for the storm internal precipitation model (coefficients stored as event SIMcodes); and as time subperiods describing the patterns of temperature fluctuations due to frontal passage (semiquantitative segment values as Tcodes), combined with diurnal temperature cycles (section 3.3A). However, most of the physical linkages among storm precipitation, temperature, and wind remain unexplored in this project.

E) Elevation-related functions Since regional observations indicate that the total precipitation, event duration, and snow amounts commonly increase orographically, the statistical parameters of those quantities are estimated as functions of elevation. The exponentialdistribution parameters for stochastic event precipitation are calculated from one of two linear equations. One is based on the higher-precipitation sites, Palmer, Cedar Lake, Snoqualmie Pass and Stampede Pass; the other from the lower-precipitation stations, Mud Mountain Dam, Greenwater and Crystal Creek-White River Ranger Station (Landsburg is used for both; Table D.1). The log-mean and log-standard deviation for duration are derived from a single linear elevation function using all stations. For both, these calcula- 
tions are made at the beginning of a Monte Carlo run, and then used throughout.

The probability of snow on the ground and its amount vary with both season and elevation. I apply a statistical model merging the probability of no snow $(P[0])$ with a log-normal distribution of non-zero amounts (Thom, 1966); the parameters $(P[0], \log$ mean and log-standard deviation) are probabilistically calculated from several $4^{\text {th }}$-order polynomial trend surfaces as functions of date and elevation (Brunengo, 1990).

F) Effective elevations The elevations used in the relations described above are not the listed or official values, but an estimate of the general terrain elevation of the site (section 4.3). Broad-scale topography is expressed through effective elevations assigned to the weather stations, snow courses and SNOTEL facilities; they also provide a single value for stations that have occupied multiple nearby sites, and for abandoned stations and old snow courses whose exact locations are uncertain. I used 10-m digital elevation model (DEM) data to measure mean elevations within circles of 2.5, 4 and $8 \mathrm{~km}$ radii around each observation site (enclosing areas approximately 25, 50 and $200 \mathrm{~km}^{2}$ ). The nominal elevations and the three sets of effective elevations (independent variables) were analyzed against mean annual precipitation and several statistical parameters describing storm precipitation at the NWS stations; and against monthly snow depth and/or SWE at all sites. The 2.5-km averaging was judged most suitable: superior to the larger circles as evaluated by linearity of graphic trends, better correlation, etc.; and equivalent or slightly better than the nominal elevations, particularly when the precipitation parameters are partitioned between wetter and drier areas. Nominal and effective elevations for the observation sites are shown on Tables D.1 and D.2. 


\section{MODEL CALIBRATION, TESTING \& INITIAL APPLICATIONS}

\section{$\underline{5.1 \text { Introduction }}$}

The first applications of my model occurred in many interrelated trial runs. Tests proceeded from the individual program modules, checking intermediate and ultimate computations to ensure proper performance; to the deterministic single-event version, chiefly the snowpack and percolation algorithms, with calibration for a few adjustable elements; to full Monte Carlo simulations, including scrutiny of the probabilistic model outputs with respect to the input parameters governing the generating equations, as well as applications to begin answering the research questions. These overlapping activities continued intermittently over many months, during which a variety of problems were corrected, leading to modifications in other model components and additional testing. Results of the model-assessment and application phases are summarized in this chapter, in three major parts.

First (section 5.2) I evaluate the deterministic model components, employing the single-event version (sections 3.1, 3.3B-C; Fig. 3.1). These modules must properly simulate the important physical processes relevant to rain-on-snow in order for the model to produce acceptable results. For trial cases, I use one hypothetical ROS situation introduced by Colbeck (1976); and four events observed at field sites, in which rain fell on snowpacks and meltwater was generated. These test the snow accumulation, melt and percolation algorithms relative to measurements of controlling hourly weather conditions and water outflows; if they work in these situations, they will also behave properly in simpler conditions (rain on bare ground or cold snowfall). Test runs with the SE version were also used to calibrate three factors in the model (section 5.2). 
Next I assess the probabilistic model by means of two sets of simulations. Recall that the Monte Carlo version incorporates the snow and percolation functions of the SE version, but in addition generates many state and forcing variables of storm timing and duration, precipitation amount and distribution, initial snowpack, and hourly weather conditions, all for several thousand virtual events per model run (sections 3.2, 3.3; Fig. 3.2). Testing a Monte Carlo model is difficult because it can produce physically reasonable events that may not have been captured in a limited data record. We assume that if the probabilistic components of the model reproduce the statistical characteristics of the instrumental record incorporated as governing parameters (and the deterministic modules properly emulate the processes, as noted above), then the MC program will generate valid and informative results (McCracken, 1955; Barros and Lettenmaier, 1994).

The Monte Carlo model is applied with two sets of governing parameters, both pertaining in great degree to Stampede Pass weather and snow records (and using the exponential distribution to organize the major hydrologic series), but differing in several important ways. In the first, inputs are nearly all specific to Stampede Pass; as explained in section 3.3, the model operating on the factors for a particular place is called MC-EXP (or just EXP). The results of model runs StpP EXP are used to assess the model's ability to simulate 1000 years of reasonable events, and particularly the fidelity of the model realizations to the inputs and statistics from the Stampede Pass facilities (section 5.3).

The Monte Carlo model can also use governing parameters based on all of the weather and snow stations utilized in this study (section 4.4), then applied to a designated elevation. Thus, the parameters of MC-EXE are either averages from all weather stations (number of storms per year and storm date); or derived from common lists of observed 
storms (contributing to hourly precipitation, temperature and wind values); or functions of elevation, from all weather and snow sites having relevant information (total precipitation, duration, initial snow amount and air temperature; section 4.5, Table 4.1). In short, EXE operates on elevation as an input value whereas EXP does not. In the last part of this chapter, I run this version for the effective elevation of the Stampede Pass station, 1065 $\mathrm{m}$, thus called 1065 EXE, particularly to evaluate the ability of the elevation-based mode to approximate the results of the comparable place-based mode, as well as the original governing parameters from Stampede Pass (section 5.4). The results of both EXP and EXE test runs are germane to the first set of project hypotheses, regarding rain-on-snow at a particular site (section 2.3).

\subsection{Model calibration \& testing, ROS hypothetical \& observed events}

For a simple initial assessment of the percolation component, I compare my model against a hypothetical case proposed by Colbeck (1976) to demonstrate his equations for vertical flow in snow, later adopted as a benchmark by others (R. Jordan, 1991; Albert and Krajeski, 1998). The situation (Fig. 5.1) involves $10.8 \mathrm{~cm}$ of rain over $3 \mathrm{~h}$ on $100 \mathrm{~cm}$ of ripe snow ( $30 \mathrm{~cm} \mathrm{SWE}$, snow grain diameter $0.2 \mathrm{~cm}$ ); no melt occurs (thus no test of my accumulation and melt algorithms). Colbeck's analytical solution finds water reaching the ground in $0.69 \mathrm{~h}$, then uniform outflow (equal to rainfall rate), until drainage declines exponentially over several hours on the falling limb.

Despite some differences, my percolation module compares adequately with respect to infiltration volume and timing. The total amounts of water leaving the snowpack are identical, since my model conserves mass, so rain in equals WAR out. There are discrepancies in timing: running the SE model using the same $0.2 \mathrm{~cm}$ grain diameter causes 
faster percolation, and WAR occurs $\sim 26$ min sooner (lag $0.25 \mathrm{~h}$ ) than Colbeck's results; with $0.1 \mathrm{~cm}$ snow grains, my model produces somewhat slower flows (lag to initial WAR $0.39 \mathrm{~h}$ ). The earlier outflow is due mainly to my model's numerical distribution of some WAR back 60 min prior to the calculated flux arrival time at the ground (section 3.3C). To slow the flow, I generally assume $0.1 \mathrm{~cm}$ snow grains, yielding results closer $(\sim 18$ min sooner) to Colbeck's. After the rain, final drainage in my model occurs at 3.25 or $3.39 \mathrm{~h}$ (for 0.2 and $0.1 \mathrm{~cm}$ grains, respectively), also sooner than the analytical solution. My model does not account for dispersion of the post-rain percolation, thus the lack of an exponentially decreasing falling limb and earlier, more abrupt cessation of WAR.

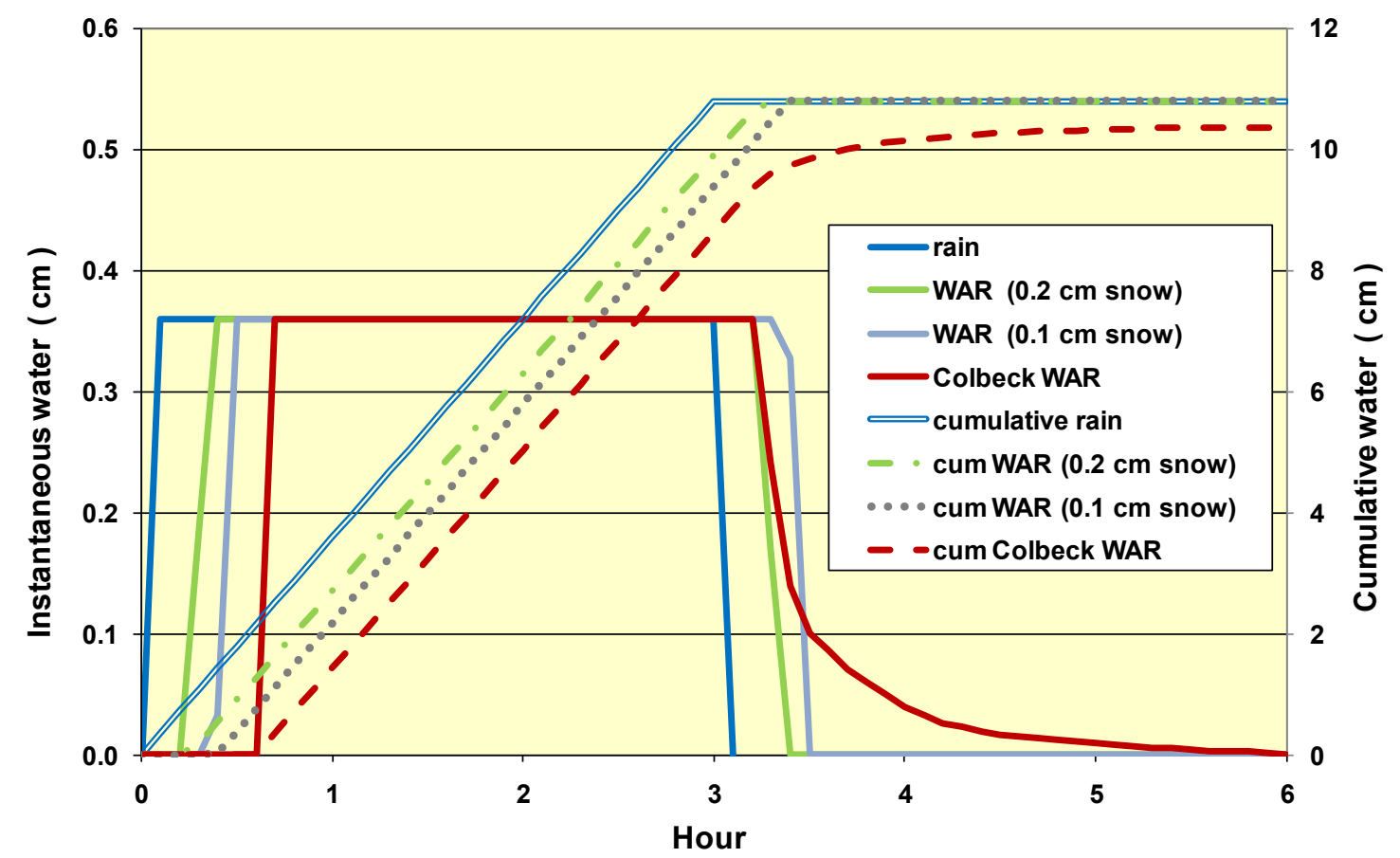

Figure 5.1. Comparison of SE model outputs with Colbeck's (1976) case: ripe snow $\left(0^{\circ} \mathrm{C}\right), 100 \mathrm{~cm}$ deep, $30 \mathrm{~cm} \mathrm{SWE}$, rain for $3 \mathrm{~h}$ at $3.6 \mathrm{~cm} / \mathrm{h}$; resultant instantaneous and cumulative percolation $(0.1 \mathrm{~h}$ time steps).

On the whole, my model seems to pass this first test: the mass of percolating water is conserved; and the faster drainage causing earlier WAR arrivals $(<0.5 \mathrm{~h})$ is trivial in modeling storm events of $\sim 12-250 \mathrm{~h}$ duration. 
Next, I had to demonstrate the model's effectiveness against measurements from typical large Pacific Northwest storms. My calibration and testing processes were hindered by the scarcity of full data sets recording rain-on-snow events, including hourly temperature, wind speed, precipitation, melt/accumulation, snow depth, SWE, and WAR. Even concentrating on the Stampede Pass NWS station and SNOTEL facility, I could find few cases in which all instruments were functional. Two serviceable events at Stampede Pass were identified, occurring on 16-23 January 2005 and 22-29 December 2005. Both are imperfect: they started with freezing rain, violating assumptions of consistent air-rain temperatures inherent in the model; in the December event, the NWS data are missing after the morning the $24^{\text {th }}$, and snow depth is sporadic. The two sets of instruments are separated by some distance and elevation (section 4.4): measured temperatures and precipitation are usually different; wind speed at the open weather station is certainly faster than in the small clearing around the snow pillow.

Two other ROS events were obtained from Wetherbee's (1995) observations at USFS Demonstration of Ecosystem Management Options (DEMO) Watson Falls project sites in the Umpqua National Forest, southwest Oregon Cascades (Storck et al., 1999, 2002). These data included hourly temperature, wind, precipitation, and lysimeter WAR. Snow was sampled broadly but intermittently; Wetherbee reported mean SWE and mean density for his snow surveys, requiring back-calculation of mean (measured) depth. The two best ROS events for my purposes, each about $72 \mathrm{~h}$ long, occurred on 29 November- 2 December 1994 (DEMO \#1) and 29 January-1 February 1995 (DEMO \#4).

Background information from the four events is summarized in appendix G, and the results of calibration tests in appendix $\mathrm{H}$. In these trials, the single-event model ver- 
sion uses the observed weather data $\left(\mathrm{T}_{\mathrm{h}}, \mathrm{W}_{\mathrm{h}}, \mathrm{P}_{\mathrm{h}}\right)$ to compute snow accumulation/melt and water percolation, which are then compared against snow and WAR measurements, shown in tables and graphs. Table H.1 summarizes the important parameters and results of the major SE test runs, conducted once the model's procedures were substantially in present form.

Three kinds of adjustable factors in the model's deterministic components were calibrated using these four events. My choices were based on several considerations: the temporal patterns of snowpack changes and water available for runoff; the similarity between total WAR for the model results and field measurements, in magnitude, proportion and timing; and the root mean square errors (RMSE), gauging the fidelity to observations for each hour's WAR realizations.

A) Snow density In the model, hourly change in snow depth is determined from the change in calculated SWE (sections 3.1A, 3.3B). If an hour experiences net melt, the loss in depth is simply $\triangle \mathrm{SWE}$ divided by the average pack density. However, for accumulation, the density factor is considered a function of the hour's rain/snow mix, thus of air temperature. Also, in some hours of the observed events, the value for either snow depth or SWE was missing, demanding estimation of the unmeasured quantity from the other, again involving density.

Thus, both model and field situations require reasonable values for snow density, especially minimum and maximum limits. Density of snow varies broadly: about $0.03-$ $0.8 \mathrm{~g} / \mathrm{cm}^{3}$ based on the literature (e.g., Singh and Singh, 2001); for snow on the ground, in the 20 regional snow-course records utilized in this project, measured ratios of SWE to depth range $\sim 0.075-0.80$ (both lengths, so $\rho_{\mathrm{s}}$ is considered dimensionless). 
To establish standards and limits for $\rho_{\mathrm{s}}$, I ran the SE model with several combinations of minimum (0.1-0.2), maximum (0.7-0.9), and temperature-dependent values, comparing the results against snow depth and SWE data in the test cases, seeking the best correspondence to observed patterns of accumulation and ablation. Accordingly, the range of possible initial and hourly snow densities in the model was set at $0.1-0.8$. For accumulation, I chose a range of $\rho_{\mathrm{s}}=0.15$ at $\leq-1.5^{\circ} \mathrm{C}$, and then a linear increase to 0.85 at $+2.5^{\circ} \mathrm{C}$; the ranges are identical to those used for the rain/snow mixture of precipitation. These densities may seem high, but reflect local conditions: 0.15 is appropriate for the typically wet snow in the maritime Northwest, though in colder conditions the snow would be drier and lighter. With mixed precipitation, I expect the growing fraction of rain with warmer temperatures to make any accumulating snow increasingly dense and compactable, so the growth in snow depth for a given $\triangle \mathrm{SWE}$ becomes smaller. Although 0.85 is too high for bulk snowpack density, it seems reasonable for an incremental addition of wet snow for temperatures approaching the point at which precipitation would become entirely rain $\left(\sim 2.5^{\circ} \mathrm{C}\right)$. These parameters were evaluated with respect to modeled snow and WAR outflow during the sample events, and performed adequately (Table H.1). B) Snow grain size Another significant variable is the grain size of the snowpack medium, a property rarely measured in the field. As mentioned, I adopted Shimizu's (1970) equation to estimate snow permeability as a function of density and grain diameter (Eq 11, section 3.1C): larger grains make bigger pores, enabling greater conductivity and faster infiltration. Actual sizes are heterogeneous and varying, though snow metamorphism during ROS usually coarsens the snow; rather than implying an imaginary uniformity, perhaps a better term is hydraulically effective grain size, as used by Kohl et al. (2001). 
In the first calibration test against Colbeck's (1976) hypothetical, I found that $g_{d}=0.1 \mathrm{~cm}$ best matches his results, though he assumed $0.2 \mathrm{~cm}$ snow. In tests against empirical measurements of WAR, I applied snow diameters of 0.1, 0.15 and $0.2 \mathrm{~cm}$ (Table H.1). Generally, modeled percolation rates produced by heavy rain plus melt onto larger snow grains are too fast. Setting $g_{d}=0.1 \mathrm{~cm}$ in the model produced fluxes and WAR amounts closest to the field observations in these four events.

C) Wind Wind speed is an element of the model's snowmelt equation, so melt rate is sensitive to suppression of wind in the forest (section 3.1B). In utilizing field observations for model testing, adjustments were necessary for the Stampede Pass facilities, where wind is observed in the open at the NWS station while WAR is interpreted from the SNOTEL pillow in a small forest opening (Fig. 4.6). To examine compensation for canopy differences, modeling of the January and December 2005 events at Stampede assumed winds to be $100,50,25$ and $10 \%$ of open-terrain values ("wind F" of $1,0.5$, etc. in Table H.1). A reduction of velocity by $50 \%$ produced melt estimates similar to those measured. No adjustment is warranted for the cases at the Watson Falls DEMO sites because their anemometers are close to the snow lysimeters, within the same forest stands.

Among the many tests (Table H.1), a few examples are offered for illustration, concentrating on model runs with the best values of adjustable factors (snow density limits, grain diameter $0.1 \mathrm{~cm}$, wind speed $50 \%$ of open at the Stampede SNOTEL). The two events at the DEMO sites were classic rain-on-snow, with temperatures above freezing and dominantly rainfall throughout each three-day observation period. The two Stampede Pass events were less canonical, with several breaks in precipitation and temperatures fluctuating around $0^{\circ} \mathrm{C}$, causing mixed rain, snow, freezing rain, and intermittent 
melting. The model gave somewhat poorer results in these cases.

DEMO \#4 (29 Jan-1 Feb 1995) provides the closest match. Wetherbee (1995) considered the conditions during this event (of his five) to best agree with the assumptions of the USACE-based melt formula, and had the finest correspondence between modeled and measured melt rates. The data are not entirely complete: Wetherbee did not report observations after rainfall ended (at $72 \mathrm{~h}$ ), so I estimated temperature and wind speed for the next $6 \mathrm{~h}$ as the average of the last two reported hours $\left(2.8^{\circ} \mathrm{C}\right.$ and $\left.0.35 \mathrm{~m} / \mathrm{s}\right)$. Also, he did not have continuous snowpack data: SWE was measured on 25 January and 7 February, but not during the ROS period; I calculated depths from his reported average densities at those times. Thus, assessment of the results involves some interpretation.

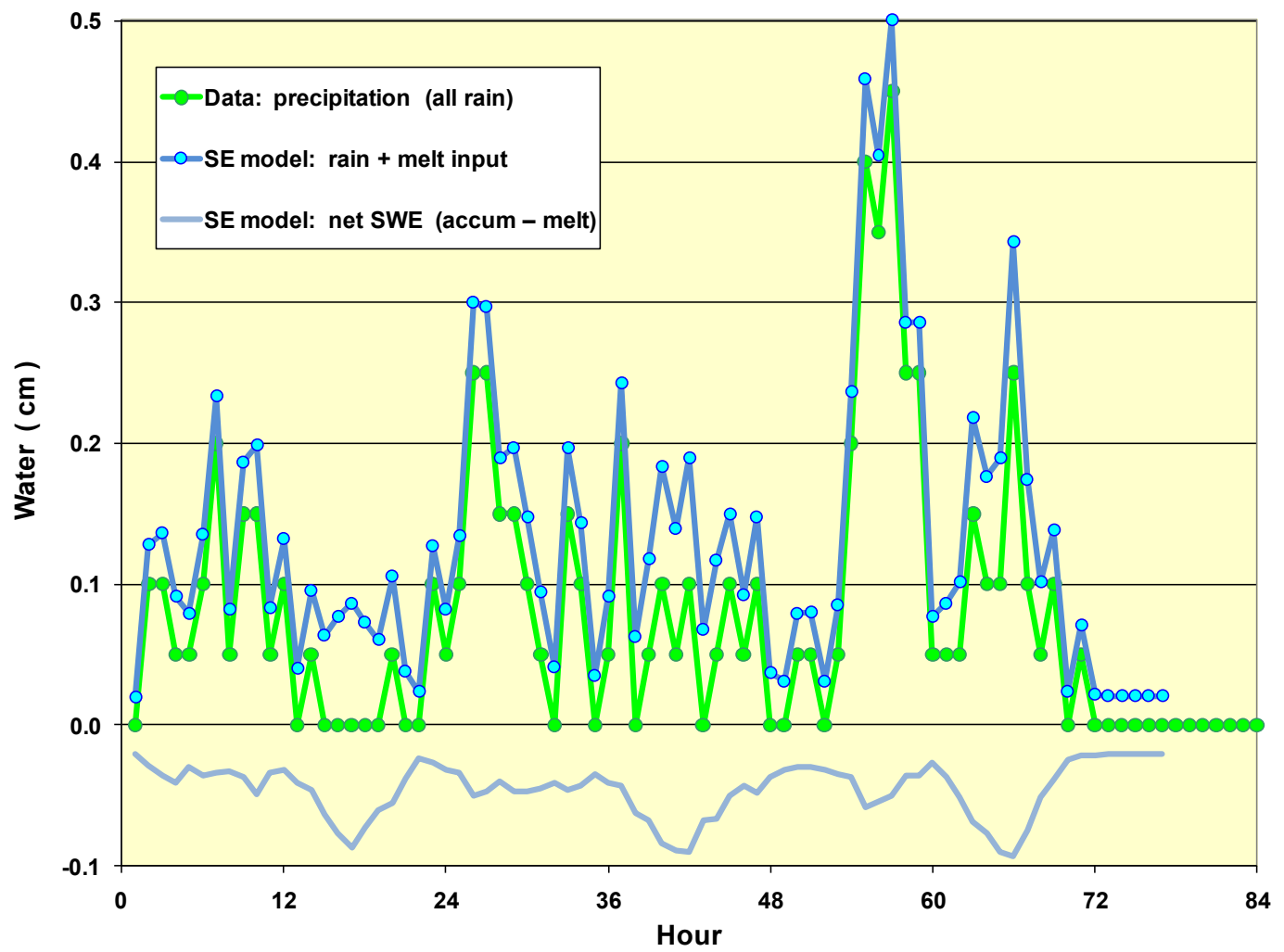

Figure 5.2. Comparison of SE model output (test F 2 a, Table H.1) and field measurements for DEMO event \#4, 29 Jan-1 Feb 1995 at units 1 and 4 (Wetherbee, 1995). Measured rainfall (no snowfall in this event); modeled rain + melt input; and snowpack change (negative net SWE indicates that the pack loses water through this event, as all temperatures $>2^{\circ} \mathrm{C}$ ). 
Nevertheless, the model showed good agreement with measured snowpack and WAR in this event (Fig. 5.2 to 5.4, test F 2 a on Table H.1). The model's estimated snowmelt augments the observed rainfall by a small amount (maximum $\sim 0.1 \mathrm{~cm}$ ) every hour; with temperatures all above freezing $\left(2.2-5.8^{\circ} \mathrm{C}\right)$, no new snow accumulates; net change in snow-water equivalent is negative throughout, and snow depth and SWE decline through the event. As noted, there are no snow measurements until almost a week after the ROS event ended, but projection of the modeled snow amounts shows that the trends closely approach the depth and SWE on 7 February (Fig. 5.3). SNOTEL data from the nearest sites in southwest Oregon (King Mountain and Diamond Lake, both higher in elevation) confirm that snowmelt continued in the region during that week.

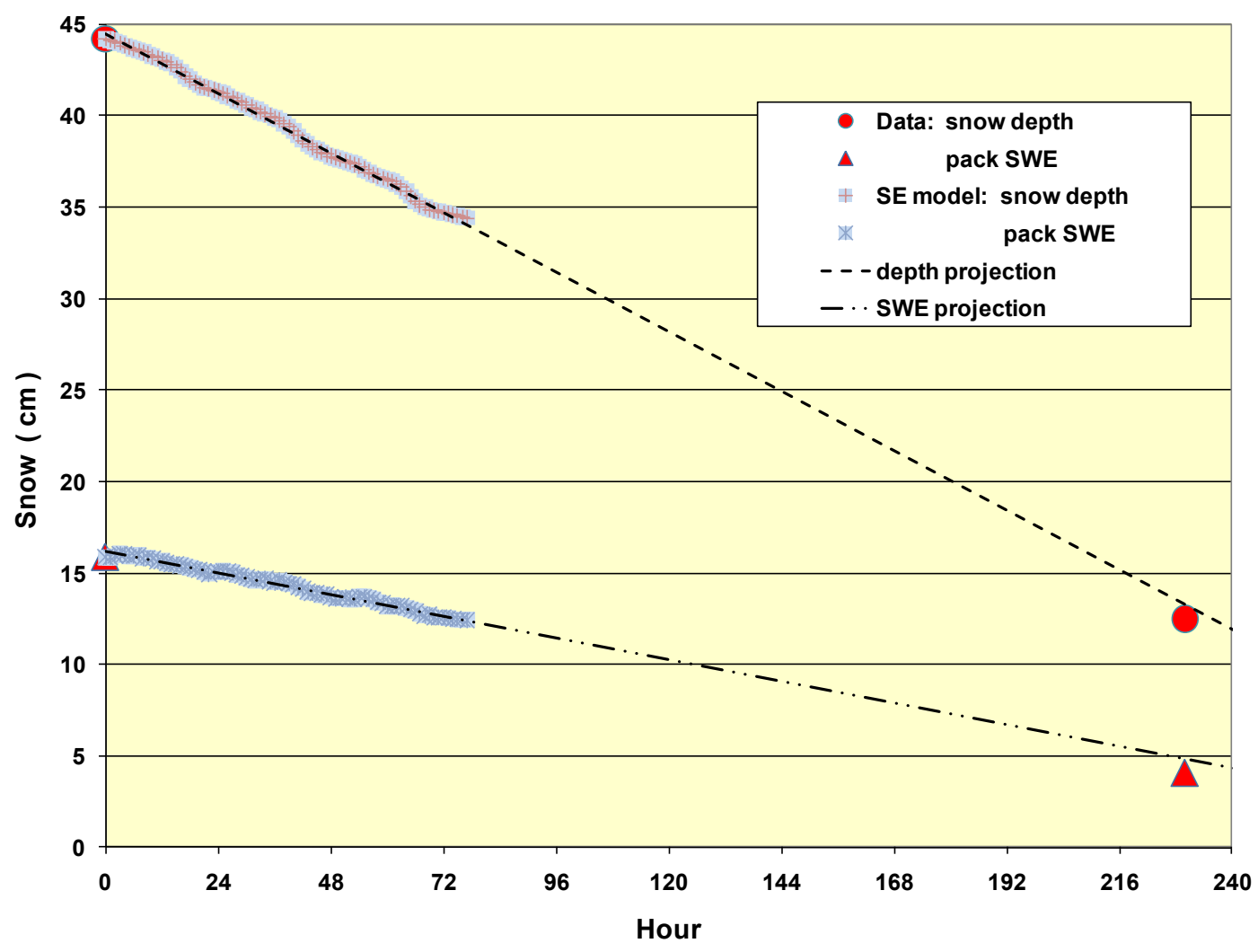

Figure 5.3. Comparison of SE model output (test F 2 a) and field measurements for DEMO event \#4, 29 Jan-1 Feb 1995 at units 1 and 4 (Wetherbee, 1995). Measured snow depth and SWE on 25 Jan and 7 Feb; modeled snowpack changes; and projection of model snow depth and SWE to the 7 Feb snow survey. 
Comparison of the hourly outputs from Wetherbee's snow lysimeters and my model's WAR realizations shows good correspondence (Fig. 5.4). This is somewhat expected, since the model allows rain plus meltwater to pass through this shallow pack $(\sim 35-45 \mathrm{~cm}$ deep) in about an hour. In test F 2 a, the total modeled WAR was $2.3 \%$ less than the lysimeter outflow. The patterns of WAR output track inputs closely: the strongest peaks correspond well, though model WAR commonly runs an hour behind the lysimeters in periods with lower input, as the model's kinematic waves slow down when input declines; yet RMSE for the best model scenario was $0.064 \mathrm{~cm}$. Most of the $0.24 \mathrm{~cm}$ difference between measured output $(10.24 \mathrm{~cm})$ and the model's estimate can be attributed to the initial few hours, when the lysimeters were recording outflow before the model does, and even an hour prior to observed rainfall. Wetherbee (1995) noted above-freezing temperatures for $24 \mathrm{~h}$ before rain began, so there was almost certainly free water draining through the snowpack prior to the event's "beginning", yielding the premature outflow. Model results for the other three test events are less splendid, even with the best tunable parameters, but still satisfactory. In DEMO event \#1 (Nov-Dec 1994; Fig. 5.5A for test F $1 \mathrm{~b}$ ), lysimeter outflow starts earlier than the model's WAR, due certainly to preexisting melt and/or percolation, and the later peaks do not match as well as for DEMO \#4. Yet, the model's total outflow is just $1.6 \%(0.081 \mathrm{~cm})$ less than measured, with RMSE $0.052 \mathrm{~cm}$ (Table H.1). 


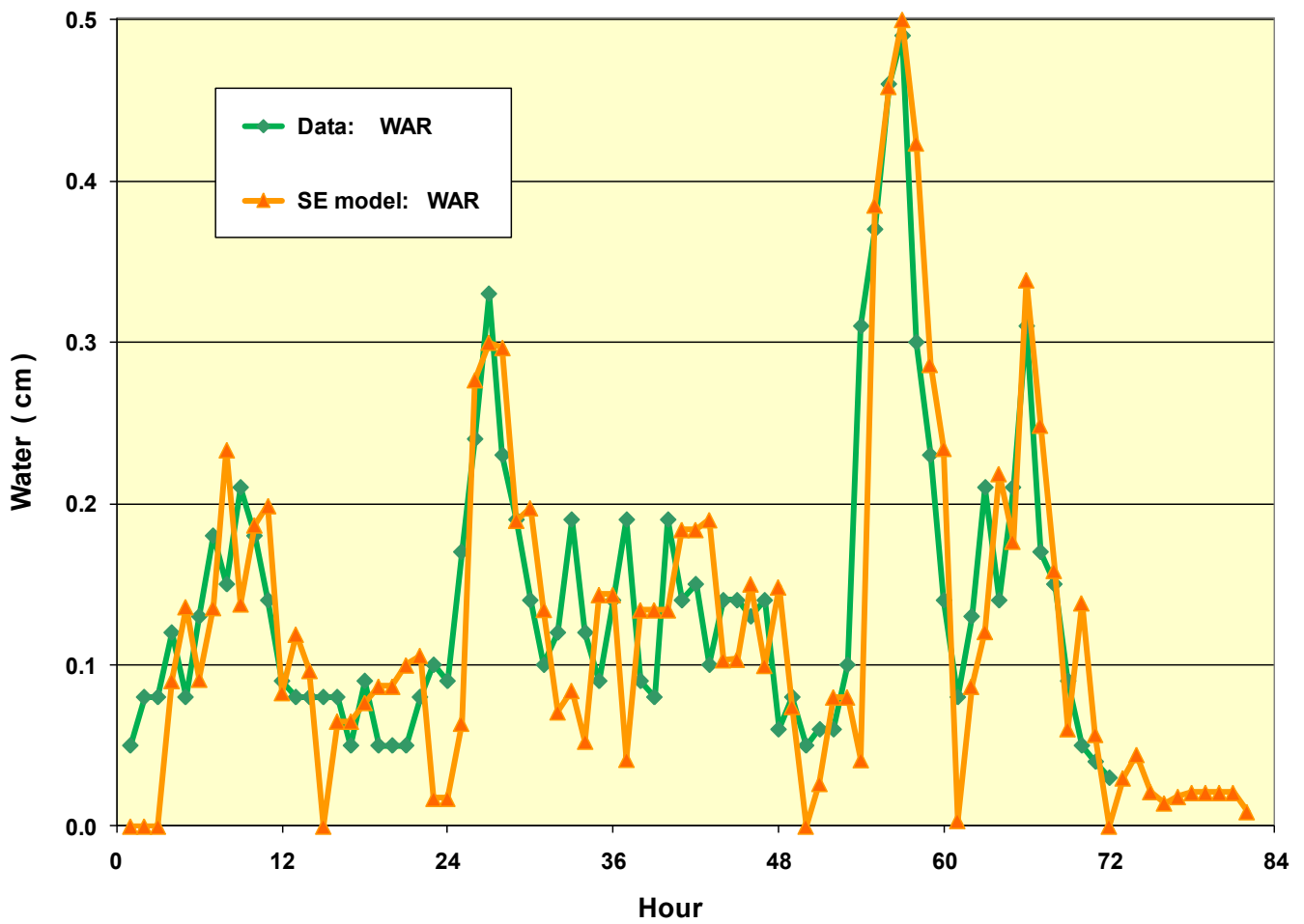

Figure 5.4. Comparison of SE model output (test F 2 a) and field measurements for DEMO event \#4, 29 Jan-1 Feb 1995. Data are averages of observed lysimeter outflows at sites 1 and 4; single-event model WAR generated by percolation algorithms. (Zero values in model WAR reflect water absorbed in simulated kinematic-shock waves.)

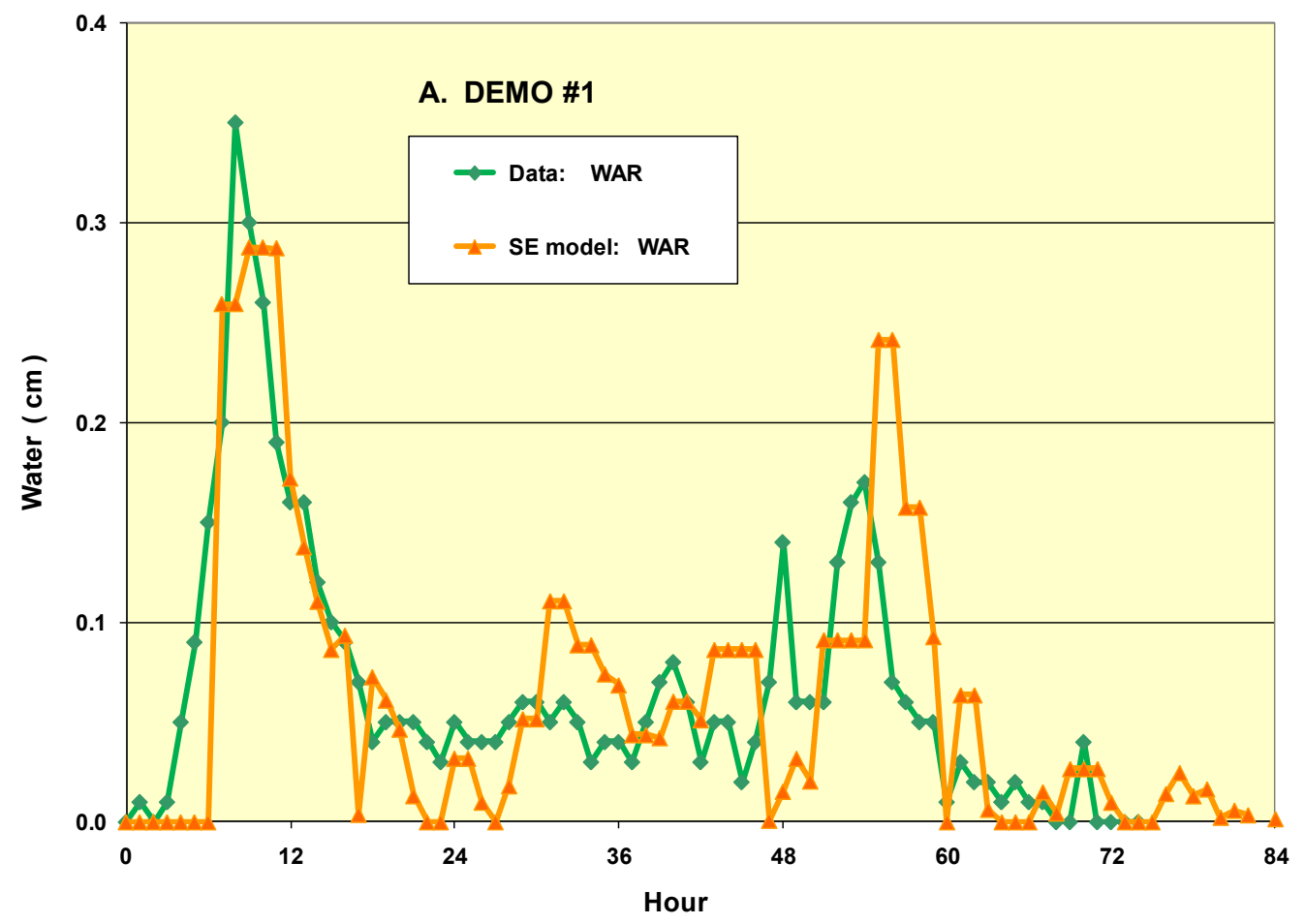



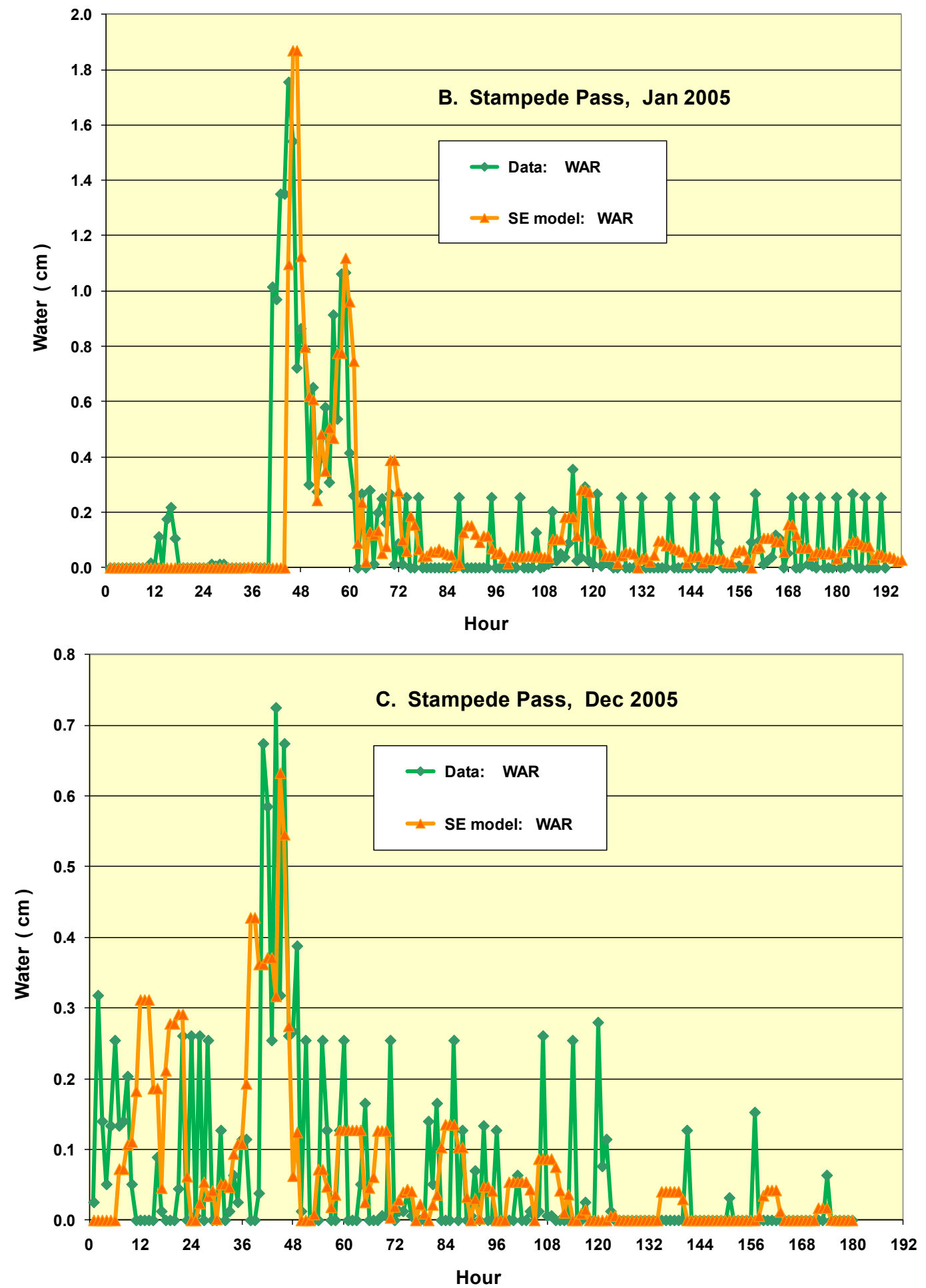

Figure 5.5. Comparison of SE model outputs and field measurements (note differences in ordinate scale). A: DeMO event \#1 (29 Nov-7 Dec 1994), test F 1 b; B: Event of 15-23 Jan 2005 at Stampede Pass, tests C $1 \mathrm{c}$ and C 2 b; C: event of 22-29 Dec 2005 at Stampede Pass, tests E 1 a, E 2 a and E 3 a.

The two test ROS events at Stampede Pass gave somewhat poorer results than the 113 
DEMO cases, but the inconsistencies are explainable. The January and December 2005 storms both began with sub-freezing air temperatures, inducing the model to show initial snow accumulation and delayed outflow. But observed freezing rain indicates warmer air aloft, and precipitation warmer than that of air near the ground; freezing rain would probably cause less snowpack growth, plus WAR before air $\mathrm{T}>0^{\circ} \mathrm{C}$ at the weather station. Furthermore, discrepancies in hydrograph peak heights between measured and model values (Fig. 5.5B, 5.5C) are partly due to the lower reported precision of the snow-pillow measurements $(0.1 \mathrm{in}=0.25 \mathrm{~cm}$, compared to $0.1 \mathrm{~cm}$ for the DEMO lysimeters), causing apparently choppier field outflows. Yet for these events, using weather factors averaged between NWS and SNOTEL and the best-calibrated parameters (Table H.1), the differences between total-event model WAR and measurements was always $<3 \mathrm{~cm}$ and usually less than half that. In the January storm, the model underestimated outflow by $4.6 \%$ (1.22 $\mathrm{cm}$; RMSE $0.20 \mathrm{~cm}$ ) for the full $185 \mathrm{~h}$; in the December event, the model overestimated outflow by $\sim 3.1-7.3 \%(0.34-0.99 \mathrm{~cm}$ event WAR; RMSE 0.098-0.12 cm).

Therefore, I consider that the results of the four cases show that my model reasonably reproduces the processes leading to WAR. It is unfortunate that useful data sets for additional ROS events were lacking, which could allow more model calibration and testing. Nevertheless, the resemblance between model WAR and field measurements for these cases is encouraging. I accept that the model is working adequately, and move on to the Monte Carlo simulations.

\subsection{Monte Carlo simulation specific to Stampede Pass (StpP EXP)}

The next steps are to examine the operation of the Monte Carlo model version, comparing the statistics of realization series against the governing series and parameters 
of the input distributions. As explained in section 2.3, I focus on the record from Stampede Pass because of the quality of the records at its weather station, snow course and SNOTEL installation. In particular, I analyze the frequency of storm occurrence, precipitation, LCS duration, air temperature, wind speed, seasonal snow volume, etc., and evaluate the model on its ability to imitate important aspects of the observations. Here, the program is demonstrated with a 1000-year run (comprising 4101 events) using place-specific parameters from Stampede Pass (StpP EXP, as defined in section 5.1).

To begin, the results of one event are offered as illustrative of model operations and outputs. Event number 3230 occurs in late March of WY 800, with very warm air temperatures over three out of four days, during which $\sim 12.4 \mathrm{~cm}$ of mostly rain falls on a substantial snowpack (initially $\sim 80 \mathrm{~cm} \mathrm{SWE,} \sim 180 \mathrm{~cm}$ depth), generating much melt. Hourly temperatures through the event (Fig. 5.6) are calculated by combining stochastically selected initial temperature, range, frontal-diurnal ratio (FDR), a set of time segments (Tcode), and random components (see section 3.3A). A hydrograph (Fig. 5.7) tracks the precipitation, rain plus melt inputs to the snowpack, and water to the ground through the event; WAR closely follows inputs, $\sim 1-2 \mathrm{~h}$ behind (except for late flux to ground due to a kinematic shock arriving after the model's duration limit). The maximum inputs and outputs for a sample of time periods are summarized by a bar graph (Fig. 5.8). Precipitation of this magnitude is not unusual at Stampede Pass, where it is exceeded about twice per year, but the melt in such a warm event would be significant. Over the 93-h duration, the total WAR of $22.8 \mathrm{~cm}$ ( $>180 \%$ of storm rainfall) is enough to promote this storm to $2+$-yr recurrence (Fig. 4.8). This example is atypical for Stampede Pass, as only $\sim 11 \%$ of StpP EXP events produce WAR $>\mathrm{P}$. 


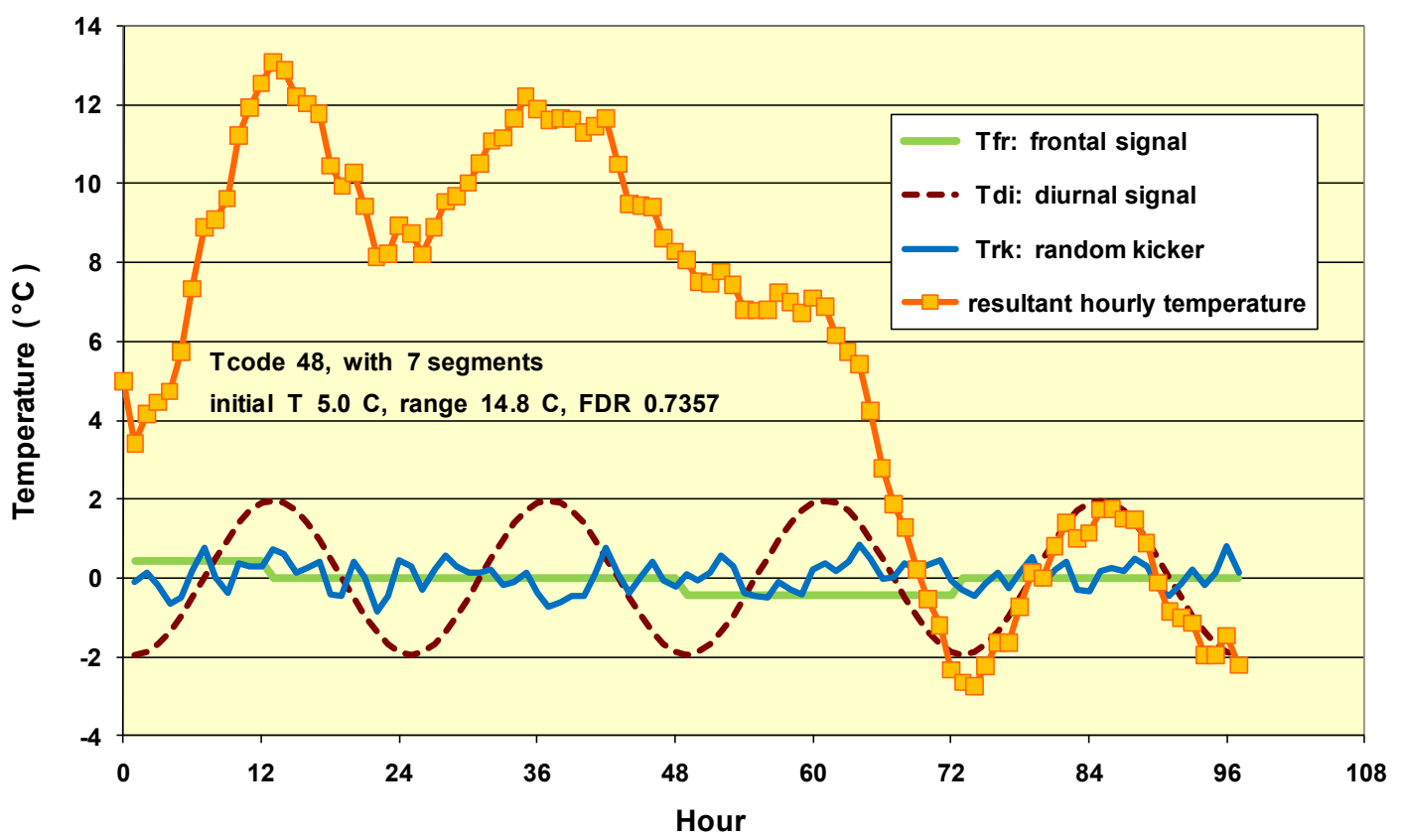

Figure 5.6. Hourly temperatures for StpP EXP event 3230. Initial temperature and range set general limits; frontal-diurnal ratio divides the range between frontal and diurnal signals (74 and 26\%); Tcode \#48 dictates 7 segments of $\sim 12 \mathrm{~h}$ each, with frontal component rising $(+)$, stable $(0)$ or falling $(-)$.

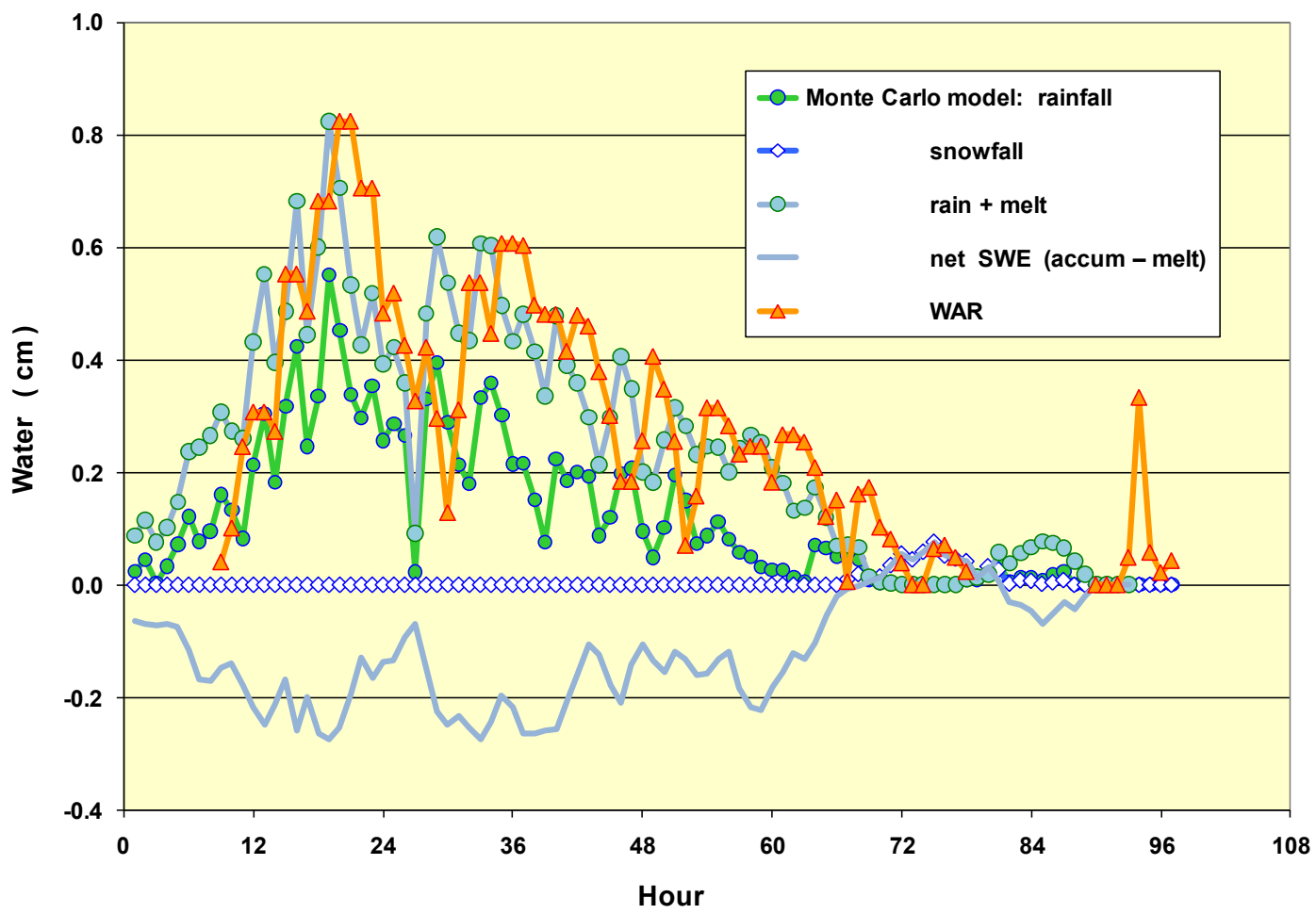

Figure 5.7. Hourly water input and output values, StpP EXP event 3230. Precipitation partitioned between rain and snow based on temperature (all rain until last day); negative net SWE indicates the snowpack loses water through most of the event. 


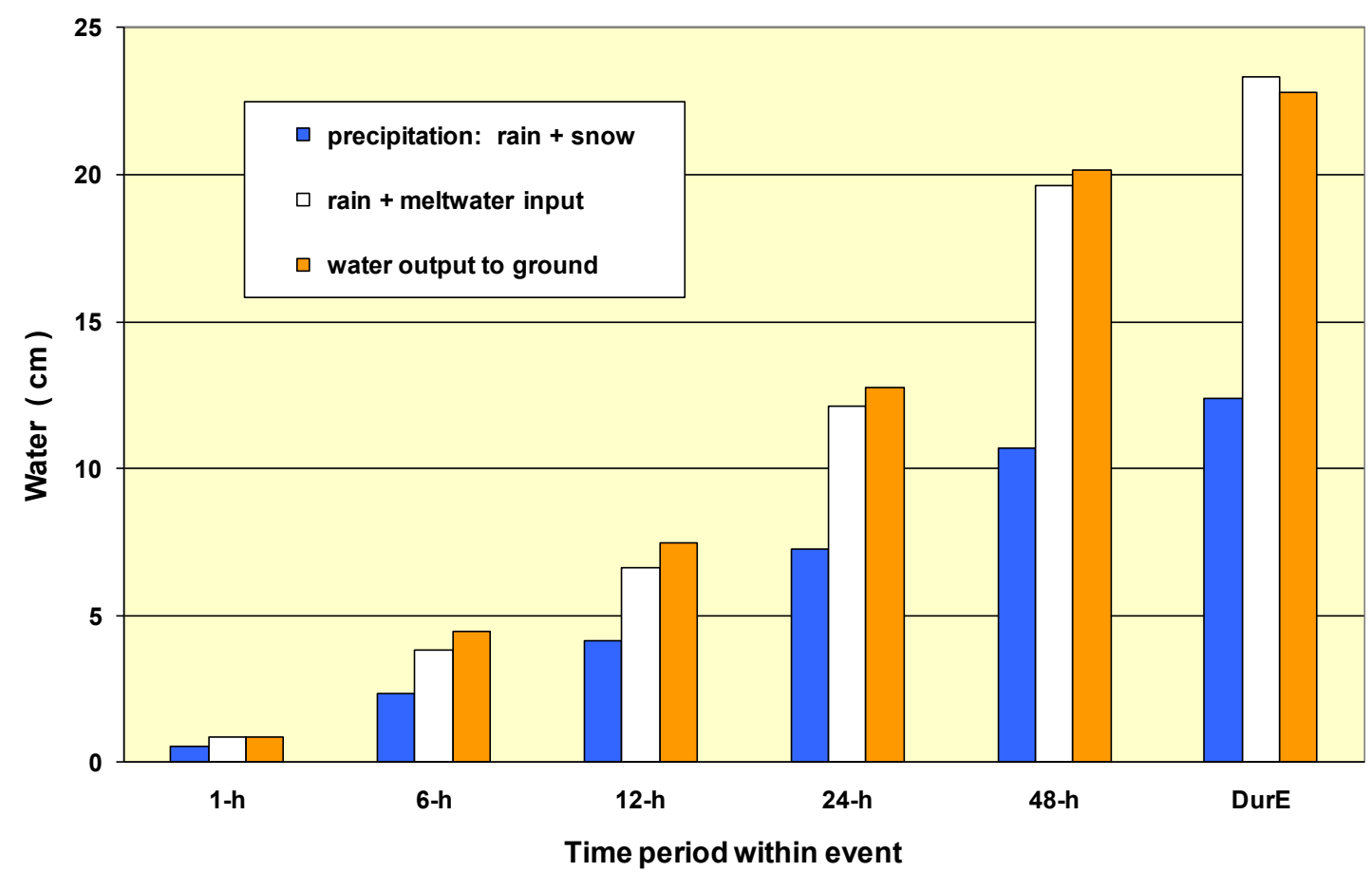

Figure 5.8. Summary of maximum total precipitation, rain + melt, and water available for runoff over various time periods, StpP EXP event 3230. Snowmelt accounts for $>40 \%$ of WAR for this event.

More important than results for individual cases are the aggregate series for all 4101 events over the model millennium. The Monte Carlo simulation reproduces the Stampede Pass input distributions quite well, as shown by the nominal/governing parameters, statistics of the EXP realizations, and results of statistical analyses summarized in Table 5.2. To evaluate the likelihood that the observed series and the model realizations are derived from similar populations, I used the non-parametric Kolmogorov-Smirnov $(\mathrm{K}-\mathrm{S})$ test, and the parametric $\mathrm{F}$ test on variances and Student's $\mathrm{t}$ test on means. Many are comparisons of simple series statistics, and I infer that the records and realizations belong to the same populations in most instances. However, the statistical expectations for some factors are clouded by intermediate modeling steps. For example, initial temperature and initial snowpack are functions of storm date; duration and snow depth are calculated from 
bivariate-normal relationships; and hourly precipitation, temperature, and wind speed include random components. These modeling devices all loosen the ties between observational records and realizations.

In general, the correspondence between nominal and realization parameters (Table 5.1) is acceptable. Nevertheless, a few particular elements merit further comment. 


\begin{tabular}{|c|c|c|c|c|c|}
\hline & Stati & stics & Comparisons, & & \\
\hline Parameter & Nominal & Realizations & Non-Parametric Tests & Parametric Tests & Notes \\
\hline \multicolumn{6}{|l|}{ Storm timing } \\
\hline $\begin{array}{r}\text { Number: events /year } \\
(\#)\end{array}$ & $\begin{array}{c}1-12 \\
4.00 \quad 2.20 \\
0.490\end{array}$ & $\begin{array}{c}1-12 \\
4.101 \quad 2.064 \\
0.420\end{array}$ & $\begin{array}{l}\text { similar - slightly right- } \\
\text { skewed distributions } \\
\text { K-S: << critical } 0.05\end{array}$ & $\begin{array}{l}\mathrm{F}:<<\text { critical } 0.05 \\
\mathrm{t}:<<\text { critical } 0.10\end{array}$ & $\begin{array}{l}\text { modes: data }=4, \\
\text { realizations }=5 ; \\
\text { truncated: minimum 1event } \\
/ \text { yr } \rightarrow \text { slight positive skew }\end{array}$ \\
\hline $\begin{array}{l}\text { Event starting date } \\
\text { ( WY date ) }\end{array}$ & $\begin{array}{c}-\mathbf{- 7 5 - + 3 1 0} \\
\mathbf{9 1 . 8 5} \mathbf{5 1 . 9} \\
0.019\end{array}$ & $\begin{array}{c}-75-+279 \\
92.289 \quad 51.012 \\
0.044\end{array}$ & $\begin{array}{l}\text { single mode at } \sim 90-100 \\
\text { (data are somewhat } \\
\text { bimodal) } \\
\mathrm{K}-\mathrm{S}:<<\text { critical } 0.05\end{array}$ & $\begin{array}{l}\text { F: }<<\text { critical } 0.05 \\
\text { t: }<<\text { critical } 0.10\end{array}$ & $\begin{array}{l}\text { dates overlap in } 307 \text { of } \\
\text { model events }(19 \text { more } \\
\text { within } 6 \mathrm{~h}), \sim 8 \% \text { of total }\end{array}$ \\
\hline $\begin{array}{l}\text { Starting time } \\
\text { ( } h \text { of day) }\end{array}$ & $\begin{array}{c}\mathbf{1 - 2 4} \\
12.50 \quad 6.951 \\
0.000\end{array}$ & $\begin{array}{c}1-24 \\
12.543 \quad 6.885 \\
0.000\end{array}$ & $\begin{array}{l}154-194 \text { events began at } \\
\text { each hour }- \text { uniform is } \sim 171 \\
\text { each } \\
\text { K-S: }<<\text { critical } 0.05\end{array}$ & $\begin{array}{l}\text { F: }<<\text { critical } 0.05 \\
\text { t: }<<\text { critical } 0.10\end{array}$ & $\begin{array}{l}\text { uniform distribution - } \\
\text { nominal parameters } \leftarrow \\
\text { ideal uniform }\end{array}$ \\
\hline $\begin{array}{r}\text { Event duration } \\
(\ln \text { of } \mathrm{h}) \\
(\mathrm{h})\end{array}$ & $\begin{array}{c}\mathbf{1 2 - 2 2 8} \\
\text { variable } \\
81.83 \quad 38.41 \\
1.774\end{array}$ & \begin{tabular}{|c|c|}
$12-252$ \\
$-\overline{-}$ & $-\overline{-}$ \\
80.149 & 34.507 \\
1.250
\end{tabular} & $\begin{array}{l}\text { right-skewed distribution } \\
\mathrm{K}-\mathrm{S}:<<\text { critical } 0.05\end{array}$ & $\begin{array}{l}\mathrm{F}:<\text { critical } 0.05 \\
\text { t: }<<\text { critical } 0.10\end{array}$ & $\begin{array}{l}\text { bivariate log-N distribution } \\
\text { as } \mathrm{f}[\text { precip ] - hours used } \\
\text { for tests; actual Dur } \\
\text { realizations shown - initial } \\
\text { values slightly different }\end{array}$ \\
\hline \multicolumn{6}{|l|}{ Precipitation } \\
\hline 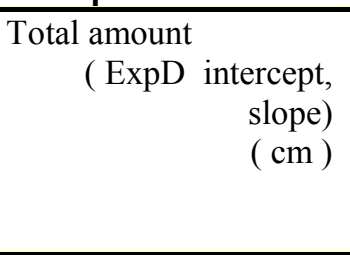 & \begin{tabular}{cc}
\multicolumn{2}{c}{$1-125$} \\
7.2569 & 7.0468 \\
14.283 & 7.113 \\
2.849
\end{tabular} & $\begin{array}{cc}7.014-104.61 \\
7.167 & 7.175 \\
14.340 & 7.1865 \\
2.284\end{array}$ & $\begin{array}{l}\text { close correspondence to } \\
\text { exponential line (Fig. } 5.9)- \\
\text { despite } 104.6 \mathrm{~cm} \text { outlier }\left(2^{\text {nd }}\right. \\
\text { largest realization } 64.3 \mathrm{~cm}) \\
\text { K-S: }<<\text { critical } 0.05\end{array}$ & $\begin{array}{l}\text { F: }<<\text { critical } 0.05 \\
\text { t: }<<\text { critical } 0.10\end{array}$ & $\begin{array}{l}\text { exponential distribution - } \\
\text { intercept (ExDp) and slope } \\
\text { (ExDa) control, but precip } \\
\text { amounts used for tests; } \\
\text { modal class } 10-15 \mathrm{~cm}- \\
\text { same for both }\end{array}$ \\
\hline $\begin{array}{l}\text { Hourly distribution } \\
\text { SIMcodes }\end{array}$ & $\begin{array}{c}\mathbf{1}-\mathbf{1 0 0 0} \\
500.5 \quad 288.82 \\
0.000\end{array}$ & $\begin{array}{c}1-1000 \\
494.67 \quad 291.06 \\
0.033\end{array}$ & $\mathrm{~K}-\mathrm{S}:<<$ critical 0.05 & $\begin{array}{l}\text { F: }<<\text { critical } 0.05 \\
\text { t: }<<\text { critical } 0.10\end{array}$ & $\begin{array}{l}\text { uniform distribution }- \\
\text { nominal parameters } \leftarrow \\
\text { ideal uniform } \\
\text { no tests on patterns }- \text { see } \\
\text { Fig. } 5.2 \text { for example; K-S } \\
\text { tests on SIM outputs from a } \\
\text { few record events }\end{array}$ \\
\hline
\end{tabular}




\begin{tabular}{|c|c|c|c|c|c|}
\hline \multicolumn{6}{|l|}{ Snow } \\
\hline $\begin{array}{ll}\text { Initial SWE } & (\mathrm{cm})\end{array}$ & $\begin{array}{l}\mathbf{0}-235.7 \\
\text { variable }\end{array}$ & $\begin{array}{c}0-707.7 \\
46.54 \quad 51.59 \\
2.444\end{array}$ & $\begin{array}{l}\text { scatter plot: Fig. } 5.10 \\
\text { day 93: } \\
\text { K-S: < critical } 0.05\end{array}$ & $\begin{array}{l}\text { day 93: } \\
\text { F: < critical } 0.025 \\
\text { t: }<<\text { critical } 0.10\end{array}$ & $\begin{array}{l}\text { model } P[0] \text { restricted to } \\
\text { range } 0.015-0.985 ; \\
\text { calculate mean \& std dev }= \\
f[\text { date ] }\end{array}$ \\
\hline $\begin{array}{l}\text { Initial depth } \quad(\mathrm{cm}) \\
\end{array}$ & $\begin{array}{l}\mathbf{0}-591.8 \\
\text { variable }\end{array}$ & $\begin{array}{c}0-2324 \\
150.44 \quad 174.36 \\
2.737\end{array}$ & $\begin{array}{l}\text { day 93: } \\
\text { K-S: < critical } 0.05\end{array}$ & $\begin{array}{l}\text { day 93: } \\
\text { F: }<<\text { critical } 0.05 \\
\text { t: }<<\text { critical } 0.10\end{array}$ & $\begin{array}{l}\text { model } P[0] \text { restricted to } \\
\text { range } 0.015-0.985 ; \\
\text { calculate mean \& std dev }= \\
\text { f [ date, initial SWE ] }\end{array}$ \\
\hline $\begin{array}{l}\text { Initial density } \\
\qquad(\sim \mathrm{cm} / \mathrm{cm})\end{array}$ & $0.1-0.8$ & $\begin{array}{c}0.1-0.8 \\
0.330 \quad 0.1205 \\
1.092\end{array}$ & $\begin{array}{l}\text { scatter plot: Fig. } 5.11 \\
\text { model } \rightarrow \text { min }=0.1 \mathrm{in} 1 \% \text {, } \\
\text { no-snow default }=0.35 \text { in } \\
14 \% \text {, } \\
\max =0.8 \text { in } 0.7 \% \text { of events }\end{array}$ & & $\begin{array}{l}\text { no hypothetical or } \\
\text { empirical distributions } \rightarrow \\
\text { no statistical tests, but } \\
\text { realizations fall within } \\
\text { reasonable limits }\end{array}$ \\
\hline $\begin{array}{l}\text { Porosity (effective) } \\
\qquad\left(\sim \mathrm{cm}^{3} / \mathrm{cm}^{3}\right)\end{array}$ & $0.1-0.95$ & $\begin{array}{c}0.124-0.867 \\
0.623 \quad 0.128 \\
-1.092\end{array}$ & & & \multirow{2}{*}{$\begin{array}{l}\text { calc porosity }=\mathrm{f}[\text { density ], } \\
\text { permeability }=\mathrm{f}[\text { density, } \\
\text { snow grain diam ] } \\
\text { (min density } \rightarrow \text { max } \\
\text { porosity \& hydr cond, and } \\
\text { vice versa) } \\
\text { no hypothetical or empir- } \\
\text { ical distributions for com- } \\
\text { parison } \rightarrow \text { no statistical } \\
\text { tests }\end{array}$} \\
\hline $\begin{array}{l}\text { Permeability, } \\
\text { affecting hydraulic } \\
\text { conductivity } \\
\qquad(\mathrm{cm} / \mathrm{h})\end{array}$ & $10-150000$ & $\begin{array}{c}295.7-69524 \\
16328 \quad 13151 \\
1.700\end{array}$ & & & \\
\hline \multicolumn{6}{|l|}{ Temperature } \\
\hline $\begin{array}{l}\text { Initial temperature } \\
\qquad\left({ }^{\circ} \mathrm{C}\right)\end{array}$ & \begin{tabular}{lr}
$-6.26-+11.21$ \\
$0.796 \quad 3.762$ \\
variable & $\mathbf{2 . 3}$ \\
\multicolumn{2}{c}{0.678}
\end{tabular} & $\begin{array}{c}-12.40-+17.19 \\
-0.402 \quad 3.045 \\
0.535\end{array}$ & $\begin{array}{l}\text { scatter plot: Fig. } 5.12 \\
\text { realizations not expected to } \\
\text { equal Tcode sample }- \\
\text { K-S: < critical } 0.01 \text { (> crit } \\
0.05 \text { ) }\end{array}$ & $\begin{array}{l}\mathrm{F}:<<\text { critical } 0.05 \\
\text { t: }<<\text { critical } 0.10\end{array}$ & $\begin{array}{l}\text { parameters from Tcode } \\
\text { sample ( } 133 \text { events) } \\
\text { mean is } f \text { [ date ] }\end{array}$ \\
\hline $\begin{array}{l}\text { Temperature range } \\
\left({ }^{\circ} \mathrm{C}\right)\end{array}$ & $\begin{array}{cl}\mathbf{1}-21.11 \\
7.335 & 3.55 \\
\mathbf{7 . 7 5} & \mathbf{3 . 6} \\
1.431 & \end{array}$ & $\begin{array}{c}1.00-19.92 \\
7.695 \quad 3.550 \\
0.155\end{array}$ & $\begin{array}{l}\text { realizations not expected to } \\
\text { equal Tcode sample }- \\
\mathrm{K}-\mathrm{S}: \approx \text { critical } 0.01 \text { ( }>\text { crit } \\
0.05 \text { ) }\end{array}$ & $\begin{array}{l}\mathrm{F}:<<\text { critical } 0.05 \\
\text { t: }<<\text { critical } 0.10\end{array}$ & $\begin{array}{l}\text { controlling params slightly } \\
\text { higher to reflect sample } \\
\text { events }>\mathrm{PD}_{\min }\end{array}$ \\
\hline
\end{tabular}




\begin{tabular}{|c|c|c|c|c|c|}
\hline $\begin{array}{l}\text { Hourly temperature } \\
\text { Tcodes }\end{array}$ & $\begin{array}{c}-15.56-+15.00 \\
\mathbf{0}-\mathbf{1 0 0 / 2 0 0} \\
50.0 \quad 29.30 \\
0.000 \\
\mathbf{0 . 0 1}-\mathbf{0 . 9 9} \\
\mathbf{0 . 8 6} \mathbf{0 . 1 6} \\
-1.502\end{array}$ & $\begin{array}{c}0-167 \\
50.28 \quad 26.79 \\
0.945 \\
0.32-0.99 \\
0.840 \quad 0.133 \\
-0.713\end{array}$ & $\begin{array}{l}\text { for all Tcodes } 0-100 \\
\text { K-S: < critical } 0.05 \\
\\
\text { FDRs of Tcode sample } \\
\text { strongly left-skewed - } \\
\text { normal distribution of } \\
\text { realizations fails K-S test }\end{array}$ & $\begin{array}{l}\text { F: }<<\text { critical } 0.05 \\
\text { t: }<<\text { critical } 0.10 \\
\text { F: }<\text { critical } 0.05 \\
\text { t: }<\text { critical } 0.025 \quad \approx \text { crit } \\
0.05)\end{array}$ & $\begin{array}{l}\text { model allows Tcodes to } \\
200 \text {, sampled as biv- } \\
\text { normal with duration, from } \\
100 \text { events; } \\
\text { tested hourly T from a few } \\
\text { individual event } \\
\text { realizations }\end{array}$ \\
\hline \multicolumn{6}{|l|}{ Wind } \\
\hline $\begin{array}{l}\text { Central wind speed } \\
\qquad(\mathrm{m} / \mathrm{s})\end{array}$ & $\begin{array}{c}\mathbf{2}-9.52 \\
\mathbf{5 . 1 5} \mathbf{1 . 6} \\
0.372\end{array}$ & $\begin{array}{c}2.00-10.40 \\
5.174 \quad 1.5515 \\
0.102 \\
\end{array}$ & K-S: $<<$ critical 0.05 & $\begin{array}{l}\text { F: }<<\text { critical } 0.05 \\
\text { t: }<<\text { critical } 0.10\end{array}$ & $\begin{array}{l}\min \text { of } \mathrm{W}_{\mathrm{c}} 1.7 \mathrm{~m} / \mathrm{s} ; \\
\sim 2.4 \% \text { of realizations } \leq 2 \\
\mathrm{~m} / \mathrm{s}\end{array}$ \\
\hline $\begin{array}{l}\text { Wind speed std dev } \\
\qquad(\mathrm{m} / \mathrm{s})\end{array}$ & $\begin{array}{c}\mathbf{1}-4.38 \\
\mathbf{2 . 6} \quad \mathbf{0 . 8} \\
0.211 \\
\end{array}$ & $\begin{array}{c}1.00-5.59 \\
2.595 \quad 0.785 \\
0.180 \\
\end{array}$ & K-S: $<<$ critical 0.05 & $\begin{array}{l}\text { F: }<<\text { critical } 0.05 \\
\text { t: }<<\text { critical } 0.10\end{array}$ & $\begin{array}{l}\text { data event range } 2.06- \\
18.52 ; \sim 2.3 \% \text { of } \\
\text { realizations } \leq 1 \mathrm{~m} / \mathrm{s}\end{array}$ \\
\hline $\begin{array}{l}\text { Hourly wind speed } \\
\qquad(\mathrm{m} / \mathrm{s})\end{array}$ & $\begin{array}{c}\mathbf{0 - 3 0} \\
0-20.06\end{array}$ & & & & $\begin{array}{l}\text { event } 3230: \text { range } 0.04- \\
10.71 ; \text { avg } 4.64 \text { (nom } \\
4.61 \text { ), std dev } 2.22 \text { (nom } \\
2.275 \text { ), skew } 0.453\end{array}$ \\
\hline \multicolumn{6}{|c|}{ Notes } \\
\hline \multicolumn{6}{|c|}{$\begin{array}{l}\text { Statistics columns: nominal are the parameters from data series and/or governing the model's probabilistic selections; realizations are outputs from the } \\
\text { model run. (See appendix E for detail on properties and parameters; appendix I for StpP EXP realizations.) All parameters and results are for partial- } \\
\text { duration (PD) series of long continuous storms (LCS). } \\
\text { Statistics include relevant ranges, means, standard deviations, skews. Nominal limits and statistics that control program calculations in bold; data (from } \\
\text { Stampede Pass) and realizations in plain font. } \\
\text { Significant figures: The variety of decimal places/SFs shown reflect differences among categories. Nominal values indicated as they appear in model } \\
\text { inputs: most limits as integers; most means, deviations, and logarithms thereof as rational numbers. In nominal column, values of statistics from } \\
\text { observations (plain font) reflect apparent precision due to transformation from English to metric units (e.g., } 0.01-1 \text { in } \rightarrow 0.0254-2.54 \mathrm{~cm} ; 1 \mathrm{~F}^{\circ} \rightarrow 0.55 \ldots \\
\mathrm{C}^{\circ} ; 1 \mathrm{mi} / \mathrm{h} \rightarrow 0.45 \mathrm{~m} / \mathrm{s} \text { ), and reduction to statistics. For realizations, "precision" depends on Excel dimensions (DIM = integer, single, double) rather than } \\
\text { measurement (data) accuracy or precision; figures shown here are intended to enable comparison, not to suggest spurious exactitude. (Final SF: within } \\
\text { nn } 4 \text { to nn6 reported as nn5) } \\
\text { Statistical tests: Minimal levels of significance (critical } \alpha \text { ) are } 0.05 \text { for Kolmogorov-Smirnov and Student's t, and } 0.10 \text { for F, unless indicated; } t \text { and F } \\
\text { tests strictly pertain to normal distributions, although they can be applied to transformed log-normal and exponential distributions having large samples. } \\
\text { Effects of initial snow-density limits and defaults on statistics discussed in sections } 3.3 \mathrm{~B}-\mathrm{C} \text { and } 5.2 \mathrm{~A} \text {. }\end{array}$} \\
\hline
\end{tabular}


The modeled intraseasonal distribution of events is imperfect, despite the statistical concurrence of event starting-date realizations with the controlling data (Tables 3.1, 4.1). Storm dates are chosen from a normal distribution empirically centered on WY day 92 (31 Dec), producing events dominantly in November through February. However, the model chooses the dates randomly from this distribution and does not account for the sequencing of storms within a given year, thus permitting the unreality of model events overlapping by hours or even days. In this Stampede Pass EXP run, $\sim 8 \%$ of events coincide in this way. Similarly, there is no accounting for snowpack changes occurring during one event that might affect pack volume at the beginning of another following soon after. These model simplifications have little effect on the aggregate frequency relations. However, they complicate possible use of this model to generate intraseasonal storm series, unless the program is altered to ensure temporal consistency through each year. (One possibility is to recalculate intersecting events as longer continuous storms: summing precipitation amounts in the common hours might be simple, but it would be challenging to combine the two events' temperatures, wind speeds, and snow amounts, all determined by separate random numbers in the current model.)

Some variables are not based on site or regional data distributions that are amenable to statistical comparison. Among these are the snow hydraulic characteristics: recall (sections 3.3C, 5.2A) that the initial snow density of an event is restricted to $0.1-0.8$ (ratio of SWE to depth), and depth may be adjusted to maintain this range. Low initial density (0.1) generates high effective porosity (0.867) and hydraulic conductivity (69524 $\mathrm{cm} / \mathrm{h})$; high density $(0.8)$ produces low values of both $(0.124$ and $296 \mathrm{~cm} / \mathrm{h})$. The mean, variance and skewness of these parameters (Table 5.1) are all affected by such limits. In 
the StpP EXP application, the maximum and minimum were each called in fewer than $1 \%$ of events, so they had little effect; the no-snow default density ( 0.35$)$ was used in $\sim 14 \%$ of events, influencing the average of 0.330 . However, these proportions are small (and generally less than those produced in the $1065 \mathrm{~m}$ EXE run or across elevation zones; section 5.4, chapter 6). Although we lack a measured sample for comparison, these realizations seem to indicate that the functions for choosing initial snow depth and SWE do not introduce any serious distortions.

Total storm precipitation, the chief driving variable of the model, is reproduced very well by the EXP simulation (Fig. 5.9; also Fig. 4.8). Statistical tests (Table 5.1) show that the model realizations can be considered belonging to the same population as the partial-duration record of long continuous storms as measured at Stampede Pass.

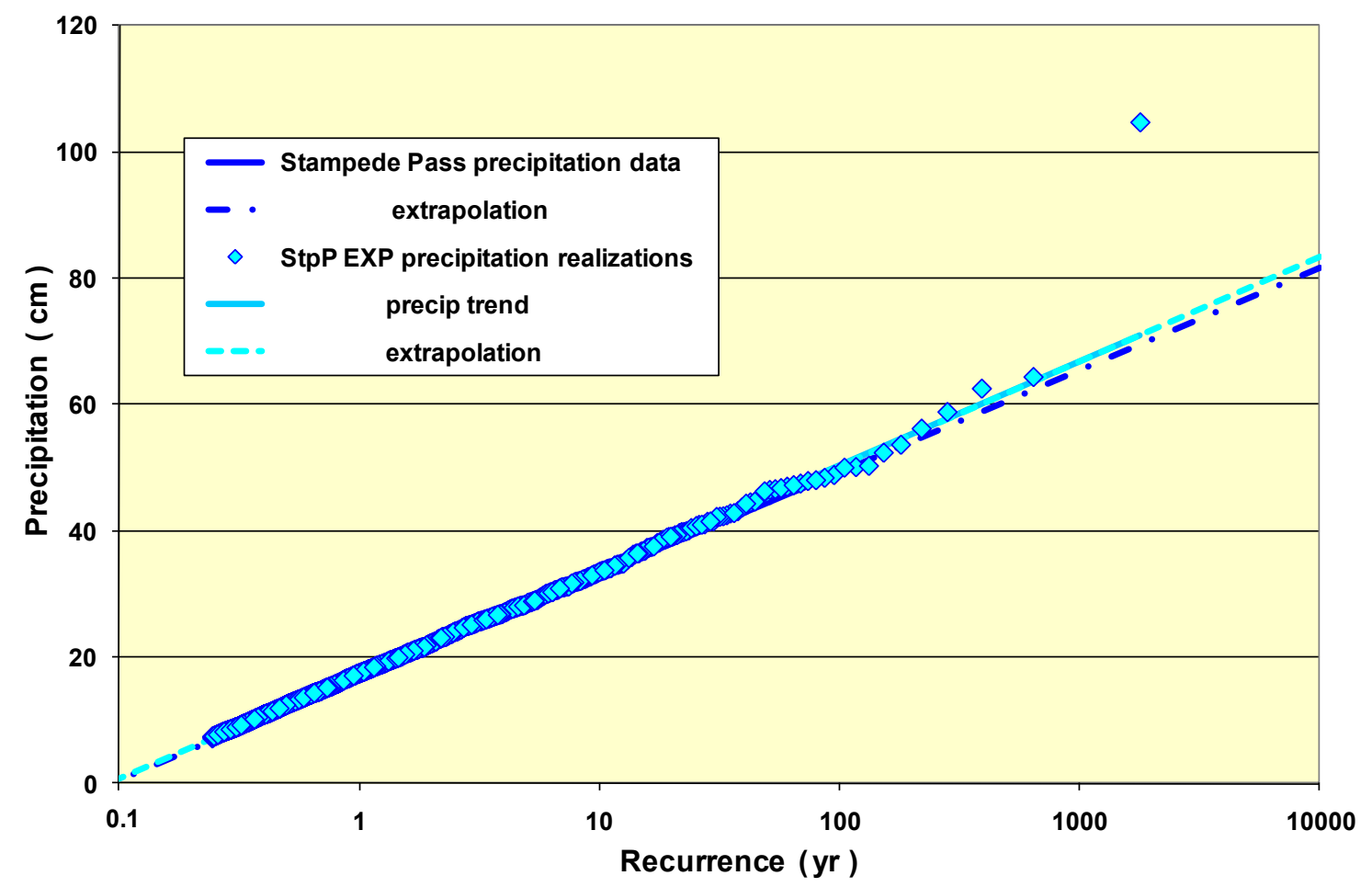

Figure 5.9. Realizations of total precipitation ( ) for StpP EXP (4101 events over 1000 WY). Model trend is very close to the frequency distribution of 225 storms measured at Stampede Pass (partial duration series; see Fig.4.8). The outlier has little effect on the trend. 
Radical outliers can appear among the model realizations. Once in each run (here at event \#3 of WY 188), the minimum possible random number (0.000001) is chosen for event precipitation, yielding a very small exceedance probability and thus a very large amount, here $\sim 105 \mathrm{~cm}$ in a 9-d late-June model storm. (Increasing the probability tenfold to 0.00001 would reduce the simulated precipitation to $\sim 88 \mathrm{~cm}$, but that would still be a major outlier in the output series.) One might distrust such a realization, as this amount is approximately double the maxima recorded in the region, at least in generally shorter storms: e.g., NWS data show $>42 \mathrm{~cm}$ in $>3.6 \mathrm{~d}$ at Snoqualmie Pass, Nov-Dec 1975; 46 $\mathrm{cm}$ in $1.5 \mathrm{~d}$ at Mt Rainier, Nov 2006; $57 \mathrm{~cm}$ in $10.4 \mathrm{~d}$ at Stampede Pass, Dec 1956. We don't expect the kind of heavy, long-duration rain in the Northwest in the summer, as suggested by this model outcome, but a wintry pineapple express storm in early June 2010 demonstrated the potential for such atmospheric patterns. It seems at least possible, once in 1000 years. Another interpretation is that the outlier simply represents an event with a "true" recurrence of $>100,000$ yr fortuitously occurring within the 1000-yr model run period. Note that this anomalous event occurs on snow-free ground, so no melt is generated, and the statistics comparing precipitation and WAR (especially \%ROS) are not seriously affected by this rarity.

The Monte Carlo model also yields reasonable realizations of other stochastic elements. Two of the more complex variables are illustrated: initial snowpack amount (Fig. 5.10, 5.11) and initial temperature (Fig. 5.12). Both are functions of the event's starting date, selected based on empirical storm arrivals, in this run ranging from WY day -75 to +279. (Note that the abscissa scales of Fig. 5.10 and 5.12 overlap in July: WY day $-90=$ 
$2 \mathrm{Jul}$, and WY day $300=27$ Jul.) The concentrations of points on both graphs reflect the preponderance of big storms in October to March, with fewer events in warmer months.

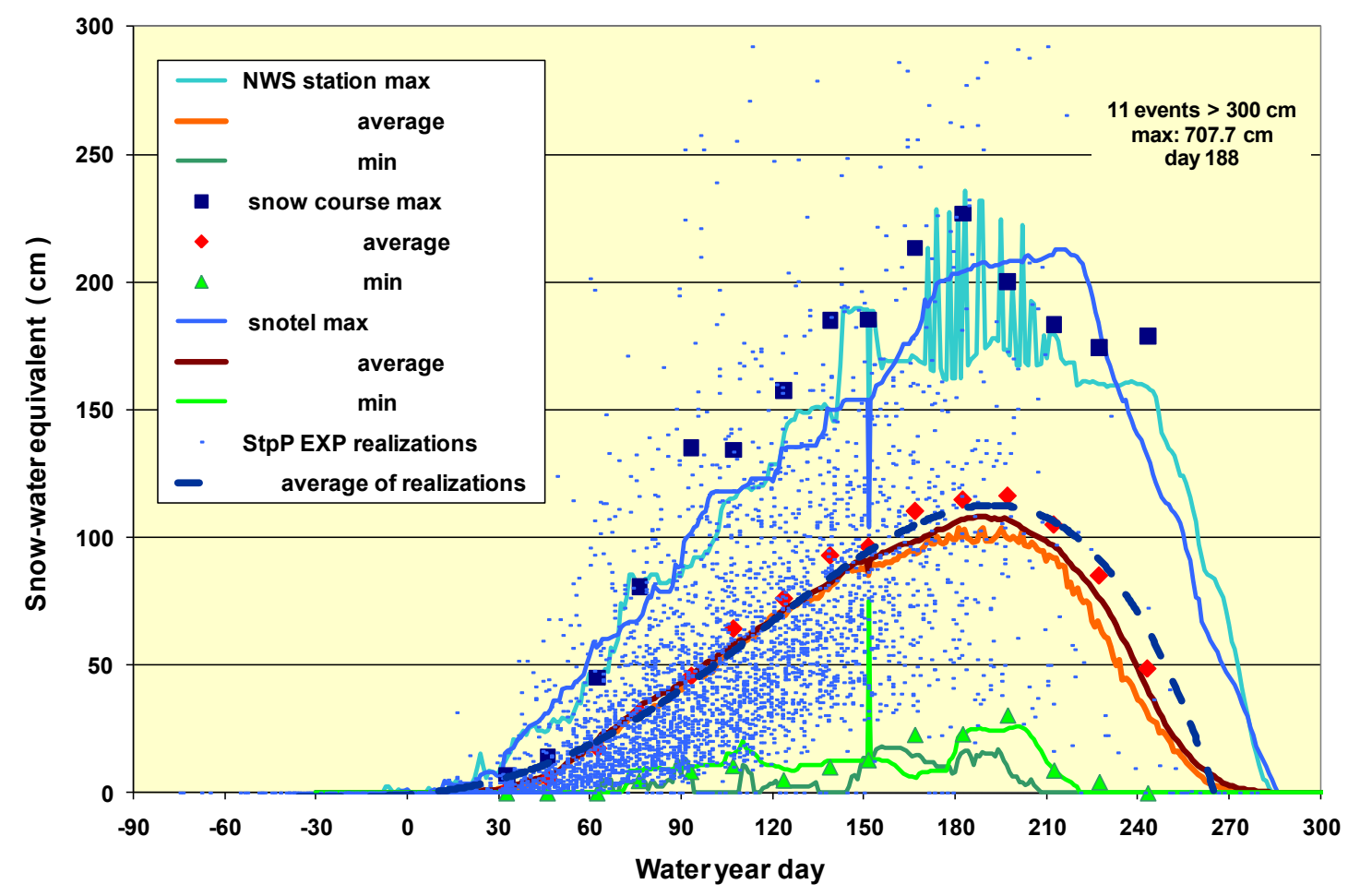

Figure 5.10. Realizations of initial snow volume, StpP EXP. Lines and large markers indicate maximum/mean/minimum SWE recorded at Stampede Pass weather station, snow course and SNOTEL; data from NWS and NRCS for available observation periods 1944-2005. (Jagged maximum SWE at NWS due to non-daily measurements in WY 1956, leaving data from WY 1974 as the greatest for other days; maximum at SNOTEL in WY 1997, while the NWS station was inactive; maxima for WY 1969 earlier in the season, WY 1964 later; most minima recorded in WY 1981.) Dashed curve averages EXP model realizations, based on regression ( $4^{\text {th }}$-order polynomial).

The distribution of event-initial SWE realizations can be compared with the recorded means and extremes from the three observation types at Stampede Pass, though only semi-quantitatively since each of the three data sets and the realization set contain different biases, particularly relating to date (e.g., course measurements can be sporadic, and skipped when snow is meager; the snow-pillow record is relatively short; model realizations are controlled by storm dates). The main band of model points (Fig. 5.10) falls just below the records' SWE averages; some points exceed the measured maxima; $\sim 20 \%$ 
of the EXP events began with no snow, mostly in the seasons before mid-January and after mid-May. This pattern is reasonable: recall that starting snowpack is modeled as lognormal, and so should be positively skewed and certainly able to go beyond the observed maxima. (Think of each date-specific slice of Fig. 5.10 as a log-normal curve with a mode at the dominant point cluster and skewed upward.)

It is difficult to statistically compare the record (three dissimilar data sets) against the realizations in whole, due to the latter's dependence on model storm dates. However, a $4^{\text {th }}$-order polynomial trend line (the same order as the governing function) calculated for the realizations lies very close to the mean trends of the three data sources (dashed line, Fig. 5.10). Examining one particular date: 26 model events beginning on WY day 93 (1 Jan, near the peak of storm occurrence) can be compared to NWS data from the same date ( $\mathrm{n}=41$ for SWE, 53 for snow depth). The $\mathrm{K}-\mathrm{S}$ and $\mathrm{t}$ tests indicate similarity for both snow depth and SWE, as does the F test for depth (Table 5.1). The F statistic for SWE is closer to the critical level, indicating greater variance in the realizations than in these limited data, suggesting a tendency to generate overly large snow amounts in the model. The model event-initial maxima were $\sim 700 \mathrm{~cm}$ SWE and $\sim 2300 \mathrm{~cm}$ depth; snow-water equivalents of $\sim 500 \mathrm{~cm}$ and depths of $\sim 1000 \mathrm{~cm}$ can be seen in the Cascades (Meier, 1990), so these are still within the proper orders of magnitude.

The credibility of stochastic snow values can also be assessed by plotting initial snow depths against corresponding SWE for each StpP EXP event (Fig. 5.11). Compared with snow-course observations at Stampede Pass, only $\sim 150$ ( 4\%) of realizations are greater than the measured maximum SWE of $227 \mathrm{~cm}$ and/or the maximum depth of 536 $\mathrm{cm}$; thus $\sim 96 \%$ of model results are below these extremes. (Recorded SWE maxima were 
$236 \mathrm{~cm}$ at the weather station and $213 \mathrm{~cm}$ at SNOTEL; depth maximum at NWS was 587 $\mathrm{cm}$.) The average snow density calculated from all these realizations $(0.33)$ is not much different from the trend defined by $\rho_{\mathrm{s}}$ calculated from bimonthly snow-course measurements, and is lower than the average density (0.39) of all measured Stampede Pass snowcourse densities.

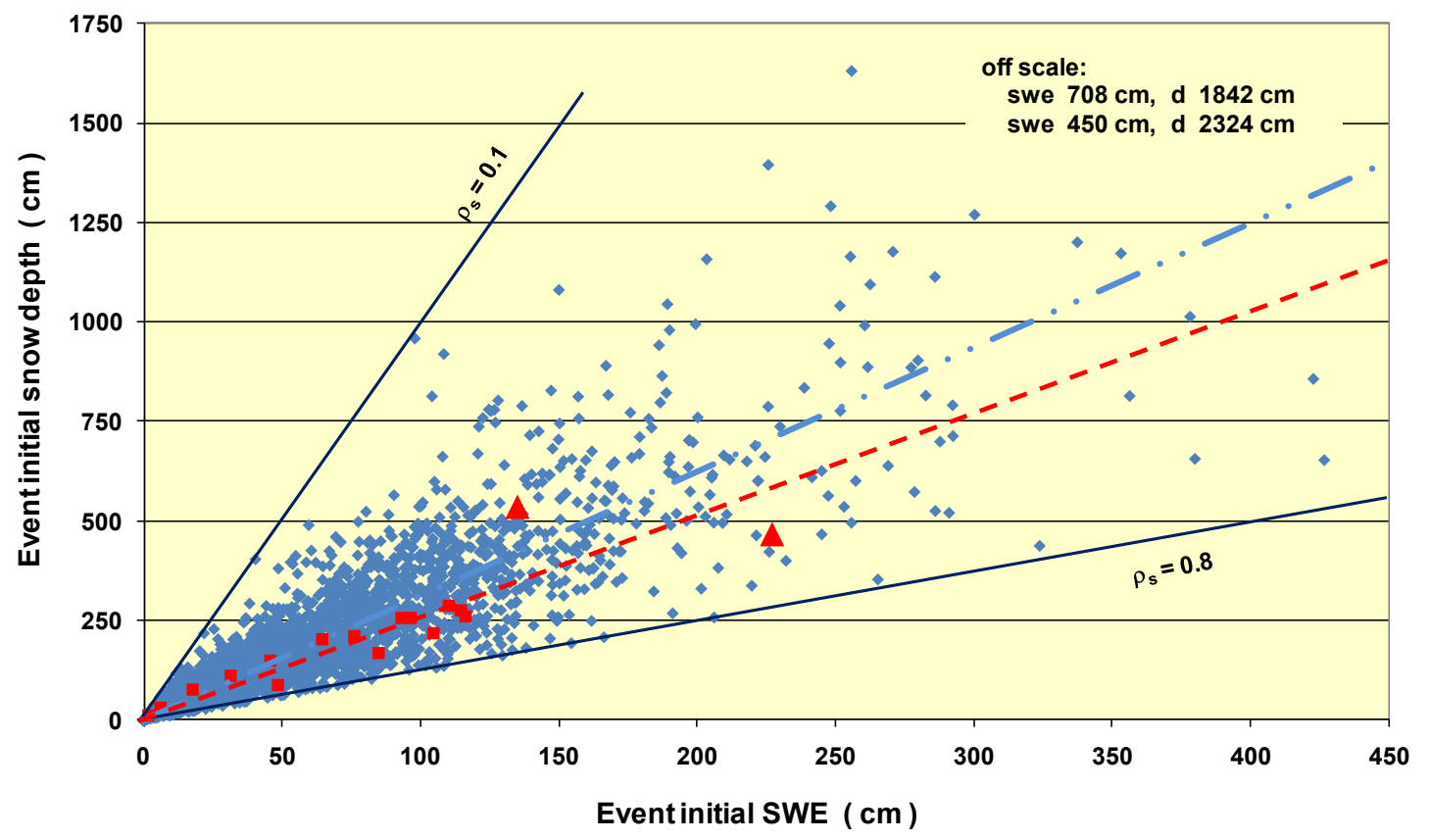

Figure 5.11. Realizations of initial snow-water equivalent vs snow depth ( $\diamond), \operatorname{Stp} P E X P$; realizations limited to $0.1 \leq \rho_{\mathrm{s}} \leq 0.8$; blue trend line $(---\ldots)$ corresponds to realization average $\rho_{\mathrm{s}}=0.33$. Stampede Pass snow course data: averages of 15 semimonthly SWE and depth ( $\square)$; maximum measured course depth and SWE ( $\boldsymbol{\Delta}$, separate days for each); red dashed line ( -- ) corresponds to semimonthly average $\rho_{\mathrm{s}}=0.39$.

These comparisons do not entirely rationalize the small number of strikingly high initial snow amounts, but are nevertheless encouraging. Given the small measurement samples for individual days, the large variances introduced by transforming log-normal into normal parameters, the positive results of the $\mathrm{K}-\mathrm{S}$ tests, the good correspondence between depth and SWE for individual events, and the conservative outcome of over-deep model snowpacks (delaying percolation), the initial-snow algorithms seem to be provid- 
ing acceptable results.

The model events' initial temperatures (starting points for simulation of each event's hourly temperatures) also demonstrate interesting patterns (Fig. 5.12). Comparing the band of mean temperatures for 125 storms at Stampede Pass with the station's 30-yr mean daily highs and lows supports a common observation (e.g., Mass, 2008): air temperatures during big storms in the PNW tend to be near or warmer than the seasonal average high temperatures from late autumn to early spring; but likely to be near or cooler than mean lows when storms occur in the warmer months. The cloud of model realizations replicate this subdued seasonal dip into winter and back up in spring, matching the data used to create the sampled distributions, and the corresponding $3^{\text {rd }}$-order polynomial regression trends of the realizations and the record-based governing function are almost indistinguishable. These all indicate that normally cooler storm temperatures reach nadir later in winter (ca $1 \mathrm{Mar}$ ) than the average daily temperatures (minimum ca $1 \mathrm{Jan}$ ): the storms are warmer than daily average early in the season, but cooler toward the end of winter.

Lastly regarding temperature parameters, we do not expect the sample and realizations of frontal-diurnal ratios and Tcodes to be statistically identical, but tests on the whole series do show close similarity (Table 5.1). 


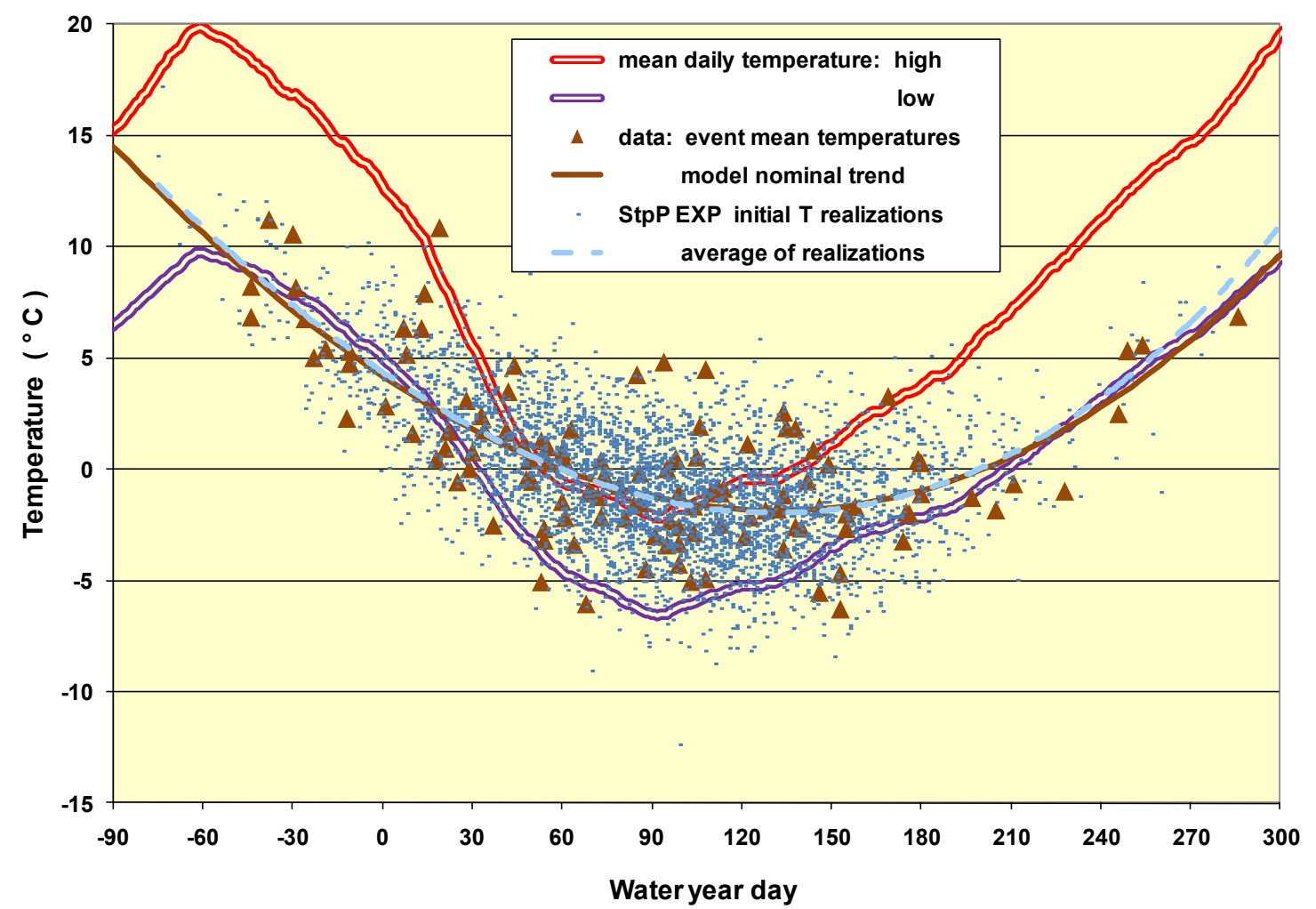

Figure 5.12. Realizations of event initial temperatures, $\operatorname{Stp} P \operatorname{EXP}(\varpi)$. Solid brown line indicates $3^{\text {rd }}$-order polynomial trend of the governing distribution, based on average of hourly temperatures over LCS event duration of 125 storms ( $\boldsymbol{\Delta}$ ) in 1970-2004 (Stampede Pass NWS data), plotted against starting date; dashed blue line indicates trend of model realizations. Double-lines show daily mean high and low temperatures at Stampede Pass for 1971-2000 (from NWS data and WRCC compilations; sections 4.2, 4.4).

Whether or not rain-on-snow is significant in a particular event can be revealed by the relationship between its total precipitation and the percolation of water to the ground (shown for the example event in Fig. 5.8). In 79\% of the realizations in this StpP EXP experiment, the amount of water transiting the pack is less than total precipitation, because modeled cold temperatures and/or deep snow retard the generation and movement of liquid; in $11 \%$, no water reaches bottom. In $7.3 \%$ of the events water available for runoff equals precipitation, usually indicating bare ground at both beginning and end. For this run, $14 \%$ of events produce WAR in excess of the precipitation. These are the "storms" in which meltwater enhances WAR, the significant rain-on-snow events. Most show just slight increases over rainfall (small distance above the 1:1 line): in these model events, 
the increments range from $0.007-20.1 \mathrm{~cm}$, averaging $3.09 \mathrm{~cm}$; proportional increases range $0.03-108 \%$, averaging $25.1 \%$. However, the upper ends of these ranges represent significant ROS augmentation.

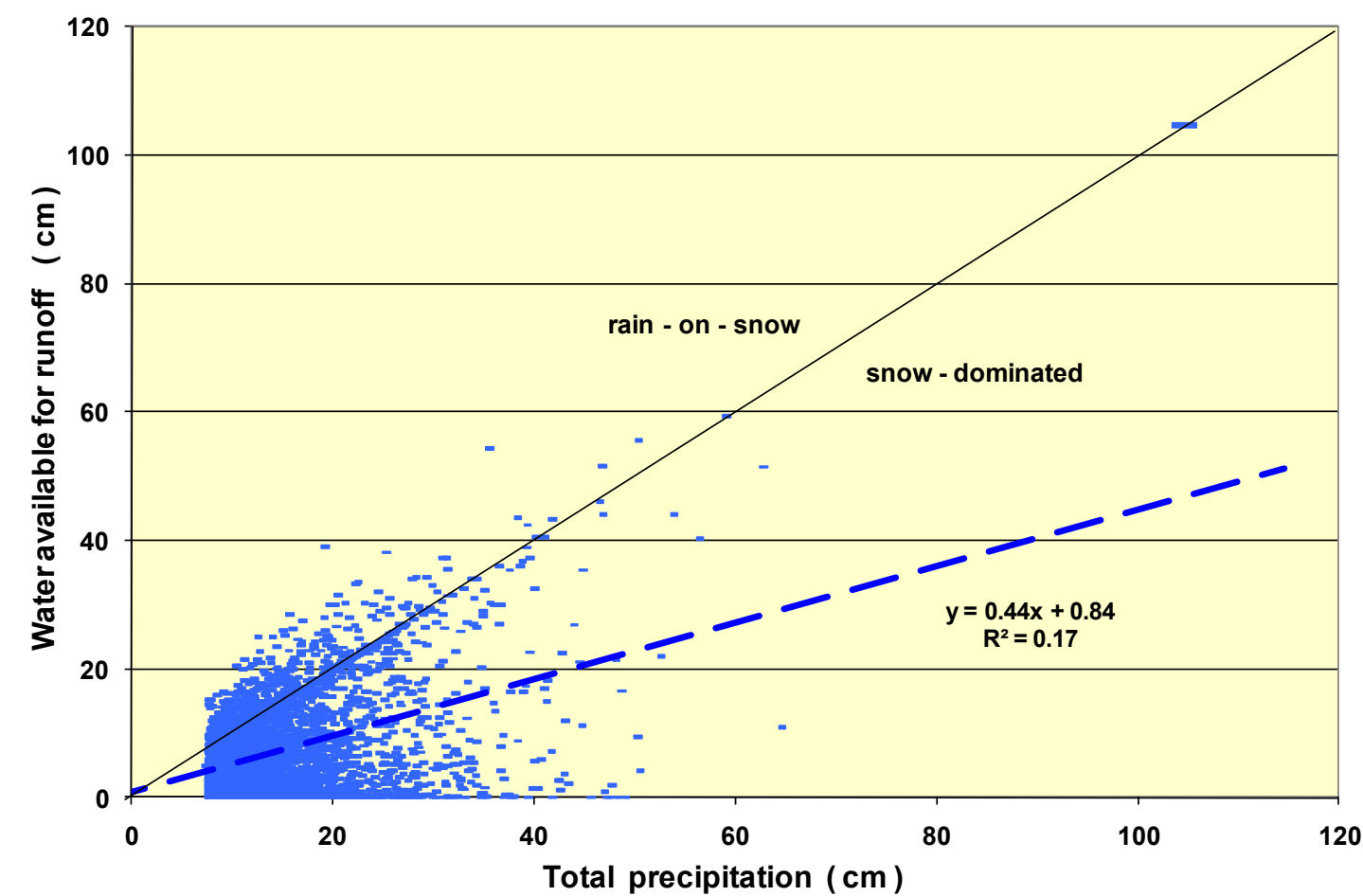

Figure 5.13. Water available for runoff compared to total precipitation, StpP EXP. Model event precipitation minimum $7.26 \mathrm{~cm}$, maximum $\sim 105 \mathrm{~cm} ; 1: 1$ line indicates that water available for runoff equals precipitation. Snowfall and snowpack dominate events below the line (WAR $<$ P); rain-on-snow enhancement above the line (WAR $>$ P). Equation of the trend line $(--)$ ) suggests that modeled WAR roughly averages $\sim 44 \%$ of precipitation (but regression $r^{2}$ is 0.17 ).

The frequency-magnitude graph for this simulation shows the trend line for model realizations of total precipitation to be very close to that of the empirical distribution from Stampede Pass (Fig. 5.14). Likewise, the rain plus meltwater and WAR trends are nearly congruent, indicating that all or most of the liquid input generated in model events usually gets to the ground within the specified duration. This is fully expected for cases with little or no snow; but with deeper packs, it might suggest that modeled percolation rates are too fast.

The dominance of events in which $\mathrm{WAR}<\mathrm{P}$ (Fig. 5.13) indicates that these two 130 
series are not the same, and Student's t statistics reveal large contrasts between precipitation and WAR (though F tests show the variances are similar; Table 5.1). Water available for runoff is typically less than precipitation at Stampede Pass (Fig. 5.14): at all recurrence periods, the magnitude of water input $(\mathrm{R}+\mathrm{M})$ and output $(\mathrm{WAR})$ are less than total (solid plus liquid) precipitation; alternately, any given amount of WAR is less probable than the same P. If the model is valid, this indicates that at Stampede Pass cooler temperatures, more snowfall and deeper snowpacks hinder the delivery of water during a significant proportion of storms, a finding pertinent to some of the research questions and hypotheses (chapter 2) that will be revisited at the end of this chapter.

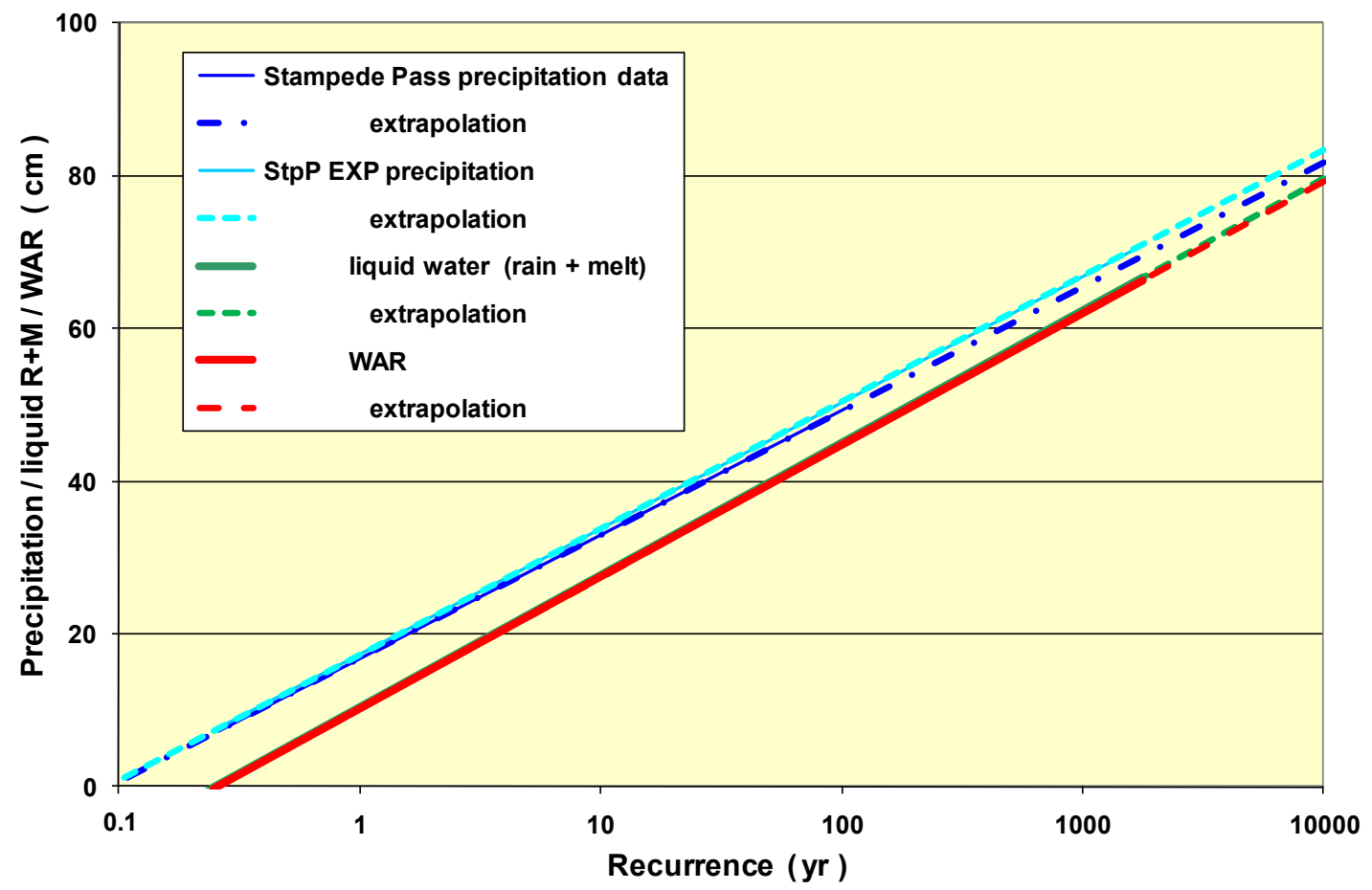

Figure 5.14. Regression lines for realizations of water inputs and outputs, StpP EXP. Trends for rain + melt and water to the ground (WAR) are almost collinear: series parameters not identical but statistically similar.

\subsection{Monte Carlo simulation for Stampede Pass elevation (1065 EXE)}

Most of my Monte Carlo experiments are performed running option EXE, still utilizing exponential frequency distributions for the hydrologic variables (precipitation, 
rain plus melt, water available for runoff) but incorporating parameters calculated from all 36 weather and snow observation stations. Before exploring the broad range of midCascade elevations (chapter 6), I now try the generalized program for a location approximating Stampede Pass, represented by that site's effective elevation of $1065 \mathrm{~m}$, to test EXE against measurements and the EXP model results.

The 1065 EXE results are similar to those of StpP EXP. The correspondence between the governing (nominal) parameters and the realizations (Table 5.2) indicates operations as good as EXP, particularly in replicating the quantities produced by simpler functions (some of which are the same in both versions). But though this EXE run assumes the effective elevation of Stampede Pass, the statistics for many quantities are not identical to those of the station data, or to the EXP results. They are not expected to be, due to generalization of parameters among multiple weather and snow observation sites. To begin with, in calculating the number of events per year, the regionalized average and deviation are slightly greater than the Stampede Pass values (4.40 \pm 2.37 instead of 4.00 \pm 2.20 ), so EXE generates 4487 storms in $1000 \mathrm{yr}$, versus 4101 in StpP EXP. This larger sample explains some differences between series in the two kinds of runs, despite drawing from the same random numbers. For example, the functions for wind speed would produce identical statistics if not for the EXE series containing 386 more events. In addition, slight dissimilarities in the nominal parameters for storm date introduce variations in the order and/or magnitude of some series, such as initial temperature and range. Differences in the governing parameters for precipitation and snow volume, all functions of elevation in EXE, affect other event properties such as duration (in turn influencing hourly precipitation and temperatures) and snow-hydraulic characteristics. 


\begin{tabular}{|c|c|c|c|c|c|}
\hline Parameter & Nominal & $\begin{array}{l}\text { tics } \\
\text { Realizations }\end{array}$ & $\begin{array}{c}\text { Comparisons with } \\
\text { Nominal Parameters }\end{array}$ & $\begin{array}{l}\text { Comparisons with } \\
\text { Stampede Pass }\end{array}$ & Notes \\
\hline \multicolumn{6}{|l|}{ Storm timing } \\
\hline $\begin{array}{r}\text { Number: events / year } \\
\text { ( \#) }\end{array}$ & $\begin{array}{c}1-12 \\
4.40 \quad 2.37 \\
0.490\end{array}$ & $\begin{array}{c}1-14 \\
4.487 \quad 2.220 \\
0.342\end{array}$ & $\begin{array}{l}\mathrm{F}:<<\text { critical } 0.05 \\
\mathrm{t}:<<\text { critical } 0.10\end{array}$ & $\begin{array}{l}\mathrm{F}:<<\text { critical } 0.05 \\
\mathrm{t}:>\text { critical } 0.01\end{array}$ & $\begin{array}{l}\text { modes: data }=4, \\
\text { realizations }=5 \\
\text { generalized EXE } \rightarrow \text { more } \\
\text { events / yr than StpP EXP }\end{array}$ \\
\hline $\begin{array}{l}\text { Event starting date } \\
\text { ( WY date ) }\end{array}$ & $\begin{array}{c}-\mathbf{7 5}-+\mathbf{3 1 0} \\
\mathbf{9 2} \mathbf{6 4} \\
0.019\end{array}$ & $\begin{array}{c}-75-+310 \\
92.082 \quad 62.647 \\
0.058\end{array}$ & $\begin{array}{l}\text { F: }<<\text { critical } 0.05 \\
\text { t: }<<\text { critical } 0.10\end{array}$ & $\begin{array}{l}\text { F: } \sim \text { critical } 0.05 \\
\text { t: }<<\text { critical } 0.10\end{array}$ & $\begin{array}{l}\text { nominal mean for EXP and } \\
\text { EXE almost identical }\end{array}$ \\
\hline $\begin{array}{l}\text { Starting time } \\
\text { ( } h \text { of day) }\end{array}$ & $\begin{array}{c}\mathbf{1 - 2 4} \\
12.50 \quad 6.951 \\
0.000\end{array}$ & \begin{tabular}{c}
\multicolumn{2}{c}{$1-24$} \\
$12.537 \quad 6.893$ \\
-0.001
\end{tabular} & $\begin{array}{l}\text { F: }<<\text { critical } 0.05 \\
\text { t: }<<\text { critical } 0.10\end{array}$ & $\begin{array}{l}\text { F: }<<\text { critical } 0.05 \\
\text { t: }<<\text { critical } 0.10\end{array}$ & $\begin{array}{l}\text { EXE realizations also near- } \\
\text { identical to StpP EXP }\end{array}$ \\
\hline $\begin{array}{l}\text { Event duration } \\
\qquad \begin{array}{r}(\ln \text { of } \mathrm{h}) \\
(\mathrm{h})\end{array}\end{array}$ & $\begin{array}{c}\mathbf{1 2 - \mathbf { 2 2 8 }} \\
\text { variable } \\
81.83 \quad 38.41 \\
1.774\end{array}$ & $\begin{array}{c}11-252 \\
-\overline{462}-\overline{30.691} \\
1.307\end{array}$ & n.a. & $\begin{array}{l}\text { F: } \sim \text { critical } 0.025 \\
\text { t: }>\text { critical }\end{array}$ & $\begin{array}{l}\text { bivariate log-N distribution, } \\
\text { as } \mathrm{f}[\text { precip ] - hours used } \\
\text { for tests } \\
\text { generalized EXE } \rightarrow \text { shorter } \\
\text { events than StpP record \& } \\
\text { EXP }\end{array}$ \\
\hline \multicolumn{6}{|l|}{ Precipitation } \\
\hline 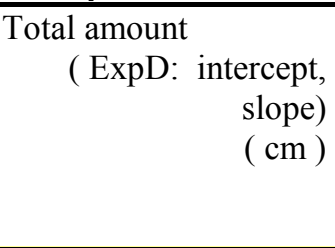 & \begin{tabular}{cc}
\multicolumn{2}{c}{$1-125$} \\
7.9989 & $\mathbf{6 . 5 1 3 6}$ \\
14.283 & 7.113 \\
2.849 &
\end{tabular} & \begin{tabular}{cc}
\multicolumn{2}{c}{$7.901-97.987$} \\
7.923 & 6.647 \\
14.565 & 6.665 \\
\multicolumn{2}{c}{2.308}
\end{tabular} & $\begin{array}{l}\text { close correspondence to } \\
\text { exponential line (Fig. 5.15) - } \\
98 \mathrm{~cm} \text { outlier }\left(2^{\text {nd }} \text { largest }\right. \\
\text { realization } 71.1 \mathrm{~cm})\end{array}$ & $\begin{array}{l}\text { F: }<<\text { critical } 0.05 \\
\text { t: }<<\text { critical } 0.10\end{array}$ & $\begin{array}{l}\text { controlling params (intcpt } \\
\text { ExDp, slope ExDa) = } \\
\text { f [ } 1065 \text { m elev ]; } \\
\text { precip amounts used for } \\
\text { tests; EXE output } \approx \text { EXP F } \\
\text { and t stats at } \sim 0.05\end{array}$ \\
\hline $\begin{array}{l}\text { Hourly distribution } \\
\text { SIMcodes }\end{array}$ & $\begin{array}{c}1-\mathbf{1 0 0 0} \\
500.5 \quad 288.82 \\
0.000\end{array}$ & $\begin{array}{c}1-1000 \\
496.60 \quad 291.58 \\
0.024\end{array}$ & $\begin{array}{l}\text { F: }<<\text { critical } 0.05 \\
\text { t: }<<\text { critical } 0.10\end{array}$ & $\begin{array}{l}\text { F: }<<\text { critical } 0.05 \\
\text { t: }<<\text { critical } 0.10\end{array}$ & $\begin{array}{l}\text { same order of SIMcodes } \\
\text { for all runs, but \# events } \\
\text { EXE }>\# \text { StpP EXP } \rightarrow \\
\text { EXE output } \approx \text { EXP F and } t \\
\text { stats at } \sim 0.05\end{array}$ \\
\hline
\end{tabular}




\begin{tabular}{|c|c|c|c|c|c|}
\hline \multicolumn{6}{|l|}{ Snow } \\
\hline $\begin{array}{ll}\text { Initial SWE } & (\mathrm{cm})\end{array}$ & $\begin{array}{l}\mathbf{0}-235.7 \\
\text { variable }\end{array}$ & $\begin{array}{c}0-1003.6 \\
28.76 \quad 42.97 \\
5.120\end{array}$ & $\begin{array}{l}\text { scatter plot: Fig. } 5.16 \\
\text { n.a. - variable by date }\end{array}$ & $\begin{array}{l}\text { day 93: } \\
\text { F: << critical } 0.05 \\
\text { t: < critical } 0.025 \\
\text { (EXE vs EXP: F, } \mathrm{t}<\text { crit } \\
0.05 \text { ) }\end{array}$ & $\begin{array}{l}\text { no snow in } \sim 32.5 \% \text { of } \\
\text { events; for all realizations: } \\
\text { EXE } \neq \text { StpP EXP - } \\
\text { generally lower, except } \\
\text { max and skew }(\text { more }+ \text { ) }\end{array}$ \\
\hline $\begin{array}{l}\text { Initial depth } \quad(\mathrm{cm}) \\
\end{array}$ & $\begin{array}{l}\mathbf{0}-591.8 \\
\text { variable }\end{array}$ & $\begin{array}{c}0-1254.5 \\
51.08 \quad 71.46 \\
3.745\end{array}$ & n.a. - variable by date & $\begin{array}{l}\text { day 93: } \\
\text { F: >> critical } \\
\text { t: > critical } \\
\text { (EXE vs EXP: } F, t>\text { crit) }\end{array}$ & $\begin{array}{l}\text { for all realizations: EXE } \neq \\
\text { StpP EXP - generally } \\
\text { much lower, except skew } \\
(\text { more }+)\end{array}$ \\
\hline $\begin{array}{l}\text { Initial density } \\
\qquad(\sim \mathrm{cm} / \mathrm{cm})\end{array}$ & $0.1-0.8$ & $\begin{array}{c}0.1-0.8 \\
0.486 \quad 0.159 \\
0.566\end{array}$ & $\begin{array}{l}\text { model } \rightarrow \min =0.1 \text { in } \\
0.09 \% \text {, } \\
\text { no-snow default }=0.35 \text { in } \\
29 \% \text {, } \\
\max =0.8 \text { in } 6.6 \% \text { of events }\end{array}$ & & $\begin{array}{l}\text { no hypothetical or } \\
\text { empirical distributions } \\
\text { EXE } \neq \text { EXP }\end{array}$ \\
\hline $\begin{array}{l}\text { Porosity (effective) } \\
\qquad\left(\sim \mathrm{cm}^{3} / \mathrm{cm}^{3}\right)\end{array}$ & $0.1-0.95$ & $\begin{array}{cc}0.124-0.867 \\
0.457 & 0.169 \\
-0.586\end{array}$ & & & $\begin{array}{l}\text { porosity }=\mathrm{f}[\text { density }] \\
\text { permeability }=\mathrm{f}[\text { density, } \\
\text { snow grain diam }] \text { - no }\end{array}$ \\
\hline $\begin{array}{l}\text { Permeability } \rightarrow \\
\text { hydraulic conductivity } \\
\qquad(\mathrm{cm} / \mathrm{h})\end{array}$ & $10-150000$ & $\begin{array}{c}295.7-69524 \\
6072.25921 .7 \\
3.000\end{array}$ & & & $\begin{array}{l}\text { hypothetical or empirical } \\
\text { distributions } \\
\text { both: EXE } \neq \text { EXP }\end{array}$ \\
\hline \multicolumn{6}{|l|}{ Temperature } \\
\hline $\begin{array}{l}\text { Initial temperature } \\
\left({ }^{\circ} \mathrm{C}\right)\end{array}$ & \begin{tabular}{l}
$-6.26-+11.21$ \\
$0.796 \quad 3.762$ \\
variable $\quad \mathbf{2 . 3}$ \\
\multicolumn{2}{c}{0.678}
\end{tabular} & $\begin{array}{c}-12.45- \\
+17.32 \\
0.084 \quad 3.513 \\
0.812 \\
\end{array}$ & $\begin{array}{l}\text { EXE not expected to } \approx \text { full } \\
\text { Tcode sample }- \text { yet good: } \\
\text { F: }<<\text { critical } 0.05 \\
\text { t: }<<\text { critical } 0.10)\end{array}$ & $\begin{array}{l}\text { F: }<<\text { critical } 0.05 \\
\text { t: }<\text { critical } 0.01\end{array}$ & $\begin{array}{l}\text { parameters from Tcode } \\
\text { sample, same as StpP-EXP } \\
\text { - but mean }=\mathrm{f}[\text { date }] \rightarrow \\
\text { changes EXE, so EXE } \neq \\
\text { EXP }\end{array}$ \\
\hline $\begin{array}{l}\text { Temperature range } \\
\qquad\left({ }^{\circ} \mathrm{C}\right)\end{array}$ & \begin{tabular}{cc}
\multicolumn{2}{c}{$\mathbf{1}-21.11$} \\
7.335 & 3.55 \\
$\mathbf{7 . 7 5}$ & $\mathbf{3 . 6}$ \\
1.431 &
\end{tabular} & $\begin{array}{c}1.00-19.92 \\
7.692 \quad 3.541 \\
0.155\end{array}$ & $\begin{array}{l}\text { F: }<<\text { critical } 0.05 \\
\text { t: }<<\text { critical } 0.10\end{array}$ & $\begin{array}{l}\text { F: }<<\text { critical } 0.05 \\
\text { t: }<\text { critical } 0.10\end{array}$ & $\begin{array}{l}\text { controlling params same in } \\
\text { all runs }(\text { EXP \& EXE) } \rightarrow \\
\text { EXE }=\text { EXP }(F, t<< \\
\text { critical) }\end{array}$ \\
\hline $\begin{array}{l}\text { Hourly temperature } \\
\text { Tcodes }\end{array}$ & $\begin{array}{c}-15.56-+15.00 \\
\mathbf{0}-\mathbf{1 0 0} / \mathbf{2 0 0} \\
50.0 \quad 29.30 \\
0.000\end{array}$ & $\begin{array}{c}0-167 \\
50.28 \quad 26.79 \\
0.945\end{array}$ & $\begin{array}{l}\text { for all Tcodes } 0-100 \\
\text { F: } \sim \text { critical } 0.05 \\
\text { t: } \sim \text { critical } 0.025\end{array}$ & no comparable StpP data & $\begin{array}{l}\text { controlling params same in } \\
\text { all runs (EXP \& EXE) - } \\
\text { but } \\
\text { Tcodes }=\mathrm{f}[\text { Dur }] \rightarrow \text { EXE }\end{array}$ \\
\hline
\end{tabular}




\begin{tabular}{|c|c|c|c|c|c|}
\hline FDR & $\begin{array}{cc}\mathbf{0 . 0 1} & -\mathbf{0 . 9 9} \\
\mathbf{0 . 8 6} & \mathbf{0 . 1 6} \\
-1.502\end{array}$ & $\begin{array}{c}0.32-0.99 \\
0.840 \quad 0.133 \\
-0.715\end{array}$ & $\begin{array}{l}\text { F: } \sim \text { critical } 0.05 \\
\text { t: }<\text { critical } 0.025\end{array}$ & & $\begin{array}{l}\neq \text { EXP }(\text { EXE lower codes }) \\
\text { same params } \rightarrow \text { almost } \\
\text { identical: EXE }=\text { EXP }(F, t \\
<<\text { critical })\end{array}$ \\
\hline \multicolumn{6}{|l|}{ Wind } \\
\hline $\begin{array}{l}\text { Central wind speed } \\
\qquad(\mathrm{m} / \mathrm{s})\end{array}$ & $\begin{array}{c}2-9.52 \\
5.15 \quad 1.6 \\
0.372\end{array}$ & $\begin{array}{c}2.00-10.40 \\
5.174 \quad 1.548 \\
0.1055\end{array}$ & $\begin{array}{l}\text { F: }<<\text { critical } 0.05 \\
\text { t: }<<\text { critical } 0.10\end{array}$ & same & \multirow{2}{*}{$\begin{array}{l}\text { controlling params from } \\
125 \text { StpP events, same in } \\
\text { all runs (EXP \& EXE) } \rightarrow \\
\text { EXE }=\text { EXP }(F, t<< \\
\text { critical) }\end{array}$} \\
\hline $\begin{array}{l}\text { Wind speed std dev } \\
\qquad(\mathrm{m} / \mathrm{s})\end{array}$ & $\begin{array}{c}\mathbf{1}-4.38 \\
\mathbf{2 . 6} \quad \mathbf{0 . 8} \\
0.211 \\
\end{array}$ & $\begin{array}{c}1.00-5.59 \\
2.59650 .783 \\
0.182 \\
\end{array}$ & $\begin{array}{l}\text { F: }<<\text { critical } 0.05 \\
\text { t: }<<\text { critical } 0.10\end{array}$ & same & \\
\hline $\begin{array}{l}\text { Hourly wind speed } \\
\qquad(\mathrm{m} / \mathrm{s})\end{array}$ & $\begin{array}{c}\mathbf{0 - 3 0} \\
0-20.06\end{array}$ & & & & no tests \\
\hline \multicolumn{6}{|l|}{ Notes } \\
\hline \multicolumn{6}{|c|}{$\begin{array}{l}\text { Statistics columns: nominal are the parameters from data series and/or governing the model's probabilistic selections; realizations are outputs from the } \\
\text { model run. (See appendix E for detail on properties and parameters; appendix J for } 1065 \text { EXE realizations; Table } 5.1 \text { for EXP parameters and results.) } \\
\text { All parameters and results are for partial-duration (PD) series of long continuous storms (LCS). } \\
\text { Statistics include relevant ranges, means, standard deviations, skews. Nominal limits and statistics that control program calculations in bold; data (from } \\
\text { Stampede Pass) and realizations in plain font. } \\
\text { Significant figures: The variety of decimal places/SFs shown reflect differences among categories. Nominal values indicated as they appear in model } \\
\text { inputs: most limits as integers; most means, deviations, and logarithms thereof as rational numbers. In nominal column, values of statistics from } \\
\text { observations (plain font) reflect apparent precision due to transformation from English to metric units (e.g., } 0.01-1 \mathrm{in} \rightarrow 0.0254-2.54 \mathrm{~cm} ; 1 \mathrm{~F}^{\circ} \rightarrow 0.55 \ldots \\
\left.\mathrm{C}^{\circ} ; 1 \mathrm{mi} / \mathrm{h} \rightarrow 0.45 \mathrm{~m} / \mathrm{s}\right) \text {, and reduction to statistics. For realizations, "precision" depends on Excel dimensions (DIM = integer, single, double) rather } \\
\text { than measurement (data) accuracy or precision; figures shown here are intended to enable comparison, not to suggest spurious exactitude. (Final SF: } \\
\text { within nn } 4 \text { to nn6 reported as nn5) } \\
\text { Statistical tests: Minimal levels of significance (critical } \alpha \text { ) are } 0.05 \text { for Kolmogorov-Smirnov and Student's t, and } 0.10 \text { for F, unless indicated; t and F } \\
\text { tests strictly pertain to normal distributions, although they can be applied to transformed log-normal and exponential distributions having large samples. } \\
\text { Effects of initial snow-density limits and defaults on statistics discussed in sections 3.3B-C, 5.2A and } 5.3 \text {. }\end{array}$} \\
\hline
\end{tabular}


The model precipitation realizations in 1065 EXE closely replicate the Stampede Pass LCS record and the StpP EXP results (Fig. 4.8, 5.9), and all three series can be considered statistically similar (Table 5.2). Likewise, comparison of paired model-event points and the respective regression lines (Fig. 5.15) shows close proximity, though suggesting less precipitation in many of EXE's rarest storms, whereas in the high-frequency (short recurrence) events, amounts are slightly greater in EXE than in EXP. (The EXE frequency-magnitude gradient is slightly shallower, as dictated by the somewhat greater slope term of the governing exponential regression for StpP EXP [7.047] than for 1065 EXE [6.514].) But this is a small discrepancy: the largest storms modeled closely on Stampede Pass data are estimated to deliver at most a few centimeters more precipitation than those based on the regionally averaged trend for $1065 \mathrm{~m}$ effective elevation.

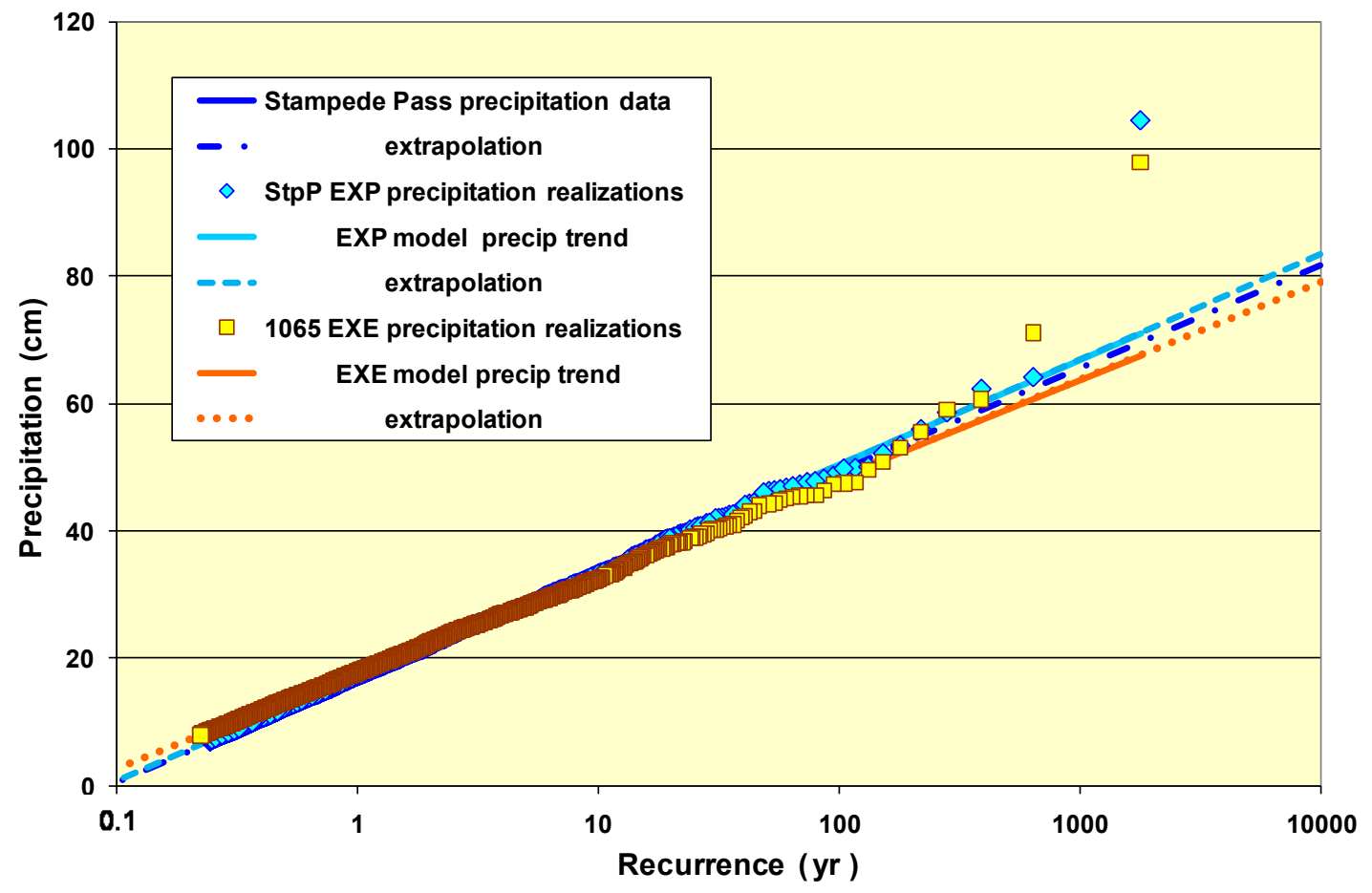

Figure 5.15. Realizations of total precipitation ( $\square$ ) for 1065 EXE (4487 events over $1000 \mathrm{WY}$ ); realizations ( ) from StpP EXP; and regression lines for model outputs, and of long continuous storms (partialduration series) measured at Stampede Pass (see Fig. 5.9). 


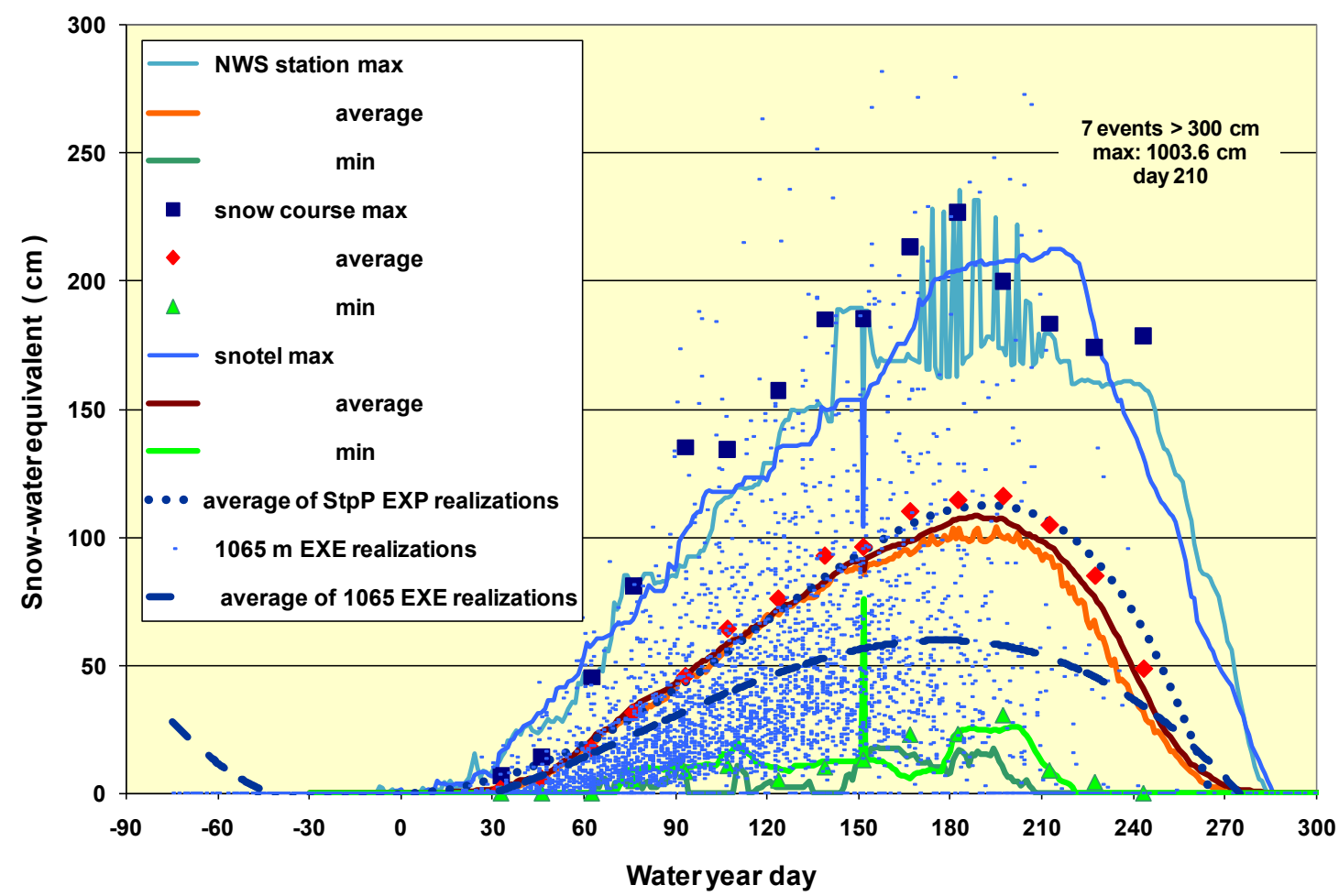

Figure 5.16. Realizations of initial snow water equivalent, 1065 EXE run. Lines and large markers indicate maximum/mean/minimum SWE recorded at Stampede Pass weather station, snow course and SNOTEL (described in Fig. 5.10); curves averaging EXP and EXE model realizations based on regression $\left(4^{\text {th }}\right.$-order polynomials; curve in summer/negative WY days an artifact of regression equations).

The distribution of initial snowpack water-equivalents for EXE (Fig. 5.16) is notably distinct from the EXP results, for good reason. As before (Fig. 5.10), model realizations fall generally below the data averages, forming positively skewed series for each date as dictated by the governing log-normal distribution. However, the modal band of points is visibly lower on this graph than for EXP, and the $4^{\text {th }}$-order polynomial regression curve for EXE realizations reflects collectively smaller initial SWE generated by the elevation-indexed parameters. (The aggregate average SWE of 1065 EXP is $\sim 62 \%$ of that in StpP EXP, and $\sim 34 \%$ for initial depth; Tables 5.1, 5.2.) Again examining WY day 93 (1 Jan), the SWE outputs from EXE are statistically similar to the Stampede Pass record and StpP EXP results. However, the EXE depth estimates are much lower than those 
from the EXP run or the record. It seems that the regionally generalized function used to calculate SWE comes close to the measured values for Stampede Pass, but that the majority of model-generated snow depths are well below station measurements, despite being coupled to SWE by bivariate-normal functions with high correlation. This is not a great flaw: it simply demonstrates that, among all the sites used to estimate the regional trends of stochastic initial snow quantities in EXE, for most of the season there is more snow on the ground at Stampede Pass than at sites with similar elevations, so that EXE estimates for 1065 m elevation will be lower than the station records or site-specific StpP EXP estimates. It might be appropriate to use separate governing functions for low- and highsnow areas, as currently done with the precipitation-elevation functions (section 7.4).

We remain interested in the model's ultimate output of water delivered to the ground in comparison with total precipitation. In this 1065 EXE experiment, the volume of water getting through the pack is less than total precipitation in $77 \%$ of the events (nearly the $79 \%$ in $\operatorname{StpP} E X P$ ), with no water penetrating during $8.7 \%$ (vs $11 \%$ ). The proportion of model storms in which WAR $=\mathrm{P}$ doubles to $14 \%$ in EXE from EXP (7.3\%). Most of that difference comes at the expense of the events in which WAR $>$ P, the significant ROS events: for this EXE run, fewer (8.8\%) storms produce enhancement to precipitation than in EXP (14\%). This suggests that 1065 EXE is modeling a "warmer" situation than the EXP run for Stampede does (i.e., less cold and snowy, given similar precipitation amounts; Tables 5.1, 5.2), with more cases of all precipitation to WAR and fewer cases of important ROS. Both imply less influence of snow, which agrees with the initial-snow results described above. Again, among EXE events having WAR $>$ P, most of the snowmelt enhancements are small but some are substantial, averaging $3.00 \mathrm{~cm}$ or $23.4 \%$ of 
precipitation (ranges $0.007-20.8 \mathrm{~cm}, 0.065-166 \%$ ).

The frequency-magnitude relations for precipitation and WAR from the StpP EXP and 1065 EXE runs also demonstrate both similarities and differences. The model again calculates less WAR than precipitation for this elevation, indicated by the relative positions of frequency lines (Fig. 5.14, 5.17). In other words, any given amount of water delivery to the ground occurs less often (lower frequency, longer return period) than the same amount of precipitation; alternately, for a specified return period, the volume of water reaching the ground is up to several centimeters less than the all-phase precipitation for that recurrence. Note also that the EXE-modeled frequency lines suggest that precipitation and WAR converge in the rarest events.

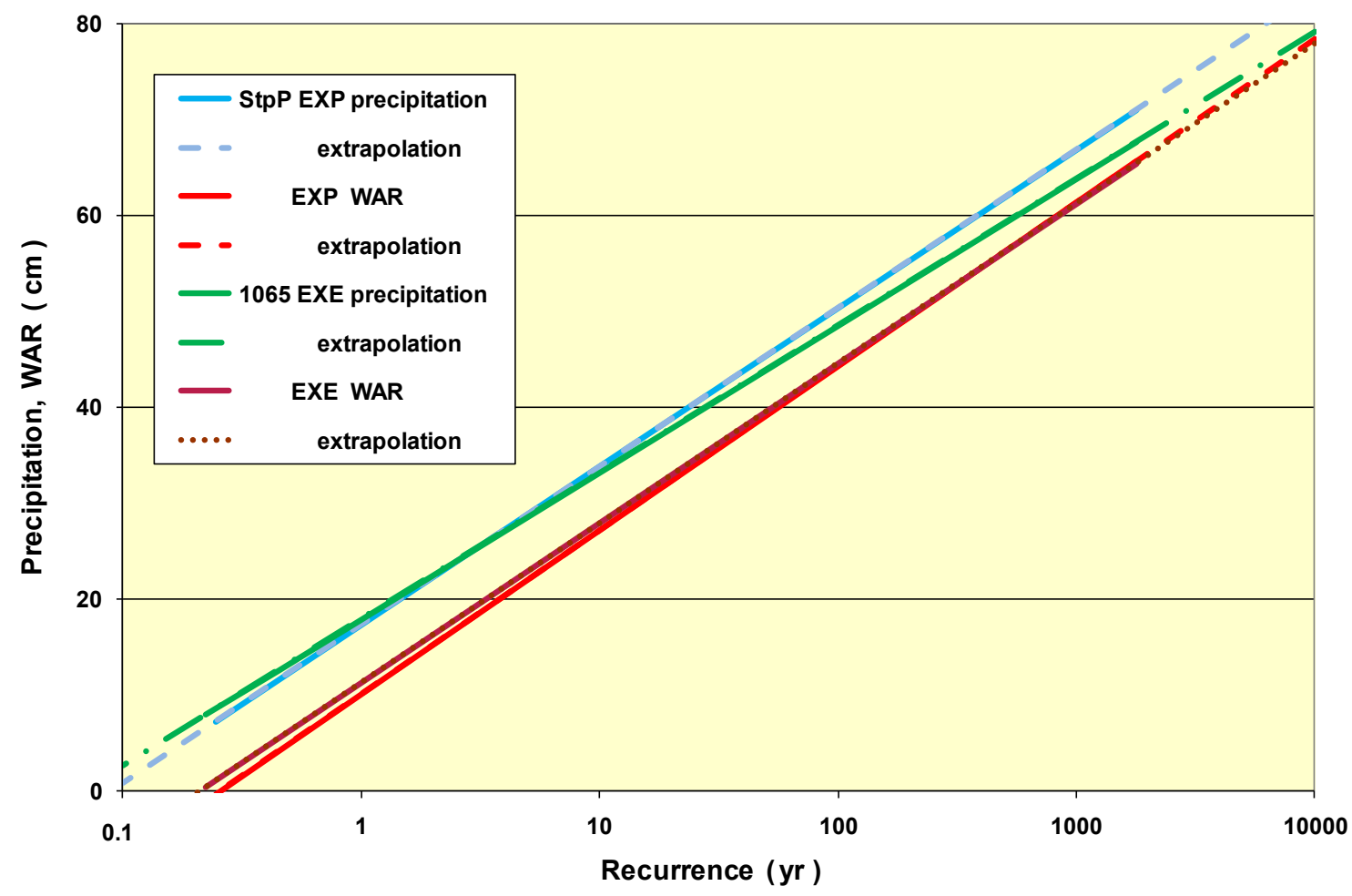

Figure 5.17. Frequency lines for realizations of water inputs and outputs, StpP EXP and 1065 EXE. Precipitation lines are the same as in Fig. 5.14; trends for rain + melt (not shown) are nearly collinear to those for water to the ground (WAR). 
In summary, the model yields suitable realizations for both the site-specific parameters of Stampede Pass (EXP) and for regionally generalized inputs corresponding to Stampede's effective elevation of $1065 \mathrm{~m}$ (EXE). It can properly reproduce the statistical properties of quantities governed by simple functions, such as storm numbers, timing, duration and precipitation magnitude; and even the more complex algorithms generate appropriately natural results of snowpack and weather conditions. Combining these probabilistic components with the deterministic procedures for snow accumulation/melt and percolation, tested earlier, initial Monte Carlo simulations tell us that at Stampede Pass or an equivalent elevation, almost $80 \%$ of events deliver less water to the ground than storm total precipitation. But a significant proportion $(\sim 8-14 \%)$ of model storms produce more WAR than precipitation, commonly in small amounts, but averaging $\sim 25 \%$ over the precipitation total and sometimes more than doubling it. Expressed in frequency-magnitude graphs, the model supports the idea (Fig. 2.1; section 2.3A) that water actually reaching the ground in storms at higher-elevation sites in the Cascades should be less than total precipitation for the same recurrence, especially in rarer events. These notions will acquire more context when combined with the EXE experiments for other elevations, described in the next chapter. 


\section{MONTE CARLO RESULTS FOR ELEVATION ZONES}

\section{$\underline{6.1 \text { Introduction }}$}

The chief project goals are to use modeling techniques to determine properties of rain-on-snow in the Pacific Northwest, particularly their long-term hydrologic significance, frequency, magnitude, and preferred locations. I seek answers to several questions (chapter 2): whether amounts of water delivered to the ground during ROS events differ significantly from the total (liquid plus solid) precipitation; what the frequency characteristics are for water inputs at sites experiencing considerable ROS; and if it is more common in middle elevations, where winter rain is most likely to fall on existing snowpacks, identifying zones of maximum long-term significance for ROS. The results reported in chapter 5 resolve some of these questions. At Stampede Pass (and its proxy effective elevation), there are clear differences between the long-term statistics and frequency characteristics of modeled precipitation and WAR series, corresponding to the proportions of different hydrologic event types: rain falling on bare ground; rain falling, snow melting, and delivery of water to infiltration and runoff that can be less or more than the precipitation amount; or snow falling, no melt and no liquid going to the ground. Frequency analyses of the StpP EXP and 1065 EXE model results quantify the differences in long-term magnitudes (Fig. 5.17), at least at this moderately high site.

The next steps are to confirm that these relations apply across elevations, and to find the zone in the central-western Washington Cascades where rain-on-snow is most likely and volumetrically significant. I continue to apply the Monte Carlo approach to simulate sets of storm events at various elevations, then use the statistics and several other metrics to analyze the realization series. My conceptual notion (Fig. 2.1) approxi- 
mates the mountain range as a simple ramp, with storm behavior varying with altitude alone (simplifying regional topography and climate; sections 4.3, 4.4). Interpretation of the model results will further consider the hydrologic processes affecting storms and ROS in this region, to reaffirm the supposed triad of rain but little snow at low elevations, snow with little rain or melt at high elevations, and rain plus snowmelt in a middle zone where ROS is likely to occur most often. But in this chapter, I address the equally important issues of "where?" - the location of a preferred ROS zone; and "how much?" - the magnitudes and differences of ROS effects, thus the relative hydrologic significance.

Model results are used to answer and illustrate these issues. The MC-EXE program version calculates several stochastic elements as direct, indirect or partial functions of elevation, including precipitation amount, storm duration, initial snowpack and temperature (Table 3.1; appendices C, I, J); these are the focus of analyses presented below. I ran the model for elevations ranging from 200 to $1500 \mathrm{~m}$, most at 100-m intervals; results for $1065 \mathrm{~m}$ (section 5.4) are incorporated. All runs utilized the same set of random numbers (as did StpP EXP and 1065 EXE), so the forcing probabilities for all elements are identical for equivalent calculations in every run. Thus, each run generates 4487 "storms" over 1000 years and the same numbers of events in each model year, as dictated by common functions for timing and dates (Table 5.2). Accordingly, all realization series have the same sets of exceedance probabilities and recurrence intervals. Using the Gringorten formula to set probability and recurrence (section $4.5 \mathrm{C}$, Table 4.1), series of 4487 events result in a probability range of $0.000125-0.9999$, corresponding to recurrence periods of 8013-1.000125 yr; calculating annual frequencies for $1000 \mathrm{yr}$, the probability range is $0.000560-4.486$ and the $R P$ range $1786-0.2229$ yr (appendix E). For several classes of 
model realizations the governing parameters lack any functional dependence on elevation, date, or other quantity. So, along with number of storms per year, all runs yield the same values and order of starting dates and times; storm internal rainfall pattern; nominal temperature range and frontal-diurnal ratios; and the midpoint and range of wind speed. The results for these elements are largely the same as those generated in 1065 EXE (Table 5.2; appendix $\mathrm{J}$ ), and no further treatment of them is necessary.

However, for other elements the results of runs at various elevations present diverse patterns, a few of which were only dimly foreseen in model development. Some outcome values differ among equivalent events, even when determined by the same probabilities. The most stable of these are quantities calculated once for each event and contingent on just one other simple property such as elevation or storm date; total precipitation is an example (discussed below). The variability among runs increases with the number of contributing factors. For example, initial snowpack water equivalent is a function of elevation and date; initial snow depth depends on those factors as well as SWE; their ratio (snow density) influences the snow-hydraulic properties. Date and elevation also control an event's initial temperature. Each storm's duration is influenced by precipitation magnitude; duration, in turn, affects the pattern of hourly temperatures. Quantities modeled hourly, deterministically, and/or having random components produce a rich variety of precipitation, temperature, wind, and snowpack fluctuations; but this diversity complicates the comparisons among events and experiment runs.

The model's chief driving variable, total event precipitation, can be generated in two ways. Four weather stations in the study area delineate a steeper precipitation gradient with elevation; three stations show less orographic enhancement (one station is com- 
patible with both groups; section 4.5E). These trends establish separate sets of linear equations relating event-precipitation parameters to site elevation: i.e., the slope and intercept used to calculate event precipitation from probability by the exponential distribution are themselves controlled by one of two functions of elevation, whose coefficients are entered before the run in appropriate cells of the Params page (appendix C). (Placeholders are also provided for calculation by the Gumbel extreme-value distribution, so far unused.) At the start of each run I designate the site elevation, which then determines the ExpD parameters for that experiment. Most of the model runs described here use the high-precipitation (HP) functions, but a smaller sample (at 400-1250 m) using low-precipitation (LP) equations provides comparisons suggesting possible differences between wetter and drier areas within the region.

\section{$\underline{6.2 \text { Example event }}$}

Although most of my analysis focuses on the 1000 -yr series of realizations, it is instructive to first examine the case of one particular event across the elevation runs, to illustrate the similarities and differences the model produces. Model event number 3359 lasts four to six days in early December, dropping $\sim 10-40 \mathrm{~cm}$ of precipitation, depending on elevation (Fig. 6.1). Median temperatures are everywhere $>0{ }^{\circ} \mathrm{C}$, so most precipitation is rain. There is a preexisting snowpack above $600 \mathrm{~m}$, with complete melt-out below $1000 \mathrm{~m}$; hours with subfreezing temperatures produce some snowfall above $\sim 1000 \mathrm{~m}$ and net accumulation above $\sim 1200 \mathrm{~m}$. Water infiltration or runoff occurs everywhere, and exceeds precipitation between $\sim 500-1200 \mathrm{~m}$. Thus, many event properties exhibit anticipated trends with elevation: storm durations, precipitation amounts, and snowpacks increase, while temperatures decline. The linear increase of precipitation combined with slightly 
steeper event lengthening indicates that the model produces somewhat dissimilar average intensities (magnitude per time) at different elevations, a reasonable variation within storms. Most importantly, snowmelt in middle elevations produces WAR greater than event precipitation, with the maximal ROS effect for this event at $1000 \mathrm{~m}$.

Although most of the event results are either constants or simple correlates of elevation, more complex outcomes are also possible. One such exception, unforeseen in model development, produced noteworthy deviations. In the program, an event's initial temperature varies with elevation, based on a wet-weather lapse rate $\left(-0.00625 \mathrm{C}^{\circ} / \mathrm{m}\right)$. However, the sequence of frontal passage used to help determine hourly air temperatures is selected from among 100 patterns from the Stampede Pass storm record (section 3.3A). These depend on storm duration and precipitation amount (Tables 3.1, 4.1), so longer and wetter events are more likely to pick patterns derived from observed storms with more days and more frontal segments. The modeled precipitation magnitude and duration both increase with elevation, so the choice of temperature pattern also changes, even for parallel events at different elevations. Each event 3359 of these 14 EXE runs chose a different hourly temperature pattern, as reflected by the changes in median temperatures (Fig. 6.1B). The run at $1065 \mathrm{~m}$ happens to select a pattern having abrupt and prolonged cooling late in the event, suggested by the dip in the median temperature compared to 1000 and $1100 \mathrm{~m}$. Hence, the $1065-\mathrm{m}$ run shows greater net snow accumulation, and so less WAR, than those indicated by the general trends across elevations. Of three other events examined (numbers 1116, 4178, 4452), all show similar deviations at various elevations, due to the temperature patterns imposed by the model. 

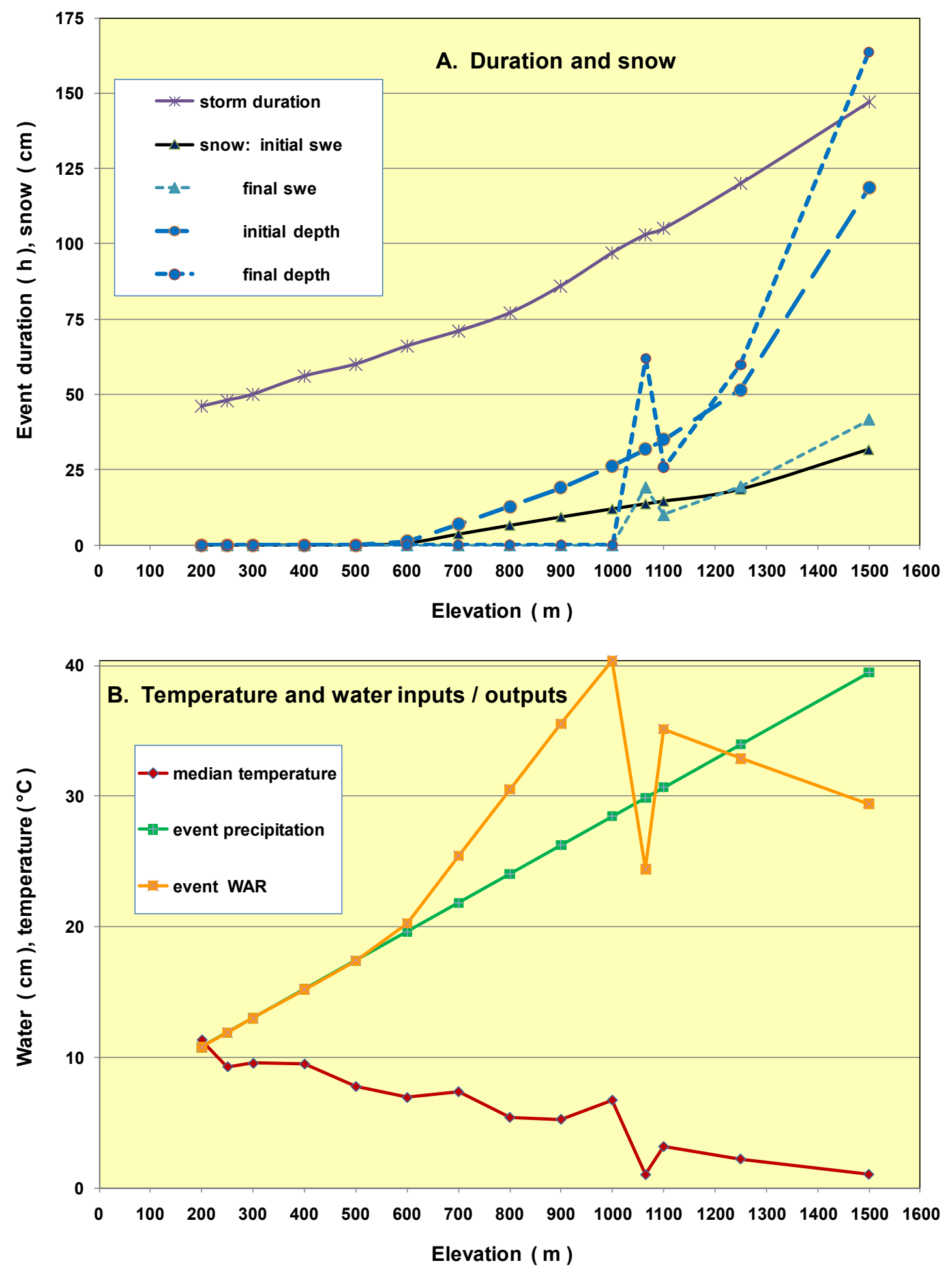

Figure 6.1. Realizations of weather and hydrologic elements for example event 3359 (WY 753, begins day $63=2 \mathrm{Dec}$ ), from EXE runs at 200 to $1500 \mathrm{~m}$ elevation (high-precipitation functions). A: Storm durations; initial and final snow depths and water equivalents. B: Median of event temperatures; storm precipitation and water available for runoff. 
More irregularities in the graphed trends would doubtless emerge with a denser elevation sample (say, every $50 \mathrm{~m}$ ); and such anomalies would probably appear for most of the model elements, excepting those that are constant or purely dependent on elevation. It is reasonable to expect some variation along a mountain transect during a particular event, since elevation is not the only control on storm weather, but it is not likely that parts of the transect would experience radically different conditions. While generating largely consistent patterns for precipitation and wind speed, my model allows major divergence in temperature patterns. Thus, it is currently inappropriate to directly compare specific events across elevation zones, or use them for input in other models (say, to generate soil-water inputs for runoff modeling distributed over the landscape), until this shortcoming is addressed. However, such irregularities have little mathematical effect on the statistical and graphical characteristics produced in 1000-yr series of realizations, the main targets of my experiments and analysis.

\subsection{EXE series across elevation zones: basic statistics}

The results of these modeling experiments comprise thousands of realizations for $>4000$ events in each 1000-yr run. I performed 23 model runs, including 14 using the HP elevation functions across $200-1500 \mathrm{~m}$, and nine using the LP functions at $400-1250 \mathrm{~m}$ (section 4.5E). Major products of my statistical and frequency analyses are tabulated in appendices K and L. Here, results are rendered in tables and graphs which I use to characterize and quantify variations with elevation. These serve as the basis for my interpretations regarding ROS, especially with respect to my hypotheses regarding its behavior and magnitude with elevation in the west-central Cascades.

The statistics, regression coefficients, hydrologic-event proportions, and magni- 
tude $\times$ frequency integrals for a sample of five of the wet-site elevation runs are listed in Table 6.1. Only model elements that are elevation-dependent are shown; other quantities are the same as those produced in 1065 EXE (including event number, start time, temperature range, frontal-diurnal ratio, and wind speed; Table 5.2), and have already been described in section 5.4. Generally, results are consistent with expectations, the governing input parameters, and model outputs presented so far. The mean and range statistics exhibit longer storm durations, lower temperatures, and deeper initial snowpacks at higher elevations. Standard deviations for duration and snow (and precipitation, described below) also increase uphill, corresponding to greater variance in series with wider ranges. Note that confidence declines toward the lowest and highest elevations, where contributing observations are limited and the elevation-based functions weaken, so inferences from the 1500-m run (and $<300 \mathrm{~m}$, not tabulated) may be less reliable. Maximum snow amounts generated at mid- to high-elevations appear unrealistically large, though the means are credible (see Fig. 5.10, 5.16); these extremes are not considered fatal flaws in the model or its results, as discussed previously (sections 5.3, 5.4) and later (section 6.6).

Key model outputs include the 1000 -yr series of precipitation, liquid water generated by rain plus snowmelt, and water available for runoff; their properties are revealed (Table 6.1) by several classes of metrics. The series ranges and major statistics, and the amounts of water delivered to the ground relative to precipitation (all changing with elevation), are described and interpreted here; frequency analyses of these series and their metrics are presented in the next section. 


\begin{tabular}{|c|c|c|c|c|c|c|}
\hline \multirow[b]{2}{*}{ Parameters } & \multicolumn{5}{|c|}{ Site Elevation } & \multirow[b]{2}{*}{ Notes } \\
\hline & $500 \mathrm{~m}$ & $800 \mathrm{~m}$ & $1100 \mathrm{~m}$ & $1250 \mathrm{~m}$ & $1500 \mathrm{~m}$ & \\
\hline \multicolumn{7}{|c|}{ Storm duration $(h):$ true event value } \\
\hline $\begin{array}{l}\text { Mean } \\
\text { Standard deviation } \\
\text { Skew }\end{array}$ & $\begin{array}{l}46.22 \\
20.76 \\
1.540\end{array}$ & $\begin{array}{l}57.77 \\
25.35 \\
1.367\end{array}$ & $\begin{array}{l}72.33 \\
31.77 \\
1.298\end{array}$ & $\begin{array}{l}80.95 \\
34.94 \\
1.224\end{array}$ & $\begin{array}{l}97.31 \\
40.73 \\
1.032\end{array}$ & $\begin{array}{l}\min =7 \mathrm{~h}(500 \mathrm{~m})-14 \mathrm{~h} \\
(1500 \mathrm{~m}) \\
\max =252 \mathrm{~h} \text { at all elevs } \\
\text { (program limit) }\end{array}$ \\
\hline \multicolumn{7}{|c|}{ Temperature $\left({ }^{\circ} \mathrm{C}\right)$ : event initial value } \\
\hline $\begin{array}{l}\text { Range: } \min \max \\
\text { Mean }\end{array}$ & $\begin{array}{c}-8.92+20.85 \\
3.615 \\
\end{array}$ & $\begin{array}{c}-10.78+18.98 \\
1.740 \\
\end{array}$ & $\begin{array}{c}-12.67+17.10 \\
-0.135 \\
\end{array}$ & $\begin{array}{c}-13.61+16.16 \\
-1.073 \\
\end{array}$ & $\begin{array}{c}-15.17 \quad+14.60 \\
-2.635 \\
\end{array}$ & $\begin{array}{l}\text { std } \mathrm{dev}=3.513, \text { skew }= \\
0.812 \text { for all elevs }\end{array}$ \\
\hline \multicolumn{7}{|c|}{ Snow (cm): event initial amount } \\
\hline $\begin{array}{l}\text { \% starting with no snow } \\
\text { SWE: maximum } \\
\text { Mean } \\
\text { Standard deviation } \\
\text { Skew } \\
\text { Depth: maximum } \\
\text { Mean } \\
\text { Standard deviation } \\
\text { Skew }\end{array}$ & 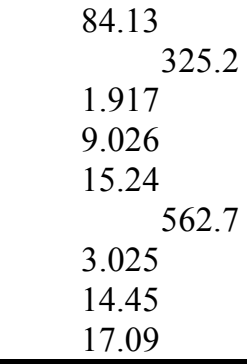 & $\begin{array}{l}38.96 \\
\quad 445.0 \\
13.00 \\
23.57 \\
5.29 \\
{ }^{7} 748.1 \\
20.19 \\
34.09 \\
5.36 \\
\end{array}$ & \begin{tabular}{ll}
23.67 & \\
\multicolumn{1}{c}{1113} \\
33.59 & \\
47.84 & \\
5.12 & \\
\multicolumn{2}{c}{1472} \\
62.30 \\
84.52 \\
3.89 \\
\end{tabular} & \begin{tabular}{l}
25.45 \\
\multicolumn{2}{|c|}{1256} \\
48.42 \\
64.17 \\
3.76 \\
\multicolumn{1}{c}{4135} \\
116.15 \\
193.91 \\
6.08 \\
\end{tabular} & $\begin{array}{l}22.84 \\
1577 \\
93.67 \\
113.40 \\
2.305 \\
15771 \\
336.7 \\
654.26 \\
6.63 \\
\end{array}$ & $\begin{array}{l}\min =0 \text { for SWE and } \\
\text { depth at all elevations } \\
\text { statistics derived from } \\
\text { realizations at all dates - } \\
\text { many low values with } \\
\text { fewer extremes } \rightarrow \text { high } \\
\text { variance \& skew }\end{array}$ \\
\hline \multicolumn{7}{|c|}{ Precipitation $(\mathrm{cm})$ : event total P } \\
\hline $\begin{array}{l}\text { Maximum: \# } 1 \quad(\# 2) \\
\text { minimum } \\
\text { Mean } \\
\text { Standard deviation } \\
\text { Skew } \\
\text { ExpD regression } \\
\text { intercept: on event, year } \\
\text { slope: } \log R P, \quad \ln R P\end{array}$ & $\begin{array}{cc}52.93 & (38.90) \\
5.655 \\
9.416 \\
3.474 \\
2.308 \\
\\
5.949 & 11.154 \\
7.985 & 3.468\end{array}$ & $\begin{array}{cc}76.85 & (56.00) \\
6.748 \\
12.152 \\
5.166 \\
2.309 \\
\\
6.995 & 14.738 \\
11.876 & 5.158\end{array}$ & $\begin{array}{cc}100.8 & (73.095) \\
7.9915 \\
14.8835 \\
6.851 \\
2.307 \\
\\
8.045 & 18.312 \\
15.749 & 6.840\end{array}$ & $\begin{array}{cc}112.7 & (81.64) \\
8.273 \\
16.248 \\
7.694 \\
2.308 \\
\\
8.568 & 20.098 \\
17.686 & 7.681\end{array}$ & $\begin{array}{cc}125 & (95.89) \\
8.701 \\
18.5185 \\
9.077 \\
2.240 \\
\\
9.451 & 23.065 \\
20.882 & 9.069\end{array}$ & $\begin{array}{l}\text { means \& maxima of } \\
\text { precip rise with elevation } \\
\text { lower skew at } 1500 \mathrm{~m} \text { due } \\
\text { to more events at program } \\
\max =125 \mathrm{~cm}\end{array}$ \\
\hline \multicolumn{7}{|c|}{ Rain + snowmelt $(\mathrm{cm}):$ event total $R+M$} \\
\hline $\begin{array}{l}\text { Maximum: \# } 1 \text { (\# 2) } \\
\text { Mean } \\
\text { Standard deviation } \\
\text { Skew }\end{array}$ & $\begin{array}{c}52.93(46.54) \\
8.186 \\
4.017 \\
1.353 \\
\end{array}$ & $\begin{array}{c}76.85(54.25) \\
8.922 \\
6.358 \\
1.4015 \\
\end{array}$ & $\begin{array}{c}100.8(59.64) \\
7.618 \\
7.591 \\
1.904 \\
\end{array}$ & $\begin{array}{c}112.7 \quad(61.38) \\
6.600 \\
7.704 \\
2.199 \\
\end{array}$ & $\begin{array}{c}125(58.76) \\
4.872 \\
7.480 \\
2.972\end{array}$ & $\begin{array}{l}\min \mathrm{R}+\mathrm{M}=0 \text { at all } \\
\text { elevations }\end{array}$ \\
\hline
\end{tabular}




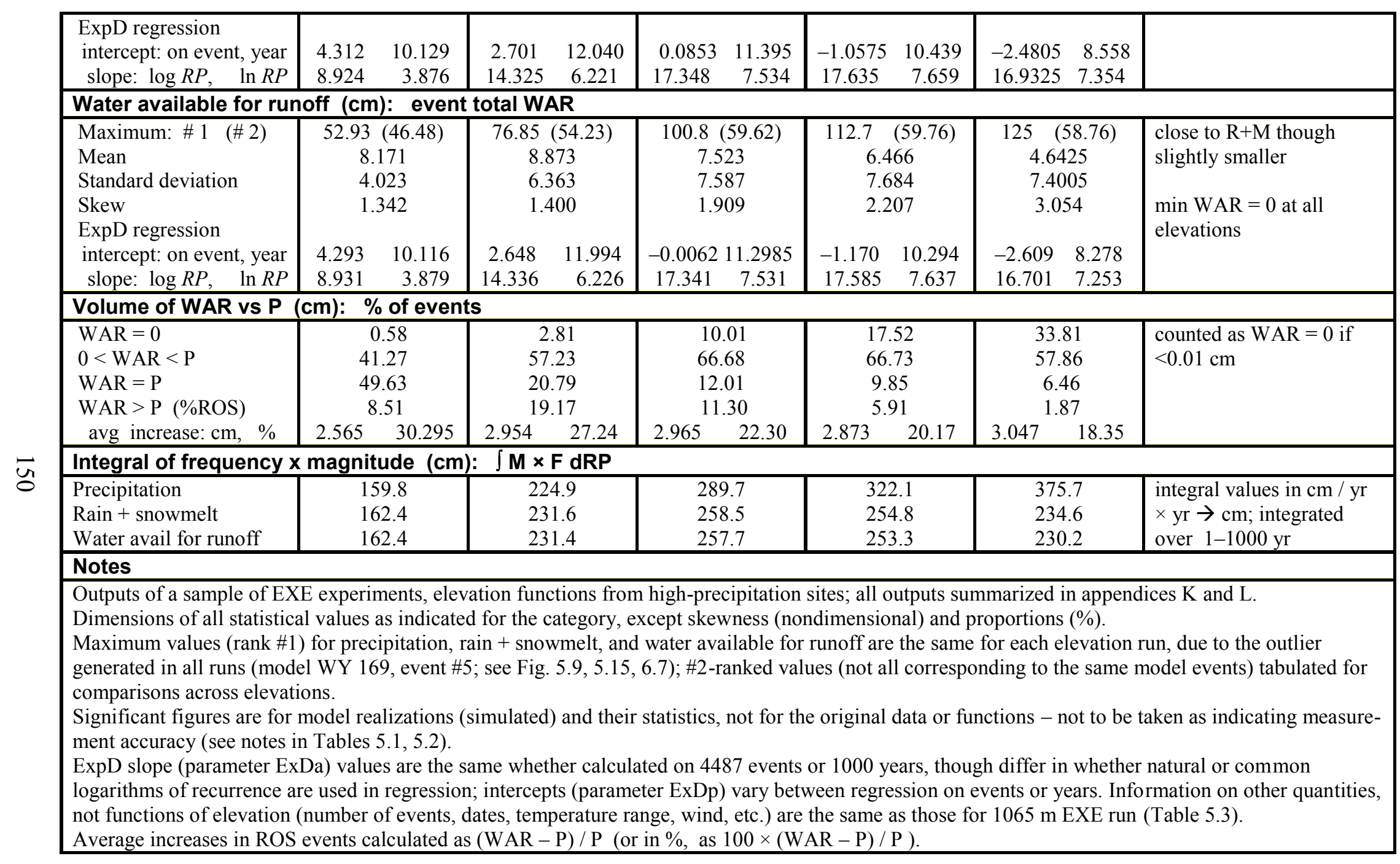


A) Series ranges, means \& standard deviations Statistics of the realization series vary within and across elevations (Table 6.1). For each run, the water amounts generally decline from precipitation to rain + melt to WAR, and these divergences increase from lower to higher elevations, but there are anomalies. Considering the extreme values, little can be learned from the maxima for these three hydrologic series, which are the same at each elevation due to the outlier. However, the more edifying second-ranked amounts behave variably: at elevations above $600 \mathrm{~m}$ they decline from $\mathrm{P}>\mathrm{R}+\mathrm{M} \approx \mathrm{WAR}$ (consistent with the means, as shown below); but at $\leq 600 \mathrm{~m}$, the second-ranked $\mathrm{R}+\mathrm{M}$ and WAR are greater than the \#2 precipitation. Although these sub-maximal amounts do not always occur in the same events, this ordering mirrors nature, with significant snowmelt enhancement in at least a few of the largest events even at lower elevations. Minimal precipitation values generated in each run (basically the partial-duration series limits) predictably rise with elevation. The minima for $\mathrm{R}+\mathrm{M}$ and $\mathrm{WAR}$ are all zero, occurring in events with no liquid water generated and/or reaching the ground; the frequency of $\mathrm{WAR}=0$ events increases at higher elevations, thus affecting the statistics (B, below). 

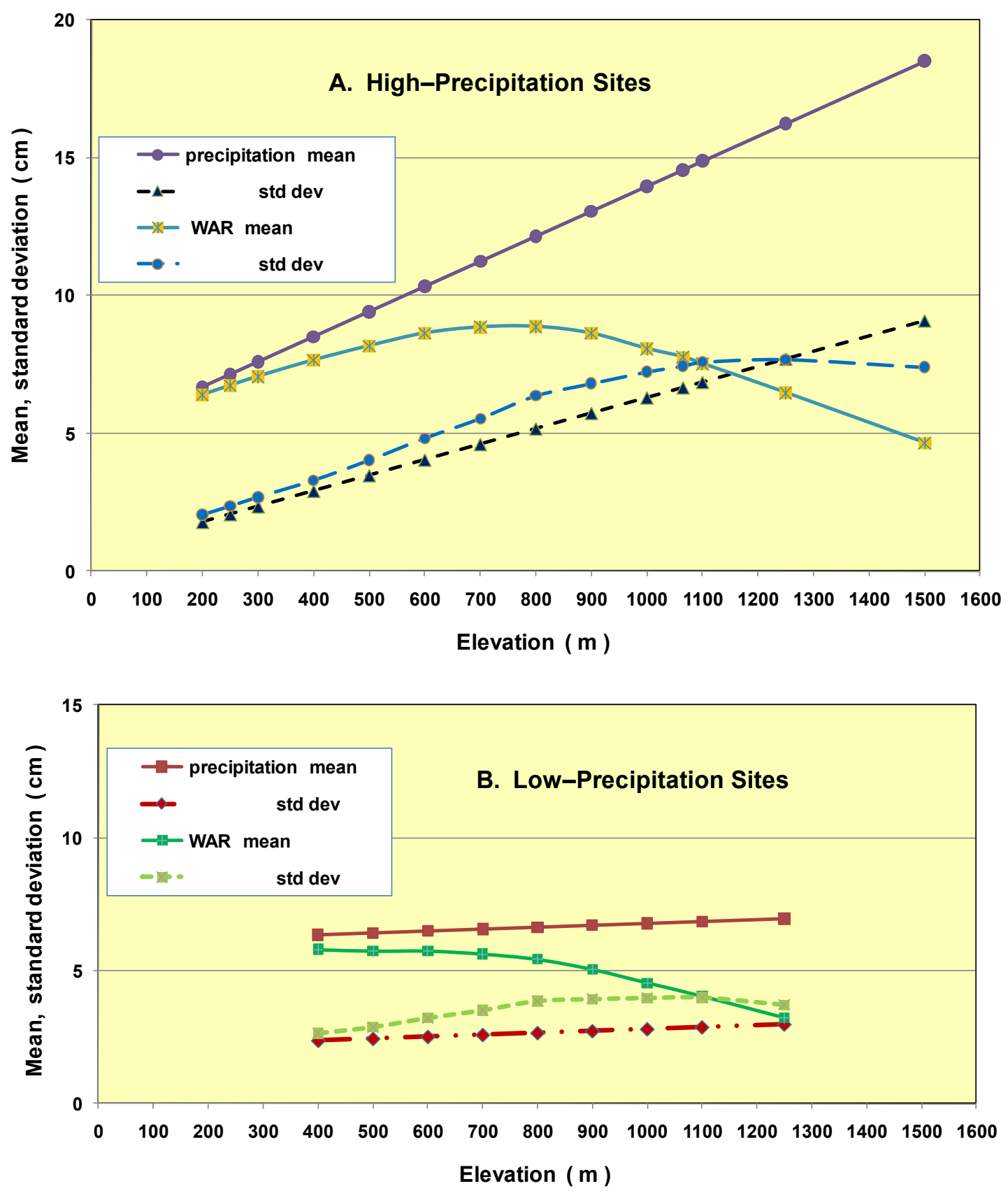

Figure 6.2. Elevation trends of series statistics for precipitation and water available for runoff from EXE realizations (curves for rain + melt would be nearly indistinguishable from those for WAR; Table 6.1).

A: Precipitation-elevation functions for wetter areas. B: Precipitation-elevation functions for drier areas.

More illuminating than the extremes, the mean and variance statistics also display interesting changes between series and elevations. The average and standard deviation of 
precipitation increase linearly with elevation, having steeper gradients for the wetter than for drier sites, as the governing functions demand (Fig. 6.2). But an event's rain + melt and WAR realizations depend on interactions among modeled precipitation, snowpack changes and percolation at each elevation, so their statistics are not linear with elevation. $(\mathrm{R}+\mathrm{M}$ statistics are very close to those of WAR, so are not shown on Fig. 6.2.) For both high-precipitation (Fig. 6.2A) and low-precipitation (Fig. 6.2B) areas, mean P and mean WAR are nearly equal in lowlands and diverge with elevation. However, the HP average WAR peaks at $\sim 700-800 \mathrm{~m}$, then decreases; no apex occurs in the LP mean WAR, just a slight inflection at $\sim 800 \mathrm{~m}$ (probably due to model algorithms generating less rain but the same snowpacks for drier sites). These patterns suggest processes yielding long-term average WAR slightly less than average precipitation in the lowlands, due to occasional snowfall; more infiltration/runoff during storms in middle elevations as snowmelt enhancement is increasingly important there during ROS events (though mean WAR $<$ mean P); then less water to the ground at high elevations, where colder storms and deeper snow inhibit melt and percolation. Variances show the opposite ordering: standard deviations of WAR are greater than those for P at all but the highest elevations, especially so at $\sim 900-1200 \mathrm{~m}$. These trends reflect the broader range of WAR values, in the model and nature, which extend from zero $(<\mathrm{P}$ minima) to $>\mathrm{P}$ (in WAR $>\mathrm{P}$ events), particularly at mid-high elevations.

B) Hydrologic event types To provide further insight into hydrometeorologic variation with elevation, the proportions among EXE model realizations of four event types are examined, based on the relative amounts of precipitation and water reaching the ground: $\mathrm{WAR}=0,0<\mathrm{WAR}<\mathrm{P}, \mathrm{WAR}=\mathrm{P}$, and WAR $>\mathrm{P}($ Table 6.1; Fig. 6.3). The patterns of 
these metrics are similar for both low- and high-precipitation sites. The ratio of events in which all precipitation gets to the ground $(\mathrm{WAR}=\mathrm{P})$ is greatest at low elevation, dominated by rainfall on bare ground, with rarely enough snow to either enhance runoff or store water. Conversely, at higher elevations much more storm precipitation falls as snow, and thick snowpacks frequently retard any rain or meltwater present, so the proportion of WAR $=0$ events rises sharply in the highlands. The ratio of events experiencing partial inhibition $(0<\mathrm{WAR}<\mathrm{P})$ peaks at $\sim 60 \%$ over $\sim 1000-1250 \mathrm{~m}$; the combined share of all events with some precipitation failing to reach the ground (i.e., WAR $<$ P) increases almost linearly with elevation.

My chief interest is ROS, therefore the events when precipitation is augmented by snowmelt. Model results show WAR $>$ P (i.e., \%ROS) proportions peaking over $\sim 700$ 900 m elevation, comprising $\sim 19 \%$ (HP) and $\sim 25 \%$ (LP) of events at $800 \mathrm{~m}$ (Fig. 6.3). Note that \%ROS is higher at drier sites, despite previous trends (as in Fig. 6.2B) showing poorly defined elevation zeniths: slightly less melt can exceed much less rain in more events. (This is consistent with previous findings that melt can make a larger proportional contribution to smaller storms; Harr, 1981; Perkins and Jones, 2008.) To establish approximate boundaries for peak ROS zones from these relations, I recognize a lower edge at $\sim 500-600 \mathrm{~m}$, where \%ROS ratios increase steeply; and an upper edge where these curves cross the WAR $=0$ lines, at $\sim 1100+\mathrm{m}$. 

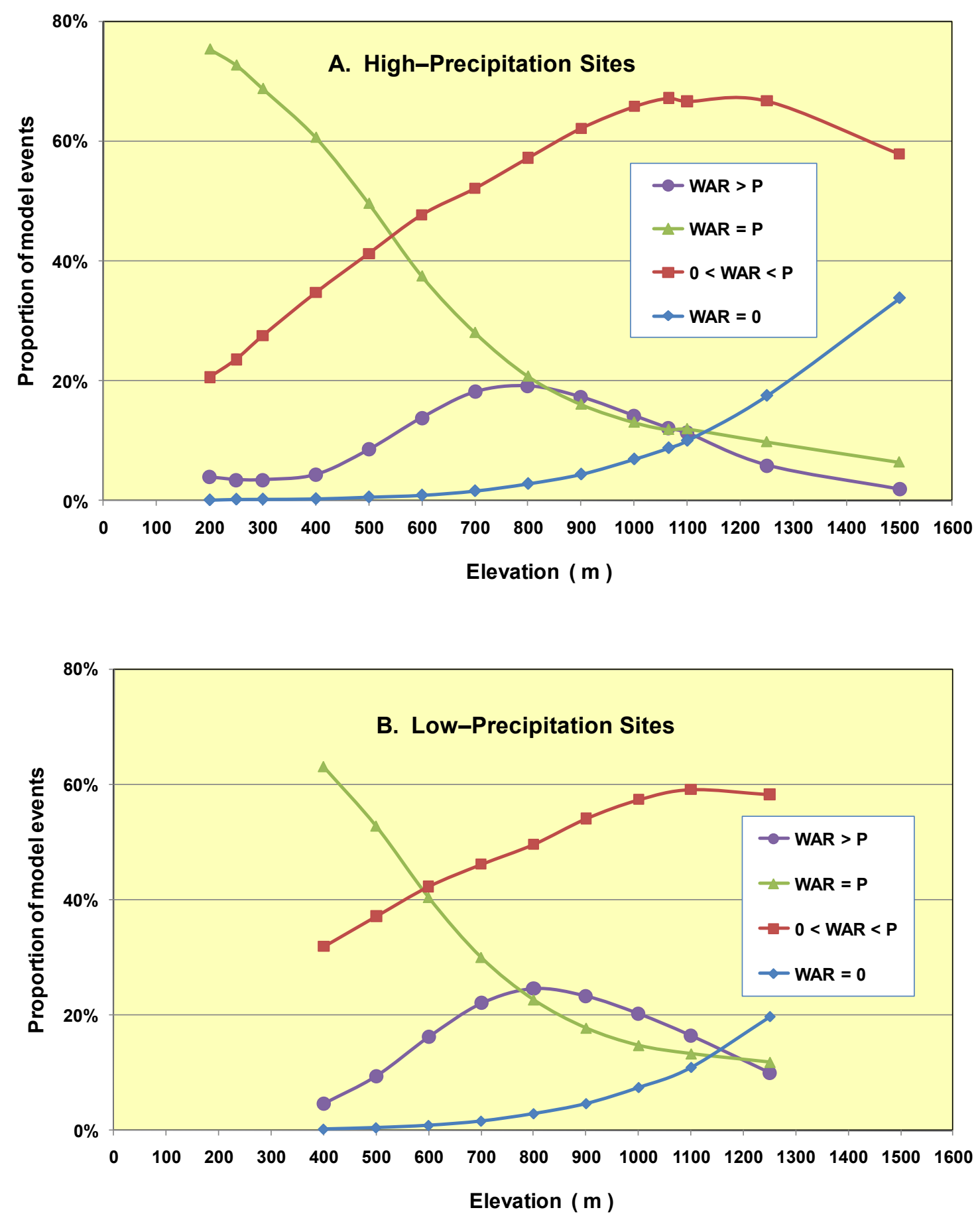

Figure 6.3. Proportion of hydrologic event types, as relative magnitudes of precipitation and water available for runoff in event realizations. A: Functions from wetter areas. B: Functions from drier areas.

The volumetric enhancement of WAR over precipitation in model ROS events does not vary much with elevation (Table 6.1; appendix L). The average increment rises 
from $\sim 1.9$ to $\sim 3.1 \mathrm{~cm}$ for the HP sites across $200-1500 \mathrm{~m}$, and $\sim 2.4-2.7 \mathrm{~cm}$ in the narrower elevation range for LP areas. However, the mean increment ratio generally declines with elevation, from $\sim 30$ to $18 \%$ for wetter sites. Again, the model is reflecting steep orographic precipitation gradients but lesser increases of the snowmelt and percolation (WAR) realizations, in cooler temperatures and/or deeper snow, and thus smaller melt-increment proportions at higher elevations even for ROS events. (The consistent enhancement ratios of $\sim 40-45 \%$ for drier sites are probably model artifacts, due to lower precipitation amounts and a narrower sample range.)

\subsection{Frequency analysis of EXE results}

We employ frequency analysis to render hydrologic series into quantitative estimates of their magnitudes at a range of probabilities. In this work, the partial-duration series of storm-event precipitation, rain plus meltwater, and water available for infiltration/runoff are modeled as exponential distributions (ExpD). Each series member is ranked and assigned a PD-based recurrence period (and its inverse, probability $=1 / R P$ ) based on the Gringorten plotting formula (section 4.5C, Table 4.1); then magnitudes are regressed against the logarithm of recurrence (using common $\log R P$ and natural $\ln R P$, both useful in different ways; appendix F). Aspects of the model realizations' frequency properties are examined to confirm the elevation-varying processes and the preferred elevation zone for ROS, and to quantify the probabilistic differences between series and elevations.

A) Exponential regression coefficients Like the series means and variances, the coefficients derived by regression of model realizations against $R P$ can characterize entire series, with the added benefit of accounting for their skewness (Table 6.1), allowing us to 
recognize associations with elevation. For exponential distributions, the coefficients of magnitude $=$ intercept + slope $\times \log R P$ have simple meanings. The intercept (location factor, based on years) is the value at $R P=1 \mathrm{yr}(\log 1=\ln 1=0)$. The slope (shape factor) reflects the change in magnitude with recurrence (probability), with a value corresponding to the increment for each factor of 10: the sum of the intercept and the $\log R P$ slope is the amount at 10 -yr $R P$; adding another slope increment gives the 100 -yr value, etc. (The sequence can be derived with slope coefficients from $\ln R P$ by multiplying by $\ln$ $10=2.3 ; \ln R P$ also has another useful meaning, as shown in $\mathrm{C}$, below.)

Not surprisingly, the regression intercepts and slopes produced from P and WAR realization series (Fig. 6.4) display patterns similar to those of the means and variances, respectively. All coefficients for precipitation are linear with elevation, as demanded by model algorithms, with gradients that are steeper for HP sites (Fig. 6.4A) and gentler for LP sites (Fig. 6.4B). Once more, values of the WAR coefficients are close to the corresponding $\mathrm{P}$ amounts at low elevations, then rise to broad maxima before declining; the peaks are much subtler for the drier sites. These coefficients control the position and orientation of frequency-magnitude lines determined from the output series ( $\mathrm{B}$, below), but intercept and slope act together, so we should not over-interpret each factor. Nevertheless, returning to the coefficients' meanings, these results indicate that the 1 -yr recurrence amounts (intercepts) and order-of-magnitude increments (slopes) for WAR reach relative maxima in middle-elevation zones, with lesser values at higher and lower elevations. Again, I interpret such WAR peaks as identifying elevations susceptible to more frequent enhancement during rain-on-snow, relative to lower and higher elevations; taken together, these indices suggest that the significant ROS zone extends over $\sim 700-1250 \mathrm{~m}$. 

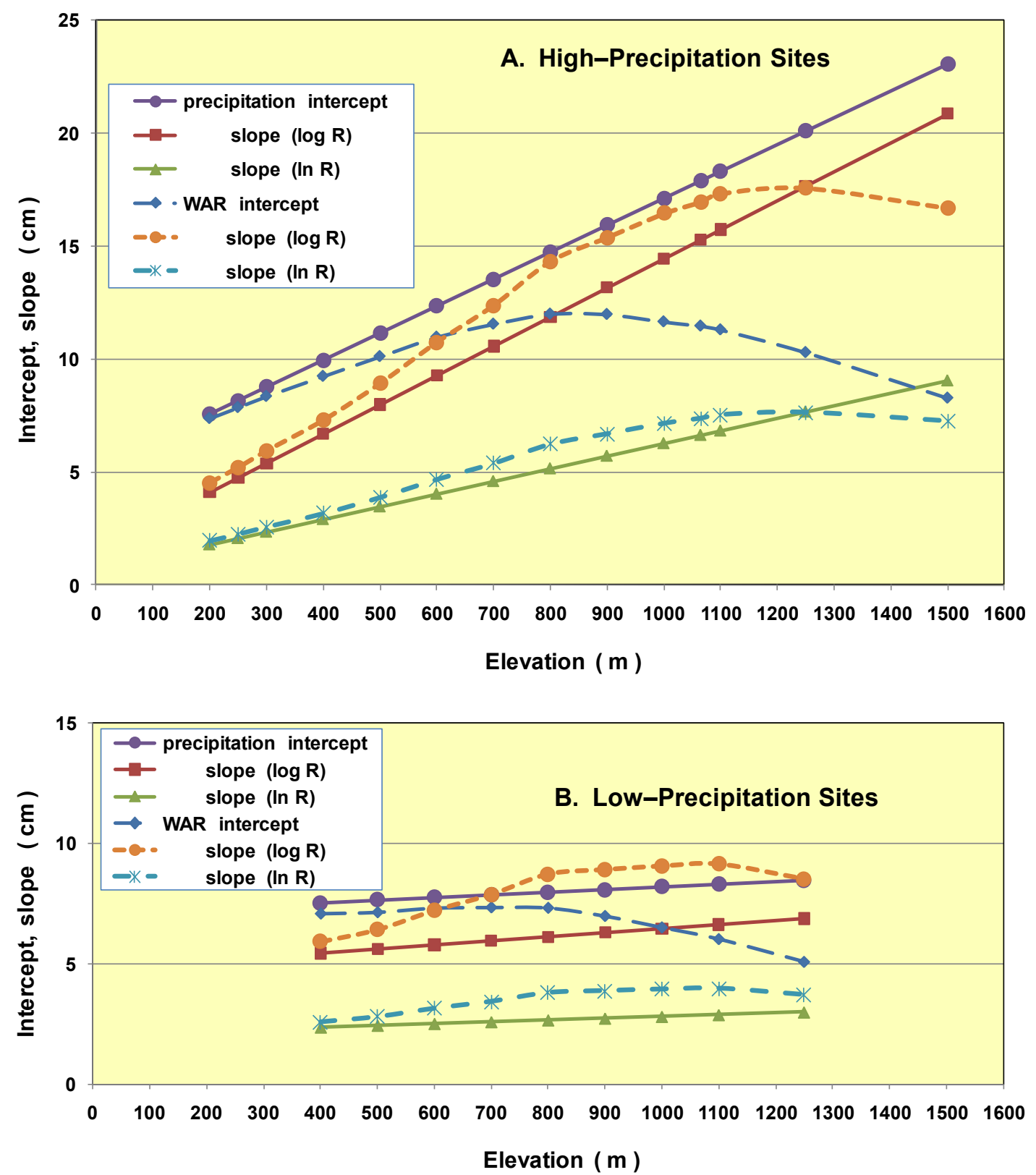

Figure 6.4. Exponential regression coefficients from realizations for EXE precipitation and water available for runoff series; intercepts are series values at recurrence $1 \mathrm{yr}$; slopes (based on log or $\ln$ of recurrence) indicate increments for each 10-fold recurrence increase. A: Precipitation functions from wetter areas. B: Precipitation functions from drier areas.

B) Frequency-magnitude of P \& WAR series by elevation The exponential regression coefficients are used to construct the familiar graphs of frequency analysis. The lines for precipitation and WAR magnitudes at the five elevations sampled in Table 6.1 are shown 
on Figure 6.5; I plot the data this way to continue illustrating the elevation-related differences between P and WAR generated by the model realization series, and especially to quantify their relative magnitudes. The graph provides approximate quantities, but more precise magnitudes of $\mathrm{P}, \mathrm{R}+\mathrm{M}$ and $\mathrm{WAR}$ at any recurrence period can be calculated from the regression coefficients listed in Table 6.1 and appendix L. For example, at $800 \mathrm{~m}, \mathrm{P}=$ $14.738+11.876 \log R P$, so the $100-\mathrm{yr}$ precipitation is $14.738+11.876 \times 2=38.5 \mathrm{~cm}$. Differences can also be calculated: the $800-\mathrm{m} W A R=11.994+14.336 \log R P$, so the divergence is $\mathrm{P}-\mathrm{WAR}=2.744-2.460 \log R P$, or $\sim 2.2 \mathrm{~cm}$ at $100-\mathrm{yr} R P$. Mutual values can be found by algebraically equating lines: e.g., the crossover point where $\mathrm{P}=\mathrm{WAR}$ for $800 \mathrm{~m}$ has $R P 13 \mathrm{yr}$. The convergence of all $\mathrm{P}$ lines at $R P \sim 0.12$, corresponding to events delivering $\sim 3.8 \mathrm{~cm}$ recurring $\sim 8.3$ times per year, must somehow be determined by the model's precipitation-generating functions (equivalent values for LP sites are $\sim 0.23 \mathrm{yr}, 4.4 / \mathrm{yr}$, and $4.0 \mathrm{~cm}$ ), but the meaning of these commonalities is unclear to me. At lower elevations there is little difference between P and WAR series (but not statistical equality), as characterized by the very close frequency lines for $500 \mathrm{~m}$. I interpret this similarity as a consequence of the rarity of major snowmelt enhancement in this zone. At this and other low elevations (not shown on Fig. 6.5), the proportion of model events with WAR exceeding precipitation (\%ROS) rises from $\sim 4 \%$ at $200 \mathrm{~m}$ to $15 \%$ at $600 \mathrm{~m}$ (Fig. 6.3); WAR $>$ P in very few of the largest (long-recurrence/low-probability) water-input events ( 3 of the top 15 at $500 \mathrm{~m} ; 10$ are $\mathrm{WAR}=\mathrm{P}$ ). On the other hand, the model generates many more events in which WAR is reduced by the effects of snowfall, non-melt, and/or snowpack water storage: the proportion of WAR $<$ P events climbs from $\sim 20$ to $50 \%$ at $200-600 \mathrm{~m}$, and the deficit can be considerable (model-event WAR can 
fall to zero but minimal $\mathrm{P}$ magnitudes are no lower than $\sim 5 \mathrm{~cm}$ ). These factors combine to make the frequency-magnitude estimates slightly unequal even at the lower elevations, with WAR exceeding $\mathrm{P}$ at long $R P$ despite few major ROS events, and falling below $\mathrm{P}$ for the most common storms. But the differences are small: $<2 \mathrm{~cm}$ at all $R P \sim 1-1000 \mathrm{yr}$, less in middle return periods, and equal at $\sim 12.5 \mathrm{yr}$.

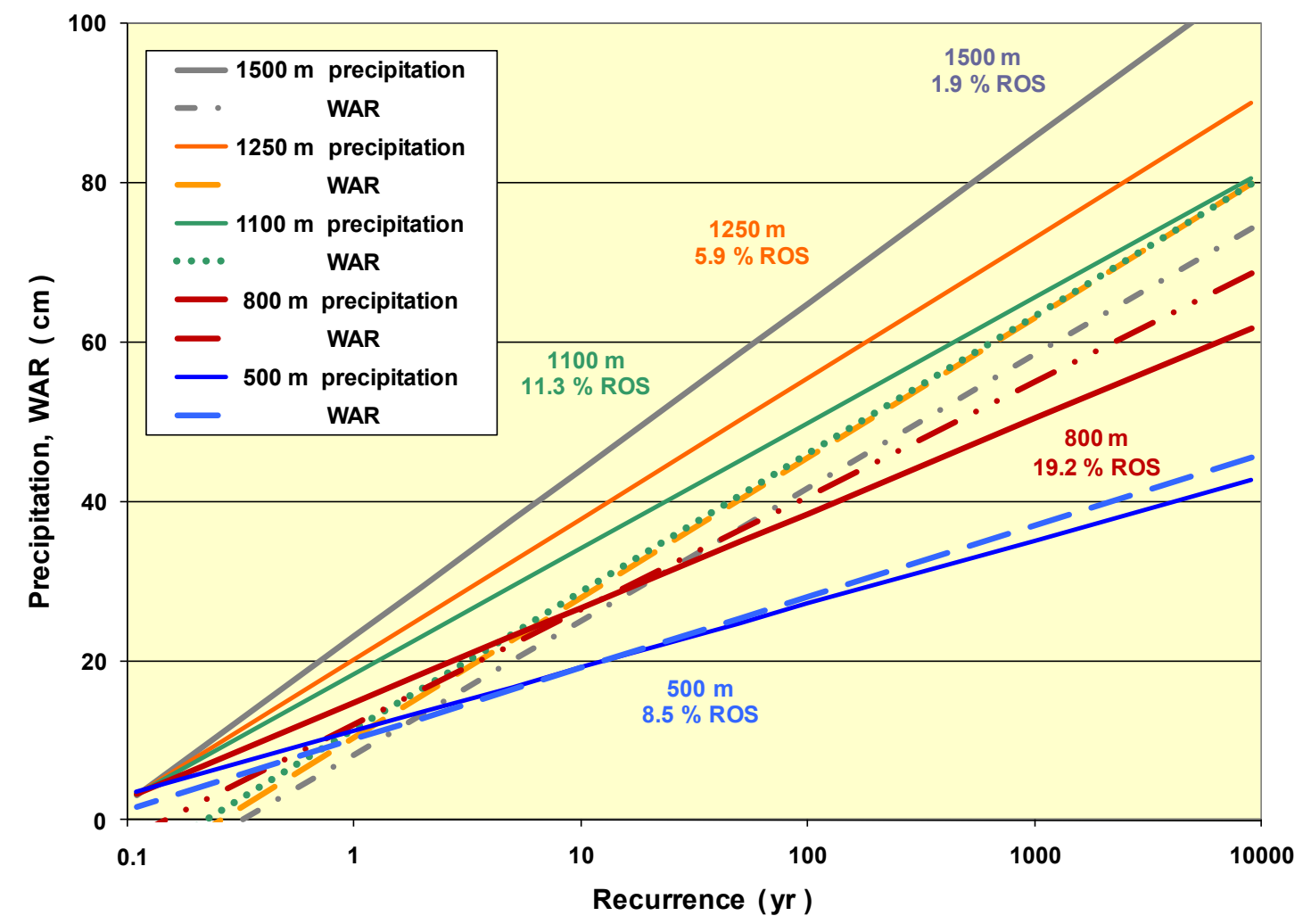

Figure 6.5. Exponential trend lines for realizations of precipitation (solid lines) and water outputs (WAR, dashed/dotted lines) from EXE runs for a sample of five site elevations; the lines express the ExpD intercept and slope values presented in Table 6.1 and illustrated in Fig. 6.4. \%ROS is the proportion of model events having WAR $>\mathrm{P}$ for runs at the given elevation.

In contrast, at high elevations WAR is much less than $\mathrm{P}$ at any given recurrence, as the orographic precipitation increase is overwhelmed by the suppression of liquid percolation in most storms. In simulations at 1100, 1250 and $1500 \mathrm{~m}$, the proportion of events in which WAR $<$ P increases from $\sim 75$ to $>90 \%$, while $\%$ ROS declines from $\sim 11 \%$ at $1100 \mathrm{~m}$ to $<2 \%$ at $1500 \mathrm{~m}$ (Fig. $6.3,6.5$ ). This reinforces the notion that hydro160 
logically significant ROS is rare in the higher mountains, where it is more likely for big storms to bring snowfall, and any liquid from $\mathrm{R}+\mathrm{M}$ to be absorbed in deep snowpacks. The differences between P and WAR increase from $\sim 10$ to almost $30 \mathrm{~cm}$ at 1250 and $1500 \mathrm{~m}$ for most $R P$. (At $1100 \mathrm{~m}$, Fig. 6.5 suggests that $\mathrm{WAR}>\mathrm{P}$ at $>10,000 \mathrm{yr} R P$, but that inference goes beyond the model's reasonable extrapolation limits.)

In middle elevations the corresponding pairs of WAR and P lines intersect, with markedly different relations on either side of the crossover points, owing to the mixture of events they experience. Water delivery to the ground is reduced in many cold storms, when snow falls or liquid percolation is delayed though deep snow; WAR $<$ P in $54 \%$ of model events at $700 \mathrm{~m}$ to $>70 \%$ at $1000 \mathrm{~m}$ (Fig. 6.3). But WAR is increased during many storms when snowmelt appreciably augments rainfall, up to $\sim 20 \%$ of events at $800 \mathrm{~m}$, the apparent regional zenith of ROS occurrence. The greatest divergence between $\mathrm{P}$ and WAR series also occurs at $800 \mathrm{~m}$ (Fig. 6.5), increasing at all $R P$ longer than 13 yr. This frequency analysis indicates that at $1 \%$ exceedance probability (100-yr event), WAR delivers $\sim 40.7 \mathrm{~cm}$ of water to the ground, whereas in the equivalent event $\sim 38.5 \mathrm{~cm}$ of rain and/or snow falls; at $0.1 \%$ (1000 yr) exceedance, WAR delivers $\sim 4.6 \mathrm{~cm}$ more water than the storm precipitation. In other words, for these rare events, a given amount of liquid delivered to infiltration/runoff is more common than the same amount of all-phase precipitation: the 100-yr WAR is comparable to the $\sim 152$-yr precipitation, the 1000-yr WAR to the $\sim 2640$-yr precipitation. For the common events $(<13-\mathrm{yr} R P)$ the order is reversed: any given quantity of precipitation is more common than the same amount of WAR, due to the greater likelihood of WAR $<$ P events.

These interpretations for $800 \mathrm{~m}$ apply to a fairly narrow elevation band. The re- 
sults for the 700-m and 900-m runs (not plotted; appendix L) are similar, but their series magnitudes and/or divergences are lower by $\sim 1-2 \mathrm{~cm}$. In all the series for $\sim 700-900 \mathrm{~m}$, WAR values are smaller than $\mathrm{P}$ for the high-frequency events $(\sim 2-3 \mathrm{~cm}$ less at $R P \sim 1-2$ $\mathrm{yr}$ ), as suppression of liquid input is increasingly common (large proportion of WAR $<\mathrm{P}$ events) upward through the middle elevations. Model results indicate a transition to highelevation conditions by $1100 \mathrm{~m}$, where WAR series have less volume than precipitation at all equivalent recurrence periods.

C) Long-term magnitude $\times$ frequency Although frequency lines are quantitative expressions of the model results, comparisons between them such as those above are inexact. Additionally, they beg for appraisal of the relative consequence of events having high magnitude but low probability versus those that are more common but small in size. This problem has been addressed by considering the product of magnitude and frequency, thus weighting the range of effects by their likelihood, to find the combination that dominates the relevant process (Wolman and Miller, 1960; de Ploey et al., 1991; appendix F). Due to the mathematics of exponential distributions, the maximum of the $M \times F$ product equals the slope coefficient of the exponential regression equation when calculated with the natural logarithm of recurrence (i.e., $=\mathrm{f}[\ln R P])$. Thus, the values of "slope $(\ln R P)$ " tabulated and plotted previously (Table 6.1, Fig. 6.4; appendix L) identify the "dominant events". Note that these are fairly small, $\sim 2-9 \mathrm{~cm}$; all are less than the $1-\mathrm{yr}$ events indicated by the corresponding intercept values. Furthermore, they have little physical meaning, in terms of exceeding a critical threshold for performing hydrologic or geomorphic work. Those for precipitation include snow as well as rain, perhaps falling on an existing snowpack (both increasingly so at higher elevations), so commonly having no immediate 
effect at all. For WAR, which at least denotes liquid water reaching the ground, the dominant amounts are no more than $\sim 8 \mathrm{~cm}$ over storms lasting many days (average intensities at most a few $\mathrm{mm} / \mathrm{h}$ ); it takes larger storms to have significant erosive effect on most Northwest soils and slopes.

However, a further extension of the magnitude $\times$ frequency concept suggests another useful metric. The integral of $M \times F$ over some range of recurrence period (i.e., $\int M$ $\times F d R P$ ) provides a quantitative measure of the relative importance among large infrequent events and frequent small events. Since my hydrologic realization series are modeled as exponential distributions, their regression equations are easily integrated. I calculate $\int M \times F d R P$ over the recurrence range of 1-1000 yr (disregarding very common and extremely rare events). The integral area under the $M \times F$ curve has dimensions $\mathrm{L} \times \mathrm{T}^{-1} \times$ $\mathrm{T}=\mathrm{L}$, so the value can be understood as relative depth of water. I adopt this index to assess the relative size and significance of the frequency trends calculated for precipitation, $\mathrm{R}+\mathrm{M}$ and WAR series at each site, and among the series at a range of elevations.

The integrals for event precipitation rise monotonically with elevation, whereas those for $\mathrm{R}+\mathrm{M}$ and WAR (almost identical to each other) have middle-elevation maxima (Fig. 6.6), rather like those seen previously for other parameters (Fig. 6.2-6.4). For samples using both the high- and low-precipitation functions, the integrals of WAR each exceed those of precipitation over middle elevations. For wetter areas, the range is between 500 and $900 \mathrm{~m}$, with the largest (though small) difference of $6.7 \mathrm{~cm}$ at $800 \mathrm{~m}$; the crest for WAR is at $\sim 1100 \mathrm{~m}$, then declining uphill. These values confirm the interpretations from the frequency parameters and lines (Fig. 6.5) regarding long-term water delivery from big storms: WAR most exceeds $\mathrm{P}$ at $\sim 800 \mathrm{~m}$, the WAR series reaches maximum 
magnitudes at $\sim 1100 \mathrm{~m}$, and values are smaller at lower and higher elevations. At LP sites, the elevation range in which the integral for WAR is greater than that for $\mathrm{P}$ is broader, between $\sim 400-1200 \mathrm{~m}$, with top value and difference $(22 \mathrm{~cm})$ both at $800 \mathrm{~m}$. This implies that a frequency-magnitude graph for those sites would show the WAR lines at more elevations exceeding their corresponding $\mathrm{P}$ lines (though all would probably plot at lower magnitudes).

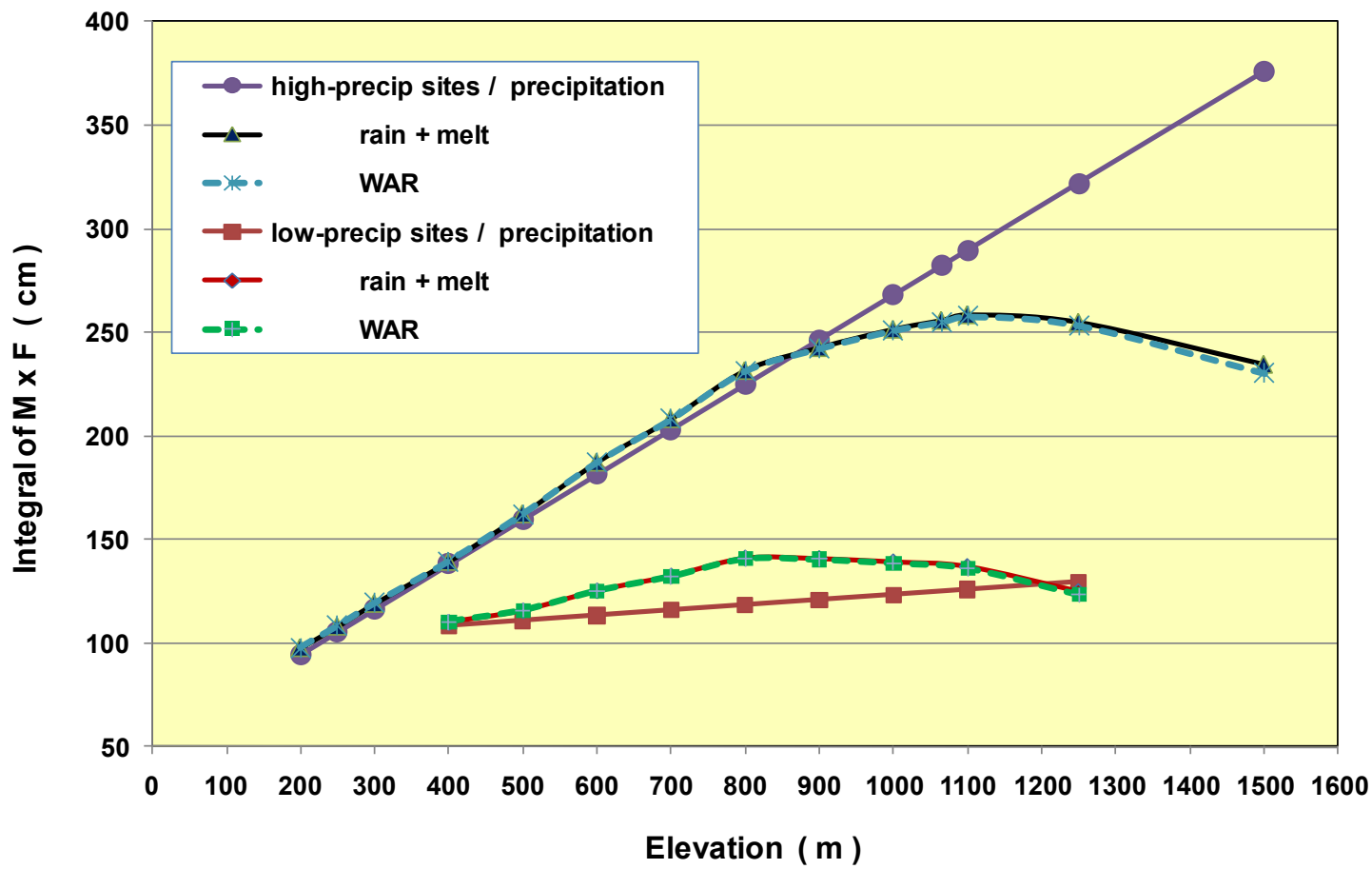

Figure 6.6. Values of the integral of the magnitude-frequency product ( $\int M \times F d R P$, limits 1-1000 yr) for realizations from EXE runs at various site elevations. Curves for precipitation are linear with elevation; those for rain plus melt and water available for runoff reach maxima in middle elevations.

Note that these results depend partly on the limits of integration, in this case over the recurrence range of 1 to 1000 years. If the upper limit is reduced to $100 \mathrm{yr}$, the elevation range over which the integral for WAR is greater than that of precipitation, for HP sites, effectively disappears. (However, the peak of the WAR integral remains at $\sim 1100$ m.) Given that the Monte Carlo model simulations are run for $1000 \mathrm{yr}$, producing maxi- 
mum-event recurrence periods of $1786 \mathrm{yr}$ (by Gringorten's plotting formula), it is appropriate to extend the frequency-magnitude integrals under consideration here to $1000 \mathrm{yr}$. Regardless of the integration limits, this $M \times F$ index is consistent with most of the other metrics applied to the realization series in showing highest values in middle elevations, indicating long-term enhancement of precipitation with snowmelt in that zone relative to lesser amounts at lower (less snow) and higher (less rain and melt) elevations.

\section{$\underline{6.5 \text { Model sensitivity }}$}

Many of my inferences and interpretations from the Monte Carlo model results are based on subtle distinctions among the series statistics and frequency characteristics, and their relations to the elevations simulated. One might challenge the significance of the putative differences between precipitation and water delivery, and in particular whether the apparent associations are robust under different model-run conditions. In this section, I present appraisals of the sensitivity of important results to the modeling and analytical methods employed. Since many metrics show the model generating the most pronounced differences between precipitation and WAR at $\sim 800 \mathrm{~m}$, I use that elevation to examine some outcome characteristics with additional model runs and analyses (see appendix K).

A) Realization values \& ExpD regression trends Frequency analysis requires the selection of probability distributions and location methods, based chiefly on considerations of computational utility and suitability to the data or realizations (Haan, 1977). My choices were guided by experience as expressed in the literature: I modeled partial-duration series as exponential distributions, with frequency/probability plotted by Gringorten's formula (Gringorten, 1963; Cunnane, 1978; de Ploey et al., 1991), then fit by simple linear regres- 
sion. The appropriateness of these methods is judged to some degree by the correspondence between the resulting trends and their constituent data or realizations. Such comparisons have been made above for precipitation at various durations from Stampede Pass records (Fig. 4.8), and for the precipitation realizations of the StpP EXP and 1065 EXE Monte Carlo runs (Fig. 5.9, 5.15); their fidelity was judged to be adequate.

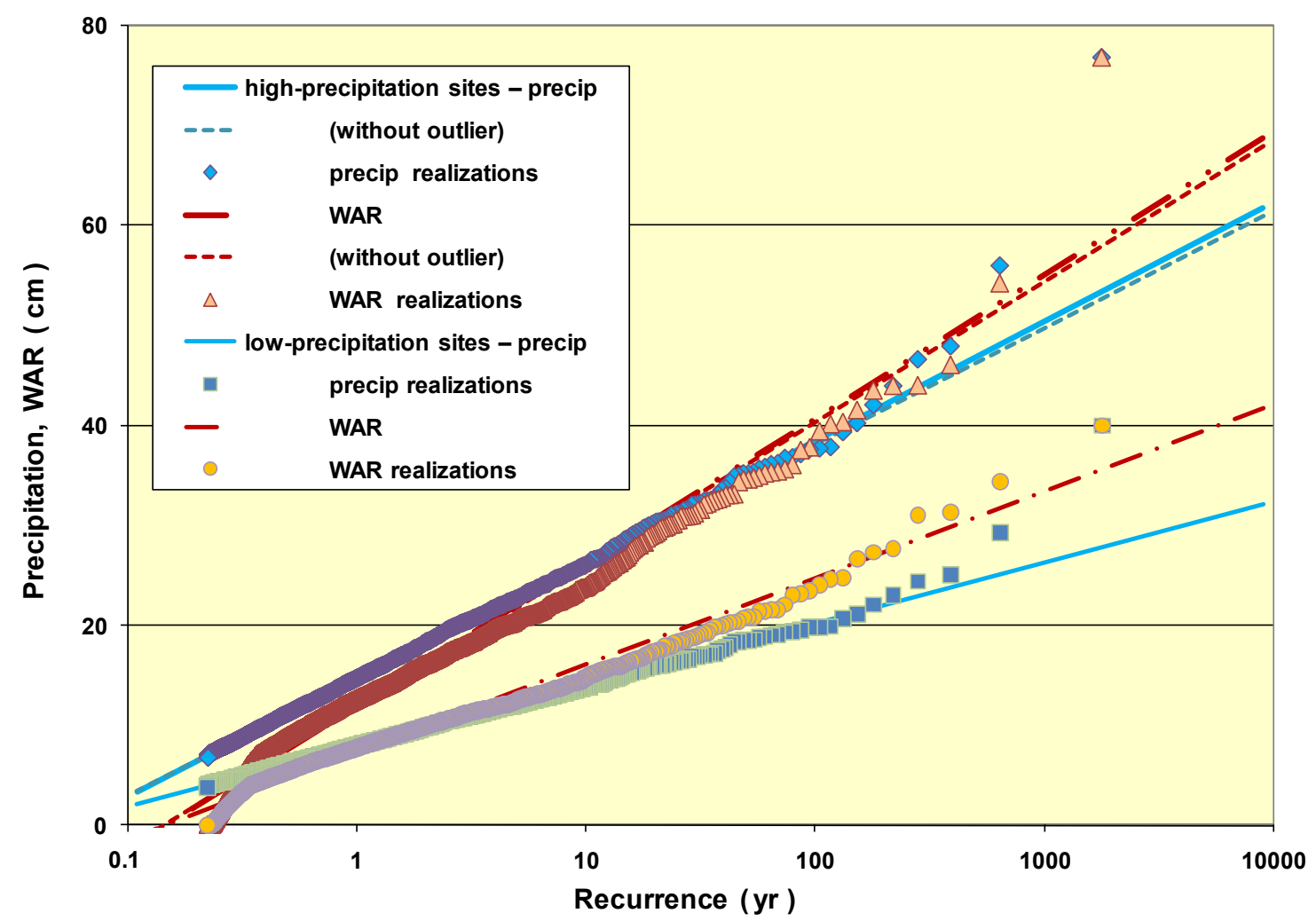

Figure 6.7. Realizations and frequency-magnitude lines of water inputs and outputs from EXE runs at 800 $\mathrm{m}$ elevation, using both wetter- and drier-site precipitation-elevation functions. For the HP sites, dashed lines show trends recalculated if the large outlier is disregarded.

The trends for WAR have not yet been evaluated in this manner, so I plot their realizations (along with P) for model runs at $800 \mathrm{~m}$ on Figure 6.7. Markers reveal the degree of association between individual event realizations and the corresponding exponential regression lines. For precipitation, as before, most points fall on or near the calculated regression lines, with the exception of the largest points. Notwithstanding those outliers, 
the regression coefficients of determination $\left(r^{2}\right)$ are 0.994 for all elevations; standard errors are $0.39 \mathrm{~cm}$ for wetter sites and $0.12 \mathrm{~cm}$ for drier sites at $800 \mathrm{~m}$, and $<0.59 \mathrm{~cm}(\mathrm{HP})$ and $<0.23 \mathrm{~cm}$ (LP) for all EXE elevation runs. I take this as indicating very good agreement between the model's precipitation results and the assumptions of my frequency analysis. However, the match is not as close for the WAR lines, chiefly at the extremes. Their $r^{2}$ values are respectably 0.955 (HP) and 0.957 (LP) at $800 \mathrm{~m}$, and $>0.928$ at all other elevations; standard errors are 1.35 (HP) and 0.80 (LP) $\mathrm{cm}$ at $800 \mathrm{~m}$, and up to 1.5 $\mathrm{cm}$ at higher elevations in wet areas.

Mismatches between realizations and their trends occur at both high and low recurrence periods (low and high probabilities). That several of the highest precipitation amounts depart from their regression lines reflects the inherent uncertainty in frequency analysis of locating the true probability/recurrence for extreme events. This is especially so for a limited observational record (Fig. 4.8), but applies even to Monte Carlo simulations with a large number of realizations. However, the largest precipitation and WAR outliers have little effect on the regressions: if deleted, the recalculated trends are very similar, within $\sim 1 \mathrm{~cm}$ or less even at 1000-yr $R P$ (dashed lines on Fig. 6.7, for HP sites), much less than the disparity in predicted magnitudes between P and WAR, or when simulated using alternate sets of random numbers (see C, below).

At high probabilities/short recurrence periods, the regression trends and the smallest WAR magnitudes diverge, unlike the precipitation series (Fig. 6.7). In the latter, all realizations exceed $\sim 5 \mathrm{~cm}$, corresponding to the partial-duration record minima; no such restrictions are imposed in the model or analysis for WAR series, which can be $<\mathrm{P}$ and as small as zero. These small WAR values fall below their regression predictions for events 
expected several times per year; in other words, the trends overestimate the realizations at very short $R P$. In particular, the WAR $=0$ points $(\sim 2.5 \%$ of the events at $800 \mathrm{~m})$ are plotted along the abscissa, a clustering that is even more common for the high-elevation runs having greater proportions of such events (Table 6.1). These model results are somewhat unreal: in the maritime Northwest (or almost anywhere), minimal amounts of water are frequently delivered to the ground in small rains in snow-free seasons and rain-free snowmelt, thus often yielding WAR amounts greater than those generated in the model. But such events are not part of my limited storm population of major precipitation events, and so are not reflected in these WAR series. It is not feasible to purge the small WAR amounts from consideration in the frequency analyses; anyway, recalculating the regressions without the WAR $=0$ events produces extremely small changes in the trends (about the same as the non-outlier differences dashed in Fig. 6.7).

(If the realizations were reduced to the annual maximum series, most of the WAR $=0$ events would disappear from the graph. For $800-\mathrm{m} \mathrm{HP}$ sites, only three out of $1000 \mathrm{yr}$ have model $\mathrm{AM}$ of $\mathrm{WAR}=0$, with just a few more $<1 \mathrm{~cm}$, so the markers would track the regression lines more faithfully down to $R P=1 \mathrm{yr}$.)

Thus, the WAR regression lines seem to overestimate many of the realizations at both long and short recurrence periods. Ultimately though, their slopes are controlled by the thousands of events in the middle, and the coefficients of determination mentioned above $\left(r^{2}>0.994\right.$ for all $\mathrm{P}$ and $>0.928$ for all WAR) inspire confidence in their validity. The fact that the highest precipitation and WAR realizations do not perfectly fit the regression lines simply shows the probabilistic irregularity due to limited numbers of events at the extreme tail of the distributions; and the mismatch between the smallest 
WAR amounts and their trends caused by the lack of any truncation for PD minima and/or exclusion from the series of unmodeled small events. Again, we apply conceptual error bands around the regression lines: $\sim 1 \mathrm{~cm}$ on both sides of the trends in middle recurrences, and up to $\pm 2-3 \mathrm{~cm}$ for rare events, for HP sites; about half that at the LP sites.

B) Results from high-precipitation versus low-precipitation sites Compared to the differences between series regressed with and without outliers, the disparity between the sets of frequency lines generated from functions based on HP and LP areas are quite large (Fig. 6.7; appendix K). Most obvious is the substantial gap between any pair of corresponding lines: at $800 \mathrm{~m}$, the wet-site precipitation for moderate to rare events is about twice that of the drier sites, and the WAR values $\sim 1.6 \times$ as large, or $\sim 20+\mathrm{cm}$ difference at 100 -yr $R P$. This divergence suggests the range of frequency-magnitude conditions possible in the region, caused by all the meteorologic and geographic factors that are not incorporated in my model (i.e., other than elevation).

Note also the different spreads of the paired P and WAR lines for the HP and LP sites at $800 \mathrm{~m}$ (Fig. 6.7). The regression-predicted WAR $>$ P deviation is greater at longer recurrence for the drier sites, and the point at which the two are equal falls at shorter $R P$. Thus, for these realizations, WAR can apparently be greater than precipitation more often, and WAR $>\mathrm{P}$ for all $R P$ longer than $\sim 1.8$ years; in contrast, for the wetter sites, WAR magnitude exceeds precipitation only above $\sim 13 \mathrm{yr} R P$. On its face, this implies that ROS enhancement is relatively more significant for LP sites, e.g., that the "true" 100 -yr event delivers much more water than the 100 -yr gauge-estimated all-phase precipitation; such a contention was part of my argument that $\sim 800 \mathrm{~m}$ is the peak ROS zone. However, I suspect that these relations are probably model artifacts of the lesser rainfall yet equal snow- 
packs modeled in the dry-site experiments. Both sets of realizations are generated from identical snow-depth and SWE functions but different storm precipitations. In other words, the same amounts of snowmelt in each set of runs can exceed a smaller amount of precipitation more often than they would exceed a larger amount of precipitation. This conforms with my interpretations of many elements of the model results presented already (sections $6.3,6.4$ ); again, this anomaly could probably be ameliorated with snowestimation functions that discriminate between wetter and drier sites, as the precipitation estimators do.

Therefore, comparison of the frequency lines generated in 800-m runs calculated separately for HP and LP sites shows that, although the precise quantities differ between them (as expected), they are similar in the ordering of the series, indicated by the predictions of WAR at greater magnitudes than P at a broad range of longer recurrence/lower probability. The model yields similar results, in this respect, regardless of the precipitation-elevation functions employed.

C) Model runs with alternate sets of random numbers All the Monte Carlo experiments presented so far have operated with the same set of random numbers, called $R \#$ seed 1 (Excel terminology; section 3.3). It is reasonable to wonder whether the suites of realizations, and particularly the ultimate frequency-magnitude interpretations of the $\mathrm{P}$ and WAR series, would be equivalent if generated from other $R \#$ sets. For comparison, I performed EXE runs for $800 \mathrm{~m}$ using the random numbers from seedings 2 and 3 (appendix K). Although utilizing the same combinations of controlling parameters and functions, these trials understandably produced differing arrays of event outcomes. For example, the number of events in 1000 model years was 4487 with $R \#$ seed 1, 4463 for seed 2, and 
4473 for seed 3 (all generated from a governing mean of 4.4 events/yr).

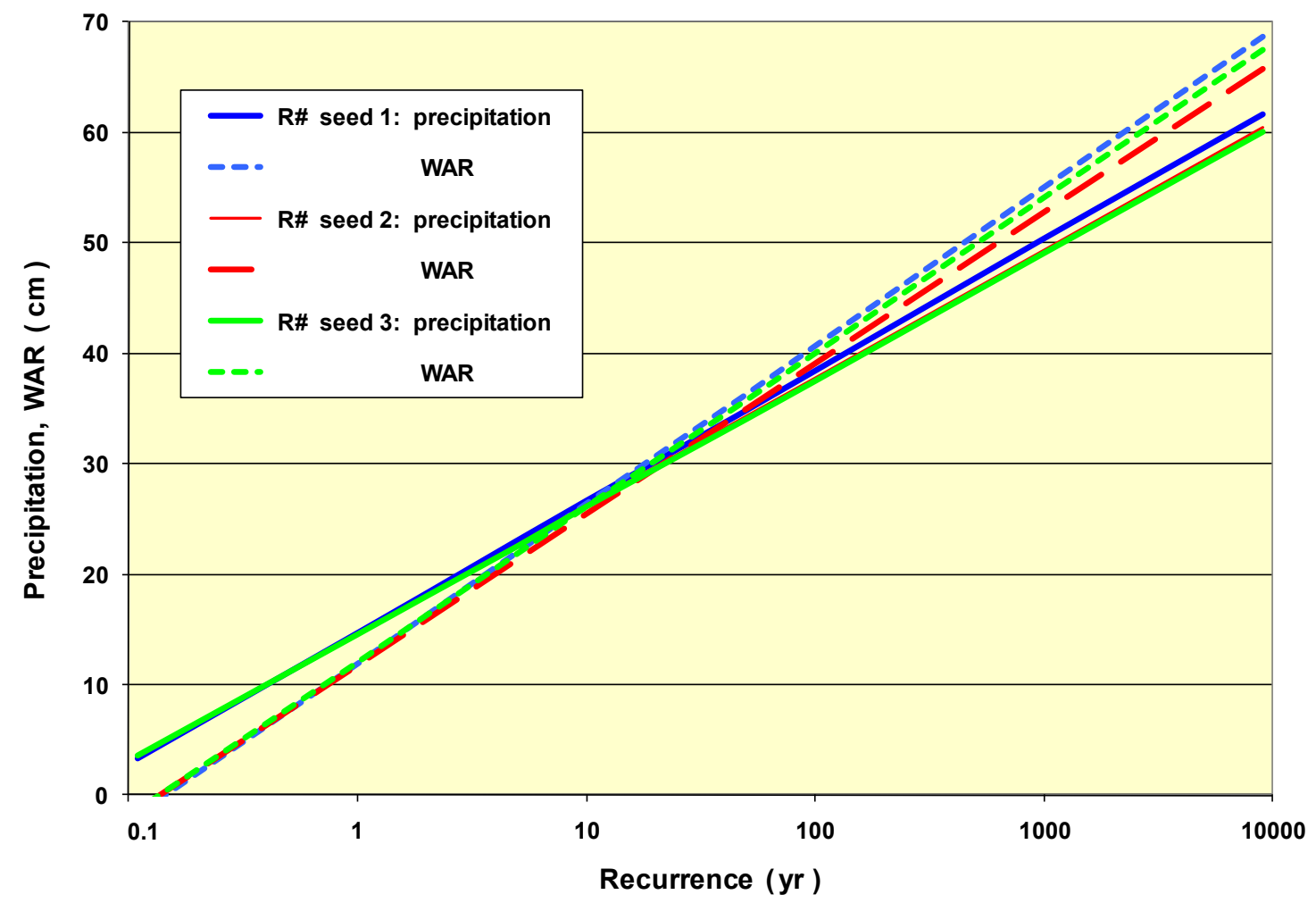

Figure 6.8. Frequency-magnitude lines produced by three $800-\mathrm{m}$ (wetter areas) EXE model runs using different random-number seeds. Three pairs of lines for precipitation (solid) and WAR (dashed), using R\# seed 1 (as previously; Fig. 6.5, 6.7) as well as seeds 2 and 3. The P and WAR lines cross at $13.0 \mathrm{yr}$ for seed $1,23.5 \mathrm{yr}$ for seed 2 , and $9.9 \mathrm{yr}$ for seed 3 , indicating recurrence above which WAR $>$ P.

The frequency-magnitude relations for P and WAR are represented by three pairs of exponential regression lines (Fig. 6.8). As with previous comparisons, the precise line positions and match of markers to regression lines (not shown) differ among the three runs because the P and WAR series (and most of the probabilistic realizations that determine them) are the products of different random numbers at every individual model calculation. The fits of WAR points to trends are slightly poorer for seeds 2 and 3 than for seed 1 (Fig. 6.7); but on the other hand, the large outliers produced by $R \#$ seed 1 do not appear in the realizations from seeds 2 and 3. However, the relative positions of the $\mathrm{P}$ and 
WAR curves in each of the three pairs is the same, indicating consistently greater water inputs than precipitation at the higher recurrence intervals at $800 \mathrm{~m}$. The divergence between each P and WAR line can differ (e.g., for seed 3, WAR $>$ P by a greater amount at long $R P$ than are the seed 1 and 2 pairs), but the differences are slight and the orders are the same. Tests on series means and variances show that each pair of P and WAR series differs from each other, while the three P series and the three WAR series are statistically identical to one another ( $F$ test on variances and Student's $t$ test on means, at $\alpha=0.05$ ). Also, the proportions of hydrologic events for the three pairs tested (such as \%ROS) are all within $\sim 1 \%$, and the $M \times F$ integrals are similar.

Recall that these WAR versus P differences are small even at the peak ROS elevation of $800 \mathrm{~m}, \sim 3-5 \mathrm{~cm}$ at 1000 -yr recurrence. It might be risky to use any particular set of precipitation/WAR recurrence regressions for quantitative prediction of water magnitudes. However the Monte Carlo simulations, with thousands of events per experiment, are fairly robust judging from comparison of the chief controlling input series $(\mathrm{P})$ and the ultimate consequent output series (WAR). It seems valid to interpret these results as indicating that the model produces consistent results regardless of low-probability events or differences in random-number sets utilized.

\subsection{Probabilistic elements of the Monte Carlo simulations - discussion}

Initial evaluations of the model and its experimental outputs have been presented in this and the previous chapter. Before moving to conclusions regarding the hydrologic significance and elevation aspects of ROS (chapter 7), I offer some discussion of a few points regarding model performance and results.

My Monte Carlo model includes a dozen stochastic components producing values 
of event date, duration, total precipitation, etc.; several deterministic algorithms act on the probabilistic elements to generate hourly weather, snow and percolation quantities. Each module could be programmed in simple to complex ways (Tables 3.1, 4.1). In each case, the routines I selected and developed were based on a combination of applicability to the large storms of interest affecting the Pacific Northwest (particularly ROS events), including available observational data; and a balance between theoretical validity and program simplicity within the VBA-spreadsheet platform. A frugal prototype is more appropriate for this initial modeling attempt, and easier for others to understand and manipulate. So although almost every component is improvable, I believe that the techniques chosen are justified by the modeling strategy and the satisfactory results. Nevertheless, it is worthwhile to address some aspects that may strain the boundaries of realism.

Several concerns involve the model's water inputs (precipitation, and rain plus snowmelt in the pack) and outputs (water at the ground surface). The goal of generating multiple events per year dictated the tactical choices of partial-duration series (rather than annual-maximum series) and exponential distributions (more applicable to PD series than extreme-value functions; chapters 3, 4; appendix F). But as with any frequency analysis, the fit is imperfect between the points representing a given hydrologic series of data or realizations, plotted using a chosen formula, against the trends generalized from those points according to the assumed parent distribution (or any alternative). Interpretations of these functions and their graphics must include the stipulation to the extent that these phenomena behave as exponential distributions.

For example, storm-precipitation data from Stampede Pass (Fig. 4.8) show better correspondence between the points and lines for PD than for AM series (the latter poorly 
represented by ExpD), and for shorter event durations than for the long continuous storms. Several of the largest (low-probability/long-recurrence) LCS amounts exceed those based on the ExpD trend; this is also common for other weather stations analyzed in this project. This pattern suggests that the records' biggest storms may warrant longer return periods than their plotting formulas specify. The kink in the Stampede Pass LCS data is noteworthy: though such discontinuities occur in many storm- and flood-frequency curves (including most of the LCS precipitation records in my sample), this bend implies at least two subsets within the population being sampled. Waylen and Woo (1982, 1983; Waylen, 1985a,b), studying flood-generating processes in similar climate and terrain in British Columbia, suggest that a refined analysis of dual storm populations (rainvs snowmelt-generated) might be appropriate for data like those collected in this project. Nevertheless, the coefficient of determination for this PD series of LCS precipitation at Stampede Pass is a respectable 0.956; for the other seven stations, $r^{2}$ ranges $0.947-0.993$ (appendix E).

The use of exponential distributions to generate Monte Carlo realizations raises other issues. The model seems to reproduce proper collections of precipitation values (as in Fig. 5.9, 5.15 and 6.7), fitting the governing trends generally better than in the Stampede Pass data (Fig. 4.8). However, outcomes from this array of random numbers do produce one extreme outlier, exceeding $100 \mathrm{~cm}$ (in $\sim 7-8 \mathrm{~d}$ ) at all model elevations $>1100 \mathrm{~m}$; extrapolated, it would have a recurrence $>200,000$ yr at Stampede Pass. The model's ability to generate seemingly extraordinary precipitation amounts, particularly for highelevation sites using the wet-site model functions, is a consequence of the simple linear estimation of those ExpD parameters with elevation. Perhaps a different estimator would 
be more suitable (e.g., so that $\mathrm{P}=\mathrm{f}\left[\mathrm{elev}^{<1}\right]$ ), but would require some data on storm precipitation at elevations above Snoqualmie Pass, Crystal Creek-White River, and Stampede Pass. On the other hand, it is possible that the exponential regression trends derived from storm precipitation data may underestimate events at long recurrence intervals (Fig. 4.8). Finally, huge storms may not be that unrealistic within a hypothetical $1000 \mathrm{yr}-$ especially considering the recorded maximum LCS at Stampede Pass, $\sim 57 \mathrm{~cm}$ in $250 \mathrm{~h}$ (8-18 Dec 1956), or $\sim 46 \mathrm{~cm}$ in just $36 \mathrm{~h}$ at Mt Rainier National Park (6-7 Nov 2006). Correspondence is likewise imperfect, but satisfactorily explainable, between the ExpD regressions and model results for the key output of water available for runoff (Fig. 6.7). The realizations for WAR are less than the regression-calculated exponential trends for high-probability/short-recurrence events, indicating model outcomes in which little or no liquid water is generated or reaches the ground; these negative residuals appear in all runs. In this 800-m EXE experiment, the WAR realizations in low-probability/long-recurrence events are greater than the regression-predicted values (the largest cases again determined by the outlier). In runs at different elevations or using alternate random-number sets, such realizations can be above or below the ExpD regression trends, but the residuals must sum to zero. The combination of negative residuals at high frequencies and positive or negative residuals for rare events can create visual patterns of points forming convex or inflected curves around the straight lines, and an impression that the exponential distribution does not fit these quantities well. But the bulk of middle-rank outcomes dominate the position and slope of the ExpD lines; and $r^{2}$ values in the EXE runs are acceptable: all $>0.994$ for precipitation, and $>0.923$ for $\mathrm{R}+\mathrm{M}$ and WAR.

Further analysis of storm precipitation and WAR series might include finding a 
more appropriate frequency distribution. Also, examination of the properties of the annual maximum series has been left for future work: they could be analyzed with ExpD, EV1, and/or some other distribution to see how AM series derived by simulation from these model realizations correspond with those of the instrumental record.

A similar consideration involves the longest storm durations the model can generate. Duration is related to total precipitation through bivariate-normal functions, so very large precipitation amounts are more likely to be realized during long storms; the larger $\mathrm{P}$ amounts at higher elevations call for longer events, too (Fig. 6.1). The model currently restricts event durations to $252 \mathrm{~h}$ (10.5 d), so as to fit within the 256 columns of Excel 2003 spreadsheets (Excel 2007 and 2010 have more columns, but the model was designed for earlier versions.) This maximum is reached in runs at all elevations, but rarely ( $\leq 8$ times in 4487 events). The average durations at higher sites is $\sim 60-100 \mathrm{~h}$, which is comparable to the LCS record averages of $66 \mathrm{~h}$ at SnqP and $87 \mathrm{~h}$ at StpP. However, as with precipitation magnitude, modeled durations should not rise limitlessly with elevation.

Although more deterministic than stochastic, another duration-related matter is the $6 \mathrm{~h}$ added to model events after precipitation ends $(D u r E=D u r+6)$, simulating time when water can continue to drain from a snowpack and still be considered part of that event's WAR. The drainage period could range from zero, counting no percolation after precipitation ends, to however long it takes for all water to drain out - perhaps many days in the case of very deep snowpacks. For long drainage periods, algorithms would have to be included for declining drainage rates and freezing within the snowpack. The post-rainfall period of $6 \mathrm{~h}$ is a conservative compromise, chosen because it is the break period that was originally used to define long continuous storms (section 3.3). Note that WAR values 
generated in model events depend in part on the length of the post-rainfall period selected. In the example of StpP EXP event \#3230 (Fig. 5.7, 5.8), WAR would be $\sim 0.5 \mathrm{~cm}$ greater if the extra bit of post-DurE infiltration were counted.

Questions may surround the model's ability to generate very large snow quantities, as described in sections 5.3 and 5.4. For event-initial depth and SWE, tests on the Stampede Pass EXP results (Table 5.1; Fig. 5.10, 5.11) show good agreement between realizations and the controlling input parameters based on snow measurements. The EXE realizations for 1065 m (StpP's effective elevation; Table 5.3, Fig. 5.16) are generally lower than those using the station record, particularly for snow depth (calculated as bivariate normal following SWE), but that difference is explainable since data compiled in this project show that Stampede's snowpack is usually deeper than the norms at comparable regional elevations.

However, all the Monte Carlo experiments produce some realizations of initial snow amount that are greater than anything in the record, particularly for the highest elevations. At 1065-1500 m, model maxima are 1004-1577 cm SWE and 1254-15,771 cm snow depth (Tables 5.2, 6.1). In contrast, the most voluminous packs measured in the region have been much smaller. Of the sites in this study, Snowshoe Butte snow course (1494 m elevation) was greatest at $\sim 258 \mathrm{~cm} \mathrm{SWE}$ and $\sim 564 \mathrm{~cm}$ depth (separately, late winters of 1972 and 1974); several have experienced $>200 \mathrm{~cm} \mathrm{SWE}$ and/or $>500 \mathrm{~cm}$ depth (e.g., Stampede Pass, Olallie Meadows; all from CoopSS data). In the near vicinity, the Cayuse Pass course (1615 m elevation) has held $381 \mathrm{~cm} \mathrm{SWE} \mathrm{(836} \mathrm{cm} \mathrm{depth),} \mathrm{with}$ several other sites having peak accumulations greater than $250 \mathrm{~cm} \mathrm{SWE}$ and/or $600 \mathrm{~cm}$ depth. Although the modeled maxima substantially exceed these quantities, the averages 
of model-event initial snow amounts appear much more reasonable, ranging up to $\sim 94 \mathrm{~cm}$ SWE and $337 \mathrm{~cm}$ depth at $1500 \mathrm{~m}$ (Table 6.1). It is impractical to statistically evaluate sets of randomly chosen event values against the more regular measurements at snow and weather stations, but these averages are at least within the same orders of magnitude as the average winter-time volumes at high elevations (and close at StpP: Fig. 5.10, 5.16). Nonetheless, the occasionally extreme values of model SWE and depth, and the large ratios of modeled over observed maxima (up to $\sim 19 \times$ ) are worrisome.

The high model maxima are explicable (sections 5.3, 5.4) as artifacts of the mathematical formulae used to calculate initial snow amounts, allowing generation of very large quantities when extreme random numbers dictate values on the far right tail of the log-normal distribution. This effect is inflated because the log-means and log-standard deviations are functions of elevation (along with storm date), calculated from polynomial trend surfaces chosen by best fits to many data sets, plus compromises in evaluating their shapes across elevations and through the storm season. Not all the available data were used to generate the parameters of initial SWE and depth. In particular the figures from Corral Pass, the study area's highest snow station but with relatively light packs due to Mt Rainier's rain shadow, were excluded from the function for log-mean of SWE, allowing that snow-elevation gradient to continue increasing for higher elevations. Both Corral Pass and Crystal Creek-White River (another high but rain-shadow site; Tables D.1, D.2) were included in the log-mean depth functions, which tend to lower the trend surfaces and limit calculation of extreme snowpacks, but the generation of depth as bivariatenormal on SWE may permit the production of large water-equivalents and thus very large depths in some model events. On the other hand, the $0.1-0.8$ limits on snow density re- 
strict the maximum depths generated from selected SWE (i.e., depth must be $\leq 10 \times$ SWE), although these defaults do not seem to have affected many of the largest realization values (Fig. 5.11).

Further work on the snow-estimation functions could incorporate more stations at elevations $>1200 \mathrm{~m}$ (and $<250 \mathrm{~m}$, also poorly represented), but would require expanding the study region, as all available stations with sufficient record are used already. Another approach would be to split the population into high-snow and low-snow sites (as done in calculating precipitation parameters for HP and LP areas), which would be helped by greater sample size; then the Monte Carlo simulations could be run separately for wetter/snowier versus drier areas within the central Cascades. Also, the bivariate-normal relationship between snow depth and water-equivalent calculations could be explored further, to ensure that their joint outcomes correspond to natural variability. This is additionally important because in this model depth and SWE together determine snow density, which affects snow accumulation/melt rates, porosity, and hydraulic conductivity, which all influence modeled percolation speed and volume.

Fortunately, the largest snowpack realizations do not seriously distort the model's frequency-magnitude results. The extremes are rare, and occur only at the highest elevations. For example, in the 1500-m run, initial snowpacks of SWE $>400 \mathrm{~cm}$ and depth $>$ $1000 \mathrm{~cm}$ (beyond any measured amounts) were exceeded in only 2.05 and $8.4 \%$ of the 4487 events, respectively; for $1250 \mathrm{~m}$ and lower, $<1 \%$ of the events. Furthermore, with respect to runoff, model snowpacks cannot contribute an unreasonable amount of WAR even under extreme conditions. During a storm with the model-maximum $252 \mathrm{~h}$ and 125 $\mathrm{cm}$ precipitation, plus very warm temperatures $\left(\sim 22^{\circ} \mathrm{C}\right)$ and strong winds $(\sim 10 \mathrm{~m} / \mathrm{s})$ 
throughout, about $260 \mathrm{~cm}$ of meltwater could be generated. (Doubling the precipitation melts $\sim 295 \mathrm{~cm} \mathrm{SWE}$; for the stated conditions except $\sim 10^{\circ} \mathrm{C}$ temperature, the total drops to $\sim 125 \mathrm{~cm}$ of melt.) These values are in the neighborhood of the maximum observed snowpack water-equivalents cited above. Thus, an initial (or accumulated) $1000 \mathrm{~cm}$ or more SWE simulated in a model event cannot yield more meltwater than could 200-300 cm packs, the size actually observed in this area.

In contrast to SWE, the oversized model-generated snow depths present knottier complications, due to their effects on water's travel times through extreme snowpacks. Recall that the calculated percolation rate of rain plus meltwater depends on snow depth, along with the $\mathrm{R}+\mathrm{M}$ input flux and the snow porosity and hydraulic conductivity (both functions of snow density; section 3.1C). We must consider whether outflow from an ex-

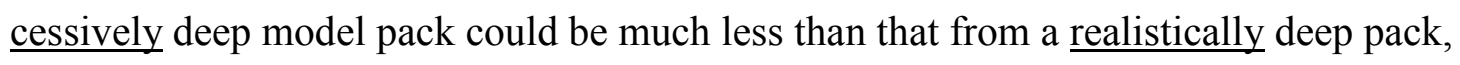
and whether such differences affect event proportions and magnitudes.

In this model, liquid water will be present and mobile only if air temperature is above freezing for at least part of an event. In EXE runs at higher elevations, no percolation to the ground occurred in $\sim 10 \%$ (at $1100 \mathrm{~m}$ ) to $35 \%$ (1500 m) of model storms, in most of which the temperatures rarely rose above freezing. So excessively deep initial model snowpacks do not significantly affect these events (except to produce even deeper accumulations). However, when temperatures are above freezing for large parts of the event, the difference between reasonable and extraordinary pack depths might affect the resulting percolation volumes. In such model cases, as mentioned, whether and how much water can transit very deep snow depends on the interaction of rain + melt input rates, the snow's hydraulic properties, and event duration. Considering the magnitude of 
the deepest snowpacks simulated (Table 6.1), this model's kinematic equations show that heavy water inputs of $1-2 \mathrm{~cm} / \mathrm{h}$ could move through $10,000 \mathrm{~cm}$ of high-conductivity snow in $\sim 57-36 \mathrm{~h}$ (or longer, when slowed by shock interactions with slower fluxes). But even with these rapid rates, some water would be stranded in the pack at the end of any practical storm duration - i.e., WAR would be $<\mathrm{R}+\mathrm{M}$, and probably $<\mathrm{P}$. At the other extreme, a small (but common) input of $\sim 0.1 \mathrm{~cm} / \mathrm{h}$ would not pass all the way through a low-conductivity snowpack $>2000 \mathrm{~cm}$ deep in the maximum $252 \mathrm{~h}$, and this event would appear as $\mathrm{WAR}=0$, even though $\sim 25 \mathrm{~cm}$ of liquid water started the trip.

These latter combinations of circumstances contribute to the proportions of model events in which percolation is inhibited, particularly the $\sim 75-90+\%$ of EXE events at 1100-1500 $\mathrm{m}$ for which WAR $<$ P. So model events that begin with excessive snowpacks can add to the statistics of low-WAR events, especially at the higher elevations. However, they do not add to the rosters of WAR $>$ P events, due to the suppression of liquid transit through great snow depths. This provides a conservative constraint on the proportions of excessive ROS events generated by the model: that is, \%ROS is probably underestimated somewhat by this Monte Carlo experiment. 


\section{DISCUSSION, SUMMARY \& CONCLUSIONS}

\subsection{Storm simulation model - discussion}

Communal curiosity among hydrologists about rain-on-snow in the Pacific Northwest (chapter 1) led me to a series of research questions and hypotheses (chapter 2), particularly regarding the long-term magnitude and frequency of ROS across elevations in the western Cascade Range. To address them, I created a computer model to portray the broad range of conditions during large storms/ROS common in the region, because that variability is not captured by the instrumental record.

When this project began (1982), ROS had been investigated using measurements and modeling over several decades, particularly in the PNW (e.g., USACE, 1956; Harr, 1981); since then, attention has spread from western North America to other parts of the world (Table A.1). However, most approaches have temporal and/or spatial limitations. The general deficiencies of the observational record are illustrated by the compilation of ROS occurrence in the U.S. West, in which McCabe et al. (2007) counted days at weather stations with ROS-favorable temperature and precipitation, but could not know whether any water left the snowpack, let alone the quantities. We do not have hourly temperature, wind or lysimeter measurements, at more than a few research-grade field stations and a small fraction of the time, so it is difficult to synthesize ROS frequency series from the record, or find observed events for calibration and validation of model results. Likewise, previous modeling of ROS processes was limited to techniques for percolation of water through snow (e.g., Colbeck, 1972, 1975b, 1977b,c). Opportunities for snow-hydrology modeling have expanded with theoretical advances and computer capability, but no programs were designed to examine the frequency-magnitude properties of ROS phe- 
nomena over the long term, pertinent to the Northwest or anywhere else. Despite recent interest in ROS, to my knowledge there are no other models synthesizing long sequences of storms in order to generate a sample of ROS events and examine their characteristics.

Having decided on a modeling approach, particularly a novel integration of probabilistic storm properties with deterministic snow and percolation elements in a frugal computer format, I have been challenged to ensure the validity of my methods and results. As noted (chapter 2, section 3.2), there are inherent problems testing models such as this that simulate potential but unobserved conditions. Ideally, such a model would be calibrated against several full data sets and then validated against separate data series, each spanning a respectable observational record. This is not always possible; here, as in many situations, it is the dearth of adequate long-term observations that necessitate modeling. Lacking a good record, the best surrogates are a combination of partial data sets and other models performing analogous simulations for components of the whole.

At the least, the model should be able to reproduce the statistical properties of the controlling inputs. Model results presented in chapters 5 and 6 support the suitability of this model's algorithms in mimicking the important weather and snowpack features of large storms in the PNW. Most importantly, the chief governing input of precipitation during long continuous storms is reliably reproduced, as the partial-duration series generated by the model's exponential distributions successfully imitate the observed series. In the tests for Stampede Pass (StpP EXP) and its effective elevation (1065 EXE), the realizations can be considered statistically the same as the observed series (Tables 5.1, 5.2, and associated text and figures). Likewise, the model's algorithms for simulating storm duration, initial snowpack, temperature, wind speed, etc. produce appropriate values, 
even though some of these factors are synthesized independently or semi-randomly rather than emulating their interconnections more realistically.

Turning from the probabilistic to the deterministic model components, the modules that manipulate snow accumulation and melt (mass- and energy-balance functions simplified for ROS conditions) and snow-water percolation (adaptations of kinematic wave equations) also behave satisfactorily. Section 5.2 presents the techniques and results of tests using the single-event model version against a hypothetical 3-h rain-on-snow (Colbeck, 1976; Fig. 5.1); and against conditions measured during ROS at Stampede Pass and at field sites in southwest Oregon (Wetherbee, 1995; Table H.1). The sample of wellrecorded storms was small, and calibration and testing utilized all of them. However, the model could satisfactorily reproduce the measured outflows caused by observed precipitation under extant temperatures and wind speeds. Questions remain regarding the complementary changes in snow depth and water equivalent, partly because recorded events rarely had simultaneous measurements of both quantities. Also, despite good correspondence between field results and model simulations (as in Fig. 5.2 for DEMO event \#4), the nearly identical quantities of total $\mathrm{R}+\mathrm{M}$ and WAR for most test events hints that the model's percolation rates may be too fast. Yet, the modeled flux rates are similar to measurements reported in the literature (e.g., Floyd and Weiler, 2008).

Again, it would be preferable to compare my model to others, also combining stochastic and deterministic approaches, to evaluate relative performance. Unfortunately, no such models exist, apparently, and certainly none focusing on the combination of winter storms affecting western North America, rain-on-snow conditions, or the generation of long stochastic series for frequency analysis. There are more elaborate snowpack-perco- 
lation models that could be combined with my probabilistic storm series, but attempting that from the beginning would have nullified the advantages of the simple model developed here.

Thus, ultimate judgments as to the suitability and usefulness of the model components must rest partly on their ability to generate reasonable realizations. Although each element is improvable (Tables 3.1, 4.1), I believe that the techniques chosen are justified by the modeling strategy and, ultimately, the satisfactory results. Despite these questions and reservations, this model does an adequate job simulating the processes involved, in both its deterministic and probabilistic components.

\subsection{Hydrologic significance \& favored elevations of rain-on-snow}

Having accepted that the model effectively replicates large storms, including rain-

on-snow events, we return to the questions and hypotheses proposed early in this dissertation to discuss the findings from long series of simulated storms over a range of elevations in the Northwest. The research questions regarding quantitative aspects of water input during large storms/ROS (section 2.3) were:

- Precipitation versus water available for infiltration/runoff: Can the magnitude of liquid water delivered to the ground during ROS events be different from the measured total (liquid plus solid) precipitation, so that gauge records during such events are over- or underestimated? If so, what are the true frequency characteristics for a site or a region?

- Elevation: ROS seems to be most common in the middle elevations, where winter rain is liable to fall on existing snowpacks. Is there a definable elevation zone of maximum long-term hydrologic and geomorphic significance for ROS? 
The model results address the two sets of proposed hypotheses concerning storm behavior and ROS. The results are elevation dependent, as expected, although some inferences from the several evaluation metrics are ambiguous.

A) Are the frequency characteristics of stormwaters actually reaching the ground different from those of the measured total precipitation? These results are clear: in experimental runs for Stampede Pass weather station (StpP EXP, section 5.2) and the corresponding $1065 \mathrm{~m}$ effective elevation (1065 EXE; section 5.3), Student's t-tests show significant divergence between the $\mathrm{P}$ and WAR series means (although their variances are not different according to the F test). So for Stampede Pass, using both site-specific and regional-elevation input parameters, we can reject the null hypothesis for high sites, $H_{0}$ : WAR $[\mu, \sigma]$ $\geq \mathrm{P}[\mu, \sigma]$, leaving the alternative $H_{I}$ : WAR [ ] $<\mathrm{P}[$ ] uncontradicted.

\begin{tabular}{|c|c|c|c|}
\hline Elevation zone & Hypotheses & EXE results & Inference \\
\hline high & $\begin{array}{c}H_{0}: \text { WAR }[\mu, \sigma] \geq \mathrm{P}[\mu, \sigma] \\
H_{l}: \operatorname{WAR}[]<\mathrm{P}[]\end{array}$ & $\begin{array}{l}\text { reject } \\
\rightarrow \text { yes }\end{array}$ & WAR [ ] < P [ ] \\
\hline middle & $\begin{array}{l}H_{0}: \text { WAR }[] \leq \mathrm{P}[] \\
H_{l}: \text { WAR }[]>\mathrm{P}[]\end{array}$ & $\begin{array}{l}\text { do not reject } \\
\rightarrow \text { no }\end{array}$ & WAR [ ] $<\mathrm{P}[]$ \\
\hline low & $\begin{aligned} H_{0}: \text { WAR }[]<>\mathrm{P}[] \\
H_{l}: \text { WAR }[] \approx \mathrm{P}[]\end{aligned}$ & $\begin{array}{l}\text { do not reject } \\
\rightarrow \text { no }\end{array}$ & WAR [ ] $<$ P [ ] * \\
\hline \multicolumn{4}{|l|}{ Notes } \\
\hline $\begin{array}{l}\text { Elevation zones gene } \\
\text { Hypotheses tested us } \\
* \text { perhaps true at }<2\end{array}$ & $\begin{array}{l}\text { this point }- \text { see Table } 7.3 \text { for } \mathrm{q} \\
\text { udent's } \mathrm{t} \text { for means }(\mu) \text { and } \mathrm{F} \text { fo } \\
\text { (minimum run elevation) }\end{array}$ & $\begin{array}{l}\text { ication. } \\
\text { ances }\left(\sigma^{2}\right) \text {. }\end{array}$ & \\
\hline
\end{tabular}

Furthermore, in every case examined by Monte Carlo simulation - for each elevation, whether using functions for high- or low-precipitation sites - the series of precipitation and WAR realizations were distinct (Fig. 6.2; Table 7.1). Although the variances were similar throughout the tested elevation range, the means were different even for the 
low-elevation runs. In the run at $200 \mathrm{~m}$, the $\sim 3 \mathrm{~mm}$ gap between average $\mathrm{P}(6.68 \mathrm{~cm})$ and average WAR $(6.39 \mathrm{~cm})$ is about twice the difference necessary to be considered statistically different (even at $\alpha=0.001$, due chiefly to the very large sample of 4487 model events). Even though the low-elevation P and WAR series appear alike (seen for $500 \mathrm{~m}$ in Fig. 6.5), the statistics indicate that all such pairs are different. Thus, model results confirm the first supposition for individual sites: WAR $<$ P, in terms of series volume and frequency parameters, at all elevations tested.

B) Where are the elevations of greatest rain-on-snow significance in the west-central Washington Cascades? The general P-WAR difference across elevations seems to refute many of my initial notions, as expressed in the transect (Fig. 2.1) and hypotheses (section 2.3B). Based on the cases for $200-1500 \mathrm{~m}$, in wetter and drier areas, the series means and variances yield mixed results over the broad elevation zones shown in Table 7.1. By this measure alone, hypothesis $H_{l}$ is supported only for the highlands.

However, we should not yet discard the questions regarding ROS elevation preferences. The series $\mu$ and $\sigma$ are not the only ways to compare the P and WAR realizations, or determine where meltwater may most contribute to larger stormwater inputs; several other measures are available to evaluate the frequency-magnitude and significance of ROS. In addition to the basic statistics, three other types of metrics have been introduced to analyze the series and their changes with elevation, as described in sections 6.3 and 6.4 (Table 6.1; Fig. 6.2-6.4, 6.6). I employ these four classes of metrics to determine candidate thresholds for the lower boundary, optimal effect, and upper boundary of significant ROS occurrence. Table 7.2 summarizes this information: for each class of metrics, one or two tests are listed and the elevations or ranges inferred from those tests. 
In most of them, the elevations of changes or maxima of ROS frequency can be clearly identified, but other answers are murky. Note that these are my interpretations from statistical properties of the realizations, and especially the elevation-varying relationships between the P and WAR series. Some of the graphic peaks and slope changes are subtle; the deduced ROS-zone interpretations are problematic toward the edges of the elevations simulated, where few observation stations contributed to the functions guiding the model. 


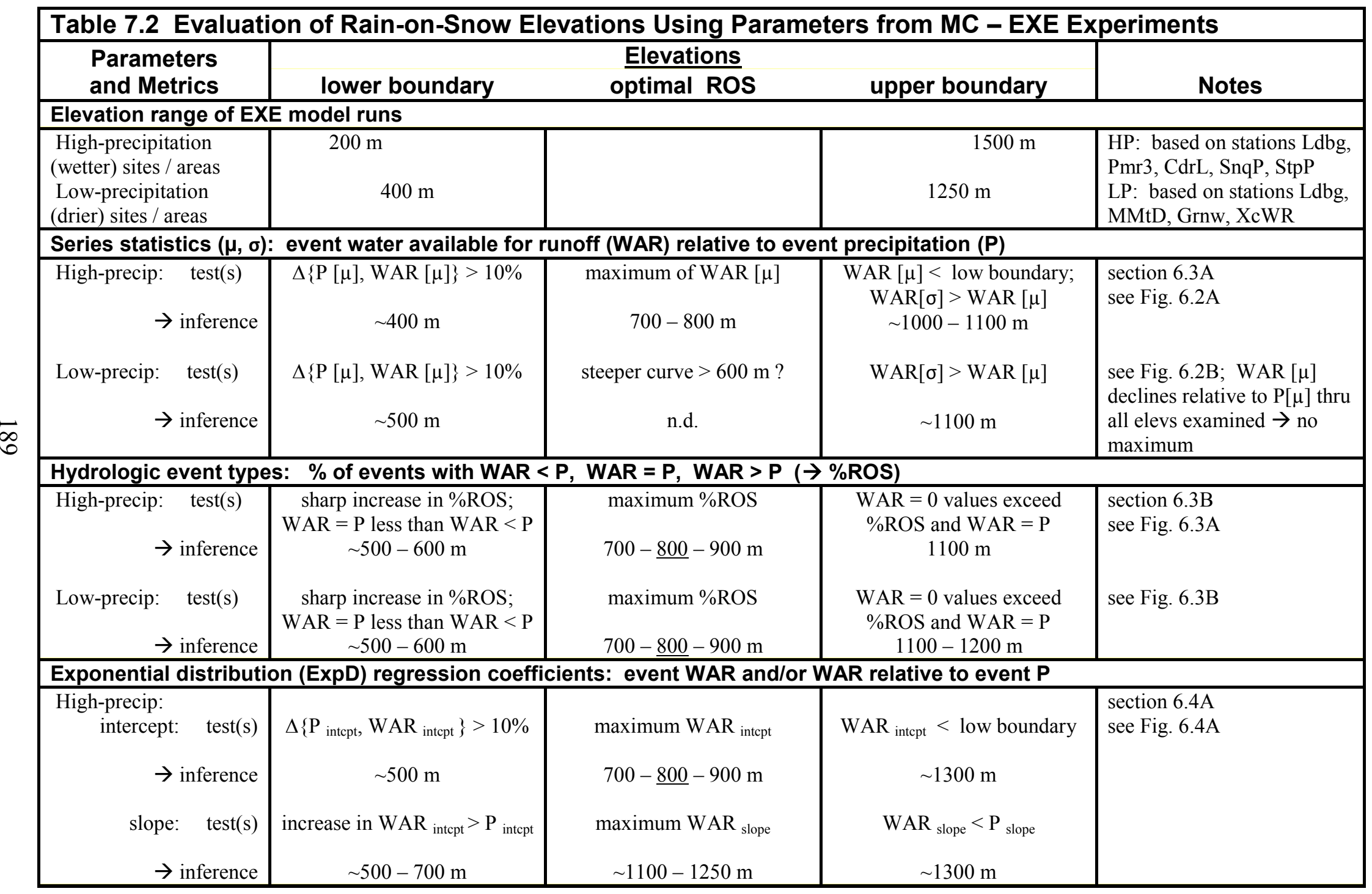




\begin{tabular}{|c|c|c|c|c|}
\hline $\begin{array}{r}\text { Low-precip: } \\
\text { intercept: test(s) } \\
\rightarrow \text { inference } \\
\text { slope: test(s) } \\
\rightarrow \text { inference }\end{array}$ & $\begin{array}{c}\text { n.d. } \\
\text { increase in } \mathrm{WAR}_{\text {intept }}>\mathrm{P}_{\text {intcpt }} \\
\sim 500-700 \mathrm{~m}\end{array}$ & $\begin{array}{c}\Delta\left\{\mathrm{P}_{\text {intept }}, \mathrm{WAR} \text { intpt }\right\} \\
\text { increasing }>800 \mathrm{~m} \\
\text { n.d. } \\
\text { maximum WAR } \\
800-1100 \mathrm{~m}\end{array}$ & n.d. & $\begin{array}{l}\text { see Fig. } 6.4 \mathrm{~B} \\
\text { small, subtle differences in } \\
\text { intercept and slope values } \\
\rightarrow \text { poor boundaries and } \\
\text { peaks }\end{array}$ \\
\hline \multicolumn{5}{|c|}{ Integral of magnitude $x$ frequency: $\int M \times F d R P$ of event WAR relative to event $P$} \\
\hline $\begin{aligned} & \text { High-precip: } \text { test(s) } \\
& \rightarrow \text { inference } \\
& \text { Low-precip: } \text { test(s) } \\
& \rightarrow \text { inference }\end{aligned}$ & $\begin{array}{c}\mathrm{WAR} \int>\mathrm{P} \int \\
\sim 500 \mathrm{~m} \\
\mathrm{WAR} \int>\mathrm{P} \int \\
\sim 400 \mathrm{~m}\end{array}$ & $\begin{array}{l}\operatorname{maximum~} \mathrm{WAR} \int>\mathrm{P} \int ; \\
\text { maximum } \mathrm{WAR} \int \\
800-1100 \mathrm{~m} \\
\\
\text { maximum } \mathrm{WAR} \int>\mathrm{P} \int ; \\
\text { maximum } \mathrm{WAR} \int \\
\sim 750-\underline{800}-1000 \mathrm{~m}\end{array}$ & $\begin{array}{c}\text { gentle decline of WAR } \int \\
\text { for }>1250 \mathrm{~m} \\
\sim 1300 \mathrm{~m} \\
\mathrm{P} \int \text { exceeds WAR } \int \\
1200 \mathrm{~m}\end{array}$ & $\begin{array}{l}\text { section } 6.4 \mathrm{C} \\
\text { see Fig } 6.6 \\
\text { values }[\mathrm{cm} / \mathrm{yr}] \times \mathrm{yr} \rightarrow \mathrm{cm} \\
\text { integrals evaluated over } \\
\text { range } 1-1000 \mathrm{yr}\end{array}$ \\
\hline \multicolumn{5}{|c|}{ Notes } \\
\hline \multicolumn{5}{|c|}{$\begin{array}{l}\text { Summary of elevation zones interpreted from outputs of all EXE experiments, using elevation functions from both high- and low-precipitation sites. } \\
\text { Underlined elevations are best estimates; n.d. = not diagnostic: tests yield poor elevation limits (not graphed on Fig. 7.1). } \\
\text { Tests } \Delta\{\mathrm{P}[\mu], \text { WAR }[\mu]\} \text { and } \Delta\left\{\mathrm{P}_{\text {intept }}, \text { WAR intept }\right\}: \text { standard for threshold difference between } \mathrm{P} \text { and WAR series values is set at }>10 \% \text {. } \\
\text { ExpD regression coefficients: intercepts are for regressions by } 1000 \text { years (not events); intercept is the value at } R P=1 \mathrm{yr} \text {; slope metrics are primarily } \\
\text { from regressions on } \log R P \text {, although equivalent information is derived from regression on } \ln R P \text {. }\end{array}$} \\
\hline
\end{tabular}




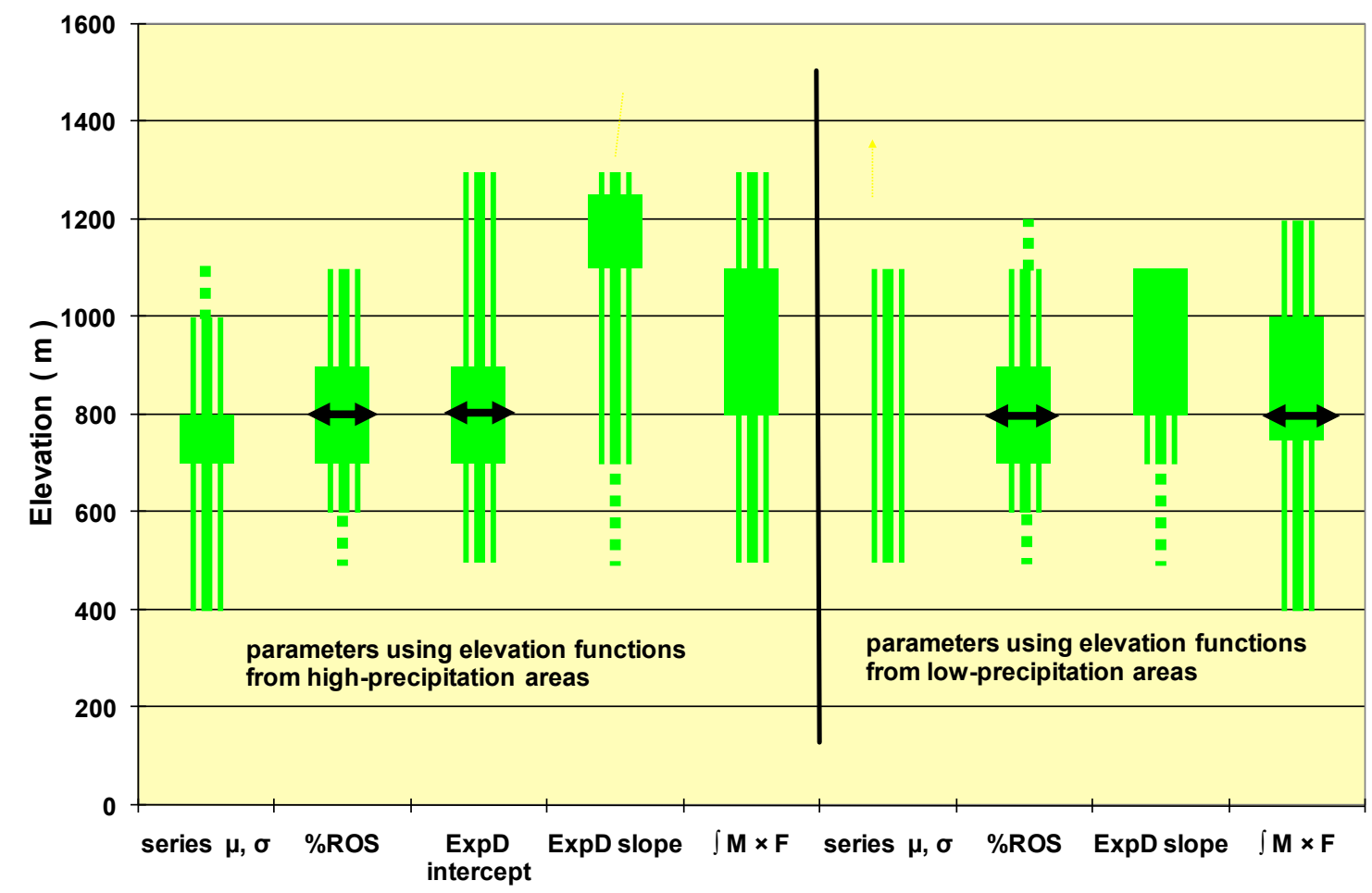

Diagnostic metrics comparing $P$ and WAR by elevation

Figure 7.1. Estimates of elevations of significant rain-on-snow occurrence in the west-central Washington Cascades, based on the diagnostic metrics of Table 7.1, for high-precipitation and low-precipitation areas: from series statistics $(\mu, \sigma)$, hydrologic event types (especially \%ROS), exponential distribution regression coefficients (ExpD intercept and slope), and integral of magnitude $\times$ frequency (abbreviated $\int \mathrm{M} \times \mathrm{F}$ ). Boxes represent the optimal (most likely and significant) elevations of ROS; solid lines extend to lower and upper boundaries; dashed lines indicate ranges in boundary estimates. Double-arrows within optimal-ROS boxes indicate best estimate for that metric. A missing box or whisker means lack of a diagnostic value for that parameter; no good estimates at all for the ExpD intercept for low-precipitation areas.

Figure 7.1 illustrates these values using the most diagnostic of the metrics. I had supposed that rain-on-snow is more effective in a middle elevation band in the Cascades: water input to the ground during big storms would be most enhanced (as long-term frequency and magnitude) where rain and warmer temperatures are likely to encounter existing seasonal snowpacks that could contribute meltwater. The model, simulating conditions and processes during such storms, was run for a range of elevations in order to identify and delineate this zone of greatest ROS significance. As interpreted from the statistical and frequency properties of the model realization series, the outer limits of substan- 
tial augmentation of water inputs seem to lie at about 400-600 $\mathrm{m}$ and $\sim 1100-1300 \mathrm{~m}$ in this region. For the optimal elevations, most metrics point to a narrower band at $\sim 700$ to $1100+\mathrm{m} ; 800 \mathrm{~m}$ is within this peak zone in seven of the categories, and the acme in four. Perhaps the most physically persuasive metrics are those for frequency and input volume (\%ROS and $\int M \times F$ on Fig. 7.1; also Fig. 6.3, 6.6). These reflect the proportions of events in which WAR $>\mathrm{P}$, and their relative contributions to long-term water input, respectively, at each elevation. They also point to $800 \mathrm{~m}$ as the ideal ROS elevation, though ambiguously for the $M \times F$ integral for wetter sites (where WAR $>$ P peaks at $800 \mathrm{~m}$ but maximum WAR occurs at 1100 m; Fig. 6.6). As further corroboration of the apparent ROS optimum, the greatest divergence of WAR over P series at the low-frequency/longrecurrence end also occurs at $\sim 800 \mathrm{~m}$ (Fig. 6.5). The least conformable metric of Figure 7.1 is the wet-areas ExpD slope suggesting a higher ROS zone; but this is rebutted by the frequency-magnitude relations at 1100 and $1250 \mathrm{~m}$, where WAR falls below P at all recurrences (Fig. 6.5), indicating that those elevations are high enough that cooler temperatures and deeper snowpacks are overwhelming the effects of ROS over the long term.

Return to the hypotheses regarding ROS by elevation (section 2.4B). As discussed previously, tests on the realization series' basic statistics show that the means of paired P and WAR are different for every case examined, with average WAR always inferior. At all elevations, the effects of snow and cold reduce WAR in some events, whereas snowmelt enhances WAR in others. In this duel, over time, the former always outgun the latter, even at low elevations; at the ROS-optimal $800 \mathrm{~m}, \sim 60 \%$ of model events have WAR $<\mathrm{P}, \sim 20 \%$ WAR $>$ P (Fig. 6.3). As shown above (Table 7.1), this contradicts my original ideas at all but the highest elevations. However, the several other approaches used to an- 
alyze the model results help us evaluate the contributions of rain versus snow in big storms. Considering all the metrics $(M)$ of the relative frequency and magnitude of $\mathrm{P}$ and WAR, and concentrating on recurrence periods $(R P)$ of 1-1000 yr, I interpret the experiments for various elevations (for the high-precipitation sites) as shown in Table 7.3. (Despite mention of only two descriptive criteria, all the metrics of Table 7.1 are considered in determining elevation bands and thresholds.)

\begin{tabular}{|c|c|c|c|c|}
\hline $\begin{array}{c}\text { Elevation } \\
\text { zone }\end{array}$ & $\begin{array}{c}\text { Hypothesis } \\
\left(\mathrm{H}_{1}\right)\end{array}$ & Model results & $\%$ ROS & $\begin{array}{l}\text { Interpreted } \\
\text { elevation }\end{array}$ \\
\hline high & $\mathrm{WAR}[M]<\mathrm{P}[M]$ & WAR $<<$ P at all $R P$ & $<10 \%$ & $\geq 1100-1200 \mathrm{~m}$ \\
\hline middle & $\mathrm{WAR}[M]>\mathrm{P}[M]$ & $\begin{array}{l}\mathrm{WAR}>\mathrm{P} \text { at } R P>\sim 100 \mathrm{yr} \\
\mathrm{WAR}>\mathrm{P} \text { at } R P>\sim 10-20 \mathrm{yr} \\
\text { WAR slightly }>\mathrm{P} \text { at all } R P\end{array}$ & $\begin{array}{l}\sim 10-15 \% \\
\sim 15-20 \% \\
\sim 5-15 \%\end{array}$ & $\begin{array}{l}\sim 1000-1100 \mathrm{~m} \\
\sim 700-900 \mathrm{~m} \\
\sim 500-600 \mathrm{~m}\end{array}$ \\
\hline low & $\mathrm{WAR}[M] \approx \mathrm{P}[M]$ & $\mathrm{WAR}>\mathrm{P}$ at $R P>\sim 10-20 \mathrm{yr}$ & $<5 \%$ & $\leq 400-500 \mathrm{~m}$ \\
\hline \multicolumn{5}{|l|}{ Notes } \\
\hline \multicolumn{5}{|c|}{$\begin{array}{l}\text { Initial elevation zones are approximate, as hypothesized (section } 2.4 \mathrm{~B}) \text {. } \\
\text { No criteria defined " } \approx \text { " for low elevations in the hypotheses; interpreted here as within } \sim 1.5-2 \mathrm{~cm}(\sim 5 \%) \text { at } \\
\text { both } 1 \text { - and } 1000 \text {-yr } R P \text {. P and WAR are dissimilar at all higher elevations. } \\
\text { For all cases listed as "WAR }>\mathrm{P} \text { at } R P>\mathrm{nn} \text { yr", the complement is that WAR }<\mathrm{P} \text { for shorter periods. }\end{array}$} \\
\hline
\end{tabular}

At this point, the conceptual model introduced in chapter 2 (Fig. 2.2) can be reevaluated and adjusted. The red dashed lines on the frequency-magnitude graphs of Figure 7.2 represent interpretations of the model WAR realizations presented in this dissertation (see Fig. 6.5). For all elevation zones, the main differences between my expectations and the Monte Carlo simulations are for high probabilities/short recurrence, where WAR is generally smaller than P. Otherwise, the hypothesized relations are borne out well. Based on model results as expressed in Table 7.3, I assign elevations for the west-central Cascades (with geographically and climatically flexible boundaries) below $\sim 500 \mathrm{~m}$ to the low zone; above $\sim 1100 \mathrm{~m}$ to the high zone; and $\sim 600-1000 \mathrm{~m}$ to the middle zone. Judg- 
ing from several criteria, as discussed, the maximal rain-on-snow effect appears to be at $\sim 800 \mathrm{~m}$ (probably $\pm 100 \mathrm{~m}$; Fig 7.1). At this elevation, ROS occurs in the greatest proportion of storms; the amount of water delivered to the ground is expected to be more than event precipitation during big storms for recurrence periods greater than $\sim 10-20 \mathrm{yr}$ (probabilities $<0.05-0.10$ ), by up to $\sim 3 \mathrm{~cm}$ at $100 \mathrm{yr}$ and $\sim 5 \mathrm{~cm}$ at $1000 \mathrm{yr}$; and the long-term cumulative liquid-water input, as indexed by the integral of magnitude $\times$ frequency, reaches levels marginally greater than those of gross precipitation.

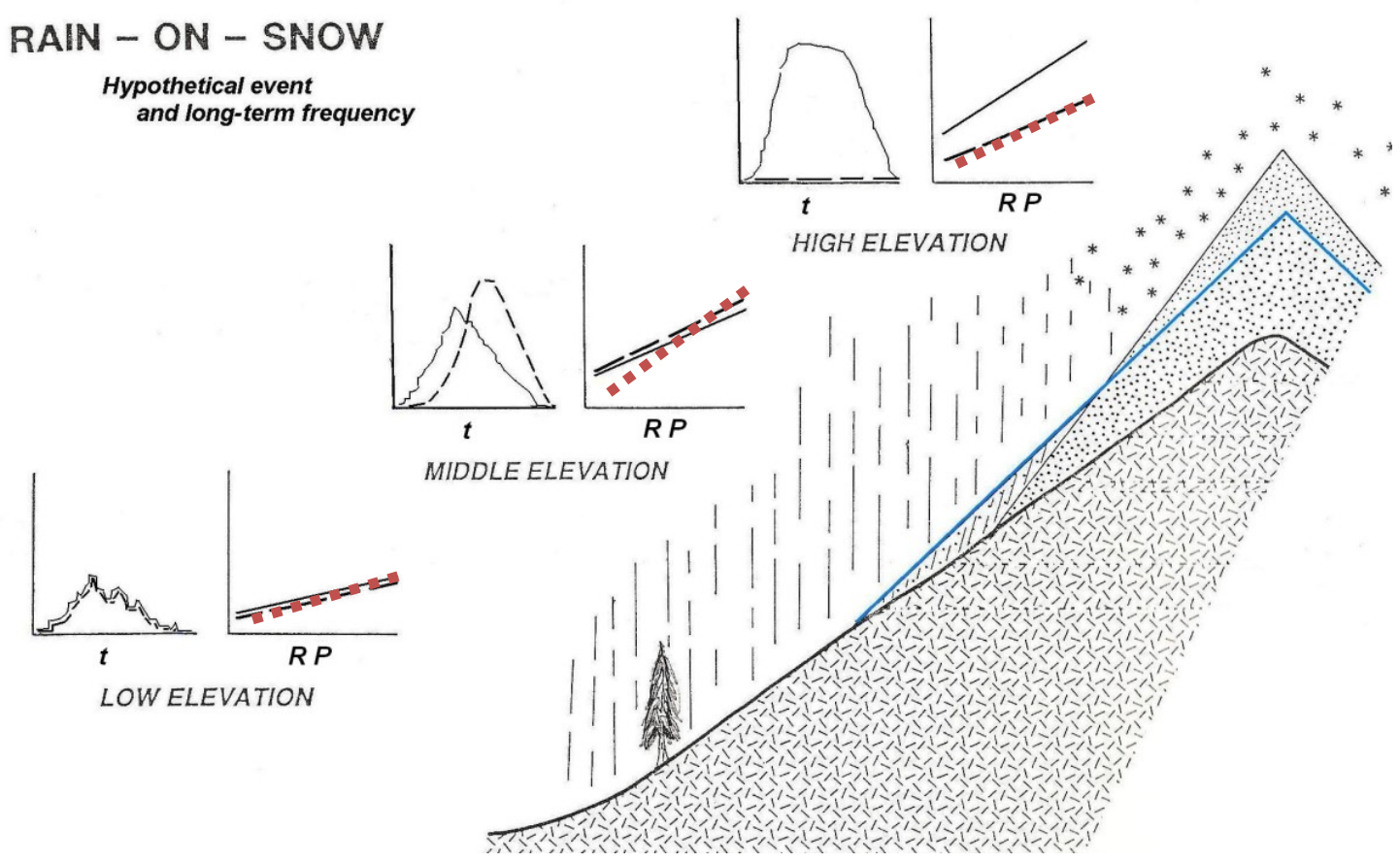

Figure 7.2. Elevation transect before/after a storm: downhill edge of the snow wedge melts, but additional snow accumulates at higher elevation. Hyeto-/hydrographs (left) and frequency-magnitude graphs (right); black solid lines for hypothesized precipitation amount, black dashed lines for hypothesized WAR; red dashed lines illustrate model results for WAR, given each hypothetical P trend.

Consideration of these elevations in the context of regional hypsometry suggests that they constitute a major proportion of the region's terrain. The outer limits of 500$1100 \mathrm{~m}$ embrace $\sim 50 \%$ of the study area; even the smaller $600-1000 \mathrm{~m}$ band covers 
$\sim 33 \%$ of the landscape (Fig. 7.3). Thus, a large share of the west-central Cascades lies at elevations susceptible to significant rain-on-snow and its concomitant effects on stormwater inputs.

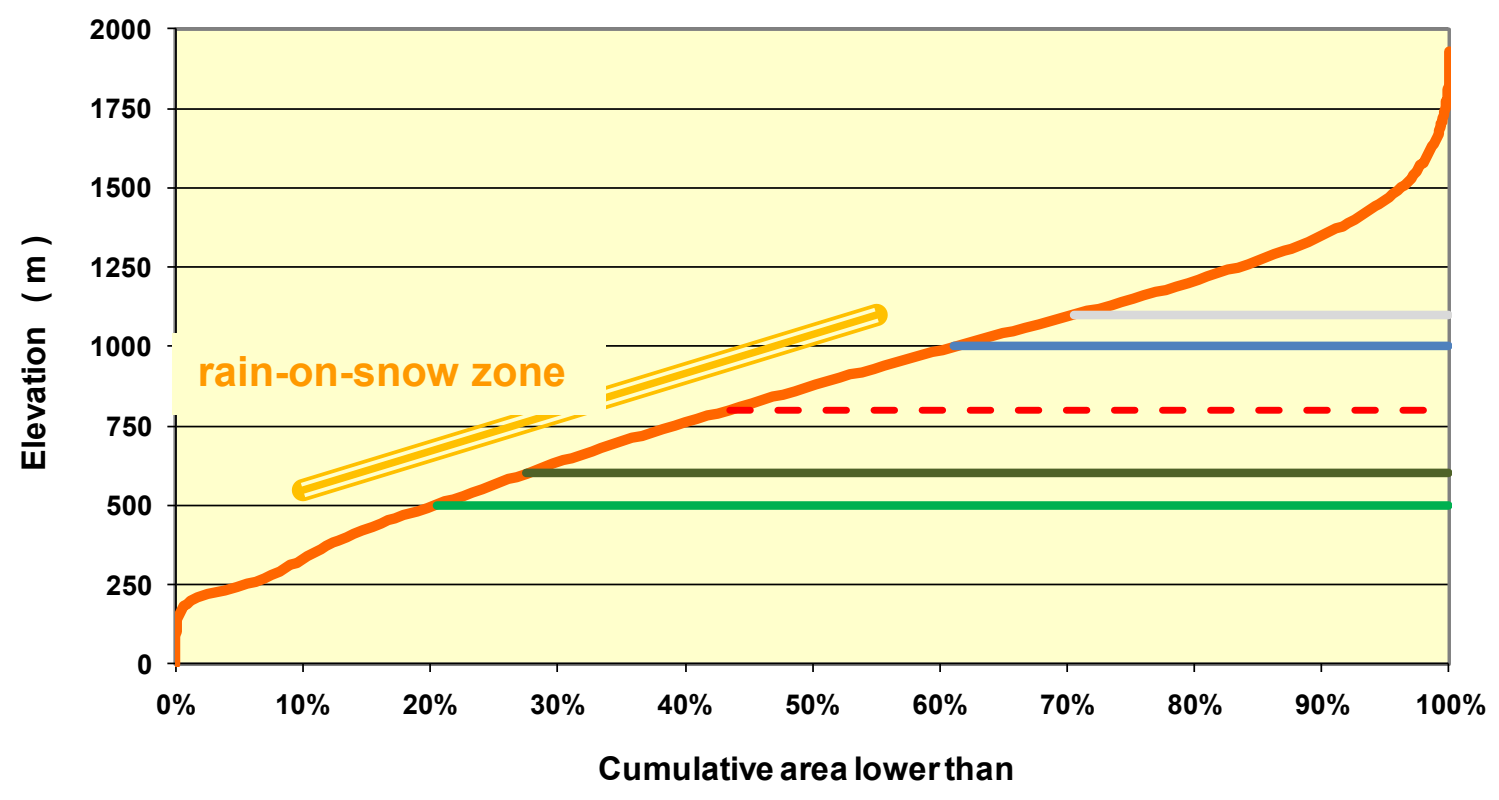

Figure 7.3. Hypsometric curve for the project area, west-central Washington Cascades. Model results indicate that the zone of significant rain-on-snow (spanned by the yellow-orange diagonal band) in this region extends from $\sim 500-600 \mathrm{~m}$ (green lines) to $\sim 1000-1100 \mathrm{~m}$ elevation (blue lines), with greatest effect at $\sim 800 \mathrm{~m}$ (dashed red line).

Over several decades, scientists and land managers in western North America (and other regions) have directly or indirectly cited elevation bands in which rain-onsnow is more likely; Table 7.4 (derived from Table A.1) lists those for the maritime Pacific Northwest and adjacent areas. Most identifications have been based on local recognition of a transient snow zone, elevations where snow can accumulate and melt several times during most winters, in contrast to lower elevations where precipitation is dominantly rain and higher zones where snowpacks normally build continuously through the winter. More precisely, Kattelmann (1997, p 367) stated that the "intermittent- (or transi- 
ent-) snow zone may be defined casually as areas where snow is present for one week to three months in most years" in the Sierra Nevada. TSZ terminology is used often by workers in the Oregon Cascades, especially in and around the H.J. Andrews Experimental Forest, where it is described communally as between $300-450 \mathrm{~m}$ and $1000-1200 \mathrm{~m}$. The relation between the TSZ and ROS is usually implied, but stated more tightly in some papers. For example, examining effects of forest harvest, Harr (1986) paired ROS processes with the TSZ in western Oregon; Connelly and Cundy (1992) modeled change scenarios in the ROS zone (730-1030 m) at HJAEF. In the Russell Creek experimental watershed on Vancouver Island, the band between 300 and $800-900 \mathrm{~m}$ is called the transitional zone by Floyd and Weiler (2008) but the ROS zone by Anderson et al. (2009). For the Washington Cascades, Coffin and Harr (1992, p 14) cited $\sim 300-900 \mathrm{~m}$ as the TSZ, and described it as a "fixed elevation zone wherein the probability of ROS is highest", while acknowledging that ROS can occur at all elevations. 


\begin{tabular}{|c|c|c|c|c|c|}
\hline Region & $\begin{array}{l}\text { Location, } \\
\text { Elevation }\end{array}$ & $\begin{array}{l}\text { Focus of Study, } \\
\text { Methods }\end{array}$ & $\begin{array}{l}\text { Elevations I } \\
\text { Zones }\end{array}$ & $\begin{array}{l}\text { Identifying } \\
\text { Methods I } \\
\text { Criteria }\end{array}$ & References \\
\hline $\begin{array}{l}\text { Western } \\
\text { continental U.S. }\end{array}$ & $\begin{array}{l}\text { NWS stations in } 11 \\
\text { states }\end{array}$ & $\begin{array}{l}\text { - determine spatial \& temporal } \\
\text { variability of ROS }\end{array}$ & $\begin{array}{l}\text { in } 500-\mathrm{m} \text { elev bands- } \\
\text { general increase in \% } \\
\text { of precip days that } \\
\text { are ROS, etc. }\end{array}$ & $\begin{array}{l}\text { from weather records } \\
\text { in all western U.S. } \\
\text { all elevs - no } \\
\text { regional breakdown } \\
\end{array}$ & $\begin{array}{l}\text { McCabe et al., } \\
2007\end{array}$ \\
\hline $\begin{array}{l}\text { Coast Mtns } \\
\text { SW British } \\
\text { Columbia }\end{array}$ & $\begin{array}{l}\text { Jamieson Ck watershed, } \\
655-730 \mathrm{~m}\end{array}$ & $\begin{array}{l}\text { - effects of forest \& clearing on } \\
\text { ROS processes \& RO over } 3 \\
\text { winters }\end{array}$ & $\begin{array}{l}\text { paired forested \& } \\
\text { clearcut sites at } \sim 730 \\
\text { m }\end{array}$ & location of field sites & $\begin{array}{l}\text { Beaudry \& } \\
\text { Golding, } 1983 \\
\text { Beaudry, } 1984\end{array}$ \\
\hline $\begin{array}{l}\text { NE Vancouver Is } \\
\text { SW British } \\
\text { Columbia }\end{array}$ & $\begin{array}{l}\text { Russell Ck watershed } \\
300-1680 \mathrm{~m}\end{array}$ & $\begin{array}{l}\text { - various projects in } \\
\text { experimental watershed } \\
\text { - develop \& test new methods to } \\
\text { monitor transitory ROS events }\end{array}$ & $\begin{array}{l}\text { snow zone } \\
800-900 \mathrm{~m} \\
\text { transitional zone } \\
300 \mathrm{~m} \quad \text { rain zone }\end{array}$ & $\begin{array}{l}\text { location of field sites } \\
\text { in transitional snow } \\
\text { zone (multiple ROS } \\
\text { per winter) }\end{array}$ & $\begin{array}{l}\text { Floyd \& Weiler, } \\
2008\end{array}$ \\
\hline $\begin{array}{l}\text { Washington: map } \\
\text { hydrologic zones } \\
\text { for use in forest } \\
\text { regulation and } \\
\text { watershed analysis }\end{array}$ & $\begin{array}{l}\text { forested areas of } \\
\text { Washington } \\
15 \text { overlapping } \\
\text { subregions }\end{array}$ & $\begin{array}{l}\text { establish } 5 \text { elevation-based } \\
\text { precipitation zones } \\
\text { (nominal boundaries established } \\
\text { by simple model; mapped } \\
\text { boundaries vary with local } \\
\text { climate, aspect, terrain, etc.) }\end{array}$ & $\begin{array}{c}\text { W-central Cascades: } \\
\text { highland } \\
\sim 4000 \mathrm{ft}(1220 \mathrm{~m}) \\
\text { snow-dominated } \\
\sim 2800 \mathrm{ft}(850 \mathrm{~m}) \\
\text { peak ROS } \\
\sim 1700 \mathrm{ft}(520 \mathrm{~m}) \\
\text { rain-dominated } \\
\sim 600 \mathrm{ft}(180 \mathrm{~m}) \\
\text { lowland }\end{array}$ & $\begin{array}{l}\text { snow available for } \\
\text { melt (avg SWE) in } \\
\text { 24-h ROS on } 1 \text { Jan: } \\
\text { maximum response } \\
\text { (event melt } \approx \text { avail) } \\
\text { in peak ROS zone; } \\
\text { avail < SM in lower } \\
\text { zones; avail > SM in } \\
\text { higher zones }\end{array}$ & $\begin{array}{l}\text { Brunengo et al., } \\
\text { 1992a,b } \\
\text { Brunengo, } 1995 \\
\text { (also: MJB notes } \\
\text { from designation } \\
\text { \& mapping } \\
\text { procedures) }\end{array}$ \\
\hline
\end{tabular}




\begin{tabular}{|c|c|c|c|c|c|}
\hline $\begin{array}{l}\text { North Cascades } \\
\text { Washington }\end{array}$ & $\begin{array}{l}\text { Finney \& Canyon Ck } \\
\text { basins } \\
460-760 \mathrm{~m}\end{array}$ & $\begin{array}{l}\text { - effects of mature forest, } \\
\text { plantation \& clearing on ROS } \\
\text { \& RO over } 3 \text { winters }\end{array}$ & $\begin{array}{l}\text { transient snow zone } \\
\text { at } \sim 300-900 \mathrm{~m} \\
\text { in both basins (N \& } \\
\mathrm{S} \text { sides of mtn } \\
\text { block), multiple } \\
\text { forest, clearcut \& } \\
\text { plantation sites at } \\
460 \mathrm{~m}, 610 \mathrm{~m}, 760 \mathrm{~m}\end{array}$ & $\begin{array}{l}\text { location of field sites } \\
\text { - chosen for best } \\
\text { likelihood of } \\
\text { experiencing ROS } \\
\text { over the range of } \\
\text { snow accum \& melt }\end{array}$ & $\begin{array}{l}\text { Coffin, 1991 } \\
\text { Coffin \& Harr, } \\
1992\end{array}$ \\
\hline $\begin{array}{l}\text { Central } \\
\text { Washington } \\
\text { Cascades }\end{array}$ & $\begin{array}{l}\text { Snoqualmie Pass area } \\
915 \mathrm{~m}\end{array}$ & $\begin{array}{l}\text { - effects of water movement } \\
\text { during ROS on snow ripening, } \\
\text { strength change \& avalanches }\end{array}$ & $\begin{array}{l}\text { instrumented } \\
\text { snowpack sites at } \\
915 \mathrm{~m}\end{array}$ & $\begin{array}{l}\text { midwinter rain } \\
\text { common at this } \\
\text { elevation }\end{array}$ & $\begin{array}{l}\text { Conway \& } \\
\text { Raymond, } 1993 \\
\text { Conway \& } \\
\text { Benedict, } 1994 \\
\end{array}$ \\
\hline \multirow[t]{5}{*}{$\begin{array}{l}\text { Northern \& central } \\
\text { Oregon Cascades }\end{array}$} & $\begin{array}{l}\text { Willamette NF } \\
6 \text { basins, with avg elevs } \\
914-1262 \mathrm{~m} \\
\end{array}$ & $\begin{array}{l}\text { - comparison of peak flows in } \\
\text { natural \& logged basins }\end{array}$ & $\begin{array}{l}\text { transient snow zone } \\
\text { in western Oregon } \\
\sim 450-1200 \mathrm{~m} \\
\end{array}$ & none specified & $\begin{array}{l}\text { Christner \& Harr, } \\
1982\end{array}$ \\
\hline & $\begin{array}{l}\text { Lookout Ck basin, } \\
\text { HJAEF } \\
420-1520 \mathrm{~m}\end{array}$ & $\begin{array}{l}\text { - simulation of } 11 \text { ROS events: } \\
\text { hillslope to channel RO under } \\
9 \text { harvest patterns }\end{array}$ & 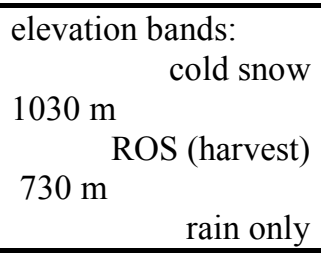 & $\begin{array}{l}\text { none stated } \\
\text { (in C \& C 1992) } \\
\text { HJA info (2400 ft, } \\
3380 \mathrm{ft} \text { )? }\end{array}$ & $\begin{array}{l}\text { Connelly \& } \\
\text { Cundy, } 1992\end{array}$ \\
\hline & $\begin{array}{l}\text { USFS HJAEF } \\
\text { basins } \\
433-1067 \mathrm{~m}\end{array}$ & $\begin{array}{l}\text { - evaluate harvest / ROS effects } \\
\text { on snow accum, melt, } \\
\text { streamflow }\end{array}$ & $\begin{array}{l}\text { transient snow zone } \\
\text { in western Oregon } \\
\sim 350-1100 \mathrm{~m}\end{array}$ & none specified & Harr, 1986 \\
\hline & $\begin{array}{l}\text { USFS HJAEF } \\
\text { Blue River } \\
900 \mathrm{~m}\end{array}$ & $\begin{array}{l}\text { - effects of forest \& clearing on } \\
\text { ROS processes \& RO over } 2 \\
\text { winters }\end{array}$ & $\begin{array}{l}\text { transient snow zone } \\
\text { in western Oregon } \\
350-1100 \mathrm{~m} \\
\text { paired forested \& cut } \\
\text { sites at } \sim 900 \mathrm{~m}\end{array}$ & $\begin{array}{l}\text { none specified } \\
\text { location of field sites }\end{array}$ & $\begin{array}{l}\text { Harr \& Berris, } \\
1983 \\
\text { Berris, } 1985 \\
\text { Berris \& Harr, } \\
1987\end{array}$ \\
\hline & $\begin{array}{l}\text { Santiam Valley } \\
536-1142 \mathrm{~m}\end{array}$ & $\begin{array}{l}\text { - Feb } 1996 \text { case study: energy } \\
\text { balance in forest \& clearings } \\
\text { during ROS across elevs }\end{array}$ & $\begin{array}{l}\text { snow transition zone } \\
\text { (ROS common) in } \\
\text { west Oreg \& Wash, } \\
\text { coastal BC \& Calif } \\
\sim 300-1000 \mathrm{~m}\end{array}$ & $\begin{array}{l}\text { cite Beaudry \& } \\
\text { Golding, 1983; Harr, } \\
1986\end{array}$ & Marks et al., 1998 \\
\hline
\end{tabular}




\begin{tabular}{|c|c|c|c|c|c|}
\hline & $\begin{array}{l}\text { USFS HJAEF } \\
\text { upper Lookout } \mathrm{Ck} \text { basin }\end{array}$ & $\begin{array}{l}\text { - energy balance during all ROS } \\
\text { events over } 8 \text { winters }\end{array}$ & $\begin{array}{l}\text { transient snow zone } \\
\text { (ROS common) at } \\
\text { HJAEF } \sim 500-1000 \\
\text { m } \\
\text { (climate stations at } \\
1018,1273,1294 \mathrm{~m} \text { ) }\end{array}$ & $\begin{array}{l}\text { none specified - HJA } \\
\text { info? }\end{array}$ & $\begin{array}{l}\text { Mazurkiewicz et } \\
\text { al., } 2008\end{array}$ \\
\hline & $\begin{array}{l}\text { HJAEF, Lookout Ck; } \\
\text { Blue, No Santiam, } \\
\text { Breitenbush, No \& } \\
\text { Middle Willamette, } \\
\text { Salmon Ck }\end{array}$ & $\begin{array}{l}\text { - effects of snow, antecedent } \\
\text { soil moisture \& slope form on } \\
\text { storm RO over decades }\end{array}$ & $\begin{array}{l}\text { transient snow zone } \\
\text { in Western Cascades } \\
\text { of Oregon } 400-800 \\
\mathrm{~m} \text { (snow seasonal to } \\
\text { permanent above) }\end{array}$ & none specified & $\begin{array}{l}\text { Perkins \& Jones, } \\
2008 \\
\text { Jones \& Perkins, } \\
2010\end{array}$ \\
\hline $\begin{array}{l}\text { Southern Oregon } \\
\text { Cascades }\end{array}$ & $\begin{array}{l}\text { USFS DEMO } \\
\text { upper N Umpqua basin } \\
\text { Watson Falls area } \\
\sim 915 \mathrm{~m}, \sim 1220 \mathrm{~m}\end{array}$ & $\begin{array}{l}\text { - evaluate snowmelt WAR } \\
\text { equations during ROS } \\
\text { - observe processes controlling } \\
\text { snow interception by forest } \\
\text { canopy and under-canopy }\end{array}$ & $\begin{array}{l}\text { transient snow zone } \\
\text { multiple forested, } \\
\text { shelterwood \& } \\
\text { cleared sites at } \sim 915 \\
\text { and } \sim 1220 \mathrm{~m}\end{array}$ & $\begin{array}{l}\text { none specified } \\
\text { location of field sites }\end{array}$ & $\begin{array}{l}\text { Wetherbee, } 1995 \\
\text { Storck et al., } \\
\text { 1999, } 2002\end{array}$ \\
\hline $\begin{array}{l}\text { Sierra Nevada } \\
\text { (SN) }\end{array}$ & $\begin{array}{l}\text { Sacramento, San } \\
\text { Joaquin, Lahontan } \\
\text { basins }\end{array}$ & $\begin{array}{l}\text { examination of flow \& met } \\
\text { records to determine } \\
\text { occurrence of rain-dominated } \\
\text { storms \& ROS }\end{array}$ & $\begin{array}{l}\text { intermittent- (or } \\
\text { transient-) snow } \\
\text { zone, in most years } \\
\sim 700-1200 \mathrm{~m} \text { in No } \\
\mathrm{SN}, \sim 1200-1800 \mathrm{~m} \\
\text { in So SN }\end{array}$ & $\begin{array}{l}\mathrm{I}-/ \mathrm{T} \text {-snow zone } \\
\text { "defined (casually) } \\
\text { as areas where snow } \\
\text { is present for one } \\
\text { week to three months } \\
\text { in most years" }\end{array}$ & $\begin{array}{l}\text { Kattelmann et al., } \\
1991 \\
\text { McGurk et al., } \\
1993 \\
\text { Kattelmann, 1997 } \\
\text { (definition p 367) } \\
\end{array}$ \\
\hline \multicolumn{6}{|l|}{ Notes } \\
\hline
\end{tabular}


Nearly all TSZ or ROS-zone designations are founded on the experience of hydrologists, foresters, and other professionals over many years in their regions (personal communications, 2011: Fred Swanson, USFS; Julia Jones, Oregon State Univ.; Dan Moore, Univ. of British Columbia; Bill Floyd, BC Ministry of Forests, Lands \& Natural Resources). Throughout the American West (as well as other parts of the world), organizers of ROS-related field projects sought to establish sites at elevations most likely to experience such events; their judgments are listed in Tables 7.4 and A.1. Very few studies have incorporated explicit climatic or hydrologic methods in delineating elevations subject to transient snow and/or ROS. The compilation of McCabe et al. (2007) for the western continental U.S. has been mentioned, although their classification criteria for ROS days and broad geographic span make it impossible to directly compare their results with mine. In an early offshoot of this project, the Washington Department of Natural Resources designated five precipitation zones to help regulate forestry for ROS effects, based on the amount of snow available to be melted at various elevations in a standardized 24-h storm on 1 January (Brunengo et al., 1992a,b; Brunengo, 1995). For the westcentral Cascades region considered in this research, the nominal boundaries of the socalled peak-ROS zone were $\sim 520$ and $\sim 850 \mathrm{~m}$; along with the snow-dominated zone, also regulated for ROS effects, the range was $\sim 520-1220 \mathrm{~m}$, similar to my model results.

Outside western North America, there seems to have been little interest in the variation of rain-on-snow occurrence and/or effects with elevation, though some researchers have explored such themes: e.g., Graybeal and Leathers (2006) in the mid-Atlantic U.S., and Sui and Koehler (2001) in Bavaria. The issue has slight relevance in regions with little relief, but would potentially be important in mountains with elevations spanning 
thousands of meters.

It was the desire to obtain more rational quantities for the elevations and hydrologic significance of rain-on-snow in the Northwest that led me to employ the Monte Carlo simulation described here. To my knowledge, there are no analogous models approaching the same problem, in the PNW or elsewhere, and thus no other studies with which to compare my specific results.

\section{$\underline{7.3 \text { Summary \& conclusions }}$}

Rain-on-snow is an important hydrometeorological process in western North America, because winter storms with heavy rainfall and warm temperatures often cause snowmelt to augment the precipitation, sometimes producing moderate to extreme runoff, flooding and erosion. The sporadic nature and geographic variability of ROS events makes them hard to characterize in detail from the observational record, which is limited in time span, areal coverage, and the kinds of instruments commonly deployed. These inadequacies make it especially difficult to estimate the properties of such inherently probabilistic phenomena as ROS events. However, stochastic modeling is a useful tool for studying multifaceted processes such as the big storms generating ROS.

I developed a computer model for Monte Carlo simulation of large cool-season storms, applicable to the maritime Pacific Northwest. The program combines sampling of stochastic factors, including storm timing, precipitation amount, snowpack and weather conditions, along with deterministic components for estimating snow accumulation, melt, and the movement of liquid water through a snowpack. The model generates realizations of storm events for 1000 "years", based on data series, frequency distributions and elevation trends from weather and snow stations in the central-western Cascade Range of 
Washington. Given its simplifications, underlying assumptions, and deliberately minimalist data requirements, the results suggest that the model faithfully reproduces the frequency and magnitude characteristics of the storm events, snowpacks and percolation responses, though several components can be improved.

The Monte Carlo model generates appropriate frequency-magnitude distributions of precipitation, liquid input (rain plus meltwater), and water available for infiltration and runoff, for simulations of specific weather stations (particularly Stampede Pass) or of generalized elevations. I use several kinds of metrics to evaluate the realizations, particularly series of total precipitation ( $\mathrm{P}$, all phases) and the water actually reaching the ground (WAR) during model events. These include the series means and variances; the intercept and slope coefficients of their exponential distributions (calculated by regression of the realizations against logarithm of recurrence period); the proportions of events having various classes of relative volumes of P and WAR, and especially those for which WAR $>$ P (\%ROS), in which melt significantly enhances precipitation; and the integral of the product of magnitude and frequency $\left(\int M \times F d R P\right)$, an indicator of the relative long-term contributions of $\mathrm{P}$ versus WAR.

The Monte Carlo apparatus has been used to perform a series of experiments, testing variations of storm behavior with elevation in the west-central Washington Cascades. They show that cold temperatures and/or snowpacks interfere with the generation of liquid water and its delivery to the ground in a considerable portion of storms at all elevations. This occurs even at lower sites, where WAR $<\mathrm{P}$ in $\sim 20-35 \%$ of storms (at $200-$ $400 \mathrm{~m}$ ), sufficient to make series-averaged WAR less than average P even in lowlands. At high elevations, the proportion of events having WAR $<$ P increases greatly $(>70 \%$ 
above $\sim 1100 \mathrm{~m}$ ) and the frequency-magnitude values for WAR become much inferior to those for precipitation, indicating that the true quantity of water delivered to the ground is indeed less than the amount captured in precipitation gauges, in many to most events over long time periods.

At intermediate elevations, the expected optimal rain-on-snow zone is evident but not as clearly marked out as anticipated. There, as in the lower and higher elevations, modeled results show series-average $\mathrm{WAR}<\mathrm{P}$. However, my evaluation criteria in combination support the notion that ROS occurrence reaches maximum in a middle elevation band, broadly between $\sim 500$ and $1100 \mathrm{~m}$. At $\sim 800 \mathrm{~m}$, the proportion of model events having WAR $>$ P peaks $(\sim 20-30 \%)$, as does the long-term integrated magnitude-frequency product and several of the statistical and regression parameters; WAR is maximally greater there than precipitation for infrequent events (medium to long recurrence periods). This suggests that big storms at those elevations are most likely to drop rain on resident snowpacks and produce enough meltwater to appreciably enhance infiltration and runoff. I interpret this as the preferred rain-on-snow zone in the west-central Washington Cascades, the elevation band of its greatest hydrologic significance, where it constitutes $\sim 33-50 \%$ of the landscape. To my knowledge, no comparable record-based or modeling project has addressed similar questions, in this region or elsewhere. But it has not escaped notice that $\sim 800 \mathrm{~m}(\sim 2625 \mathrm{ft})$ is similar to the elevation that many hydrologists have been mentioning as a transient-snow or rain-on-snow zone in the Northwest - and siting their ROS field studies - over many decades.

\subsection{Future work}

This Monte Carlo model, its operations, and the background information used to 
inform it all leave multiple avenues for additions and improvements; some of these are listed in (A) and (B) below (and other ideas for further investigation may be suggested by Table 4.1). Such tinkering with model components can be carried out as occasions present themselves, but none are critical. More interestingly, the model can be used to advance our knowledge of ROS by applying it to simulate additional sites and distributions (C), and alternate scenarios of climate and land use (D).

\section{A) Areal coverage, data compilations, statistics}

- $\quad$ Extend NWS precipitation and snow records beyond WY 2005 (for stations still operating); update the frequency distributions.

- $\quad$ Add more stations to the sample: sites within the project area not previously used because records were short (e.g., newer SNOTEL sites); consider stations higher $(>1000$ $\mathrm{m})$ and lower $(<250 \mathrm{~m})$ than most of the current sample; perhaps expand the study region. - Explore the possibility of a statistical relationship between event date and precipitation magnitude; further examine the bivariate-normal statistical relationships between snow depth and SWE.

- $\quad$ Expand the sample of hourly temperature and wind speed during storms: extend Stampede Pass records beyond WY 2005; perhaps use first-order weather stations other than Stampede Pass (e.g., Sea-Tac and Olympia airports) and/or RAWS stations.

- $\quad$ Explore the feasibility and means of extrapolating the model to other regions without the laborious hydrometeorological data-mining as performed for this project.

\section{B) Possible modifications of model components \& operations; sensitivity}

- Split snow-predicting functions into separate sets for high- and low-snowfall sites.

- Develop or adapt more realistic ways to model internal storm precipitation (SIM). 
- Integrate hourly temperature, wind speed and precipitation within model storms more realistically.

- Reexamine whether storm temperatures at Stampede Pass are representative of the region; run the model with different average temperatures and lapse rates (Minder et al., 2010).

- $\quad$ Modify the selection of temperature codes (Tcodes) to make them consistent across elevations, at least for a specialized model version.

- Make selection of storm initiation date and time within each water year consistent in sequencing: no event overlaps; snow amounts carried over from events close in time.

- $\quad$ Resolve discrepancies between my kinematic-wave percolation equations and those of Albert and Krajeski (1998).

- $\quad$ Develop/adapt more realistic functions for percolation/drainage, refreezing, layered snowpacks, etc.

- If not overly elaborate, program for hourly changes in snow hydraulic properties.

C) New experiments with current stations/data

- Complete analysis of precipitation records at all durations for study-area stations other than Stampede Pass.

- $\quad$ Perform EXP runs using annual-maximum series, and compare to station data using both exponential and extreme-value distributions; do AM or EV-1 distributions provide better estimates of WAR, especially at long return periods?

- $\quad$ Explore possibility of mixed populations of storm types - rain, ROS, snowmelt.

D) New experiments, alternate scenarios

- $\quad$ Explore use of the model to evaluate variation among geographic/climatic factors 
other than elevation, such as aspect, east-west differences, etc.

- $\quad$ Develop methods to adapt the Monte Carlo model to investigate effects of big storms/ROS on different levels of canopy cover (old-growth, mature forest, plantation, clearing).

- $\quad$ Run the model for a range of climatic scenarios, incorporating hypothetical/projected changes in temperature, storm precipitation, snow volume, etc., to evaluate possible effects of climate change on ROS (Brunengo, 2007). 


\section{REFERENCES CITED}

\section{(Includes references from the appendices.)}

Agee, J.K., 1993, Fire Ecology of Pacific Northwest Forests: Washington DC, Island Press, $497 \mathrm{p}$.

Akan, A.O., 1984, Simulation of runoff from snow-covered hillslopes: Water Resources Research, v. 20, p. 707-713.

Albert, M., and Krajeski, G., 1998, A fast, physically based point snowmelt model for use in distributed applications: Hydrological Processes, v. 12, p. 1809-1824.

Anderson, E.A., 1968, Development and testing of snow pack energy balance equations: Water Resources Research, v. 4, p. 19-37.

Anderson, E.A., 1976, A point energy and mass balance model of a snow cover: U.S. Dept. of Commerce, NOAA Technical Report NWS 19, 150 p.

Anderson, H.W., and Hobba, R.L., 1959, Forests and floods in the northwestern United States, in Symposium of Hannoversch-Münden [West Germany]: AIHS-IASH Publication no. 48, v. 1, p. 30-39.

Anderson, A.E., Weiler, M., Alila, Y., and Hudson, R.O., 2009, Subsurface flow velocities in a hillslope with lateral preferential flow: Water Resources Research, v. 45, $15 \mathrm{p}$.

Anma, S., Fukue, M., and Yamashita, K., 1997, Slush lahar hazards on the flank of Mt. Fuji - a history and perspective on climatic change, in $1^{\text {st }}$ International Conference, Debris-flow hazards mitigation: mechanics, prediction, and assessment, San Francisco, p. 299-308.

Ashley, S.T., and Ashley, W.S., 2008a, Flood fatalities in the United States: Journal of Applied Meteorology and Climatology, v. 47, p. 805-818.

Ashley, S.T., and Ashley, W.S., 2008b, The storm morphology of deadly flooding events in the United States: International Journal of Hydroclimatology, v. 28, p. 493-503.

Azuma, D.L., 1985, Estimating snow load in California for three recurrence intervals:

U.S. Forest Service, Pacific Southwest Forest \& Range Experiment Station, Research Note PSW-379, 6 p.

Barros, A.P., and Lettenmaier, D.P., 1994, Dynamic modeling of orographically induced 
precipitation: Reviews of Geophysics, v. 32, p. 265-284.

Beals, E.A., 1910, Avalanches in the Cascades and northern Rocky Mountains during winter of 1909-10: Monthly Weather Review, v. 38, p. 951-957.

Beaudry, P.G., 1984, Effects of forest harvesting on snowmelt during rainfall in coastal British Columbia [M.For. thesis]: Vancouver, University of British Columbia, $183 \mathrm{p}$.

Beaudry, P., and Golding, D.L., 1983, Snowmelt during rain on snow in coastal British Columbia, in Proceedings, $51^{\text {st }}$ Western Snow Conference, Vancouver WA, p. 5566.

Bengtsson, L., 1982, Percolation of meltwater through a snowpack: Cold Regions Science and Technology, v. 6, p. 73-81.

Berg, N.H., and Hannaford, M.A., 1983, Application of a snowpack water-equivalent model to rain-on-snow events in the central Sierra Nevada, in Proceedings, $51^{\text {st }}$ Western Snow Conference, Vancouver WA, p. 155-158.

Berg, N., Osterhuber, R., and Bergman, J., 1991, Rain-induced outflow from deep snowpacks in the Sierra Nevada, California: Hydrological Sciences Journal, v. 36, p. 611-629.

Berris, S.N., 1985, Comparative snow accumulation and melt during rainfall in forest and clearcut plots in western Oregon [M.S. thesis]: Corvallis, Oregon State University, $152 \mathrm{p}$.

Berris, S.N., and Harr, R.D., 1987, Comparative snow accumulation and melt during rainfall in forested and clear-cut plots in the western Cascades of Oregon: Water Resources Research, v. 23, p. 135-142.

Beven, K., 1982, On subsurface stormflow: predictions for simple kinematic theory for saturated and unsaturated flows: Water Resources Research, v. 18, p. 1627-1633.

Bond, N.A., and Vecchi, G.A., 2003, The influence of the Madden-Julian Oscillation on precipitation in Oregon and Washington: Weather and Forecasting, v. 18, p. 600613.

Booth, D.B., 1990, Surficial geologic map of the Skykomish and Snoqualmie Rivers area, Snohomish and King Counties, Washington: U.S. Geological Survey, Miscellaneous Investigations Series, Map I-1745. 
Booth, D.B., Troost, K.G., Clague, J.J., and Waitt, R.B., 2004, The Cordilleran Ice Sheet, in Gillespie, A.R., Porter, S.C., and Atwater, B.F., eds., The Quaternary Period in the United States: Developments in Quaternary Science, 1: Amsterdam, London, International Union for Quaternary Research (INQUA), Elsevier Ltd., p. 17-43.

Borah, D.K., Prasad, S.N., and Alonso, C.V., 1980, Kinematic wave routing incorporating shock fitting: Water Resources Research, v. 16, p. 529-541.

Brabb, E.E., and Harrod, B.L., editors, 1989, Landslides: extent and economic significance, in $28^{\text {th }}$ International Geological Congress, Symposium on Landslides, Washington DC, p. 385.

Brunengo, M.J., 1990, A method of modeling the frequency characteristics of daily snow amount, for stochastic simulation of rain-on-snowmelt events, in Proceedings, $58^{\text {th }}$ Western Snow Conference, Sacramento CA, p. 110-121.

Brunengo, M.J., 1995, Estimation of snow available for melting during model rain-onsnow events: Washington Dept of Natural Resources, Forest Practices Division, Open-File Report 95-2, 50 p.

Brunengo, M.J., 2007, A Monte Carlo model for simulation of rain-on-snow events in the Pacific Northwest, in Proceedings, $75^{\text {th }}$ Western Snow Conference, Kailua-Kona HA, p. 89-102.

Brunengo, M.J., Smith, S.D., and Bernath, S.C., 1992a, Screening for watershed analysis-a GIS-based method of modeling the water input from rain-on-snow storms, for management and regulation of clearcut forest harvest: Washington Dept of Natural Resources, Forest Practices Division, Open-File Report 92-2, 21 p.

Brunengo, M.J., Smith, S.D., and Bernath, S.C., 1992b, A GIS-based method of modeling water input from rain-on-snow storms, for management and regulation of clearcut forest harvest, in Proceedings, $60^{\text {th }}$ Western Snow Conference, Jackson Hole WY, p. 125-128.

Burns, S.F., Burns, W.J., James, D.H., and Hinkle, J.C., 1998, Landslides in the Portland, Oregon metropolitan area resulting from the storm of February 1996: inventory map, database and evaluation: Portland State Univ., Report for Metro Contract 905828, $41 \mathrm{p}+$ database.

Cayan, D.R., 1996, Interannual climate variability and snowpack in the western United 209 
States: Journal of Climate, v. 9, p. 928-948.

Cayan, D.R., and Peterson, D.H., 1989, The influence of North Pacific atmospheric circulation on streamflow in the West, in Peterson, D.H., ed., Aspects of Climate Variability in the Pacific and the Western Americas: American Geophysical Union, Geophysical Monograph 55, p. 375-397.

Cayan, D.R., Dettinger, M.D., Diaz, H.F., and Graham, N.E., 1998, Decadal variability of precipitation over western North America: Journal of Climate, v. 11, p. 31483166.

Cayan, D.R., Redmond, K.T., and Riddle, L.G., 1999, ENSO and hydrologic extremes in the western United States: Journal of Climate, v. 12, p. 2881-2893.

Christner, J., and Harr, R.D., 1982, Peak streamflows from the transient snow zone, Western Cascades, Oregon, in Proceedings, $50^{\text {th }}$ Western Snow Conference, Reno NV, p. 27-37.

Church, J.E., 1933, Snow surveying: its principles and possibilities: Geographical Review, v. XXIII, p. 529-563.

Church, J.E., 1935, Principles of snow surveying as applied to forecasting stream flow: Journal of Agricultural Research, v. 51, p. 97-130.

Church, P.E., 1940, Ice-crusts and snow settling at Snoqualmie Pass, season of 1939-40, in $8^{\text {th }}$ Western Interstate Snow Survey Conference: American Geophysical Union (Hydrology Section), Transactions of 1940, Seattle WA, Part III-B, p. 928-932.

Clark, M.P., Serreze, M.C., and McCabe, G.J., 2001, Historical effects of El Niño and La Niña events on the seasonal evolution of the montane snowpack in the Columbia and Colorado River basins: Water Resources Research, v. 37, p. 741-757.

Clyde, G.D., 1929, The effect of rain on the snow cover: Monthly Weather Review, v. 57, p. 328.

Coffin, B.A., 1991, Effects of forest cover on rate of water delivery to the soil during rain-on-snow [M.S. thesis]: Seattle, University of Washington, 132 p.

Coffin, B.A., and Harr, R.D., 1992, Effects of forest cover on volume of water delivery to soil during rain-on-snow: USFS and University of Washington College of Forest Resources, Report TFW-SH1-92-001, 118 p.

Colbeck, S.C., 1972, A theory of water percolation in snow: Journal of Glaciology, v. 11, 210 
p. $369-385$.

Colbeck, S.C., 1973a, Effects of stratigraphic layers on water flow through snow: USACE Cold Regions Research \& Engineering Laboratory, Research Report RR $311,15 \mathrm{p}$.

Colbeck, S.C., 1973b, Theory of metamorphism of wet snow: USACE Cold Regions Research \& Engineering Laboratory, Research Report RR 313, 12 p.

Colbeck, S.C., 1974, The capillary effects on water percolation in heterogeneous snow: Journal of Glaciology, v. 13, p. 85-97.

Colbeck, S.C., 1975a, A theory for water flow through a layered snowpack: Water Resources Research, v. 11, p. 261-266.

Colbeck, S.C., 1975b, Analysis of hydrologic response to rain-on-snow: USACE Cold Regions Research \& Engineering Laboratory, Research Report RR 340, 13 p.

Colbeck, S.C., 1976, An analysis of water flow in dry snow: Water Resources Research, v. 12 , p. 523-527.

Colbeck, S.C., 1977a, Short-term forecasting of water run-off from snow and ice: Journal of Glaciology, v. 19, p. 571-588.

Colbeck, S.C., 1977b, Roof loads resulting from rain-on-snow: USACE Cold Regions Research \& Engineering Laboratory, CRREL Report 77-12, 19 p.

Colbeck, S.C., 1977c, Roof loads resulting from rain on snow: results of a physical model: Canadian Journal of Civil Engineering, v. 4, p. 482-490.

Colbeck, S.C., 1979, Water flow through heterogeneous snow: Cold Regions Science and Technology, v. 1, p. 37-45.

Colbeck, S.C., 1982, An overview of seasonal snow metamorphism: Reviews of Geophysics and Space Physics, v. 20, p. 45-61.

Colbeck, S.C., 1987, History of snow-cover research: Journal of Glaciology, Special Issue Commemorating the Fiftieth Anniversary of the International Glaciological Society, p. 60-65.

Colbeck, S.C., and Anderson, E.A., 1982, The permeability of a melting snow cover: Water Resources Research, v. 18, p. 904-908.

Colbeck, S.C., and Davidson, G., 1973, Water percolation through homogeneous snow, in The Role of Snow and Ice in Hydrology, Banff AB, p. 242-257. 
Colle, B.A., and Mass, C.F., 2000, The 5-9 February 1996 flooding event over the Pacific Northwest: sensitivity studies and evaluation of the MM5 precipitation forecasts: Monthly Weather Review, v. 128, p. 593-617.

Connelly, B.A., 1992, The cumulative effects of forest management on peak flows during rain-on-snow events [M.S. thesis]: Seattle, University of Washington, 130 p.

Connelly, B.A., and Cundy, T.W., 1992, Cumulative effects of forest management on peak streamflows during rain-on-snow events, in Jones, M.E., and Laenen, A., eds., Interdisciplinary approaches in hydrology and hydrogeology: American Institute of Hydrology, Portland OR, p. 470-484.

Conway, H., and Raymond, C.F., 1993, Snow stability during rain: Journal of Glaciology, v. 39, p. 635-642.

Conway, H., and Benedict, R., 1994, Infiltration of water into snow: Water Resources Research, v. 30, p. 641-649.

Cooley, K.R., and Robertson, D.C., 1983, Monitoring a rain-on-snow event, in Proceedings, $51^{\text {st }}$ Western Snow Conference, Vancouver WA, p. 19-26.

Crandell, D.R., 1963, Surficial geology and geomorphology of the Lake Tapps quadrangle, Washington: U.S. Geological Survey, Professional Paper 388-A, 84 p.

Crandell, D.R., 1971, Postglacial lahars from Mount Rainier volcano, Washington: U.S. Geological Survey, Professional Paper 677, 75 p.

Crandell, D.R., and Miller, R.D., 1974, Quaternary stratigraphy and extent of glaciation in the Mount Rainier region, Washington: U.S. Geological Survey, Professional Paper 847, $59 \mathrm{p}$.

Cunnane, C., 1978, Unbiased plotting positions - a review: Journal of Hydrology, v. 37, p. 205-222.

Daly, C., Neilson, R.P., and Phillips, D.L., 1994, A statistical-topographic model for mapping climatological precipitation over mountainous terrain: Journal of Applied Meteorology, v. 33, p. 140-158.

Danard, M., 1976, On frictional and orographic effects on precipitation in coastal areas: Boundary-Layer Meteorology, v. 10, p. 409-422.

Danard, M., 1977, A simple model for mesoscale effects of topography on surface winds: Monthly Weather Review, v. 105, p. 572-581. 
de Ploey, J., Kirkby, M.J., and Ahnert, F., 1991, Hillslope erosion by rainstorms - a magnitude-frequency analysis: Earth Surface Processes and Landforms, v. 16, p. 399409.

del Moral, R., and Long, J.N., 1977, Classification of montane forest community types in the Cedar River drainage of western Washington: Canadian Journal of Forest Research, v. 7, p. 217-225.

Denoth, A., Seidenbusch, W., Blumenthaler, M., Kirchlechner, P., Ambach, W., and Colbeck, S.C., 1979, Study of water drainage from columns of snow: USACE Cold Regions Research \& Engineering Laboratory, CRREL Report 79-1, 13 p.

Dettinger, M., 2004a, 52 years of pineapple-express circulations across the West Coast of North America [abs], in Twenty-first Annual PACLIM Workshop, Pacific Grove CA, p. 8-9.

Dettinger, M., 2004b, Fifty-two years of "pineapple-express" storms across the West Coast of North America: U.S. Geological Survey, Scripps Institution of Oceanography for the California Energy Commission, PIER Energy-Related Environmental Research, CEC-500-2005-004, 15 p.

Dragovich, J.D., Logan, R.L., Schasse, H.W., Walsh, T.J., Lingley, W.S. Jr., Norman, D.K., Gerstel, W.J., Lapen, T.J., Schuster, J.E., and Meyers, K.D., 2002, Geologic map of Washington-Northwest quadrant: Washington Division of Geology \& Earth Resources, Geologic Map GM-50, 72 p.

Dunne, T., and Leopold, L.B., 1978, Water in Environmental Planning: San Francisco, W.H. Freeman and Company, 800 p.

Dunne, T., Price, A.G., and Colbeck, S.C., 1976, The generation of runoff from subarctic snowpacks: Water Resources Research, v. 12, p. 677-685.

Dyrness, C.T., 1967, Mass soil movements in the H.J. Andrews Experimental Forest: U.S. Forest Service, Research Paper PNW-42, 12 p.

Dyrness, T., Swanson, F., Grant, G., Gregory, S., Jones, J., Kurosawa, K., Levno, A., Henshaw, D., and Hammond, H., 1996, Flood of February, 1996 in the H.J. Andrews Experimental Forest: U.S. Forest Service, Forest Sciences Laboratory, Long-Term Ecological Research at Oregon State University; www.fsl.orst.edu/lter/pubs/webdocs/reports/flood.cfm 
Eimers, M.C., Buttle, J.M., and Watmough, S.A., 2007, The contribution of rain-on-snow events to annual $\mathrm{NO}_{3}-\mathrm{N}$ export from a forested catchment in south-central Ontario, Canada: Applied Geochemistry, v. 22, p. 1105-1110.

Eisbacher, G.H., and Clague, J.J., 1984, Destructive mass movements in high mountains: hazard and management: Geological Survey of Canada, Paper 84-16, 230 p.

Elder, K., and Kattelmann, R., 1993, A low-angle slushflow in the Kirgiz Range, Kirgizstan: Permafrost and Periglacial Processes, v. 4, p. 301-310.

Enfield, D.B., 1989, El Niño, past and present: Reviews of Geophysics, v. 27, p. 159-187.

Ewing, K., 1982, A comparison of treeless areas in the forested foothills of the Cascade Mountains of western Washington: Northwest Science, v. 56, p. 180-189.

Feiccabrino, J., and Lundberg, A., 2007, Precipitation phase discrimination by dew point and air temperature, in Proceedings, $75^{\text {th }}$ Western Snow Conference, Kailua-Kona HA, p. 141-145.

Ferber, G.K., Mass, C.F., Lackmann, G.M., and Patnoe, M.W., 1993, Snowstorms over the Puget Sound lowlands: Weather and Forecasting, v. 8, p. 481-504.

Ferguson, S.A., 2000, The spatial and temporal variability of rain-on-snow, in Proceedings, International Snow Science Workshop: American Avalanche Association, Big Sky MT, 6 p. http://www.fs.fed.us/pnw/fera/publications/fulltext/ferguson2000.pdf

Fitzharris, B.B., Stewart, D., and Harrison, W., 1980, Contribution of snowmelt to the October 1978 flood of the Pomahaka and Fraser Rivers, Otago: Journal of Hydrology [New Zealand], v. 19, p. 84-93.

Floyd, W., and Weiler, M., 2008, Measuring snow accumulation and ablation dynamics during rain-on-snow events: innovative measurement techniques: Hydrological Processes, v. 22, p. 4805-4812.

Franklin, J.F., and Dyrness, C.T., 1973, Natural vegetation of Oregon and Washington: USDA Forest Service, General Technical Report PNW-8, 417 p.

Franklin, J.F., and Blinn, T., 1988, Natural vegetation of Oregon and Washington-Commentary and bibliographic supplement: Oregon State University Press for the U.S. Forest Service, $36 \mathrm{p}$.

Frederick, R.H., and Tracey, R.J., 1976, Water available for runoff for 4 to 15 days dura214 
tion in the Snake River Basin in Idaho: NOAA Technical Memorandum NWS HYDRO-29.

Gallino, G.L., and Pierson, T.C., 1984, The 1980 Polallie Creek debris flow and subsequent dam-break flood, East Fork Hood River basin, Oregon: U.S. Geological Survey, Open-File Report 84-578, $37 \mathrm{p}$.

Gallino, G.L., and Pierson, T.C., 1985, Polallie Creek debris flow and subsequent dambreak flood of 1980, East Fork Hood River basin, Oregon: U.S. Geological Survey, Water-Supply Paper 2273, 22 p.

Gerdel, R.W., 1945, The dynamics of liquid water in deep snow-packs: Transactions, American Geophysical Union, v. 26 Part I, p. 83-90.

Gerdel, R.W., 1948a, The storage and transmission of liquid water in the snow pack as indicated by dyes, in Proceedings, $16^{\text {th }}$ Western Snow Conference, Reno NV, p. 81-91.

Gerdel, R.W., 1948b, Physical changes in snow-cover leading to runoff, especially to floods, in Association Internationale d'Hydrologie Scientifique, Congres d'Oslo; Tome II. Commission des Neiges et Glaciers; IAHS-IASH Publication 30, p. 4254.

Gerdel, R.W., 1954, The transmission of water through snow: Transactions, American Geophysical Union, v. 35, p. 475-456.

Gershunov, A., and Barnett, T.P., 1998, ENSO influence on intraseasonal extreme rainfall and temperature frequencies in the contiguous United States: observations and model results: Journal of Climate, v. 11, p. 1575-1586.

Gerstel, W.J., Brunengo, M.J., Lingley, W.S., Jr., Logan, R.S., Shipman, H., and Walsh, T.J., 1997, Puget Sound bluffs: the where, why and when of landslides following the Holiday 1996/97 storms: Washington Geology, v. 25, p. 17-31.

Goldin, A., 1992, Soil survey of Snoqualmie Pass area, parts of King and Pierce counties, Washington: USDA Soil Conservation Service, $601 \mathrm{p}$.

Goodison, B.E., Ferguson, H.L., and McKay, G.A., 1981, Measurement and data analysis (chapter 6), in Gray, D.M., and Male, D.H., eds., Handbook of Snow: Principles, Processes, Management \& Use: Toronto, Pergamon Press, 776 p.

Grant, G.E., and Swanson, F.J., 1995, Morphology and processes of valley floors in 215 
mountain streams, western Cascades, Oregon, in Costa, J.E., Miller, A.J., Potter, K.W., and Wilcock, P.R., eds., Natural and Anthropogenic Influences in Fluvial Geomorphology: Washington DC, American Geophysical Union, Geophysical Monograph 89, p. 83-101.

Graybeal, D.Y., and Leathers, D.J., 2006, Snowmelt-related flood risk in Appalachia: first estimates from a historical snow climatology: Journal of Applied Meteorology and Climatology, v. 45, p. 178-193.

Grenfell, T.C., and Putkonen, J., 2008, A method for the detection of the severe rain-onsnow event on Banks Island, October 2003, using passive microwave: Water Resources Research, v. 44, 9 p.

Griffin, A.A., 1918, Influence of forests upon the melting of snow in the Cascade Range: Monthly Weather Review, v. 46, p. 324-327.

Gringorten, I.I., 1963, A plotting rule for extreme probability paper: Journal of Geophysical Research, v. 68, p. 813-814.

Groisman, P.Y., Sun, B., Vose, R.S., Lawrimore, J.H., Whitfield, P.H., Førland, E., Hanssen-Bauer, I., Serreze, M.C., Razuvaev, V.N., and Alekseev, G.V., 2003, Contemporary climate changes in high latitudes of the northern hemisphere: daily time resolution, in $14^{\text {th }}$ Symposium on Global Change and Climatic Variations: Long Beach CA, American Meteorological Society; 10 p. http://ams.confex.com/ams/pdfpapers/54814.pdf;

Gude, M., and Scherer, D., 1995, Snowmelt and slush torrents-preliminary report from a field campaign in Kärkevagge, Swedish Lappland: Geografiska Annaler, Series A, v. 77A, p. 199-206.

Gumbel, E.J., 1945, Simplified plotting of statistical observations: Transactions, American Geophysical Union, v. 26, Part I, p. 69-82.

Gumbel, E.J., 1958, Statistics of Extremes: New York, Columbia University Press, 375 p. Haan, C.T., 1977, Statistical Methods in Hydrology: Ames, Iowa State University Press, $378 \mathrm{p}$.

Hamlet, A.F., Mote, P.W., Clark, M.P., and Lettenmaier, D.P., 2005, Effects of temperature and precipitation variability on snowpack trends in the western United States: Journal of Climate, v. 18, p. 4545-4561. 
Hardy, J.P., and Albert, D.G., 1993, The permeability of temperate snow; preliminary links to microstructure, in Proceedings, $61^{\text {st }}$ Western Snow Conference and $50^{\text {th }}$ Eastern Snow Conference, Quebec City QE, p. 149-156.

Harp, E.L., Chleborad, A.F., Schuster, R.L., Cannon, S.H., Reid, M.E., and Wilson, R.C., 1996, Landslides and landslide hazards in Washington state due to February 5-9, 1996 storm: U.S. Geological Survey, administrative report to FEMA, 29 p.

Harr, R.D., 1981, Some characteristics and consequences of snowmelt during rainfall in western Oregon: Journal of Hydrology, v. 53, p. 277-304.

Harr, R.D., 1986, Effects of clearcutting on rain-on-snow runoff in western Oregon: a new look at old studies: Water Resources Research, v. 22, p. 1095-1100.

Harr, R.D., and Berris, S.N., 1983, Snow accumulation and subsequent melt during rainfall in forested and clearcut plots in western Oregon, in Proceedings, $51^{\text {st }}$ Western Snow Conference, Vancouver WA, p. 38-45.

Harr, R.D., and Cundy, T.W., 1992, The November 1990 floods in western Washington, U.S.A., in Proceedings, Internationales Symposion Interpraevent 1992, Bern, Switzerland, p. 229-239.

Hayes, P.S., Rasmussen, L.A., and Conway, H., 2002, Estimating precipitation in the central Cascades of Washington: Journal of Hydrometeorology, v. 3, p. 335-346.

Hemstrom, M.A., and Franklin, J.F., 1982, Fire and other disturbances in the forests in Mount Rainier National Park: Quaternary Research, v. 18, p. 32-51.

Henderson, J.A., Lesher, R.D., Peter, D.H., and Shaw, D.C., 1992, Field guide to the forested plant associations of the Mt. Baker-Snoqualmie National Forest: USDA Forest Service, Technical Paper R6 ECOL TP 028-91, 196 p.

Hestnes, E., 1985, A contribution to the prediction of slush avalanches: Annals of Glaciology, v. 6, p. 1-4.

Hestnes, E., 1998, Slushflow hazard - where, why and when? 25 years of experience with slushflow consulting and research: Annals of Glaciology, v. 26, p. 370-376.

Hestnes, E., and Sandersen, F., 1987, Slushflow activity in the Rana district, North Norway, in Symposium on Avalanche Formation, Movement and Effects, Davos, Switzerland (1986): IAHS Publication no 162, p. 317-330.

Higgins, R.W., Schemm, J.-K.E., Shi, W., and Leetma, A., 2000, Extreme precipitation in 217 
the western United States related to tropical forcing: Journal of Climate, v. 13, p. 793-820.

Hofmeister, R.J., 2000, Slope failures in Oregon-GIS inventory for three 1996/97 storm events: Oregon Department of Geology and Mineral Industries, Special Paper 34, $20 \mathrm{p}+\mathrm{CD}$.

Hopkins, G.F., 1940, Hydrological investigations for Mud Mountain reservoir, in Hydrology Section, AGU Regional Meeting, Seattle WA: American Geophysical Union Transactions of 1940, p. 1006-1011.

Horton, R.E., 1905, Snowfalls, freshets, and the winter flow of streams in the state of New York: Monthly Weather Review, v. 33, p. 196-202.

Horton, R.E., 1915, The melting of snow: Monthly Weather Review, v. 43, p. 599-605.

Horton, R.E., 1941, The role of snow, ice, and frost in the hydrologic cycle, in Central Snow Conference, Michigan State College, East Lansing MI, p. 5-21.

Horton, R.E., 1945, Infiltration and runoff during snow-melting season, with forest cover: Transactions, American Geophysical Union, v. 26, Part I, p. 59-68.

Houze, R.A., Jr., and Hobbs, P.V., 1982, Organization and structure of precipitating cloud systems: Advances in Geophysics, v. 24, p. 225-315.

Hoyt, W.G., and Langbein, W.G., 1939, Some general observations of physiographic and climatic influences on floods, in Symposium on Floods, Section of Hydrology, Washington DC: American Geophysical Union Transactions of 1939, Part IV, p. 166-174.

Hubbard, L.L., 1991, Oregon floods and droughts; in Paulson, R.W., Chase, E.B., Roberts, R.S., and Moody, D.W., compilers, National water summary 1988-89 - hydrologic events and floods and droughts: U.S. Geological Survey, Water-Supply Paper 2375, p. 459-465.

Hubbard, L.L., 1994, Floods of November 1990 in western Washington: U.S. Geological Survey, Open-File Report 93-631, 10 p.

Illangasekare, T.H., Walter, R.J. Jr., Meier, M.F., and Pfeffer, W.T., 1990, Modeling of meltwater infiltration in subfreezing snow: Water Resources Research, v. 26, p. 1001-1012.

Isyumov, N., and Davenport, A.G., 1974, A probabilistic approach to the prediction of 218 
snow loads: Canadian Journal of Civil Engineering, v. 1, p. 28-49.

Jarvis, C.S., 1939, Great floods in the United States, in Symposium on Floods, Section of Hydrology, Washington DC: American Geophysical Union Transactions of 1939, Part IV, p. 142-234.

Johnson, D.M., and Koch, R.W., 1992, Climate and streamflow in the Pacific Northwest: teleconnections with the tropical Pacific Ocean, in Interdisciplinary Approaches in Hydrology and Hydrogeology: American Institute of Hydrology, p. 406-426.

Johnson, J.B., and Marks, D., 2004, The detection and correction of snow water equivalent pressure sensor errors: Hydrological Processes, v. 18 (Special Issue: 2002 $59^{\text {th }}$ Eastern Snow Conf $/ 70^{\text {th }}$ Western Snow Conf, 2002 Granby CO), p. 35133525 .

Johnson, J.B., and Schaefer, G.L., 2002, The influence of thermal, hydrologic, and snow deformation mechanisms on snow water equivalent pressure sensors: Hydrological Processes, v. 16 (Special Issue: $59^{\text {th }}$ Eastern Snow Conf $/ 70^{\text {th }}$ Western Snow Conf, 2002 Granby CO), p. 3529-3542.

Jones, J.A., and Perkins, R.M., 2010, Extreme flood sensitivity to snow and forest harvest, western Cascades, Oregon, United States: Water Resources Research, v. 46, p. 21.

Jordan, P., 1983a, Meltwater movement in a deep snowpack; 1. Field observations: Water Resources Research, v. 19, p. 971-978.

Jordan, P., 1983b, Meltwater movement in a deep snowpack; 2. Simulation model: Water Resources Research, v. 19, p. 979-985.

Jordan, R., 1991, A one-dimensional temperature model for a snow cover: technical documentation for SNTHERM.89: U.S. Army Cold Regions Research \& Engineering Laboratory (CRREL), Special Report 91-16, 49 p.

Jordan, R.E., Hardy, J.P., Perron, F.E., Jr., and Fisk, D.J., 1999, Air permeability and capillary rise as measures of the pore structure of snow: an experimental and theoretical study: Hydrological Processes, v. 13, p. 1733-1753.

Kattelmann, R., 1985, Temperature indices of snowmelt during rainfall, in Proceedings, $53^{\text {rd }}$ Western Snow Conference, Boulder CO, p. 152-155.

Kattelmann, R., 1986, Measurements of snow layer water retention, in Cold Regions 219 
Hydrology Symposium, Fairbanks AK: American Water Resources Association, TPS-86-1, p. 377-386.

Kattelmann, R., 1997, Rapid changes in snow cover at low elevations in the Sierra Nevada, California, U.S.A.: Annals of Glaciology, v. 25, p. 367-370.

Kattelmann, R., Berg, N., and McGurk, B., 1991, A history of rain-on-snow floods in the Sierra Nevada, in Proceedings, $59^{\text {th }}$ Western Snow Conference, Juneau AK, p. 138-141.

Knowles, N., Dettinger, M.D., and Cayan, D.R., 2006, Trends in snowfall versus rainfall in the western United States: Journal of Climate, v. 19, p. 4545-4559.

Koch, R.W., Buzzard, C.F., and Johnson, D.M., 1991, Variation of snow water equivalent and streamflow in relation to the El Niño/Southern Oscillation, in Proceedings, $59^{\text {th }}$ Western Snow Conference, Juneau AK, p. 37-48.

Koch, R.W., and Fisher, A.R., 2000, Effects of inter-annual and decadal-scale climate variability on winter and spring streamflow in western Oregon and Washington, in Proceedings, $68^{\text {th }}$ Western Snow Conference, Port Angeles WA, p. 1-11.

Kohl, B., Fuchs, M., Markert, G., and Patzelt, G., 2001, Heavy rain on snow cover: Annals of Glaciology, v. 32, p. 33-38.

Krist, G., 2007, The White Cascade - The Great Northern Railway Disaster and America's Deadliest Avalanche: New York, Henry Holt and Company, 317 p.

Kroczynski, S., 2004, A comparison of two rain-on-snow events and the subsequent hydrological responses in three small river basins in central Pennsylvania: National Weather Service, Eastern Regional Technical Attachment No. 2004-04.

Lackmann, G.M., and Gyakum, J.R., 1999, Heavy cold-season precipitation in the northwestern United States: synoptic climatology and an analysis of the flood of 17-18 January 1986: Weather and Forecasting, v. 14, p. 687-700.

Laenen, A., editor, 1997, The Pacific Northwest Floods of February 6-11, 1996: Proceedings of the Pacific Northwest Water Issues Conference (1996), Portland OR: American Institute of Hydrology, 318 p.

Larocque, S.J., Hétu, B., and Filion, L., 2001, Geomorphic and dendroecological impacts of slushflows in central Gaspé Peninsula (Québec, Canada): Geografiska Annaler, Series A, v. 83, p. 191-201. 
Leathers, D.J., Kluck, D.R., and Kroczynski, S., 1998, The severe flooding event of January 1996 across north-central Pennsylvania: Bulletin of the American Meteorological Society, v. 79, p. 785-797.

Legates, D.R., and DeLiberty, T.L., 1993, Precipitation measurement biases in the United States: Water Resources Bulletin, v. 29, p. 855-861.

Lighthill, M.J., and Whitham, G.B., 1955, On kinematic waves: I. Flood movement in long rivers: Proceedings of the Royal Society, London, Series A, v. 229, p. 281316.

Loukas, A., and Quick, M.C., 1996, Spatial and temporal distribution of storm precipitation in southwestern British Columbia: Journal of Hydrology, v. 174, p. 37-56.

Loukas, A., Vasiliades, L., and Dalezios, N.R., 2000, Flood producing mechanisms identification in southern British Columbia, Canada: Journal of Hydrology, v. 227, p. 218-235.

Loukas, A., Vasiliades, L., and Dalezios, N.R., 2002, Potential climate change impacts on flood producing mechanisms in southern British Columbia, Canada using the CGCMA1 simulation results: Journal of Hydrology, v. 259, p. 163-188.

Lucia, E., 1965, Wild Water: The Story of the Far West's Great Christmas Week Floods: Portland OR, Overland West Press, $72 \mathrm{p}$.

Lundquist, J.D., Cayan, D.R., and Dettinger, M.D., 2004, Spring onset in the Sierra Nevada: when is snowmelt independent of elevation?: Journal of Hydrometeorology, v. 5 , p. 327-342.

Lundquist, J.D., Neiman, P.J., Martner, B., White, A.B., Gottas, D.J., and Randolph, F.M., 2008, Rain versus snow in the Sierra Nevada, California: comparing Doppler profiling radar and surface observations of melting level: Journal of Hydrometeorology, v. 9, p. 194-211.

Mackin, J.H., 1941, Glacial geology of the Snoqualmie-Cedar area, Washington: Journal of Geology, v. XLIX, p. 449-481.

Maclean, R.A., English, M.C., and Schiff, S.L., 1995, Hydrological and hydrochemical response of a small Canadian Shield catchment to late winter rain-on-snow events: Hydrological Processes, v. 9, p. 845-863.

Mantua, N.J., Hare, S.R., Zhang, Y., Wallace, J.M., and Francis, R.C., 1997, A Pacific 221 
interdecadal climate oscillation with impacts on salmon production: Bulletin of the American Meteorological Society, v. 78, p. 1069-1079.

Marks, D., Domingo, J., Susong, D., Link, T., and Garen, D., 1999, A spatially distributed energy balance snowmelt model for application in mountain basins: Hydrological Processes, v. 13 (Special Issue: Snow Hydrology), p. 1935-1959.

Marks, D., and Dozier, J., 1992, Climate and energy exchange at the snow surface in the alpine region of the Sierra Nevada; 2. Snow cover energy balance: Water Resources Research, v. 28, p. 3043-3054.

Marks, D., Kimball, J., Tingey, D., and Link, T., 1998, The sensitivity of snowmelt processes to climate and forest cover during rain-on-snow: a case study of the 1996 Pacific Northwest flood: Hydrological Processes, v. 12, p. 1569-1587.

Marks, D., Link, T., Winstral, A., and Garen, D., 2001, Simulating snowmelt processes during rain-on-snow over a semi-arid mountain basin: Annals of Glaciology, v. 32, p. 195-202.

Marsh, P., and Woo, M-k., 1984a, Wetting front advance and freezing of meltwater within a snow cover; 1. Observations in the Canadian Arctic: Water Resources Research, v. 20, p. 1853-1864.

Marsh, P., and Woo, M-k., 1984b, Wetting front advance and freezing of meltwater within a snow cover; 2. A simulation model: Water Resources Research, v. 20, p. 1865-1874.

Marsh, P., and Woo, M-k., 1985, Meltwater movement in natural heterogeneous snow covers: Water Resources Research, v. 21, p. 1710-1716.

Mass, C., 1981, Topographically forced convergence in western Washington State: Monthly Weather Review, v. 109, p. 1335-1347.

Mass, C., 2008, The Weather of the Pacific Northwest: Seattle, University of Washington Press, $280 \mathrm{p}$.

Matthai, H.F., 1990, Floods, in Wolman, M.G., and Riggs, H.C., eds., Surface Water Hydrology: Boulder CO, Geological Society of America, Geology of North America, v. O-1, p. 97-120.

Mazurkiewicz, A.B., Callery, D.G., and McDonnell, J.J., 2008, Assessing the controls of the snow energy balance and water available for runoff in a rain-on-snow environ222 
ment: Journal of Hydrology, v. 354, p. 1-14.

McCabe, G.J., and Clark, M.P., 2005, Trends and variability in snowmelt runoff in the western United States: Journal of Hydrometeorology, v. 6, p. 476-482.

McCabe, G.J., Clark, M.P., and Hay, L.E., 2007, Rain-on-snow events in the western United States: Bulletin of the American Meteorological Society, v. 88, p. 319328.

McCabe, G.J., and Dettinger, M.D., 2002, Primary modes and predictability of year-toyear snowpack variations in the western United States from teleconnections with Pacific Ocean climate: Journal of Hydrometeorology, v. 3, p. 13-25.

McCabe, G.J., and Wolock, D.M., 1999, General-circulation-model simulations of future snowpack in the western United States: Journal of the American Water Resources Association, v. 35, p. 1473-1484.

McCracken, D.D., 1955, The Monte Carlo method: Scientific American, v. 192, p. 90-96.

McGurk, B.J., Berg, N.H., and Kattelmann, R.C., 1993, Identification and regional/spatial extent of rain-dominated winter storms in California's Sierra Nevada, in Proceedings, $61^{\text {st }}$ Western Snow Conference and $50^{\text {th }}$ Eastern Snow Conference, Quebec City QE, p. 67-74.

McGurk, B.J., and Kattelmann, R.C., 1986, Water flow rates, porosity, and permeability in snowpacks in the central Sierra Nevada, in Kane, D.L., editor, Cold Regions Hydrology Symposium: American Water Resources Assoc., p. 359-366.

Meeker, E., 1905, Pioneer Reminiscences of Puget Sound: Seattle, Lowman \& Hanford Stationary and Printing Co., 555 p.

Meier, M.F., 1990, Snow and ice, in Wolman, M.G., and Riggs, H.C., eds., Surface water hydrology: Boulder CO, Geological Society of America, Geology of North America, v. O-1, p. 131-158.

Mergen, B., 1993, Snow sciences in North America - the Eastern and Western Snow Conferences in the context of environmental history, in Proceedings, $61^{\text {st }}$ Western Snow Conference and $50^{\text {th }}$ Eastern Snow Conference, Quebec City QE, p. 175181.

Mergen, B., 1997, Snow in America: Washington, Smithsonian Institution Press, 321 p. Miller, D.H., 1950, Rain-on-snow flood of 18-20 November 1950, CSSL: Preliminary 223 
report and outline for investigation as of 24 November 1950: Office memo to USACE/NWS Cooperative Snow Investigations technical director.

Miller, G.R., 1999, The Great Willamette Flood of 1861: Oregon Historical Quarterly, v. 100, p. 182-207.

Miller, G.R., 2002, Pacific Northwest Weather: But My Barometer Says Fair!: Portland OR, Frank Amato Publications, Inc., 174 p.

Miller, J.E., 1984, Basic concepts of kinematic-wave models: U.S. Geological Survey, Professional Paper 1302, 29 p.

Miller, J.F., 1970, Precipitation frequency maps for Washington and Oregon: NOAA/NWS Office of Hydrology, Special Studies Branch, Atlas 2, Volume IX.

Minder, J.R., Mote, P.W., and Lundquist, J.D., 2010, Surface temperature lapse rates over complex terrain: lessons from the Cascade Mountains: Journal of Geophysical Research, v. 115, 13 p.

Mishra, S., 2001, Dealing with uncertainty in environmental model predictions: Eos, Transactions American Geophysical Union, v. 82, p. 568.

Mitchell, S.G., and Montgomery, D.R., 2006, Influence of a glacial buzzsaw on the height and morphology of the Cascade Range in central Washington State, USA: Quaternary Research, v. 65, p. 96-107.

Mo, K.C., and Higgins, R.W., 1998, Tropical convection and precipitation regimes in the western United States: Journal of Climate, v. 11, p. 2404-2423.

Mote, P.W., 2003, Trends in snow water equivalent in the Pacific Northwest and their climatic causes: Geophysical Research Letters, v. 30, p. 4.

Mote, P., and 18 others, 1999, Impacts of climate variability and change in the Pacific Northwest: JISAO/SMA Climate Impacts Group, University of Washington, JISAO Contribution \#715, 109 p.

Mote, P.W., Hamlet, A.F., Clark, M.P., and Lettenmaier, D.P., 2005, Declining mountain snowpack in western North America: Bulletin of the American Meteorological Society, v. 86, p. 39-49.

Neiman, P.J., Ralph, F.M., Wick, G.A., Lundquist, J.D., and Dettinger, M.D., 2008a, Meteorological characteristics and overland precipitation impacts of atmospheric rivers affecting the West Coast of North America based on eight years of SSM/I 224 
satellite observations: Journal of Hydrometeorology, v. 9, p. 22-47

Neiman, P.J., Ralph, F.M., Wick, G.A., Kuo, Y-h., Wee, T-k., Ma, Z., Taylor, G.H., and Dettinger, M.D., 2008b, Diagnosis of an intense atmospheric river impacting the Pacific Northwest: storm summary and offshore vertical structure observed with COSMIC satellite retrievals: Monthly Weather Review, v. 136, p. 4398-4420.

Newell, R.E., Newell, N.E., Zhu, Y., and Scott, C., 1992, Tropospheric rivers? - a pilot study: Geophysical Research Letters, v. 19, p. 2401-2404.

Nolin, A.W., and Daly, C., 2006, Mapping "at risk" snow in the Pacific Northwest: Journal of Hydrometeorology, v. 7, p. 1164-1171.

Nyberg, R., 1989, Observations of slushflows and their geomorphological effects in the Swedish mountain area: Geografiska Annaler, Series A, v. 71A, p. 185-198.

O'Connor, J.E., and Costa, J.E., 2003, Large floods in the United States: where they happen and why: U.S. Geological Survey, Circular 1245, 13 p.

O'Connor, J.E., and Costa, J.E., 2004, The world's largest floods, past and present: their causes and magnitudes: U.S. Geological Survey, Circular 1254, 13 p.

Onesti, L.J., 1985, Meteorological conditions that initiate slushflows in the central Brooks Range, Alaska: Annals of Glaciology, v. 6, p. 23-25.

Onesti, L.J., and Hestnes, E., 1989, Slush-flow questionnaire: Annals of Glaciology, v. 13, p. 226-230.

Parsons, D.B., 1982, Origin, behavior, and dissipation of mesoscale rainbands, including the effects of orography and comparisons with theory [Ph.D. thesis]: Seattle, University of Washington, $242 \mathrm{p}$.

Parsons, W.J. Jr., 1940, The relation of snow to maximum flood peaks, in $8^{\text {th }}$ Western Interstate Snow Survey Conference: American Geophysical Union (Hydrology Section), Transactions of 1940, Seattle WA, Part III-B, p. 951-953.

Parsons, W.J. Jr., 1941, Potential floods in the Sacramento Valley, in South Pacific Regional Meeting, American Geophysical Union (Hydrology Section), Transactions of 1941, Sacramento CA, Part I-A, p. 106-110.

Patra, K.C., 2001, Hydrology and Water Resources Engineering: Boca Raton FL, CRC Press, $561 \mathrm{p}$.

Paulsen, C.G., 1949, Floods of May-June 1948 in Columbia River Basin: U.S. Geologic225 
al Survey, Water-Supply Paper 1080, 476 p.

Perkins, R.M., and Jones, J.A., 2008, Climate variability, snow, and physiographic controls on storm hydrographs in small forested basins, western Cascades, Oregon: Hydrological Processes, v. 22, p. 4949-4964.

Phillips, E.L., 1968, Washington climate - King, Kitsap, Mason and Pierce Counties: Washington State University, Extension Service Report E.M. 2734, 66 p.

Pirot, R., 2010, Initiation zone characterization of debris flows in November, 2006, Mount Hood, Oregon [M.S. thesis]: Portland OR, Portland State Univ., 180 p.

Porter, S.C., 1976, Pleistocene glaciation in the southern part of the North Cascade Range, Washington: Geological Society of America Bulletin, v. 87, p. 61-75.

Putkonen, J., and Roe, G., 2003, Rain-on-snow events impact soil temperatures and affect ungulate survival: Geophysical Research Letters, v. 30, 1188, 4 p.

Putkonen, J., Grenfell, T.C., Rennert, K., Bitz, C., Jacobson, P., and Russell, D., 2009, Rain on snow: little understood killer in the North: Eos (American Geophysical Union Transactions), v. 90, p. 221-222.

Ralph, F.M., and Dettinger, M.D., 2011, Storms, floods, and the science of atmospheric rivers: Eos, Transactions, American Geophysical Union, v. 92, p. 265-266.

Rapp, A., 1995, Case studies of geoprocesses and environmental change in mountains of northern Sweden: Geografiska Annaler, Series A, v. 77A, p. 189-198.

Rasmussen, L.A., and Tangborn, W.V., 1976, Hydrology of the North Cascades region, Washington; 1. Runoff, precipitation, and storage characteristics: Water Resources Research, v. 12, p. 187-202.

Redmond, K.T., and Koch, R.W., 1991, Surface climate and streamflow variability in the western United States and their relationship to large-scale circulation indices: Water Resources Research, v. 27, p. 2381-2399.

Reiter, M., 2008, December 1-4, 2007 storm events summary: Weyerhaeuser Company, $19 \mathrm{p}$.

Rennert, K.J., Roe, G., Putkonen, J., and Bitz, C.M., 2009, Soil thermal and ecological impacts of rain on snow events in the circumpolar Arctic: Journal of Climate, v. 22, p. 2302-2315. 
Richards, F., Miller, J., Zurndorfer, E., and Foat, N., 1983a, Frequency estimates of water available for runoff due to precipitation and/or snowmelt, in Johnson, A.I., and Clark, R.A., eds., International Symposium on Hydrometeorology: Denver CO, American Water Resources Association, AWRA Technical Publication TPS-82-1, p. 535-540.

Richards, F., Miller, J.F., Zurndorfer, E.A., and Foat, N.S., 1983b, Water available for runoff for 1 to 15 days duration and return periods of 2 to 100 years for selected agricultural regions of the northwest United States: NOAA Technical Report NWS 36, 20 p.

Risley, J.C., 2004, Floods of November 1996 through January 1997 in the Umpqua River basin, Oregon: U.S. Geological Survey, Fact Sheet 2004-3134, http://water.usgs.gov/pubs/fs/2004/3134/.

Roden, G.I., 1989, Analysis and interpretation of long-term climatic variability along the west coast of North America, in Peterson, D.H., ed., Aspects of Climate Variability in the Pacific and the Western Americas: American Geophysical Union, Geophysical Monograph 55, p. 93-111.

Ropelewski, C.F., and Halpert, H.S., 1986, North American precipitation and temperature patterns associated with the El Niño/Southern Oscillation (ENSO): Monthly Weather Review, v. 114, p. 2352-2362.

Rothacher, J.S., and Glazebrook, T.B., 1968, Flood damage in the National Forests of Region 6: U.S. Forest Service, Pacific Northwest Forest and Range Experiment Station, $20 \mathrm{p}$.

Salathé, E.P. Jr, Leung, L.R., Qian, Y., and Zhang, Y., 2009, Regional climate model projections for the state of Washington, chapter 2 in Littell, J.S., Elsner, M.M., Whitely Binder, L.C., and Snover, A.K., eds., The Washington Climate Change Impacts Assessment: Evaluating Washington's Future in a Changing Climate: Climate Impacts Group, JISAO, University of Washington, p. 45-67.

Schasse, H.W., 1987a, Geologic map of the Centralia quadrangle, Washington: Washington Division of Geology \& Earth Resources, Open File Report 87-11, 27 p.

Schasse, H.W., 1987b, Geologic map of the Mount Rainier quadrangle, Washington: Washington Division of Geology \& Earth Resources, Open File Report 87-16, 43 227 
p.

Scherer, D., Gude, M., Gempeler, M., and Parlow, E., 1998, Atmospheric and hydrological boundary conditions for slushflow initiation due to snowmelt: Annals of Glaciology, v. 26, p. 377-380.

Schermerhorn, V.P., 1967, Relations between topography and annual precipitation in western Oregon and Washington: Water Resources Research, v. 3, p. 707-711.

Schuster, R.L., and Highland, L.M., 2001, Socioeconomic and environmental impacts of landslides, in Third Panamerican Symposium on Landslides, Cartagena, Colombia, p. 39.

Serreze, M.C., Clark, M.P., Armstrong, R.L., McGinnis, D.A., and Pulwarty, R.S., 1999, Characteristics of the western United States snowpack from snowpack telemetry (SNOTEL) data: Water Resources Research, v. 35, p. 2145-2160.

Shimizu, H., 1970, Air permeability of deposited snow: Contributions, Institute of Low Temperature Science, Hokkaido Univ., Series A22, p. 1-32.

Sidle, R.C., and Ochiai, H., 2006, Landslides - Processes, Prediction, and Land Use: Washington DC, American Geophysical Union, Water Resources Monograph 18, $312 \mathrm{p}$.

Singh, P., and Singh, V.P., 2001, Snow and Glacier Hydrology: Dordrecht, Netherlands, Kluwer Academic Publishers, Water Science \& Technology Library, 742 p.

Singh, P., Spitzbart, G., Hübl, H., and Weinmeister, H.W., 1997, Hydrological response of snowpack under rain-on-snow events: a field study: Journal of Hydrology, v. 202, p. 1-20.

Singh, V.P., 2001, Kinematic wave modeling in water resources: a historical perspective: Hydrological Processes, v. 15, p. 671-706.

Smith, J.L., 1974, Hydrology of warm snowpacks and their effects upon water delivery some new concepts: in Santeford, H.S., and Smith, J.L., eds., Advanced Concepts and Techniques in the Study of Snow and Ice Resources, U.S. International Hydrologic Decade Symposium, National Academy of Sciences, p. 76-89.

Sommerfeld, R.A., and Rocchio, J.E., 1993, Permeability measurements on new and equitemperature snow: Water Resources Research, v. 29, p. 2485-2490.

Speers, D.D., Barcellos, D.J., and Wortman, R.T., 1990, The 1948 flood on the Columbia 228 
River - an analysis of its cause and its importance in operational planning, in Proceedings, $58^{\text {th }}$ Western Snow Conference, Sacramento CA, p. 160-163.

Speers, P., 1986, Precipitation analysis and modeling in western Washington State [M.S. thesis]: Seattle, University of Washington, $164 \mathrm{p}$.

Steenburgh, W.J., Mass, C.F., and Ferguson, S.A., 1997, The influence of terrain-induced circulations in wintertime temperature and snow level in the Washington Cascades: Weather and Forecasting, v. 12, p. 208-227.

Storck, P., Kern, T., and Bolton, S., 1999, Measurement of differences in snow accumulation, melt, and micrometeorology due to forest harvesting: Northwest Science, v. 73, Special Issue 1000, p. 87-100.

Storck, P., Lettenmaier, D.P., Connelly, B.A., and Cundy, T.W., 1995, Implications of forest practices on downstream flooding: University of Washington (College of Engineering and College of Forest Resources), Phase II Report, 98 p.

Storck, P., Lettenmaier, D.P., and Bolton, S.M., 2002, Measurement of snow interception and canopy effects on snow accumulation and melt in a mountainous maritime climate, Oregon, U.S.: Water Resources Research, v. 38, p. 5-1-5-16.

Sturm, M., and Holmgren, J., 1993, Rain-induced water percolation in snow as detected using heat flux transducers: Water Resources Research, v. 29, p. 2323-2334.

Sui, J., and Koehler, G., 2001, Rain-on-snow induced flood events in Southern Germany: Journal of Hydrology, v. 252, p. 205-220.

Sui, J., and Koehler, G., 2007, Impacts of snowmelt on peak flows in a forest watershed: Water Resources Management, v. 21, p. 1263-1275.

Suwa, H., and Yamakoshi, T., 2000, Estimation of debris-flow motion by field surveys, in Wieczorek, G.F., and Naeser, N.D., editors, Second International Conference on Debris-Flow Hazard Mitigation: Rotterdam, A.A. Balkema, p. 293-299.

Sverdrup, H.U., 1936, The eddy conductivity of the air over a smooth snow field: Geofysiske Publikasjoner, v. 11, p. 1-69.

Swanson, F.J., Franklin, J.F., and Sedell, J.R., 1990, Landscape patterns, disturbance, and management in the Pacific Northwest, USA, in Zonneveld, I.S., and Forman, R.T.T., eds., Trends in Landscape Ecology: New York, Springer-Verlag, p. 191213. 
Tabor, R.W., Frizzell, V.A. Jr., Booth, D.B., Waitt, R.B., Whetten, J.T., and Zartman, R.E., 1993, Geologic map of the Skykomish River 30- by 60-minute quadrangle, Washington: U.S. Geological Survey, Miscellaneous Investigations Series I-1963, $42 \mathrm{p}$.

Tabor, R.W., Frizzell, V.A. Jr., Booth, D.B., and Waitt, R.B., 2000, Geologic map of the Snoqualmie Pass 30 x 60 minute quadrangle, Washington: U.S. Geological Survey, Geologic Investigations Series I-2538, 57 p.

Taylor, G.H., 1997, Causes of the great flood of 1996 and a comparison to other climate events, in Laenen, A., editor, The Pacific Northwest Floods of February 6-11, 1996: Proceedings of the Pacific Northwest Water Issues Conference (1996), Portland OR: American Institute of Hydrology, p. 3-6.

Taylor, G.H., and Hatton, R.R., 1999, The Oregon Weather Book, a State of Extremes: Corvallis, Oregon, Oregon State University Press, 242 p.

Thom, H.C.S., 1966, Distribution of maximum annual water equivalent of snow on the ground: Monthly Weather Review, v. 94, p. 265-271.

Thornthwaite, C.W., 1948, An approach toward a rational classification of climate: Geographical Review, v. 38, p. 55-94.

Tobiasson, W., Buska, J., Greatorex, A., Tirey, J., Fisher, J., and Johnson, S., 2002, Ground snow loads for New Hampshire: USACE Cold Regions Research \& Engineering Laboratory, CRREL Technical Report TR-02-6, 38 p.

Tseng, P-h., Illangasekare, T.H., and Meier, M.F., 1994, Modeling of snow melting and uniform wetting front migration in a layered subfreezing snowpack: Water Resources Research, v. 30, p. 2363-2376.

USACE [U.S. Army Corps of Engineers], 1956, Snow hydrology: Summary report of the snow investigations: U.S. Army Corps of Engineers, North Pacific Division (in cooperation with U.S. Weather Bureau), 437 p + apps.

USACE [U.S. Army Corps of Engineers], 1960, Runoff from snowmelt: U.S. Army Corps of Engineers, Engineering and Design Manual EM 1110-2-1406, 73 p.

U.S. Soil Conservation Service, Natural Resources Conservation Service (U.S. Dept. of Agriculture)

SCS, 1971?, Summary of snow survey measurements for Washington, 1915-1969: Fed230 
eral-State-Private Cooperative Snow Surveys, USDA Soil Conservation Service, Washington Dept of Ecology, 266 p.

1940s-1997?, Water supply outlook for Washington, Washington water supply outlook, Washington basin outlook report [and other names?]: winter months (Jan-Jun), with annual data summary: various sources: Spokane, Mt Vernon, Portland; Soil Conservation Service to Natural Resources Conservation Service ca 1995.

\section{U.S. Weather Bureau, National Weather Service:}

1892-present, Climatological data, Washington: daily data; monthly compilations, with annual summaries; collected by National Weather Service and cooperators: previously Army Signal Corps 1870-91; U.S. Weather Bureau, in Dept. of Agriculture 1891-1940, Commerce Dept from 1940; in NOAA since 1970 (when renamed NWS); archived/published by National Climatic Data Center, Asheville NC (since 1951, previously called National Weather Records Center).

1940-1948, Hydrologic Bulletin - North Pacific District: daily and hourly precipitation, North Pacific states (WA, OR, ID, MT), compiled at Weather Bureau District Office, Portland OR, by U.S. Weather Bureau; in cooperation with War Dept, Corps of Engineers, and U.S. Dept of Agriculture, Office of Land Use Coordination Flood Control.

1948-present, Hourly precipitation data, Washington: hourly data; monthly compilations, with annual summaries; collected by National Weather Service and cooperators: previously U.S. Weather Bureau; archived/published by National Climatic Data Center, Asheville NC (since 1951), Dept of Commerce.

van Heeswijk, M., Kimball, J.S., and Marks, D., 1996, Simulation of water available for runoff in clearcut forest openings during rain-on-snow events in the western Cascade Range of Oregon and Washington: U.S. Geological Survey, Water-Resources Investigations Report 95-4219, 67 p.

Waananen, A.O., Harris, D.D., and Williams, R.C., 1970, Floods of December 1964 and January 1965 in the Far Western States, Part 2. Streamflow and sediment data: U.S. Geological Survey, Water-Supply Paper 1866-B, 861 p.

Waananen, A.O., Harris, D.D., and Williams, R.C., 1971, Floods of December 1964 and January 1965 in the Far Western States, Part 1. Description: U.S. Geological Sur231 
vey, Water-Supply Paper 1866-A, 265 p.

Walsh, T.J., 1987, Geologic map of the south half of the Tacoma quadrangle, Washington: Washington Division of Geology \& Earth Resources, Open File Report 87-3, $10 \mathrm{p}$.

Walsh, T.J., Korosec, M.A., Phillips, W.M., Logan, R.L., and Schasse, H.W., 1987, Geologic map of Washington-Southwest quadrant: Washington Division of Geology \& Earth Resources, Geologic Map GM-34, 28 p.

Waylen, P.R., 1985a, Stochastic flood analysis in a region of mixed generating processes: Transactions, Institute of British Geographers, N.S. 10, p. 95-108.

Waylen, P.R., 1985b, A method of predicting daily peak flows in the high-flow season: Journal of Hydrology, v. 77, p. 89-105.

Waylen, P.R., and Woo, M-k., 1982, Prediction of annual floods generated by mixed processes: Water Resources Research, v. 18, p. 1283-1286.

Waylen, P. R., and Woo, M-k., 1983, Stochastic analysis of high flows generated by mixed processes: Canadian Journal of Civil Engineering, v. 10, p. 639-648.

Westrick, K.J., and Mass, C.F., 2001, An evaluation of a high-resolution hydrometeorological modeling system for prediction of a cool-season flood event in a coastal mountainous watershed: Journal of Hydrometeorology, v. 2, p. 161-180.

Wetherbee, P.K., 1995, A comparison of observed and predicted snowpack outflow during rain-on-snow, Umpqua National Forest, Oregon [M.S. thesis]: Seattle, University of Washington, $98 \mathrm{p}$.

Whitlock, C., and Bartlein, P.J., 1997, Vegetation and climate change in northwest America during the past 125 kyr: Nature, v. 388, p. 57-61.

Wiberg, E.J., 1990, The probability distribution of snowmelt in clearcuts from a rain-on-snow event in the central Cascades of Washington [M.S. thesis]: Columbus, Ohio State University, $210 \mathrm{p}$.

Wieczorek, G.F., 1996, 4. Landslide triggering mechanisms, in Turner, A.K., and Schuster, R.L., eds., Landslides-Investigation and Mitigation: Washington DC, National Academy Press, Transportation Research Board Special Report 247, p. 76-90.

Wieczorek, G.F., and Glade, T., 2005, Climatic factors influencing occurrence of debris flows, in Jacob, M., and Hungr, O., eds., Debris-Flow Hazards and Related Phe232 
nomena: Chichester UK, Praxis Publishing Ltd, Springer, p. 325-362.

Wigmosta, M.S., Vail, L.W., and Lettenmaier, D.P., 1994, A distributed hydrology-vegetation model for complex terrain: Water Resources Research, v. 30, p. 1665-1679. Williams, J.R., 1991, Washington floods and droughts; in Paulson, R.W., Chase, E.B., Roberts, R.S., and Moody, D.W., compilers, National water summary 1988-89hydrologic events and floods and droughts: U.S. Geological Survey, WaterSupply Paper 2375, p 551-557.

Wolman, M.G., and Miller, J.P., 1960, Magnitude and frequency of forces in geomorphic processes: Journal of Geology, v. 68, p. 54-74.

Woo, M-k., and Steer, P., 1986, Monte Carlo simulation of snow depth in a forest: Water Resources Research, v. 22, p. 864-868.

Wooster, W.S., and Fluharty, D.L., 1985, El Niño North: Niño Effects in the Eastern Subarctic Pacific Ocean: Seattle, Washington Sea Grant Program, College of Ocean and Fishery Sciences, University of Washington, 312 p.

Wu, T.H., Abdel-Latif, M., Wiberg, E.J., and Brunengo, M.J., 1995, Probability distribution of rain-plus-snowmelt in Washington Cascades, in Lemaire, M., Favre, J-L., and Mebarki, A., editors, ICASP 7 Conference: Applications of Statistics and Probability, Civil Engineering Reliability and Risk Analysis, Paris: Rotterdam, A.A. Balkema, p. 565-571.

Yamada, T., Suizu, S., Nishimura, H., and Wakahama, G., 1979, Relationships between snow distribution and climate in mountain areas, in Sea Level, Ice, and Climate Change (Canberra Symposium): IAHS Publication no 131, p. 109-118.

Yang, D., Goodison, B.E., Metcalfe, J.R., Louie, P., Leavesley, G., Emerson, D., Hanson, C.L., Golubev, V.S., Elomaa, E., Gunther, T., Pangburn, T., Kang, E., and Milkovic, J., 1999, Quantification of precipitation measurement discontinuity induced by wind shields on national gauges: Water Resources Research, v. 35, p. 491-508.

Yarnal, B., Johnson, D.L., Frakes, B.J., Bowles, G.I., and Pascale, P., 1997, The Flood of '96 and its socioeconomic impacts in the Susquehanna River basin: Journal of the American Water Resources Association, v. 33, p. 1299-1312.

Ye, H., Yang, D., and Robinson, D., 2008, Winter rain on snow and its association with air temperature in northern Eurasia: Hydrological Processes, v. 22, p. 2278-2736. 
Zhang, C., 2005, Madden-Julian Oscillation: Reviews of Geophysics, v. 43, RG2003, 36 p.

Zhu, Y., and Newell, R.E., 1994, Atmospheric rivers and bombs: Geophysical Research Letters, v. 21, p. 1999-2002.

Zhu, Y., and Newell, R.E., 1998, A proposed algorithm for moisture fluxes from atmospheric rivers: Monthly Weather Review, v. 126, p. 725-735.

Zuzel, J.F., Greenwalt, R.N., and Allmaras, R.R., 1983, Rain on snow: shallow, transient snowpacks with frozen soils, in Proceedings, $51^{\text {st }}$ Western Snow Conference, Vancouver WA, p. 67-75.

Zuzel, J.F., and Greenwalt, R.N., 1985, Probability distributions of rain on snow for northcentral Oregon, in Proceedings, $53^{\text {rd }}$ Western Snow Conference, Boulder CO, p. 37-43. 


\section{APPENDIX A}

Summary of Selected Studies Involving ROS

Table A.1 Summary of Selected Studies Involving ROS 


\begin{tabular}{|c|c|c|c|c|c|}
\hline Region & $\begin{array}{l}\text { Location, } \\
\text { Elevation }\end{array}$ & $\begin{array}{c}\begin{array}{c}\text { Focus of Study, } \\
\text { Methods }\end{array} \\
\end{array}$ & $\begin{array}{c}\text { Years, } \\
\text { \# of Events }\end{array}$ & Notes & References \\
\hline \multicolumn{6}{|c|}{ Multi-region surveys, case studies, modeling } \\
\hline $\begin{array}{l}\text { Western U.S.: } \\
\text { Western Cascades, } \\
\text { Oregon } \\
\text { Sierra Nevada } \\
\text { W of Donner Pass } \\
\text { Rocky Mtns, } \\
\text { Montana } \\
\text { continental divide }\end{array}$ & $\begin{array}{l}\text { mainly snow labs (SL): } \\
\text { - Willamette Basin SL, } \\
\text { Blue River (nr HJA- } \\
\text { EF), 610-1675 m } \\
\text { - Central Sierra SL, } \\
\text { upper Yuba R basin, } \\
2100-2775 \mathrm{~m} \\
\text { - Upper Columbia SL, } \\
\text { Flathead - Marias } \\
\text { Pass, } 1370-2620 \mathrm{~m}\end{array}$ & $\begin{array}{l}\text { - fundamental snow physics; } \\
\text { data analysis, application to } \\
\text { project design and operation, } \\
\text { including derivation of } \\
\text { probable maximum floods, } \\
\text { forecasting seasonal runoff, } \\
\text { and hydrograph synthesis for } \\
\text { melt \& ROS events } \\
\text { - field observations of weather, } \\
\text { snow accum \& melt, } \\
\text { lysimeters, RO, stream flows }\end{array}$ & $\begin{array}{l}\text { 1945-56 } \\
\text { a few (?) ROS events } \\
\text { documented in } \\
\text { separate technical } \\
\text { reports, etc. }\end{array}$ & $\begin{array}{l}\text { Cooperative Snow } \\
\text { Investigations, } \\
\text { USACE and USWB } \\
\text { development of } \\
\text { snowmelt calculation } \\
\text { methods, including } \\
\text { simplified equations } \\
\text { for ROS }\end{array}$ & $\begin{array}{l}\begin{array}{l}\text { USACE, } 1956 \\
\text { (project report) }\end{array} \\
\text { USACE, } 1960 \\
\text { (engineering } \\
\text { manual) }\end{array}$ \\
\hline $\begin{array}{l}\text { Physical model, } \\
\text { roof loads due to } \\
\text { ROS }\end{array}$ & $\begin{array}{l}25 \text {-yr rainfall at } \\
\text { Hanover, } \\
\text { New Hampshire }\end{array}$ & $\begin{array}{l}\text { - extend physical infiltration } \\
\text { model of water into snow } \\
\text { - apply to roof loads; develop } \\
\text { computer program }\end{array}$ & n.a. & $\begin{array}{l}\text { largest loads can be } \\
\text { due to short/high- } \\
\text { intensity or long/- } \\
\text { low-intensity storms }\end{array}$ & $\begin{array}{l}\text { Colbeck, 1975b, } \\
\text { 1977b,c }\end{array}$ \\
\hline $\begin{array}{l}\text { Model for central } \\
\text { Washington } \\
\text { Cascades }\end{array}$ & $\begin{array}{l}\text { Snoqualmie to Rainier } \\
\text { (MJB area); Finney Ck } \\
\text { basin (Coffin \& Harr) }\end{array}$ & $\begin{array}{l}\text { - statistical modeling of ROS in } \\
\text { clearings, related to landslides } \\
\text { - FOSM modeling of melt, RO }\end{array}$ & $\begin{array}{l}\text { ca } 1940-82 \\
\text { several ROS cases }\end{array}$ & $\begin{array}{l}\text { used USACE melt } \\
\text { equations for ROS }\end{array}$ & $\begin{array}{l}\text { Wiberg, } 1990 \\
\text { Wu et al., } 1995\end{array}$ \\
\hline $\begin{array}{l}\text { Washington: map } \\
\text { hydrologic zones } \\
\text { for use in forest } \\
\text { regulation and } \\
\text { watershed analysis }\end{array}$ & $\begin{array}{l}\text { forested areas of } \\
\text { Washington ( } 15 \text { over- } \\
\text { lapping subregions) }\end{array}$ & $\begin{array}{l}\text { - use GIS to define elevation } \\
\text { zones, from snow available to } \\
\text { melt in } 24 \text {-h storm with geo- } \\
\text { graphically varying T, W, P } \\
\text { calculate } 1 \text { Jan avg SWE by } \\
\text { elevation within regions, for } \\
\text { use in estimating hydrologic } \\
\text { response to forest harvest }\end{array}$ & $\begin{array}{l}\text { from NWS (1959- } \\
\text { 95) and COOP Snow } \\
\text { Survey/SNOTEL } \\
(1940-95) \text { stations; } \\
\text { data for SWE, or } \\
\text { depth } \times 0.15=\text { SWE }\end{array}$ & $\begin{array}{l}\text { maximum response } \\
\text { in the peak-ROS } \\
\text { zone (middle); less } \\
\text { in adjacent rain- and } \\
\text { snow-dominated } \\
\text { zones; little in } \\
\text { lowland and } \\
\text { highland zones }\end{array}$ & $\begin{array}{l}\text { Brunengo et al., } \\
\text { 1992a,b } \\
\text { Brunengo, } 1995\end{array}$ \\
\hline $\begin{array}{l}\text { Models for } \\
\text { transient snow } \\
\text { zone, western } \\
\text { Oregon \& } \\
\text { Washington } \\
\end{array}$ & $\begin{array}{l}\text { met/energy elements at } \\
\text { Finney Ck \& Canyon } \\
\text { Ck (Coffin \& Harr); } \\
\text { flows at Lookout Ck, } \\
\text { HJAEF, } 420-1520 \mathrm{~m} \\
\end{array}$ & $\begin{array}{l}\text { - evaluate effects of harvest on } \\
\text { peak flows during ROS } \\
\text { - met data driving SSARR } \\
\text { model, linking hillslopes and } \\
\text { channels } \\
\end{array}$ & $\begin{array}{l}\text { simulated } 11 \text { ROS } \\
\text { events, over } 3 \text { elev } \\
\text { bands and } 9 \text { harvest } \\
\text { patterns }\end{array}$ & $\begin{array}{l}\text { increases in peak } \\
\text { flows due to harvest, } \\
\text { but variable spatial } \\
\text { patterns due to elev, } \\
\text { aspect, cover, etc. } \\
\end{array}$ & $\begin{array}{l}\text { Connelly \& } \\
\text { Cundy, } 1992 \\
\text { Connelly, } 1992\end{array}$ \\
\hline
\end{tabular}




\begin{tabular}{|c|c|c|c|c|c|}
\hline & $\begin{array}{l}\text { simulation for } \\
\text { Snoqualmie R basin at } \\
\text { Carnation }(18-2400 \mathrm{~m})\end{array}$ & $\begin{array}{l}\text { - evaluate effects of forest } \\
\text { harvest on peak flows during } \\
\text { ROS } \\
\text { - met data driving modified } \\
\text { DHSVM in a large basin }\end{array}$ & $\begin{array}{l}\text { for 1948-93 } \\
\text { includes } 5 \text { ROS } \\
\text { floods }\end{array}$ & $\begin{array}{l}\text { little effect on larger } \\
\text { peak flows due to } \\
\text { harvest; model } \\
\text { doesn't reflect roads }\end{array}$ & Storck et al., 1995 \\
\hline & $\begin{array}{l}\text { ROS data from HJAEF } \\
\text { (Berris \& Harr); long- } \\
\text { term climate at Cedar } \\
\text { Lk, Snoqualmie Pass }\end{array}$ & $\begin{array}{l}\text { - simulate snow accum \& melt } \\
\text { during ROS in clearcuts } \\
\text { - apply Marks (1992) energy- } \\
\text { balance model to field data, try } \\
\text { to generalize over the region } \\
\end{array}$ & $\begin{array}{l}3 \text { events (Feb-Mar } \\
\text { 1984, HJAEF) used } \\
\text { in model }\end{array}$ & $\begin{array}{l}\text { difficult to simulate } \\
\text { hourly ROS effects: } \\
\text { conditions variable, } \\
\text { measurements } \\
\text { limited }\end{array}$ & $\begin{array}{l}\text { van Heeswijk et } \\
\text { al., } 1996\end{array}$ \\
\hline $\begin{array}{l}\text { Western } \\
\text { continental U.S. }\end{array}$ & $\begin{array}{l}4318 \text { NWS stations in } \\
11 \text { states }\end{array}$ & $\begin{array}{l}\text { - determine spatial \& temporal } \\
\text { variability of ROS } \\
\text { - weather records: ROS event } \equiv \\
\text { precip day \& snow decreased }\end{array}$ & 1949-2003 & $\begin{array}{l}\text { regions, elev, } \\
\text { seasonality, inter- } \\
\text { annual variability, } \\
\text { trends, etc. }\end{array}$ & $\begin{array}{l}\text { McCabe et al., } \\
2007\end{array}$ \\
\hline $\begin{array}{l}\text { Pacific Northwest } \\
\text { case studies of } \\
\text { prominent ROS } \\
\text { events }\end{array}$ & $\begin{array}{l}\text { mainly western } \\
\text { Washington \& Oregon; } \\
\text { also upper Columbia } \\
\text { Basin }(1948,1996)\end{array}$ & $\begin{array}{l}\text { - case studies } \\
\text { - various aims, methods, data } \\
\text { types, sources: historical } \\
\text { reconstruction; analysis of } \\
\text { weather \& flow records; site } \\
\text { studies of flooding, landslides; } \\
\text { reconstruction of energy } \\
\text { budget; synoptic storm } \\
\text { climatology, some using } \\
\text { atmospheric and/or hydrologic } \\
\text { models } \\
\text { - study focus and/or effects: } \\
\text { history (H), storm meteoro- } \\
\text { logy (M), wind (W), energy } \\
\text { budget (E), flooding/channels } \\
\text { (F), slope instability/landslides } \\
\text { (L), effects on urban areas, } \\
\text { transportation \& engineered } \\
\text { works (U) }\end{array}$ & $\begin{array}{l}\text { December } 1861 \\
\text { May } 1948 \\
\text { Dec } 1964 \text { - Jan } 1965 \\
\text { December } 1980 \\
\text { January } 1986 \\
\text { November } 1990 \\
\text { February } 1996 \\
\text { Nov } 1996 \text { - Jan } 1997 \\
\end{array}$ & $\begin{array}{l}\text { H M F U } \\
\text { F M U } \\
\text { F U L } \\
\text { F L E } \\
\text { F M } \\
\text { F L } \\
\text { F L M E U }\end{array}$ & $\begin{array}{l}\text { Miller, } 1999 \\
\text { Paulsen, } 1949 \\
\text { Lucia, 1965 } \\
\text { Dyrness, 1967 } \\
\text { Rothacher \& } \\
\text { Glazebrook, } 1968 \\
\text { Waananen et al., } \\
\text { 1970, 1971 } \\
\text { Gallino \& Pierson, } \\
\text { 1984, 1985 } \\
\text { Lackmann \& } \\
\text { Gyakum, 1999 } \\
\text { Harr \& Cundy, } \\
\text { 1992 } \\
\text { Hubbard, 1994 } \\
\text { Harp et al., 1996 } \\
\text { Dyrness et al., } \\
\text { 1996 } \\
\text { Laenen, 1997 } \\
\text { Marks et al., } 1998 \\
\text { Burns et al., } 1998 \\
\text { Colle \& Mass,2000 }\end{array}$ \\
\hline
\end{tabular}




\begin{tabular}{|c|c|c|c|c|c|}
\hline & & & $\begin{array}{l}\text { November } 2006 \\
\text { December } 2007\end{array}$ & $\begin{array}{l}\text { M F } \\
\text { F M W }\end{array}$ & $\begin{array}{l}\text { Gerstel et al., } 1997 \\
\text { Hofmeister, 2000 } \\
\text { Westrick \& Mass, } \\
\text { 2001; Risley, 2004 } \\
\text { Neiman et al., } \\
\text { 2008b } \\
\text { Reiter, 2008 }\end{array}$ \\
\hline \multicolumn{6}{|c|}{ North America, west coast } \\
\hline $\begin{array}{l}\text { Chugach Mtns } \\
\text { S-central Alaska }\end{array}$ & $\begin{array}{l}\text { Valdez area } \\
\text { Lowe \& Tsaina basins } \\
0-500 \mathrm{~m}\end{array}$ & $\begin{array}{l}\text { - detect water flow through } \\
\text { snow, especially in ROS } \\
\text { - heat flux transducers in snow }\end{array}$ & $\begin{array}{l}\text { WY 1990-92 } \\
0-7 / \mathrm{yr}\end{array}$ & $\begin{array}{l}\text { all HF signals coin- } \\
\text { cident with ROS, but } \\
\text { not all ROS } \rightarrow \text { signals }\end{array}$ & $\begin{array}{l}\text { Sturm \& } \\
\text { Holmgren, } 1993\end{array}$ \\
\hline $\begin{array}{l}\text { Coast Mtns } \\
\text { SW British } \\
\text { Columbia }\end{array}$ & $\begin{array}{l}\text { Jamieson Ck } \\
\text { watershed, } \\
655-730 \mathrm{~m}\end{array}$ & $\begin{array}{l}\text { - effects of forest \& clearing on } \\
\text { ROS processes, RO } \\
\text { - paired sites; met, lysimeters }\end{array}$ & $\begin{array}{l}\text { WY 1982-84 } \\
\text { none in } 82 \text {, several } \\
\text { in ' } 83-84\end{array}$ & $\begin{array}{l}\text { USACE equations } \\
\text { seem satisfactory }\end{array}$ & $\begin{array}{l}\text { Beaudry \& } \\
\text { Golding, } 1983 \\
\text { Beaudry, } 1984\end{array}$ \\
\hline $\begin{array}{l}\text { NE Vancouver Is } \\
\text { SW British } \\
\text { Columbia }\end{array}$ & $\begin{array}{l}\text { Russell Ck watershed } \\
300-1680 \mathrm{~m}\end{array}$ & $\begin{array}{l}\text { - develop \& test new methods to } \\
\text { monitor transitory ROS events } \\
\text { - met; snow lysimeters, spring } \\
\text { scales for snow throughfall; } \\
\text { remote cameras } \\
\text { - image analysis of canopy } \\
\text { snow }\end{array}$ & $\begin{array}{l}\text { WY } 2007 \\
20 \text { Feb-12 Mar } \\
\sim 4 \text { ROS events }\end{array}$ & $\begin{array}{l}\text { instruments allowed } \\
\text { improved monitoring } \\
\text { of plot hydrology } \\
\text { during ROS }\end{array}$ & $\begin{array}{l}\text { Floyd \& Weiler, } \\
2008\end{array}$ \\
\hline $\begin{array}{l}\text { North Cascades } \\
\text { Washington }\end{array}$ & $\begin{array}{l}\text { Finney \& Canyon Ck } \\
\text { basins } \\
460-760 \mathrm{~m}\end{array}$ & $\begin{array}{l}\text { - effects of mature forest, } \\
\text { plantation \& clearing on ROS, } \\
\text { RO } \\
\text { paired sites at range of elevs; } \\
\text { met, lysimeters }\end{array}$ & $\begin{array}{l}\text { WY 1989-91 } \\
13 \text { events over } 3 \\
\text { winters }\end{array}$ & $\begin{array}{l}\text { responses depend on } \\
\text { weather \& snow } \\
\text { conditions; generally } \\
\text { open > forest RO, } \\
\text { plantation variable } \\
\end{array}$ & $\begin{array}{l}\text { Coffin, 1991 } \\
\text { Coffin \& Harr, } \\
1992\end{array}$ \\
\hline \multirow[t]{2}{*}{$\begin{array}{l}\text { Central } \\
\text { Washington } \\
\text { Cascades }\end{array}$} & $\begin{array}{l}\text { Snoqualmie Pass } \\
920 \mathrm{~m}\end{array}$ & $\begin{array}{l}\text { observe ice crusts and snow } \\
\text { settling } \\
\text { snow pits, dye tracers, } \\
\text { thermistors }\end{array}$ & $\begin{array}{l}\text { WY } 1940 \\
\text { some melt but no } \\
\text { major ROS }\end{array}$ & $\begin{array}{l}\text { report of } \\
\text { observations }\end{array}$ & Church, 1940 \\
\hline & $\begin{array}{l}\text { Snoqualmie Pass area } \\
915 \mathrm{~m}\end{array}$ & $\begin{array}{l}\text { - effects of water movement } \\
\text { during ROS on snow ripening, } \\
\text { strength change \& avalanches } \\
\text { snow pits, thermistors, dyes, } \\
\text { stress plates }\end{array}$ & $\begin{array}{l}\text { WY } 1988-89 \\
8 \text { events; } \\
2 \text { events in January } \\
1992\end{array}$ & $\begin{array}{l}\text { pack } \rightarrow 0^{\circ} \mathrm{C} \text { in a few } \\
\text { hours; wetting to } \sim 70 \\
\mathrm{~cm} \text { in } 10 \mathrm{~h} \text {, but rates } \\
\& \text { patterns affected } \\
\text { by snow stratigraphy }\end{array}$ & $\begin{array}{l}\text { Conway \& } \\
\text { Raymond, } 1993 \\
\text { Conway \& } \\
\text { Benedict, } 1994\end{array}$ \\
\hline
\end{tabular}




\begin{tabular}{|c|c|c|c|c|c|}
\hline \multirow[t]{6}{*}{$\begin{array}{l}\text { Northern \& central } \\
\text { Oregon Cascades }\end{array}$} & $\begin{array}{l}\text { Willamette NF } \\
6 \text { basins } \\
\text { avg elev 914-1262 m }\end{array}$ & $\begin{array}{l}\text { - compare peak streamflows } \\
\text { over time, in dominantly } \\
\text { natural \& logged basins } \\
\text { - paired gauged watersheds: } \\
\text { mass curves of peak flows }\end{array}$ & $1920 \mathrm{~s}-70 \mathrm{~s}$ & $\begin{array}{l}\text { increased peaks in } \\
\text { logged basins, } \\
\text { possibly caused by } \\
\text { changes in snow } \\
\text { accum \& melt rates }\end{array}$ & $\begin{array}{l}\text { Christner \& Harr, } \\
1982\end{array}$ \\
\hline & $\begin{array}{l}\text { USFS HJAEF } \\
\text { basins HJA } 1 / 2 \& 9 / 10 \\
433-1067 \mathrm{~m}\end{array}$ & $\begin{array}{l}\text { - update/reanalyze streamflow } \\
\text { data to evaluate harvest effects } \\
\text { on snow accum, melt, RO } \\
\text { - paired gauged watersheds }\end{array}$ & $1952-82$ & $\begin{array}{l}\text { data suggest that } \\
\text { clearcut logging has } \\
\text { affected size of peak } \\
\text { flows during ROS }\end{array}$ & Harr, 1981, 1986 \\
\hline & $\begin{array}{l}\text { USFS HJAEF } \\
\text { Blue River } \\
900 \mathrm{~m}\end{array}$ & $\begin{array}{l}\text { - effects of forest \& clearing on } \\
\text { ROS processes, RO } \\
\text { - paired sites: met, lysimeters }\end{array}$ & $\begin{array}{l}\text { WY } 1983-84 \\
16 \text { signif accum-melt } \\
\text { sequences }\end{array}$ & $\begin{array}{l}\text { USACE equations } \\
\text { satisfactory }\end{array}$ & $\begin{array}{l}\text { Harr \& Berris, } \\
1983 \\
\text { Berris, } 1985 \\
\text { Berris \& Harr, } \\
1987\end{array}$ \\
\hline & $\begin{array}{l}\text { Santiam Valley } \\
536-1142 \mathrm{~m} \\
\text { (\& other sites) }\end{array}$ & $\begin{array}{l}\text { - case study: energy balance in } \\
\text { forest \& clearings during ROS } \\
\text { across elevs } \\
\text { - paired sites: met, snow depth } \\
\text { \& WE; E-balance calcs }\end{array}$ & $\begin{array}{l}\text { WY } 1996 \\
\text { February } 1996 \text { ROS } \\
\text { event }\end{array}$ & $\begin{array}{l}\text { most energy for melt } \\
\text { from sensible \& } \\
\text { latent heat (warm, } \\
\text { humid, windy); sen- } \\
\text { sitive to forest cover }\end{array}$ & Marks et al., 1998 \\
\hline & $\begin{array}{l}\text { USFS HJAEF } \\
\text { upper Lookout Ck } \\
\text { basin } \\
\text { stations at } 1018 \mathrm{~m} \text {, } \\
1273 \mathrm{~m}, 1294 \mathrm{~m}\end{array}$ & $\begin{array}{l}\text { - energy balance during all ROS } \\
\text { events over many winters } \\
\text { - E-balance calcs (SNOBAL } \\
\text { model) driven by met } \\
\text { measurements, compared to } \\
\text { measured snow WE }\end{array}$ & $\begin{array}{l}\text { WY } 1996-2003 \\
56-83 \text { ROS events } \\
\text { (defined as 24-h RF } \\
\text { on snow) } \\
\sim 7-10 \text { ROS/site/yr }\end{array}$ & $\begin{array}{l}\text { energy inputs depend } \\
\text { on time of season, } \\
\text { elev, aspect, canopy; } \\
\text { radiation \& ground } \\
\text { heat are important } \\
\text { energy sources; } \\
\text { ROS yielded 35\% of } \\
\text { total WAR; most } \\
\text { WAR during ROS } \\
\text { was precip }\end{array}$ & $\begin{array}{l}\text { Mazurkiewicz et } \\
\text { al., } 2008\end{array}$ \\
\hline & $\begin{array}{l}\text { small basins: HJAEF, } \\
\text { Lookout Ck } \\
\text { large basins: Blue } \\
\text { River, N Santiam, } \\
\text { Breitenbush, N \& } \\
\text { Middle Willamette, } \\
\text { Salmon Ck } \\
\end{array}$ & $\begin{array}{l}\text { - effects of snow, antecedent } \\
\text { soil moisture \& slope form on } \\
\text { storm RO } \\
\text { - met stations, basin discharge; } \\
\text { retrospective moisture \& SWE }\end{array}$ & $\begin{array}{l}\text { various by basin, } \\
\text { over } 1964-96 \\
800 \text { storms }\end{array}$ & $\begin{array}{l}\text { ROS } \sim 10-40 \% \text { (low } \\
\text { to high elevs) events; } \\
\text { highest peaks due to } \\
\text { ROS } \\
\text { hydrographs depend } \\
\text { on slope form \& } \\
\text { contributing area }\end{array}$ & $\begin{array}{l}\text { Perkins \& Jones, } \\
2008 \\
\text { Jones \& Perkins, } \\
2010\end{array}$ \\
\hline
\end{tabular}




\begin{tabular}{|c|c|c|c|c|c|}
\hline \multirow[t]{2}{*}{$\begin{array}{l}\text { Southern Oregon } \\
\text { Cascades }\end{array}$} & \multirow[t]{2}{*}{$\begin{array}{l}\text { USFS DEMO } \\
\text { upper N Umpqua basin } \\
\text { Watson Falls area } \\
\sim 915 \mathrm{~m}, \sim 1220 \mathrm{~m}\end{array}$} & $\begin{array}{l}\text { - evaluate snowmelt WAR } \\
\text { equations during ROS } \\
\text { - paired sites: met, lysimeters }\end{array}$ & $\begin{array}{l}\text { WY } 1995 \\
5 \text { ROS events }\end{array}$ & $\begin{array}{l}\text { USACE equations } \\
\text { satisfactory; also } \\
\text { used energy-balance } \\
\text { and DHSVM models }\end{array}$ & Wetherbee, 1995 \\
\hline & & $\begin{array}{l}\text { - observe processes controlling } \\
\text { snow interception by forest } \\
\text { canopy and under-canopy, } \\
\text { snow accum \& ablation; } \\
\text { develop \& test models } \\
\text { - paired forest \& shelterwood } \\
\text { sites, cut-tree experiments, } \\
\text { met, lysimeters }\end{array}$ & $\begin{array}{l}\text { WY 1997-99 } \\
1 \text { major ROS event, } \\
\text { Dec } 96 \text { - Jan } 97\end{array}$ & $\begin{array}{l}60 \% \text { of snowfall } \\
\text { intercepted; more } \\
\text { RO from shelter- } \\
\text { wood; differences } \\
\text { observed between } \\
\text { forest \& clearings - } \\
\text { but not easily } \\
\text { interpreted }\end{array}$ & $\begin{array}{l}\text { Storck et al., 1995, } \\
2002\end{array}$ \\
\hline \multirow[t]{3}{*}{ Sierra Nevada } & $\begin{array}{l}\text { Sacramento, San } \\
\text { Joaquin \& Lahontan } \\
\text { river basins }\end{array}$ & $\begin{array}{l}\text { - examine flow \& met records } \\
\text { to determine occurrence of } \\
\text { rain-dominated storms \& ROS } \\
\text { - streamflow records, historical } \\
\text { \& anecdotal info }\end{array}$ & $\begin{array}{l}1805-1990 \\
\sim 18 \text { ROS floods to } \\
1937 \text {; at least } 8 \\
\text { major } 1937-90 \\
1948-88 \text { met }\end{array}$ & $\begin{array}{l}\text { big floods about } \\
\text { once per decade, } \\
\text { largest from ROS in } \\
\text { most basins; rain } \\
\text { dominates storms in } \\
\mathrm{N} \& \text { on west side }\end{array}$ & $\begin{array}{l}\text { Kattelmann et al., } \\
1991 \\
\text { McGurk et al., } \\
1993 \\
\text { Kattelmann, } 1997\end{array}$ \\
\hline & $\begin{array}{l}\text { Central Sierra Snow } \\
\text { Lab } \\
\text { Tahoe-Donner Pass } \\
\text { area } \\
\text { near Soda Springs } \\
\end{array}$ & $\begin{array}{l}\text { - develop dielectric capacitance } \\
\text { probes to monitor water move- } \\
\text { ment in ripe snow } \\
\text { - snow pits, probes, dye tracers } \\
\text { for natural melt and sprinkling } \\
\end{array}$ & $\begin{array}{l}\text { May } 1948 \\
10 \text { experiments }\end{array}$ & $\begin{array}{l}\text { transmission rates up } \\
\text { to } 2 \mathrm{ft} / \text { min; ripe } \\
\text { snow develops many } \\
\text { small, temporary } \\
\text { drainage channels } \\
\end{array}$ & Gerdel, 1945, 1954 \\
\hline & $\begin{array}{l}\text { Central Sierra Snow } \\
\text { Lab } \\
\text { Tahoe-Donner Pass } \\
\text { area } \\
2100 \mathrm{~m}\end{array}$ & $\begin{array}{l}\text { - evaluate process-response } \\
\text { hypotheses on factors } \\
\text { affecting outflow in ROS } \\
\text { plots in forest \& openings - } \\
\text { met, lysimeters; regression } \\
\text { analysis }\end{array}$ & $\begin{array}{l}\text { WY 1984-90 } \\
20 \text { monitored ROS } \\
\text { events }-16 \text { in accum } \\
\text { season, } 4 \text { in spring }\end{array}$ & $\begin{array}{l}\text { outflow correlated } \\
\text { with precip, } \\
\text { duration, snow } \\
\text { depth, melt energy; } \\
\text { no signif differences } \\
\text { between forest \& } \\
\text { open OF }\end{array}$ & $\begin{array}{l}\text { Berg \& Hannaford, } \\
1983 \\
\text { Berg et al., } 1991\end{array}$ \\
\hline \multicolumn{6}{|c|}{ North America, western interior } \\
\hline $\begin{array}{l}\text { Wasatch Plateau } \\
\text { Utah }\end{array}$ & $\begin{array}{l}\text { USDA Utah Agric'l } \\
\text { Exper't Station } \\
\text { (field, lab) } \\
2650 \mathrm{~m}\end{array}$ & $\begin{array}{l}\text { - observe \& measure water } \\
\text { movement in snow, under } \\
\text { rain, sprinkling, warm } \\
\text { snowmelt } \\
\text { cores, dye tracers }\end{array}$ & May 1928 & $\begin{array}{l}\text { water moved through } \\
\text { small, crooked paths }\end{array}$ & Clyde, 1929 \\
\hline
\end{tabular}




\begin{tabular}{|c|c|c|c|c|c|}
\hline $\begin{array}{l}\text { Owyhee Mtns } \\
\text { SW Idaho } \\
\text { (range land) }\end{array}$ & $\begin{array}{l}\text { USDA Reynolds Ck } \\
\text { Exper'l Watershed } \\
\text { Nancy Gulch } \\
1200-1700 \mathrm{~m}\end{array}$ & $\begin{array}{l}\text { - water balance during ROS in } \\
\text { range land } \\
\text { - monitoring of met, lysimeters, } \\
\text { photos of snow }\end{array}$ & $\begin{array}{l}\text { WY } 1982-83 \\
7 \text { accum-melt events } \\
\text { (6 with data) } \\
\text { 9-13 February } 1982 \\
\text { case study }\end{array}$ & $\begin{array}{l}\text { ROS event } \\
\text { infiltration } 0-100 \% \text {, } \\
\text { depending on temp, } \\
\text { snow cover, frozen } \\
\text { soil, soil moisture }\end{array}$ & $\begin{array}{l}\text { Cooley \& } \\
\text { Robertson, } 1983\end{array}$ \\
\hline $\begin{array}{l}\text { Owyhee Mtns } \\
\text { SW Idaho } \\
\text { (forest and range } \\
\text { land) }\end{array}$ & $\begin{array}{l}\text { USDA Reynolds Ck } \\
\text { Exper'l Watershed } \\
\text { Reynolds Mtn East } \\
\text { subbasin } \\
2027-2137 \mathrm{~m}\end{array}$ & $\begin{array}{l}\text { - apply distributed models to } \\
\text { estimate snow volume, WAR, } \\
\text { and basin/weir discharge } \\
\text { met \& snow from climate sta } \\
\text { and SNOTEL, driving seasonal } \\
\text { and event E-balance calcs }\end{array}$ & $\begin{array}{l}\text { WY } 1997 \\
\text { December 1996-- } \\
\text { January } 1997 \text { ROS } \\
\text { event }\end{array}$ & $\begin{array}{l}\text { model works } \\
\text { reasonably well; } \\
\text { WAR during ROS } \\
\text { sensitive to wind, as } \\
\text { modified by terrain } \\
\text { \& vegetation } \\
\end{array}$ & $\begin{array}{l}\text { Marks et al., } 2001 \\
\text { (SNOBAL model } \\
\text { details in Marks et } \\
\text { al., 1999) }\end{array}$ \\
\hline \multirow[t]{2}{*}{$\begin{array}{l}\text { Columbia Basin } \\
\text { N-central Oregon } \\
\text { (wheat land) }\end{array}$} & $\begin{array}{l}\text { USDA Agric Exper’t } \\
\text { Sta plots in } 6 \text { counties } \\
400-1100 \mathrm{~m} \\
\text { Gwendolyn, Gilliam } \\
\text { Co., } 915 \mathrm{~m}\end{array}$ & $\begin{array}{l}\text { - compare model simulation } \\
\text { based on met conditions } \\
\text { against runoff } \\
\text { - lysimeters w/closed \& open } \\
\text { bottoms, met }\end{array}$ & $\begin{array}{l}\text { WY } 1980-83 \\
20 \text { RO events due to } \\
\text { radiative \& ROS } \\
\text { melt; cases January } \\
1980 \text { \& } 1982\end{array}$ & $\begin{array}{l}\text { "warm" (1980) and } \\
\text { "cold" (1982) SM } \\
\text { events, with differ- } \\
\text { ing RO amounts }\end{array}$ & Zuzel et al., 1983 \\
\hline & $\begin{array}{l}\text { Moro, Sherman Co } \\
560 \mathrm{~m} \\
\\
\text { Gordon Hollow } \\
475-664 \mathrm{~m}\end{array}$ & $\begin{array}{l}\text { - identify ROS events in the } \\
\text { region } \\
\text { - Moro station met records, } \\
\text { Gordon Hollow streamflows } \\
\text { used to detect ROS events }\end{array}$ & $\begin{array}{l}1948-78 \\
133 \text { ROS (half }<2.5 \\
\text { mm RF) } \\
\text { 1959-78: } 8 \text { of } 14 \\
\text { peak flow events }\end{array}$ & $\begin{array}{l}\text { most "ROS" events } \\
\text { have little RF, but } \\
\text { still a significant } \\
\text { RO-producing } \\
\text { process in the region }\end{array}$ & $\begin{array}{l}\text { Zuzel \& } \\
\text { Greenwalt, } 1985\end{array}$ \\
\hline \multicolumn{6}{|c|}{ Other mid-latitude areas } \\
\hline \multirow[t]{2}{*}{$\begin{array}{l}\text { Canadian Shield } \\
\text { central Ontario } \\
\text { (mixed forest) }\end{array}$} & $\begin{array}{l}\text { Harp Lake basin } \\
\text { Muskoka district } \\
\text { subbasin Harp 4-21 } \\
\text { 340-390 m }\end{array}$ & $\begin{array}{l}\text { - measure hydrologic \& } \\
\text { hydrochemical effects of ROS } \\
\text { in a small catchment } \\
\text { - met stations, snow survey \& } \\
\text { profiles, lysimeters, soil temp, } \\
\text { moisture; piezometers, wells; } \\
\text { basin discharge, chemical } \\
\text { sampling at weir } \\
\end{array}$ & $\begin{array}{l}\text { 1989-1991 } \\
2 \text { major ROS, early } \\
\text { \& late March } 1991 \\
\text { ( } 2 \text { minor ROS in } \\
\text { between) }\end{array}$ & $\begin{array}{l}\text { response to ROS } \\
\text { depends on air temp, } \\
\text { snow ripeness \& soil } \\
\text { moisture } \\
\text { ROS causes loss of } \\
\text { chemical load from } \\
\text { snowpack before } \\
\text { spring SM season } \\
\end{array}$ & $\begin{array}{l}\text { Maclean et al., } \\
1995\end{array}$ \\
\hline & $\begin{array}{l}\text { Harp Lake basin } \\
\text { Muskoka district } \\
\text { subbasin Harp 3A } \\
320-410 \mathrm{~m}\end{array}$ & $\begin{array}{l}\text { - assess the contribution of ROS } \\
\text { to nitrate in streams } \\
\text { - met stations; basin discharge } \\
\text { and chemical sampling at weir }\end{array}$ & $\begin{array}{l}\text { 1980-2000 } \\
\text { Jan-Feb only } \\
0-4 \text { ROS events per } \\
\text { Jan-Feb (avg } \\
0.75 / \text { 'yr') }\end{array}$ & $\begin{array}{l}\text { ROS causes substan- } \\
\text { tial stream input of } \\
\mathrm{NO}_{3}-\mathrm{N}(2-39 \% \text { of } \\
\text { annual export in } 2- \\
9 \% \text { of annual precip) }\end{array}$ & Eimers et al., 2007 \\
\hline
\end{tabular}




\begin{tabular}{|c|c|c|c|c|c|}
\hline \multirow[t]{2}{*}{$\begin{array}{l}\text { Mid-Atlantic } \\
\text { states, Appalachian } \\
\text { Mtns }\end{array}$} & $\begin{array}{l}\text { N-central Pennsylvania } \\
\text { Upper Susquehanna } \\
\text { basin } \\
\sim 100-600 \mathrm{~m}\end{array}$ & $\begin{array}{l}\text { - case studies of storm \& flood } \\
\text { - seasonal to synoptic } \\
\text { meteorology } \\
\text { - E-balance estimates } \\
\text { (SNTHERM model) affecting } \\
\text { melt }\end{array}$ & $\begin{array}{l}\text { WY } 1996 \\
\text { January } 1996 \text { ROS } \\
\text { event } \\
\text { (January 1978 - } \\
\text { minor flood) }\end{array}$ & $\begin{array}{l}\text { above-average snow } \\
\text { prior to event; } \\
\text { sensible \& latent } \\
\text { heat } 85 \% \text { of energy } \\
\text { for melt (warm, } \\
\text { windy) }\end{array}$ & $\begin{array}{l}\text { Yarnal et al., } 1997 \\
\text { Leathers et al., } \\
1998 \\
\text { Kroczynski, } 2004\end{array}$ \\
\hline & $\begin{array}{l}\text { Pennsylvania to North } \\
\text { Carolina } \\
\sim 600-2000 \mathrm{~m}\end{array}$ & $\begin{array}{l}\text { - snowmelt climatology for } \\
\text { floods in NE US, 1993-2003 } \\
\text { - freq of annual maximum } \\
\text { snowfall and depth from NWS } \\
\text { COOP stations } \\
\end{array}$ & $\begin{array}{l}\text { various data, } \\
1947-2000\end{array}$ & $\begin{array}{l}\text { for flood-producing } \\
\text { snow conditions, } \\
\text { return periods of a } \\
\text { few years (PA) to a } \\
\text { few decades (NC) } \\
\end{array}$ & $\begin{array}{l}\text { Graybeal \& } \\
\text { Leathers, } 2006\end{array}$ \\
\hline \multirow[t]{2}{*}{ Austrian Alps } & $\begin{array}{l}\text { Glatzbach basin } \\
\text { Hohe Tauern near } \\
\text { Grossglockner, } \\
2640 \mathrm{~m}\end{array}$ & $\begin{array}{l}\text { - measure } \mathrm{R}+\mathrm{M} \text { movement and } \\
\text { runoff generation under heavy } \\
\text { rain } \\
\text { - snow pits, dye tracers; } \\
\text { artificial RF (2 plots); met, } \\
\text { "lysimeter" }\end{array}$ & $\begin{array}{l}\text { May } 1996 \\
3 \text { experiments: } 5 \mathrm{~h} \\
\text { sprinkling over } 8 \mathrm{~h}+ \\
1 \mathrm{~h} \text { drainage }\end{array}$ & $\begin{array}{l}\text { simulating rain on } \\
\text { spr-sum SM; rapid } \\
\text { perc of rain / } \\
\text { irrigation and melt; } \\
60 \% \text { of precip } \\
\text { drained in } 8 \mathrm{~h} \\
\end{array}$ & Singh et al., 1997 \\
\hline & $\begin{array}{l}\text { Patscherkofel ski area } \\
\text { near Innsbruck } \\
1680-1960 \mathrm{~m}\end{array}$ & $\begin{array}{l}\text { - determine effects of snow } \\
\text { cover, vegetation \& soil on } \\
\text { RO during heavy rain } \\
\text { artificial RF (4 plots); met, } \\
\text { snow \& soil moisture; } \\
\text { modeled RO }\end{array}$ & $\begin{array}{l}\text { Mar 1998-Jun } 1999 \\
\text { multiple experiments } \\
\sim 10 \mathrm{~cm} \text { sprinkling } \\
\text { over } \sim 1 \mathrm{~h}\end{array}$ & $\begin{array}{l}\text { RO } \sim 40-70 \% \text { of } \\
\text { water volumes; RO } \\
\text { delay } \sim 10-45 \mathrm{~min} \\
\text { for } \sim 20-100 \mathrm{~cm} \\
\text { snow }\end{array}$ & Kohl et al., 2001 \\
\hline Northern Bavaria & $\begin{array}{l}\text { Donau River } \\
\text { Kalteneck basin } \\
\text { near Regensberg } \\
320-1456 \mathrm{~m}\end{array}$ & $\begin{array}{l}\text { - examine variability of precip } \\
\text { and snow; importance of RF } \\
\text { for SM, occurrence of ROS; } \\
\text { characteristics of discharge } \\
\text { record from long-term climatic } \\
\text { stations \& stream gauges }\end{array}$ & $\begin{array}{l}1961-95 \\
28 \text { melt events }\end{array}$ & $\begin{array}{l}\text { precip max in sum- } \\
\text { mer but RO max in } \\
\text { winter; } 7 \text { of top } 10 \\
\text { peak flows were } \\
\text { ROS - esp important } \\
\text { for elev }>400 \mathrm{~m}\end{array}$ & $\begin{array}{l}\text { Sui \& Koehler, } \\
\text { 2001, } 2007\end{array}$ \\
\hline $\begin{array}{l}\text { South Island } \\
\text { New Zealand }\end{array}$ & $\begin{array}{l}\text { Central Otago area } \\
\text { Fraser \& Pomahaka } \\
\text { river basins }\end{array}$ & $\begin{array}{l}\text { - case study } \\
\text { - met stations, energy budget, } \\
\text { snow pillows, streamflow }\end{array}$ & $\begin{array}{l}\text { ROS event of } \\
13-16 \text { October } 1978\end{array}$ & $\begin{array}{l}\text { melt was } \sim 40 \% \text { of } \\
\sim 25 \mathrm{~cm} \text { water input, } \\
\sim 10-33 \% \text { of flows }\end{array}$ & $\begin{array}{l}\text { Fitzharris et al., } \\
1980\end{array}$ \\
\hline $\begin{array}{l}\text { Kirgizstan } \\
\text { (highland steppe) }\end{array}$ & $\begin{array}{l}\text { Kirgiz Range } \\
\text { West Karakol Valley } \\
3140 \mathrm{~m}\end{array}$ & $\begin{array}{l}\text { - case study of slushflow } \\
\text { - geomorphic observation; local } \\
\text { met station }\end{array}$ & May 1992 & $\begin{array}{l}\text { some rain on spring } \\
\text { melt }\end{array}$ & $\begin{array}{l}\text { Elder \& } \\
\text { Kattelmann, } 1993\end{array}$ \\
\hline
\end{tabular}




\begin{tabular}{|c|c|c|c|c|c|}
\hline $\begin{array}{l}\text { Nagano Prefecture, } \\
\text { central Honshu, } \\
\text { Japan }\end{array}$ & $\begin{array}{l}\text { Gamahara-zawa Gully } \\
\text { Hime-kawa basin } \\
1300 \mathrm{~m}\end{array}$ & $\begin{array}{l}\text { - case study of landslide-debris } \\
\text { flow triggered by ROS } \\
\text { - geomorphic analysis }\end{array}$ & $\begin{array}{l}\text { December } 1996 \\
\text { snowmelt on several } \\
\text { days before rainfall }\end{array}$ & $\begin{array}{l}\text { debris flows are rare } \\
\text { in winter in Japan }\end{array}$ & $\begin{array}{l}\text { Suwa \& } \\
\text { Yamakoshi, } 2000\end{array}$ \\
\hline \multicolumn{6}{|l|}{ High latitudes } \\
\hline $\begin{array}{l}\text { Arctic, subarctic } \\
\text { and high-latitude } \\
\text { maritime zones } \\
\text { (tundra, forest) }\end{array}$ & $\begin{array}{l}\text { Norway, Sweden, } \\
\text { Spitsbergen/Svalbard, } \\
\text { Alaska, Quebec }\end{array}$ & $\begin{array}{l}\text { - identify processes, evaluate } \\
\text { hazards of slush avalanches/- } \\
\text { slushflows/slush torrents } \\
\text { - mechanistic studies, field } \\
\text { studies (snow pits, met, etc.), } \\
\text { geomorphic mapping \& } \\
\text { analysis, questionnaires }\end{array}$ & various case studies & $\begin{array}{l}\text { liquid water in snow } \\
\text { is common trigger - } \\
\text { can be midwinter } \\
\text { ROS (especially in } \\
\text { maritime climates), } \\
\text { spring ROS, or } \\
\text { spring SM }\end{array}$ & $\begin{array}{l}\text { Hestnes, 1985, } \\
\text { 1998; Hestnes \& } \\
\text { Sandersen, 1987; } \\
\text { Onesti \& Hestnes, } \\
\text { 1989; Nyberg, } \\
\text { 1989; Rapp, 1995 } \\
\text { Larocque et al., } \\
\text { 2001 }\end{array}$ \\
\hline \multirow[t]{3}{*}{$\begin{array}{l}\text { Arctic \& subarctic, } \\
\text { northern } \\
\text { hemisphere }\end{array}$} & $\begin{array}{l}\text { Canada, Alaska and } \\
\text { Russia, weather stations } \\
\geq 50^{\circ} \mathrm{N} \text { latitude }\end{array}$ & $\begin{array}{l}\text { - interpret weather data to detect } \\
\text { climate trends \& changes in } \\
\text { high latitudes, including } \\
\text { frequency of ROS events } \\
\text { - analyze GDCN data }\end{array}$ & $\begin{array}{l}1950-2000 \\
\text { many: defined as } \\
\text { days with } \geq 1 \mathrm{~mm} R F \\
\text { on snow depth } \geq 3 \\
\mathrm{~cm}\end{array}$ & $\begin{array}{l}\text { ROS more frequent } \\
\text { in maritime Canada, } \\
\text { Alaska, W Russia; } \\
\text { spring ROS central } \\
\text { Canada, Russia }\end{array}$ & $\begin{array}{l}\text { Groisman et al., } \\
2003\end{array}$ \\
\hline & $\begin{array}{l}\text { Eurasia, especially } \\
\text { European Russia } \\
\geq 40^{\circ} \mathrm{N} \text { latitude }\end{array}$ & $\begin{array}{l}\text { - interpret weather data to relate } \\
\text { ROS frequency with air tem- } \\
\text { perature, rainfall and snow } \\
\text { days, atmospheric circulation } \\
\text { patterns } \\
\text { - detect climate trends \& } \\
\text { changes in ROS frequency } \\
\text { - synoptic weather records } \\
\end{array}$ & $\begin{array}{l}\text { winter (Jan-Mar) } \\
1936-90\end{array}$ & $\begin{array}{l}\text { greater frequency of } \\
\text { ROS days with in- } \\
\text { creasing warmth and } \\
\text { rain days } \\
\text { (perhaps limited by } \\
\text { decreasing } \\
\text { snowpacks) }\end{array}$ & Ye et al., 2008 \\
\hline & all circumpolar Arctic & $\begin{array}{l}\text { - establish climatology for ROS } \\
\text { events in the Arctic } \\
\text { - evaluation of Canadian met, } \\
\text { plus } 40 \text { yr data from ECMRF; } \\
\text { synoptic weather for cases }\end{array}$ & $\begin{array}{l}\text { Spitsbergen/Svalbard } \\
\text { December } 1995 \\
\text { Banks Is } \\
\text { October } 2003\end{array}$ & $\begin{array}{l}\text { ROS affecting } \\
\text { permafrost limited to } \\
\text { Svalbard, Beringia, } \\
\text { etc.; more commonly } \\
\text { affecting ungulates }\end{array}$ & $\begin{array}{l}\text { Rennert et al., } \\
2009\end{array}$ \\
\hline $\begin{array}{l}\text { Eurasian Arctic } \\
\text { (tundra) }\end{array}$ & $\begin{array}{l}\text { Spitsbergen/Svalbard } \\
\text { near Ny-Ålesund } \\
30 \mathrm{~m}\end{array}$ & $\begin{array}{l}\text { - study patterned ground, with } \\
\text { met and soil temperatures } \\
\text { - evaluation of daily data from } \\
\text { ECMRF for all northern high } \\
\text { latitudes } \\
\end{array}$ & $\begin{array}{l}\text { 1984-2003 } \\
2 \text { in January } 1996 \\
\text { reanalysis } 1980-89\end{array}$ & $\begin{array}{l}\text { ROS is rare, but can } \\
\text { have significant } \\
\text { effects on soil } \\
\text { temperatures/perma- } \\
\text { frost thawing }\end{array}$ & $\begin{array}{l}\text { Putkonen \& Roe, } \\
2003 \\
\text { Putkonen et al., } \\
2009\end{array}$ \\
\hline
\end{tabular}




\begin{tabular}{|c|c|c|c|c|c|}
\hline $\begin{array}{l}\text { Canadian Arctic } \\
\text { (tundra) }\end{array}$ & $\begin{array}{l}\text { Banks Island } \\
\text { Northwest Territories }\end{array}$ & $\begin{array}{l}\text { - detect snow \& soil moisture } \\
\text { changes during regional ROS } \\
\text { events from satellite imagery } \\
\text { - time series of multifrequency } \\
\text { passive microwave spectra }\end{array}$ & $\begin{array}{l}2002-04 \\
\text { October } 2003\end{array}$ & $\begin{array}{l}\text { techniques detect } \\
\text { meltwater, grain } \\
\text { coarsening during } \\
\text { the event }\end{array}$ & $\begin{array}{l}\text { Grenfell \& } \\
\text { Putkonen, } 2008 \\
\text { Putkonen et al., } \\
2009\end{array}$ \\
\hline \multicolumn{6}{|c|}{ Notes, Abbreviations } \\
\hline & & DHSVM & \multicolumn{2}{|c|}{$\begin{array}{l}\text { Distributed Hydrology Soil-Vegetation } \\
\text { Model }\end{array}$} & $\begin{array}{l}\text { Wigmosta et al., } \\
1994\end{array}$ \\
\hline & & E-balance & \multicolumn{2}{|c|}{ energy balance calculation } & \\
\hline & & ECMRF & \multicolumn{2}{|c|}{$\begin{array}{l}\text { European Centre for Medium Range } \\
\text { Forecasting }\end{array}$} & \\
\hline & & FOSM & \multicolumn{2}{|c|}{ first-order second-moment } & \\
\hline & & GDCN & \multicolumn{2}{|c|}{ Global Daily Climatology Network } & \\
\hline & & $\begin{array}{l}\text { SNOBAL } \\
\text { ISNOBAL }\end{array}$ & \multicolumn{2}{|c|}{$\begin{array}{l}\text { SNOwpack energy \& mass-BALance model } \\
\text { image [areal] SNOBAL }\end{array}$} & $\begin{array}{l}\text { Marks et al., 1999, } \\
2001\end{array}$ \\
\hline & & SNTHERM & \multicolumn{2}{|c|}{ 1-dimensional snow temperature model } & Jordan, 1991 \\
\hline & & SSARR & \multicolumn{2}{|c|}{$\begin{array}{l}\text { Streamflow Synthesis and Reservoir } \\
\text { Regulation model }\end{array}$} & $\begin{array}{l}\text { USACE, North } \\
\text { Pacific Div }\end{array}$ \\
\hline \multicolumn{6}{|c|}{$\begin{array}{l}\text { This table does not include theoretical or laboratory studies of meltwater percolation, or field studies chiefly involving spring snowmelt. Among rain-on- } \\
\text { snow studies, the list is not exhaustive; in particular, it does not include most of the references to geomorphic/engineering studies about mass movements } \\
\text { in midlatitude zones that were triggered by ROS. See also sections } 1.3,1.4 \text {; Table 7.4. }\end{array}$} \\
\hline
\end{tabular}




\section{APPENDIX B}

Simulation Model for Single Events

B.1 ROS Simulation for Single Events (SE) - Excel Workbook

(B.1 ROS Sim Prog basic.xls)

in supplemental files

B.2 VBA Code for ROS Simulation for Single Events (SE) 


\section{Appendix B.2 VBA Code for ROS Simulation for Single Events (SE)}

\section{Option Explicit}

Option Base 1 ' all arrays start at element 1 (not 0)

Sub ROSSimulationSE()

' This program is a simulation of storm events, particularly rain-on-snow,

' in one observed event

' This SE version written 25 May - 12 Jun 2006; addns Oct 2006

' Edits and testing thru Dec 2006 (esp re snow, perc)

' Initiation

' Many of the model's controlling parameters \& formats supplied through and/or

' stored on several worksheets:

' "Params": factors, coefficients, etc. for governing equations

' "SIM codes": coefficients of polynomial equations governing storm internal model

' "Temp codes": values showing frontal temperature changes, modeled as segments

' "Summary": table to contain the major inputs and outputs from all events in a run

' "Working": for calculations of active event

' Dimension statements

' probably won't need most of these params (could use \%, !, \& symbols)

Dim i As Integer, j As Integer, $\mathrm{k}$ As Integer

Dim $m$ As Integer, $\mathrm{n}$ As Integer

Dim H1 As Single, $\mathrm{H} 2$ As Single

Dim rSc As Integer, cSc As Integer ' for SIM code page

Dim rTc As Integer, cTc As Integer ' for Temp code page

Dim rS As Integer, cS As Integer ' for Summary page

Dim rE As Integer, cE As Integer ' for active event page

Dim SiteName\$, PrecOpt\$

Dim Ho As Integer, Hrd As Integer

Dim SiteElev As Single

Dim DEvt As Integer

Dim RunHr As Integer, Hr As Integer

Dim Dur As Integer, DurE As Integer, DurMin As Integer, DurMax As Integer

Dim PrecEvt As Single, SitePrecM As Single, SitePrecSD As Single, PrecEvtMin As Single, 
PrecEvtMax As Single

Dim ExDp As Single, ExDa As Single, ExDm As Single

Dim ExDpL As Single, ExDaL As Single, ExDmL As Single

Dim EV1u As Single, EV1a As Single

Dim HrP As Single, PrecHr As Single, PrecCum As Single, AvgPrInt As Single, PropRn As Single

Dim SIMcode As Integer

Dim SIMa As Single, SIMb As Single, SIMc As Single, SIMd As Single, SIMe As Single

Dim SIMkicker As Single, SIMnew As Single, SIMold As Single, SIMbase As Single

Dim ProbSnoZ As Single

Dim SnoD As Single, SnoW As Single

Dim SnoWL As Single, SnoDbivM As Single, SnoDbivSD As Single

Dim SnoDLM As Single, SnoDLSD As Single

Dim SnoWLM As Single, SnoWLSD As Single

Dim SnoCorln As Single

Dim SnoDen As Single, SnoDenMin As Single, SnoDenMax As Single

Dim Sgrain As Single, SnoWp As Single, SnoDenp As Single

Dim SnoPor As Single, SnoPorMin As Single, SnoPorMax As Single, SnoPorEf As Single

Dim SnoPerm As Single, SnoHydK As Single, SnoHydKMin As Single, SnoHydKMax As Single

Dim SnoSat As Single, SnoSatMax As Single, SnoSatlr As Single

Dim SnoN As Single ' maybe integer

'others:

' SWdef as Single

' change: calc some temp values on Params page; no Dims for polynom coeffs here

Dim TempM As Single, TempSD As Single, TempRM As Single, TempRSD As Single

Dim TFDR As Single, TDFR As Single, TfdrM As Single, TfdrSD As Single

Dim Tcode As Integer

Dim TCbivM As Double, TCbivSD As Double

Dim Segts As Integer, Seg1 As Integer, Seg2 As Integer

Dim SegtM As Single, SegtSD As Single, DurSeg As Single, TSeg(45) As Single

Dim TKicker As Single, Tfr As Single, Tdi As Single, Trk As Single

Dim Temp As Single, TempR As Single, TempHr As Single, Tprev As Single

Dim TRhalf As Single, TempRI As Single, TempRh As Single

Dim WindM As Single, WindSD As Single, WindRM As Single, WindRSD As Single

Dim Wmin As Single, Wmax As Single

Dim Wind As Single, WindR As Single, WindHr As Single, WKicker As Single

' for SM, perc and filter blocks

Dim Rad As Single

Dim SnAcc As Single, SnMelt As Single, Net As Single

Dim Liqln As Single, LiqOut As Single

Dim N1 As Single, N2 As Single 
Dim FluxK As Double, ShockF As Double

Dim FluxV As Double, ShockV As Double

Dim PercHr As Integer

Dim Zperc As Single, Zshock As Single

Dim Top As Single, Ta As Single

Dim maxF As Single, excess As Single, avPor As Single

Dim Pd(7) As Integer

Dim maxFilter $(14,3)$ As Single

Dim sumPr As Single, maxPr As Single, maxPrT As Single

Dim sumLiqIn As Single, maxLiqIn As Single, maxLiqInT As Single

Dim sumLiqOut As Single, maxLiqOut As Single, maxLiqOutT As Single

Dim ProbW As Double, ProbD As Double, Holder As Double, Prob\#

' Inputs for the run

Worksheets("Params").Activate

' Get some basics using input boxes

SiteName\$ = InputBox("Site/test name?")

SiteElev = InputBox("Site elevation? (m)")

Cells $(11,4)=$ SiteElev $\quad$ place on Params for use in calcs

' PrecOpt\$ = InputBox("Precipitation options: " \& Chr(13) \& " single/specified storm S" \& $\operatorname{Chr}(13)$

\& " EV-1: elev EVE, site data EVD, simple params EVP" \& $\mathrm{Chr}(13)$

\& " ExD: elev EXE, site data EXD, simple params EXP")

' MC captures most variables from Parameters page: bypassed/unnec in SE

GoTo out99:

' DEvM = Cells (21, 14): DEvSD = Cells(21, 16): DEvMin = Cells $(21,18):$ DEvMax = Cells $(21,20)$

' DurLM = Cells(25, 14): DurLSD = Cells(25, 16): DurMin = Cells(25, 18): DurMax = Cells(25, 20):

DurCorln $=$ Cells $(27,8)$

' If PrecOpt\$ = "EVE" Or PrecOpt\$ = "EXE" Then DurLM = Cells(26, 14): DurLSD = Cells(26, 16):

DurCorln $=$ Cells $(27,14)$

If PrecOpt\$ = "S" Then DEvt = Cells(21, 8): Ho = Cells $(23,8):$ Dur $=$ Cells $(25,8):$ PrecEvt $=$ Cells(31, 8)

If PrecOpt\$ = "EVE" Then EV1u = Cells $(38,14):$ EV1a = Cells $(38,16)$

If PrecOpt\$ = "EVD" Then EV1u = Cells $(37,14): \operatorname{EV1a}=\operatorname{Cells}(37,16)$

If PrecOpt\$ = "EVP" Then EV1u = Cells(37, 8): EV1a = Cells(38, 8) 


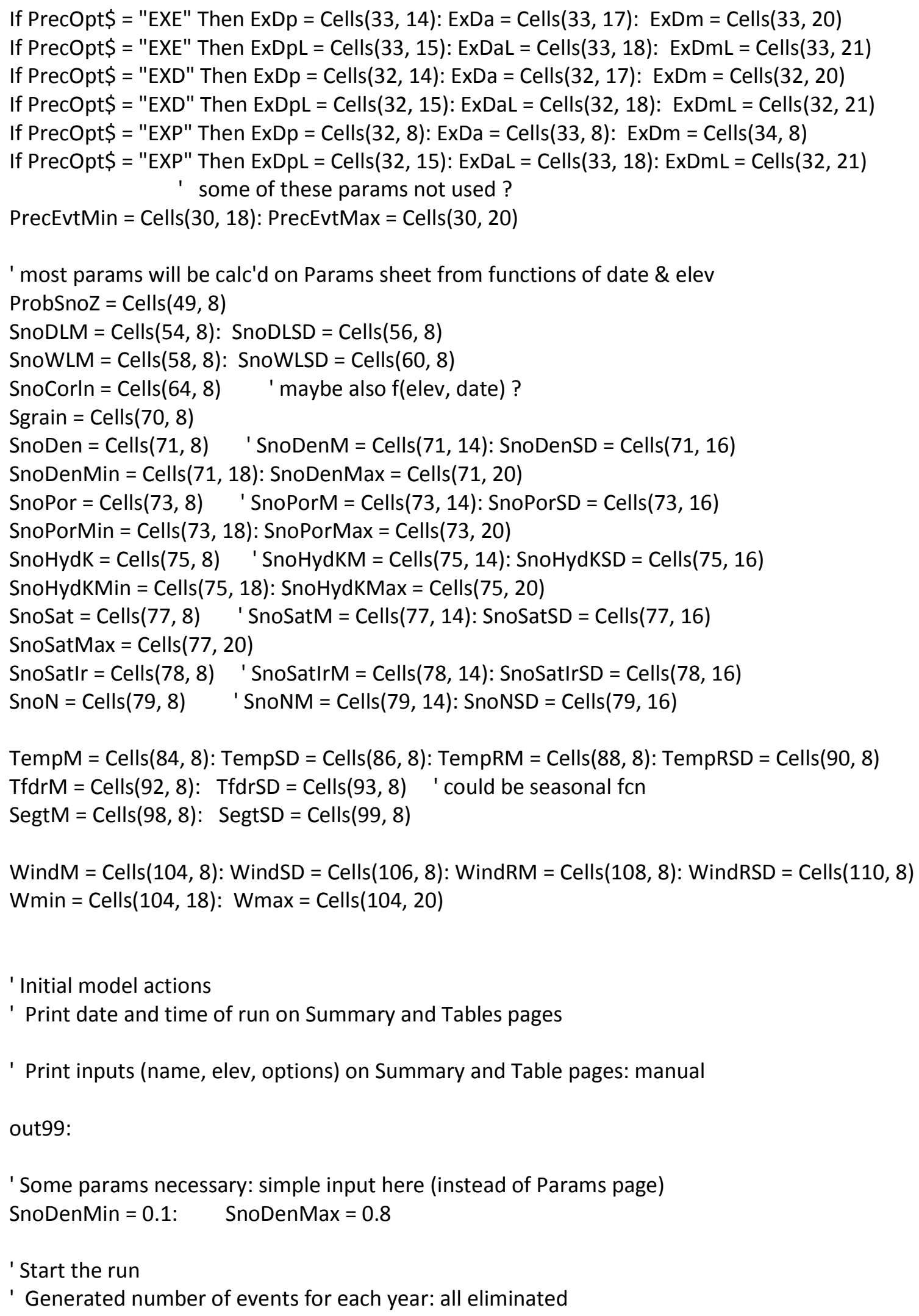




\section{Worksheets("Working").Activate}

' Start running each year

' Incorporate or calculate each parameter, from/on "Working" page

' Date, start time

DEvt $=$ Cells $(23,6)$

$\mathrm{Ho}=\operatorname{Cells}(23,9): \quad \operatorname{Cells}(30,2)=\mathrm{Ho}$

' Precip factors: duration, amount, internal distribution

Dur $=\operatorname{Cells}(23,11) \quad$ ' nominal duration

DurE = Dur $+24 \quad$ ' initital model run dur -- recalc later

PrecEvt $=$ Cells $(23,14): \quad$ Cells $(30,11)=$ PrecEvt

AvgPrInt $=$ PrecEvt $/$ Dur

' internal precip distribution: if used

SIMcode $=$ Cells $(23,16)$

GoTo out98:

Worksheets("SIM codes").Activate

$\mathrm{rSc}=\mathrm{SIMcode}+20$

SIMa = Cells $(r S c, 15):$ SIMb = Cells $(r S c, 16):$ SIMc $=$ Cells $(r S c, 17)$

SIMd $=$ Cells $(r S c, 18):$ SIMe $=$ Cells $(r S c, 19)$

out98:

' Snow factors

ProbSnoZ $=$ Cells $(23,18)$

SnoW $=$ Cells $(23,20): \quad \operatorname{Cells}(30,19)=$ SnoW

SnoD $=$ Cells $(23,22): \quad$ Cells $(30,20)=\operatorname{SnoD}$

SnoDen $=$ Cells $(23,23): \quad$ Cells $(30,21)=$ SnoDen

GoTo out2:

' If PrecOpt\$ = "S" Then GoTo out12: ' old: all bypassed

Worksheets("Params").Activate

Cells $(12,4)=$ DEvt

ProbSnoZ $=$ Cells $(49,15)$

If ProbSnoZ < Cells $(49,18)$ Then ProbSnoZ = Cells $(49,18)$ 'default min \& max P[0] ?

If ProbSnoZ $>$ Cells $(49,20)$ Then ProbSnoZ $=\operatorname{Cells}(49,20)$

If SiteElev $<335$ And ProbSnoZ $<0.9$ Then ProbSnoZ = Cells $(49,20)$ 'trend oddity

SnoDLM $=$ Cells $(54,15)$

If SnoDLM > Cells $(54,20)$ Then SnoDLM = Cells $(54,20)$ 'default max 7 (model min ok) SnoDLSD $=$ Cells $(56,15)$

If SnoDLSD < Cells $(56,18)$ Then SnoDLSD = Cells $(56,18)$ 'default min .25 (model max ok) 


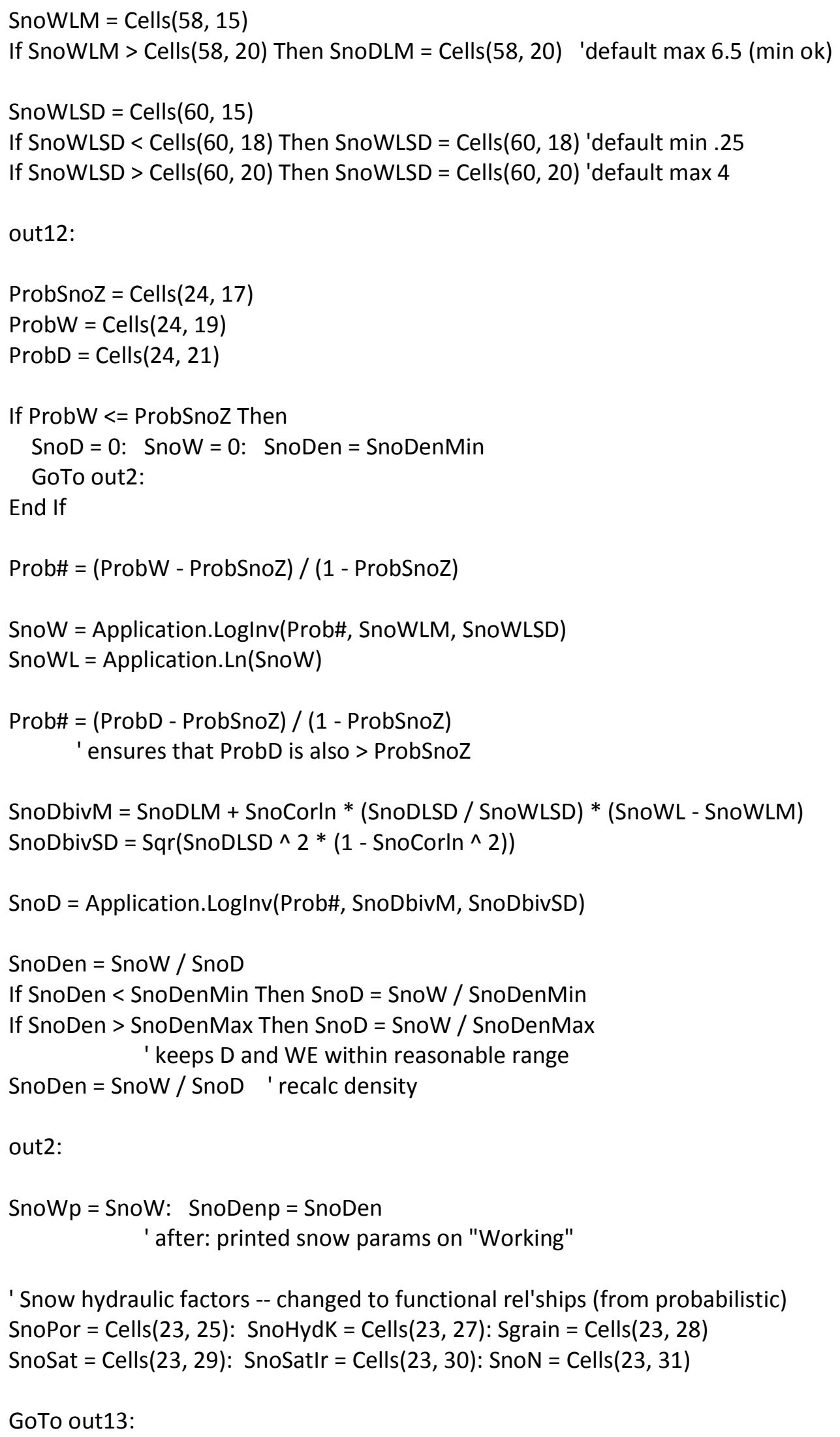




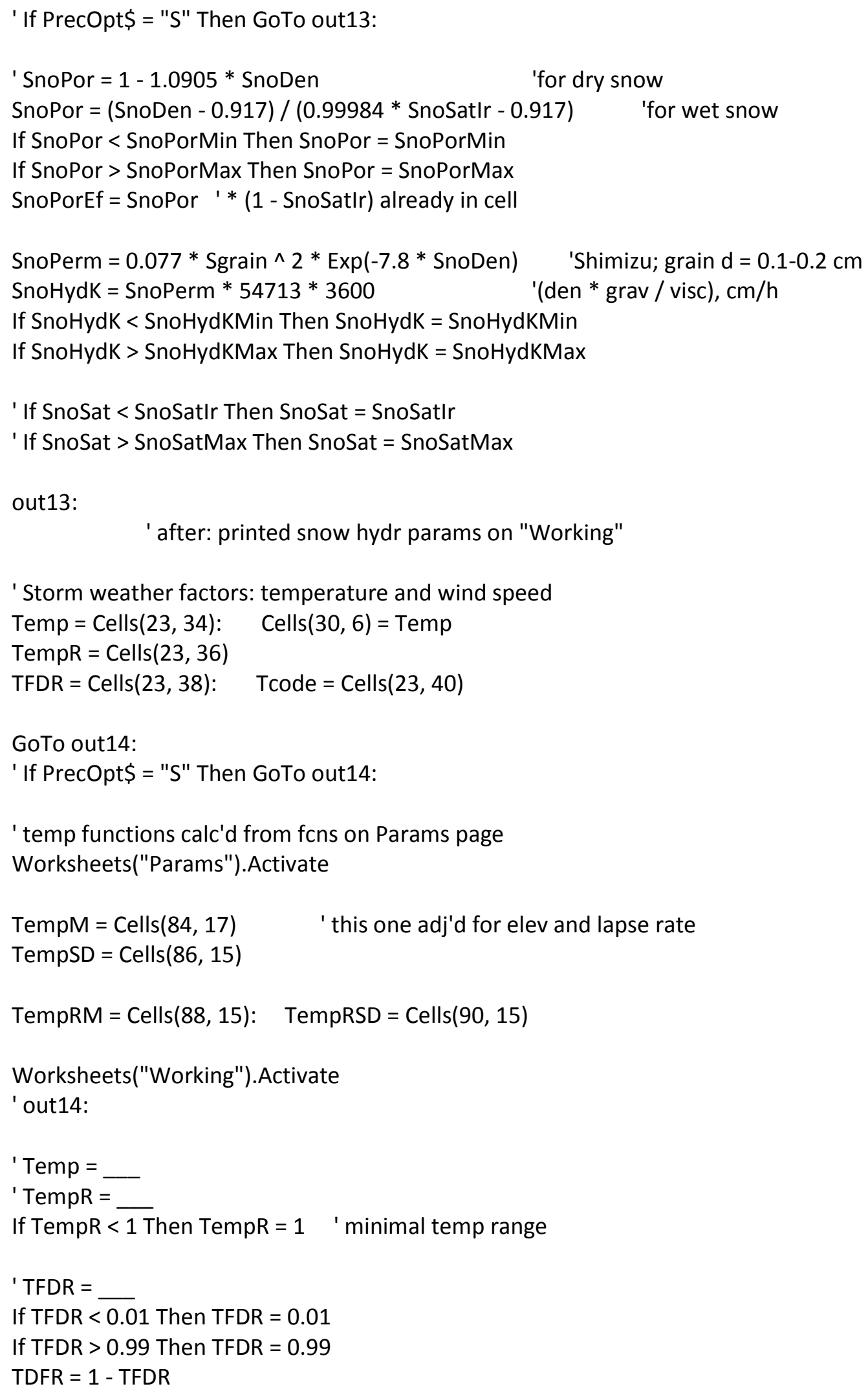


out14:

Wind $=$ Cells $(23,45): \quad$ Cells $(30,8)=$ Wind

' If Wind $<2$ Then Wind $=2$

WindR $=$ Cells $(23,47)$

' If WindR $<1$ Then WindR = 1

' NOW - the actual run starts

' reset counters, etc.

$\mathrm{HrP}=0: \quad$ SIMold $=0:$ PrecCum $=0: \quad$ 'others $?$

' set up procedures to calc temperature

' calc secondary params

TRhalf $=$ TempR $/ 2$

' TempRI $=$ Temp - TRhalf

' TempRh $=$ Temp + TRhalf $\quad$ ' neither used

' First block: calculate and print all the hrs of day, temps, wind speeds, precip all manual in this version

For RunHr $=1$ To DurE

$r E=\mathrm{RunHr}+30$

GoTo out97:

' hour of the day: manual

' hourly temp: keep equations for now

' frontal component

' determine which segment applies this $\mathrm{hr}$, and its value

For $m=1$ To Segts

If RunHr $<=m *$ DurSeg Then

$\mathrm{H} 2=\mathrm{TSeg}(\mathrm{m}):$ GoTo out16:

End If

Next $m$

out16:

Tfr $=($ H2 / DurSeg) $*$ TFDR * TRhalf '+/- change (deg T/hr) due to "frontal" segs

' diurnal component: cosine wave w/peaks at Hrd 100 and 1300

Tdi $=-\operatorname{Cos}(2 *$ Application.Pi $*($ Cells $(r E, 2)-1) / 24) *$ TDFR * TRhalf 


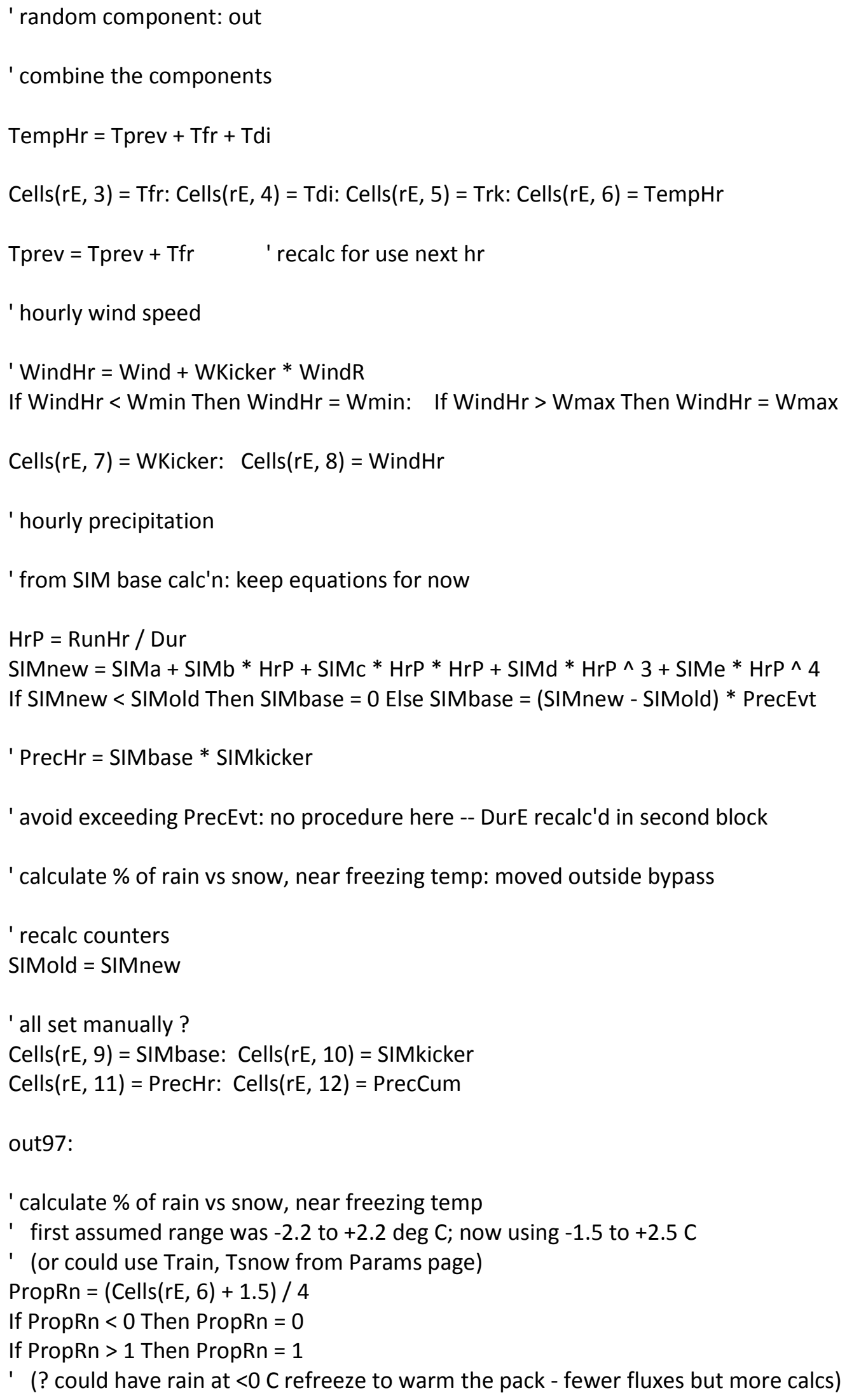




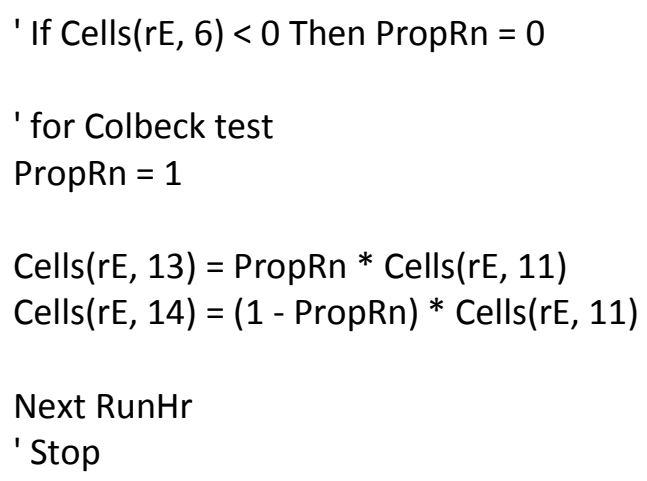

' Then calc hourly potential snowmelt -- based on D \& L version of USACE eqn 


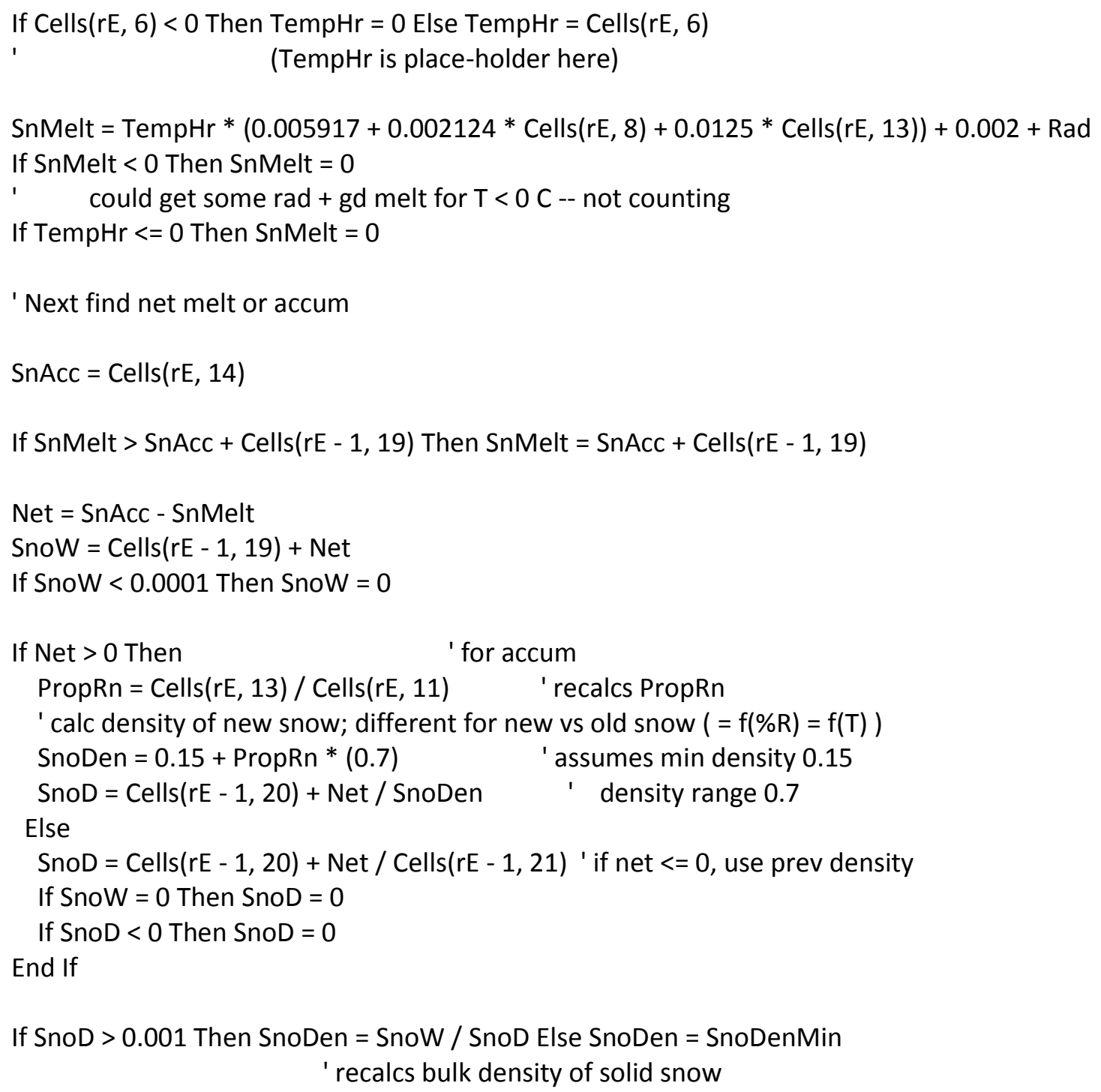

out4:

Cells $(r E, 16)=$ SnAcc: Cells $(r E, 17)=$ SnMelt: Cells $(r E, 18)=$ Net

Cells $(r E, 19)=$ SnoW: Cells $(r E, 20)=$ SnoD: Cells $(r E, 21)=$ SnoDen

Liqln $=$ Cells $(r E, 13)+$ Cells $(r E, 17)$

Cells $(r E, 24)=$ Liqln

Next RunHr

' Third block: percolation of liquid water, outputs allocated to appropriate hours

' First calc event-specific parameters needed for K-wave equations:

' assuming they're constant thru the event 


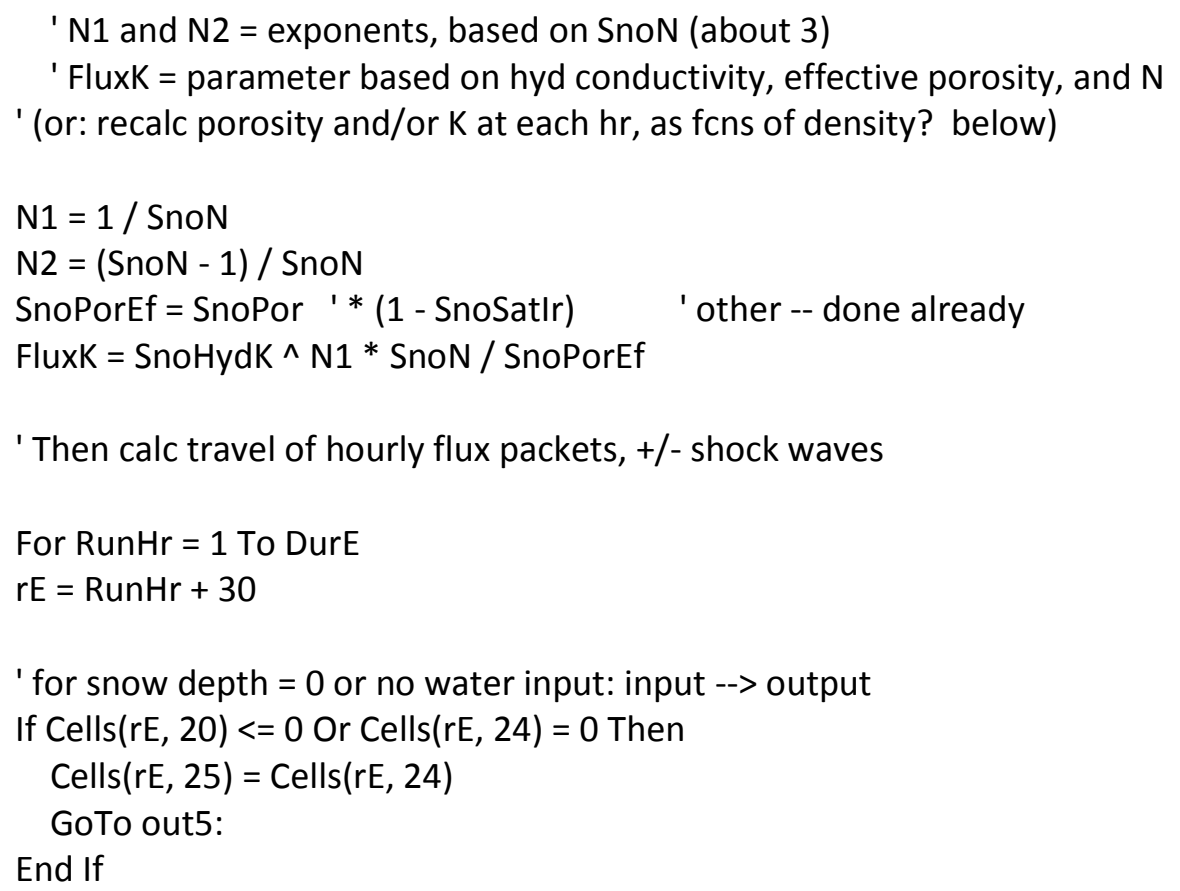


If Cells $(\mathrm{rE}, \mathrm{cE})<0$ Then GoTo out5: ' detour if already at ground

If Cells(rE, 38) >0 Then GoTo out17: ' detour for shock (flux positions set)

Zperc $=$ FluxV $*$ PercHr

' Zperc = FluxV * PercHr^N1 ' A \& K version

Cells $(r E, c E)=$ Top - Zperc

' if/when flux hits ground $(z<=0)$--> calc time of arrival (Ta)

If Cells $(\mathrm{rE}, \mathrm{cE})<=0$ Then

If Cells $(r E-1, c E+1)>0$ Then GoTo out17:

' rare case: if overtaking in last $\mathrm{hr}$

$\mathrm{Ta}=\mathrm{Top} /$ FluxV

Cells $(r E, 33)=\mathrm{Ta}+$ RunHr $\quad$ ' end of start $\mathrm{hr}+$ trav time

GoTo out5: 'skip shock test

End If

out17:

' tests for shock generation

' (if ignoring shocks - would just GoTo out5: )

For $\mathrm{i}=1$ To $24 \quad$ ' $\max$ shock-test time $-24 \mathrm{~h}$ long enough ?

' detour tests within the loop: skip test --

If $\mathrm{i}>=$ RunHr Then GoTo out6: ' don't go back before storm began

If $c E+i>256$ Then GoTo out6: ' don't go beyond column limit

If IsEmpty(Cells(rE - i, cE + i)) Then GoTo out7: ' for blank cells

If Cells $(r E-i, 30)<=0$ Then GoTo out7: ' for flux already overtaken

' the actual shock test

If Cells(rE, cE) > Cells(rE - i, cE + i) Then GoTo out7:

' earlier flux or shock not overtaken

' if a wave overtakes another, shock is generated or maintained;

' set the fast and slow fluxes, and the wave number

' for the overtaking wave:

Cells $(r E, 34)=$ Cells $(r E, 24)$

' fast: continue using old input flux

' for the overtaken wave:

If IsEmpty(Cells(rE - $i, 36)$ ) Then ' overtaken wave is a flux

Cells $(r E, 35)=$ Cells $(r E-i, 30)$

Cells $(r E, 38)=$ Cells $(r E, 38)+1 \quad$ ' set wave number

Else

' overtaken wave is a shock 


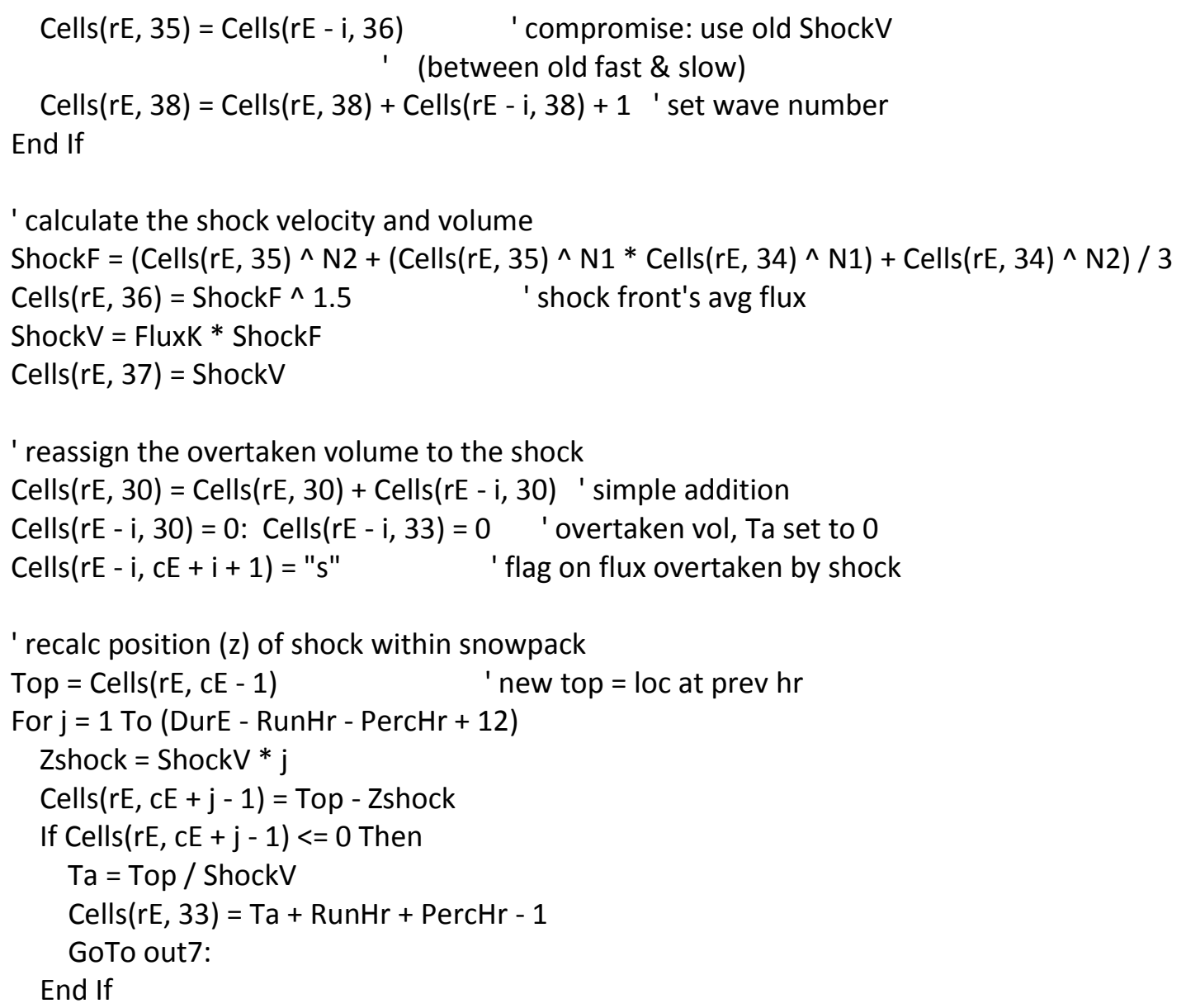


' if no flux amount initially assigned to this $\mathrm{hr}$ (no liq, gone to shock, or stranded in pack)

' --> skip to next

If Cells $(r E, 30)=0$ Or Cells $(r E, 33)<=0$ Then GoTo out8: ' Ta would also be 0

' otherwise: use Ta to allocate output to ground surface

$\mathrm{Ta}=$ Cells $(\mathrm{rE}, 33)-\mathrm{RunHr} \quad$ ' time in Ta column includes $\mathrm{RunHr}$

$\mathrm{H} 1=\operatorname{lnt}(\mathrm{Ta})$

$\mathrm{H} 2=\mathrm{Ta}-\mathrm{H} 1$

Cells $(r E+H 1+1,27)=$ Cells $(r E+H 1+1,27)+$ Cells $(r E, 30) * H 2$

Cells $(r E+H 1,27)=$ Cells $(r E+H 1,27)+$ Cells $(r E, 30) *(1-H 2)$

' set max flux rate on arrival - running maxima (ahead and behind)

' 2 possibilities -

' regular flux:

If IsEmpty(Cells(rE, 36)) Then maxF = Cells $(r E, 30)$ Else maxF = Cells(rE, 36)

' or shock:

For $\mathrm{k}=0$ To Cells $(\mathrm{rE}, 38)+1 \quad$ ' use \# waves overtaken +1

If maxF $>$ Cells $(r E+H 1+k, 28)$ Then Cells $(r E+H 1+k, 28)=\operatorname{maxF}$

Next $k$

out8:

Next RunHr

' Last -- reallocate amounts delivered to the ground, based on maxF or snow WHC

For RunHr $=1$ To DurE $+\mathrm{H} 1+1$

$r E=R u n H r+30$

' case 1: no water arriving from perc or excess in the hr, or no snow

If Cells $(r E, 27)=0$ And Cells $(r E, 26)<=0$ Then GoTo out9:

If Cells $(r E, 20)=0$ Then

Cells $(r E, 25)=$ Cells $(r E, 24)+$ Cells $(r E, 26)+$ Cells $(r E, 27)$

GoTo out9:

End If

' case 2: volume arriving + excess <= max flux rate (most simple fluxes) --> all drains out If IsEmpty(Cells $(r E, 28))$ Then Cells $(r E, 28)=$ Cells $(r E-1,28)$

If Cells $(r E, 27)+$ Cells $(r E, 26)<=$ Cells $(r E, 28)$ Then

Cells $(r E, 25)=$ Cells $(r E, 27)+$ Cells $(r E, 26)$

' case 3: vol too great: drain max \& reallocate excess to next $\mathrm{hr}$

Else

excess $=$ Cells $(r E, 27)+$ Cells $(r E, 26)-$ Cells $(r E, 28)$ 


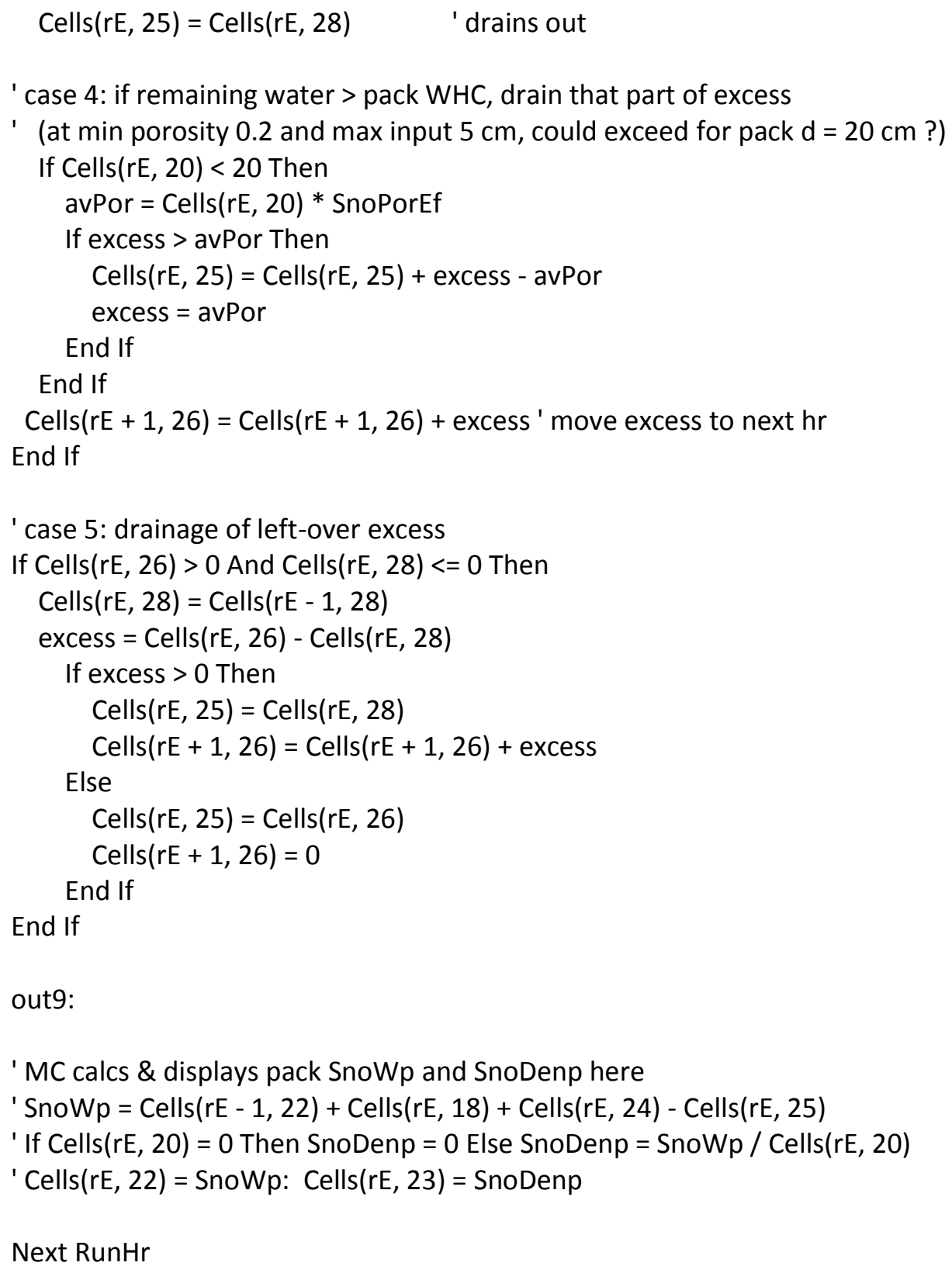




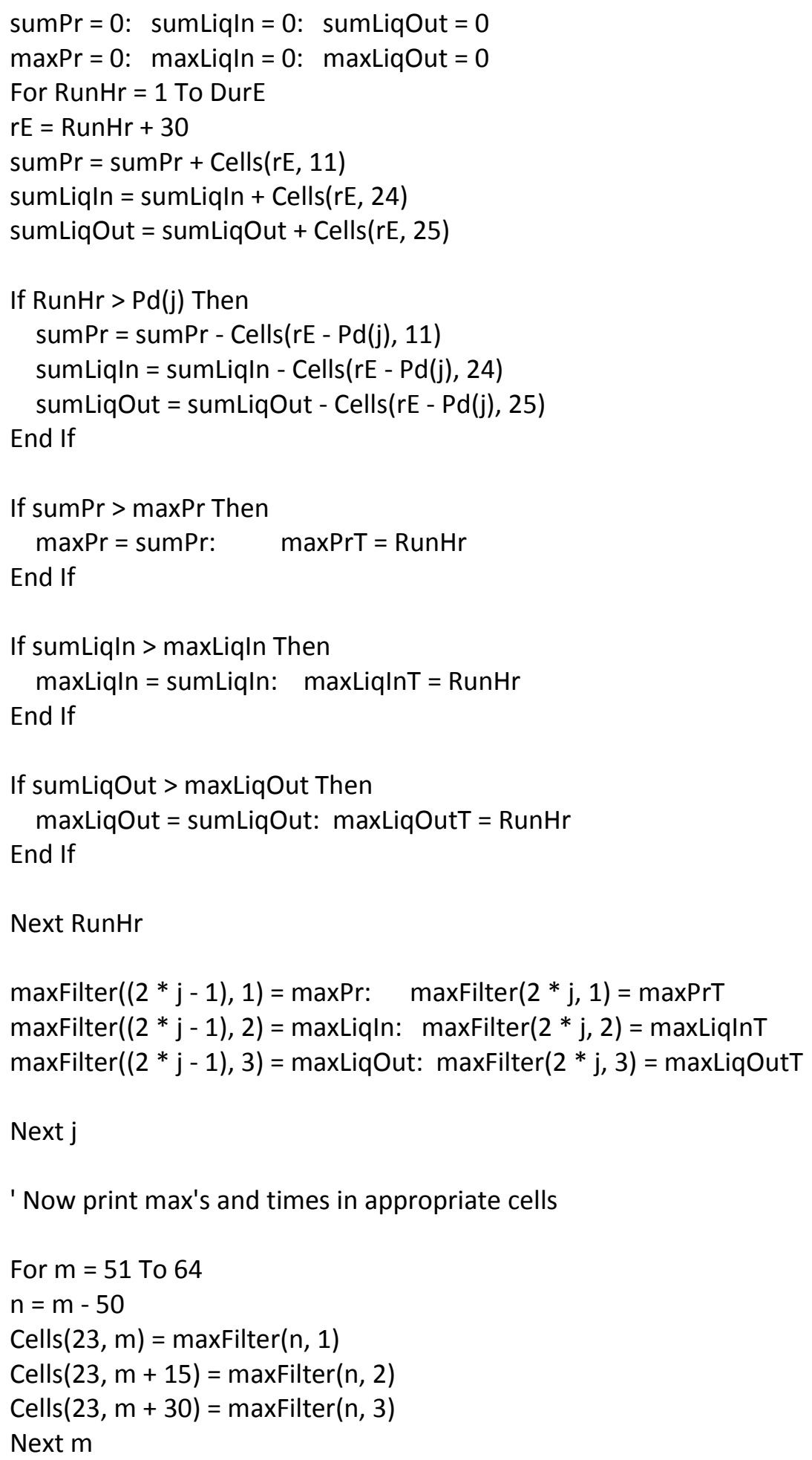




\title{
APPENDIX C
}

\author{
Monte Carlo Simulation Model \\ C.1 ROS Simulation Monte Carlo (MC) - Excel Workbook \\ (C.1 ROS Sim Program MC.xls)
}

in supplemental files

C.2 VBA Code for Monte Carlo Simulation (MC) 


\title{
Appendix C.2 VBA Code for Monte Carlo Simulation (MC)
}

\author{
Option Explicit \\ Option Base $1 \quad$ ' all arrays start at element 1 (not 0)
}

Sub ROSSimulationMC()

' This program is a Monte Carlo simulation of storm events, particularly rain-on-snow,

' over a large number of model "years", each experiencing some number of events.

' Draft begun 3 Sep 2003

' Latest work: testing file manipulation, edits Apr-May 05, Jan 06 -

' Mar 06: culling extra code; May, Dec: more edits (esp re snow, perc)

' Jan-Mar 2007: testing, editing on increasing number of years

' Jan 2008: slight corrections/changes in snow we functional params -- StpP and general;

' $\quad \mathrm{P}[0]$ for elevs < $320 \mathrm{~m}$; and corrected double-P[0] comparison

' Jul 2008: some clean-up of unused variables, etc.

' Sep 2011: editing, charts formats

' Initiation

' Many of the model's controlling parameters \& formats supplied through and/or

' stored on several worksheets:

' "Params": factors, coefficients, etc. for governing equations

' "SIM codes": coefficients of polynomial equations governing storm internal model

' "Temp codes": values showing frontal temperature changes, modeled as segments

' "Random \#s": table of random numbers used in a run (might do differently)

' "Summary": table to contain the major inputs and outputs from all events in a run

' "Tables": table formats copied to worksheets for individual runs

' "Working": for calculations of active event

' Before first use on a particular computer: set up a subdirectory as C: $\backslash R$ O S $\backslash M C$ runs

' Dimension statements

' declare all of the params and parts (could use \%, !, \& symbols)

Dim i As Integer, j As Integer, $\mathrm{k}$ As Integer

Dim $m$ As Integer, mm As Integer, $\mathrm{n}$ As Integer, nn As Integer

Dim $\mathrm{H} 1$ As Single, $\mathrm{H} 2$ As Single

' Dim rP As Integer, cP As Integer ' for Params page - unused

Dim rR As Integer, cR As Integer ' for R\# page

Dim rSc As Integer, cSc As Integer ' for SIM code page

Dim rTc As Integer, cTc As Integer ' for Temp code page

Dim rS As Integer, cS As Integer ' for Summary page

Dim rE As Integer, cE As Integer ' for active event page

Dim SiteName\$, PrecOpt\$, Ename\$, Yname\$ 
' strings; RunPath\$, FullPath\$ not used

Dim Rseed\% ' integer

Dim WYEvt As Integer, Ho As Integer, Hrd As Integer

Dim Evnt\&, NYr\&, Yr\& ' long

Dim SiteElev As Single

Dim NEvM As Single, NEvSD As Single

Dim NEvMin As Integer, NEvMax As Integer

Dim NEvts As Integer ' for set number of evts

Dim NEvt() As Integer ' array for NYr\&

Dim DEvM As Single, DEvSD As Single, DEvMin As Single, DEvMax As Single

Dim DEvt As Integer

Dim RunHr As Integer, $\mathrm{Hr}$ As Integer

Dim DurLM As Single, DurLSD As Single, DurCorln As Single

Dim DurbivM As Single, DurbivSD As Single

Dim Dur As Integer, DurE As Integer, DurMin As Integer, DurMax As Integer

Dim PrecEvt As Single, SitePrecM As Single, SitePrecSD As Single, PrecEvtMin As Single, PrecEvtMax As Single

Dim ExDp As Single, ExDa As Single, ExDm As Single

Dim ExDpL As Single, ExDaL As Single, ExDmL As Single

Dim EV1u As Single, EV1a As Single

Dim HrP As Single, PrecHr As Single, PrecCum As Single, AvgPrInt As Single, PropRn As Single

Dim SIMcode As Integer

Dim SIMa As Single, SIMb As Single, SIMc As Single, SIMd As Single, SIMe As Single

Dim SIMkicker As Single, SIMnew As Single, SIMold As Single, SIMbase As Single

' change: most snow factors calc'd on Params page

Dim ProbSnoZ As Single

' Dim ProbSnoD, ProbSnoW As Single ' using ProbSnoZ for both $d$ and we

Dim SnoD As Single, SnoW As Single

' Dim SnoDL As Single, SnoWbivM As Single, SnoWbivSD As Single

Dim SnoWL As Single, SnoDbivM As Single, SnoDbivSD As Single

Dim SnoDLM As Single, SnoDLSD As Single

Dim SnoWLM As Single, SnoWLSD As Single

Dim SnoCorln As Single

Dim SnoDen As Single, SnoDenMin As Single, SnoDenMax As Single

Dim Sgrain As Single, SnoWp As Single, SnoDenp As Single

Dim SnoPor As Single, SnoPorMin As Single, SnoPorMax As Single, SnoPorEf As Single

Dim SnoPerm As Single, SnoHydK As Single, SnoHydKMin As Single, SnoHydKMax As Single 
Dim SnoSat As Single, SnoSatMax As Single, SnoSatlr As Single

Dim SnoN As Single ' maybe integer

'others, esp if not constant or deterministic:

' SnoDenM As Single, SnoDenSD As Single,

' SnoPorM As Single, SnoPorSD As Single, SWdef as Single

' SnoHydKM As Single, SnoHydKSD As Single

' SnoSatM As Single, SnoSatSD As Single

' SnoSatIrM As Single, SnoSatIrSD As Single

' SnoNM As Single, SnoNSD As Single

' change: calc some temp values on Params page; no Dims for polynom coeffs here Dim TempM As Single, TempSD As Single, TempRM As Single, TempRSD As Single

Dim TFDR As Single, TDFR As Single, TfdrM As Single, TfdrSD As Single

Dim TCorln1 As Single, TCorln2 As Single

Dim Tcode As Integer, Tcod1 As Integer, Tcod2 As Integer

Dim TCbivM As Double, TCbivSD As Double

Dim Segts As Integer, Seg1 As Integer, Seg2 As Integer

Dim SegtM As Single, SegtSD As Single, DurSeg As Single, TSeg(45) As Single

Dim Tfr As Single, Tdi As Single, Trk As Single

Dim Temp As Single, TempR As Single, TempHr As Single, Tprev As Single

Dim TRhalf As Single ' TempRI As Single, TempRh As Single

Dim WindM As Single, WindSD As Single, WindRM As Single, WindRSD As Single, WCorln As Single

Dim Wmin As Single, Wmax As Single

Dim Wind As Single, WindR As Single, WindHr As Single, WKicker As Single

' for SM, perc and filter blocks

Dim Rad As Single

Dim SnAcc As Single, SnMelt As Single, Net As Single

Dim Liqln As Single, LiqOut As Single

Dim N1 As Single, N2 As Single

Dim FluxK As Double, ShockF As Double

Dim FluxV As Double, ShockV As Double

Dim PercHr As Integer

Dim Zperc As Single, Zshock As Single

Dim Top As Single, Ta As Single

Dim maxF As Single, excess As Single, avPor As Single

Dim Pd(7) As Integer

Dim maxFilter(14, 3) As Single

Dim sumPr As Single, maxPr As Single, maxPrT As Single

Dim sumLiqln As Single, maxLiqln As Single, maxLiqlnT As Single

Dim sumLiqOut As Single, maxLiqOut As Single, maxLiqOutT As Single

Dim ProbW As Double, ProbD As Double, Holder As Double, Prob\# 
Dim RandNumPar(18) As Double, RandNum() As Double ' R\# arrays

' could use RandNumPrc() as array, RandNumT() as array, RandNumW() as array,

' as 3 1-d arrays instead of 2-d array?

ChDir "C: \R O S\MC runs\"

'ChDir "C: \Matt B\R O S\Runs\" ' at PSU

' for storage of output

' Inputs for the run

Worksheets("Params").Activate

' Get some basics using input boxes

SiteName\$ = InputBox("Site name?")

SiteElev = InputBox("Site elevation? (m)")

Cells $(11,4)=$ SiteElev $\quad$ place on Params for use in calcs

NYr\& = InputBox("Number of years in model run?")

' Rseed\% = InputBox("Random number seed?") ' if variable -- to keep track

Rseed\% $=1 \quad$ ' current versions

PrecOpt\$ = InputBox("Precipitation options: " \& Chr(13) \& " single/specified storm S" \& $\mathrm{Chr}(13)$

\& " ExD: elev EXE, site data EXD, simple params EXP" \& Chr(13) _

\& " EV-1: elev EVE, site data EVD, simple params EVP")

' EV-1 versions not enabled

' Capture most variables from Parameters page

ReDim NEvt(NYr\&) ' others to redimension ?

NEvM = Cells $(19,14):$ NEvSD = Cells(19, 16): NEvMin = Cells $(19,18): \operatorname{NEvMax}=$ Cells $(19,20)$

$\operatorname{DEvM}=\operatorname{Cells}(21,14): \operatorname{DEvSD}=\operatorname{Cells}(21,16): \operatorname{DEv} M i n=\operatorname{Cells}(21,18): \operatorname{DEvMax}=\operatorname{Cells}(21,20)$

DurLM $=$ Cells $(25,14):$ DurLSD = Cells $(25,16):$ DurMin $=\operatorname{Cells}(25,18):$ DurMax $=$ Cells $(25,20):$

DurCorln $=$ Cells $(27,8)$

If PrecOpt\$ = "EVE" Or PrecOpt\$ = "EXE" Then DurLM = Cells(26, 14): DurLSD = Cells(26, 16):

DurCorln $=$ Cells $(27,14)$

If PrecOpt\$ = "S" Then NEvts = Cells $(19,8):$ DEvt $=$ Cells $(21,8):$ Ho $=$ Cells $(23,8):$ Dur $=$ Cells $(25$,

8): PrecEvt $=$ Cells $(31,8)$

If PrecOpt\$ = "EVE" Then EV1u = Cells $(38,14):$ EV1a = Cells $(38,16)$

If PrecOpt\$ = "EVD" Then EV1u = Cells $(37,14): \operatorname{EV1a}=\operatorname{Cells}(37,16)$

If PrecOpt\$ = "EVP" Then EV1u = Cells(37, 8): EV1a = Cells $(38,8)$ 


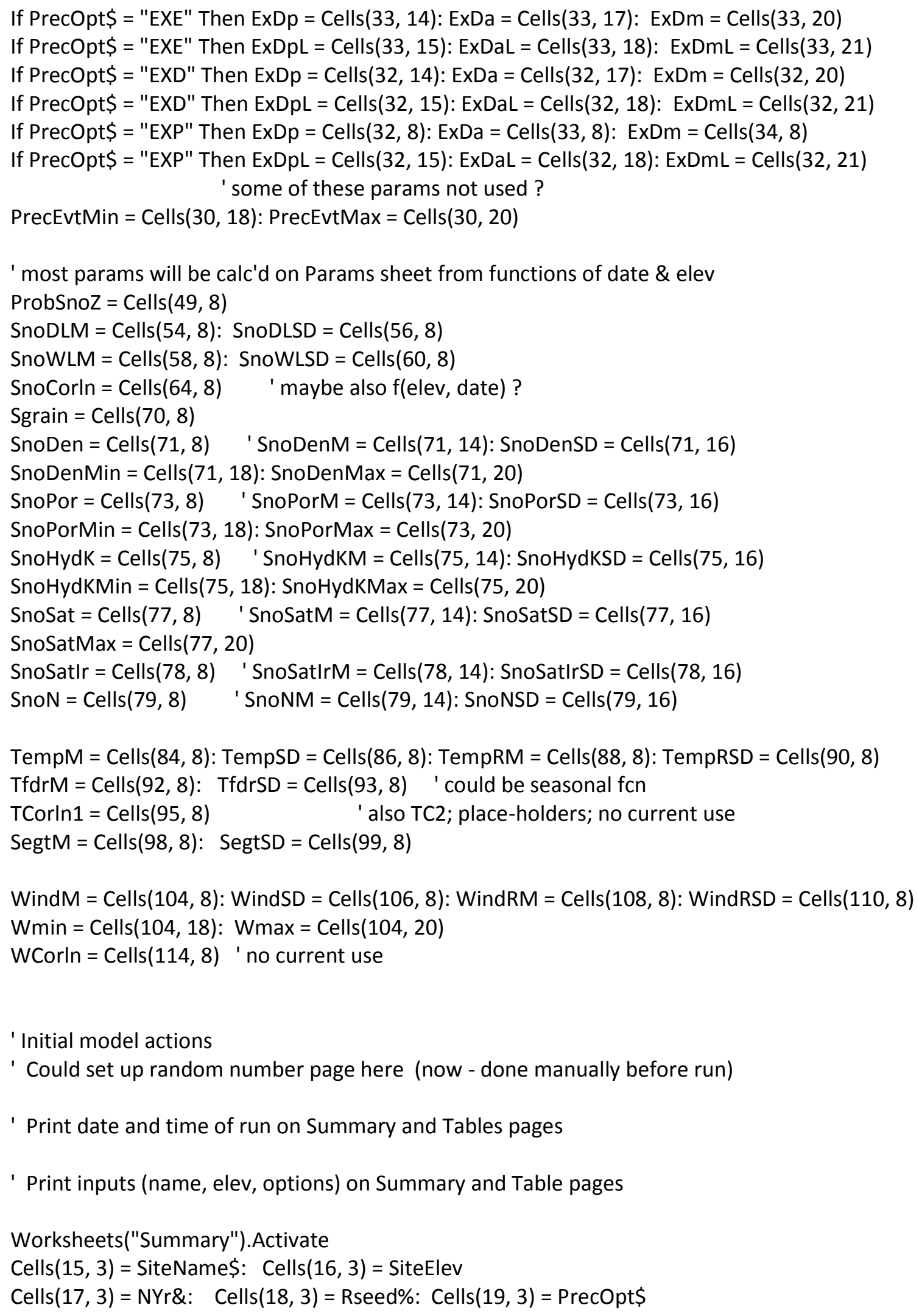




\section{Range("C15:C19").Copy Destination:=Worksheets("Tables").Range("C15")}

' Start the run

' Generate number of events for each year at this point (alt: year by year?)

' Fill the NEvt(NYr\&) array, using random \#s (first 5 rows) and Inv Norm function Worksheets("Random \#s").Activate

' move through first block of the R\# page (max 5 rows reserved)

' need almost 4 rows for 1000 yrs

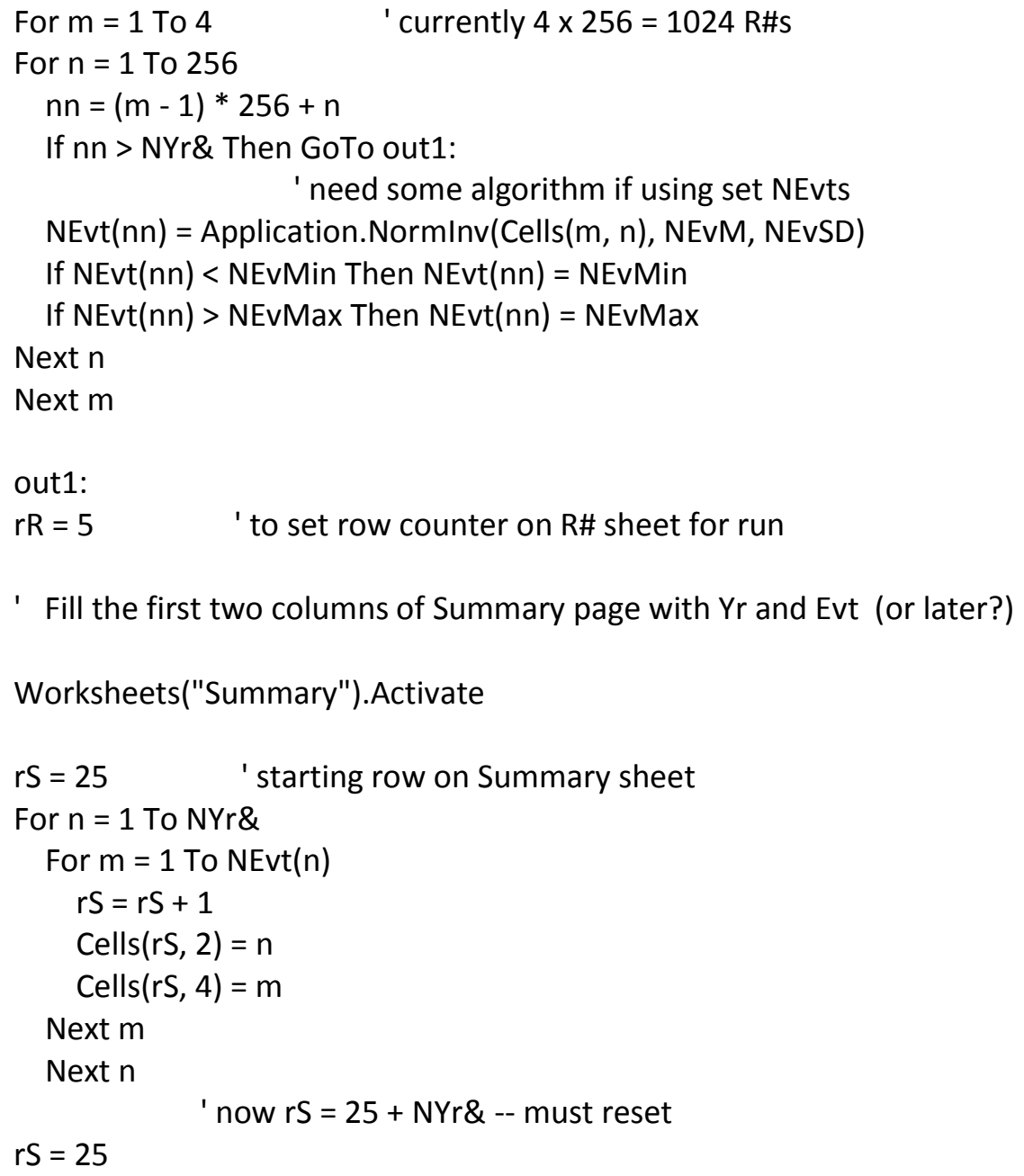

' Start running each year

' Set major counters: master event (Evnt\&), year and event

' (should some of these occur sooner ?) 


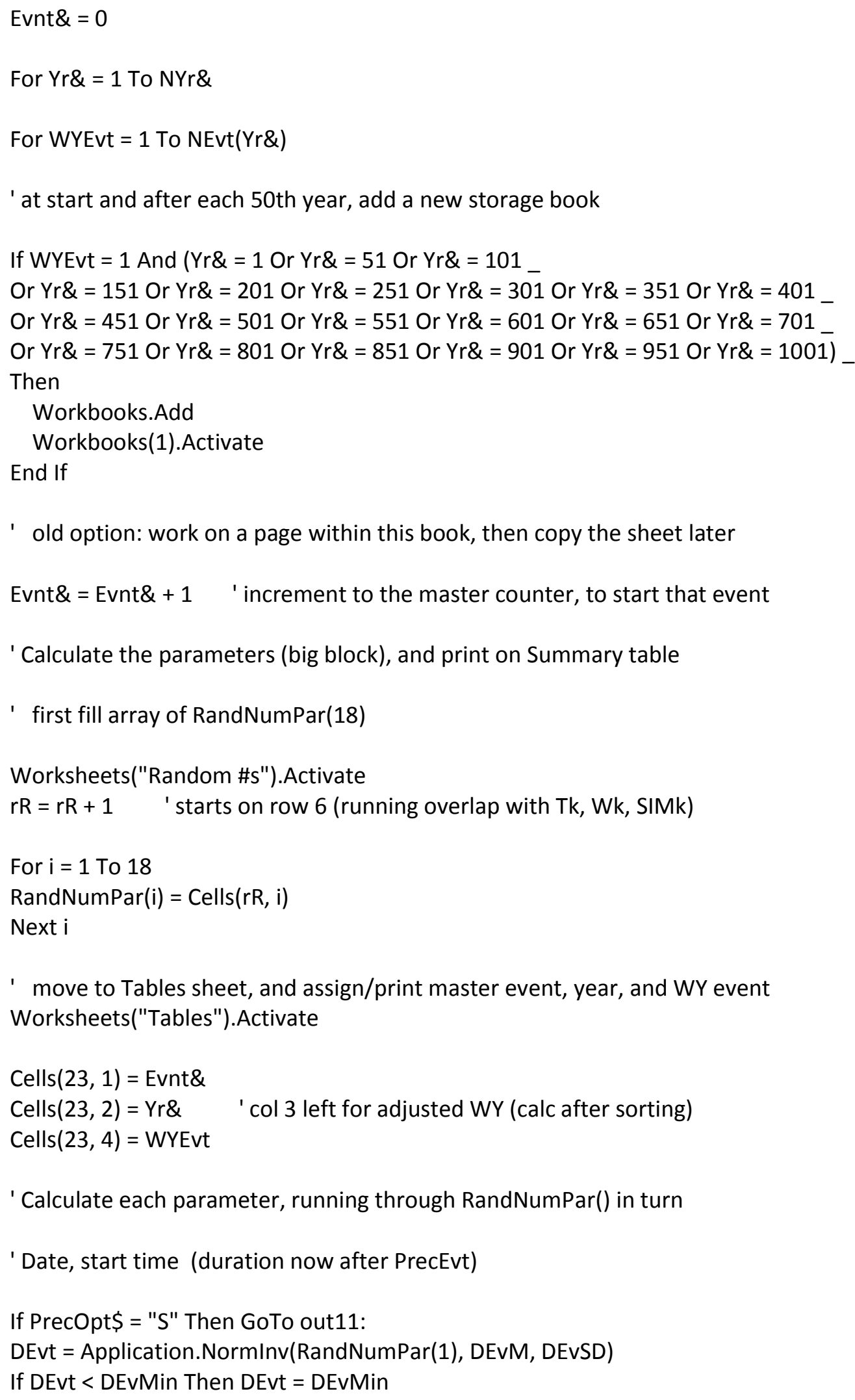




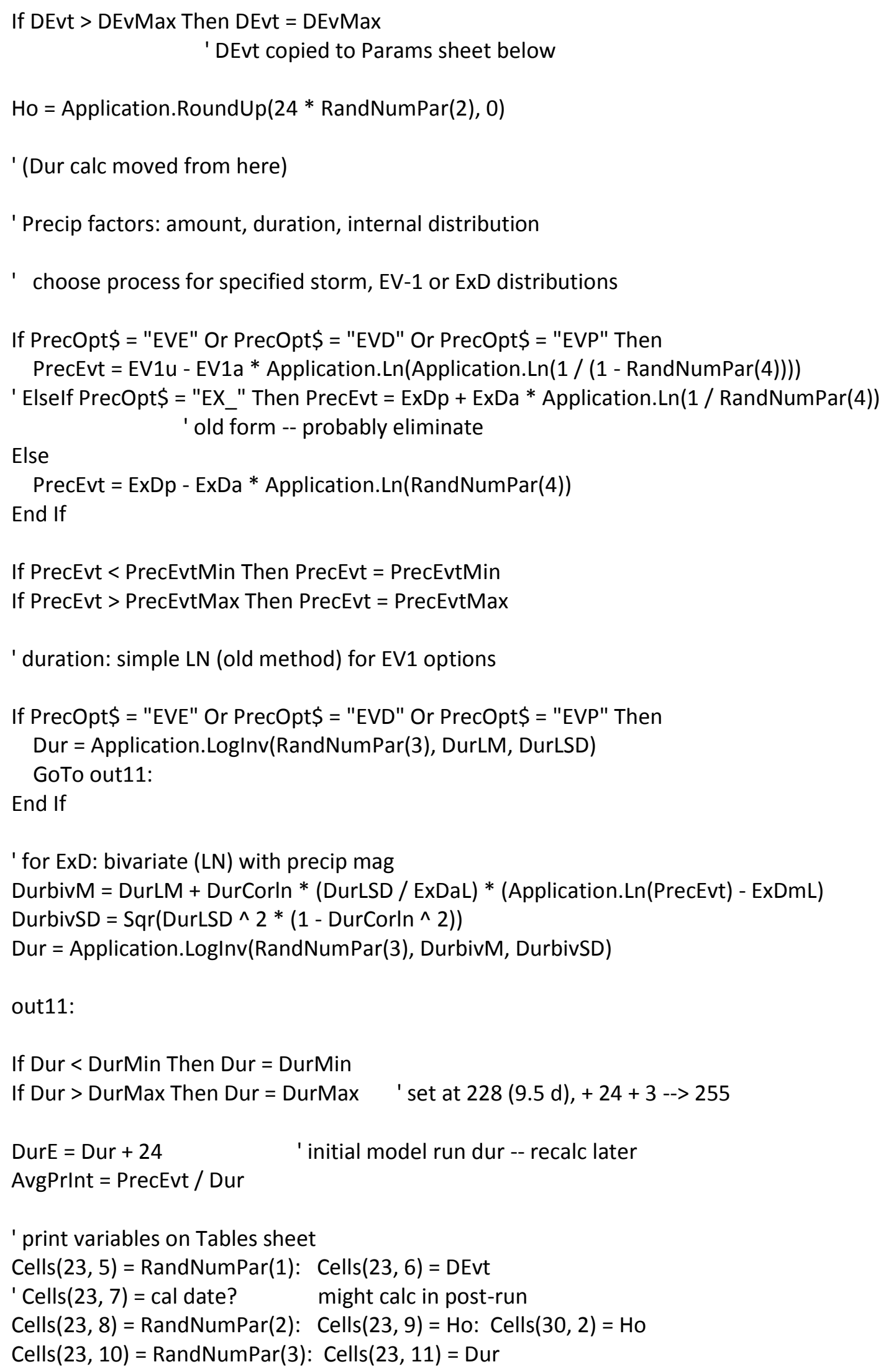




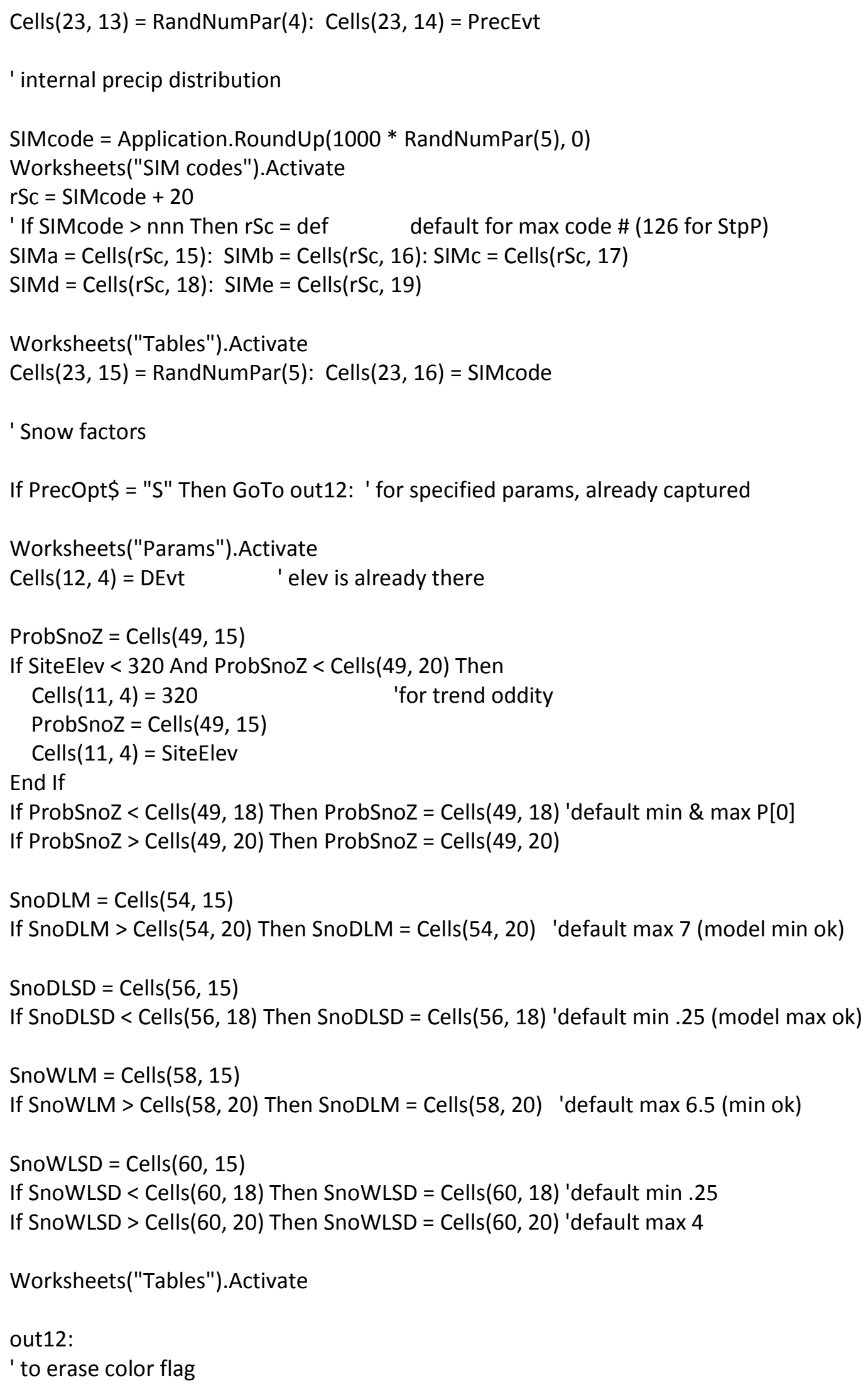




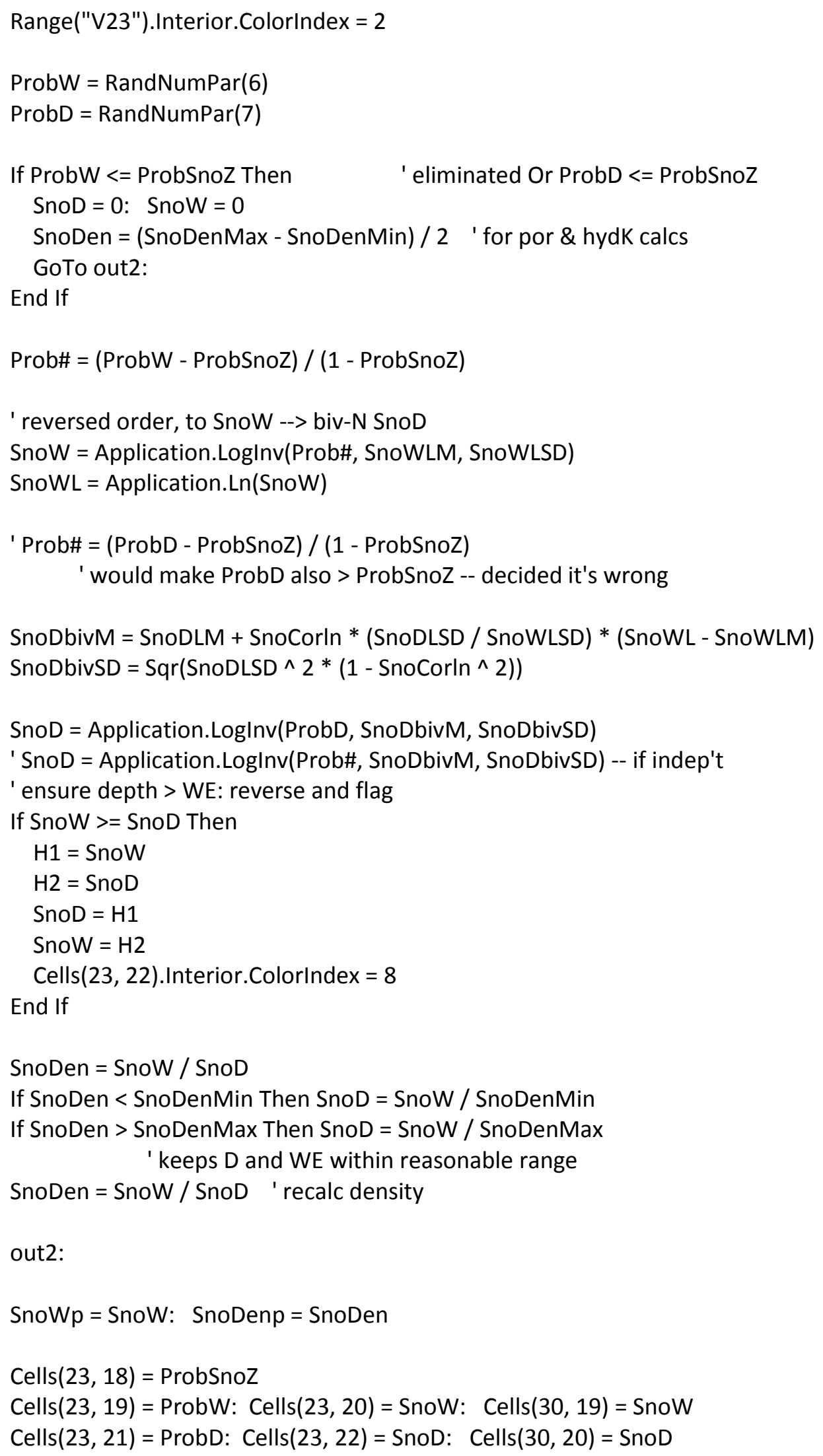




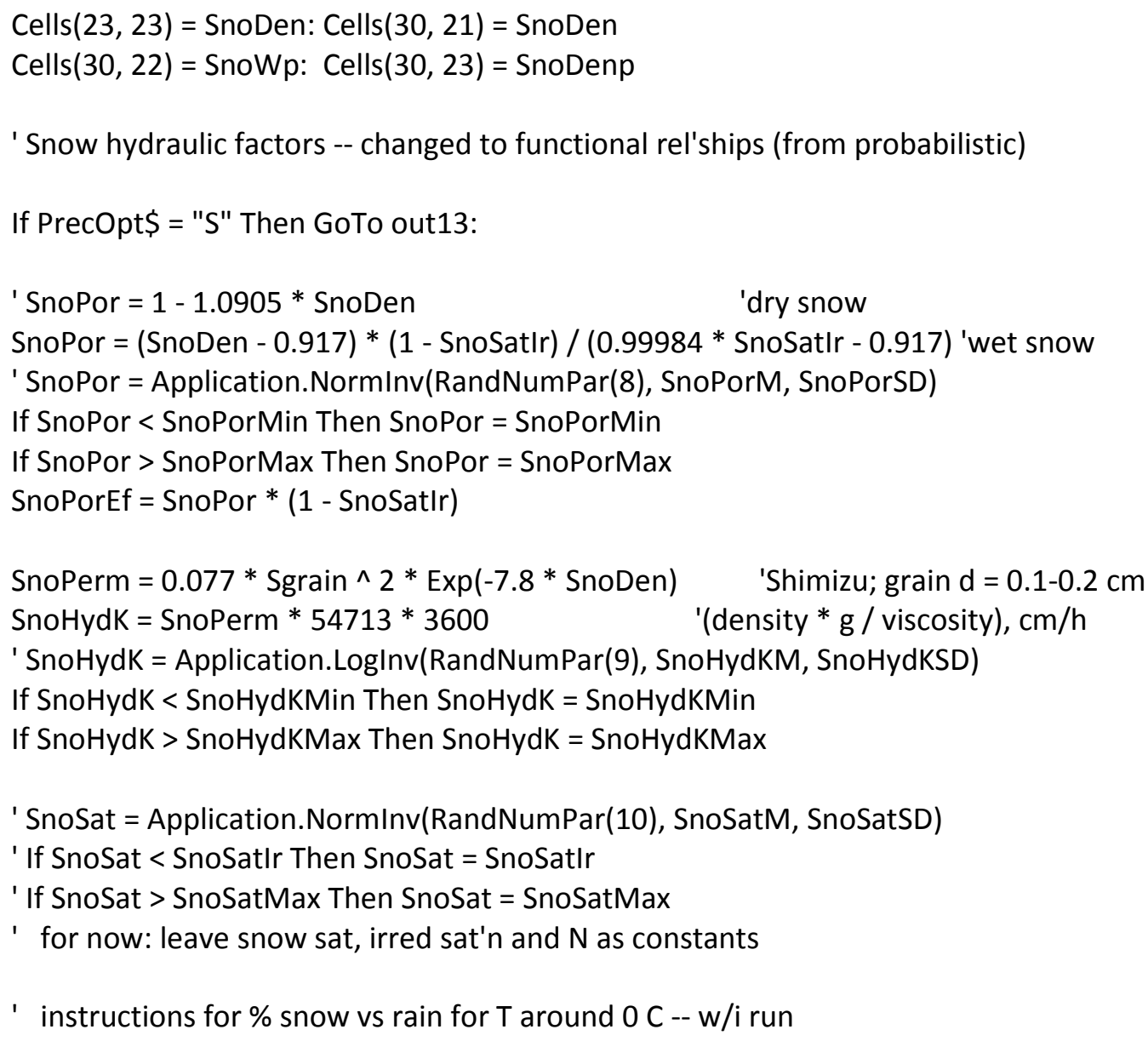




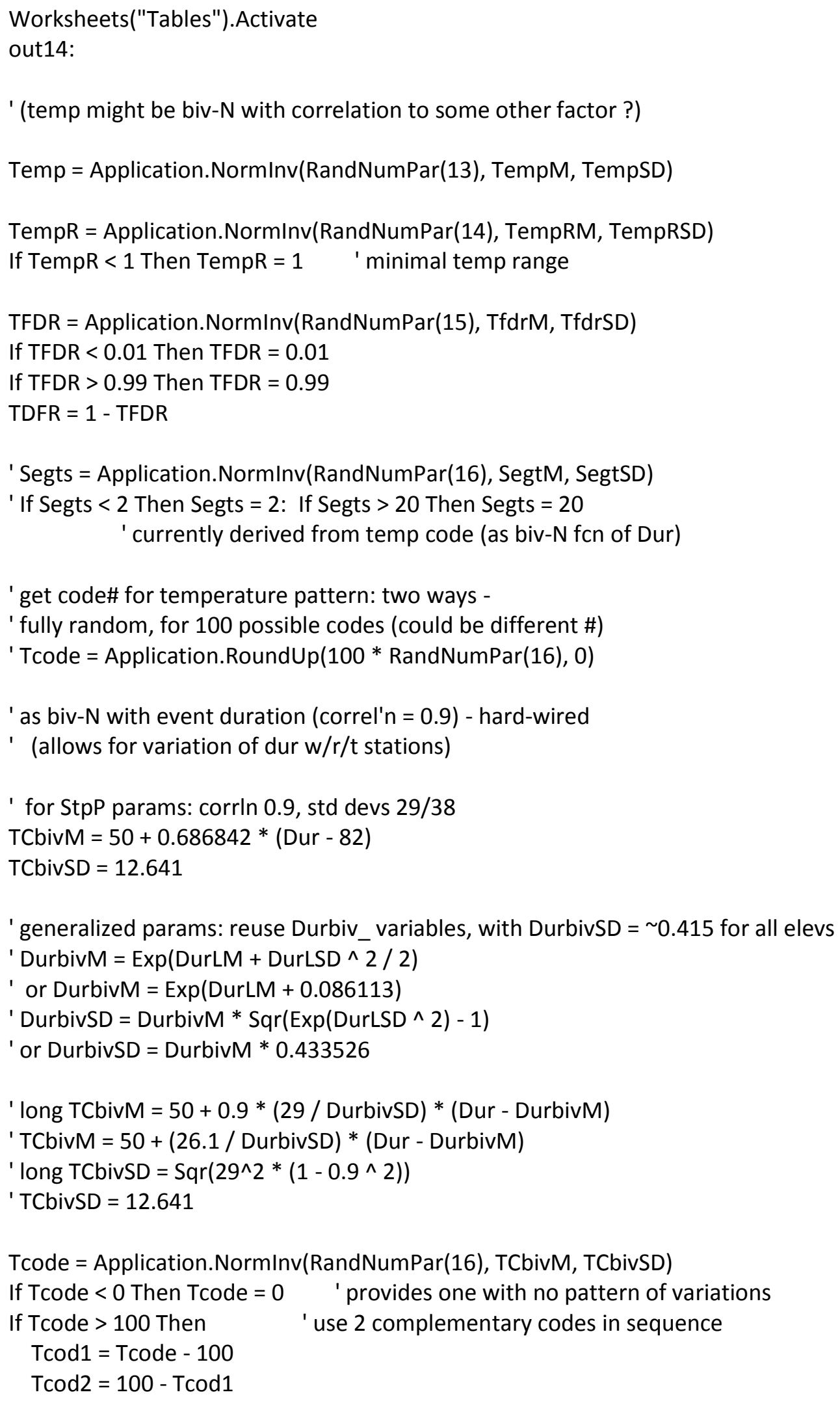


If Tcode $>200$ Then Tcod $1=100:$ Tcod $2=100$

End If

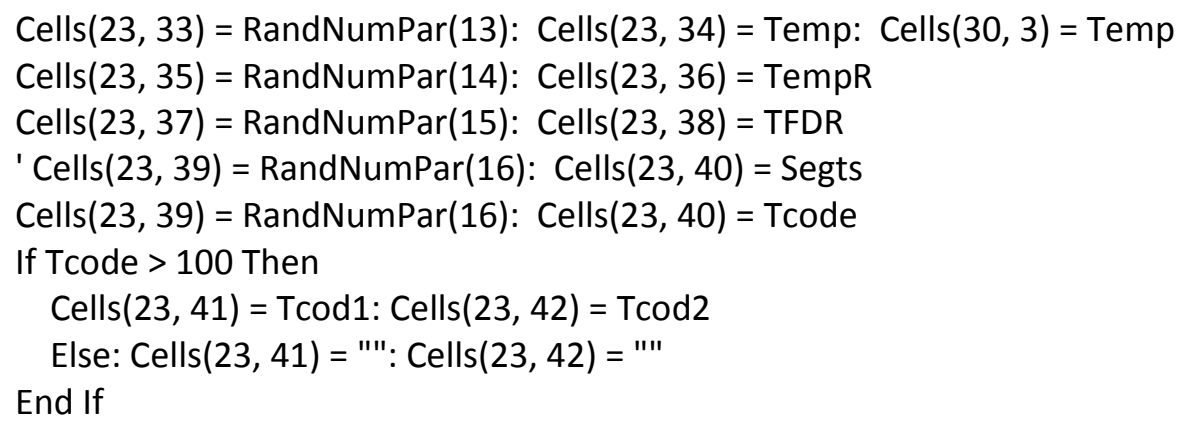

' Fill the random numbers array for the event

ReDim RandNum(3, DurE + 3) ' change dim from (5, _ ); use only 3

If DurE > 252 Then ReDim RandNum(3, 256)

' DurE $=$ Dur+24 $<=252$ if DurMax $=228$

Worksheets("Random \#s").Activate

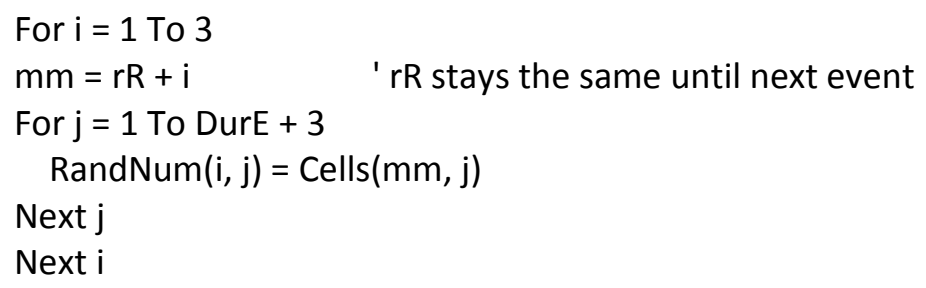

' Copy template and info from Tables sheet to Working sheet for run

Worksheets("Tables").Activate

' Option A: go directly to other open workbook for calcs

' Option B - ACTIVE: go to Working page in this book 


\section{Worksheets("Working").Activate}

' Now - the actual run starts

' reset counters, etc.

$\mathrm{HrP}=0$ : SIMold $=0$ : PrecCum $=0: \operatorname{RandNum}(3,1)=0 \quad$ 'others ?

' set up procedures to calc temperature

' calc secondary params

TRhalf $=$ TempR $/ 2$

' TempRI = Temp - TRhalf

' TempRh $=$ Temp + TRhalf unnec ?

' set up for frontal component of T

Worksheets("Temp codes").Activate ' to fill TSeg array

' can set Tcode to preferred line

' Tcode $=$ nnn

' simple way (Tcode to 100 , or start of double)

rTc $=20+$ Tcode

If Tcode $>100$ Then $r T c=20+\operatorname{Tcod} 1$

TSeg(41) = Cells $(r T c, 51):$ Segts $=$ TSeg(41)

If Tcode $>100$ Then Seg1 $=$ Segts

For $\mathrm{i}=1$ To Segts -1

TSeg $(i)=$ Cells $(r T c, 30+i)$

Next $\mathrm{i}$

$\operatorname{TSeg}(43)=$ Cells $(r T c, 53)$

$\mathrm{TSeg}(44)=$ Cells $(\mathrm{rTc}, 54)$

$\mathrm{TSeg}($ Segts $)=$ Cells $(\mathrm{rTc}, 55)$

' starting pt

' end pt

' post-Dur seg (or TSeg(45) ?)

If Tcode $<=100$ Then GoTo out15:

' for adding a second set of segments

$r T c=20+\operatorname{Tcod} 2$

$\operatorname{TSeg}(41)=$ Cells $(r T c, 51): \operatorname{Seg} 2=\operatorname{TSeg}(41)$

Segts $=$ Seg1 + Seg 2

' start pt stays the same; but account for old end pt -> second start pt

TSeg $($ Seg1 $)=$ Cells $(r T c, 53)-$ TSeg $(44) \quad$ ' old post seg $->$ transition seg

For $\mathrm{i}=$ Seg $1+1$ To Segts -1

TSeg $(i)=$ Cells $(r T c, 30+i)$ 
Next i

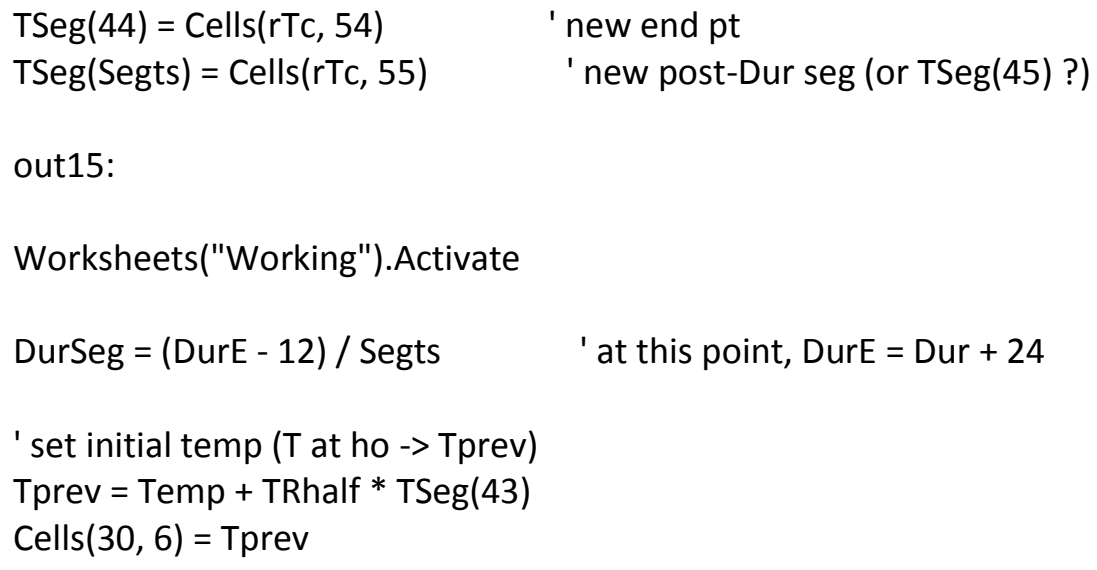

' First block: calculate and print all the hrs of day, temps, wind speeds, precip

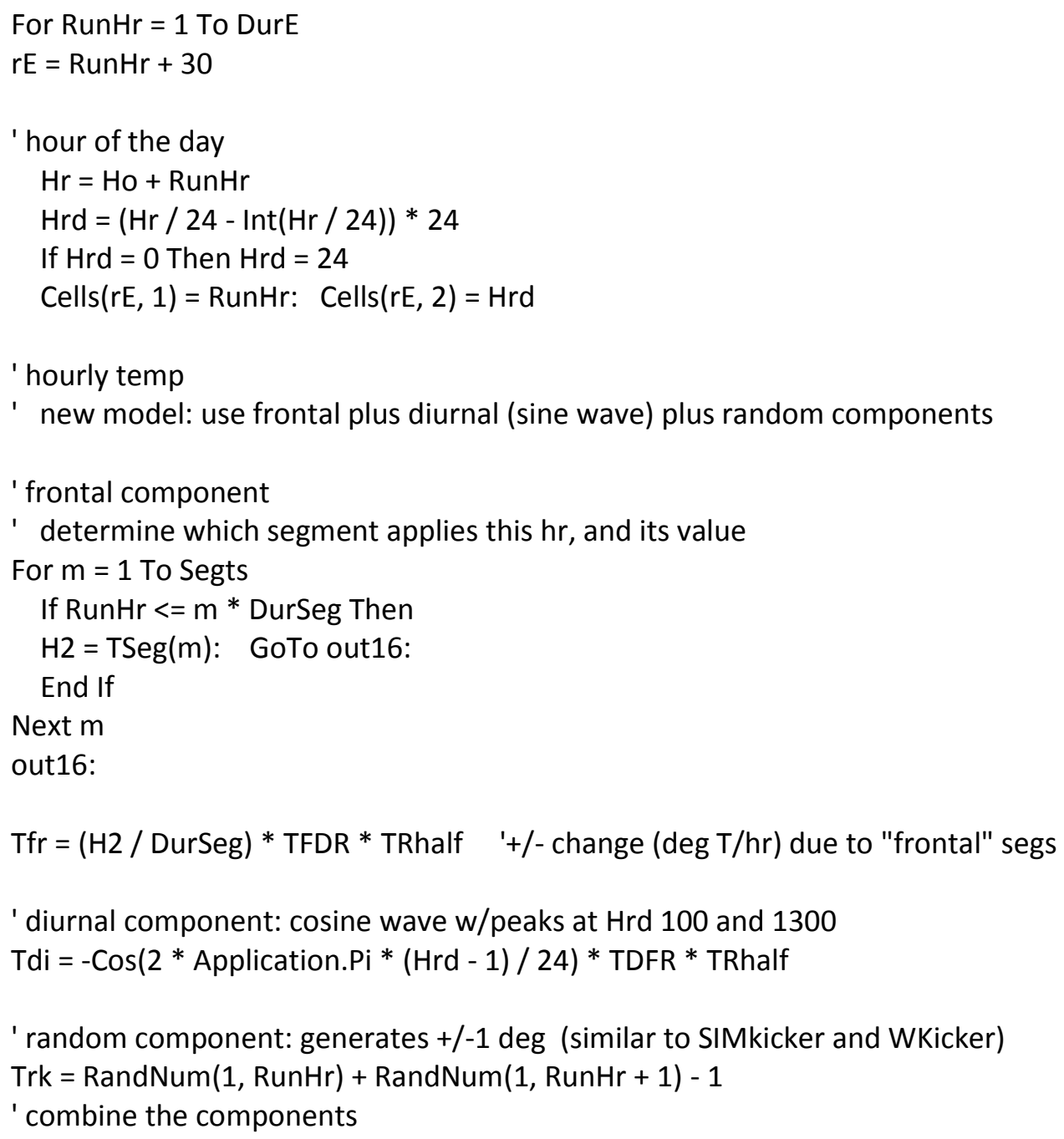




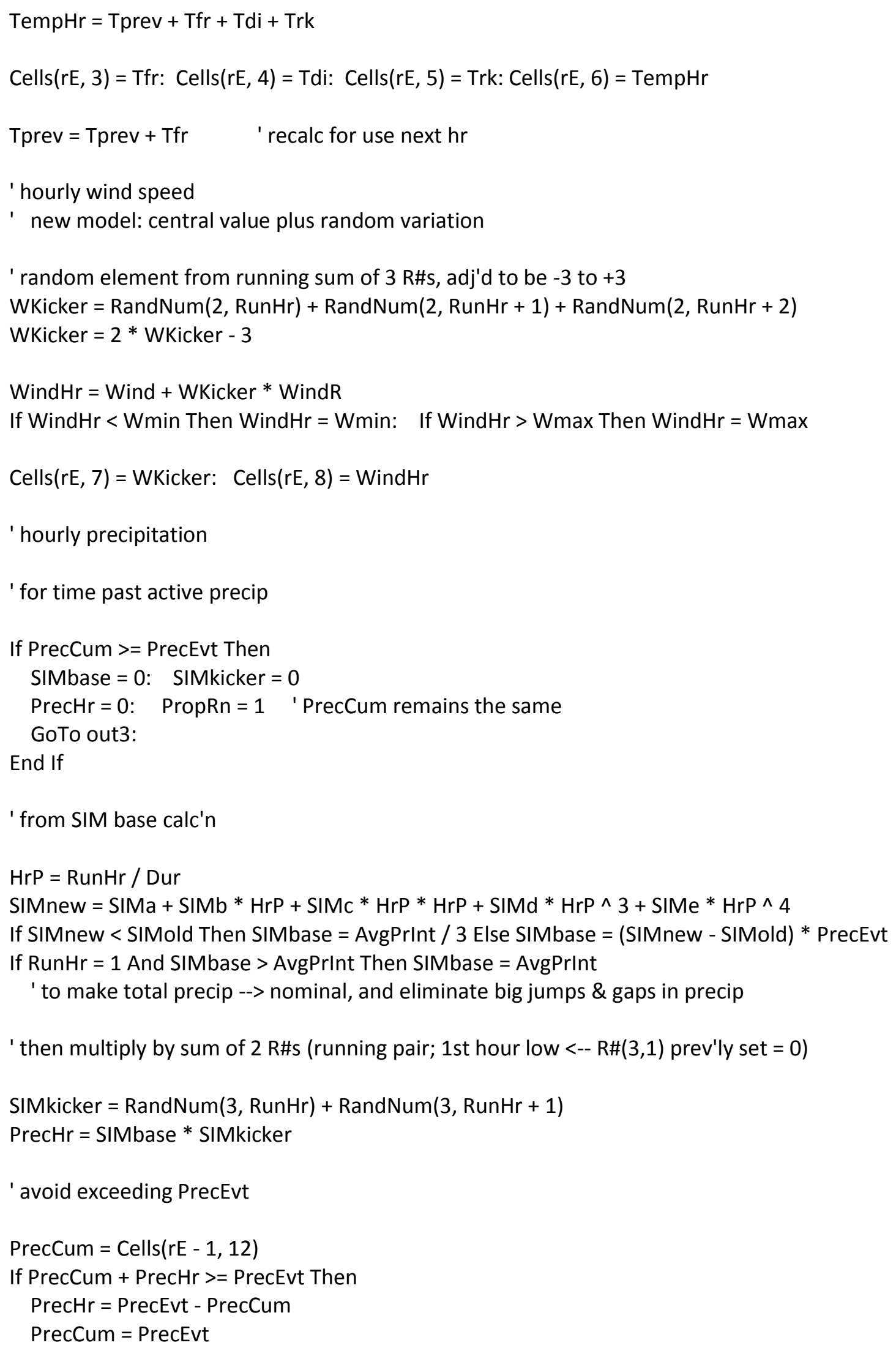




$$
\begin{aligned}
& \text { Cells }(23,12)=\text { RunHr } \\
& \text { DurE }=\text { RunHr }+6 \quad \text { ' recalcs } w / r / t \text { last precip -- } 6 \mathrm{hr} \text { as in LCS gaps }
\end{aligned}
$$

out3:

Cells $(r E, 9)=$ SIMbase: Cells $(r E, 10)=$ SIMkicker

Cells $(r E, 11)=$ PrecHr: Cells $(r E, 12)=$ PrecCum

Cells $(r E, 13)=$ PropRn * PrecHr

Cells $(r E, 14)=(1-$ PropRn $) *$ PrecHr

If RunHr >= DurE And PrecCum < PrecEvt Then Cells $(23,12)=\mathrm{RunHr}$

' in case PrecCum doesn't get to PrecEvt (need a flag ?)

Next RunHr

' Stop

' Second block: for each hour -- accum or melt snow

For RunHr = 1 To DurE ' DurE now = last precip +6

$\mathrm{rE}=\mathrm{RunHr}+30$

' Snow accum/melt: several cases -- can be calculated together

' $\mathrm{T}<-1.5 \mathrm{C}$ : snow accum

' (rad'n \& ground heat assumed --> warm the snowpack)

' T about 0: some snow accum, some rain, some SM

' $T>2.5$ C: all rain, plus SM

' calc SM, but no snow on the ground to melt?

' (problem with post-precip snowmelt? currently $6 \mathrm{~h}$ counts in DurE)

' If there's no snow and T>0 (proxy: solid precip $=0$ ), calc defaults and skip this section

If Cells $(r E, 14)=0$ And Cells $(r E-1,19)=0$ Then 


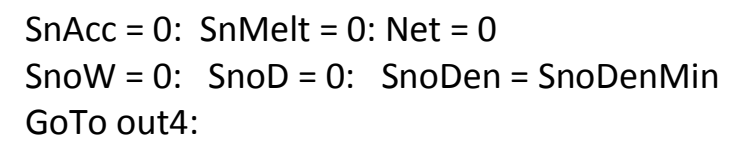


' recalcs bulk density of solid snow

out4:

Cells $(r E, 16)=$ SnAcc: Cells $(r E, 17)=$ SnMelt: Cells $(r E, 18)=$ Net

Cells $(r E, 19)=$ SnoW: Cells $(r E, 20)=$ SnoD: $\quad$ Cells $(r E, 21)=$ SnoDen

LiqIn $=$ Cells $(r E, 13)+$ Cells $(r E, 17)$

Cells $(r E, 24)=$ Liqln

Next RunHr

' Stop

' Third block: percolation of liquid water, outputs allocated to appropriate hours

' First calc event-specific parameters needed for K-wave equations:

' assuming they're constant thru the event

' N1 and N2 = exponents, based on SnoN (about 3)

' FluxK = parameter based on hyd conductivity, effective porosity, and $\mathrm{N}$

' (or: recalc porosity and/or $\mathrm{K}$ at each $\mathrm{hr}$, as fcns of density? below)

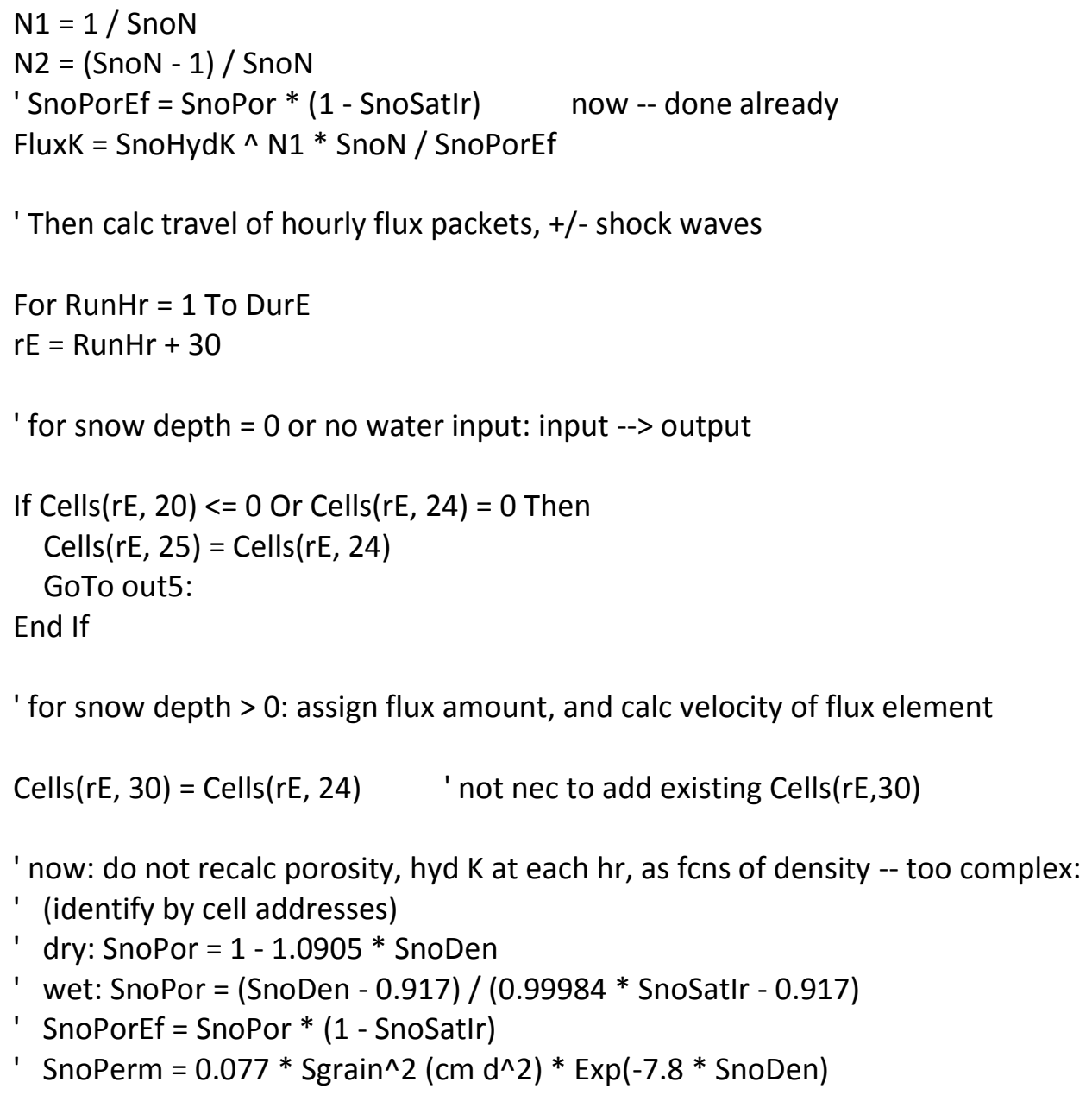


' SnoHydK = SnoPerm * 54713 (den * gravity / viscosity) $* 3600-->$ cm/h

' FluxK $=$ SnoHydK^N1 * SnoN/SnoPorEf

FluxV $=$ FluxK * Cells $(\mathrm{rE}, 30)^{\wedge} \mathrm{N} 2 \quad \mathrm{~cm} / \mathrm{h}$; redundant variable ?

' FluxV = FluxK * Cells $(\mathrm{rE}, 30)^{\wedge} \mathrm{N} 2 *(\mathrm{SnoN}-1)^{\wedge}(\mathrm{N} 1-1) \quad \mathrm{A} \& \mathrm{~K}$ version

Cells $(r E, 32)=$ FluxV

' copy initial snow depth (dummy Top)

Top $=$ Cells $(\mathrm{rE}, 20) \quad$ ' redundant variable ?

Cells $(r E, 40)=$ Top

' loop: first calc position of flux element w/i snowpack (above ground)

For PercHr = 1 To (DurE - RunHr + 24) ' sets max PercHr, esp for last RunHr $\mathrm{cE}=\mathrm{PercHr}+40$

If $\mathrm{cE}>256$ Then GoTo out5: $\quad$ ' don't go beyond column limit

If Cells $(r E, c E)<0$ Then GoTo out5: ' detour if already at ground

If Cells $(r E, 38)>0$ Then GoTo out17: ' detour for shock (flux positions set)

Zperc $=$ FluxV $*$ PercHr

' Zperc $=$ FluxV $*$ PercHr^N1 'A \& K version

Cells $(r E, c E)=$ Top - Zperc

' if/when flux hits ground $(z<=0)$--> calc time of arrival (Ta)

If Cells $(\mathrm{rE}, \mathrm{cE})<=0$ Then

If Cells $(r E-1, c E+1)>0$ Then GoTo out17:

' rare case: if overtaking in last $\mathrm{hr}$

$\mathrm{Ta}=\mathrm{Top} /$ FluxV

Cells $(r E, 33)=\mathrm{Ta}+\mathrm{RunHr} \quad$ ' end of start hr + trav time

GoTo out5: 'skip shock test

End If

out17:

' tests for shock generation

' (if ignoring shocks - would just GoTo out5: )

For $\mathrm{i}=1$ To $24 \quad$ ' max shock-test time $-24 \mathrm{~h}$ long enough ?

' detour tests within the loop: skip test --

If $\mathrm{i}>=$ RunHr Then GoTo out6: ' don't go back before storm began

If $\mathrm{cE}+\mathrm{i}>256$ Then GoTo out7: ' don't go beyond column limit

If IsEmpty(Cells(rE - i, cE + i)) Then GoTo out7: ' for blank cells

If Cells $(r E-i, 30)<=0$ Then GoTo out7: ' for flux already overtaken 


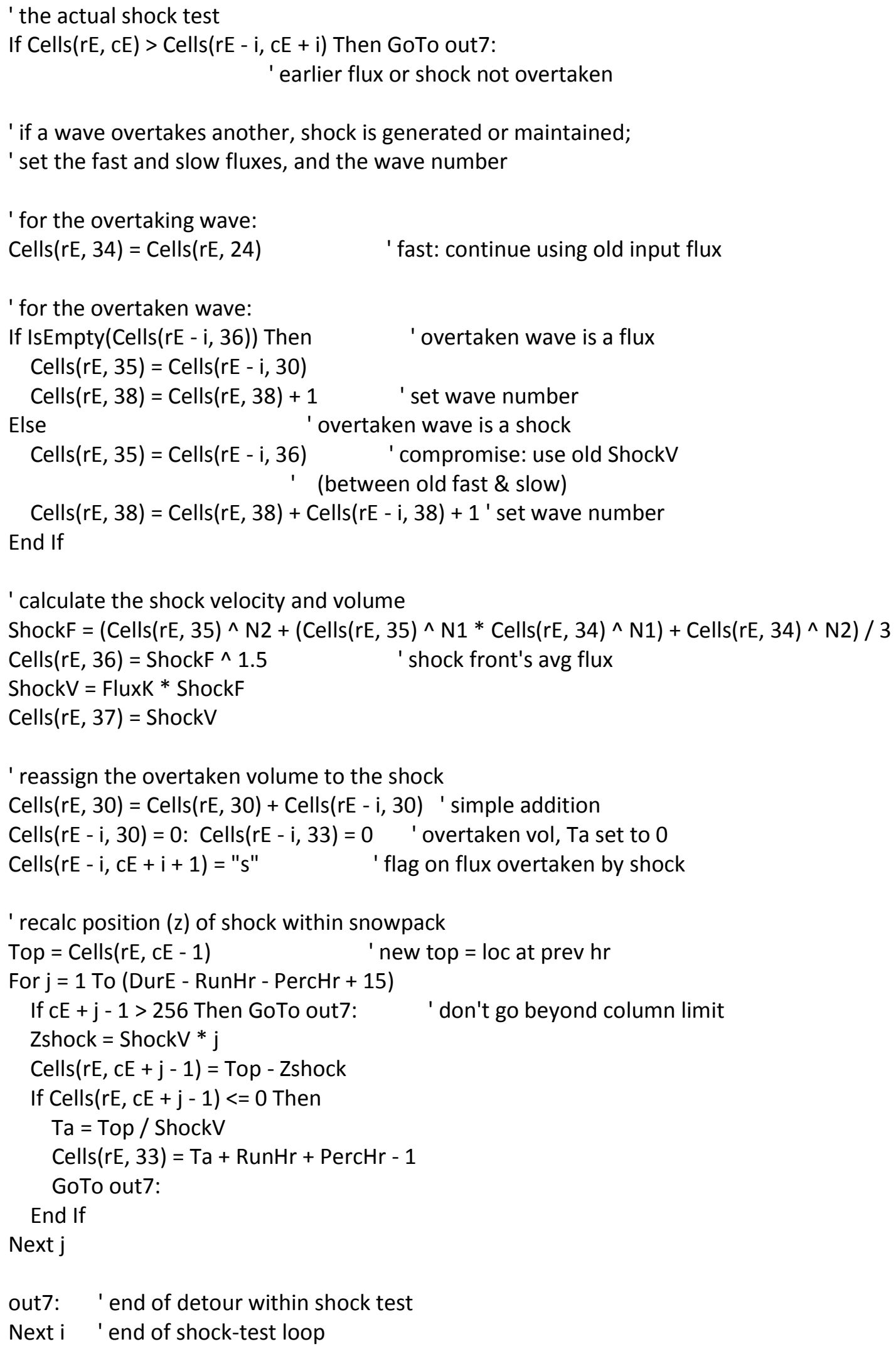


out6: ' end of detour to skip percolation calcs for no snow,

' shock test at $z=0$, or against col limit

Next PercHr

out5: ' end of detour around percolation calcs

Next RunHr

'Stop

' Next allocate outputs to the appropriate hours

For RunHr = 1 To DurE $+\mathrm{H} 1+1 \quad$ ' extra trav time for drainage of slow fluxes

$\mathrm{rE}=\mathrm{RunHr}+30$

' if no flux amount initially assigned to this $\mathrm{hr}$ (no liq, gone to shock, or stranded in pack)

' --> skip to next

If Cells $(r E, 30)=0$ Or Cells $(r E, 33)<=0$ Then GoTo out8: ' Ta would also be 0

' otherwise: use Ta to allocate output to ground surface

$\mathrm{Ta}=$ Cells $(\mathrm{rE}, 33)-\mathrm{RunHr} \quad$ ' time in Ta column includes RunHr

$\mathrm{H} 1=\operatorname{lnt}(\mathrm{Ta})$

$\mathrm{H} 2=\mathrm{Ta}-\mathrm{H} 1$

Cells $(r E+H 1+1,27)=$ Cells $(r E+H 1+1,27)+$ Cells $(r E, 30) * H 2$

Cells $(r E+H 1,27)=$ Cells $(r E+H 1,27)+$ Cells $(r E, 30) *(1-H 2)$

' set max flux rate on arrival - running maxima (ahead and behind)

' 2 possibilities -

' regular flux:

If IsEmpty(Cells(rE, 36)) Then maxF = Cells(rE, 30) Else maxF = Cells(rE, 36)

' or shock:

For $\mathrm{k}=0$ To Cells $(\mathrm{rE}, 38)+1 \quad$ ' use \# waves overtaken +1

If maxF $>$ Cells $(r E+H 1+k, 28)$ Then Cells $(r E+H 1+k, 28)=\operatorname{maxF}$

Next k

out8:

Next RunHr

' Stop

' Last -- reallocate amounts delivered to the ground, based on maxF or snow WHC

For RunHr = 1 To DurE $+\mathrm{H} 1+1$ 


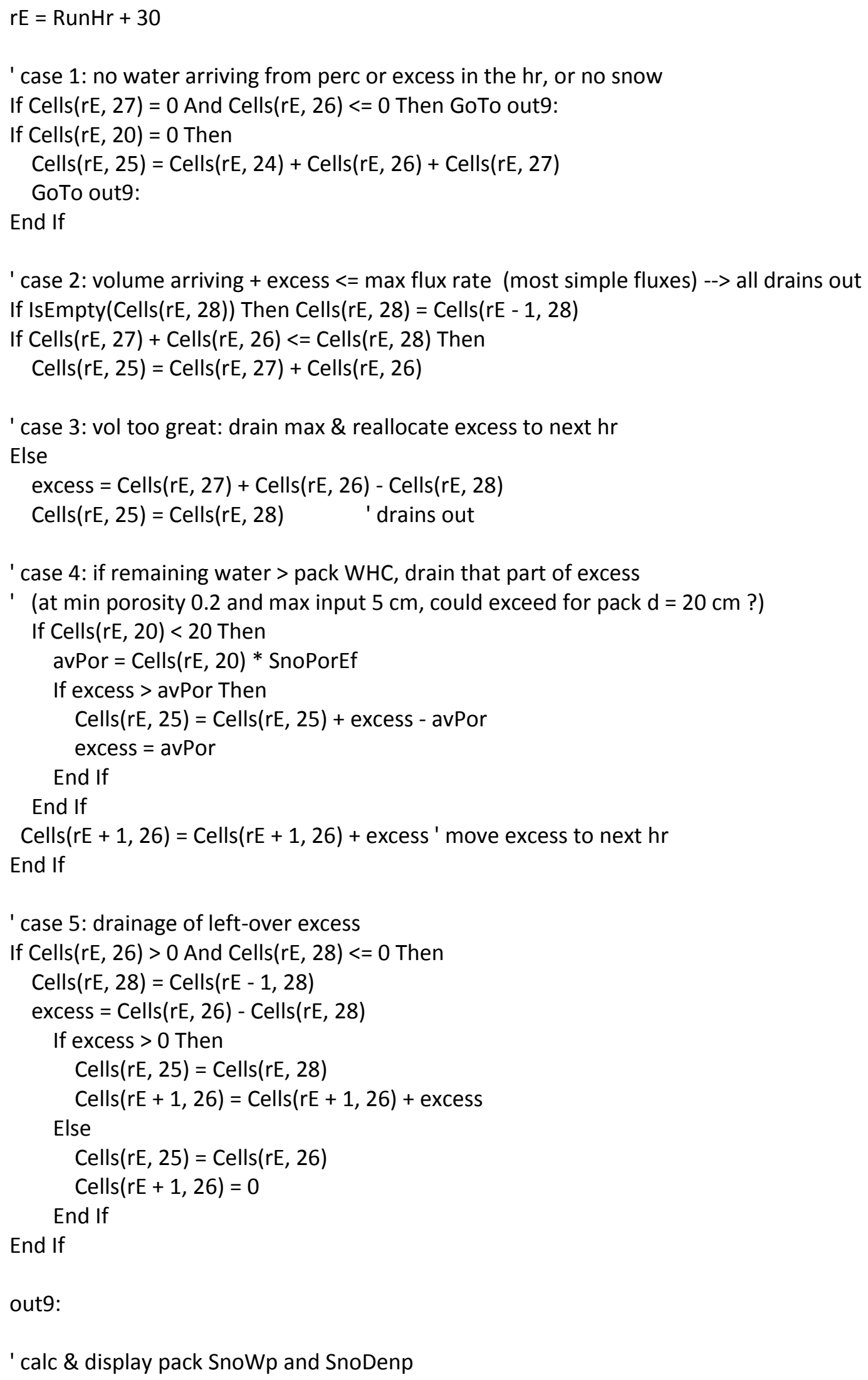




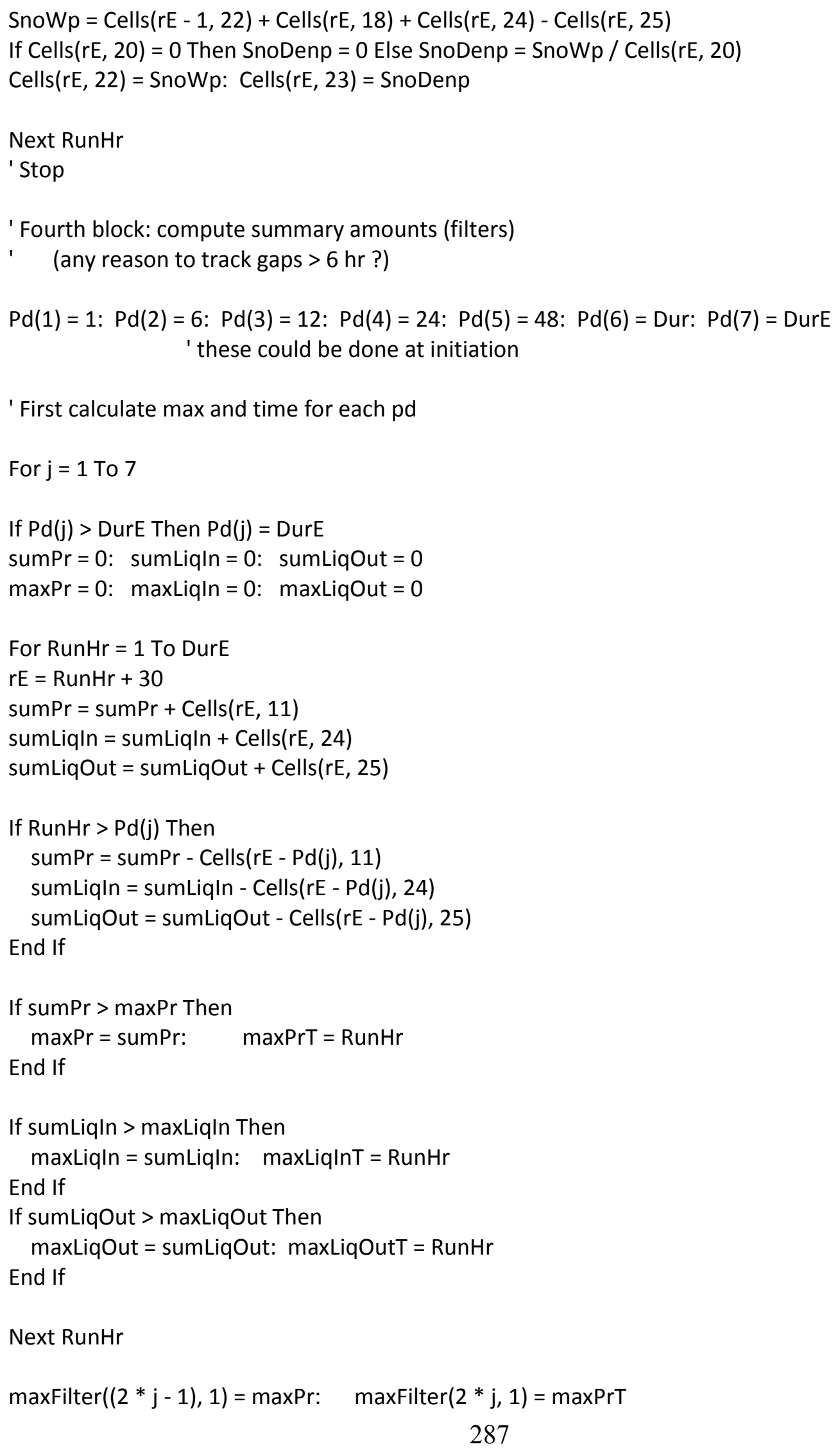


$\operatorname{maxFilter}((2 * \mathrm{j}-1), 2)=\operatorname{maxLiqIn:} \operatorname{maxFilter}(2 * \mathrm{j}, 2)=\operatorname{maxLiqInT}$

$\operatorname{maxFilter}((2 * j-1), 3)=\operatorname{maxLiqOut}: \operatorname{maxFilter}(2 * j, 3)=\operatorname{maxLiqOutT}$

Next j

' Now print max's and times in appropriate cells

For $m=51$ To 64

$\mathrm{n}=\mathrm{m}-50$

$\operatorname{Cells}(23, \mathrm{~m})=\operatorname{maxFilter}(\mathrm{n}, 1)$

Cells $(23, m+15)=\operatorname{maxFilter}(n, 2)$

Cells $(23, m+30)=\operatorname{maxFilter}(n, 3)$

Next $\mathrm{m}$

' If Evnt\& = _ Then Stop ' to check

' Fifth block: copy summaries to Summary page;

' copy "Working" page to storage book;

' if done with last event of the nnOth or last (NYr\&) year, save storage book

' Copy summary info (now only here), reset some counters

Range("A23:CP23").Copy

Worksheets("Summary").Activate

ActiveSheet.Paste Destination:=Worksheets("Summary").Range(Cells(rS, 1), Cells(rS, 94))

$r S=r S+1$

' Stop

' copy the "Working" sheet to storage workbook, and clear template

Worksheets("Working").Copy After:=Workbooks(2).Sheets(1)

Worksheets("Working").Range("A1:IV400").ClearContents

Next WYEvt

' at each 50th year, save $\&$ close the storage book

If $Y r \&=N Y r \&$ Or Yr\& $=50$ Or Yr\& $=100$ Or Yr\& $=150$ Or Yr\& $=200$ Or Yr\& $=250$

Or Yr\& $=300$ Or Yr\& $=350$ Or Yr\& $=400$ Or Yr\& $=450$ Or Yr\& $=500$ Or Yr\& $=55{ }_{-}$

Or Yr\& $=600$ Or Yr\& $=650$ Or Yr $\&=700$ Or Yr $\&=750$ Or Yr $\&=800$ Or Yr $\&=850$

Or Yr\& $=900$ Or Yr\& $=950$ Or Yr\& $=1000$

Then

Yname = SiteName\$ \& ", Yr " \& Yr\&

Sheets("Summary").Copy After:=Workbooks(2).Sheets(1)

Workbooks(2).Close SaveChanges:=True, FileName:=Yname\$

End If 


\section{Next Yr\&}

' At end of run: save the core workbook (same folder as the storage workbooks)

Ename\$ = SiteName\$ \& ", final; Yr " \& Yr\& - 1

Workbooks(1).SaveAs FileName:=Ename\$

' Workbooks(1).Close SaveChanges:=True, FileName:=Ename\$

End Sub 


\section{APPENDIX D}

Weather and Climate Observation Sites

Table D.1 Weather Stations

Table D.2 Snow Stations

(App D Observation sites.doc)

in supplemental files 


\section{APPENDIX E}

Table E.1 Summary of Model Precipitation Parameters - Excel Workbook (App E Precip parameter summary.xls)

in supplemental files 


\section{APPENDIX F \\ Exponential Distribution: Math \& Applications}

My model algorithms operate on frequency-distribution parameters that are derived from various data series. Series of hydrologic data are of three broad types (Haan, 1977): complete, with all of the available data; partial duration, a subset of the complete series, usually comprising those values greater or less than some threshold; and extreme value, a subset of largest or smallest values within some period. In most cases, frequency analysis of precipitation, streamflow, etc. is based on either the extreme values of the annual-maximum (AM) series (or annual-minimum for low flows); or the partial-duration (PD) series, commonly with the lowest yearly maximum/highest yearly minimum of a series as the threshold. They have different statistical properties, so these two kinds of data are treated using different mathematical models. In general, some form of the exponential distribution is considered appropriate for PD series (e.g., de Ploey et al., 1991). Various other distributions are typically applied to annual-maximum series, such as the double-exponential extreme value type I (EV-I, also called the Fisher-Tippett or Gumbel distribution; Gumbel, 1945, 1958) or the $\Gamma$-based log Pearson type III.

In this project, the Monte Carlo model generates realizations of three chief hydrologic quantities in each event: gross precipitation, of all phases (rain, snow, etc.); rain plus snowmelt, the water in flux; and liquid delivered to the ground surface, the water available for infiltration and runoff (WAR). The simulation generates multiple events in most model "years", so the data sets used to characterize the frequency distributions and analyze the results must consist of partial-duration series. Consequently, I have chosen to use the exponential distribution in this work, even when (rarely) considering annual maximum series. The mathematical background of the exponential distribution is outlined in this appendix, along with a discussion of the magnitudefrequency characteristics used as one of the metrics for evaluating the model results.

\section{F.1 Two-Parameter Exponential Distribution}

A complete series of precipitation data includes a vast number of small values and a decreasing number of larger ones. The histogram or density function of these data is described as exponential, declining rapidly with increasing magnitude. For a subset of the complete series (either annual-maximum or partial-duration), only the values greater than some threshold $\left(\mathrm{AM}_{\min }\right.$ or $\mathrm{PD}_{\min }$ ) are considered, but the exponential shape is retained for those values.

For some random variable $\mathrm{x}$ (say, precipitation amount), the exponential distribution is described by a probability density function (pdf) 


$$
p(x)=\quad \text { for } \mathrm{x} \geq 0, \lambda>0
$$

with scale parameter $1 / \lambda$. For this distribution, the mean $(\mu)$ and standard deviation $(\sigma)$ are both theoretically equal to $1 / \lambda$ (so $\lambda$ can be estimated from the data statistics), and the skew approaches 2.0 for a large sample.

For a PD or AM subset, it is common to apply a two-parameter exponential distribution, with a location parameter $(\gamma)$ representing the offset of the minimal values being considered. The pdf for this two-parameter distribution is

$$
p(x)=\quad \text { for } \mathrm{x} \geq \gamma, \lambda>0
$$

(Note that the one-parameter exponential distribution is the special case in which $\gamma=0$.) In this version, the scale parameter $1 / \lambda=\mu-\gamma$ (i.e., the mean $\neq 1 / \lambda=\sigma$ ).

The two-parameter cumulative distribution function (cdf) is

$$
P\left(\leq=\int_{0}^{x} \quad \int_{0}^{x} \quad-\right.
$$

The cdf, the cumulative probability that the value will be $\leq \mathrm{x}$, is the area below the pdf curve up to $\mathrm{x}$. But we are usually interested in the exceedance probability, represented by the upper tail of the curve:

$$
P(\geq \cong-\leq=--\quad=
$$

For use in calculations, the cdf can be transformed into the equation of a straight line, having the form $y(x)=a+b x$ :

$$
\begin{gathered}
P(\geq \quad \Rightarrow \quad \geq=0=- \\
\quad \geq \quad=-+
\end{gathered}
$$

In the model, we want to calculate precipitation amount (x) from a randomly generated exceedance probability and the parameters, so

$$
\begin{aligned}
& \Rightarrow-=-\quad+2 \\
& \Rightarrow=-{ }_{\lambda}^{1} \geq
\end{aligned}
$$

Thus, given an exceedance probability, the corresponding precipitation can be estimated from the location parameter $\gamma$ (intercept) and the scale parameter $-1 / \lambda$ (slope). If the calculation is to be made from the inverse of the exceedance probability, $R=1 / P$ (usually the return period or recurrence interval), the derivation just reverses the sign of the scale parameter: 


$$
x=+\begin{array}{lll}
1 & 1 & -1 \\
\lambda & \geq
\end{array}
$$

Note that the occurrence rate $R$ of a series can be calculated based on all events $\left(R_{e v t}\right)$, or more often as the number of events divided by the number of years, producing the return period or recurrence interval $\left(R_{y r}\right)$. Both kinds of parameters are calculated and used in this project (appendices E, I, J, K, L): $R_{\text {evt }}$ for generating realizations in Monte Carlo simulations, $\mathrm{R}_{\mathrm{yr}}$ for analyzing and communicating the data and realizations. Recurrence interval, usually expressed in years, has slightly different meanings as applied to AM or PD series (particularly for periods $<1 \mathrm{yr}$ ), but their values typically converge, and the term is used in a general sense here.

In practice, probabilities and parameters for a given series typically are approximated in some manner from the data or realizations. Series statistics can be used to estimate parameters analytically: as stated above, the parameters of the exponential distribution are related to the mean $(1 / \lambda=\mu-\gamma$, so $\mu=1 / \lambda+\gamma)$ and standard deviation $(\sigma=1 / \lambda)$ of the data. However, the meaning of the location parameter $(\gamma)$ could be different for AM and PD series. It remains the minimum value for the $\mathrm{AM}$ series (i.e., $\gamma_{\mathrm{AM}} \approx \mathrm{AM}_{\min }$ ), corresponding to the maximal probability and minimal recurrence interval (about 1.00 and $1 \mathrm{yr}$, respectively). But for the PD series, $\mathrm{PD}_{\min }$ represents a return period $<1 \mathrm{yr}$. In this case, the appropriate location (intercept) value is that at which $\mathrm{P}=$ 1.00 and $\mathrm{R}_{\mathrm{yr}}=1 \mathrm{yr}$ if the plotting formula (see below) is used with $\mathrm{n}$ as the number of years (rather than events). However, as the simulation model is generating amounts from probabilities based on random numbers (range $0<\mathrm{P}<1$ ), the governing intercept has to be based on all PD events, using $R_{e v t}$, and is estimated by $\gamma \approx \mathrm{PD}_{\min }$ (but $R_{\text {evt }}$ is not the recurrence interval in the true meaning of the term). In summary, both forms of the intercept are required in this work.

Alternately, the exponential parameters of a series can be estimated empirically by regression of values against the logarithms of exceedance probability or recurrence interval. Of course, the quality of such estimates depends partly on the degree to which any particular series of data fit the exponential model.

The first step in the regression process is to assign exceedance probability or recurrence values to the members of the series. There is an extensive literature on estimating probabilistic plotting positions (e.g., Haan, 1977; Dunne and Leopold, 1978; Patra, 2001). The simplest form is the Weibull estimation of the probability of event $i$, in which

$$
P_{i}={ }_{n+} \quad \text { for } \mathrm{i}=\text { event rank, } \mathrm{n}=\text { number in series }
$$


However, many authors have noted that Gringorten's (1963) generalized plotting formula for the $\mathrm{i}^{\text {th }}$-ranked item,

$$
P_{i}={ }_{n+-} \quad \text { for } \mathrm{a} \approx 0.44 \text { for } \mathrm{n}>20
$$

is more appropriate for both exponential and EV distributions, in contrast to the traditional Weibull formula, which is a special case (e.g., Cunnane, 1978).

Ranks are arranged from largest $(i=1)$ to smallest. Among my LCS data, ties were resolved based on storm duration (i.e., the same magnitude in a shorter period is considered a higher-ranked event); in data series for shorter periods (1-, 6-, 12-h, etc.), ties were not adjusted. Exact ties are rare in the model realizations, except for rain + snowmelt $=0$ and $\mathrm{WAR}=0$, which are common in most series. To prevent clustering points in the lowest ranks (possibly distorting the slopes of the resulting frequency lines), I have distributed the rankings across the range of tied values.

Next, series values are regressed against the logarithms of either $P$ or $R$, yielding an intercept ( $\mathrm{p}$, or distinguished between $\mathrm{p}_{\mathrm{yr}}$ and $\left.\mathrm{p}_{\mathrm{evt}}\right)$ and slope $\left(\mathrm{A}_{\mathrm{n}}\right.$ or $\mathrm{A}$; terms adapted from de Ploey et al., 1991). Similar results are obtained whether using either natural (base e) or common (base 10) logs: if calculated separately, regression on a series produces two different slope parameters, $A_{n}$ and $A$, related by $A_{n}=A \log$ e and $A=A_{n} \ln 10$. The same intercept (p) is generated either way, since it is the value at which $R_{y r}=1$, so $\log 1=\ln 1=0$. The resulting linear equations are:

$$
\begin{aligned}
& x=+ \\
& x=+
\end{aligned}
$$

(Again, regressions in this project use both $R_{e v t}$ and $R_{y r}$, for different purposes.)

There are separate advantages to using natural versus common logarithms, so both are utilized here. Natural logarithmic and exponential functions are more convenient in differential and integral calculus, as implemented below. But base-10 logs have explanatory benefits (as discussed by de Ploey et al., 1991). Intercept $\mathrm{p}$ is the regression estimate at $R_{y r}=1 \mathrm{yr}$; then, with A as the slope, $\mathrm{p}+\mathrm{A}$ gives the value at $R_{y r}=10 \mathrm{yr} ; \mathrm{p}+2 \mathrm{~A}$ the value at $R_{y r}=100 \mathrm{yr}$; and so on. These two parameters, combined into a magnitude-frequency index, $\mathrm{MFI}=(\mathrm{p} ; \mathrm{A})$, can be used to compare data series. 


\begin{tabular}{|c|c|c|c|c|c|}
\hline \multirow[b]{2}{*}{ Parameter } & \multirow[b]{2}{*}{$\begin{array}{c}\text { Stampede } \\
\text { Pass storm } \\
\text { data }\end{array}$} & \multicolumn{2}{|c|}{$\begin{array}{c}\text { Estimates from } \\
\text { theoretical } \\
\text { parameters }\end{array}$} & \multicolumn{2}{|c|}{$\begin{array}{c}\text { Estimates from } \\
\text { regression } \\
\text { parameters }\end{array}$} \\
\hline & & $\begin{array}{l}\mathbf{P D}_{\text {min }} \\
\text { std dev }\end{array}$ & $\begin{array}{c}1-y r \\
\text { intercept, } \\
\text { std dev } \\
\end{array}$ & $\begin{array}{c}\text { Site- } \\
\text { specific } \\
\text { for StpP }\end{array}$ & $\begin{array}{c}\text { Elevation } \\
\text { from all } \\
\text { stations } \\
\end{array}$ \\
\hline \multicolumn{6}{|c|}{ Controlling parameters } \\
\hline $\begin{array}{l}\text { location/intercept } \\
\text { scale/slope }\end{array}$ & $\begin{array}{l}\mathrm{n} \mathrm{a} \\
\mathrm{n} \mathrm{a}\end{array}$ & $\begin{array}{l}8.560 \\
7.113\end{array}$ & $\begin{array}{r}15.415 \\
7.113\end{array}$ & $\begin{array}{r}16.799 \\
7.047\end{array}$ & $\begin{array}{r}16.226 \\
6.514\end{array}$ \\
\hline \multicolumn{6}{|l|}{ Statistics } \\
\hline 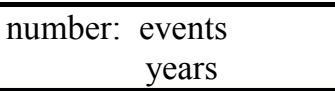 & $\begin{array}{r}225 \\
58 \\
\end{array}$ & 225 & 225 & 225 & 225 \\
\hline $\begin{array}{l}\text { maximum } \\
\text { minimum }\left(\mathrm{PD}_{\min }\right)\end{array}$ & $\begin{array}{r}57.353 \\
8.560 \\
\end{array}$ & $\begin{array}{l}41.581 \\
-1.054 \\
\end{array}$ & $\begin{array}{r}48.436 \\
5.801 \\
\end{array}$ & $\begin{array}{l}49.513 \\
7.2745 \\
\end{array}$ & $\begin{array}{l}46.466 \\
7.4215 \\
\end{array}$ \\
\hline $\begin{array}{l}\text { mean }(\mu) \\
\text { std dev }(\sigma) \\
\text { skew }\end{array}$ & $\begin{array}{r}14.283 \\
7.113 \\
2.85\end{array}$ & $\begin{array}{r}6.020 \\
7.020 \\
1.84\end{array}$ & $\begin{array}{r}12.875 \\
7.020 \\
1.84\end{array}$ & $\begin{array}{r}14.283 \\
6.955 \\
1.84\end{array}$ & $\begin{array}{r}13.900 \\
6.429 \\
1.84\end{array}$ \\
\hline \multicolumn{6}{|c|}{ Resulting parameters - estimates from: } \\
\hline $\begin{array}{l}\text { location/intercept }(\gamma) \\
\mathrm{PD}_{\min } \\
\mu-\sigma \\
\mathrm{R} \text { for } 1 \mathrm{yr} \\
\text { regression } \mathrm{p}_{\mathrm{evt}} \\
\quad \mathrm{p}_{\mathrm{yr}}\end{array}$ & $\begin{array}{r}8.560 \\
7.170 \\
15.415 \\
7.257 \\
16.799 \\
\end{array}$ & $\begin{array}{r}-1.000 \\
=p_{\mathrm{yr}} \\
\mathbf{8 . 5 6 0}\end{array}$ & $\begin{array}{r}5.855 \\
=\mathrm{p}_{\mathrm{yr}} \\
\\
\mathbf{1 5 . 4 1 5}\end{array}$ & $\begin{array}{r}7.328 \\
=p_{\mathrm{yr}} \\
(7.257) \\
\mathbf{1 6 . 7 9 9}\end{array}$ & $\begin{array}{r}7.471 \\
=\mathrm{p}_{\mathrm{y}_{1}} \\
(7.998) \\
\mathbf{1 6 . 2 2 6}\end{array}$ \\
\hline $\begin{array}{l}\text { scale/slope }(1 / \lambda) \\
\sigma \\
\mu-\mathrm{PD}_{\min } \\
\text { regression } \mathrm{A}_{\mathrm{n}} \\
\mathrm{A}\end{array}$ & $\begin{array}{r}7.113 \\
5.723 \\
7.047 \\
16.226\end{array}$ & $\begin{array}{r}7.020 \\
7.074 \\
7.113 \\
16.378\end{array}$ & $\begin{array}{r}7.020 \\
7.074 \\
\mathbf{7 . 1 1 3} \\
16.378\end{array}$ & $\begin{array}{r}6.955 \\
7.009 \\
7.047 \\
16.226\end{array}$ & $\begin{array}{r}6.429 \\
6.479 \\
\mathbf{6 . 5 1 4} \\
14.999\end{array}$ \\
\hline \multicolumn{6}{|c|}{ Frequency-magnitude of data $\&$ realizations } \\
\hline $\begin{array}{c}\text { recurrence interval } \\
\text { (yr) }\end{array}$ & $\begin{array}{l}\text { interpolated } \\
(\mathrm{cm})\end{array}$ & \multicolumn{4}{|c|}{ calculated $(\mathrm{cm})$} \\
\hline $\begin{array}{r}1 \\
2 \\
5 \\
10 \\
20 \\
50 \\
100\end{array}$ & $\begin{array}{l}15 \\
20 \\
28 \\
37 \\
42 \\
49 \\
55\end{array}$ & \begin{tabular}{r|}
8.56 \\
13.49 \\
20.01 \\
24.94 \\
29.87 \\
36.39 \\
41.32 \\
\end{tabular} & \begin{tabular}{r|}
15.415 \\
20.345 \\
26.86 \\
31.79 \\
36.72 \\
43.24 \\
48.17 \\
\end{tabular} & $\begin{array}{r}16.80 \\
21.68 \\
28.14 \\
33.025 \\
37.91 \\
44.37 \\
49.25 \\
\end{array}$ & $\begin{array}{r}16.23 \\
20.74 \\
26.71 \\
31.225 \\
35.74 \\
41.71 \\
46.22\end{array}$ \\
\hline \multicolumn{6}{|l|}{ Notes } \\
\hline $\begin{array}{l}\text { Values in parentheses d } \\
\text { Site-specific parameters } \\
\text { parameters based on all } \\
\text { MC-EXE (1065 EXE). }\end{array}$ & $\begin{array}{l}\text { ved from calcul } \\
\text { om Stampede P } \\
\text { eather stations a }\end{array}$ & $\begin{array}{l}\text { ons made els } \\
\text { are those us } \\
\text { generalized }\end{array}$ & $\begin{array}{l}\text { where in this } 1 \\
d \text { in model ver } \\
\text { y elevation are }\end{array}$ & $\begin{array}{l}\text { ject. } \\
\text { on MC-EXP } \\
\text { lose used in }\end{array}$ & $\begin{array}{l}\text { StpP EXP); } \\
\text { odel version }\end{array}$ \\
\hline
\end{tabular}


Table F.1 presents several sets of exponential model estimates based on different methods and parameters. The second column shows statistics for the source data, the PD series of long continuous storm (LCS) precipitation at Stampede Pass NWS station (StpP; values in $\mathrm{cm}$ ). The middle two columns show intercept and slope estimates from analytical parameters based on these data, and the last two using parameters derived from regression; in these four cases, the controlling factors are shown in the top rows. For the various sets of estimates, parallel series of 225 events have been generated, and the statistics and derived parameters are shown. The bold-face parameters are those used to calculate the estimates; others are derived from the realizations. All use probabilities calculated by Gringorten's plotting formula (the Weibull rule produces slightly less well-fit, generally lower values). The regression calculations utilized natural logarithms of recurrence interval. At the bottom of the table are precipitation amounts for some representative return periods, interpolated from the data and calculated from intercept and slope parameters.

Skew statistics provide indications of the relative fit of various series to exponential distributions. Based on graphs of the data, several of the larger StpP precipitation values seem to be outliers, so the inability of the estimates to quite match the apparent 100-yr data-based value is understandable. These large quantities at the low-frequency tail dictate the 2.85 skew of the StpP data, relatively high among the eight weather stations used in this project (average 2.3, range 1.43.1; appendix E), and well above the theoretical 2.0 skew for exponential distributions. At stations with data series having lower skew $(<2)$, the low-frequency values fall below their calculated exponential regression lines. For the series estimated using the exponential model shown in the table, the consistent 1.84 skew is controlled by the sample size of 225. (Skews approach 2.0 for the large realization series produced by Monte Carlo simulation: for a 1000-yr run comprising 4487 events, the skew is $\sim 1.98$.)

Of the series estimated from analytical parameters, that using $\mathrm{PD}_{\min }$ as the location factor is clearly the poorest fit to the data, especially at the low-frequency (long return period) end. It fails statistical tests of similarity to the data, as does a series based on intercept $=7.170$ and slope $=$ 5.723 (which is even worse); both of these yield high-frequency ( $\operatorname{short} R$ ) estimates that are $<0$ (impossible), reducing the series means far below those of the data. Thus, either $\mathrm{PD}_{\min }$ or $\mu-\sigma$ is too small as location factor, representing a minimum rather than the intercept at $\mathrm{R}=1$. An interpolated approximation of that value is used in the second estimated series (intercept $=15.415)$, which is much closer to the data distribution.

The estimates from regression are based on two sets of parameters. In the third column, the intercept and slope are taken directly from the Stampede Pass storm data ( $\mathrm{p}_{\mathrm{yr}}$ and $\mathrm{A}$ in the second 
column); these are the kinds of factors employed in Monte Carlo simulations incorporating sitespecific parameters (model form EXP, although that uses $p_{\text {evt }}$ to derive entire PD series).

Estimates in the last column are based on parameters generalized from all eight weather stations by elevation, for the effective elevation of StpP (1065 m); such factors are used in the elevationbased simulations (EXE mode, also with $p_{\text {evt }}$ instead of $p_{y r}$ ).

Although they too fall short of the apparent magnitudes of the data series at the low-frequency/long recurrence tail, the estimates from regression are clearly better than those using the first set of intrinsic parameters, and comparable to those using an interpolated estimate of the 1-yr $R$ as intercept. As mentioned above, underestimation at the upper tail is probably due to imperfect correspondence of these StpP data to the ideal exponential distribution. Nevertheless, the decent fit of the regression estimates to the data series, along with the ease and precision of the regression method (especially compared to interpolating intercept and slope factors from data), led me to adopt regression as the chief means of calculating exponential distribution parameters to analyze, describe, and model the data and realizations in this project. Note also that the regression estimates from elevation-generalized parameters (EXE) nicely parallel those calculated from the site-specific (EXP) parameters, indicating that the elevation-generalized calculations yield reasonable estimates, at least for the elevation around StpP.

\section{F.2 Magnitude and Frequency in the Exponential Distribution}

The concepts of magnitude (M) and frequency (F) of storm events are introduced elsewhere (chapters 1 and 2). Part of this project involves evaluating the relative hydrologic significance of total precipitation, liquid rain plus snowmelt, and liquid water delivered to the ground, including the relative contributions of $\mathrm{M}$ and $\mathrm{F}$ (and $\mathrm{M} \times \mathrm{F}$ ).

The exponential distribution is amenable to examination and comparison of $\mathrm{M}$ and $\mathrm{F}$ values, as demonstrated by de Ploey et al. (1991). Their dominant event is that at which the product of magnitude ( $\mathrm{x}$, as in the equations above) and frequency $(P(\mathrm{x} \geq 0)=1 / R)$ is a maximum:

$$
\operatorname{mag} \times \quad \Rightarrow \quad \geq \quad-\quad \times
$$

The maximum is found by setting the derivative to zero:

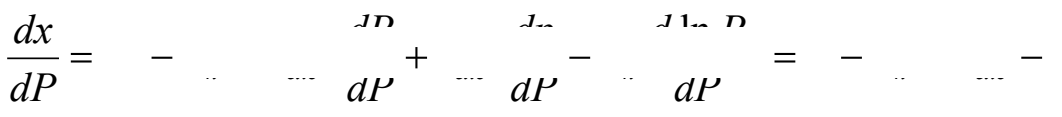

$$
\begin{aligned}
& \ln P_{\text {dom }}={ }_{A_{n}}^{-} \Rightarrow A_{n}{ }^{-}
\end{aligned}
$$

(The dominant recurrence is the inverse of this probability.) From the dominant probability, one can solve for the dominant amount of precipitation or WAR: 


$$
x_{\text {dom }}=-\quad=-A_{n}=-A_{n}=
$$

This shows that the magnitude of the dominant event $=A_{n}$, the empirical slope coefficient from regression on natural logs. At Stampede Pass, the dominant LCS PD event would have a magnitude of $\sim 7 \mathrm{~cm}$, well below the $\mathrm{PD}_{\min }$ - thus having an exceedance probability $>>1$ and a recurrence interval $<<1 \mathrm{yr}-$ i.e., events that occur at least several times annually. The dominant frequencies and magnitudes can be used to compare among data series in some contexts, but though conceptually understandable, such information seems to have little utility in comparing precipitation and WAR series in this project.

Another possible way to evaluate frequency-magnitude characteristics among series is to compare the integrals of precipitation and WAR functions. The simplest would be to integrate the frequency curve of a quantity against recurrence interval, but it seems that such an index would exaggerate the importance of very rare events. More relevant, probably, would be the product of $\mathrm{M} \times \mathrm{F}$, which indexes a value by its likelihood. Going back to Wolman and Miller (1960), at least, is the notion that while rare events may have big effects, it is the common events that can drive a system, exercising modest forces but over many more iterations. If the $\mathrm{M} \times \mathrm{F}$ curve has some explanatory power, then the integral of $\mathrm{M} \times \mathrm{F}$ might be a useful index of the significance of those curves. (Note that the treatment of the frequency characteristics of storm or ROS events here is limited to amounts of water, and does not extend to actual hydrologic or geomorphic effects such as sediment transport, slope movement, etc.; such downhill/downstream effects are beyond the scope of this project.)

Starting with the equations derived above, multiply $\mathrm{M} \times \mathrm{F}$ :

$$
\begin{aligned}
\operatorname{mag} \times \quad \times \quad & \times \\
= & +\times_{K}^{1}
\end{aligned}
$$

and then integrate for the area under the line:

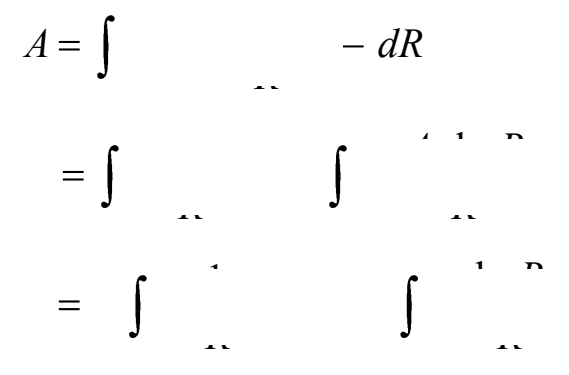




$$
\left.=\quad+\begin{array}{ll}
1 & 2
\end{array}\right]_{\text {Rlow }}^{\text {Rhigh }}
$$

The integrals are evaluated between some chosen upper and lower limits of occurrence rate $\left(R_{\text {high }}\right.$ and $R_{\text {low }}$ ). The recurrence intervals of the model results range from $\sim 0.22$ (1000 yr / 4487 events) to $1786 \mathrm{yr}$ (the $R P$ of the largest event in $1000 \mathrm{yr}$ using the Gringorten plotting formula). For my comparisons, I have set limits representing the broad middle and higher amounts: $1 \mathrm{yr}(100 \%$ annual exceedance) to $1000 \mathrm{yr}(0.1 \%$ exceedance $)$, leaving out the most frequent and most rare events of the tails, where the lines are the least reliable.

It is difficult to conceive of a clear physical meaning for these integrals, and they are probably best considered to be largely symbolic. Dimensionally, integration of the product of magnitude (L, expressed in $\mathrm{cm}$ ) and frequency $\left(\mathrm{T}^{-1}\right.$, per yr) against recurrence interval $(\mathrm{T}, \mathrm{yr})$ yields an amount in $\mathrm{L} \times \mathrm{T}^{-1} \times \mathrm{T}=\mathrm{L}(\mathrm{cm})$, which suggests a long-term depth of water input, although obviously not the simple sum of 999 years of storms ( 0.001 times the 1000 -yr event, 0.01 of the 100-yr event, etc.). Perhaps the amount is most easily used as an index. For example: for the LCS precipitation PD series at Stampede Pass, the value of $\int M \times F d R=284 \mathrm{~cm}$; for the AM series, it is $\sim 328 \mathrm{~cm}$, reflecting the small sample of annual maxima having larger magnitudes. In simulations for the StpP-equivalent $1065 \mathrm{~m}$ EXE run, the precipitation integral is $282 \mathrm{~cm}$ (very similar to the data) whereas the WAR integral is $255 \mathrm{~cm}$, suggesting that long-term WAR is less than gross precipitation at that elevation. 


\section{APPENDIX G}

\section{Description of Storm Events Utilized in SE Model Tests}

(Events modeled in section 5.2; test results in Table H.1.)

\section{Stampede Pass}

Location: just south of Stampede Pass, WA, Mt. Baker-Snoqualmie National Forest (see Tables D.1, D.2 for site locations and history)

National Weather Service airways observation station, 47'17'N, $121^{\circ} 20^{\prime} \mathrm{W}, 3961 \mathrm{ft}$ (1207 m) asl; Cascade crest, near King-Kittitas county line

Cooperative Snow Survey (NRCS) SNOTEL installation, $47^{\circ} 16.45^{\prime} \mathrm{N}, 121^{\circ} 20.5^{\prime} \mathrm{W}, 3860 \mathrm{ft}$ (1176 m) asl; downhill west of weather station

\section{Data sources:}

NWS: digital download of Unedited Local Climatological Data hourly observations table from NCDC data repository (www.ncdc.noaa.gov); used observations at hh:56, or average of all measurements during an hour $\rightarrow \mathrm{hh}+1$; supplemented with data from Hourly Precipitation-Washington

NRCS: SNOTEL data reports (hourly or daily), from National Water and Climate Center web site (www.wcc.nrcs.usda.gov/nwcc); corrected hourly data supplied by Scott Pattee, NRCS Washington Snow Survey Office, June 2006

Observations/instruments used in SE (data dimensions and precision):

Temperature: at SNOTEL and NWS (both $0.1^{\circ} \mathrm{C}$ ) - values typically not consistent Wind speed: anemometer $\sim 10 \mathrm{~m}$ above ground; avg over $2 \mathrm{~min}$ at NWS (1 kt thru 2004, $1 \mathrm{mi} / \mathrm{h}$ since 2005$)$ - adjusted in model tests $(10 / 25 / 50 / 100 \%)$ for forested conditions at pillow site

Precipitation: both hourly - heated, shielded rain gauge at NWS (0.01 in.); hourly separation from storage gauge at SNOTEL (0.1 in.)

Snow WE: interpreted from weight on SNOTEL pillow (0.1 in.)

Snow depth: since WY 2003; depth sensor at SNOTEL (0.1 in.) - some hours bogus/missing (especially during Dec 2005 event)

WAR: interpreted from $\triangle \mathrm{SWE}$ (input/storage/output) thru SNOTEL snow pillow (0.1 in.) 


\section{$\underline{15 / 16 / 17-21 / 23 ~ J a n u a r y ~} 2005$}

Tested with varying combinations of NWS and SNOTEL data, and averages (Table H.1)

Duration: model short 74 - mid 169 - long 185 h

Precipitation: avg of both sites $21.438-23.216-23.254 \mathrm{~cm}$, or SNOTEL $25.146-27.178$ cm (NWS 17.602-19.101 cm); $10-66-77 \mathrm{~h}$ without precip (longest gaps 32 and $26 \mathrm{~h}$ )

Temperature: SNOTEL: range -13.6 to $+9.2^{\circ} \mathrm{C}$, avg $2.49^{\circ} \mathrm{C}$

Wind speed: mean of all obs for the hour: range 0 to $7.75 \mathrm{~m} / \mathrm{s}$, avg $2.58 \mathrm{~m} / \mathrm{s}$

Snow: $\quad$ start (midnight $15^{\text {th }} / 16^{\text {th }}$ ) at $15.748 \mathrm{~cm} \mathrm{WE}, 55.88 \mathrm{~cm}$ depth; end (mid-day $23^{\text {rd }}$ ) $13.208 \mathrm{~cm} \mathrm{WE}, 21.590 \mathrm{~cm}$ depth (odd - very dense snow [WE/depth goes $0.282 \rightarrow$ 0.612 during event] - depth sensor mistaken?); tested $g_{d}=0.1 / 0.15 / 0.2 \mathrm{~cm}$ WAR: net outflow $24.792-30.126-31.650 \mathrm{~cm}$ for three durations Notes: Used corrected SNOTEL data; early in event - freezing rain recorded at StpP NWS until late 17 Jan, though net outflow from snow pillow started by mid-day 16 Jan; SNOTEL storage gauge sometimes odd, negative - freezing, leaks? (daily precip amounts redistributed among hours having precip); multiple gaps $\rightarrow$ would be several LCS events within $185 \mathrm{~h}$

\section{$\underline{22-26 / 27 / 29 \text { December } 2005}$}

Tested with varying combinations of NWS and SNOTEL data, and averages; NWS data missing after 24 Dec 0500, except hourly precipitation (in paper publication) Duration: model short 109 - mid 129 - long $174 \mathrm{~h}$ Precipitation: avg of both sites $11.309-14.103-16.764 \mathrm{~cm}$ (NWS $9.868-14.681 \mathrm{~cm}$, SNOTEL $12.700-18.796 \mathrm{~cm}$ ); $38-11-12 \mathrm{~h}$ without precip (longest gaps 7 and $11 \mathrm{~h}$ ) Temperature: average of SNOTEL and available NWS: range -1.9 to $+4.1^{\circ} \mathrm{C}$, avg $0.76^{\circ} \mathrm{C}$ Wind speed: average of all obs for the hour: range 0 to $5.56 \mathrm{~m} / \mathrm{s}$, avg $2.91 \mathrm{~m} / \mathrm{s}$ (hourly values missing after 24 Dec $0500 \rightarrow$ all considered $2.913 \mathrm{~m} / \mathrm{s}$ )

Snow: $\quad$ start $\left(060022^{\text {nd }}\right)$ at $25.654 \mathrm{~cm} \mathrm{WE}$, end (mid-day $\left.29^{\text {th }}\right) 30.988 \mathrm{~cm} \mathrm{WE}$; no depth data - estimated from WE and density at last measured depth $(0.273$ on 20 Dec) $\rightarrow$ start $\sim 94.1 \mathrm{~cm}$, end $\sim 111.8 \mathrm{~cm}$; tested $\mathrm{g}_{\mathrm{d}}=0.1 / 0.15 / 0.2 \mathrm{~cm}$ WAR: outflow $10.293-11.055-11.430 \mathrm{~cm}$ for the three durations Notes: Slightly corrected SNOTEL data; early in event - freezing rain at StpP NWS $\sim 6$ h; 302 
SNOTEL storage gauge sometimes negative - freezing, leaks?; precip gaps $\rightarrow 3$ LCS events in $174 \mathrm{~h}$

\section{Demonstration of Ecosystem Management Options (DEMO) Project}

Location: North Umpqua River basin, OR, Toketee Ranger District, Umpqua Nat'1 Forest

Primary in these events - Units 1, 4 (Mowich Loop Rd): $43^{\circ} 15.8^{\prime} \mathrm{N}, 122^{\circ} 14.6^{\prime} \mathrm{W}, 1219$ $\mathrm{m}$ asl

Supplementary - Units 2, 5, 6, 7, 8 (Toketee Airstrip): $\sim 15 \mathrm{~km} \mathrm{W,} 914 \mathrm{~m}$ asl

All: Western Oregon Cascades, valley bottom, forested except Units 7 \& 8 (15\% canopy)

Data source: Paul K. Wetherbee (1995): Results (p 34-67), Appendix B (p 92-98)

Observations/instruments used in SE (data dimensions and precision):

Temperature: thermoprobes $\sim 1 \mathrm{~m}$ above ground $\left(0.2^{\circ} \mathrm{C}\right.$, avgs $\left.0.1^{\circ} \mathrm{C}\right)$

Wind speed: cup and propeller anemometers, $2.4 \mathrm{~m}$ height, average readings over $1 \mathrm{~min}$ $(0.4 \mathrm{~m} / \mathrm{s}$, avgs $0.05 \mathrm{~m} / \mathrm{s})$

Precipitation: open-stand PVC storage gauges ( $30.5 \mathrm{~cm}$ diameter, $1.2 \mathrm{~m}$ tall) to tipping buckets $(0.1 \mathrm{~cm}$, avgs $0.01 \mathrm{~cm})$, antifreeze charged, shielded in open

Snow WE: $\quad$ snow courses measured weekly, 5 sites per unit $(1.0 \mathrm{~cm})$

Snow depth: snow courses measured weekly, 20 sites per unit $(1.3 \mathrm{~cm})$

WAR: $\quad$ snow lysimeters $\left(2.6 \mathrm{~m}^{2}\right)$ to tipping buckets $(0.1 \mathrm{~cm}$, avgs $0.01 \mathrm{~cm})$

Other: two instrument sites per unit, both having rain gauges and lysimeters; one temperature and wind sensor per unit, plus incident short-wave radiation, relative humidity, barometric pressure; checked SNOTEL data from King Mtn (near S UmpquaRogue divide, $1322 \mathrm{~m}$ ) and Diamond Lake (near Cascade crest, $1620 \mathrm{~m}$ ) for time patterns of accum/melt around and between DEMO snow course measurements (SNOTEL installed at Toketee Airstrip in Oct 2003)

\section{Event \#1, 29 November - 2 December 1994}

Duration: $\quad 72 \mathrm{~h}$ - data for $080029 \mathrm{Nov}-07002 \mathrm{Dec}$

Precipitation: avg of 3 gauges, $4.31 \mathrm{~cm}$; $\max 0.4 \mathrm{~cm} / \mathrm{h} ; 29 \mathrm{~h}$ without precip (longest gap $10 \mathrm{~h})$ 
Temperature: range $0.4-5.4^{\circ} \mathrm{C}$, avg $2.10^{\circ} \mathrm{C}$

Wind speed: avg of 2 sites, range $0.15-3.75 \mathrm{~m} / \mathrm{s}$, avg $0.815 \mathrm{~m} / \mathrm{s}$

Snow: $\quad 23 \operatorname{Nov}$ (units 1, 4); $28 \operatorname{Nov}$ (units 2, 5, 6, 7, 8); 30 Nov (units 1, 4); 5

Dec (units 1, 2, 4, 6)

range of mean SWE 4.6-9.0 cm $\rightarrow$ 16.6-19.3 cm $\rightarrow 7.2-20.0 \mathrm{~cm}$; depth back-calculated from reported mean density

WAR: $\quad$ avg of 4 sites; total $5.00 \mathrm{~cm}$, $\max 0.35 \mathrm{~cm} / \mathrm{h}$; USACE equation predicted $2.12 \mathrm{~cm}$ melt $\rightarrow 6.45 \mathrm{~cm}$ WAR

Notes: average $\mathrm{T}$ and $\mathrm{W}$ for $\mathrm{h} 71$ and 72 extended for $\mathrm{h} 73$ on; outflow began $1 \mathrm{~h}$ after precip, but pack absorbed water (net) in first $24 \mathrm{~h} ; 10 \mathrm{~h}$ precip gap $\rightarrow 2$ LCS events

\section{Event \#4, 29 January - 1 February 1995}

Duration: $\quad 72 \mathrm{~h}$ - data for $210029 \mathrm{Jan}-20001 \mathrm{Feb}$

Precipitation: avg of 4 gauges, $6.60 \mathrm{~cm}$; $\max 0.45 \mathrm{~cm} / \mathrm{h} ; 15 \mathrm{~h}$ without precip (longest gap $5 \mathrm{~h}$ )

Temperature: range $2.2-5.8^{\circ} \mathrm{C}$, avg $3.82^{\circ} \mathrm{C}$

Wind speed: range $0.2-4.0 \mathrm{~m} / \mathrm{s}$, avg $1.00 \mathrm{~m} / \mathrm{s}$

Snow: $\quad 25 \mathrm{Jan}, 7 \mathrm{Feb}$ (both at units 1, 4)

range of mean SWE 13.9-17.8 $\mathrm{cm} \rightarrow 3.2-5.0 \mathrm{~cm}$ (well after event end); depth backcalculated from reported mean density

WAR: $\quad$ avg of 4 sites; total $10.29 \mathrm{~cm}$, $\max 0.49 \mathrm{~cm} / \mathrm{h}$; USACE equation predicted $3.8 \mathrm{~cm}$ melt $\rightarrow 10.4 \mathrm{~cm}$ WAR

Notes: average $\mathrm{T}$ and $\mathrm{W}$ for $\mathrm{h} 71$ and 72 extended for $\mathrm{h} 73$ on; lysimeters recorded outflow before rain began - snowmelt prior to ROS; most closely meets assumptions of the SM model (Wetherbee, 1995, p 53); also modeled with DHSVM $\rightarrow$ WAR $10.3 \mathrm{~cm}$; all one LCS 


\section{APPENDIX H}

Summary of Selected Calibration and Test Runs, Single Event Model

Table H.1 Summary of Selected Calibration and Test Runs, Single Event Model

(App H SE calib \& test runs.doc)

in supplemental files 


\section{APPENDIX I}

Output \& summary of $S t p P E X P$ runs

(App I StpP EXP tests.xls)

in supplemental files 


\section{APPENDIX J}

Output \& summary of $1065 E X E$ runs

(App J 1065 EXE tests.xls)

in supplemental files 


\section{APPENDIX K}

Output \& summary of $E X E$ runs for $800 \mathrm{~m}$ elevation, various conditions and random-number seeds (sensitivity)

(App K 800 EXE runs.xls)

in supplemental files 


\section{APPENDIX L}

Summary of EXE runs for all elevations: high-precipitation and low-precipitation functions, and 800-m sensitivity tests

(App L EXE summary tables \& graphs.xls)

in supplemental files 